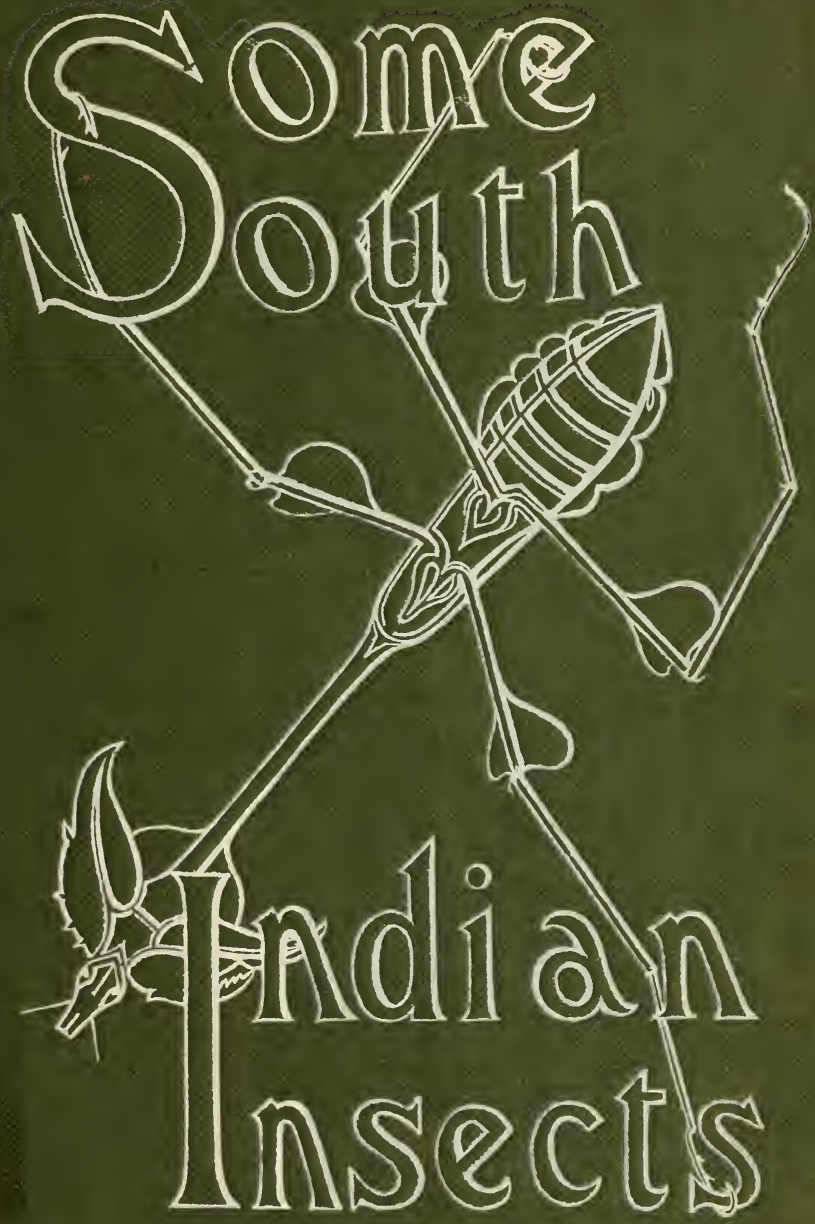




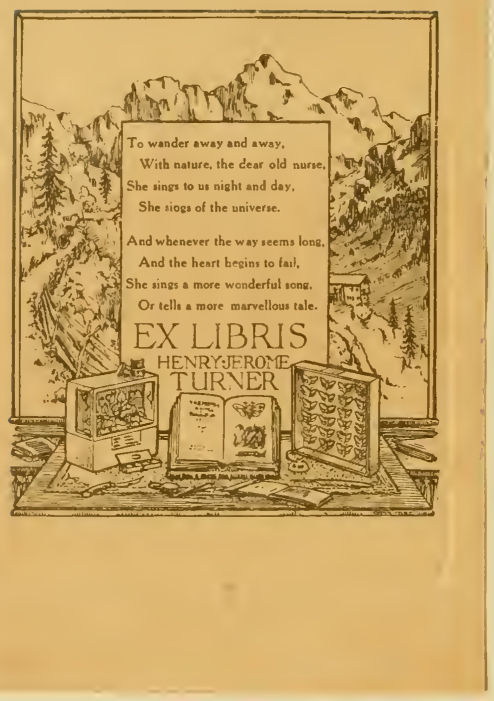




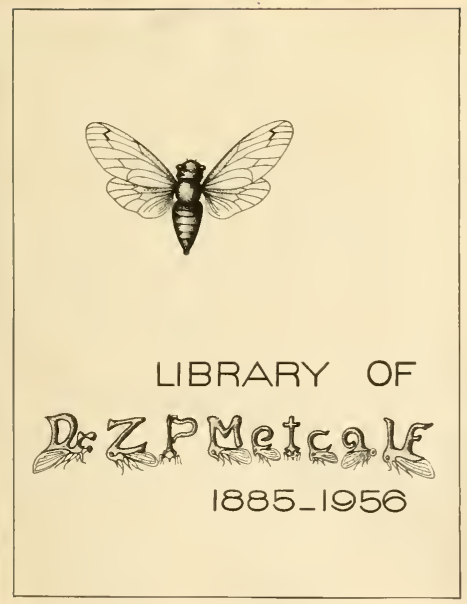





\section{SOME}

\section{SOUTH INDIAN INSECTS}

AND

\section{OTHER ANIMALS OF IMPORTANCE}

CONSIDERED ESPECIALLY FROM AN

ECONOMIC POINT OF VIEW

BY

T. BAINBRIGGE FLETCHER, R.N.,

$$
\text { F.L.S., F.E.S., F.Z.S., }
$$

Imperial Entomologist to the Government of India

(late Government Entomologist, Madras).

MADRAS :

PRINTED BY THE SUPERINTENDENT, GOVERNMENT PRESS. 
[Copyright by the Government of Madras, by whom all Rights of Translation and Reproduction are reserved. There is, however, no objection to the reproduction of short extracts or figures in bona fide agricultural, economic or technical publications, provided that their sources are duly acknowledged.] 


\section{PREFACE.}

$W^{\mathrm{E}}$ are assured on excellent authority that "of the making of books there is no end," whilst to authors may be commended the equally excellent Arab proverb which says that "hurry is of the devil." It is to be hoped that readers of this book may see the connection between these two saws and duly ascribe to the proper quarter any noticeable shortcomings. This volume has, indeed, no pretensions to the assumption of any status as a text-book and does not pretend to do much more than provide a narrow and tortuous entrance into the vast and almost untrodden field of Insect Life in Southern India.

In the closing years of the eighteenth century, thanks to the collections made mainly by the Tranquebar missionaries, the insects of Southern India were perhaps better known than those of any other part of Eastern or Southern Asia, but it is remarkable how little work was done in the succeeding century in Madras in comparison with that done in Ceylon, in Northern India, in China, Japan and Malaysia. It is difficult to say why this should be so, but the fact remains that the Insect Fauna of Southern India is now probably less well known than that of the Himalayan Region.

Entomology has hitherto been an entirely exotic science in India and collections and observations of Indian Insects have, as a rule, been made only by those Government Officials whose tastes lay in that direction and who have looked on Entomology as a hobby. During the first half of the nineteenth century an extensive collection of Lepidoptera was made in the Coimbatore district by Walhouse and towards the end of the century collections (chiefly of Lepidoptera and Coleoptera! were made in the Nilgiris by Sir George Hampson and Messrs. Andrewes, whilst Bolivar described an extensive collection of Orthoptera formed by St. Joseph's 
College at Trichinopoly. It remained for the twentieth century to place the study of entomology on broader and more scientific lines by the appointment of official Entomologists firstly in Mysore and subsequently in Madras.

In Madras Entomology has been studied, especially from the standpoint of Economic Agricultural Entomology, since 1906, when an Entomological Assistant was appointed to work under Dr. Barber, then Government Botanist, and the number of Assistants was subsequently increased to three, at which it remained when I took over the newly-created post of Government Entomologist in April 1912. Under ordinary circumstances the issue of a book on South Indian Insects would have been deferred for some years pending a more thorough investigation into the lifehistories of those insects of greater economic importance, but orders for my transfer from Madras led me to overhaul the collections and records formed before and during my tenure of office primarily with the idea of leaving them in order for my successor. The information gathered together proved (unexpectedly) so large as to appear to merit publication, not as a definitive text-book, but as a basis for further work. Hinc ille liber!

In the "Indian Crow, His Book," we are told that Prefaces are either apologetic or defiant. Well, of course-

"There are some might be found entertaining a notion

That such an entire and exclusive devotion

To that part of Science folks style entomology

Really demanded some sort of apology,"

although even such folk might change their views if transported to India and exposed to the ordinary insect-plagues of everyday life. And no apology is needed for the study of insects in a country in which thousands are swept away every year by insect-borne diseases and in which seven-tenths of the population are entirely dependent upon their crops whose produce is always lessened and sometimes wholly destroyed by the ravages of insects. Any apology, therefore, shall not be concerned with the subject-matter of this book except as 
regards the incomplete state in which it is presented and the reason for this has already been explained. Any merits it may possess consist in its efficacy as a stop-gap until a more complete account can be prepared.

The preliminary chapters, giving some general account of the structure, habits, etc., of insects and of insect-pests are necessarily brief and incomplete and indeed any one of these might readily be expanded into a whole volume by itself, whilst the various aspects of Entomology that have been omitted would form a companion series of tomes.

In the succeeding and main portion of the book some of the more important insects are briefly considered, each being treated under the head of (I) References, (2) Distribution in Southern India, (3) Lifehistory, (4) Foodplants, (5) Status from an economic view-point, and (6) Control. Under the first heading, the synonyms and references, which will generally only appeal to entomologists, are necessarily limited to the original description and the more important or accessible references. Under the last heading, only such controlmethods are usually given as are generally efficacious, special methods being often applicable to local conditions ; in some cases in which no effective method has yet been found, the information under this head is left blank or represented by a "?".

The list of Crop Pests is not complete and it must be clearly understood that it cannot be complete for very many years, if ever. Every month new pests come to light, many of them altogether unknown even by name, and our knowledge of old pests is augmented. Many of the commoner species may, it is hoped, be identified by the figures here given and specimens of any others found as pests should be sent to the Government Entomologist, Coimbatore, for identification and advice.

The writing of a Preface to a book of this nature provides a welcome opportunity for acknowledgment of assistance freely rendered by various helpers. The whole of the Insect Pests enumerated in the latter half of this volume were discussed in collaboration with M.R.Ry. T. V. Ramakrishna 
Ayyar, B.A., and M.R.Ry. Y. Ramachandra Rao, M...., the two Senior Assistants on the staff of the Government Entomologist, Madras, and in several cases I have availed myself of notes on lifehistories made by them, such notes being distinguished by their initials. Mr. R. D. Anstead, the Planting Expert, kindly sent me a list of the principal pests found in the Planting Districts and several of these have been included on his authority, as I have not seen them myself in Southern India. Captain W. S. Patton, I.M.S., read over the manuscript of the Chapter on "Insects and Disease" and gave the benefit of his criticism on several points, as did Mr. H. C. Sampson with regard to the section on "Agricultural Methods" in the discussion of the control of Insect Pests of Crops. The illustration on the cover was executed by the facile pencil of Mr. R. C. WVood after a rough idea furnished by me. Finally, the book owes its completion and production to the kind encouragement afforded by the Director of Agriculture, the Board of Revenue, and the Government of Madras.

A few words are required with regard to the illustrations. The whole of the coloured plates have been reproduced from original drawings made at the Agricultural Research Institute, Pusa; most of these had been published previously, having been used in Indian Insect Life, Fasaler Poka, the Agricultural Journal of India or in other departmental publications, and it is solely owing to their previous publication that so many coloured plates have been able to be included without unduly increasing the cost of the book. A few textfigures have been copied from standard publications, their sources being duly acknowledged. All the other illustrations are original and have been newly prepared under my supervision from actual specimens of the various insects concerned, many of which have never been figured before. That these original illustrations are not entirely uniform in quality is to be ascribed to the fact that they have been prepared by artists who had no previous experience in making drawings of insects for purposes of reproduction and who have had to be trained in this during the progress of the work. 
To any in search of a distraction or a hobby, either to fill an idle hour or to provide a welcome change of thought and occupation, the study of Entomology may well be commended. Insects are always with us, by day and by night, in the bungalow, at the office or in camp, and the field for observation of lifehistories and habits, even of the commonest species, is absolutely boundless. If this book lends aid to any whose tastes lie in this direction. its aim will have been achieved. Gratus certe labor, quo scientice nitor magnopere augetur.

\section{T. BAINBRIGGE FLETCHER.}





\section{CONTENTS.}

\section{Chapter}

PAGE

$\begin{array}{lllllllll}\text { Preface } & \ldots & \ldots & \ldots & \ldots & \ldots & \ldots & \ldots & \text { ii }\end{array}$

$\begin{array}{lllllllll}\text { List of Plates } & \ldots & \ldots & \ldots & \ldots & \ldots & \ldots & \text { xi }\end{array}$

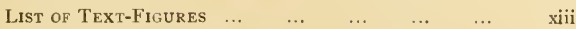

I. Definition and Structure of Insects $\quad \ldots \quad \ldots \quad$ I

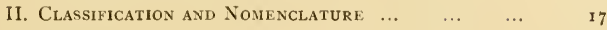

III. Metamorphosis ... $\quad \ldots \quad$.

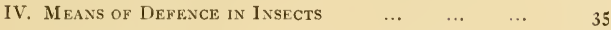

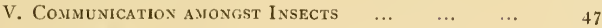

$\begin{array}{llllllllll}\text { VI. TROPISMS } \ldots & \ldots & \ldots & \ldots & \ldots & \ldots & \ldots & 53\end{array}$

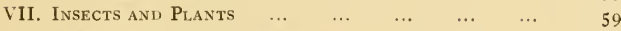

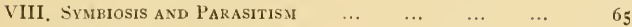

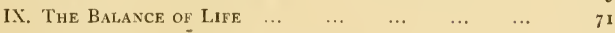

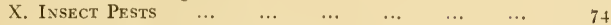

XI. The Control of Insect Pests of Crops :-

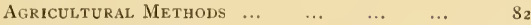

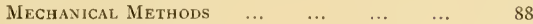

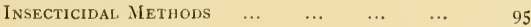

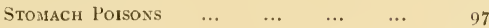

Contact Poisons $\quad \ldots \quad$... $\quad \ldots \quad$...

$\begin{array}{llllllll}\text { REPELLENTS } & \ldots & \ldots & \ldots & \ldots & \ldots & 105\end{array}$

$\begin{array}{llllll}\text { SPRAYING MACHIXERY } & \ldots & \ldots & \ldots & 106\end{array}$

THE SELECTION OF SPRAIERS $\quad \ldots \quad \ldots$ I 6

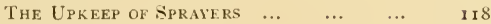

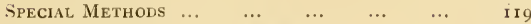

APpendix of Weights and Meisures $\ldots . \quad \ldots \quad 126$

XiI. The Classification of Pests $\quad \ldots \quad$...

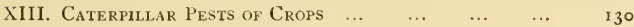

XIV. Grasshoppers, Crickets and Termites $\quad \ldots . \quad \ldots \quad 137$

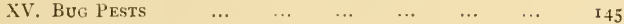

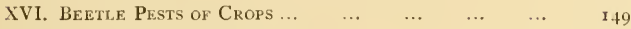

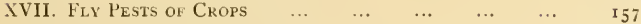

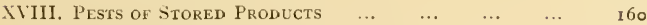

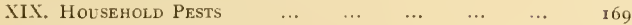

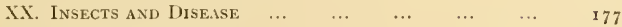

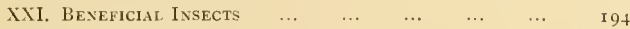

$\begin{array}{lllllllll}\text { XXII. USEFUL INSECTS } \ldots & \ldots & \ldots & \ldots & \ldots & \ldots & 205\end{array}$

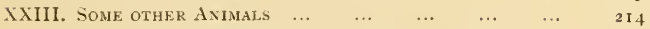

LIST OF CROPS WITH THE INSECTS WHICH ATTACK

$\begin{array}{llllllllll}\mathrm{EACH} & \ldots & \ldots & \ldots & \ldots & \ldots & \ldots & \ldots & 240\end{array}$ 


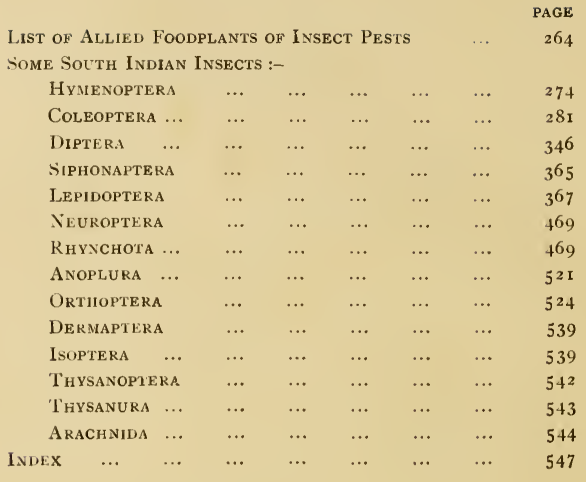




\section{LIST OF PLATES.}

I. Household and Granary Pests

OPPOSITE PAGE

II. Pests of Cruciferie

III. Oryctes rhinoceros

IV. Anomala varians

V. Coccinella septempunctata

VI. Epilachna Beetles

VII. Lasioderma sirrieorne

VIII. Sphenoptera gossypii

IX. Phidodonta modesta

X. Hispa armigera (anescens)

XI. Apomecynu pertigera ...

XIII. Culandru oryse...

XIV. Rhynchophorus ferrugineus

XV. Syrphid Fly

XVI. Dacus cucurbita

XVII. Amsacta albistriga

XVIII. Cirphis unipuncta

XIX. Prodenia litura ...

XX. Spodoptera mauritia

XXI. Sesamia inferens

XXII. Earias insuluna...

XXIII. Earias fabia

XXIV. Acherontia styx...

XXV. Papilio demoleus

XXVI. Catochrjsops cnejus

XXVII. Parnara mathias

XXVIII. Galleria mellonella

XXIX. Schanobius bifunctifer ..

XXX. Pests of Brinjal ...

XXXI. Phycita infusella

XXXII. Nymphula depunctalis

XXXIII. Marasmin trapezalis ...

XXXIV. Dichocrocis punctiferalis

XXXV. Sylepta derogata

XXXVI. Maruca testulalis

XXXVII. Antigastra catalaunalis

XXXVIII. Exelastis atomosa

XXXIX. Eucelis critica $\ldots . . \quad \ldots$.

XL. Laspeyresia tricentra ...

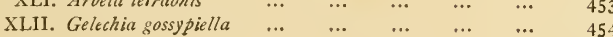

$2+3$

285

287

29 I

292

295

298

3 I 5

3I 5

327

335

$3+1$

343

$35^{8}$

354

369

376

377

378

379

$3^{8} 4$

$3^{8} 5$

402

4 I 2

414

417

421

$+26$

428

428

430

432

433

$+34$

$4+40$

$4+1$ 


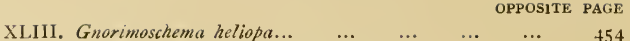

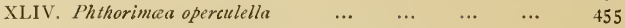

$\begin{array}{lllllllll}\text { XLV. Chrysopa... } & \ldots & \ldots & \ldots & \ldots & \ldots & \ldots & 469\end{array}$

$\begin{array}{llllllll}\text { XLV1. Dysdercus cingulatus } & \ldots & \ldots & \ldots & \ldots & \ldots & 48_{4}\end{array}$

$\begin{array}{lllllllll}\text { XLVII. Psyllin isitis } & \ldots & \ldots & \ldots & \ldots & \ldots & \ldots & 498\end{array}$

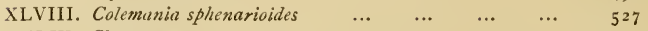

$\begin{array}{lllllllll}\text { XLIX. Chrotogonus } & \ldots & \ldots & \ldots & \ldots & \ldots & \ldots & 528\end{array}$

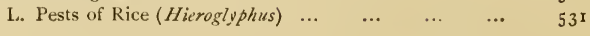




\section{LIST OF TEXT-FIGURES.}

1. Batocera rubus, Simple Anatomy

2. Principal anatomical features of an adult Insect $\quad \ldots \quad \ldots \quad$... 3

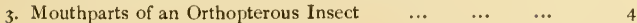

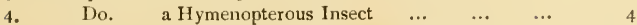

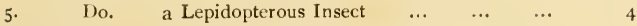

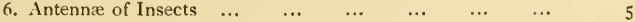

$\begin{array}{llllllll}\text { 7. Eyes of Insects } & \ldots & \ldots & \ldots & \ldots & \ldots & \ldots & 6\end{array}$

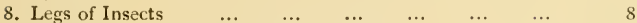

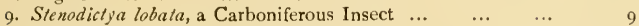

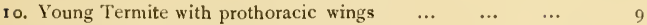

Ir. Diagram of a generalized type of wing $\quad \ldots \quad \ldots \quad \ldots \quad \ldots \quad$ Io

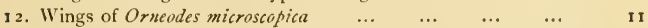

13. IVing of Brodia priscotincta, a fossil Neuropteroid ... $\quad \ldots \quad$ I8

r. Diagram illustrating supposed Phylogeny of Hexapods $\quad . . \quad 19$

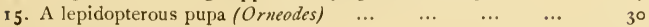

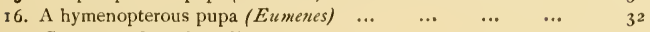

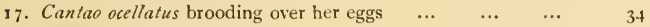

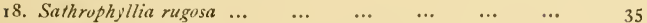

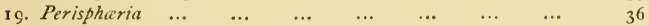

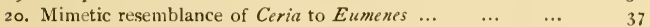

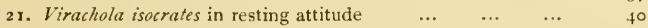

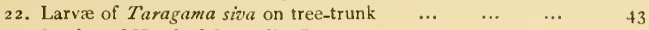

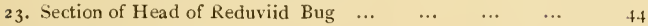

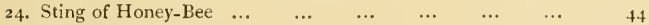

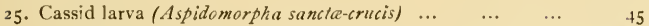

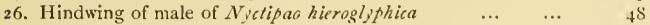

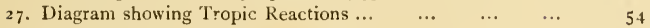

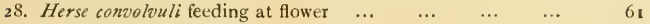

29. Section of fly-attracting Aristolochia flower ... $\quad \ldots \quad \quad \ldots \quad 62$

30. Head of Hawkmoth with Pollinia attached ... $\quad \ldots \quad$... $\quad 62$

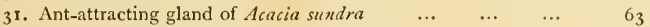

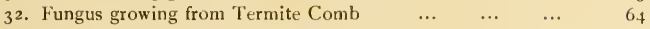

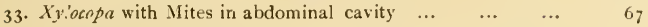

34. Graphic Curves showing increase and decrease of Host and $\begin{array}{lllllllll}\text { Parasite } & \ldots & \ldots & \ldots & \ldots & \ldots & \ldots & \ldots & 69\end{array}$

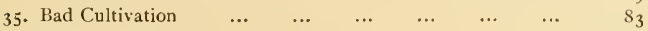

$\begin{array}{llllllllll}36 . & \text { Hand-Net } & \ldots & \ldots & \ldots & \ldots & \ldots & \ldots & \ldots & 89\end{array}$

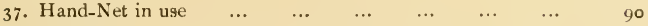

$\begin{array}{llllllllll}38 & \text {. Bag-Net } & \ldots & \ldots & \ldots & \ldots & \ldots & \ldots & \ldots & 90\end{array}$

39. Bag-Net in use $\quad \begin{array}{lllllllll} & \ldots & \ldots & \ldots & \ldots & \ldots & \ldots & 9^{\text {I }}\end{array}$

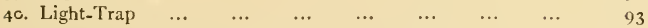

4r. Applying powdered insecticides with cloth bags $\quad \ldots \quad \ldots \quad$ ro6 


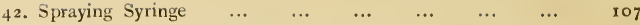

43. Do. in action

44. Bucket pump ... ...

45. Do. in use ...

45. Gould's Knapsack Sprayer ...

47. Do. in use

48. Barrel Pump

49. Do. in action

50. "Autospray" in parts

5 I.

52. "Holder" Pressure Sprayers

53

54. "Universal" Ant Exterminator

55

56. "Squire"

do. in use

do.

57. Banyan Trees stripped by caterpillars of Hypsa ficus

58. Ailanthus excelsa do.

Eligma ...

59. Caterpillar of Acherontia

6o. Injection Syringe for wood-borer

61. "Kumbli-puchis" (Amsacta albis/riga)

62. Chrotogonus

63. Castes of a Termite

64. Odontotermes obesus, soldier ...

65. Mud casing deposited on tree by Termites

66. Rice-bug

67. Gogu Plants attacked by beetles

68. Nilgiri Cockchafers

69. Oryctes rhinoceros boring into sugarcane

71. Mylabris indica

72. Protective device against toddy-flies...

73. Ephestia kuchniclla

74. Common Indian House-Cockroach (Periplaneta americana).

75. Damage by Fish-insects

76. A Carpet Beetle

77. Stegomyia fasciata

78. Resting-attitude of Anopheline Mosquito

79.

Do.

Culicine

di).

8o. Life-cycle of Malaria-parasite

81. Dragonflies

82. Eumenes conica

83. Noctuid larva stored by Eumenes

84. Asilid fly

85. Larval Cases of Eublemma scilula

86. Parasite of Dialrca

87. Jo. Aproarema nerieri

88. Xanthopimpla pedator

8y. Chalcid Parasite (Erelmocerus) of Castor Aleurodid

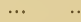

$\cdots$


90. Proctotrypid parasite of Tettigoniella

91. Mulberry Silkworm ... ... ...

206

92. Eri

do.

207

93. Tasar

do.

208

94. Where Apis dorsata builds its comb

209

95. Beehive

2 II

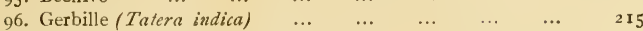

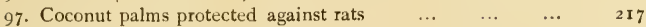

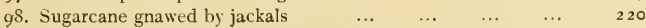

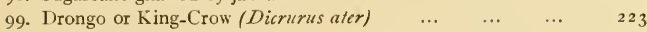

$\begin{array}{llllllll}\text { 100. Mynah (Acridotheres tristis) } & \ldots & \ldots & \ldots & \ldots & \ldots & 224\end{array}$

IоI. Golden Woodpecker (Brachypternus aurantius) $\quad \ldots \quad \ldots \quad$... 225

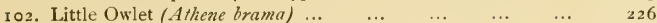

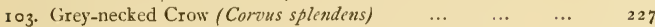

$\begin{array}{lllllllll} & \text { 104. Crows following harrow } & \ldots & \ldots & \ldots & \ldots & \ldots & 228\end{array}$

$\begin{array}{llllllll}\text { 105. Parroquet (Palaornis torquatus) } & \ldots & \ldots & \ldots & \ldots & 229\end{array}$

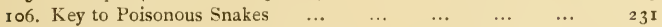

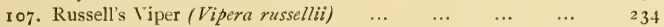

$\begin{array}{lllllllll}\text { 108. Cacopus systoma } & \ldots & \ldots & \ldots & \ldots & \ldots & \ldots & 235\end{array}$

109. A mosquito-eating Fish (Haplochilus lineatus) $\quad \ldots \quad \ldots \quad \ldots \quad 236$

$\begin{array}{llllllllll}\text { I 10. Eelworms } & \ldots & \ldots & \ldots & \ldots & \ldots & \ldots & \ldots & { }_{2} 3^{8}\end{array}$

$\begin{array}{lllllllll} & 11 \text { I. Dorylus orientalis } & \ldots & \ldots & \ldots & \ldots & \ldots & \ldots & 274\end{array}$

$\begin{array}{llllllllll} & 112 . \\ 1\end{array}$

$\begin{array}{llllllll}\text { II 3. Monomorium gracillimum } & \ldots & \ldots & \ldots & \ldots & \ldots & 275\end{array}$

$\begin{array}{lllllllll}\text { I } 4 . \text { E Cophylla smaragdina } & \ldots & \ldots & \ldots & \ldots & \ldots & 276\end{array}$

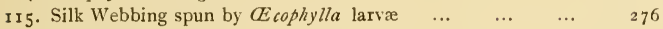

$\begin{array}{lllllllll} & \text { I 6. Camponotus compressus... } & \ldots & \ldots & \ldots & \ldots & \ldots & 277\end{array}$

$\begin{array}{llllllllll}117 . & \text { Apis dorsata } & \ldots & \ldots & \ldots & \ldots & \ldots & \ldots & \ldots & 278\end{array}$

$\begin{array}{llllllllll} & \text { I } 8 . \text { Apis indica } & \ldots & \ldots & \ldots & \ldots & \ldots & \ldots & \ldots & 278\end{array}$

$\begin{array}{llllllllll}\text { I I } 9 . \text { Apis florea } & \ldots & \ldots & \ldots & \ldots & \ldots & \ldots & \ldots & 279\end{array}$

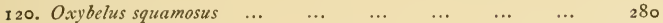

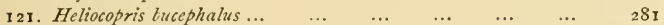

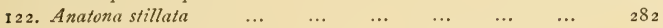

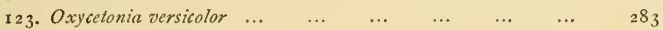

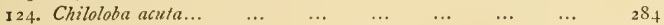

$\begin{array}{llllllll}\text { 125. Adoretus langalorensis... } & \ldots & \ldots & \ldots & \ldots & \ldots & & \mathbf{2} 86\end{array}$

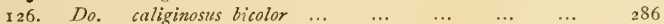

$\begin{array}{llllllllll}\text { 127. Do. ovalis ... } & \ldots & \ldots & \ldots & \ldots & \ldots & \ldots & { }_{2} 87\end{array}$

$\begin{array}{lllllllll}\text { I 28. Carpophilus dimidiatus } & \ldots & \ldots & \ldots & \ldots & \ldots & & 288\end{array}$

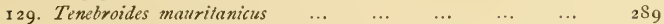

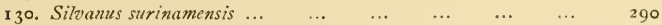

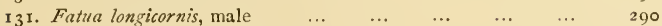

$\begin{array}{lllllllll}\text { I32. } \quad \text { Do. } & \text { female } & \ldots & \ldots & \ldots & \ldots & \ldots & 290\end{array}$

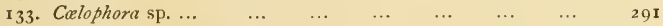

$\begin{array}{lllllllll}\text { 134. Dermestes vulpinus } & \ldots & \ldots & \ldots & \ldots & \ldots & \ldots & 292\end{array}$

$\begin{array}{lllllllllll}\text { 135. Do. } & \text { sp. } & \ldots & \ldots & \ldots & \ldots & \ldots & \ldots & \ldots & 293\end{array}$

$\begin{array}{lllllllll}\text { 136. Sinoxylon sudanicum } & \ldots & \ldots & \ldots & \ldots & \ldots & \ldots & 293\end{array}$

$\begin{array}{lllllllll}\text { I } 37 . \text { Rhizopertha dominica } & \ldots & \ldots & \ldots & \ldots & \ldots & \ldots & 294\end{array}$ 
138. Sitodrepa panicea

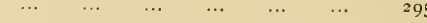

$\begin{array}{lllll}\cdots & \cdots & \cdots & \cdots & \cdots\end{array}$

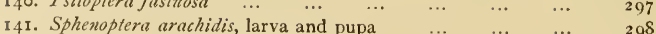

$\begin{array}{llllllll}\text { I42. Do. } & \text { do. adult } & \ldots & \ldots & \ldots & \ldots & \ldots & 298 \\ \end{array}$

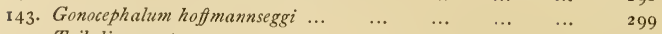

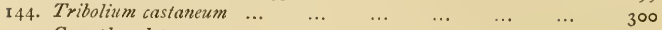

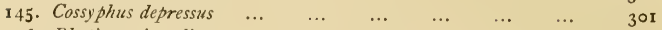

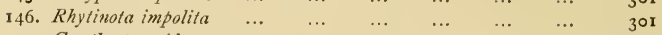

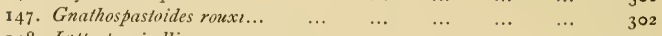

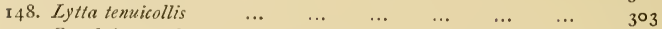

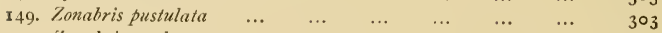

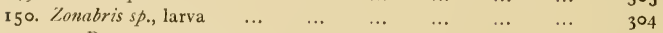

$\begin{array}{llllllll}\text { 151. Do. } & \text { coarctate larva } & \ldots & \ldots & \ldots & \ldots & \ldots & 304\end{array}$

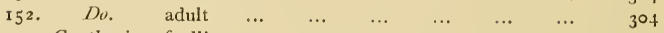

$\begin{array}{lllllllll}\text { 153. Cantharis ruficollis } & \ldots & \ldots & \ldots & \ldots & \ldots & \ldots & 305\end{array}$

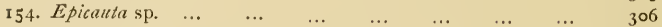

$\begin{array}{lllllllll} & \text { 155. Pachymerus chinensis } & \ldots & \ldots & \ldots & \ldots & \ldots & \ldots & 306\end{array}$

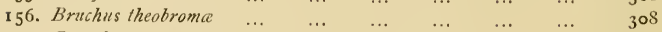

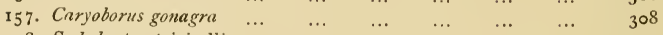

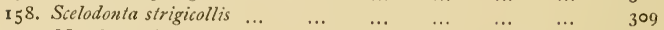

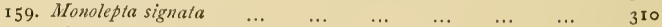

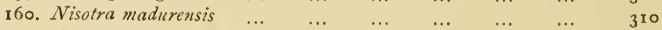

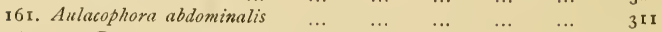

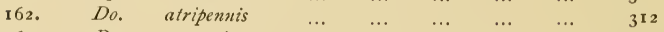

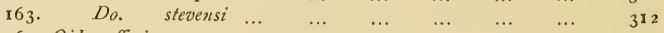

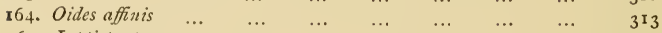

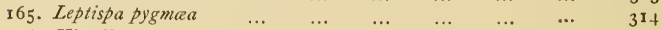

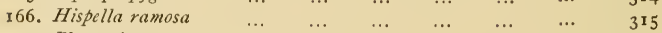

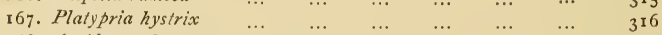

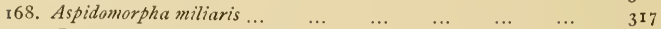

$\begin{array}{lllllllll}\text { I69. Coptocycla } \mathrm{sp} . & \ldots & \ldots & \ldots & \ldots & \ldots & \ldots & 3 \mathrm{I} 7\end{array}$

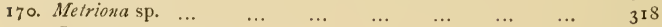

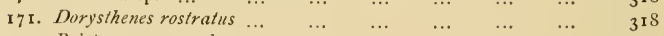

$\begin{array}{llllllll}\text { 17 2. Priotyranums mordax } & \ldots & \ldots & \ldots & \ldots & \ldots & \ldots & 3 \text { I9 }\end{array}$

$\begin{array}{llllllll}\text { 173. Acanthophorus serraticornis } & \ldots & \ldots & \ldots & \ldots & \ldots & 320\end{array}$

$\begin{array}{lllllllll}\text { I 74. Xystrocera globosa } & \ldots & \ldots & \ldots & \ldots & \ldots & \ldots & 32 \text { I }\end{array}$

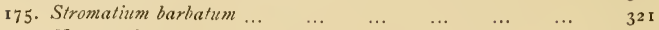

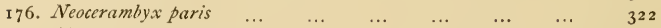

177. Chloridolum alcmene $\begin{array}{llllllll} & \ldots & \ldots & \ldots & \ldots & \ldots & \ldots & 323\end{array}$

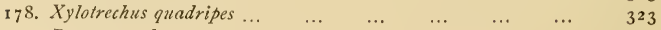

$\begin{array}{lllllllll}\text { 179. Batocera rubus } & \ldots & \ldots & \ldots & \ldots & \ldots & \ldots & 324\end{array}$

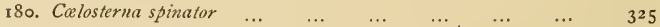

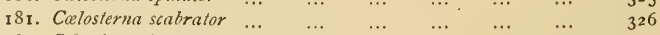

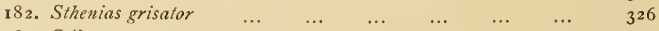

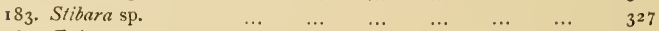

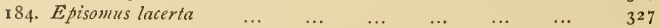

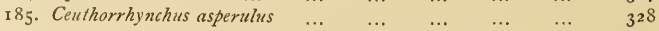


186. Eugnamptus marginatus

PAGE

187. Do. do. ovipositing in Mango-leaf

I88. Jute Apion

330

$\begin{array}{llllll} & \ldots & \ldots & \ldots & \ldots & \ldots\end{array}$

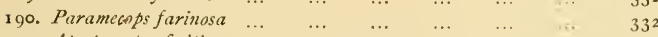

I91. Atactogaster finitimus $\ldots \begin{array}{llllllll}\text { 19. } & \ldots & \ldots & \ldots & \ldots & \ldots & 333\end{array}$

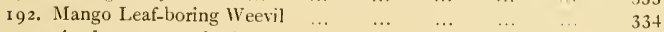

$\begin{array}{lllllll}\text { 193. Apoderus tranquebaricus } & \ldots & \ldots & \ldots & \ldots & \ldots & 334 \\ & \ldots & \ldots & \ldots & \ldots & 335\end{array}$

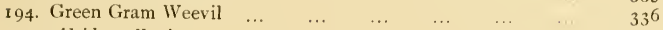

$\begin{array}{lllllll}\text { I } 95 . \text { Alcides collaris ... } & \ldots & \ldots & \ldots & \ldots & \ldots & \\ \end{array}$

$\begin{array}{lllllllll}\text { I96. Do. bubo } & \ldots & \ldots & \ldots & \ldots & \ldots & \ldots & & \ldots \\ 19 & \ldots & \ldots & \ldots & \ldots & \ldots & 337\end{array}$

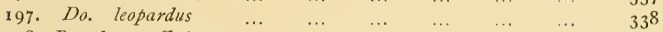

$\begin{array}{llllllll}198 . \text { Pempheres affinis } & \ldots & \ldots & \ldots & \ldots & \ldots & \ldots & 338 \\ & \ldots & \ldots & \ldots & \ldots & \ldots & 339\end{array}$

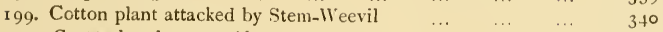

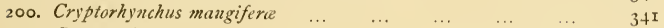

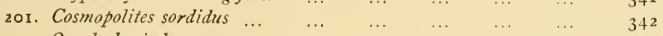

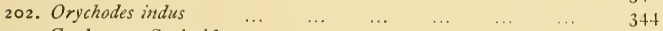

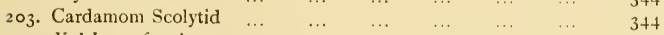

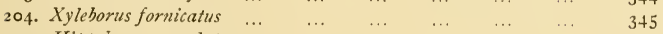

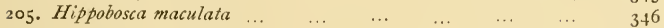

$\begin{array}{lllllllll}\text { 206. Do. capensis } & \ldots & \ldots & \ldots & \ldots & \ldots & \ldots & \ldots & 347\end{array}$

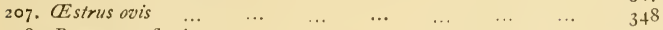

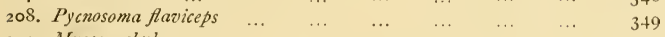

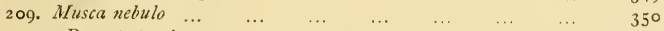

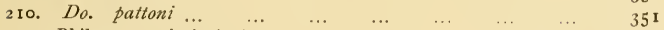

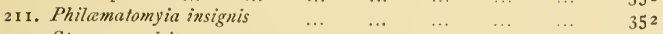

$\begin{array}{llllllll}\text { 21 2. Stomoxys calcitrans } & \ldots & \ldots & \ldots & \ldots & \ldots & \ldots & 352\end{array}$

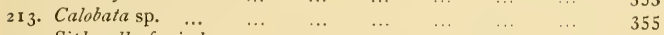

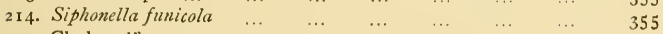

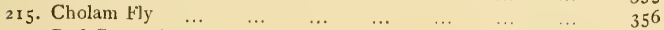

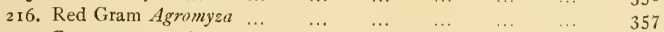

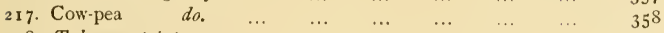

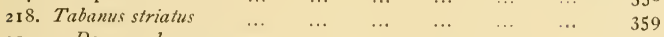

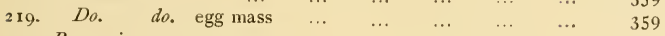

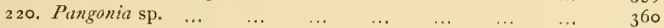

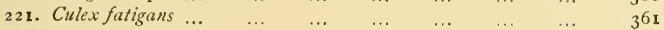

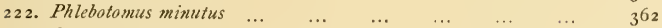

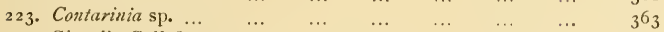

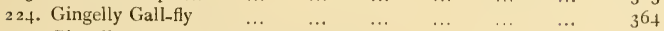

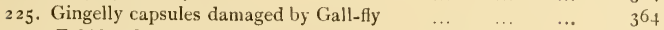

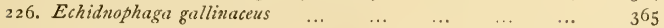

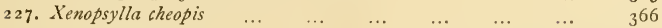

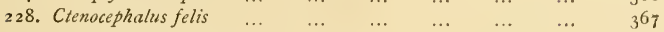

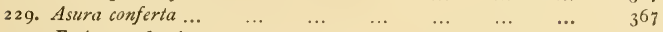

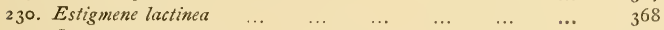

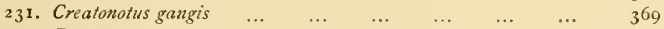

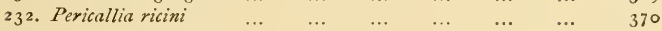

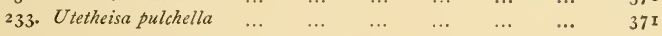


234. Egocera venulia

235. Chloridea obsoleta

236 . Do. assulta

237. Euxoa segetis ...

240. Laphygma exigua

241. Eublemma olivacea

380

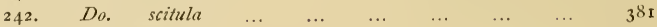

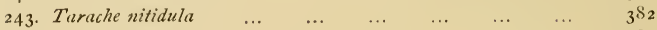

$\begin{array}{llllllllll}\text { 244. Do. opalinoides } & \ldots & \ldots & \ldots & \ldots & \ldots & \ldots & 38_{2}\end{array}$

$\begin{array}{llllllllll}2 & 45 . & \text { Bombotelia jocosatrix } & \ldots & \ldots & \ldots & \ldots & \ldots & \ldots & 38_{2}\end{array}$

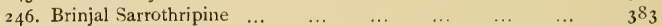

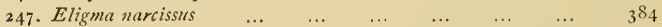

$\begin{array}{lllllllll}\text { 248. Do. do. larva } & \ldots & \ldots & \ldots & \ldots & \ldots & 38_{4}\end{array}$

$\begin{array}{llllllllll}\text { 249. Acontia grallsi } & \ldots & \ldots & \ldots & \ldots & \ldots & \ldots & 3{ }^{S_{5}}\end{array}$

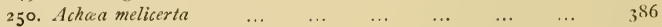

$\begin{array}{lllllllll}251 . & \text { Grammodes stoilida } & \ldots & \ldots & \ldots & \ldots & \ldots & \ldots & 3^{8} 7\end{array}$

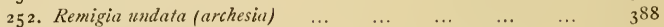

$\begin{array}{lllllllll}\text { 253. Do. frugalis } & \ldots & \ldots & \ldots & \ldots & \ldots & \ldots & 388\end{array}$

$\begin{array}{lllllllll}\text { 254. Azazia rubricans } & \ldots & \ldots & \ldots & \ldots & \ldots & \ldots & 389\end{array}$

$\begin{array}{lllllllll}\text { 255. Homoptera glaucinans ... } & \ldots & \ldots & \ldots & \ldots & \ldots & 390\end{array}$

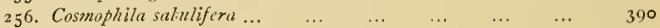

$\begin{array}{llllllllll}\text { 257. Do. } & \text { erosa } & \ldots & \ldots & \ldots & \ldots & \ldots & \ldots & 39 \mathbf{1}\end{array}$

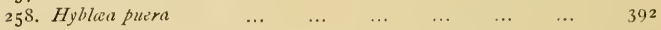

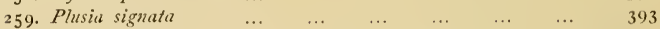

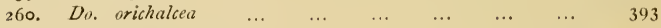

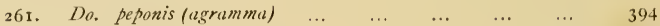

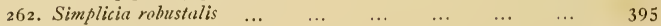

$\begin{array}{lllllllll}\text { 263. Orgyia postica } & \ldots & \ldots & \ldots & \ldots & \ldots & \ldots & 395\end{array}$

$\begin{array}{llllllll}\text { 264. Olene mendosa } & \ldots & \ldots & \ldots & \ldots & \ldots & \ldots & 396\end{array}$

$\begin{array}{llllllll}\text { 265. Psalis securis } & \ldots & \ldots & \ldots & \ldots & \ldots & \ldots & 397\end{array}$

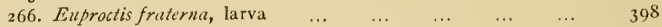

267. Do. do. moth $\begin{array}{llllllll} & \ldots & \ldots & \ldots & \ldots & \ldots & 398\end{array}$

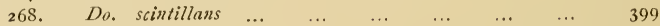

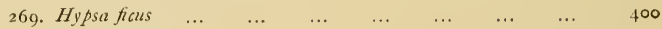

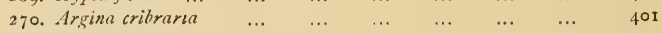

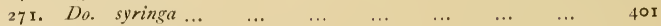

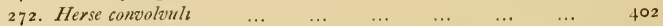

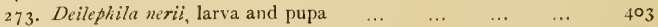

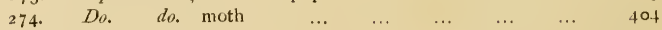

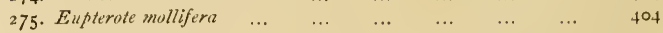

$\begin{array}{llllllllll}\text { 276. Actias selene } & \ldots & \ldots & \ldots & \ldots & \ldots & \ldots & \ldots & 405\end{array}$

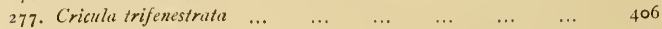

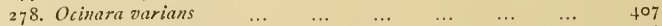

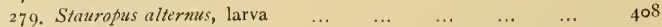

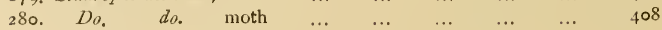

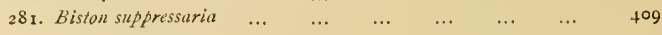


PAGE

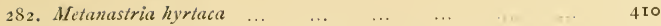

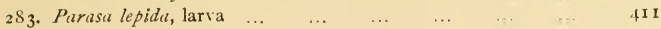

284. Do. do. moth .. ... ... ... ... . I I

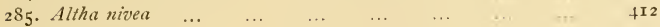

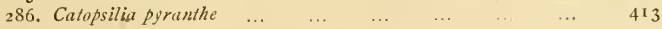

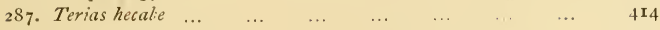

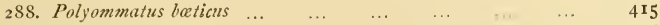

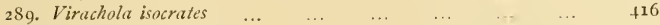

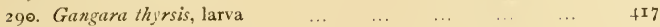

$\begin{array}{llllllll}\text { 29r. } D_{0} \text {. } & \text { butterfly } & \ldots & \ldots & \ldots & \ldots & \ldots & \text { + } \mathrm{I} 7\end{array}$

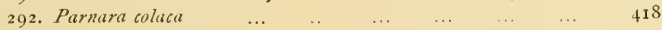

$\begin{array}{llllllllll}\text { 293. Suastus gremius } & \ldots & \ldots & \ldots & \ldots & \ldots & \ldots & +19\end{array}$

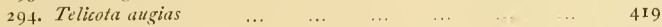

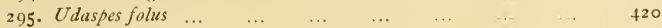

296. Stenachroia elongella $\quad \ldots \quad \begin{array}{llllllll} & \ldots & \ldots & \ldots & \ldots & \ldots & +2 \mathrm{I}\end{array}$

297. Galleria mellonelia, larval webbing over bees' comb 42 I

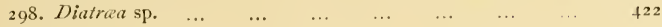

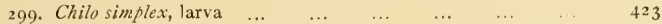

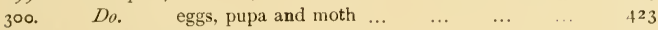

$\begin{array}{lllllllll}\text { 301. Ancylolomia chrysographella } & \ldots & \ldots & \ldots & \ldots & \ldots & 42+\end{array}$

302. Scirpophaga auriflua $\begin{array}{llllllllll} & \ldots & \ldots & \ldots & \ldots & \ldots & \ldots & 425\end{array}$

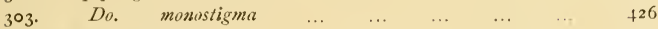

$\begin{array}{lllllllll}\text { 30. Saluria inficita } & \ldots & \ldots & \ldots & \ldots & \ldots & \ldots & 427\end{array}$

$\begin{array}{lllllllll}305 . & \text { Etsella zinckenellat } & \ldots & \ldots & \ldots & \ldots & \ldots & \ldots & +29\end{array}$

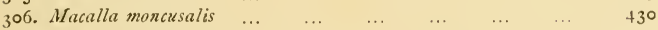

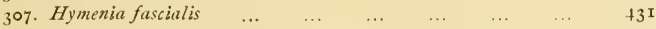

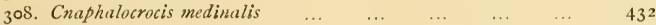

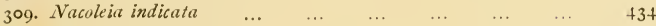

$\begin{array}{llllllllll}\text { 310. } & \text { Do. } & \ldots & \ldots & \ldots & \ldots & \ldots & \ldots & 434\end{array}$

$\begin{array}{lllllllll}3 \text { II. Glyphodes casalis } & \ldots & \ldots & \ldots & \ldots & \ldots & \ldots & +35\end{array}$

$\begin{array}{llllllllll}\text { 312. Do. indica } & \ldots & \ldots & \ldots & \ldots & \ldots & \ldots & 43^{6}\end{array}$

$\begin{array}{llllllll}\text { 313. Crocidolomia binotalis } & \ldots & \ldots & \ldots & \ldots & \ldots & 437\end{array}$

$\begin{array}{lllllllll}3 \text { r } 4 . \text { Hellula undalis } & \ldots & \ldots & \ldots & \ldots & \ldots & \ldots & 438\end{array}$

$\begin{array}{llllllll}315 & \text { Terastia meticulosalis ... } & \ldots & \ldots & \ldots & \ldots & \ldots & 439\end{array}$

$\begin{array}{llllllll}\text { 316. Omphisa anastomosalis } & \ldots & \ldots & \ldots & \ldots & \ldots & +39\end{array}$

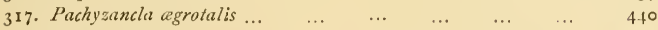

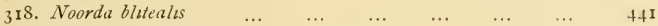

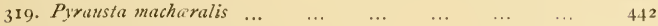

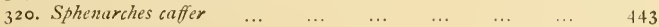

$\begin{array}{llllllll}\text { 32 I. Platyptilia pusillidactyla } & \ldots & \ldots & \ldots & \ldots & \ldots & 4+4\end{array}$

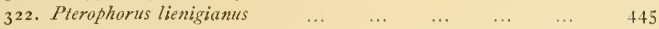

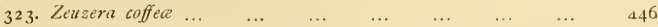

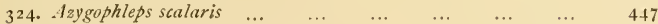

$\begin{array}{lllllllll}\text { 325. Clania crameri... } & \ldots & \ldots & \ldots & \ldots & \ldots & \ldots & 448\end{array}$

$\begin{array}{lllllllll}\text { 326. Heterusia virescens } & \ldots & \ldots & \ldots & \ldots & \ldots & \ldots & 449\end{array}$

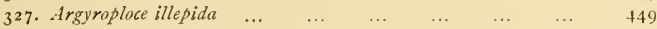

328. Laspeyresia koenigana $\ldots \begin{array}{lllllllll} & \ldots & \ldots & \ldots & \ldots & \ldots & \ldots & 450\end{array}$

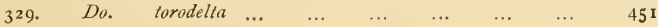


330. Homona coffearia

33r. Sitotroga cerealella

332. Dichomeris ianthes

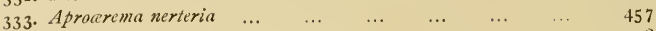

$\begin{array}{lllllllll}33+\text {. Pyroderces coriacella } & \ldots & \ldots & \ldots & \ldots & \ldots & \ldots & 45^{8}\end{array}$

$\begin{array}{llllllllll}\text { 335. Tonica sizyphi... } & \ldots & \ldots & \ldots & \ldots & \ldots & \ldots & 459\end{array}$

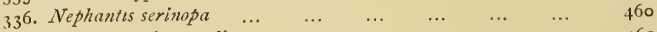

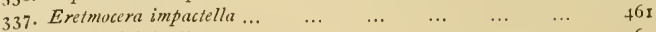

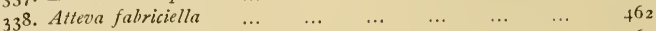

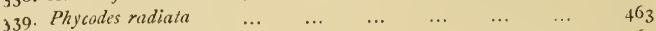

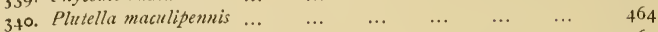

$\begin{array}{lllllllll}\text { 34r. Phyllocnistis citrella } & \ldots & \ldots & \ldots & \ldots & \ldots & \ldots & 465\end{array}$

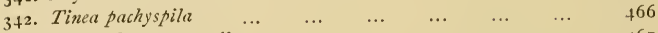

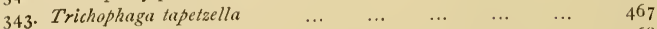

$\begin{array}{llllllll}\text { 3+4. Phassus malaburicus } & \ldots & \ldots & \ldots & \ldots & \ldots & \ldots & 468\end{array}$

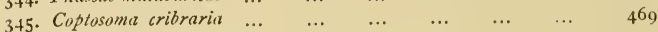

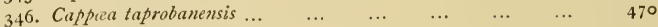

$\begin{array}{lllllllll}3+7 . & \text { Dolycoris indicus } & \ldots & \ldots & \ldots & \ldots & \ldots & \ldots & 470\end{array}$

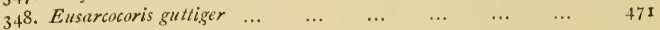

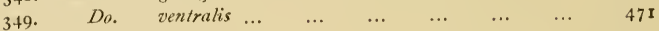

$\begin{array}{lllllllll}\text { 350. Antestia cruciata } & \ldots & \ldots & \ldots & \ldots & \ldots & \ldots & 472\end{array}$

$\begin{array}{lllllllll}35 & \text { r. Agonoscelis nubila } & \ldots & \ldots & \ldots & \ldots & \ldots & \ldots & 472\end{array}$

$\begin{array}{lllllllll}\text { 352. Nezara viridula } & \ldots & \ldots & \ldots & \ldots & \ldots & \ldots & 473\end{array}$

$\begin{array}{llllllll}\text { 353. Piezodorus rubrofasciatus } & \ldots & \ldots & \ldots & \ldots & \ldots & 474\end{array}$

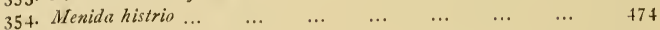

$\begin{array}{lllllllll}\text { 355. Canthecona furcellata } & \ldots & \ldots & \ldots & \ldots & \ldots & \ldots & 475\end{array}$

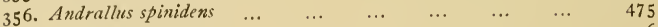

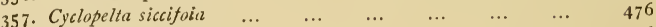

$\begin{array}{lllllllll} & \text { 358. Aspongopus janus } & \ldots & \ldots & \ldots & \ldots & \ldots & \ldots & 476\end{array}$

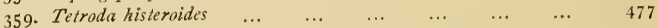

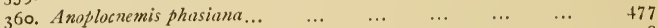

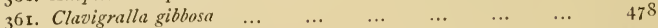

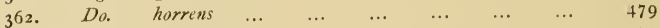

363. Leptocorisa varicornis $\ldots \begin{array}{llllllll} & \ldots & \ldots & \ldots & \ldots & \ldots & \ldots & 479\end{array}$

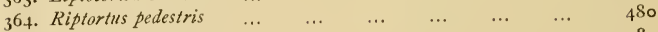

$\begin{array}{llllllllll}\text { 365. Lygaus pandurits } & \ldots & \ldots & \ldots & \ldots & \ldots & \ldots & \ldots & 48 \text { I }\end{array}$

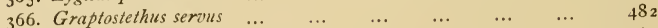

$\begin{array}{lllllllll}\text { 367. Oxycarenus letus } & \ldots & \ldots & \ldots & \ldots & \ldots & \ldots & 482\end{array}$

$\begin{array}{lllllllll}\text { 368. Aphanus sordidus } & \ldots & \ldots & \ldots & \ldots & \ldots & \ldots & 48_{3}\end{array}$

$\begin{array}{lllllllll}\text { 369. Stephanitis typicus } & \ldots & \ldots & \ldots & \ldots & \ldots & \ldots & 484\end{array}$

$\begin{array}{lllllllll}\text { 370. Urentius echinus } & \ldots & \ldots & \ldots & \ldots & \ldots & \ldots & 485\end{array}$

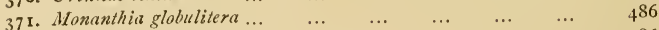

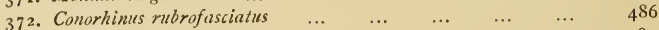

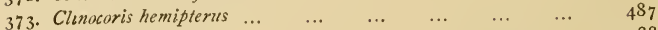

$\begin{array}{lllllllll}\text { 374. Helopeltis antonii } & \ldots & \ldots & \ldots & \ldots & \ldots & \ldots & 488\end{array}$

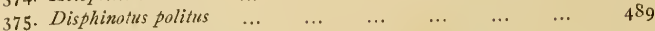

$\begin{array}{lllllllll}\text { 376. Calocoris angustatus } & \ldots & \ldots & \ldots & \ldots & \ldots & \ldots & 490\end{array}$

$\begin{array}{lllllllll}\text { 377. Gallobelicus crassicornis } & \ldots & \ldots & \ldots & \ldots & \ldots & 49 \text { I }\end{array}$ 
378. Ragmus importunitas

379. Eurybrachys tomentosa ...

380 . Phenice masta ...

38г. Pyrilla perpusilla

382. Pundaluóya simpliciu ..

494

383 . Cosmoscarta relata

495

496

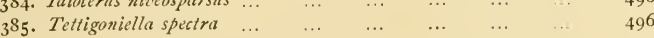

$\begin{array}{llllllll}\text { 386. Nephotettix bipunctatus } & \ldots & \ldots & \ldots & \ldots & \ldots & 497\end{array}$

$\begin{array}{lllllllll}387 . & \text { Empoasca flavescens } & \ldots & \ldots & \ldots & \ldots & \ldots & \ldots & 498\end{array}$

$\begin{array}{llllllllll}388 . \text { Aphis gossypii } & \ldots & \ldots & \ldots & \ldots & \ldots & \ldots & \ldots & \ldots & 499\end{array}$

$\begin{array}{llllllllll}389 . & \text { Schizoneura lanigera } & \ldots & \ldots & \ldots & \ldots & \ldots & \ldots & 500\end{array}$

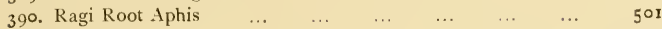

$\begin{array}{lllllllllll}\text { 391. Lachmus pyri } & \ldots & \ldots & \ldots & \ldots & \ldots & \ldots & \ldots & \ldots & 503\end{array}$

$\begin{array}{lllllllll}\text { 392. Oregma bambusa } & \ldots & \ldots & \ldots & \ldots & \ldots & \ldots & 504\end{array}$

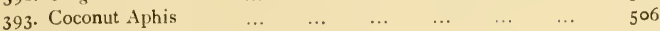

$\begin{array}{llllllllll}\text { 394. Aleurodes bergi ... } & \ldots & \ldots & \ldots & \ldots & \ldots & \ldots & 507\end{array}$

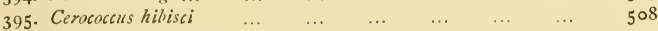

$\begin{array}{lllllllll}\text { 396. Dactylopius citrl } & \ldots & \ldots & \ldots & \ldots & \ldots & \ldots & 509\end{array}$

$\begin{array}{lllllllllll}397 . & \text { Do. } & \text { nipa } & \ldots & \ldots & \ldots & \ldots & \ldots & \ldots & 509\end{array}$

$\begin{array}{llllllllll}398 . & \text { Do. virgatus } & \ldots & \ldots & \ldots & \ldots & \ldots & \ldots & 510\end{array}$

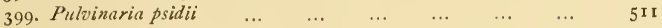

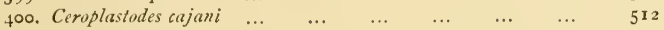

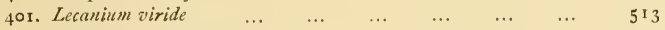

402. Do. hemispharicum $\quad \ldots \quad$...

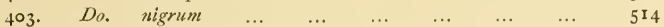

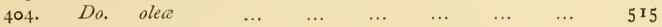

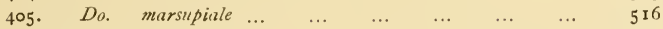

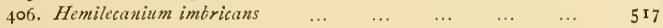

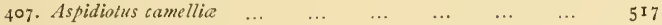

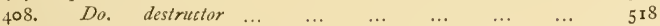

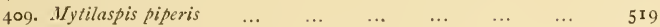

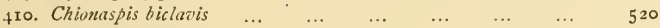

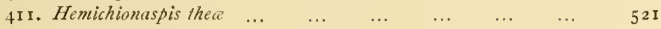

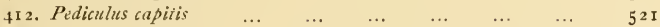

$\begin{array}{lllllllll}413 & \text { Do. humanus } & \ldots & \ldots & \ldots & \ldots & \ldots & \ldots & 522\end{array}$

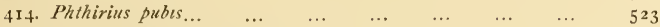

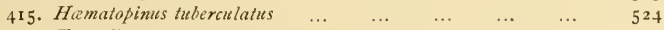

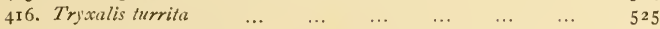

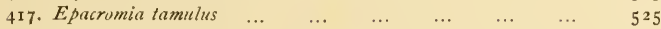

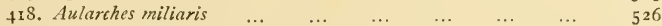

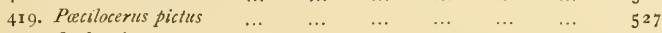

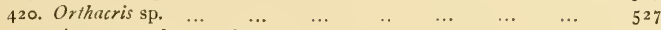

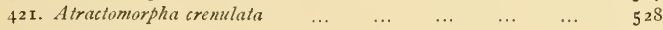

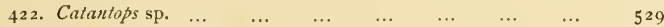

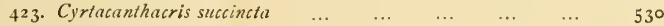

$\begin{array}{llllllllll}424 & \text { Do. } & \text { ranacea } & \ldots & \ldots & \ldots & \ldots & \ldots & 53 \text { I }\end{array}$

$\begin{array}{lllllll}\text { 425. Hieroglyphus nigro-repletus } & \ldots & \ldots & \ldots & \ldots & \ldots & 53^{2}\end{array}$ 


\section{Oxya velox}

427. Schizodactylus monstrosus

428. Gryllotalpa africana ...

429. Ecanthus indicus

430. Brachytrypes portentosus

43r. Liogryllus bimaculatus...

432. Periplaneta australasia

433. Blattella germanica

434. Nala lvvidipes

435. Coptotermes heimi

436. Odontotermes and Microtermes...

437. Thrips ...

438. Ctenolepisma sp.

439. Tetranychus bioculatus...

4fo. Phytoptus carinatus

$\begin{array}{lllll}\ldots & \ldots & \ldots & \ldots & \ldots \\ \ldots & \ldots & \ldots & \ldots & \ldots\end{array}$

533

534

535

535

$53^{6}$

537

537

$53^{8}$

539

$5+0$

$5+1$

$5+2$

543

544

$5+5$ 


\title{
SOME SOUTH INDIAN INSECTS AND OTHER ANIMALS OF IMPORTANCE CONSIDERED ESPECIALLY FROM AN ECONOMIC POINT OF VIEW.
}

\author{
Chapter I. \\ DEFINITION AND STRUCTLRE OF INSECTS. \\ "And whal of insects, present everywhere, \\ Through sea and land, and flitling in the air? \\ Why, half the matter charged with life on land \\ These little crcatures, countless, must command. \\ See how in orders, legions filled, they rise, \\ Living alone, and in communities; \\ From mites so small as scarce to meel the eye, \\ To anl, and hee, and gorgeons butterfly."
}

KNiPE-Vebula to Man.

IN its original meaning the word "animal" signified a breathing being, but a more modern and exact definition would state that an animal is an organism which is able to move and which can assimilate food which must contain proteids. This definition is not exact because there are some plants which can do both of these things; a familiar example is to be found commonly in marshy places in the Hills (as at Ootacamund) in the shape of the Sundew (Drosera), a true plant which captures insects, moves its tentacles into contact with them and assimilates the proteids contained in their bodies. There is in fact no rigid demarcation between animals and plants, and very lowly organisms occur which may be referred with equal propriety to either class; but the point need not be laboured here, because in popular language the ideas of animals and plants are sufficiently distinct.

Animals are divided into many races, or Phyla. The Protozoa, or animals consisting of only a single cell, form the least specialized of these phyla and are usually microscopic in size; the organism which causes malaria may be quoted as an example. All other animals constitute the Metazoa, which consists of many phyla, the more important of which are the Porifera (or Sponges), the Colenterata (Jelly-fish, Coral-polyps, etc.), the Platyhelminthes (Flukes and Tape-worms) the Nemertinea, Nematoda and Annelida (all popularly called "worms"), the Arthroporla (Crabs, Scorpions, Spiders, Insects), the Mollusca (Snails and Shell-fish) the Brachiopoda (Lamp-shells), the Polyzoa, the Echinodermata (Star-fish, Sea-urchins, etc.) and the Vertebrata (Fishes, Frogs, Snakes, Birds, Mammals). 
Of these phyla by far the most numerous at the present day is that of the Arthropoda, a name derived from two Greek words meaning "jointed feet" and applied to these animals because the appendages of the body are composed of segments jointed to one another. More than half a million different kinds of animals, of which accurate descriptions have been published, belong to this single phylum.

The Arthropoda are sub-divided into the Crustacea (Crabs, Lobsters, Shrimps, Water-fleas, etc.), the Arachnida (Scorpions, Spiders and Mites), and the Hexapoda or Insecta (Insects), and it is to the study of this last group that we apply the term Entomo$\log y$, a word derived from two Greek words meaning "insect discourse."

The word "insect" itself, both in its Greek and Latin forms, signifies "something cut into" and is applied to these animals, because the body as a whole is divided by two constrictions into the three separate divisions of head, thorax and abdomen. The name Hexapoda ("six-footed ") is applied to this group, because the true insects are provided with not more than three pairs of legs. Spiders, Scorpions, Ticks and Mites, which are often popularly called "insects," differ from true insects by having the head and thorax fused together to form a cephalothorax and by possessing more than three pairs of legs in the adult state.

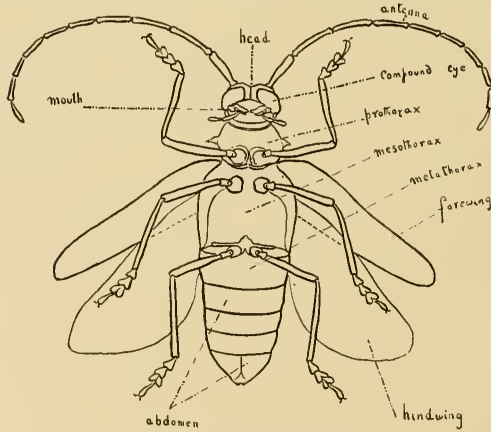

FiG. 1.-Simple external anatomy of an insect

(Batocera rubus), (Original.)
In a typical insect the head is provided with paired mouthparts, compound eyes each composed of a large number of facets, and antennæ each composed of several or many joints, and simple eyes (ocelli) which are often both paired and unpaired. The

thorax, which is itself composed of three segments (pro-, meso-, and metathorax, reckoning from the head tailwards) bears three pairs 


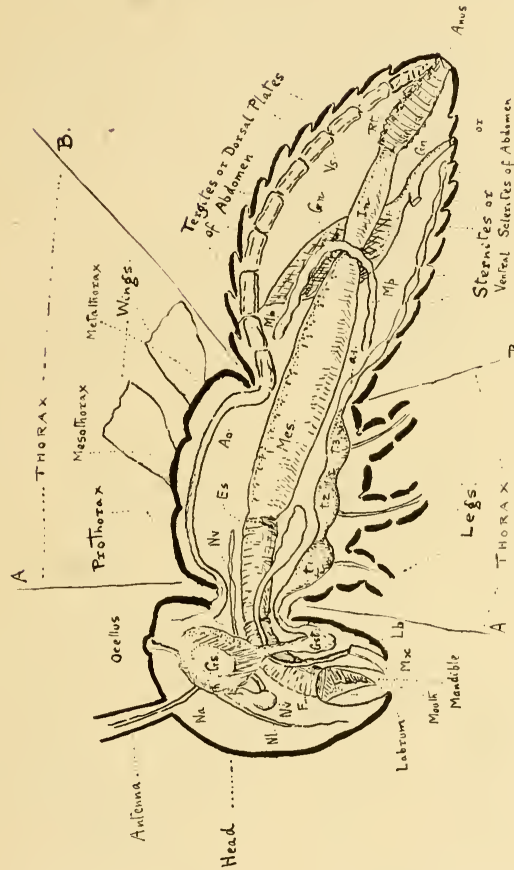

Fig. 2.-Principal anatomical features of an adult Insect. (After Berlese.)

AA. Line of division between Head and Thorax and (BB) between Thorax and Abdomen; Na, Antennary Nerve; N1. Labral Nerve; Nv, Nerve-ganglia: F, Pharynx; Gs, Supra(esophageal Nerve-ganglion; Gst, Sub-csophageal Nerveganglion: Mx, Maxilla ; Lb, Labium ; Es, Esophagus ; Ao, Aorta; Mes, Mid.gut or Stomach; $\mathrm{t} 1, \mathrm{t} 2, \mathrm{t} 3$, Nerve-ganglia of thoracic segments; a1, Nerve-ganglia of abdominal segments; Mp, Malpighian Tubules; In. Intestine: Rt, Rectum; Gn, Genital System; Or, Genital Opening; Vs, Dorsal Pulsating Vessel.

ed under the heads of Nervous System, Respiratory System, Circulatory System, Alimentary System, and Reproductive System.

of $\mathrm{jointed}$ legs, one affixed to each $\mathrm{se} \mathrm{g} m \mathrm{e} n \mathrm{t}$, and the two posterior segments each bear in addition a pair of wings. There may also be one or more pairs of

$m$ spiracles or breat hing pores. The a b d o m e n, consisting of about eleven $\mathrm{s}$ e $\mathrm{g} m \mathrm{~m} \mathrm{n} \mathrm{s}$, bears only the spiracles and genitalia as a rule, although in some forms there are e $\mathrm{xt}$ e r n a l a ppendages such as cerci. setæ, forceps of earwigs and Japy gids, etc.

The internal anatomy, so far as it need be considered here, is s ufficient 1 y simple and may be treat- 


\section{The appendages of the Head.}

Figures I and 2 show the main facts of the simpler anatomy of insects. The mouth-parts are of such various forms in the different groups that no general account can be attempted here and we can only state that the mouth-parts are usually adapted either for biting the food or for sucking or lapping juices, but sometimes, as in bees, the mouth-parts may partake of both characters and occasionally they may be quite atrophied. (See figures 3, 4 and 5.)
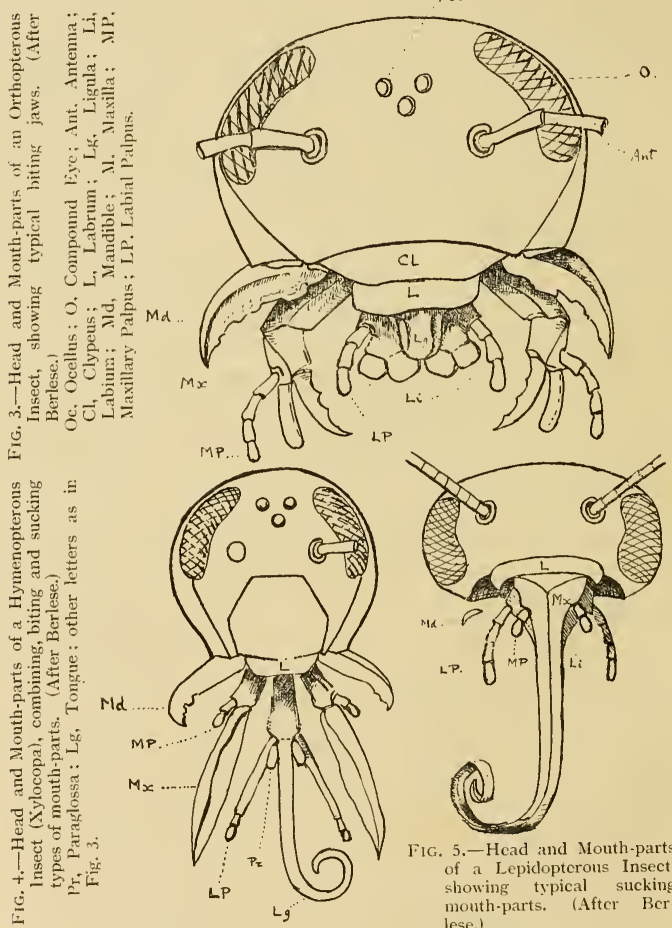

FIG. 5.-Head and Mouth-parts of a Lepidopterous Insect, showing typical sucking mouth-parts. (After Berlese.)

Letters as in Fig. 3. 
The antennæ, a pair of organs situated on the top or front of the head, are movable at the will of the insect and are usually long threadlike appendages composed of a variable number of joints. The shape and telative proportions of these joints are very various and in many families are of great importance as a means of distinguishing between different groups of insects. The antennæ contain delicate olfactory bulbs and are apparently also connected with the faculty of flight. The various shapes exhibited by the antennal joints have caused the bestowal of different names to indicate the various structural types, and of these the commonest are :-

sctaceos, when the size of the joints gradually decreases to a point at the apex or tip, as is the case in Crickets,

filiform, or threadlike, when the joints are cylindrical and of the same thickness throughout, as in many Carabidæe and Termites,

moniliform, or beadlike, when the joints are globose, like beads strung on a string,

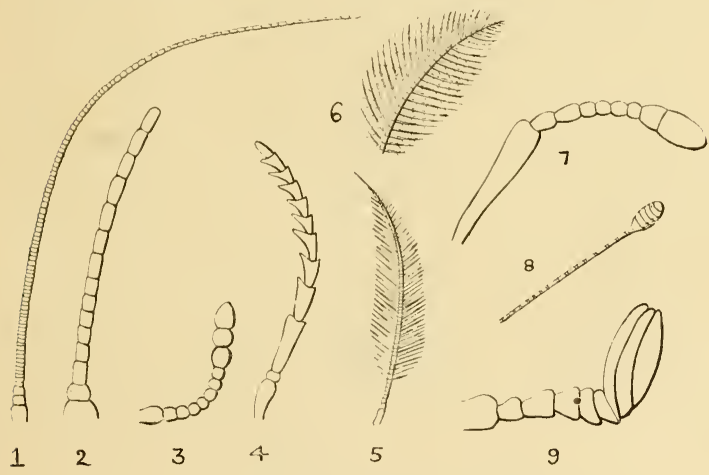

Fig. 6.-Common types of Antennæ. (Original.1

1, Setaceous; Periplancta americana (Blattidæ) : 2, Filiform ; Cyrtacan. thacris ranacea (Acrididæ): 3. Moniliform : Trachclizus politus (Brenthidæ): 4, Serrate; Dorysthenes rostratus (Cerambycida): 5, Pectinate; Gongy. lus gongylodes, male (Mantidx) : 6. Plumose; Orgyia postica, male (Lymantriadæ): 7. Clavate; Episomus montanus (Curculionidæ): 8, Capitate; Rapala jarbas (Lycænidæ): 9. Lamellate: Heliocopris buccplualus (Scarabæidæ).

serrate, or sawlike, when the joints are triangular with a sharp projecting anterior angle, like the teeth of a saw, 
pectinate, or comb-like, when the joints have long processes jutting out sideways, like the teeth of a comb. These processes may project on one side only, when the antenna is called unipectinate, or on both sides, when it is called bipctinate. When these branches are themselves fringed with hair the antennæe are said to be pinmosc,

clavate, or clublike, when the joints become gradually broader towards the tip, so that the whole antenna assumes the form of a club,

capitate, or knobbed, when the terminal joint or joints form a projecting club, as in most Butterflies,

lamellate, when the terminal knob is composed of expansile broad, flat leaves or plates, as in Cockchafers.

The antennæ are often different in form in the two sexes, those of the male (many moths, Gongylus) being of ten extensively branched whilst the same organs in the female are simple. The object of the branching in these cases is to secure a maximum area of sensitive surface for the reception of sexual odours diffused by the female, and this end is attained in more generalized insects $(c, g$., Adelidæ) by simple repetition of joints so that the antenna is many times the length of the whole body of the male insect.
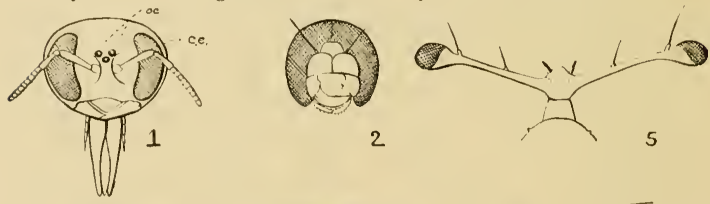

2

5
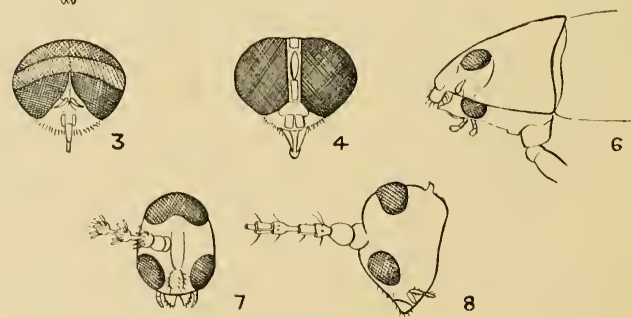

8

F1G. 7.-Various forms of Eyes in Insects. (Original.)

1, Xylocopa iridipennis (Hymenoptera), c.e. Compound Eye, oc. Ocelli ; 2, Pantala flavescens (Odonata); 3, Tabanus striatus (Diptera), male, and 4 , female of the same; 5 , Tcleopsis sykesii (Diopsida): 6, Orcctochilus scmivestitus (Gyrinidæ); 7,8, Trisopsis olece (Cecidomỵiadie), frontal and lateral views. (After Kieffer.) 
The eyes of insects are of two kinds, simple eyes (called ocelli) and compound eyes, but either compound eyes or ocelli may be totally absent, as in most Termites. The ocelli vary in number from one to twenty or more; when few in number they are generally situated on the top of the head, but when numerous they are usually grouped on either side of the head. They are frequently obsolete and often, even when present, are covered with scales and apparently functionless in the adult insect. The compound eyes, which are peculiarly characteristic of insects and are practically only found in adult insects, are composed of numerous separate and self-contained eyes whose exposed surfaces form numerous facets of which the whole eye is composed. The compound eyes, each of which may contain thousands of facets, * are usually paired and placed on either side of the head, but their shape and position is often much modified in accordance with the habits of the insect concerned. In the predaceous Dragonflies the eyes may occupy practically the whole surface of the head and this is also the case in the males of Tabanid flies, whose females have large but normal eyes. In the Diopsidæ the eyes are placed at the extremities of long hornlike stalks which project on either side of the head and it has been suggested that this arrangement provides increased accuracy of vision on the principle of a range-finder; these flies are supposed to be predaceous, but very little is known of their habits. In the Gyrinidæ, which are the well-known "Whirligig Beetles" so' commonly seen on the surfaces of ponds and streams, the compound eyes are each divided into two portions, so that the beetle is able to see both above and beneath the water whilst it is swimming on the surface. In a curious little fly lately described from South Africa the compound eyes are three in number, one on each side and one on top of the head; the object of this triple distribution is not apparent. It may be added that the lenses of the compound eyes are often unequal in size and shape in different portions of the eye and that this fact is sometimes useful for the discrimination of species.

\section{The appendages of the Thorax.}

The legs are affixed in pairs to the lower surfaces of the three thoracic segments and are hence six in number. They are almost always present both in the larval and perfect stages, although there are many totally legless larvæ, especially amongst the Diptera and Hymenoptera, whilst in the adult insect some of the legs may be specially modified, obsolescent or obsolete. In the

* The number of facets in each compound eye is very variable; in some ants there are only about 50 , in dragonflies there may be as many as 12,000 and in some beetles (.1Yordella) more than 25,000 . 


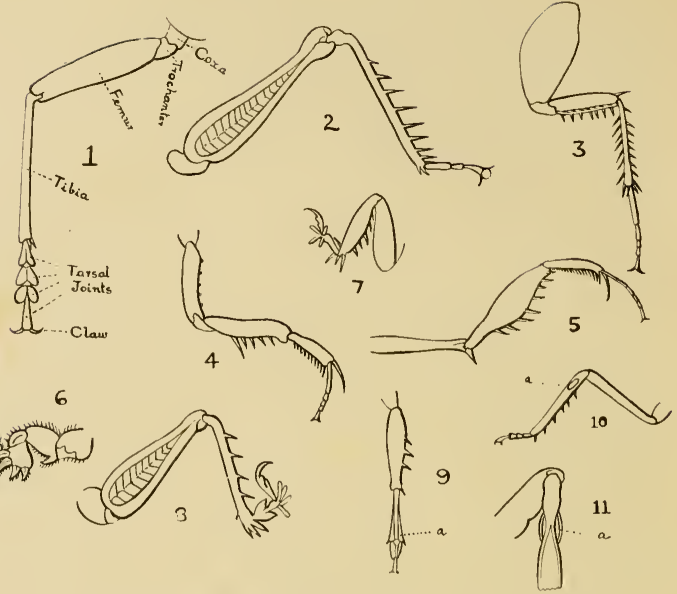

F1G. 8.-Various forms of Legs in Orthopterous Insects. (Original.)

1, Typical Leg of walking Insect, showing division into joints; 2, Jumping Leg (Cyrtacanthacris ranacea); 3, Running Leg (Hind) of Periplancta americana; Predaceous Forelegs of (4) a Mantid and (5) Gongylus gongylodes; Digging Forelegs of (6) Gryllotalpa africana and (7) Schizodactylus monstrosus-note thickened tibia of latter; 8 , Hindleg of $S$. monstrosus with accessory tarsal lobes; 9. Swimming Hindleg of Scclimena-note lateral expanded margin at $a$; Forelegs of (10) Mecopoda elongata and (I1) Sathrophyllia rugosa carrying aural cavities (marked $a$ in each). It should be noted that all these various types of Legs occur within the limits of the single Order of Orthoptera.

adult insect they are ordinarily composed of five distinct portions which (reckoning from the body outwards) are called the coxa, trochanter, femur, tibia and tarsus, these parts being jointed to one another and the coxa to the body, and the tarsus being divided as a rule into a variable (up to five) number of joints and terminating in a pair of claws. The coxa and trochanter are generally small and inconspicuous, but the former is large in the case of cockroaches. All the parts, but especially the tibia and tarsus, may be provided with hairs, spines, spurs or other appendages which are used for particular purposes, or the whole leg may be modified to fulfil a special purpose; as instances of this may be specified the 
jumping legs of grasshoppers, the modification of the structure of legs to accord with swimming, burrowing or raptorial habits, and the peculiar legs of bees which are used for the collection and transport of pollen.

The legs, though primarily used for the purpose of walking, occasionally assume other functions, such as tactile organs. The manner in which Musquitos hold up their hindlegs to detect the approach of any danger is well known to everybody, whilst other insects (Chironomidæ, Micropezidæ) use their forelegs in somewhat the same manner. The legs may also be used for stridulatory purposes, as in many grasshoppers, or may contain auditory organs, as in the Phasgonuridr.
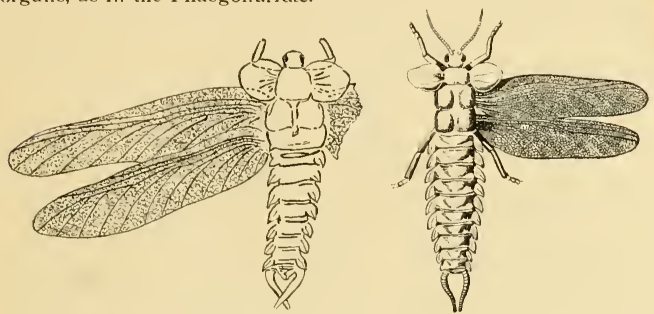

FIG. 9.-Stenodictya lobata, a Carboniferous Insect, showing prothoracic lobes.

The left-hand figure shows the original fossil. that on the right is a restoration of the insect by Handlirsch. (After Berlese.)

The wings are placed as a rule on the upper surface of the two posterior segments of the thorax, but either or both pairs are not infrequently obsolescent or quite absent. In the earliest insects it is probable that three pairs of wings were originally present, traces of a pair of prothoracic wings being seen in some of the earliest known fossil insects such as Stenodictya lobata, which lived millions of years ago in the Carboniferous Epoch. But even at the present

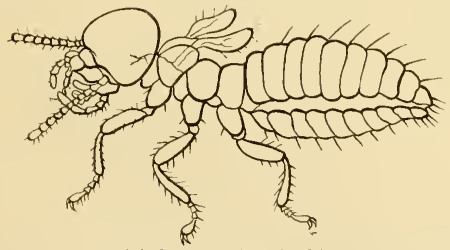

FIG, 10.-An in.nature Sinhalcse Termite (Arrhinotermes flarus), 275 mm. long, bearing rudimentary prothoracic wings. (After Bugnion.) 
day occasional traces are found of this primitive tendency, as may be seen in figure Io, which shows an inunature nymph of a Sinhalese Termite. The fact that all known adult modern insects have concurred in the nondevelopment of the prothoracic wings seems to lend some support to the idea of a monophyletic descent of the Hexapods.

The wings are composed of two layers, each a thin membrane of chitinous material, between which there may be tracheæ. Each layer is traversed by horny ribs or nervures, often loosely hut incorrectly called veins, which serve as a framework for the support of the wing. The size, shape, number and interconnections of these nervures are extremely various although usually fairly constant in general pattern in each group of insects and they are thus of great importance for purposes of classification for which they have been used especially in the case of the Lepidoptera and

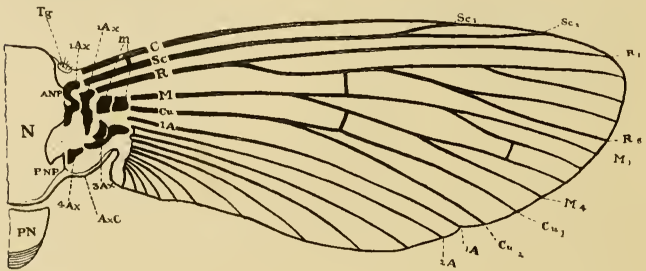

FiG. 11.-Diagram of a generalized Insect-wing. (After Snodgrass, U.S.A. Techn. Bull. No. 18.1

C, Costa. Sc, Sub.costa, typically dividing into two branches Sc1 and Sc2. $\mathrm{R}$, Radius dividing dichotomously into five branches $\mathrm{R} 1-\mathrm{R} 5$, the anterior fork of the first branch remaining single. M, Media, dividing into four branches, $\mathrm{M} 1-\mathrm{M}+$. Cu, Cubitus, which is again two-branched, $\mathrm{Cu1}, \mathrm{Cu2}$. The remaining single free veins at base of wing are Anals, 1A, 2A, etc. The cross-vein between $\mathrm{C}$ and $\mathrm{Sc}$, near base, is the Humeral Cross-vein; that between $\mathrm{R}$ and II near centre of wing is the Radio-medial Cross-vein ; that between $\mathrm{M}$ and $\mathrm{Cu}$ near centre of wing is the Medio-cubital Cross-vein; that between $\mathrm{M}_{2}$ and $\mathrm{M} 3$ is the Median Cross-vein. The areas enclosed by cross-veins are called cells.

Diptera. As the wings in all insects are presumably modifications of one original pattern, many attempts have been made to prepare and name one general type of neuration applicable to all modern insects, but no system of this kind has hitherto met with general acceptance. An example of a generalized type of insect neuration is shown in figure II but in practice it is often extremely difficult to 
compare the patterns of neuration exhibited by wings of insects belonging to widely-separated Orders.

The wings themselves are usually more or less triangular but the shape is extremely various and often greatly modified. The wings may, for example, be deeply cleft (as in the Pterophoridæ

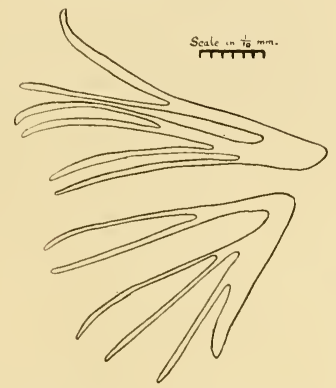

FIG. I2.-Wings of Orncodes-microscopica, showing deep clefts, Iuthor's original sketch from Spolia Keylanica.)

and Orneodidx), extremely elongated (as in the hindwings of some Nemoptera), or modified to form stridulating organs (see figure 26). They may be naked or covered with hairs or scales or both. The portion which is articulated to the thorax is called the base of the wing, the anterior margin which is nearest to the head is called the costa, the margin opposite the base is called the termen or outer-margin, whilst the posterior edge is called the dorsum or inner-margin. The tip of the wing at the junction of costa and termen is called the apex and that at the junction of the termen and dorsum is called the tornus or inner angle.

\section{The Abdomen and its appendages.}

The abdomen, or body proper, consists of about eleven more or less similar segments, although many of these are often greatly modified and are difficult to trace, so that not more than seven or eight may actually be visible. The abdomen is often remarkably extensile, this mobility being permitted by the arrangement of the segments which are arranged below one another during contraction (see figure 2) but which can be widely separated by the extension of the membrane which connects them. Along the sides of the abdomen are found the spiracles (see Respiratory System) and the extremity of the body may be provided with cerci or other 
appendages. In some insects the cerci may be long, many-jointed organs, not unlike antennæ, as in some Mantidæ; in others (most Termites) they may be quite short and comprise only a very small number of joints; whilst in the majority of insects they are quite absent. In the Earwigs and Japygidæ a pair of horny, hooked forceps is present at the end of the body. In many female insects special organs for the deposition of eggs may be present and these may normally be concealed within the body, being extensile at will, or may be placed permanently outsicle the body, in which latter case more especially the instrument is called an ovipositor (Lat. egg-placer). In some insects (e.g., Ichneumonidæ) the ovipositor may be a narrow threadlike appendage longer than the whole insect, or it may be broad and sword-shaped (e.g., Mecopoda elongata) or provided with special digging appendages (c.g., Cicindelidæ) or other apparatus for the successful deposition of the eggs. The tip of the body may also carry tufts of hair which are detached by the female as a covering for the eggs.

\section{The Nervous System.}

The Nervous System in insects is fairly simple in general structure and consists of three divisions, (I) the cephalic system or brain, (2) the ventral ganglionic cord with its branches, and (3) the nervous system of the alimentary tract. The cephalic system consists of two main masses, a larger and very complex one placed above the œsophagus and hence called the supra-œsophageal ganglion (Figure 2, Gs) and a smaller one, placed below the œsophagus and therefore known as the sub-œsophageal ganglion (Figure 2, Gst), these two ganglia being connected to one another by a strip of nerve-material passing on either side of the gullet. The supra-œsophageal ganglion is connected with the nerves running from the eyes, antennæ, and other sense-organs of the head, whilst the sub-œsophageal ganglion connects directly with the nerves of the mouth-parts. These two great ganglia, or bunches of nerves, are intimately connected with the ventral ganglionic cord which runs along the ventral side of the thorax and abdomen (Figure $2, t_{1}, t_{2}, t_{3}, a_{1}$ ), throwing out from the main masses smaller nerves which run into the limbs and body. In the more highly developed insects these ventral ganglia are reduced in number and increased in size, being sometimes massed in the thorax to form what may be called a thoracic brain ; but in the more generalized types, the ganglia are smaller and more numerous. It is usually the case that larvæ show a more generalized type of nervous system in this respect in comparison with the perfect insects into which thev subsequently develop. The third division 
of the Nervous System, that of the alimentary tract, consists of small and obscure nerves in connection with the posterior part of the digestive system.

\section{Respiratory System.}

Insects are as a rule air-breathers and take in air through special holes (spiracles or stigmata) placed along the sides of the abdomen and thorax, thus differing widely from the higher animals which breathe through the head. The thoracic spiracles are usually reduced to a single pair situated in the prothorax but sometimes (as in Pulicidæ) all three pairs may be present. The spiracles, which can generally be opened and closed at the will of the insect, are defended against the entrance of foreign bodies by various devices, of which we may mention here the hairs found on the body of many Lepidoptera and Diptera and the waxy excretion produced by many Scale-insects. The spiracles communicate with a chamber opening into a system of tubes (tracheæ) which lead the air into contact with the chyle. In some insects, especially those living in a wet or moist environment, there are often peculiar structural modifications to enable air to be obtained; the larva of the dipterous fly Eristalis, which is commonly found in small accumulations of water in tree-trunks, etc., has a long extensile tube which can be thrust up to the surface of the water. Many aquatic insects, however, obtain their air supply directly from the water by means of pseudo-branchiæ, which are usually flat plate-like out-growths, often fringed with hairs, occurring along the sides of the body; the Ephemerids (Mayflies) are familiar examples and almost any paddy-field will yield specimens of Nympluula depunctalis (see Plate XXXII) in which the pseudobranchiæe are seen as a series of delicate filaments all down the body. It is because this caterpillar breathes in this way that it is controlled by draining the water off the rice fields.

\section{Circulatory System.}

Insects do not possess a closed Circulatory System as found in the higher animals in which the blood is circulated in special vessels (veins and arteries), but insects have a single vessel, pulsating in parts, through which the circulating liquid flows and runs through the spaces (lacunæ) of all the organs, being regulated in its course by special diaphragms which, in the shape of movable connective membranes, divide these lacuna into chambers variously disposed. So that the circulation is partly vascular and partly lacunar. The dorsal pulsating vessel (Figure 2, Vs), also 
called the propulsory apparatus or commonly (but incorrectly) the heart, may often be seen, especially in internal-feeding larvæ, beneath the skin in the central part of the back. By the pulsatory action of this tube, the circulatory fluid is drawn into the small openings (osteoli) occurring along that portion (ventriculus) which lies within the abdomen and driven forward through the thoracic and cephalic portions (aorta. Figure 2, $A o$ ) into the head, whence it flows back outside the tube and into the various organs of the body. The fluid itself is often improperly called blood but more correctly chyle; it is usually colourless, or slightly tinted green or yellow and consists of two parts, a fluid part (serum or hæmolymph) in which swim active amoboid bodies (amcebocites; also called leucocytes, phagocytes, etc.).

\section{Alimentary System.*}

The Alimentary System lies along the middle portion of an insect throughout the whole length of the latter. The food is received through the mouth into the osophagus or pharynx (Figure 2, F) whence it passes into the crop and thence (through the proventriculus when this is present) into the stomach or midgut (Figure 2, Mcs), and from thence into the small intestine $(I n)$ and on into the large intestine or rectum $(R t)$. At the junction of the stomach and small intestine are found the Malpighian tubules $(M p)$, which are almost always present, though variable in number and hence sometimes used for classificatory purposes; they are believed to function, much like kidneys in the higher vertebrates, for the excretion of urates from the system.

\section{Fat Glands and Stink Glands.}

Of the internal organs connected with the Alimentary System it is only necessary to mention here the Fat Bodies, which atre often immensely developed, and the Stink Glands which sometimes open into the rectal aperture, as in many Coleoptera.

\section{Reproductive System.}

In its main features, the type of the reproductive system is comparatively simple. In the male the internal organs consist of testes and accessory glands (both usually paired but sometimes multiple, though always symmetrical) and paired seminal vesicles leading into a common ejaculatory duct which in turn leads into

* In this and similar accounts the reader must remember that only very general descriptions are possible in a look of this nature and that more advanced treatises must be cunsulted for the elucidation of details. The Alimentary System in particular is extrenely variable in structure and the relative proportions of parts in different insects. 
the protrusible penis. In the female there are generally paired ovaries from which the eggs are discharged through the oviducts into a common tube (the vagina) into which also runs the open end of the spermatheca or receptacle in which the male spermatozoa are received and stored. The ovipositor, which as its name implies, is the instrument by which the eggs are placed in position, assumes very different forms in different groups, and is often placed externally, as in many grasshoppers, Ichneumon-flies, etc.; when internal it is capable of protrusion often to a considerable extent. Besides the actual sexual organs there are also in both sexes various accessory structures; in the male, for example, there is frequently a complex armature of chitinous hooks and claspers which often differ in character in species otherwise hardly distinguishable and which are thus of great assistance in systematic work; and in the female there may be sebific glands, such as occur in various grasshoppers, which pour out a gummy fluid which cements the eggs into a mass and at the same time gives them it protective covering. A great deal of work has been done on the spermatogenesis and oogenesis of insects but this subject cannot be entered into here.

Fertile reproduction is generally attained in insects, as in the higher animals, by the union of the two sexes but occasionally aberrant forms of reproduction are met with. Of these the commonest is Agamogenesis (a name derived from Greek words meaning "birth without marriage"), commonly called Parthenogenesis (Greek, "virgin-birth"); in this case the female lays fertile eggs without the intervention of the male and this phenomenon is the normal mode of reproduction in the case of many Aphids and is also commonly met with in some other groups (scale-insects, bees, and moths).

The case of the honey-bee is well known but is of considerable interest. The queen-bee has the power of withholding the passage of spermatozoa from the spermatheca in which these are stored. When eggs descend from the ovary, if the queen-bee allows spermatozoa to issue, the eggs are fertilized and become females, workers or queens according to the food on which the young larvæ are fed. If, however, exit of spermatozoa is prevented by the queen-bee (or if she is old and the spermatozoa exhausted) the unfertilized eggs only develop into males (drones). The name Pedogenesis is given to cases in which agamogenetic reproduction occurs in the larval stage and this is known to occur in a few Diptera and Coleoptera (Miastor, Chironomus, Micromalthide). A minute wingless fly (Tormitoxcnia), commonly found in Termites' mounds in India, is reputed to be hermaphroditic, combining both 
male and female reproductive organs in the same individual, but this point has been disputed and must be considered for the present as sub judice. In the case of a few Braconid parasites, there occurs the phenomenon of Polyembryony, in which a single egg divides to give rise to several embryos. Finally, we may make a brief reference to the phenomenon of Hypergamesis, found in some Heteroptera (c.g., the Bed-Bug, Clinocoris lcctularins) in which the great mass of spermatozoa take no part in the actual work of reproduction, which is accomplished by relatively few of the male cells, but are stored up in the body of the female and serve as a source of nutriment for the development of the eggs. But it may be added that the actual facts regarding most of these abnormal methods of reproduction are still open to doubt. 


\section{Chapter II. \\ CLASSIFICATION AND NOMENCLATURE. \\ "Our little systems have their day ; \\ They have their day, and cease to be."}

TENNYSON-In Hemoriam.

"Nomina Insectorum distincte tradere convenit. Nomina si pereunt, perit et cognitio rerum ; nomina si confundantur, confundantur omnia necesse est."

FABRICICs-Philosophia Entomolegica

T-HE correct classification of insects is a problem which has exercised the minds of entomologists for at least three centuries and that various systems and schools of thought are in existence at the present day affords perhaps the best proof that the problem is not so simple of solution as may at first appear.

The casual observer who walks through a field and sees grasshoppers jumping away before his advance may think that grasshoppers are easily defined as insects that jump. But such a definition would also include many other insects, such as fleas and sonze bugs and beetles, which no one would call grasshoppers. A fly, it may be said, is easily distinguished by having only one pair of wings; but other insects, such as the males of some scaleinsects, share this similarity yet differ from flies in many other - respects. Bees and wasps may be defined as stinging insects, but many caterpillars can sting just as badly, whilst the males of the bees and wasps have no sting at all. Caterpillars of butterflies and moths may be said to feed on leaves, but so do those of sawflies, beetles, etc. Such definitions-or, it would be better to say, such popular generalisations-have very little value, but they may serve at the same time to give some idea of the difficulty of classifying such an enormous assemblage as the world of insects by characters either natural or easily observed.

The systems of classification generally used have been based as a rule on the structural characters of the adult insect, especially on those of the wings and mouth-parts, or on the type of metamorphosis or series of changes which insects undergo before attaining the adult condition. Each system has its good points and its bad and neither by itself can be accepted as satisfactory.

A system based solely on the type of wings, for example, might unite grasshoppers and bugs and also flies and scale-insects, whilst the wingless crickets, wasps, moths, fleas, lice, etc., could not be separated at all. The possession of sucking or biting mouth-parts seems at first sight to offer a reliable distinctive character and the nectar-sucking butterflies and moths may be quoted as examples until we find that some of the moths have biting month-parts, and that some insects, such as bees and Thrips, 
have mouth-parts which combine the biting and sucking types. Nor is it always easy to draw any strict line between insects having "complete" and "incomplete" metamorphosis, that is to say, between those insects having a larva differing greatly from the alult and separated in time from the adult by a resting (pupal) stage and those in which the larval stage is mainly separated in appearance and time from the adult by the absence of wings and lack of any pupal period. Termites, for example, cannot be said to undergo any complete metamorphosis, in the ordinary acceptation of the term, yet, in some species at least, there is a period or periods of "nymphosis" scarcely distinguishable from a true pupal period as regards quiescence and structural change. Aleurodidæ also are closely allied in all respects to the Rhynchota, yet they possess a quiescent pupal stage, whilst in their near relatives, the Coccidæ, a definite pupal stage occurs in the case of males, but not in females, of the same species. In other cases, as in the females of some glow-worms, even when the metamorphosis is nominally "complete," there is scarcely any notable difference between the larval and the final form of the insect.

As a matter of fact, it is generally easier to divide insects more or less arbitrarily into groups than it is to divide them into Orders by any one system of classification. Such a remark is an obvious truism, but yet even at the present day one still sees attempts to apply some particular rule-of-thumb method to the classification of insects. The truth is, of course, that insects have gradually evolved during a period of millions of years, from one common ancestor or perhaps from several different types, and that in some cases groups of modern insects originally of the same stem have become extremely different in structure, metamorphosis or other conditions, whilst in other cases groups originally distinct may by convergence have assumed details of structure, metamorphosis, etc., which at first sight are deceptively similar.

No fossil insects appear to have been found in India, but Geology

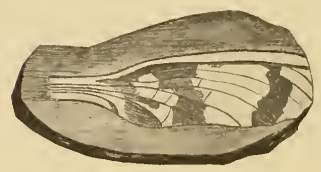

FIG. 13.-Wing of Brodia priscot. incta, Scudder, a Neuropteroid Insect from the Staffordshire Coal-Measures. (Geol. Mag. (2) VIII 293-July 1881.) tells us that insects existed in almost the earliest times (Lower Silurian) of which any fossil records have come down to us. The very earliest insects known are perhaps hardly referable to any of the orders now extant but the three modern Orders of Orthoptera, Neuroptera and Hemiptera were already represented in the Devonian period by forms which, though not strictly comparable with the modern 
representatives of those Orders, already possessed facies which may fairly be called orthopteroid, neuropteroid, and hemipteroid. In the Carboniferous period these Orders, and especially the two former, were clominant whilst the Coleoptera began to make their appearance towards its close. The Lepidoptera, Diptera and Hymenoptera only appeared later, although all of these are known from rocks of the Secondary periol. In the succeeding epoch, however (the

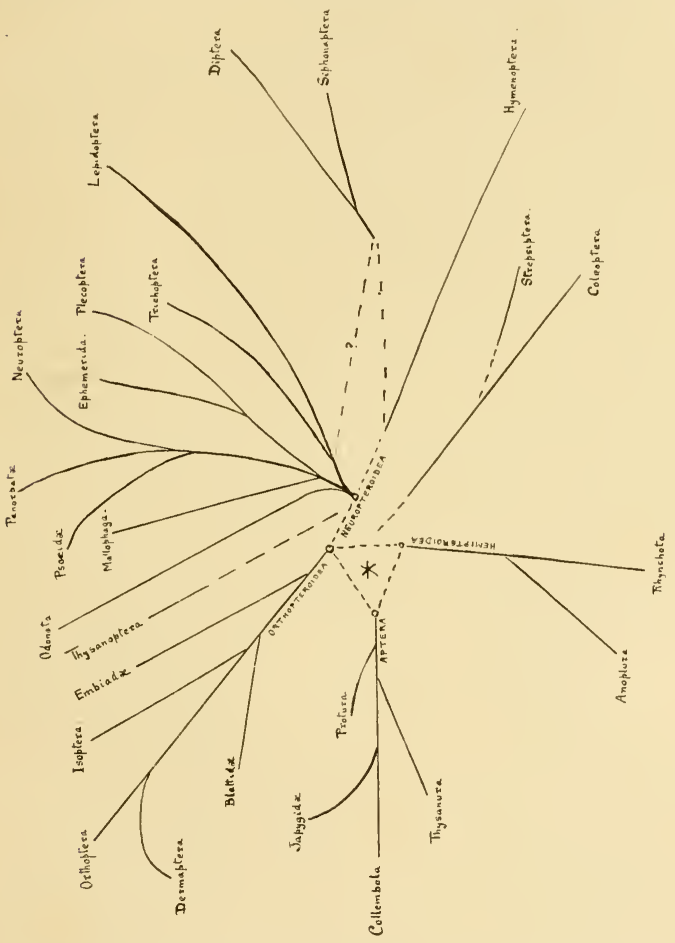

F1G. 1+.-Diagram illustrating supposed Phylogeny of Hexapods. (Original.)

* Marks point of origin. The dotted lines indicate doubtful lines of descent. 
[CHAP. II.

Tertiary), Insects seem to have flourished exceedingly and many of the fossils found in these rocks are referable to genera still in existence.

The scheme of descent of the modern groups of Insects is indicated roughly in figure 14 , but the limitations of an area containing only the two dimensions of length and breadth render it impossible to give a true idea, which will be grasped better by imagining the different stems to be branches emitting twigs and growing at different angles and at various heights from the paper, in some cases convelging together and in others separating widely. It must, of course, be remembered also, in speaking of more recent or more ancient forms, that all existing groups of Insects a re equally far removed in point of time from the archaic members of the Class, and that all that is meant is that some groups have adapted themselves better than others to special conditions.

A glance at figure 14 will show the impossibility of exhibiting the natural relationships of the various groups in any linear method of arrangement.

There are, roughly speaking, two commonly accepted methods of the classification of insects, one system making use of about nine principal Orders, the other of about thirty. Both systems have their good points and their bad, but a system admitting many Orders seems to exhibit in truer perspective the real relationships of its components. The following list exhibits the various groups adopted in this book, arranged in order, commencing with the more specialized and concluding with the more generalized Orders :- -

Gromps aciopted in this
book.

I. Hymenoptera $* \ldots$

2. Coleoptera * $\ldots$ )

3. Strepsiptera ...

4. Diptera *

5. Siphonaptera *...

6. Lepidoptera $\div$...

7. Trichoptera

8. Neuroptera *

9. Panorpatæ

I o. Psocida

I I. Mallophaga

I2. Ephemerida

I3. Plecoptera

4. Odonata *

$\ldots$
$\ldots$
$\ldots$
$\ldots$
$\ldots$
$\ldots$
$\ldots$
$\ldots$
Orders in which the groups in

column I would be placed

in the Nine-Order system

Remarks.

Hymenoptera

Coleoptera

Diptera

Lepidoptera ...
Insects with distinct metamorphosis and with quiescent pupa structurally distinct from the larva.

Neuroptera (part)

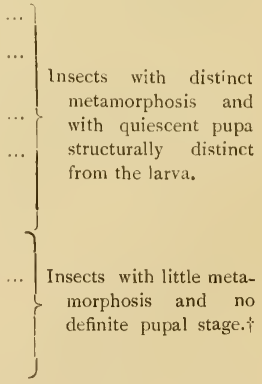

† Except in Aleurodidx and Coccide, two families of Rhynchota, in which a quiescent pupal stage occurs. 
Groups arlopted in this book.
Orders in which the groups in column 1 would be placed in the Nine-Order system.
Remarks.

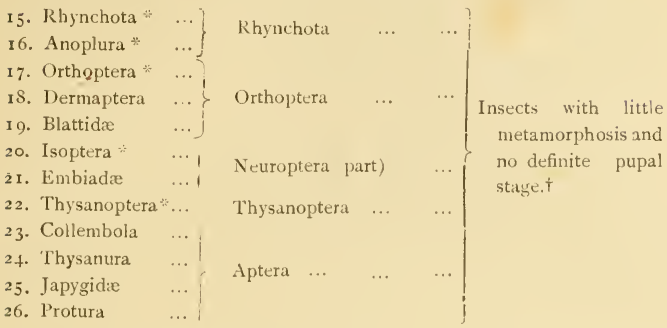

Of these groups, however, only those marked * are of sufficient economic importance to be considered here and the adult insects of these groups may be separated by the following artificial key :--

I

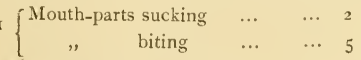

Only one pair of wings $+\ldots$ Diptera (Flies).

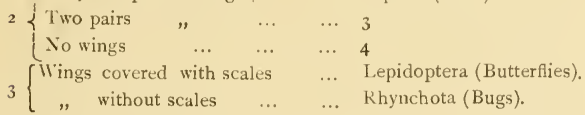

Metamorphosis complete; hind-)

legs usually formed for jumping; $>$ Siphonaptera (Fleas).

not clinging to hairs of host.

4

Metamorphosis incomplete; hind-? legs not formed for jumping; Anoplura (Lice).

legs modified to cling to hairs

of host.

Two pairs of wings of approxi- 6 mately equal size.

5

Two pairs of wings of unequal 8 size.

Antennæe longer than length of 7 head.

Antennæe shorter than lezgth of Odonata (Dragon-flies). head.

+ Except in Aleurodidx and Coccida, two families of Rhynchota, in which a qniescent pupal stage occurs.

$\mp$ Male Coccidx (Scale-insects) form an exception but are not likely to come under non-entomological notice. 
Wings permanent, with strong Neuroptera (Lace-wing Flies). crossveins in central area.

Wings soon shed, without cross- Isoptera (Termites). veins in central area.

The two pairs of wings differing 9

( First pair of wings narrow, membranous, often longer than body, sometimes used as true wings in

Orthoptera (Grasshoppers). flight; metamorphosis incomplete.

9 First pair of wings usually broad, horny, projecting little if at all beyond body, kept erect during flight which is accomplished solely by the second pair of Coleoptera (Beetles). wings; metamor phosis complete.

Minute insects, forewings narrow and oar-shaped; metamorphosis incomplete; no sting.

Minute to large insects, forewings usually more or less triangular ; a sting often present ; metamorHymenoptera (Wasps, etc.). phosis complete.

There are numerous exceptions even to an artificial key of this sort, as, for example, all the wingless forms (such as ants, beetles, termites, etc.) of the Orders which normally possess wings. It is, therefore, hardly necessary to repeat here that it is easier to place insects into groups arranged around typical forms than it is to separate them exactly by any hard-and-fast rules.

Over four hundred thousand different kinds of insects have been described from all parts of the world and of these probably about fifteen thousand are known from Southern India, where at least an equally large number remain to be discovered and described.

By examination and comparison we can place an insect in its appropriate Order, Family and often its Genus and Species, that is, we can say that it resembles other examples so closely that it may be considered identical. But, having done this, we are no nearer knowing whether any information has already been pub. lished regarding this particular insect. Perhaps we find it damag. ing a crop and wish to ascertain whether it has been noted before as a pest and what remedies have been found efficacious. This 
want is met by an artificial system of nomenclature which gives a name to every Order, Family, Genus and Species of animal, every different kind of animal being known by two names, those respectively of the genus and species to which it belongs. A knowledge of these names gives us a key to all that has been recorded about the animals concerned.

In olden times insects, which were then little studied, were known by long descriptive phrases, such as "the brown butterfly which flies in fields in the Summer," and it will readily be understood that such phrases were not only cumbrous but often very vague. In the middle of the eighteenth century, however, Carl von Linné, better known by his latinized name of Linnæus, introduced the binomial system of nomenclature under which every animal and plant known at that time was given two names, a generic name common to each group and a specific name peculiar to each organism. This system was first fully elaborated in the Tenth Edition of Linné's "System of Nature" ("Systema Naturæ"), published in 1758 , and this book and date are taken as the startingpoints of our modern nomenclature.

All names are in Latin or, if derived from other than a Latin word, they are required to be latinized, although of late years it must be confessed that this rule is very loosely interpreted. When binomial nomenclature was introduced, a knowledge of Latin was an essential equipment of every educated man in Europe and books and descriptions written in Latin were therefore intelligible to the educated of all civilized Nations. Even nowadays short descriptions of new insects are often written in Latin and this language remains (nominally at least) the universal vehicle of zoological nomenclature. It is true that the commoner and more conspicuous insects of almost every country have acquired popular names but such names have usually only a very local and limited application, the same insect being known under different names in each country speaking a different language or different insects being known under the same name in different countries, whereby confusion is worse confounded. The "Cotton Bollworm" of America, for instance, is quite a different insect from that to which the same name has been applied in India. And as I write there is before me a popular book on injurious insects, issued in America in I9I2, in which one and the same insect is called in different places the "Potato-Tuber Worm," the "Tobacco Leafminer," and the "Splitworm;" this insect has been called in India the "Potato Moth," and it would be merely a waste of time to hunt up and quote here the various and yet different names under which this same insect is known popularly in England, Germany, France, Italy, 
Russia, etc. But it will readily be seen how little useful would be a knowledge of only one or a few of such names to an inquirer desirous of ascertaining the distribution, lifehistory, or control of such an insect. So-called "popular" names are generally merely sops to ignorance and their use often serves to conceal a want of exact knowledge. Whilst of very limited and inexact application, they are no easier to learn or remember than the proper scientific names, which should always be employed, when known, in referring to any one particular insect.*

Not infrequently it happens that a previous description is overlooked, with the result that an insect, which has already been described and named, is regarded as a novelty and again described and renamed as such. Such cases are dealt with by the Law of Priority which provides that the name which was published first in point of time, if valid, shall be used and that the later-published names shall be sunk as synonyms. As an example of this rule we may quote the case of the common Indian Bedbug which was first described in 1803 under the name of hemipterus and redescribed in 1852 and again in $186 \mathrm{I}$ respectively under the names rotundatus and macrocephalus; the name hemipterus, having priority, must be used, the other names becoming synonyms.

A generic name may not be used more than once in Zoology and a specific name may not be used more than once within the same genus. If names are given contrary to this rule, the latergiven names are invalid. Thus, the name Arbcla was given to a genus of Rhynchota in 1865 and was again used for a genus of moths in 1879; the latter use was invalid, the name being preoccupied.

* The following note on the use of scientific names in California is so a propus that I have no hesitation in transcribing it here :-

"At first glance they may appear rather formiclable to a majority of our readers, but by embracing them at once, will otviate the necessity of associating a popular term, and again later learning the scientific term for many of the intricate actions of insect species ; it will also avoid confusion later on. As an example, when the South African hymenopterous parasite, Siutellista granta, was first presented to the growers of this State a cry aruse inmediately, suggesting that this species simpiy be called "scutes." This, however, met with considerable objections from entomological sources, and the use of the entire name, Siztellista cyanca, became general, and now the State Insectary is in receipt of thousands of letters from various growers over the State, asking for colonies of Sicutilista cyanea. The same rule also applies to the names of onr other beneficial insects. It, therefore, shows that it is as easy for the average layman to embrace the scientific term immediately, as it is sume common phrase, which actually means nothing and is only a source of confusion and trouble throughcut later years."

If scientific names can be adopted so easily in the "Land of Ifurry," where lenglish: is the common language, it should be still easier to introduce their use into India where the English "popular" name is as much an alien as the Latin one. 
A generic name is always written with a capital initial letter. A specific name is always commenced with a small letter even when it is derived from a proper name.

A name, to be accepted as valid, must be (I) published and (2) defined. By publication it is meant that the public can purchase copies of the description in a form other than manuscript and the earliest date on which such matter is accessible is the date of publication. Definition must convey, by description or illustration or both, information sufficient to enable the author's conception to be recognised. A name published without description is therefore invalid; example, Plotheia ncphelotis was published as a name by Lefroy in "Indian Insect Life" but no description has ever been given and this name must therefore be disregarded as a nomen nudum ("bare name").

A valid name, once published, is inviolable and may not be changed even by the author except in the case of a printer's error, for which there is evidence. An exception is made in the case of adjectival specific names, whose terminations may be changed to agree with the gender of the name of the genus in which the species is placed.

The same name may be used for a species as is applied to the genus in which such species is contained. Example: Cossus cossus, All confusion is avoided by the use of different initial letters in each grade.

In writing names of animals we usually add the name (often contracted) of the author of the specific name. Example: Phycita infusella, Meyr.

Names of families are indicated by the suffix $-d c$ and of subfamilies by -na. Such names are usually formed from the name of the oldest (i.e. first published) genus included in them.

It is impossible to enter here into the question of "types," subspecific nomenclature and various other details, which are better suited for discussion in technical publications. The desirability of having a universally accepted and permanently stable system of nomenclature is unanimously agreed upon by systematic and economic workers alike and this result is only likely to be achieved by the acceptance by economic entomologists of the results attained by a rigid application of the rules of nomenclature. In this connection the words written by Spence in 1834 are no less applicable today: "Knowledge as to the structure, habits and economy of insects ought to be the grand and ultimate aim of entomologists; but this knowledge can be neither acquired nor diffused without systematic classification, which is the dictionary that must enable us duly to read the great book of Nature, and to which therefore, 
so long as that dictionary still remains so incomplete, even the largest portion of the entomologist's labours may be justly given, while at the same time no fact, however trifling, relating to the habits and economy of the objects of his study is suffered to be lost, the two great branches of the science, system and the natural history of insects (taken in its largest sense) being made to go hand in hand, and mutually to support each other." 


\section{Chapter III.}

\section{METAMORPHOSIS.}

"There is a differency between a grub and a butterly ; yet your butterfly was a grub."

SHAKESPEARE.

INSECTS, like most other animals, commence their existence in the egg stage and before attaining the adult state undergo a series of changes which are more exactly expressed by the term metamorphosis. In the more primitive and generalized forms, of which the Fish Insect may be taken as a type, the amount of metamorphosis undergone is comparatively slight, the newly-hatched insect differing in little except size from the adult. In the case of a grasshopper, the metamorphosis undergone is also slight, but the adult differs from the young in possessing wings, although some grasshoppers are wingless even in the adult stage. In the more specialized groups of insects, however, the changes between the newly-hatched young and the adult insect are not only considerable but they are abruptly separated by a third stage, different from that which precedes and follows it, in which the insect undergoes a period of quiescent inactivity during which it is known as a "pupa." Of this last group we may cite a butterfly as an example. It may be noted as a general rule that insects with slight metamorphosis usually grow very slowly, whilst those with a pupal stage often complete a generation in a very short period of time, and that (speaking very gencrally and bearing in mind that all existing inscets arc equally far removed in point of time from any common ancestor, although, as pointed aut above, the more specialized insects may be so removed by a greater number of generations than the unspecialized) insects with little metamorphosis are less specialized and approach closer on the whole to the more primitive types of insects than do those with considerable metamorphosis.

The various orders of insects with much or little metamorphosis are shown in the table on pages $20-2 \mathrm{I}$, but it may be useful to compare here the lifehistory of a Butterfly and a Grasshopper, as a type of each class. 

Butterfly
(Holometabolic.)
Grasshopper
(Heterometabolic).

I. Egg stage common to botli.

II. Larva, wingless, active, feeding on different food from adult, growing and moulting, when fullgrown transforming to-

III. Pupa, quiescent, not feeding or growing or moulting, from which emerges -

IV. Imago or adult butterfly, winged, active, (usually) feeding on different food from larva, not growing or moulting but reproducing and (in the case of a female) laying eggs from which the next generation commences.

Summary.-Four stages, each distinct from others.
II. Young insect, wingless, active, feeding on same food as adult, growing and moulting, when full-fed transforming,

(without quiescent stage) to

III. Adult insect, winged, active, feeding on same food as stage II, not growing or moulting but reproducing and (in case of female) laying eggs.

Summary.- Three stages of which the second is comparatively little distinct from the third.

Speaking generally-and only general statements can be made when speaking of all the Orders of Insects as a whole-the presence or absence of a quiescent pupal stage is a factor by which all insects can be divided into two categories, sharply separated from one another, and this division appears to be one of fundamental importance. It is, indeed, largely on this account that we reject the "Nine-Order" system which unites such diversely metamorphosic insects under the heading of "Neuroptera" and interpolates the more specialized Orders between the less specialized.

The ovum or egg varies very greatly in size, shape, ornamentation, and method of deposition in the different groups of insects. In its simplest and probably most primitive form it may be considered as a spherical, colourless, transparent object consisting of a smooth chitinous outer shell enclosing protoplasm which is at first homogeneous. At one point on the shell there is, as a rule, a microscopic depression, called the micropyle or micropylar area, in which occur minute canals leading into the interior of the egg by which the spermatozoa obtain access to the interior in order to unite with the female element for the purpose of fertilization. The micropylar 
asea is usually considered as the apex of the egg, the opposite side being the base, and the intervening portions being called the walls or sides. It follows from this that, in the case of an egg attached to a surface, the attached portion is not necessarily the base. As regards shape, eggs are rarely perfectly spherical but are usually more or less flattened or produced in one or more directions. The outer surface of the shell is sometimes most elaborately sculptured or ornamented, sometimes merely covered with rough pittings or elevations which may be arranged in roughly polygonal reticulations, or may be quite smooth. The method of deposition is equally variable; in some groups the eggs are laid singly, either scattered at random or carefully deposited in, on or near suitable food for the future hatchlings, in other groups the eggs may be laid in a mass sometimes covered with down from the body of the parent or with waterproof varnish or enclosed in a common shell or covering which may exhibit most elaborate structure. Amongst the most familiar of types of egg-masses found in India are those of various Mantids which are so commonly seen attached to twigs, walls, etc. The number of eggs deposited varies very greatly in different insects from a dozen or less (some wasps, probably Hippoboscids) to several hundred or, in some social insects (Honey Bees, Termites), many thousands - perhaps over a million. The embryological development of Insects cannot be discussed here and it must suffice to say that the hatchling insect, when it has attained its full embryonic * growth, escapes from the egg, often by gnawing a passage through the shell with its mandibles in the case of eggs deposited singly, but some larvæ have special organs for opening the shell and others merely rupture it by their contortions.

The term "larva," though often applied to all insects in an active ante-imaginal condition, is better restricted to denote the second stage of those insects which possess a true pupa, the word "nymph" being used for the immature, active stages of those insects in which metamorphosis is slight (grasshoppers, bugs, etc). In popular language, in the case of butterflies and moths the larva is of ten called a "caterpillar," in flies a " maggot," and in beetles and wasps, etc., a "grub," but the term "larva" is more properly used to denote a stage which is strictly homologous in all these four Orders.

* The term "embryonic " is here used as applied to the individual in the inactive egg-state only but the embryonic condition is not strictly completed until the insect has assumed adult characters. Ante-natal conditions in oz'o are best studied in the case of some of the lower moths (Pyralide, Tortricina and Tineina) in which the egg-shell is often so transparent as to facilitate observation of living material. 
A typical larva may be considered as long and cylindrical, somewhat flattened along the ventral surface, and composed of about fifteen segments or rings between each of which the borly is more or less constricted transversely. The first segment is the head, itself composed of four or more sub-segments fused together and not distinguishable after hatching, and this is a more or less chitinous (horny) oval case carrying the mouth with its appendages and (in free-living forms) a small number of ocelli arranged in lunular form on each cheek. The second, third and fourth segments (corresponding to the pro-, meso-, and meta-thoracic segments of the adult insect) each carry a pair of more or less horny legs which terminate each in a single claw. The fifth to fifteenth segments (of which, however, two or more are usually fused together) correspond to the abdomen or body of the adult insect and in free-living forms may carry a variable number of pro-legs which are generally present in the Lepidoptera (not more than five pairs), rarely present in the Hymenoptera (Saw-flies, more than five pairs) and absent in the other Orders. Breathing is provided for by a tracheal system communicating with the open air by means of spiracles which are small round openings found on each side of the second and fifth to twelfth segments in lepidopterous larvæ but in some larvæ (especially some of the dipterous larvæ) the breathing system is very greatly modified. Larvæ living a concealed existence are usually whitish in colour, occasionally reddish, those living an active exposed existence are often highly procryptically coloured or show vivid warning coloration. The larva, when full-fed, casts its skin for the last time and changes into a pupa in which stage it is inactive and motionless except for wriggling or occasional
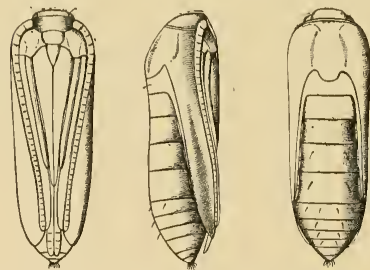

FIG, 15,-Pupa of Orncodes hexadactyla, a Lepidopterous Insect, showing ventral. lateral, and dorsal aspects. (After Chapman.) jumping movements). In the more generalized groups of the Lepidoptera and generally in the Coleoptera and Hymenoptera the limbs of the future perfect insect are more or less separate, each encased in its own pupal sheath, but in the more specialized groups of the Lepidoptera and in the Diptera the appendage sheaths are (so to speak) soldered into the rigid, smooth, uniform pupal shell. In all the holometabolic insects the cocoon-making instinct is 
highly developed, the full-fed larva usually spinning a cocoon of silk or of fragments of vegetable matter spun together with silk, in the shelter of which it pupates and passes its pupal existence; when the larva lives within a case or within a burrow, however, a true cocoon is not formed as a rule and those larvæ which pupate $i n$ the soil generally dispense with a silken covering. In the more highly-specialized groups of Lepidoptera the cocoon is sometimes dispensed with, the pupa being left exposed and trusting to its procryptic coloration to elude discovery by enemies; most of the butterflies, for example, have naked pupæ which are suspended by the tail by peculiar cremastral hooks (Nymphatida) or attached at the tail and girt by a loop around the midalle (Papitionida, Pierida); in such cases there is often a marked degree of individual colour adjustment to agree with environment, and this power is also seen even in the case of some cocoons.

Turning now to the heterometabolic groups, in which metamorphosis is slight, we find that the immature insect, on emergence from the egg, leads an active existence and is (broadly speaking) similar to the adult except as regards the absence of wings, and these may be permanently absent or imperfect in some forms. In these groups the immature insect generally consumes the same food as the adult, whereas in holometabolic insects the food of the larva generally differs from that of the adult insect.

In all cases, whether larva or nymph, the function of the immature active stage is to assimilate nourishment and to grow, and this is often done at an astonishing rate. The immature insect being encased in a more or less horny outer covering which is only capable of expansion within limits, growth is usually accomplished by throwing off this outer skin, such process being termed a mout or ecdysis and the periods between moults being called stadia (singular, stadium) or instars. The frequency of moulting differs in different groups of insects and sometimes varies (as in some grasshoppers) in the two sexes. Usually there are about five moults but the number may be decreased in insects undergoing rapid metamorphosis (e.g., House-fly, with about three moults) or increased in the case of insects whose immature condition is greatly prolonged (e.g., some Cicadida, with $25-30$ moults ${ }^{\circ}$ spread over a period of fifteen years or longer). The process of moulting, which is not

- Observations on the number of moults in long-lived Cicadas have been made in America and it has recently been stated that this number is not so large as had been supposed. Riley's observations, however, were usually accurate and may prove to be so in this case of individuals or races and I therefore leave the above paragraph as originally written.--T.B.F. 
always accompanied by a subsequent increase in size, is also necessitated in order to get rid of the waste products of metabolism induced by feeding and growth.

The appearance of the immature insect often alters very considerably at each or any particular moult, especially in the case of caterpillars, in which the changes of colour and more particularly in the arrangement of the tubercles and primary hairs have often,

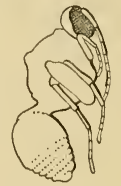

1

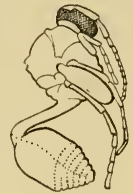

2.

F1G. 16.-Pupa of Eumenes conica (1) newly turned, less than one day old, and (2) the same a week later, showing development of petiole.

The earlier stage show's primitive relationship to ancestral thick-waisted wasps, the development of the individual thus epitomizing that of the race. (Original.)

in the earlier stadia at least, a phylogenetic significance which is of great importance in any natural system of classification. In a few cases, especially amongst parasitic insects (Cantharid beetles, Strepsiptera, etc.), we find more than three immature stages, due to the development of more than one larval form; this phenomenon is called Hypermetamorphosis.

The time occupied by the metamorphosis of any particular insect, that is to say, practically speaking, the life of a single generation, is very variable and may extend from a couple of weeks to twenty years. An average period in Southern India is probably about two months though many pests pass through a generation in a month or less. Some insects may delay metamorphosic changes until the advent of suitable climatic conditions and this may occur in either of the passive (oval or pupal) stages. Thus the eggs may retain their vitality until stimulated by an influence such as moisture, as in the case of eggs of mosquitos of the genus Stcgomyia in which the eggs retain vitality for months in a desiccated condition (such as normally occurs during the dry weather preceding the monsoon in the localities-hollows in tree-trunks, etc.-in which they are deposited), hatching out when exposed to humidity. This is perhaps the case also with some grasshoppers. Or the eggs may not hatch out all at once, but a few individuals of each batch may emerge at intervals during a period of several months (as in the case of Orgyia antiqua) thus ensuring that some at least may meet 
with congenial conditions. Observations on abnormally extended pupal periods have chiefly been made in the case of Lepidoptera in which Order pupæ from one batch of eggs, in the case of some species at any rate, are known to eclose moths, some in the first year after pupation and some in the second and subsequent years up to the seventh or later. Such an irregular eclosion will give the species concerned a better chance of survival by spreading the descendants of one generation over several seasons, some of which are likely to be favourable as regards climatic conditions or scarcity of parasites, and will also tend to secure cross-fertilization between different stocks.

Although, as already noted, insects are usually developed from eggs deposited by the parent female, yet in most groups (e.g., Coleoptera, Lepidoptera, Diptera, Rhynchota) we meet with cases of viviparity, that is to say, the female extrudes, not passive eggs, but active living larvæ. In the Pupiparous Diptera, of which the common Dog-fly is a familiar example, the larva is retained and nourished within the body of the female until it is full-grown, when it is deposited and pupates immediately afterwards. Instead, therefore, of the nutriment requisite to the growth and reproduction of the individual fly being absorbed by the larva directly, it is the adult fly only which feeds actively.

In the great majority of cases the eggs are simply laid by the female which takes no further care of them, and as a rule she dies shortly after having deposited them. Sometimes the dead body of the mother remains by the eggs and forms the first meal eaten by the newly-hatched larvæ. Even in cases where special provision is made for the young, as in the examples offered by the solitary wasps which collect and lay up a store of spiders or caterpillars on which or near which the eggs are laid, instinct rathes than intelligent solicitude seems to be involved, for the cell is sealed and left to its fate. In some cases, however, true instances of maternal solicitude are known to occur and it is not uncommon, for example, to find a mother-earwig watching (one might almost say brooding) over her eggs; on one occasion at Yercaud, on turning over a log, I found a pair of earwigs with a pile of eggs which, when they were disturbed, the female carried away in her mouth into a safer place, whilst the male sought safety in flight. In the Hills also old rotten logs are commonly found to contain Passalid beetles which occur in little colonies, larvæ, pupæ and adults often being found together, and it has been shown that the adult beetles masticate the wood with their jaws to render it fit for the food of the larvæ which are unable to feed by themselves on the unchewed wood. Care for the young by the mother-insect is also well known to occur 
amongst the Rhynchota, in which group the females of several species of Pentatomidæ, Reduviidæ and even of the Membracidæ have been noted to watch over their eggs and young. Amongst the Orthoptera the Mole-crickets (Gryllotalpa) are known to exercise maternal solicitude, taking particular care of their eggs and acting as unceasing sentinels around the nest. No special care of the eggs or young seems to be displayed by the Butterflies and Moths (Lepidoptera) or the Flies (Diptera), although in the latter group we meet with cases in which the eggs are hatched within the body of the parent and the larvæ nourished there until fully grown; but amongst a few Hymenoptera and Social Insects generally great care of the young is often taken.

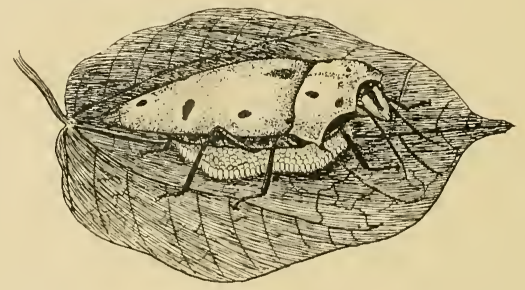

F1G: 17.-Maternal solicitude in Cantao ocellatus, a Pentatomid Bug whose female broods over her eggs, which are generally laid on a leaf. It is interesting to note that, in batches of eggs found under natural conditions, the exterior eggs are almost always parasitized whilst those protected by the body of the mother escape parasitic attack. (Original.)

A Tasmanian Sawfly * has been recorded as watching over the spot where she has laid her eggs, which are deposited in an incision between the two surfaces of a leaf of Eucalyptus, until the exclusion of the young, "upon which, when hatched, she sits with outstretched legs, preserving them from the heat of the sun and protecting them from the attacks of enemies, with admirable perseverance . . . . until death terminates her own existence." Amongst social insects (Bees, Wasps, Ants, Termites, etc.), the young are usually fed by the adults, at first by the female parent and later on, when the colony attains large dimensions, by menibers of a "worker" caste. But these cases, except at the very commencement of the foundation of a new colony, scarcely answer to the term of maternal solicitude.

- Perga lezisii Westwd.; See Trans. Ent. Soc., I, p. 234 and Arcana Entomologica, Vol. I, p. 2 . 


\section{Chapter IV. \\ - MEANS OF DEFENCE IN INSECTS. \\ " Cet animal est très mèchant, Quand on l' attaque il se défend."}

THE means of defence adopted by insects against the attacks of their enemies are very numerous and can only be touched on here very lightly but, broadly speaking, they may be divided into (I) passive and (2) active defence. In the first group we find protective resemblance and mimicry, etc., whilst warning coloration is perhaps intermediate between the two groups, active means of defence including the use of more or less poisonous bites or stings, urticating hairs, the discharge of [acrid, volatile or nauseous liquids, etc.

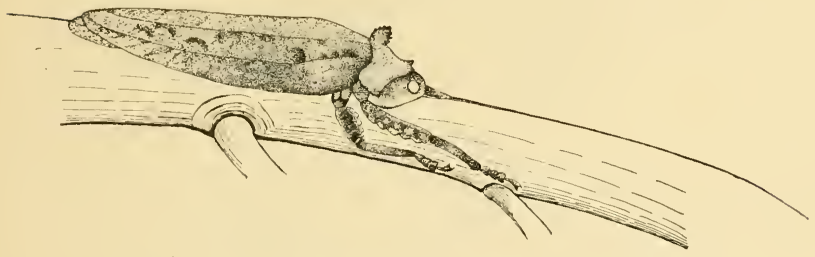

F1G. 18.-Sathrophyllia rugosa, a long-horned grasshopper common on tree trunks in Southern India. (Original.)

Protective resemblance is probably the most primitive and also in modern times the most usual (and hence, we may add, the most successful) method of defence practised by insects, and under this term are included all cases in which insects resemble their surroundings or any object commonly found in those situations in which they occur normally. Millions of years ago, when the Coal Measures were being deposited in the Palæozoic Epoch, the cockroaches of those ancient times had acquired a type of neuration strikingly similar to that found on the fronds of a fern (Neuropteris odontopteroides) which was one of the plants from which the coal was derived. In modern days the prevalence of protective resemblance is best (and perhaps only) appreciated by the eye trained by field observation. On pointing out some protectively-coloured animal in its natural surroundings, nothing is commoner than the observation, "However can you see such things? I never see them ;" 
when it is not the individual that is at fault but merely the want of training in observation.

Protective resemblance may be (usually) general, in which case the insect or other animal may exhibit in its shape or coloration or in both the general pattern-effect produced by its normal surroundings, or it may be (more rarely) special, in which case the insect or animal bears a close resemblance to some different object (living or inanimate) found in its normal habitat. It would be tedious to attempt to give any general list (even of insects) of examples in each group. Those who are interested in the subject will find it an easy matter to make observations of their own in their particular field. There is no strict line of demarcation between the two groups and some animals may belong to both; thus, the common Green Whipsnake (Dryophis mycterizans) may blend generally into the general appearance of the green bush in which it is stretched out or, if noticed in more detail, it may readily pass for a branch of the square-stemmed jungle vine (Vitis quadrangularis). In passing it may be noted that, to be successful, protective resemblance does not necessarily connote inconspicuousness.
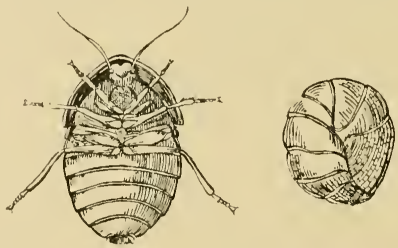

F1G. 19.-Perispheria, a Cockroach which rolls itself up into a ball when threat. ened with danger. (After British Museum Guide to the Insect Gallery.)

Some insects, when threatened by danger, simply roll themselves up into a ball, at the same time generally dropping to the ground if not already on it. Such are many caterpillars, especially some of the hairy ones in which the hairs radiate out "like quills upon the fretful porcupine," serving the purpose of directly offensive weapons and also readily slipping through the grasp of any enemy attempting to pick up the caterpillar. Some cockroaches of the genus Perispharia have also the power of rolling themselves into a ball, when they greatly resemble a small Pill-millipede, the two extremities of the body fitting closely together so that the head and legs are completely hidden inside and protected.

From such examples it is but a step to cases in which insects, on finding themselves discovered by enemies, simply drop to the 
ground and lie motionless, thus escaping detection. Instances might be quoted in almost all Orders but are most commonly seen amongst Moths and Beetles. The Weevils especially are noted for exhibiting the "death-feint," a name given to a special manner in which the limbs are held rigidly contracted; this is accomplished by a voluntary stiffening of the muscles, as is shown by inducing the "death-feint" repeatedly in one individual, when the periods become shorter as the muscles become tired.

An observer will soon discover that many insects, in an apparently deep state of quiescent rest on tree-trunks, etc., are yet acutely conscious of discovery and will often escape, even when they have not been disturbed, if observation is removed from them for an instant. Other insects, on the contrary, are so sluggish that they will permit themselves to be transfixed with a pin without even moving.
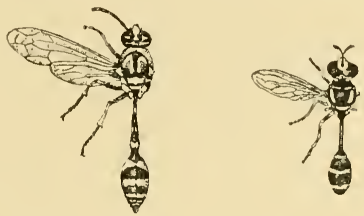

Fig. 20.-The figure on the left is of Eumenes flavopicta, a long-waisted wasp armed with a powerful sting, that on the right is of a stingless Syrphid Fly (Ceria sp.) which mimics the wasp. Both insects occur contemporaneously in the same localities in Southern India. (Original.)

The term "mimicry" is properly restricted to cases in which an animal externally resembles another and biologically distinct kind of animal. The resemblance may be extremely close and detailed or it may be very rough and general; it may occur in any stage of the lifehistory and may be produced by similar coloration, shape, or action, or a combination of any or all of these, but the internal and non-visible portions of the animal are never affected. The animal whose external appearance is thus copied is called the "model" and is generally distasteful to enemies in some way, as by the possession of a sting or poisonous bite or nauseous taste or smell. The animal which copies the external appearance of the possessor of such noxious qualities is called the "mimic." When the mimic is palatable or defenceless the mimicry is called "Batesian " mimicry; but, in some cases, the mimic is equally distasteful as its model, and such cases form what is called "Mullerian" mimicry, both these cases (or theories) being called after the names of the men who first clearly enunciated them. 
Both these forms of mimicry are founded on the fact that the normal enemies (especially birds, lizards, and amphibians) learn by actual experience which of their insect-prey are palatable or the reverse. A young bird, which first commences to forage for itself and catches (let us say) a white moth or a yellow-and-black wasp and finds that it has a nauseous mouthful or that it has been badly stung, will quickly learn to avoid insects which are pure-white or black-and-yellow in colour. Arnchair critics may deny this, but no one who has lived for any time in the tropics and experimented on the gastronomic educability of insectivorous animals is likely to agree with them, and we may safely affirm that insectivorous animals do learn by experience to avoid insects of certain (generally conspicuous) types of coloration. Such common types are bold mixtures of red and black, black and yellow, red and white, white and (less commonly) other mixtures, of blue and yellow, etc. Generally speaking, we may say that an insect which is conspicuous in its normal environment is nauseous in taste and that such insects fall into a very small number of types of "warning" coloration.

The result of this state of things is of equal benefit to the insectivorous animal and the nauseous insect, the former having only to learn a few common colour-combinations in order to know which to avoid as food, the latter having only to sacrifice a small proportion of $i$ in individual numbers in order to secure immunity after a short period of sampling on the part of each individual enemy. For example, if all wasps were coloured differently (some red and black, some white and black, some green, some yellow, some green and yellow, some blue and yellow, etc.), every insectivorous bird would have to sample at least one individual of each differently coloured kind of wasp and would have to remember which forms were palatable and which were not; whilst actually, most wasps being coloured black and yellow, a very few tests on individuals so coloured teaches the bird to avoid insects exhibiting those colours, with equal benefit to the bird and the insects, as the former incurs fewer unpleasant experiences and the latter avoid considerable loss in individuals, collectively at least. For it must be remembered, as a general rule, that an insect attacked usually connotes an insect destroyed; an unpalatable insect may be rejected after capture, but often it is then in such an injured condition as to be practically moribund.

From this it will be seen that the individuals of species forming a Mullerian mimetic group are practically members of a mutualbenefit association. If one individual each of species $A$ and $B$ suffice to teach a young bird that their common type of coloration is of a "warning" character, then other individuals of species, 
C, D, E, etc., belonging to the same group, share in the benefit conferred by future immunity from attack by that individual bird. In the case of such a "Mullerian" association, therefore, there is no "model," strictly speaking; all the associates are "models," but, on an average, the commonest (i.e., most numerous in individuals) member of the group will pay the heaviest toll. In the case of "Batesian" associations it is obvious that, for the mimicry to be effective, (I) the model must outnumber the mimic in individuals, and (2) both model and mimic must occur contemporaneously in the same area; if the mimic were not less numerous any enemies would discover by experience (by the law of average) that insects of that particular facies were palatable and such colours-which, we have already stated, are ex hypothesi conspicuous-would invite attack (and, incidentally, speedy extermination of the insect attacked) instead of avoidance.

Insects which are distasteful are, we have just seen, often brightly coloured, but not all the gaily-hued gems of a collection of insects are necessarily distasteful. Many are indeed surprisingly inconspicuous when seen in their natural surroundings, with which their colours blend in complete harmony, and others secure safety from enemies by their wariness, activity, or speed on the wing. Many butterflies, which exhibit most beautiful markings on the upper surface of the wings, are sombrely coloured beneath and extremely inconspicuous when at rest with their wings closed together over the back. Numerous insects, in almost all the larger Orders at least, combine a conspicuous type of marking when on the wing with a very inconspicuous appearance when at rest, such insects usually making short sudden flights on disturbance, and the sudden apparent vanishing of its prey in this way must often secure such insects from successful attack by an enemy. Really nauseously distasteful insects, on the other hand, are often conspicuous and slow-moving as if to advertise their security from attack; the term "warning colours" is therefore well applied to such combinations of colour-markings.

Some insects exhibit markings which tend to draw the attack of an enemy to some non-vital portion, usually of the wings, the insect itself thus escaping with slight damage. Amongst such "directive" markings we may specify particularly the tails, eyespots, etc., on the hind-margin of the hindwings of many butterflies. In some of the Lycænidæ (e.g., Aplmans and Virachola) the inner corner of the hindwing is not only provided with tails and eyespots but is turned downwards at right angles to the rest of the wing so that, in the resting position when the wings are appressed together over the back, these little flaps of the wing simulate the anterior 
extremity of the butterfly, the flaps themselves looking like a head and the spots and long slender tails simulating eyes and antennæ; the anterior extremity (head, antenna, etc.) is inconspicuously coloured and the apex of the abdomen does not extend as far as the false head, so that an enemy such as a lizard, seeing the butterfly at rest, in attacking the supposedly vital anterior extremity, would obtain only a mouthful of hindwing, the butterfly escaping without vital injury. A collection of butterflies made at random, without regard to the "cabinet condition" of the specimens caught, will soon convince any impartial observer that such directive markings do actually exhibit signs of attack by enemies (chiefly birds and lizards).
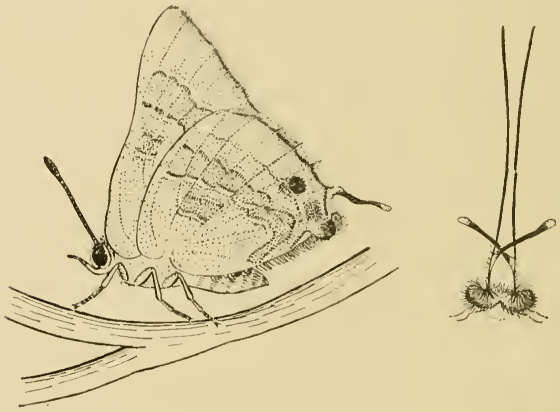

F1G. 21.-Virachola isocrates, a Lycænid Butterfly, in its resting attitude showing simulation of the head by the tails and eye-spots, which project well clear of the body. The right-hand figure shows a view of the butterfly at rest as seen from behind, showing the anal lobes and the manner in which the tails are projected on opposite sides. (Original.)

Insects which exhibit "warning" coloration may acquire a nauseous taste from feeding on plants which are poisonous to vertebrate animals or from other causes. The rich colours of the scales of some butterflies are known to be due to the deposition of waste materials (of the nature of urates) of the excretory system and it seems possible that in other cases, in which the insects feed on non-poisonous plants, their nauseous qualities may be derived from the retention and use in this way of waste products of the processes of metabolism.

From warning colours and innate nauseous qualities it is but a step to cases in which insects actually excrete substances which 
are disagreeable to their enemies. Many insects, in almost all Orders, possess special glands from which they are able to discharge a liquid which may be offensive to the taste, smell, sight, or touch of an aggressor. The stink-glands of many bugs are well known to most residents in India, whether by the characteristic odour of the common Bed-bug or by the disgusting taste in one's soup caused by a "gundy" which has been attracted by the lights on the dinner-table. In such cases the glands are usually situated on the lower surface of the thorax and some of the larger bugs are able to project a thin stream of liquid with great accuracy for a considerable distance. In Beetles the stink-glands are generally situated in the anal extremity of the abdomen and are particularly developed in some groups such as the Carabidæ, Gyrinidæ, and Staphylinidæ. Some members of the former group, common in India under stones, etc., have earned the name of "Bombardier Beetles" because they discharge a stream of liquid which volatilizes instantly in the air as a brownish mist and with quite an audible report; this liquid causes a momentary severe burning sensation on the human skin and would doubtless disconcert an enemy sufficiently for the beetle to make its escape. Many of the minute insects which cause such discomfort when they fly into the human eye are Staphylinid beetles, the smarting sensation being due to the acrid liquid discharged by the beetle when it finds itself in danger. Some Paussid and Carabid beetles discharge a liquid which has a strong smell of Iodine.

Many Ants discharge a strong solution of Formic Acid, which of course derives its name from the Latin word formica, an ant. The common Red Tree Ant (Ecophylla smaragdina), contrary to popular belief, does not sting but grips with its jaws and throws out a fine jet of liquid from the tip of its abdomen. The caterpillar of Cerura vinula has glands from which it can direct a fine stream of Formic Acid solution, and this seems to be used chiefly to drive off parasites which endeavour to oviposit in the larva. The curiously swollen thoracic segments of the larva of Carea subtilis also contain a gland which is perhaps used in a similar way. The caterpillars of the Swallow-tail Butterflies possess a curious Y-shaped organ, called an osmaterium, situated on the anterior margin of the prothoracic segment, in which it is ordinarily concealed; when annoyed or attacked the caterpillar can evert this organ which diffuses a strong, disagreeable odour, differing in various species.

In the case of Termites the soldiers are usually provided with glands in the head (sometimes extending into the abdomen), from which they can pour out a thin liquid which hardens rapidly in the 
air into a sticky substance which appears to be highly obnoxious to the true Ants which are the Termites' most relentless enemies. In Eutermes, the head of the soldier Termite is provided with a long frontal tube from which can be projected for a distance of two or three inches a very fine jet of liquid which hardens into a thin viscous thread immediately it touches the air.

In some cases the nauseous liquid oozes out from the glands in such a way as to produce small bubbles, which probably secure a larger surface for the evaporation and rapid diffusion of the smell. Aularches amongst grasshoppers and Heterusia amongst moths are conspicuous examples of this mode of defence.

Occasionally the liquid discharged is so acrid as to blister the external skin of a vertebrate enemy and the consequences of eating an insect of this kind would doubtless be very serious. The bestknown insects of this class are the Blister-beetles, many of which are extremely common in India and are conspicuously coloured redand-black, blue, green, yellow, etc. In these beetles the glands are situated in the legs, the beetle when touched exuding a yellowish oily liquid which is capable of raising a large blister on contact with the tender human skin. Some of these beetles contain quite a considerable percentage of Cantharidin.

The shape or structure of an insect may be such as to render it distasteful and secure it from hostile attack. The thickly-chitinized, almost armour-plated, integuments of some beetles and the possession of sharp spines in many beetles, bugs, grass-hoppers, etc., may be quoted as familiar examples. The two cases differ somewhat as exhibiting defence against different classes of enemy, since mere hardness (as of some weevils) would not avail against an enemy, such as a bird, large enough to swallow the weevil whole and grind it down in the gizzard or slowly dissolve its interior by digestive fluids gaining access by the joints and other apertures, whilst, on the other hand, such defences as sharp spines would help to protect an insect against large enemies but not necessarily against smaller ones.

Hairy caterpillars, in which the hairs possess more or less irritant qualities, are sufficiently familiar in Southern India, where the general terms "Kumbli-hula " or "Kumbli-puchi" are freely and loosely applied to many very different kinds. In many of such caterpillars the whole body is covered with long hairs which are often rather loosely attached and barbed at the tip, so that they readily pierce the skin and become detached or break off, leaving the barbed tips which act as a mechanical irritant in the skin. Such hairs may also enable the caterpillar to escape by slipping out of the grasp of a captor or by keeping smaller insects (e.g., ants) 
at a safe distance from the vulnerable parts of the body. In other cases special groups of hairs may be modified into defensive weapons-tussocks, spines, stinging hairs, etc. A brown caterpillar (Taragama siva) found commonly on babul (Acacin arabica) is clothed with short hairs and bears just behind the head two large patches of short black hairs which, when annoyed, it brings into contact

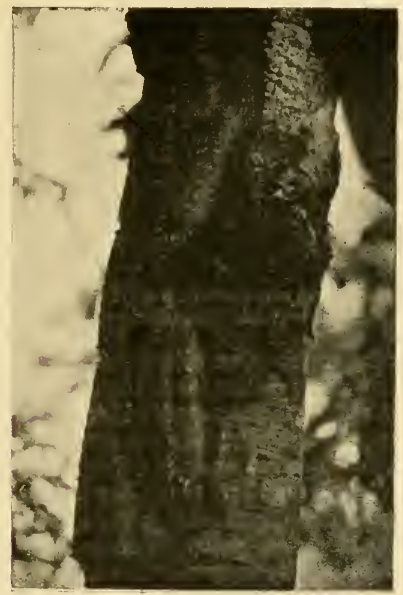

F1G. 22.-Lasiocampid larva / Taragama sival nn tree-trunk.

(From an original photograph by C. NARAYAXA AYYAR.)

with the disturber by lashing about with the fore part of its body, the short hairs readily penetrating and becoming detached in the human skin. This is a common method of defence in this farnily (Lasiocampida) and the larval hairs are often woven into the cocoon from which they project on end to form a veritable "cheveux-defrise." Sometimes, particularly in the slug-like caterpillars of the Limacodida, the hairs may be modified to form stinging organs which can inflict very severe punishment on an aggressor.

The production of sound is another mode of defence in insects, many of which stridulate when picked up. Some Cicadas, when caught, will utter a piercing shriek very different in tone from 
their ordinary song. The caterpillar of the Death's-head Moth makes a clicking sound, as do some other caterpillars, while the moth itself squeaks shrilly, at the same time depressing its wings and exposing theyellow-barred abdomen. The female of Xylotrupes, a large Dynastine beetle, when caught, emits a sudden, unexpected, loud hiss very disconcerting to its captor. The angry chidings of bees when their nest is approached too closely warn the intruder in

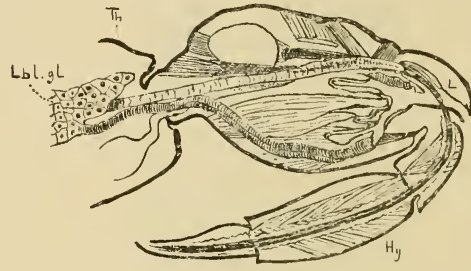

FIG. 23.--Section of Head of a Reduviid Bug (Harp. actor sp.) showing Poison-gland. (After Berlese.) tones very different from their ordinary busy hum, and at least one species of Termite (Termes convulsionarius) makes a concerted rhythmic pattering when its nest is opened.

Some of the larger insects are able to defend themselves by the use of their mouth-parts against the aggressor or by means of the sharp spines with which their fore or hind legs are armed, and some of the predaceous bugs, especially the larger water-bugs and Reduviids, are able to inflict a painful poisoned bite by means of the rostrum. It is, however, only in the Hymenoptera (Ants, Bees, Wasps, etc.) that a true sting is found in the posterior extremity of the abdomen of the perfect insect. In some of these insects the sting is used as an offensive weapon in the capture of prey, either as

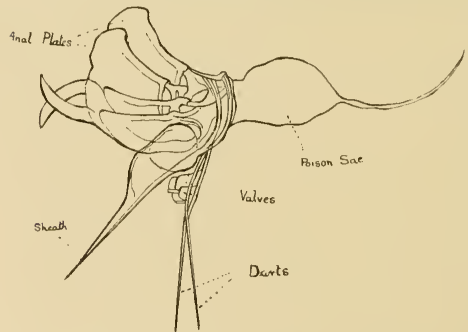

FIG. 24.--Sting of Honey-bee. (Original.) food for the insect itself or for its progeny, but as a rule the sting is only used as a means of defence. It may be noted that the sting, when present, is confined to individuals of the female sex, the males even of wasps and bees being destitute of a sting. 
Some insects secure themselves from attack by constructing shelters or little houses which they drag about with them, this being probably a highly developed form of a primitive concealed mode of living for defensive purposes. The Rice Case-worm (Nymphula dcpunctalis) and the common Bagworm (Clania crameri) are familiar instances. The larvæ of many of the Cassid beetles are provided

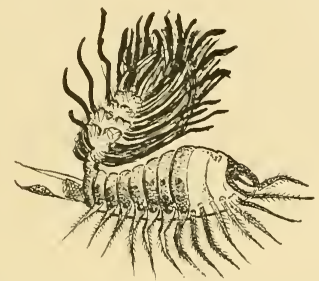

F1G. 25.-A Cassid larva (Aspidomorpha sancte-crucis), commonly found on Sweet-potato, carrying its excrement over its back.

Three times the natural size. (Original.)

with a long forked "tail" which they hold over the back and carry on it their cast skins and excrement, so that the true nature of the larva is often concealed. Several predaceous larvæ (Chrysopa, Eublemma, etc.) place the empty skins of their victims on their backs and thus achieve concealment at once from enemies and prey. For it must be remembered that a structure, marking, etc., may play more than one part in the economy of an animal, whether insect or not, and that a predaceous animal which is protected from its enemies by its procryptic coloration is equally equipped for approaching its prey. Colours which are bright and "warning" to foes may be alluring to prey and also attractive to the opposite sex.

Luminosity in insects may be briefly considered here as it is at times a means of defence although probably more often of use for sexual attraction. The best known examples of luminous insects in India are the numerous species of glow-worms, usually erroneously called "Fireflies" although the true Fireflies, belonging to the family Elateride, do not occur in India. In glow-worms the luminous organs are usually placed beneath the posterior segments of the body. In many species only the male is winged, the female being wingless and grub-like, both this sex and the larva having luminous organs. The luminosity is entirely voluntary and is often rhythmic, large numbers of individuals emitting a momentary flash with one accord. The efficiency of the light emitted by these little 
beetles is remarkably high, being estimated at practically I00 per cent. of the energy used, there being almost no heat-rays or actinic rays, whilst the light-value of the electric arc is only about ten per cent. of the energy used and that of the sun only about thirty-five per cent. Several other beetles besides the Lampyrida are known to be luminous, at least occasionally, and undoubtedly many more Indian insects will be found to be capable of emitting light. Amongst those insects in which this phenomenon has hitherto been noted, mostly outside of India, are various beetles (Carabida, Panssida, Staphylinide, Tenebrionida, Elaterida, Cerambycida, Buprestide, etc.), Ephemeridæ, larvæ of Lepidoptera and Diptera, and Collembola, but some of these are perhaps luminous as the result of disease, the luminosity being due to the activity of bacteria and not to the presence of true photogenic organs. The intermittent flash of a flying glow-worm is perhaps a means of defence by puzzling an enemy as to its whereabouts. There is also some evidence that Lampyrid beetles are distasteful to nocturnal insectivorous birds and bats, so that the light is perhaps a "warning" signal. 


\section{CHAPTER V.}

\section{COMMUNICATION AMONGST INSECTS. \\ " Ilast thou heard the butterflies, What they say betwixt their wings ?" \\ " Happy the Cicadas' lives, For they all have voiceless wives."}

TENNYSON-Adeline.
Tenarchus.

THE simplest form of communication amongst insects is by the production of sounds which may or may not be audible to human ears but, except in the case of social insects, communication is usually restricted to methods by which the sexes are brought together or rendered attractive to one another. The hum caused by the vibration of the wings or otherwise during flight, as in the case of a Hawkmoth hovering before a flower, can scarcely be considered as communication, similar sounds being produced by other rapidly-vibrating bodies such as a spinning top or wheel.

The shrill piping of Mosquitos and Midges and the chirping song of male Crickets and Cicadas are familiar instances of sounds produced by one sex in order to attract or charm the other. The song of Cicadas, though often distressingly discordant to our senses, is doubtless sufficiently pleasing to their voiceless females and is astonishingly different from the shrill shriek of alarm emitted by the insect when captured.

Several of the long-horned green grasshoppers, commonly found on plants and often attracted to light in the evenings, utter a very shrill chirping and are further remarkable as possessing welldeveloped auditory organs which may readily be seen on examination of their fore-legs. A similarly situated auditory organ is found in many crickets and mole-crickets. In other insects the auditory organs may occur on the antennæ, abdomen or elsewhere. The note of the hum of the female mosquito, for instance, causes certain of the hairs of the antenna of the male to vibrate sympathetically so that, by turning his head until both antennæ are affected equally, it is probable that the flight of the male is directed to the female with considerable accuracy.

It is impossible to enter here into the mechanism of the stridulatory organs of insects, i.e., of the organs which produce "song," as these vary so greatly in different species. Usually the sounds are made by the vibration of a membrane or the scraping of one part over another, the latter generally being ridged. Stridulation is not confined to grasshoppers or even to large insects; some 
small water-bugs (Microvelia), scarcely visible to the naked eye as they run along the surface of the water-film, are able to stridulate so loudly as to be audible from a distance of several yards. The caterpillar of the Death's-head Moth makes a clicking sound when annoyed and the moth itself produces a shrill squeak not unlike that of a bat; but these are defensive sounds rather than communicative.

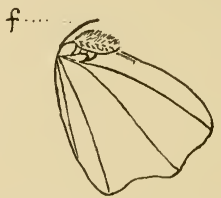

FIG. 26.- Hindwing of inale Nyctipao hieroglyphica, showing gland opened; $f$. is the frenulum. (Original.)

Several moths and a few butterflies are known to stridulate on the wing and such stridulation is doubtless sexual as a rule. As an instance we may quote the case of Nyctipao hieroglyphica, Drury, a large black Noctuid moth which is well known, especially in some of the Hill-districts of Southern India, from its habit of flying along paths at dusk and producing a loud clicking sound which is often especially disconcerting to horses because the moths seem to be attracted by moving objects and therefore often fly around the heads of horses which may be frightened by the clicking of the moths. The fact that this moth stridulates has been noted before but I am not aware that the mechanism of its stridulatory organs has been examined. In the first place we may note that it is only the male moth which makes a noise and that this is a distinct, loud, sharp click, such as might be produced by running a stout pin or quill slowly but firmly across the teeth of a comb. On examining the moth, a glandular patch covered with long flocculent hair is to be seen on the upperside of the fore-margin of the hindwing, near the base of the wing, and this appears to be part of the stridulating organ; it is hollowed and convex on the lower surface of the wing and opens like a purse (being hinged along the fore edge of the wing) and perhaps serves as a sort of sounding-board to increase the noise, which is apparently produced by the tip of the frenulum (the long horny bristle at the base of the foremargin of the hindwing which locks the wings together in flight): this tip passes through the retinaculum (the loop on underside which holds it in position) and either rubs over the outer surface of the pocket or, more probably, catches its hinder edge and pulls it open with each 
flap of the wing, thus at once making the noise and exposing the flocculent yellow androconial hairs which line the interior of the pocket and which doubtless emit a smell attractive to the female. It will be seen from figure 26 that the neurational structure of the wing is extraordinarily distorted, but in the female, in which sex the glanidular pocket is absent, the neuration (system of wing-veins) is normal.

In the foregoing case the female may be attracted to the male by sound or by smell and this instance therefore leads us to cases in which one sex is attracted by scents emitted by the other. Numerous instances of this attraction might be quoted especially in the case of moths in which the males may be attracted from distances of several miles in search of a female; in such cases the female is usually sluggish (often wingless) and the males have highly pectinated (comb-like) antennæ by which they perceive the scent emitted by the female; this principle is taken advantage of by entomologists who expose a virgin female in a small cage and capture the males as they "assemble." In many butterflies, especially the Pierids ("Whites ") and their allies, the males have on their wings specially modified scales, called " androconia," from which they emit a pleasant perfume which is quite perceptible in living or fresh specimens and which is undoubtedly attractive to the female.

Attraction of the sexes by sight is very commonly met with and has produced the evolution of many of the strikingly handsome colours exhibited by the males of sexually-dimorphic insects, spiders, lizards, birds, etc., already rendered familiar in innumerable publications. A very striking case amongst insects is, however, afforded by certain glow-worms in which the wingless female alone is luminous and gives out a beam of light by which the non-luminous winged male is attracted to her, whereupon the light is obscured.

As may be expected, it is amongst social insects that we find that means of communication have attained their maxinum efficiency and in such cases the methods employed are perhaps more truly communicative than merely sexually attractive as in the foregoing instances. There are few truly social beetles but the Passalids may fairly be included in this category. These are large black beetles found commonly in the hills in rotting wood in which they occur in small family parties usually consisting of immature and adult forms; the larvæ have the first pair of legs modified into stridulating organs and the beetles themselves also are able to stridulate. When such a family party is dislodged from a rotten 
$\log$ and its members scattered, they stridulate and collect together again by means of the communication thus established.

No one who has ever watched Termites or opened a termitarium can have failed to observe the curious vibratory movements of their bodies which evidently serve as a means of communication. By placing living specimens on a sheet of paper or table the sounds produced by these vibrations become readily audible. One large Termite found fairly commonly in the red-earth Plains of Southern India is especially noteworthy in this respect and has earned its name of Termes convulsionarius from this habit; when a nest is opened up, the noise produced by hundreds of these Termites vibrating in unison is clearly audible from some little distance as a rhythmic pattering or rustling and probably serves at once to intimidate the disturber and to sound a warning throughout the nest. There is no doubt whatever but that these vibratory movements have different and well-understood meanings and serve the purpose of speech.

It is, however, amongst the Ants, well named as the most highly developed of all insects, that communication is best established. The way in which foraging ant-scouts communicate knowledge of the presence of food may be seen daily in every bungalow in India. Belt, in his "Naturalist in Nicaragua," gives several instances of what may even be called intelligent communication amongst ants, from which the following may be quoted:- "One day when watching a small column of these ants [Ecitom hamata], I placed a little stone on one of the ants to secure it. The next that approached, as soon as it discovered the situation of the prisoner, ran backwards in an agitated manner, and communicated the intelligence to the others. They rushed to the rescue, some bit at the stone and tried to move it, others seized the captive by the legs, and tugged with such force that I thought the legs would be pulled off, but they persevered until they freed it. I next covered one up with a piece of clay, leaving only the ends of its antenna projecting. It was soon discovered by its fellows, which set to work immediately, and by biting off pieces of the clay, soon liberated it. Another time I found a very few of them passing along at intervals. I confined one of these under a piece of clay, at a little distance from the line, with his head projecting. Several ants passed it, but at last one discovered it and tried to pull it out, but could not. It immediately set off at a great rate, and I thought it had deserted its comrade, but it had only gone for assistance, for in a short time about a clozen ants rame hurrying up, evidently fully informed of the circumstances of the case, for they made directly for their imprisoned comracle and soon set him free. I do not see how this action could be 
instinctive. It was sympathetic help, such as man only among the higher mammalia shows. The excitement and ardour with which they carried on their unflagging exertions for the rescue of their comrade could not have been greater if they had been human beings, and this to meet a danger that can only be of the rarest occurrence." . . . "I shall relate two more instances of the use of a reasoning faculty in these ants. I once saw a wide column trying to pass along a crumbling, nearly perpendicular, slope. They would have got very slowly over it, and many of them would have fallen, but a number having secured their hold, and reaching to each other, remained stationary, and over them the main column passed. Another time they were passing a water-course along a small branch, not thicker than a goose-quill. They widened this natural bridge to three times its width by a number of ants clinging to it and to each other on each side, over which the column passed three or four deep. Except for this expedient they would have had to pass over in single file, and treble the time would have been consumed. Can it not be contended that such insects are able to determine by reasoning powers which is the best way of doing a thing, and that their actions are guided by thought and reflection? This view is much strengthened by the fact that the cerebral ganglia in ants are more developed than in any other insect, and that in all the Hymenoptera, at the head of which they stand, they are many times larger than in the less intelligent orders, such as beetles." And on another occasion Belt states that he found a colony of these ants shifting from an old to a new nest to which they were carrying their stores of food. "Between the old burrows and the new one was a steep slope. Instead of descending this with their burdens, they cast them down on the top of the slope, whence they rolled down to the bottom, where another relay of labourers picked them up and carried then to the new burrow. It was amusing to watch the ants hurrying out with bundles of food, dropping them over the slope, and rushing back immediately for more." And again, "I shall conclude this long account of the leaf-cutting ants with an instance of their reasoning powers. A nest was made near one of our tramways, and to get to the trees the ants had to cross the rails, over which the waggons were continually passing and repassing. Every time they came along a number of ants were crushed to death. They persevered in crossing for several days, but at last set to work and tunnelled underneath each rail. One day, when the waggons were not running, I stopped up the tunnels with stones; but although great numbers carrying leaves were thus cut off from the nest, they would not cross the rails, but set to work making fresh tunnels underneath 
them. Apparently an order had gone forth, or a general understanding been come to, that the rails were not to be crossed."

It is difficult to resist conceding a certain degree of reasoning faculties to animals displaying such intelligent methods of dealing with quite extraordinary circumstances, and such cases may perhaps be taken as bridging to some extent any gap existing between reason and instinct. The subject cannot be discussed more fully here but is certain that the majority of even the most complex of the actions of insects are regulated by instinct and that cases of reasoning are very rare and confined solely to the most highly-organized of the Social Insects. 


\section{Chapter VI.}

\section{TROPIS MI S.}

"The word tropism means the tendency to react in a definite manner towards external stimuli."

WILLEY-Convergence in Evolution.

IN the last chapter it was seen that the actions of insects are only controlled by intelligent reasoning in very rare cases, if at all. In practically all cases their actions under any given conditions are rigidly guided by what are known as tropisms. Here it may be useful to give a few definitions. A habit may be defined as the behaviour of an organism under natural conditions, a reaction as its behaviour in the laboratory or under more or less natural conditions of observation in the open. A tropism is its reaction or response to a definite external stimulus. For example, an organism may be attracted by light, in which case it is said to be positively phototropic (i.e., turning towards light); or it may be repelled by light, in which case it is said to be negatively phototropic; or light may not affect it at all, in which case it is said to be passively phototropic. All these tropisms are to be observed in every organism, either positively or negatively or passively, and often, at different times, both positively and negatively in the same individual.

Tropic responses have been divided into the following classes:-

(I) Phototropism or response to stimulus of Light.

(2) Heliotropism

(3) Chenotropism

(4) Thermotropism

(5) Thigmotropism

(6) Geotropism

(7) Rheotropism

(8) Hydrotropism

(9) Anemotropism

, ,

,
Sunlight.

Chemicals.

Temperature.

Contact with solids.

Gravity.

Water currents.

Water and moisture.

Air currents.

These are shown grapically in figure 27 , but it may be remarked that the territories of the stimuli may sometimes overlap, and that a different grouping of these tropisms may be expected as our knowledge increases.

Phototropism, sometimes known also as phototaxis, covers all responses due to the stimulus of Light, but it is perhaps better to restrict the term to cases in which direct sunlight is not employed 


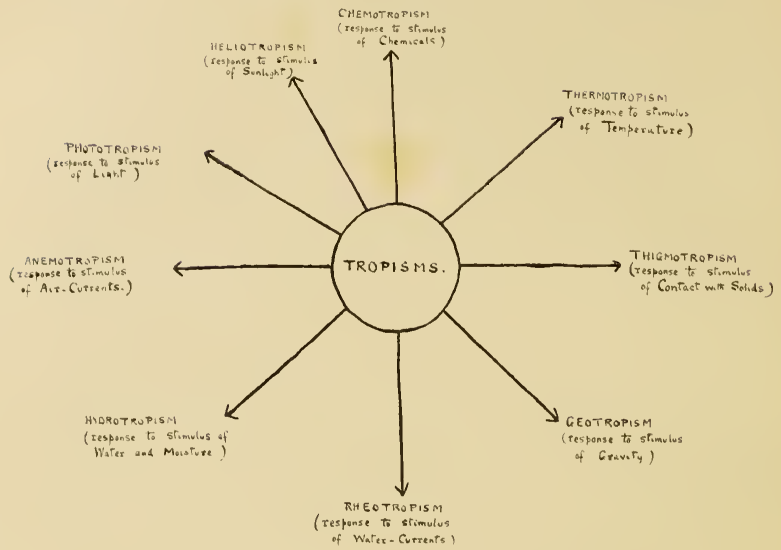

F1G. 27.-Diagram showing Tropic Reactions. (Original.)

as heliotropic reactions are not necessarily the same as phototropic and the two may indeed be opposed to one another. A moth which hides away from daylight (negatively heliotropic) is strongly attracted by artificial light at night, and that this positive phototropism is not entirely due to the fact that it only occurs during the insect's normal hours of activity is shown by the fact that this reaction is exhibited most strongly on dark nights. It is a fact of common observation that very few insects fly in to light on bright moonlight nights. The use of light-traps to capture insects and control crop-pests is a practical application of this reaction, as is also the capture of fish at night by the aid of torches. The Bedbug may be cited as an example of an insect exhibiting strong negative phototropic tendencies.

Heliotropism has been studied especially in the case of many butterflies which may be observed to settle and then carefully to orient themselves to the sun's rays so that they may obtain in some cases a maximum of heat-rays on their wings or in other cases so that a minimum amount of shadow may be thrown by the wings. Animals which are positively heliotropic have been called phanerozoic, and those which avoid the light of day cryptozoic.

Chemotropism, it must be admitted, is a vague and elastic term covering responses to such stimuli as those of smell equally with 
those induced, for example, by the solution of chemicals in the environment of aquatic organisms. The much-lauded "wonderful instinct" which impels a female insect to lay her eggs on the particular plant or substance suitable for the food of the larvæ is as a rule merely a mechanical response to definite chemical stimuli exerted by the appropriate larval food. It has been shown, for example, that a blowfly will readily lay its eggs or maggots on meat, on which the larvæ normally feed, but that it will not lay its eggs on fat, upon which the larva could not feed. This is not a case of instinct or intelligence but is simply due to the fact that certain chemical stimuli from meat cause the blowfly to lay its eggs. In fat these stimuli are lacking but can be produced artificially, when the fly will lay its eggs although the larvæ cannot feed on the fat.

Chemotropism will undoubtedly in the future be put to practical use in economic entomology to a very large extent. Its practical applications at present include the attraction of moths by assembling and by the use of baits such as sugar either painted on trees, etc., or used in combination with a special trap, and the attraction of some fruit-flies by the use of oils. In these latter cases, tins containing water with a little oil (kerosine, citronella, etc.,) are exposed in localities in which fruit-flies occur and the male flies are attracted by the smell of the oil (which doubtless exercises the same tropic reaction as the odour emitted from the scent-glands of the female of that particular fly) and are drowned in the tins.

Thermotropism, or response to the stimulus of temperature, is perhaps in some cases scarcely distinct from Chemotropism. Hibernation and Estivation (the passing of the cold and hot seasons in an inactive condition) are probably controlled directly by thermotropic responses.

Thigmotropism, or response to the stimulus of contact with solids, is generally not a very evident phenomenon. Its positive aspects are strongly exhibited by many spermatozoa, such as those of the cockroach; if these be examined in a cavity-slip under the microscope, they will be found to be adherent only to the sides of the cavity or the coverglass and not free in the cavity; when brought into contact with an egg, they adhere strongly to its surface over which they wander until one reaches and enters the micropyle, thus securing fertilisation. Some insects which are found beneath bark are positively thigmotropic.

Geotropism, or response to the stimulus of gravity, is exhibited by many caterpillars both positively and negatively at different times. Whilst feeding they are usually negatively geotropic, crawlingupwards on any vertical object should they fall off the food-plant, but when full-fed and about to pupate in many 
caterpillars the geotropic reaction becomes positive and they crawl down from the tree or plant to enter the soil. Ladybirds offer a familiar example of a negatively geotropic tendency as they always tend to crawl upwards and in a natural state this is of practical use to them because they crawl up to the tips of the twigs of plants and, if Aphids are present, they stop to feed but, if there are no Aphids, they fly off to search another twig.

Rheotropism, or response to the stimulus of water-currents, is exhibited by many aquatic insects and other animals such as fish. On streams in the hills various Gerrids may usually be seen maintaining their position against the current and on the look-out for any small insects which may have fallen irto the water.

Hydrotropism is exhibited strongly by many aquatic insects; if these are caught and liberated, even many yards away from the edge of a pond, they make straight for the water without any hesitation. The preference for a dry or a damp habitat is very distinctly shown by many insects and other animals and may sometimes be turned to practical account, as by the flooding of fields to dislodge crickets, etc.

Anemotropism, or the response to the stimulus of air currents, is closely akin to rheotropism and in both cases it is usually found that insects tend to orient themselves against the prevalent current. The large migration-flights of butterflies just before the break of the monsoon are familiar sights in many localities, the air being sometimes thick with thousands of butterflies all hurrying impetuously in one direction. The fact that these migration-flights generally take place in India about May and November seems to point to the possibility of their being due to anemotropic tendencies on the part of the butterflies concerned. According to my own observations these flights are almost always against the wind.

Having considered these various tropic reactions it may be well to acld a few words regarding their practical importance. In the first place it must be clearly understood that these tropisms are purely mechanical reactions to physical or chemical stimuli and that these reactions are set up and must necessarily and involuntarily be carried out by the organism concerned regardless of its own benefit or injury thereby. A moth immolates itself in a lighted lamp, not because it likes the light nor on account of curiosity; the light probably has a definite chemical reaction on its muscles so that its head is perforce drawn (by the contraction of the muscles) until it is oriented towards the light after which its movements in flying can only lead it to the source of light. Thus the rapidly-moving insect gets into the flame before the heat has time to check it in its flight. If one eye is covered with an opaque 
paint, the insect flies or creeps in circles, with the unaffected eye always turned towards the centre.

It cannot be too strongly emphasized that, given the requisite conditions, these tropic reactions are bound to take place; they are absolutely independent of volition and many of them can be reproduced with purely mineral or unorganized material, being brought about by ordinary chemical and physical forces. It follows, therefore, that the fuller investigation of these tropisms forms a very promising field for research work in connection with the control of insect-pests ; for, if we can find methods by which any particular insect may be attracted in obedience to a tropic reaction, we shall be in possession of a very powerful weapon for its control. Such attraction is usually strongly specific and often confined only to one sex of a particular species, both these conditions being instanced in the attraction of fruit flies to essential oils; here it is only the males which are attracted and, generally speaking, each species is attracted by a different oil. In this case the attraction is of little practical use as only the males are caught and these have generally fertilised the females before capture so that little actual control is achieved. But in other cases, notably in that of Agrotis ypsilon, greater success has been attained and that on a practical fieldscale whereby thousands of acres of crops have been saved which in previous years had been damaged by the caterpillars of this moth. It has been found, in this case, that the female moths require to feed in order to develop their eggs successfully before these are laid and that during this period, which lasts a week or ten days, the females may be attracted by exposing a mixture of :

$\begin{array}{lcccc}\text { Water } & \ldots & \ldots & \ldots & 200 \text { parts by weight. } \\ \text { iugar or jaggery } & \ldots & \ldots & 400 & , \\ \text { Alcohol } \ldots & \ldots & \ldots & 3 & . . \\ \text { Ethyl acetate } & . . & \ldots & 3 & .,\end{array}$

Trials of this mixture with the closely-allied Euxod segetis in Southern India, however, have been unsuccessful, so that this mixture also appears to be strongly specific.

The use of light-traps for the capture of crop-pests has already been mentioned as an obvious instance of the practical application of a tropic reaction. But here again we require more exact experiments to ascertain what species of insects are attracted and in what proportions, both of the total number of individuals in a given area and of the relative proportions of the sexes, and (for each insect) the optimum meteorological conditions under which lighttraps may be used, and thê relative efficiency of different values of light both as regards strength and colour. 
It will, therefore, be seen that, however, theoretical such a subject as Tropisms may seem at first, it is one that is likely to prove of great practical importance in Economic Entomology in the future when extended and patient experiments shall have yielded methods applicable to the control of insect-pests on a large scale. 


\section{Chapter VII.}

\section{INSECTS AND PLANTS.}

"Nu other animals sustain such intimate and complex relations to plants as insects du. The more luviriant and varied the flora, the more abundant and diversifict its accompanyincr inscet fauna."

\section{For.som-Eutomology}

INSECTS, in common with all other animals, derive their living ultimately from plants, either by feeding directly on green leaves, living or dead wood, etc., or by devouring other animals which so feed or which in their turn have derived their nourishment directly or indirectly from plant-eating organisms. But besides this more obvious relationship between insects and plants, there are other associations between the two groups which may be considered here briefly; such are insectivorous plants, the fertilisation of flowers by insects, and symbiotic relations between plants and insects.

Although most insects live at the ultimate expense of plants, yet on the contrary some plants capture insects, usually by means of a sticky excretion, and actually digest them. An example commonly found in the hills of Southern India is the little red sundew (Droscra) which grows commonly in marshy places and whose gum-tipped tentacles situated on the upper surface of the leavesglisten in the sun and give the plant its appropriate popular name; examination of these plants will usually reveal small flies, ants and Jassids adhering to the gummy tentacles which bend over and absorb their juices. In the Plains also small insects are often found attached to the sticky fruits of a Bochavia common in sandy places and it is probable that this sticky exudation also exercises digestive properties. The well-known Pitcher-plant (Nepenthes) also attracts insects which are drowned in the water contained in it and their soft parts dissolved and digested. It is noteworthy, however, that the tables are often turned and that even insect-eating plants are not exempt from attack or use by insects; one little caterpillar lives solely on sundew 
seeming to prefer the drops of gum exuded by the tentacles, another allied caterpillar attacks the Bocrhavia, feeding especially on the droplet of gum, and the receptacle of the Pitcher-plant supports quite a small fauna of aquatic insects.

The successful fertilisation of flowers is secured in very various ways, but as a rule plants have developed contrivances by which fertilisation of the ovaries is accomplished by means of pollen derived from another plant of the same species or, in other words, crossfertilisation is secured as far as possible. In some cases this end is attained by means of the wind which carries innumerable grains of pollen of which some few are blown indiscriminately onto the female organs of the same or another plant. But, in the case of practically all our more familar flowers, cross-fertilisation is secured by utilizing the services of insects and it is supposed, generally speaking, that the shapes, colours and perfumes of flowers have been elaborated to their present perfection largely as a result of the competition between them to attract the visits of insects. As is usually the case, competition and specialisation have proceeded hand in hand and, whilst some flowers have elaborated gatdy colours to attract insects by sight, others have specialized in the development of perfume to tempt the sense of smell of their welcome visitors; and it is for this reason that we find so many handsome flowers without perfume and so many flowers which smell sweetly but are otherwise inconspicuous. And specialisation has proceeded further than in the mere development of general attractiveness by particular methods, for many flowers have speeialized in the attraction of certain particular classes of insects; of such cases that of the Humble-bee and Clover is a familiar instance. And most observers will have noticed that those flowers which exude their perfume towards nightfall usually have white petals which are conspicuous at dusk, at which time such flowers are visited by Hawk-moths ancl similar insects which only fly after sunset.

On the other hand many insects are highly specialized by possessing habits or structural modifications which enable them to obtain the nectar offered by the flowers which at the same time they pollinate unconsciously but in the most effective manner. The development of an especially long tongue, such as is found in the Honey-bees and Hawk-moths, may be cited as an example of this, many crepuscular Hawk-moths having a tongue which is much longer than their whole bodies.

In normal cases the insect, whilst taking the nectar from a flower, touches the anthers and carries away pollen-grains which it brings into contact with the stigma of the next flower visited, 


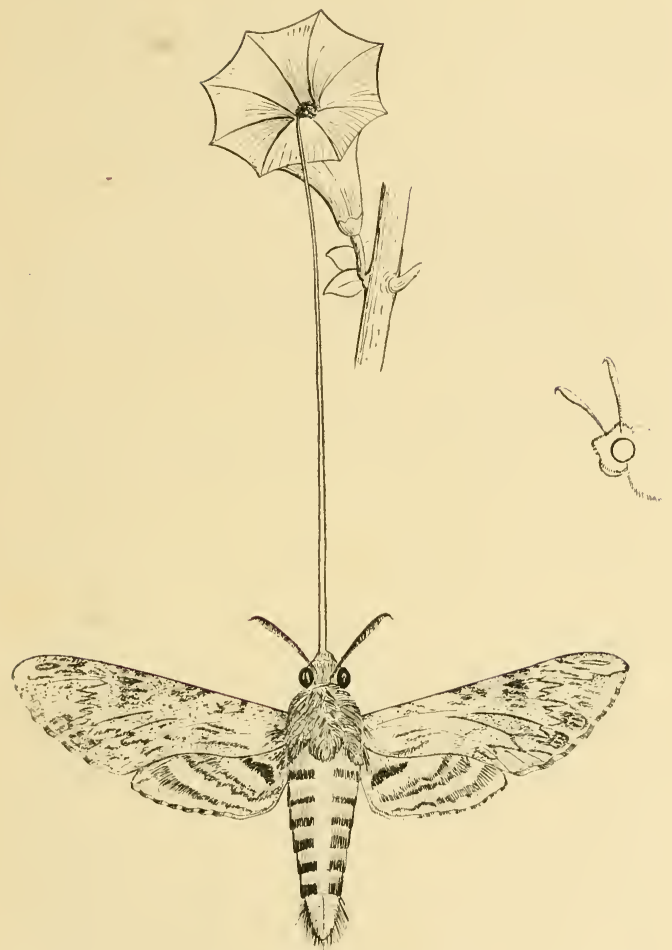

F1G. 28.- Hawk-moth iHcrse convolvuli; feeding at flower, showing length of tongue when extended (natural size'. The side view of the head shows the tongue as rolled up when not in use. (Original.)

thus securing cross-pollination, the structural arrangement of the flower being such that pollen from the last-visited flower is brought to the stigma in each case, thereby ensuring cross-fertilisation. 
It is impossible to attempt to narrate here the various adaptations in both insects and plants by which cross-fertilisation is secured but we may note in passing the curious fly-trap formed by

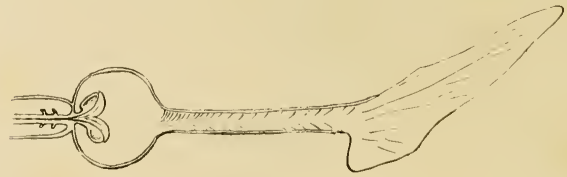

Fig. 29,-Section of Aristolochia, a flowcr which attracts flies. These are able to enter but not to escape owing to the inwardly directed hairs of the perianth tube. After the anthers have dehisced, these hairs shrivel and permit the flies to escape. (After Kuuth.)

Aristolochia, into which small flies are attracted and imprisoned until the pollen is ripe when they are again released, and the methods by which the pollinia of Asclepiads and Orchids are

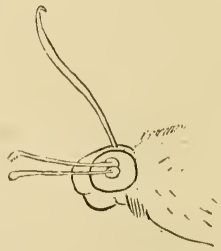

Fig. 30.-Head of Sphingid Moth with two I'ollinia attached to the left eve. (Original.)

attached to the legs or heads of insect visitors thereby ensuring a dispersal of pollen to the plants visited afterwarcls. There is a vast and almost untrodden field in Inclia for anyone who will take up the study of the pollination of flowers by different animals (insects, birds, bats, etc.). In various tropical regions, notably in South America, there are found plants which are inhabited by ants to whose use they are perhaps specially modified. These plants have usually hollow thorns or internodes, admirably adapted as nesting-places for ants which bore into them, sometimes through a specially thin portion of the outer surface, and live in the spaces thus provided. In some cases the plants provide not only shelter for the ants but also secrete from special glands a sugary fluid 
which serves the ants as food. The ants, which are usually small but provided with a virulent sting, swarm out and attack any animal which handles the tree roughly and also the leaf-cutting ants which attempt to strip the leaves. The relation between the ants and these plants seems truly symbiotic although this has been denied. The Oriental plants Myrmecodia, Hydnophytum and Dischidia.are well-known examples of plants which provide special accommodation for ants which rush out and attack any disturber. The thorns of the large-thorned Babul (Acacia latronum), common in many parts of Madras, often contain nests of small ants (Tupinoma indicum and Cremastogaster sp.), but no observations seem to have been made regarding their exact relations with the plant. Very possibly it will be found to be a case of symbiosis.

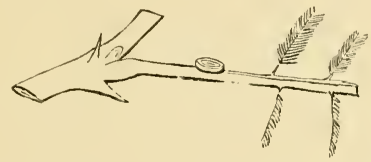

FIG. 31.-Portion of leaf of Acacia sundra, showing ant-attracting gland on base of leaf stalk. IOriginal.!

Acacia sundra, another tree conmon in Madras, has large glands, which attract ants and which are situated on the basal parts of the leaf-stalks.

A few insects even cultivate plants for their own use and amongst such insects in India we may specify the Ipicla (Scolytidæ), or Shot-hole Borers, and some of the Termites. The spongelike comb made by these latter insects is well-known, being frequently revealed during excavations or when a Termites' mound is opened up. It is composed of vegetable matter which has been passed through the bodies of the Termites several times until every particle of nutritive value has been extracted, when it is built up into combs whose size and structure are often characteristic of the particular species of builder and which provide a large surface in a small bulk. If examination be made of one of these combs freshly extracted from a nest, its surface will be seen to be sprinkled over with minute snowy-white globules, which are really small fungi cultivated by the termites and eaten when they attain a proper size, not being allowed to develop beyond this; but if the comb be abandoned, this and several other fungi, normally kept within bounds by the termites, will grow luxuriantly. Other fungi, of 
which one is shown in figure 32 , sometimes grow from the comb whilst this is still inhabited by its inmates and such fungi sometimes mark the position of a nest which is not revealed by the erection of a mound of any sort. 


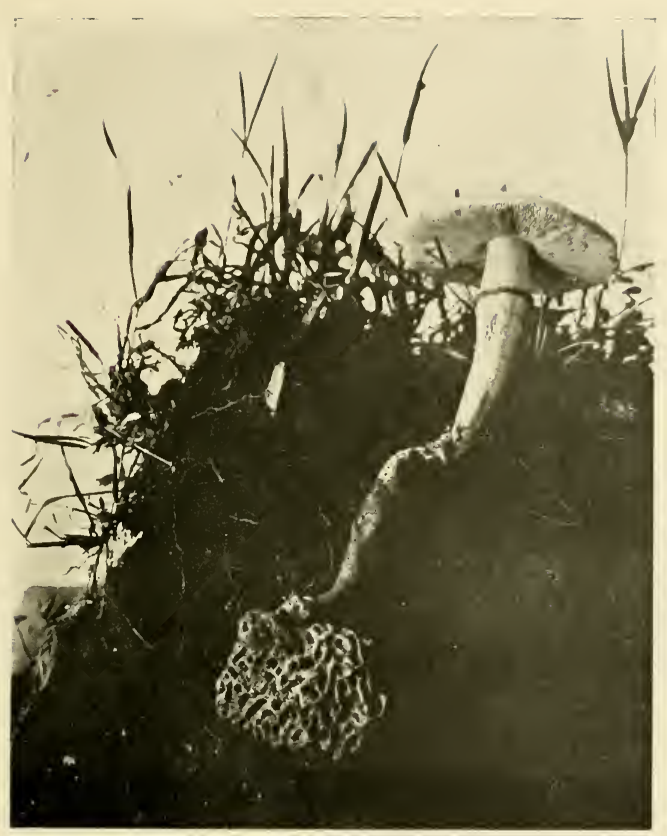

FIG. 32.--Fnngus (Collybia albuminosa = Armillaria eurhiza) growing from comb of Odontotermes sp., Coimbatore. November 1912. (From an original photo by II: IICR.AE.) 



\section{Chapter VIII. SYMBIOSIS AND PARASITISM.}

SYMBIOSIS (Greek: syn, together; bios, life) is a term applied to the state of affairs which arises when two different organisms live in company, neither harming the other, but each on the contrary obtaining benefit from its partner's activities. One of the most familiar examples of this interrelationship is afforded by the numerous tribe of lichens which occur so commonly on rocks and trees in all damp places. Until comparatively recently the lichens were considered to be a distinct class of plants but it is now known that a lichen is not one distinct organism but a compound of two plants, a fungus and an alga, utterly distinct in structure and in mode of life. Owing to the absence of chlorophyll a fungus can only obtain the carbon necessary to its growth by appropriating the tissues already elaborated by a chlorophyll-containing (green) plant for its own use and it can therefore live only on dead or living organic tissues. In the case of a lichen, the fungus absorbs water and other material from the bark or rock on which the lichen is growing and can use as nutriment those substances which have formerly been part of living organisms but the non-organic materials are passed on to the algal partner which is able to utilize them by means of its green cells. The alga and the fungus each make use of what the other cannot utilize and the waste, left over by each as the result of its vital activity, is again assimilated by the other partner. Thus the association is complete and mutually advantageous.

There are many degrees of symbiosis and it is not always necessary that the partners should live permanently in company as in the case of lichens. The association may be intermittent although the benefit is mutual. A common example of this state of things is seen in the case of cattle egrets and other birds which attend cattle and catch the flies and ticks which attack these animals. In this case the birds derive benefit by feeding on the flies whilst the cattle benefit at the same time by being rid of their parasites.

The term commensalism (Latin; cum, together with, in company with ; mensa, a table) is often used as a synonym of symbiosis, but it is better to restrict this term to cases of symbiotic relationships in which the common partners share the same food, as it seems obviously incorrect to apply the term commensalism to cases 
such as those of lichens and cattle-birds, in which the partners to the arrangement do not feed on even the same class of food. Some of the mites found so commonly on the larger dung-beetles are probably commensals rather than true parasites, helping to keep their host clean by feeding on the particles of dung which get attached to the short hairs, etc., on the body of the beetle.

The small winged Borboricl flies (Limosina cquitans) found commonly clinging to the under-surface of the large dung-beetle (Scarabaus gangeticus) probably feed on the same substances as the beetle but are not symbiotic partners, as the beetle seems to derive no benefit from the arrangement and merely provides transport for the flies, saving them the trouble of hunting for food for themselves. This is an example of what is called Phoresie.

Social insects, also, although they feed on the same food, can scarcely be called commensals, because they do not belong to different species and are therefore excluded by the definition of symbiosis given above.

Turning to a few examples of symbiotic relationships between insects we find that social insects, as partners of the one part, afford some of the best instances. Some caterpillars of the Lycænid (blue) butterflies possess on the posterior part of the back a special gland from which they exucle a sweet liquid greedily sought after by various ants, which on their part tend and protect the caterpillars; and these latter have become so dependent on the attentions of the ants that it is found impossible to rear them unless the ants are allowed access. Aphids (green-fly), Scale-insects, and other plant-sucking bugs are also tended and protected in a similar manner by ants who are repaid by the sweet honey-dew which is exuded on their solicitation; but in these cases, if ants are not present or are in numbers insufficient to collect all the honeydew, this is voided excrementitiously by the Aphids, etc., whereas the Lycænid caterpillars do not seem able to get rid of their secretion unless this is removed by the ants.

In the nests, also, of both ants and Termites are found many insects, belonging to almost all Orders, which are called myrmecophilous (ant-loving) or termitophilous (termite-loving), as the case may be, and which are only found in these nests. Many of these insects are truly parasitic on their hosts but many of them are symbiotic partners. Numerous small beetles, for example, found in these nests are fed by their hosts and in return exude from special glands a liquid which is eagerly sought after. In the case of some root-feeding Aphids and Scale-insects, also, ants are known to excavate little chambers around roots on which they place these insects which are guarded and tended by the ants in exchange for 
their sweet excretion. In countries with a cold Winter the ants have even been noted as taking care of the eggs of Aphids throughout the winter, placing the young newly-hatched Aphids out on plants in Spring during fine weather but taking them back to their nests in bad weather or on cold nights.

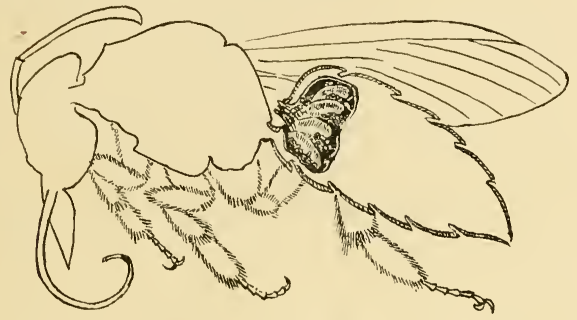

FIG. 33.-Section of $\mathrm{Xylocopa}$ showing Mites in abdominal cavity. (After Berlese.)

We must not onit mention of the extraordinary case displayed by the common large blue Carpenter Bees $(X y l o c o p a)$, although this is perhaps rather to be described as an example of symbiosis than as one of pure parasitism. These bees have at the base of the abdomen a chamber in which live small mites of the genus Greenia." The mites are apparently of no usc or inconvenience to the bee, although perhaps they may feed on other mites which are true parasites.

Examples of true symbiotic relationships exist between many ants and Aphids, Scale-insects, Caterpillars, Fulgorids, etc., the ants tending and protecting the other insects which in return yield a sweet excretion which is eagerly licked up by the ants. These relationships may prove of great practical importance in the control of insect-pests, as the ants often deliberately carry scale-insects on to plants previously uninfested, and may also prevent predators or parasites from attacking their protégés. I have actually seen an ant standing guard over a scale-insect and warding off the attack of a parasitic fly which was trying to lay its eggs in the scale. The caterpillars of some of the Lycænid butterflies, as noted above, are apparently absolutely dependent on the removal of their sweet excretions by ants and cannot survive unless the ants are allowed access to them, and this fact could doubtless be turned to practical

* The name Greenia, being preoccupied in Insecta, will have to be changed, 
account should such caterpillars require to be controlled as pests.

A parasite is an organism which lives at the expense and to the detriment of another organism, and this latter we call its host. Fleas, Itch-nites, Lice and Bed-bugs are familiar examples and some species of each class all have man as their common host. These are Ectoparasites or external parasites, living outside the body of the host, but many forms are Endoparasites living inside the body of the host, and as examples of the latter class we may cite the malarial parasite, the plague bacillus, and intestinal worms. Probably no insects are exempt from the attacks of parasites, whether these be other insects or other animals (worms, protozoa, etc.) or plants (fungi and bacteria). The parasites themselves are often attacked by other parasites, which we call Hyperparasites, and these again may be parasitized by yet others. Truly the poet wrought better than he knew in writing :-

Big fleas have little fleas

Upon their backs to bite 'em,

And little fleas have lesser fleas

- And so ad infinitum.

An original parasitic attack upon a host is called Primary Parasitism, the term Secondary Parasitism being applied to all subsequent attacks by parasites. Hyperparasitism is the normal attack of one species of parasite upon another species of parasite and superparasitism occurs when a normally primary parasite attacks a host already parasitized, the result generally being (in the case of insects and their usual endoparasites) that the tissues of the host prove insufficient to meet the needs of the latest comer so that it is forced to attack its predecessors.

The foregoing paragraph may seem technical, but it is none the less of the very first importance to obtain a very clear idea of the final result of parasitic attack. Insects which become pests of crops frequently increase to destructive numbers because parasitic control is absent or insufficient and the artificial introduction of the necessary parasites seems, to the minds of many, the final solution of the problem of control. And doubtless this is so if it is clearly realised that parasites will only control a species, that is to say, they will normally keep down its numbers, but they will not exterminate it altogether. For in practice parasitism does not seem able to deal with more than about 75 per cent. of the total number of any destructive insect. If parasites are present in such large numbers that a very high percentage of the host must be attacked to enable all the parasites to lay their eggs, they are compelled to 
oviposit in insects already parasitized, so that superparasitism occurs, with the result that very few of the parasites survive in the next generation to attack the possible hosts which have escaped being parasitized. The numbers both of host and parasite therefore undergo a sudden drop (see fig. 34), the host because of the large proportion destroyed by the vast numbers of parasites present, and these latter on account of internecine struggles caused by superparasitism. It is probable that in such cases the mortality amongst the parasites is proportionally much higher than in the case of the insect parasitized and this latter is therefore able to increase its numbers very rapidly, the parasites again increasing as their hosts provide more abundant food until the increase of the parasites once more overtakes that of their host, with the result that superparasitism again occurs and the wave of increase is again checked.

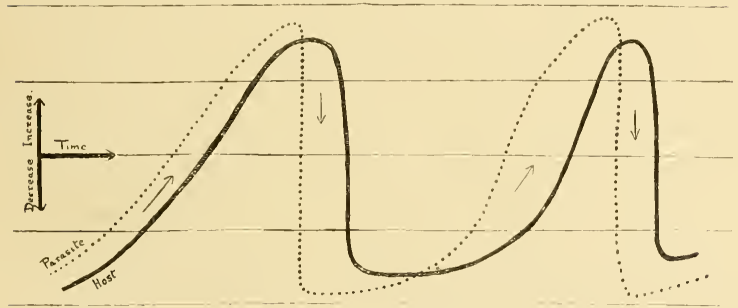

F1G. 34.-Graphic Curve showing increase and decrease of Host and Parasite. (Original.)

In economic work the study of the parasites of the various insect-pests is of the very first importance and at the same time it is often a matter of great difficulty and complexity, not only to find out which parasites attack any particular crop-pest, what are their lifehistories and what are their names, but to work out also the various relations between them and to decide therefrom which are beneficial and which are injurious. For it is not to be supposed (though too often taken for granted) that a parasite must be beneficial merely because it is a parasite. Many parasites are injurious, since they attack insects which are beneficial. If we take the case of a caterpillar, which is a crop-pest, and of a parasite which checks it, the latter may be looked on as beneficial; but this parasite may itself be attacked by a hyperparasite, which in its turn may be looked on as injurious in this particular case. But it 
is possible (and cases are known) that the hyperparasite is normally itself a parasite directly on another injurious insect, in which case it is beneficial. And so we have to know the lifehistory and occurrence of a parasite in great detail before we can say offhand whether it is beneficial or injurious. This is work of the first importance which has remained hitherto practically untouched in India but which, it is hoped, will be taken up in the near future. 


\section{Chapter IX.}

\section{THE BALANCE OF LIFE.}

\footnotetext{
"For not a creature lives beneath the sun

But has some dangers every day $t_{1}$ run."
}

KNIPE-Nebula to Man.

IN preceding chapters we have already discussed Reproduction and Metamorphosis in insects. Let us now take the case of an insect laying only two hundred eggs and passing through its lifecycle in one month and consider the possible number of its descendants if all attained maturity. Commencing for convenience sake on Ist January we have one fertilized female which lays 200 eggs, all of which hatch and mature by the end of the month; on the average half of these will be females, each of which will lay 200 eggs on Ist February and by the end of February we have $100 \times$ $200=20,000$ mature insects, of which half again will be females laying between them $10,000 \times 200=2,000,000$ eggs. It would be tedious to follow the increase month by month, but simple calculation shows that by the end of the year the descendants would reach the prodigious total of two trillions $(2,000,000,000,000,000,000,000,000)$ of individuals. The human mind is quite incapable of grasping the significance of such a figure but a few comparisons may assist imagination. If one thousand of the insects weighed only one ounce, their united weight would be $558,035,718,571,428^{\circ} 5$ tons, and if one thousand measured one cubic inch they would cover an area of almost fifty thousand millions of square miles with a uniform layer one inch deep or would fill a space of $7,862,931$ cubic miles or a cube measuring I 98 miles along each side. Taking the dry surface of the whole earth to be fifty-one millions of square miles, they would cover the whole of this to a depth of over eighty-one feet.

The case of the insect which we have considered above is by no means extraordinary as regards either the number of eggs deposited or the shortness of the life-cycle and it must also be remembered that we have only considered the case of a single individual of one species amongst the thousands of different insects found in every square mile in India.

But, after reckoning the theoretically possible rate of increase as shown above, let us descend to facts and ask, what will be the actual number of descendants of our imaginary insect which we shall 
expcct on the average to find at the end of the year? The answer is very simple. As a rule, we shall find two individuals, only one of which will be a female, still capable of laying two hundred eggs which will hatch and complete their life-cycle in a month, but whose (lescendants will not on the average either increase or decrease in numbers.

What is the explanation of the enormous difference between the potential and the actual rate of increase? Briefly speaking, it may be summed up under the three heads of (I) adverse climatic conditions, (2) a limited food-supply and (3) the attacks of enemies, and these causes may be further summarized uncler the general title of the Struggle for Existence. On the one hand, then, Reproduction and Growth constantly tend to the increase both of each individual and of the number of individuals, and on the other hand the Struggle for Existence tends to neutralize these forces, which together constitute the Balance of Life of the species as a single entity. On the whole, the balance remains fairly even and the numbers of any species in a given area remain on the average approximately constant in the absence of unusual environmental conditions, but the beam of the balance is never at rest but is always vibrating slightly on either side of its average position, and occasionally the beam swings violently in one direction or the other as dearth or disease or accident plays havoc with the numbers of the individuals or as these increase with increase of food-supply or more favourable environmental conditions.

Every kind of insect or other living thing, therefore, is constantly faced throughout its whole life with the struggle for existence, and has literally to succeed in the fight against competition and enemies to be able to live at all. All animals and plants are constantly engaged in this struggle and, whether their young or eggs or seeds may be counted on the fingers of one hand or be reckoned in millions, on an average the number of any organism remains fairly constant under unchanged environmental conditions. Man himself is not exempt from the stress of competition, although his superior intellect, in the more civilized races at least, helps him to defy many of the natural checks on increase. In older and more uncivilized times it was no uncommon thing that--

"A plague upon the people fell

A famine after laid them low,

Then thorpe and byre arose in fire,

For on them brake the sudden foe."

Even to-day in India it is not uncommon to hear of a village decimated by a man-eating tiger or leopard whilst even more destructive are the minute organisms, such as the malarial parasite and the 
bacilli of plague and cholera, which also take their toll of human life.

As noted above, the three destructive factors which are probably most important in maintaining the balance of life are climate, food, and enemies. In a country such as India we scarcely need to be reminded of the great importance of climatic influences. Defect in the monsoon rainfall means loss of crops whilst undue excess may cause disastrous floods. So far as man himself is concerned loss of crops may mean famine, although here the human intellect comes to his assistance by providing irrigation schemes to render him less dependent on the monsoon rainfall and rapid means of communication (railways, roads) by which supplies may be brought in from other more favoured districts. But for other animals the effects of climate in lessening the food-supply may be very serious.

The subject of enemies is so vast that it can only be stated here that it is the exception for any animal or plant to die of pure old age. At every stage of its existence it is subject to attack, within and without, by parasites which live at its expense and by predaceous animals or plants which kill it outright. In the fictitious insect whose rate of increase was considered at the commencement of this chapter, for every egg successfully deposited it was seen that ninety-nine failed to reach a state of reproductive maturity, and such a stringent rate of selection is the rule in the case of insects under natural conditions of existence. 


\section{Chapter X. \\ I N S E C T PEST S.}

"There is no exception to the rule that every organic being naturally increases at so high a rate that, if not destroyed, the earth would soon be covered by the progeny of a single pair."

DARW1N-Origin of Species.

THE word "pest" is so commonly used in connection with insects to denote injurious species that its meaning is usually well understood, although it is difficult to give any definition of general application. Perhaps it may be said that an insect becomes a pest when by its large number of individuals it does noticeable damage directly or indirectly to man himself or to his livestock, growing crops, stored produce, or other possessions. Such damage may be of regular or of occasional occurrence and may vary from total loss to a very small fraction. Probably damage amounting to one anna in the rupee (i.e., one-sixteenth of the total produce) is the smallest amount that is usually noticeable in ordinary crops, and it is convenient to note the amount of damage in this notation, as one, two, three or more annas in the rupee.

If we examine any crop under normal conditions it is very rarely indeed found altogether free from attack by insect-pests. Frequently half-a-dozen or more different kinds of insects will be found to be attacking it, some eating the roots, others the leaves, some boring in the stem, others sucking the juices, whilst still others eat the buds or flowers or damage the fruit. The damage done by each insect may be very small but the aggregate becomes very large and it is probably a fair estimate to state that on an average ten per cent. of all crops are destroyed by insect-pests. In other words an ordinary normal crop is only nine-tenths of what would be obtained under conditions of total absence of damage by insects. It becomes therefore a matter of some interest to attempt to place a money value on this loss, but to do this it is necessary first of all to make a valuation of the annual output of crops. Figures are not available for the whole of Southern India but the following table shows roughly the figures of area, outturn and value of crops in Madras only, and it must be clearly understood that the figures here given do not claim absolute exactitude, because that is impossible, but they arc believed to be approximately correct as a whole. 


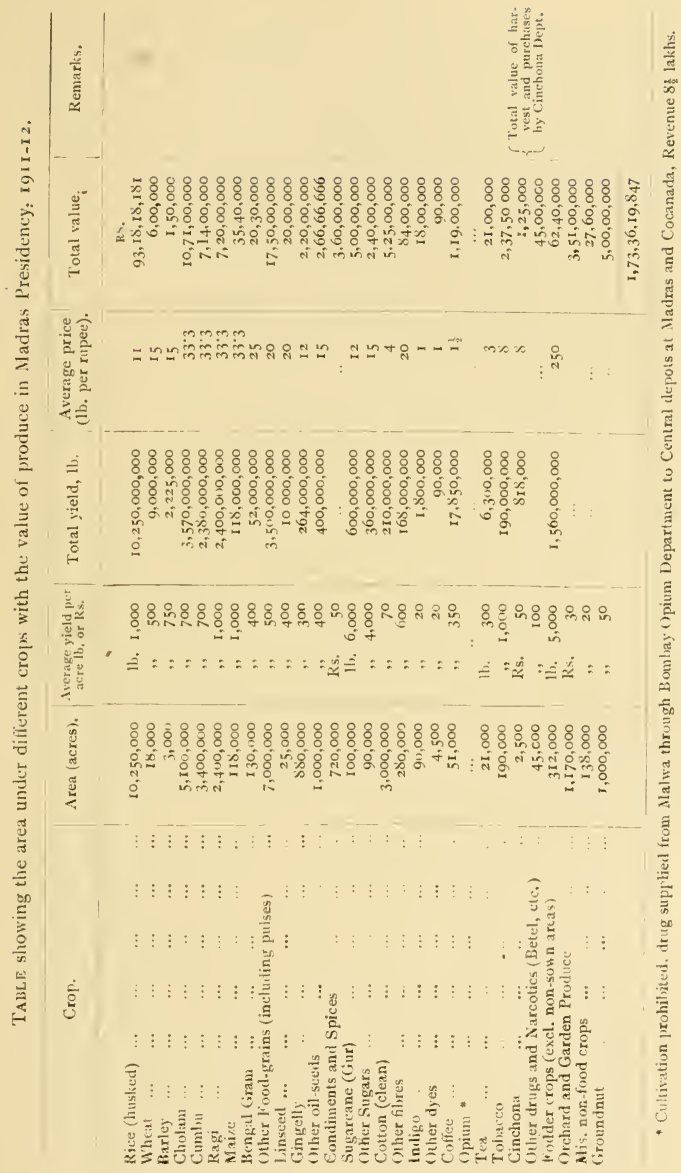


From this table it will be seen that the average annual crop-outturn of Madras is upwards of eighteen hundred millions of rupees, and this figure does not include the produce of nearly thirteen million acres under forests. Applying the ten per cent. rule of insect damage to these figures, we find that the destruction occasioned by insect-pests every year may be placed at not less than two hundred millions of rupees, of which roughly one-half is accountable to one insect-pest of paddy.

Yet even the above figures do not represent the total damage to the State wrought by insects, for they take no account of the economic loss caused by insect-carriers of diseases to man and his domestic animals. These latter alone represent a money-value of at least six hundred millions of rupees and even a small percentage on this figure runs into a very considerable amount, whilst diseases carried by the various ticks, lice, biting-flies and fleas that infest such animals are only too common. The ravages of Malaria and Plague may be cited as those of only two human diseases, both of which are solely spread by the agency of insects, and the annual death-roll in Madras from insect-borne diseases may be placed at upwards of two hundred thousand. Nor do these details exhaust the catalogue of crime suffered by man at the hands (or, rather, mouths) of his insect foes, for his various possessions-his stored food, his clothes, even his houses and all woodwork used for construction purposes-are not exempt from attack. Totalling the damage to crops, domestic animals, stored products and other possessions and to man himself, we may therefore estimate the damage done by insects every year in Southern India at not less than three hundred millions of rupees (Rs. 30,00,00,000). It is sincerely to be hoped that, by the development and application of entomological knowledge, this enormous wastage of national wealth may be reduced in the future.

Turning now to the causes which conduce to such vast losses, at least in the case of growing crops, we find that they are due as a rule to one of the following conditions, ( $\mathrm{I}$ ) the placing of large areas under one class of crop, $(2)$ deafforestisation and other alterations of natural features due to human agency, (3) the introduction of non-indigenous pests and crops, $(4)$ the destruction of birds and other predaceous or parasitic enemies, although all these conditions are often mutually interdependent and sometimes inseparable.

In the preceding chapter it was seen that, under the natural conditions of existence, the enormous natural rate of increase of any species of insect is neutralized by the destruction wrought amongst its individuals and their descendants, so that its numbers in any given area remain approximately constant, enemies and lack 
of food being the main checks on its increase; climate por se may be neglected, for it may be assumed that an insect living under natural conditions is adapted to the climate of the locality in which it lives. Taking as an example a moth which depends for its existence upon a wild jungle plant, its eggs may be parasitized before they hatch or may be discovered and eaten by some predaceous enemy, such as an ant the caterpillars are also liable to be parasitized or carried off by birds, wasps, ants or other predators before they have finished feeding and, if too many eggs have been laid on the one plant, they may starve or be exposed to special dangers whilst wandering in search of more food; when full-fed, many caterpillars leave the food-plant and lescend to the ground to pupate and at such times they are especially liable to attack by ants and predaceous birds and insects, whilst even after pupation they may be dug out and devoured by birds such as Hoopoes or burrowing mammals or insects; finally, when the insect has survived all these dangers and emerged as a moth, it has not only to feed but to search out scattered plants on which to lay its eggs and at this time especially a slow-flying egg-laden female is a special mark for attack by birds and other enemies. On the other hand an insect which feeds on a cultivated crop is spared many of these dangers. The crop is generally grown closely and therefore of itself provides a certain measure of shady security, so that predators and parasites are at an initial disadvantage, whilst the influence of dry, hot winds or other climatic factors is reduced to a minimum both as regards the direct effect on the insect and indirectly as reducing the available moisture in the foodplants. There is no lack of food and this fact consequently eliminates all necessity for searching for another plant when one has been eaten up, whilst the adult female insect also is practically exempted from dlanger in searching for the requisite foodplants on which to lay her eggs.

The destruction of forests and other alterations of natural features at the hand of man have far-reaching and often quite unforeseen influences on the flora and fauna of the areas affected. An immediate effect is often the washing away by rain of the soil which is the accumulation of the natural decay of vegetation during probably thousands of years and which has hitherto acted like a vast sponge to retain a stable condition of moisture throughout the year, so that the climate of the disafforested area tends to become less equable. After some time a secondary jungle may spring up, or very often the land is placed under a crop, but the old condition of things has been irretrievably altered and many plants and animals which lived in the forest are unable to adapt themselves to the altered conditions and die out. The interrelations between various species of animals 
and plants are often so complex and the balance of life is so delicately adjusted that the extinction of one tree or plant, for example, may lead to the extinction of certain insects dependent on that particular tree or plant, and the extinction of such insects may have an important effect on other insects or plants which at first sight would not seem to be affected; but the chain of interrelationships is often very long and complex so that the breakage of a single link gives rise to quite unexpected results. One effect of disafforesting an area which would seem obvious is that various insects, deprived of their food in the forest, would invade adjacent cultivated areas ; and this may happen to some extent, but probably far less often than is supposed. The fauna and flora of a truly forest area and those of a disafforested area recently placed under cultivation are usually very sharply differentiated and this difference may often be seen in the Hill Districts of Southern Inclia and still more distinctly in other parts of the world, such as the larger islands of the Seychelles where there is a very strongly demarcated line between the insect-fauna of the primeval jungle and that of the cultivated area immediately adjacent. The real influence of destruction of forests on the incidence of insect pests in their vicinity is almost always indirect but it is no less important for that, and the preservation of forests, certainly in all Hill Districts, should be looked on as a national affair of the first importance.

The introduction of non-indigenous pests from other countries is a very fertile source of trouble and especially so because such pests are usually brought in by themselves without the enemies which have normally kept them in check and thus they are able to increase very rapidly, so that an insect, which in its native country does little or no harm, when introduced into a new country or locality, may increase to such proportions as to become a pest. This tendency is not confined to insects but is exemplified by numerous animals and plants in all parts of the world and it is becoming almost an axiom that the worst pests of any country are introduced ones. The rabbit and thistle in Australia, the mongoose in the West Indies, Lantana and the green scale (Lecanium viride) in Southern India, are all well-known instances of introduced organisms which have become serious pests in the new countries to which they were taken. The green scale is believed to have been introduced from Brazil by way of Ceylon. It is interesting to note that it was quite unknown in $\mathrm{I} 86 \mathrm{r}$ to J. Nietner, an entomological Coffee-planter in Ceylon, who wrote a comprehensive series of "Observations on the Enemies of the Coffee Tree in Ceylon"; yet within twenty years it had gained such a footing as to lead to the ruin of the coffee plantations which had already been weakened 
by the attack of a fungoid leaf-disease. From Ceylon the scale was bronght to Inclia where it has acquired the name of the "Palni bug " on account of the damage it has done in the Palnis, but it has occurred for many years on the Shevaroys and Nilgiris and was introduced more recently in the Anamalais and was first noticed in Coorg and Mysore in I9I3; in the Nilgiris it has proved a highly rlestructive pest of coffee and it seems likely to do considerable damage to the coffee industry in Mysore and Coorg. The potato moth (Phthorimaa operculclla) is another insect-pest which has been introduced into India during recent years; it was originally brought into Bombay with seed potatoes imported from Italy and has rapidly spread to practically every potato-growing district in India, doing little damage to the plants growing in the field but destroying the stored tubers unless special precautions are taken, so that in some districts it has proved difficult or even impossible to keep seed-potatoes from one season to another and very heavy losses have resulted. The above are only two cases of imported insects which have become serious pests when introduced into a new country, but these examples are typical of many both in India and abroad, and it is therefore not surprising to find that almost every civilized country in the world has now found it necessary to impose restrictions on the importation of plants and fruits which are liable to bring in such serious pests. It is sincerely to be hoped that India also will very shortly be in a position to debar the entry of such undesirable aliens.

The introduction of new crops and of more paying strains of crops already grown has not been without a very pronounced effect on the incidence of insect-pests and of the damage done by them, quite apart from the introduction of new pests from abroad. It is a matter of common observation that newly-introduced crops are more subject than indigenous ones to the attack of indigenous insects and suffer as a rule considerably more damage. An area under the Cambodia cotton plant, for instance, which is attacked by Stem-weevil (Pempheres affinis), is usually much more badly attacked than an adjacent field of desi (native) cotton and a much larger percentage of the Cambodia plants are snapped off by a strong wind. Speaking generally, on the evidence available at present, there seems to be a certain amount of acquired immunity, or at least toleration, between plants and their pests after both have inhabited the same area for a considerable period of time. The process may perhaps be compared to the acquired tolerance of mosquito-bites exhibited by an old resident in the tropics as against that shown by a new-comer and in this case also there is an undoubted preference shown by the mosquitos for the blood of 
the less tolerant person, possibly because this contains a smaller proportion of antitoxins, perhaps merely because it is actually richer in red corpuscles. Be this as it may, we have some evidence to suggest that one method for the control of insect-pests of crops may lie in the direction of the breeding and utilizing of pestresistant stocks; this is a line of research on the border-line of Entomology and Botany, although the primary investigation of resistant strains undoubtedly lies within the domain of the Entomologist, and work on these lines will undoubtedly yield valuable results in the future.

The destruction of birds and of other predaceous or parasitic animals which act as natural checks on the increase of insects is a subject of peculiar importance in a country such as India, where so great a proportion of the population is entirely dependent on agriculture, where many birds are so largely insectivorous as to form constant and very effectual checks on the increase of insect-pests of crops, and yet where the feeding-habits of these birds and their importance are so little recognised by the agricultural classes who are most concerned. It must be clearly understood that no claim is made here that all birds, or even all insectivorous birds, are beneficial to the agriculturist. The value of birds, and their relative values, will be discussed more fully in a subsequent chapter and it will suffice to note here that districts in which the slaughter of insectivorous birds is permitted must expect to repay their debt to nature in the shape of an enhanced and perhaps ruinous toll levied on their crops by insect-pests which would normally have been kept in check by the birds. 


\title{
Chapter XI.
}

\section{THE CONTROL OF INSECT PESTS OF CROPS.}

\begin{abstract}
"Cependant, it mesure que les connaissances se précisent, la yuestion parait se ¿picialiser de plus en plus : les observateurs reconnaissent qu'il est impossible de trouver un remède général, indistinctement applicable à tous les Insectes. Chaque espéce pusséd. ant un mode de vie et des habitudes parliculieres, il faudra aussi, pour chacune, un procédé spécial de préservation et de destruction."
\end{abstract}

HOELBERT-Les Insectes Ennemis des Livres.

ONE of the commonest items in an official Entomologist's daily budget of correspondence is a letter from some inquirer stating that insects are damaging his crop (kind of crop usually omitted) and requesting some appropriate "medicine" by return of Post. It need hardly be mentioned here that it is quite impossible to apply any general remedy to meet the case of all insect pests of crops and that patent "Kill-alls," usually sold at inflated prices under fancy names, belong to the same category as the patent medicine "Cure-alls" so widely advertised under sinilar conditions. Insects have such widely different habits, some biting and devouring the tissues of the plant, some sucking its juices, some living on the leaves and others in the stem or below-ground, that it is obviously impossible to apply any general remedy which will be applicable to such diverse conditions. It is necessary to emphasize this fact because in actual experience it is so often found that it is not realized by the general public.

The control of insect-pests of all kinds is merely the application of common-sense methods based on a special knowledge of the insects concerned and of any particular details of the circumstances under which they occur; for example, in the case of insect-pests of crops some knowledge of the agricultural practice of the locality affected, together with a knowledge of the life-history of the insect in question, will often admit the devising of a practical controlmeasure based on such information, whereas means of control founded merely on a knowledge of one of these branches of information will usually prove impracticable.

The various means of control may be considered under four headings, (1) agricultural, (2) mechanical, (3) insecticidal and (4) special, but it may be added that these divisions are only given here for convenience of reference and in actual practice they are often scarcely differentiated. 


\section{AgRiCULTURAL METHODS.}

On the sound principle that "prevention is better than cure" agricultural methods aim rather at checking any undue increase of crop-pests than at actual control after they have attained destructive numbers. Such methods are therefore extremely important and should invariably form part of the regular routine of the agriculturist. They include such means as clean cultivation, the proper rotation of crops, the growing of mixed crops, ploughing, changing the time of planting, the use of poultry and encouragement of insectivorous birds, the stimulation of plant growth by means of manures, irrigation and draining, the selection of resistant varieties of crops, and the use of attacked crops as fodder.

Clean cultivation, by which is meant the careful removal of weeds and wild plants from the fields and their adjacent areas such as bunds and the removal of all crop-remnants after harvest. is by itself one of the most potent weapons in the cultivator's armoury in his ceaseless war against the ravagers of his crops. Not only the field itself should be carefully weeded before the crop is sown and while it is growing but the bunds and all similar adjacent areas should also be kept clear as far as possible. Many insect-pests feed on wild plants and, having eaten up these or finding a succulent crop alongside and more to their taste, pass into the cultivator's fields and take their toll of the produce; Kumblihulas are familiar examples of this and the Ricebug (Leptocorisa) also commonly lives on wild grasses on the edges of paddy-fields until the paddy begins to come into ear when that is invaded and attacked. Proper attention should therefore be paid to weeding not only in the field itself but on the bunds around it and in any contiguous uncultivated area. A belt of open ground forms in itself an excellent defence against invasion from outside by pests such as caterpillars which are exposed to attack by various predaceous enemies (birds, ants) before they can obtain access to the cultivated area.

A very common practice in cultivation is to leave crop remnants on the ground and this is a measure which is particularly dangerous in the case of cereals on account of the stem-boring insects which live on in the stubble and infect the next crop in the same or neighbouring fields. Cholam, ragi, paddy, wheat, and similar cereals are all affected by various stem-borers and it is a common sight to see a field in stubble from an old crop whilst alongside is a field growing a new crop of the same kind; needless to say, all the pests carried over in the stubble of the old crop simply move across and attack the new one. Leaving a field in stubble often also encourages the increase of Termites which are thereafter hard put to it for 
food and consequently attack the next crop grown in the field especially if this is weakened by stem-borers which have also been carried over in the stubble. As a general agricultural practice, therefore, I would advocate the collection and burning of stubble of all cereal crops immediately after harvest, the manurial value of the stubble being more than counterbalanced by the danger of carrying over pests. But in this, as in all similar practices co-operation is essential; for. as pointed out above, it is of very little use to practice clean cultivation in one field if it infected by adjacent or surrounding areas.

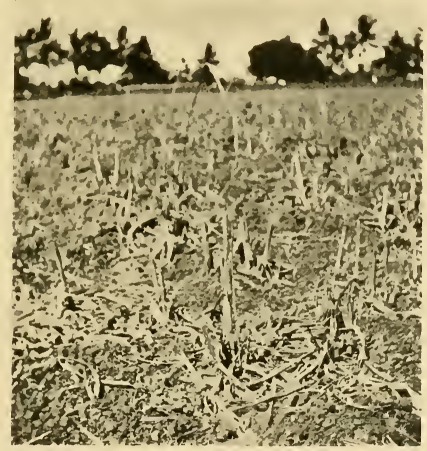

F1G. 35.-Bad cultivation from the point of view of control of Pests. Old cholain stalks have been left in the field after harvest, carrying over stem-borers and attracting termites. (Author's original photo.)

Leaving the crop itself too long in the ground is another form of the error noted above and is also a fertile source of outbreaks of insect pests. Cambodia cotton is an excellent example of this in Madras where, for the sake of a few extra handfulls of inferior lint, mostly spoiled and stained by insect-pests, a cultivator will often leave his crop standing in the ground until it is time to sow the next year's crop, which is naturally badly infected at the very start by the pests carried on by the old crop; the proper practice, of course, is to pull out and burn all the old crop at least three or four months before the new crop is due for sowing in order that all the pests of the old crop may as far as possible be starved out during the interval between the two crops. 
The proper rotation of crops is a matter of the utmost importance from the purely agricultural point of view, quite apart from the question of the control of crop-pests, yet at the same time it is an obvious and practicable means to the latter end also. Not only is it bad agriculture as a general rule to grow the same crop continuously in the same soil but, as pointed out above, such a practice is of direct assistance to the spread and increase of croppests. This again is a matter for co-operation between cultivators of adjacent lands as it is obviously of little use for one cultivator to rotate his crops if his new crop follows a similar one of his neighbour's and attracts all the pests which have lived in the latter. So far as pests are concerned also it is the rule, not only that the same crop should not be grown continuously, but that naturally allied crops should not be so grown. The potato and tobacco plants, for example, are closely allied to one another, both belonging to the same Natural Order "so that pests which attack the one are especially likely to find suitable food in the other; ginger and turmeric, cotton and gogu maly also be cited, all the known pests of the one readily attacking the other of each pair. For this reason trap-crops have been recommended, the principle being that a small crop is grown before the main crop of the same or an allied plant in order to attract all the insect-pests into the advance or trap-crop which is then destroyed before the main crop is sufficiently grown to be attacked by insects. This is all very well in theory and in practice also on experimental farms and similar places where the trap-crop can be grown under strict and intelligent supervision and where it may be destroyed in due time absolutely without fail. But unfortunately this is not the case with the great generality of cultivators and great caution should therefore be shown in recommending the growing of trap-crops on any general scale, for as a rule the simple-minded son of the soil cannot see the necessity for destroying the trap-crop at the proper time and does not do so; with the result that, instead of checking his pests, he simply provides them with food and helps them to tide over the period of normal scarcity before the main crop is ready for attack by them.

The growing of mixed crops is a common practice in many districts; in the western taluçs of Bellary, for example, five or six different crops (cereals, pulses, etc.) may often be seen growing intersown in the same field. In such cases the cultivator seems to distrust placing all his eggs in one basket, his idea being that, if one or two crops fail, he will at least secure a harvest from the others.

* A list of naturally allied plants is given on pages $264-273$. 
But the plan is sound Irom the agricultural view-point of the vary. ing requirements of different plants as regards the constituents of plant-food available in the soil and the inter-relationships of the bacterial and protozoal fauna of the soil. There is no doubt also that, if suitable mixed crops are grown, the increase of pests in each one is reduced, such reduction, in the case of drill sown crops at least, being probably largely mechanical and due directly to the fact that each area under one crop is separated from the next similar area by a barrier of other crops which are not suitable food-plants for the pests of the former; a mixed crop of groundnut and cumbu, for example, generally shows a much lessened attack on the former by the surul-pinchi (Aprocremä nerteria) as compared with that suffered by an unmixed crop of groundnut. The extra exposure of the moths when egg-laying and of the immature stages when hunting for more food undoubtedly forms a direct check on their increase. Experiments on the growing of mixed crops should be carried out from a combined view-point of agricultural, chemical, entomological, mycological and bacteriological knowledge, and such experiments would doubtless prove of great value in obtaining increased yields.

Ploughing is of course an ordinary practice of agriculture but it is often no less effective in the control of insect-pests; but for this end the ordinary country plough, which generally barely scratches the surface of the soil, is of little use and we require an iron plough capable of turning up the soil to a depth of at least six inches. The egg-masses of grasshoppers are usually deposited a few inches under the soil and many caterpillars (e.g., Kumblipüchis) also enter the soil to pupate and these egg-masses and pupæ often lie underground for months throughout the dry weather until the rains awake them to new life ; if, therefore, the soil is thoroughly plonghed up at this time and large clods are broken as far as possible, most of these egg-masses and pupæ will either be brought up to the surface and killed by the sun or devoured by insectivorous animals or they may be buried so deeply that they are unable to emerge at the proper time, and perish. Here again agriculture and pestcontrol go hand in hand, for ploughing during the dry season not only helps to check pests but, by providing a fine surface mulch, moisture is conserved to the subsequent benefit of the crop.

Changing the time of planting or of harvest when this can be done, either by sowing earlier or later, or by using early or latematuring varieties of crop, may sometimes be used with success as a control-measure in certain kinds of attack by insect-pests. A pest which appears at a particular time of the year, for example, may sometimes be defeated by delaying sowing until after its 
appearance or by sowing earlier so that the plants are sufficiently well-grown to withstand its attack. The various beetles (Cockchafers, Rose-chafers (Cetoniada), and Blister-beetles) which often do serious damage to the flowers of cereals, may be quoted as instances; their early stages are passed underground and are quite unconnected with the growth of the cereals and their appearance in the winged state is probably connected definitely with weatherconditions and always occurs at particular seasons of the year; if therefore the flowering of the cereals can be so adjusted as to take place before or after their emergence, damage may be prevented.

The common domestic fowl and other domestic poultry. especially ducks, guinea-fowl and pea-fowl, are excellent and indefatigable insect-hunters and their assistance in cultivated areas is not to be despised by the cultivator who wishes to obtain a good outturn of crop. In areas such as cotton-fields especially fowls do excellent work in checking insects with mutual benefit to themselves and the cultivator. Very many kinds of wild birds also are largely or wholly insectivorous. Their actual food and importance are discussed in another chapter and it suffices here to note that birds such as mynahs and drongos or king-crows spend their whole lives in capturing insects and should therefore be looked on as amongst the farmer's best friends and be protected and encouraged in every way. A few perches made simply of a cross piece of wood fastened to an upright thrust into the ground amongst young crops will provide resting-places on which birds such as drongos will be encouraged to sit, ready to swoop down on to any insect seen stirring amongst the surrounding crops.

The stimulation of plant-growth by means of manures or other methods is another agricultural practice which helps to minimize the incidence and effects of the attack of crop-pests. A plant which is thoroughly healthy will often escape attack or will at least suffer comparatively little, whereas a sickly plant will be attacked far more readily and its produce will be reduced to a far greater extent. It is possible plants may produce toxins as a defence against the insect-pests to which they are normally exposed and that such toxins are waste products of the metabolic changes induced by healthy growth but that, if the health of the plant is impaired by bad cultivation or uncongenial conditions of any sort, the whole of its energies are required for growth and such toxins are not elaborated and consequently the plants are more subject to attack by pests of all kinds; but this idea is only put forward as a supposition.

Irrigation, where this is possible, is sometimes a good method of control of crop-pests even when the soil is not deficient in moisture 
Crickets, for example, often do a great deal of damage to crops in some districts, living in burrows in the ground and only coming out at night to cut off tender shoots which they carry off to their burrows and devour during the day-time; in such cases irrigating the affected area will drive them out when they fall an easy prey to crows, kites, and various other enemies. The manner in which crows and kites will congregate when fields are being flooded is well known tó every agriculturist and very little observation will show that they are busy catching grasshoppers, crickets and other insects which are lliven out of cracks in the soil by the advancing water. Some caterpillars, beetles, bugs and other crop-pests may also be controlled by irrigating the affected area, but no general rules can be laid down. The addition of a bag of Crude Oil Emulsion in the irrigation channel sometimes helps to drive away certain pests, temporarily at any rate. The converse of irrigation, Draining, is used to control the Paddy Caseworm (Nymphula depunctalis) whose larva is aquatic in habit.

The selection of resistant varieties of crops is a subject which has hardly been touched in India but there is little doubt but that this line of work offers one of the most promising lines of research for the future. It is a matter of common observation to any agriculturist that particular plants or particular varieties of plants are less subject to attack by pests than are others grown under similar conditions and by selecting and breeding from such resistant strains we may hope to secure relative immunity from the ravages of pests. This is not a matter in which immediate results can be expected and it demands co-operation as regards the agricultural, botanical, entomological and mycological aspects of the question in the case of each particular strain of each crop and perhaps the required qualities may vary in different districts. In the meantime agriculturists should retain seed for sowing from the most healthy and pest-resistant plants which they can select from their fields and should look on the selection of the best seed obtainable as the very ioundation of any attempt to grow a good yield of crop.

In some cases, especially in cereals where a large area is placed under one crop and irrigation or other control methods are impracticable, small patches of a crop are sometimes found to be badly attacked by a pest. In such cases it is often possible to cut such patches and to feed the affected plants to cattle as green fodder, thus ridding the remaining area of these centres of infection and at the same time making some use of the attacked plants. The use as fodder of cholam, etc., attacked by stem-borer will not hurt the cattle but care must betaken not to feed hairy caterpillars (kumblipüchis) or blister-beetles to cattle, as the effects of such a diet may be 
serious; occasion may also be taken to point out the danger of Hydrocyanic-acid poisoning consequent on a too liberal use of young actively-growing cereals as fodder, but it is probable that this danger will be largely reduced if only plants suffering from attack by insects are used.

The advantages of sowing crops by means of a drill and of planting out seedlings in regular lines become especially apparent in the control of crop-pests by means such as hand-picking. If a cotton-field, for instance, is planted in regular rows, it is comparatively easy to go over the field row by row and collect cotton-bug. or whatever the particula1 pest is, and to be certain that no bushes have been left unexamined; but it is far more difficult to make sure that no bushes have been missed out if they are planted irregularly. It is also far easier to notice the first stages of an attack in drillsown crops and their intercultivation is more efficient and makes it more difficult for pests to spread. Such crops, too, a re more readily thinned out and the more vigorous plants which are left are hetter able to withstand the attack of pests.

\section{MECHANICAL METHODS.}

Under the heading of Mechanical Methods may be grouped those means of control which are intended to reduce the numbers of pests, either before or after they have attained destructive proportions, without making use of insecticidal liquids, powders or gases; but it may again be remarked that it is difficult to draw any definite line between mechanical and insecticidal methods. Amongst mechanical means may be included hand-picking, collection by hand-nets or bag-nets, hopperdozers, light-traps, attraction to baits and traps, trenching, burning, banding of trees, screening, destruction of borers in trees, removal of dead trees and branches of trees, and cutting out of deallearts.

The collection of insect pests by hand is an extremely simple method which has also the merit of remarkable efficacy if carried out regularly and on the first appearance of a pest whilst its numbers are still small. If pests are allowed to increase, their numbers soon become so great that hand-picking is out of the question, but in the early stages of an attack a vigorous onslaught will often nip the outbreak in the bucl. For example, in 1912 we had a small outbreak of kumblipuchi on the Central Farm at Coimbatore; one chokra was set to collect the caterpillars and in four days had collected several hundreds with the result that little damage was done by that brood and no subsequent broods were even noticed; if the first brood had not been checked, at least two subsequent 
broods would have followed and considerable damage would have been done, as actually happened in the surrounding district under similar conditions except that no action was taken. A measure of this sort is so simple and inexpensive as to be with in the reach of all, and every cultivator should make a practice of killing every croppest on sight wherever met with and more especially when found on his crop in small numbers, for it is the prevention of increase that should be aimed at. It is of little use to start killing the püchis after they have attained such numbers that the crop is alreatly spoilt.

The method of hand-picking must be adapted to the particular insect concerned, the insects being simply caught and squashed in the hand (smooth caterpillars, large bugs, many beetles) or crushed underfoot (large caterpillars) or dropped into a pan or vessel containing water with a film of oil on the top (kumblihulas, blister beetles). Or the insects may be shaken on to a sheet or cloth or into a vessel of oil and water. For the collection of cotton-bugs use is sometimes made of a tin funnel fitted into a bag in which the bugs fall and are unable to escape. For collecting insects from moderately tall plants an ordinary umbrella, held upside down, makes an excellent tray if nothing else be available.

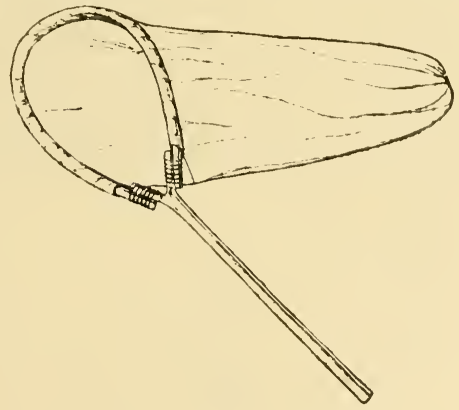

F1G. 36.- Hand-net. (Original.।

A small hand-net is particularly useful for catching the more active insects which are difficult to capture with the unassisted - hand. It is simply and cheaply made of a bag of light cloth secured around its mouth to a hoop of cane or bent wood which in its turn is fastened to the two arms of a $\mathrm{Y}$-shaped branch of which the main stem forms the handle of the net. With the help of a net 
of this kind a cultivator may easily ricl his fields of flying pests such as Rice-bug, Blister Beetles and Rose-chafers, whilst it may

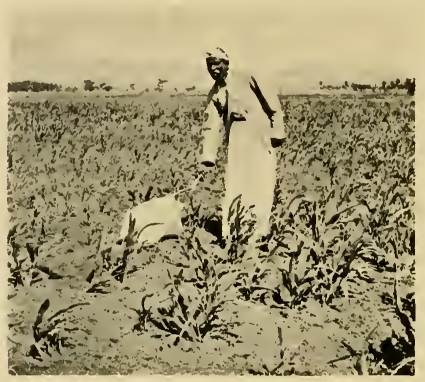

F1G. 37.-Hand-net in use. (Author's original photo.)

also be used for grasshoppers. The insects caught in the net, by sweeping it over the crop, may be killed simply by crushing them by hand or under foot or with a flat stone or the contents of the net may be emptied into a vessel containing water with a little oil on top.

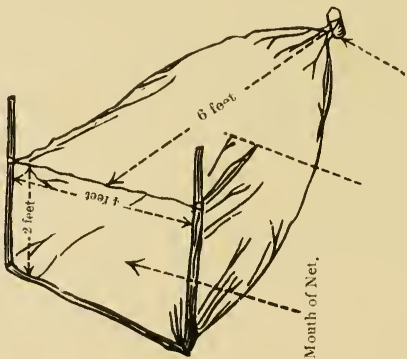

Fig. 38.-Bag-net. (From Madras Agricultural Calendar 1913-14.)

For grasshoppers a bag-net is used as this enables the whole surface of an affected area to be worked over and practically all the grasshoppers to be swept up in the bag. The bag-net is simply a large bag of cloth abont four feet wide and two feet across at the mouth and five or six feet deep and tapering to a point behind. 
The mouth of the bag is fitted at the sides (see figure 38) with two short bamboo poles each four or five feet long, to keep the mouth open and to form handles to hold the net with, and a piece of bamboo is also fastened into the lower edge of the mouth to keep it straight and so prevent it from sagging up off the ground. The end of the net is weighted with a lump of stone, brick or wood to prevent it ballooning up and spilling the catch out of the mouth when in use. The bag-net is worked by two men who each grasp one of the bamboo handles and sweep it over the crop as quickly

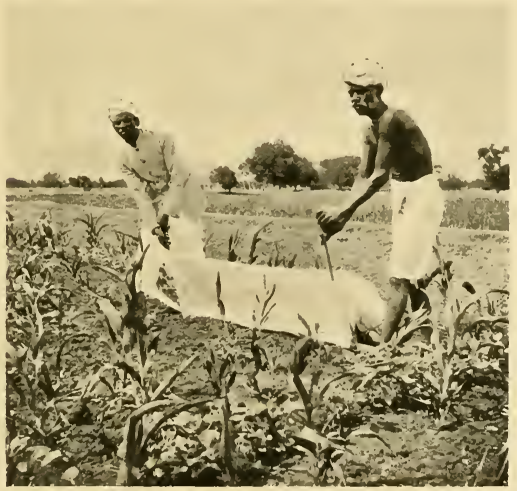

FIG. 39.-Bag-net in use. (Anthor's original photo.t

as possible. The hoppers, being disturbed by the passage of the net, jump off the plants and are swept into the net by the lower edge of the bag before they have time to reach the ground. The grasshoppers, at the end of each run, are shaken down into the bottom of the bag and killed by crushing or by emptying them into a vessel of oil and water. For obtaining as large a catch as possible the following precautions should be observed:-(I) the net must be swept as closely along the ground as possible, (2) the men working it must run at a quick pace, and (3) as far as possible the bag should be swept against the wind.

A single bag-net will work over nearly three acres of ground daily and will require the services of three men, two working it and the third relieving the others by turns. Where a field is badly infested by grasshoppers it will require to be gone over several 
times, the number of baggings required depending on the degree of infestation, and the natures of the soil and crop. It is of course impossible to bag cereal crops when they are grown up as it is impossible to get the net sufficiently near the ground to catch the hoppers and because the damage done by the workers running through the field would be too great, but such crops may easily be bagged without damage before they have attained a growth of three feet.

The efficiency of both the hand and bag-nets may be increased by soaking them with oil before use but this practice is not economically sound unless waste oil is available at a nominal cost.

Hopper-dozers are machines used for the control of grasshoppers and are made of a series of trays, usually of metal, joined in a parallel series and so interspaced that each tray fits into the interval between each row of a field-crop. The inside of each tray is painted with tar or other sticky substance or is simply filled with oil and water and the machine is then dragged through the infested field which, it is needless to add, must have been previously sown in parallel lines by means of a drill. The hoppers, disturbed by the passage of the machine, jump or are brushed off the plants and fall into the trays where they stick to the tar or are smothered by the oil, which kills them even if they succeed in escaping from the trays. A machine of this sort was tried in Bellary in connection with the Deccan Grasshopper work in I9II and was found to be quite efficient but less economical than bag-nets, whilst hopper-dozers possess the disadvantage that their use is restricted to drill-sown land. As an adjunct to the use of the bag-net, when the crops have become too high to admit of bagging, hopper-dozers may sometimes be very useful.

Light-traps are used to attract and kill the adults of various crop-pests, especially those which are stem-borers in their early life and therefore difficult to check in their directly destructive stages. They are simple in construction and inexpensive to work and it is probable that light-traps may be found to be the best means of checking such pests as the Stem-borers of paddy (Schowobius bipunctifer) and of ragi (Saluria inficita). Any ordinary lamp, holding sufficient oil to burn all night, may be used and is placed amongst the crop, either standing in or suspended just above a pan of oil and water which should project at least six inches on each side of the lamp. The lamp should be so placed that the flame is situated just above the tops of the growing crop and that the light is visible all around. A mixture of kerosine and coconut oil gives a good light at small cost. The lamp should be lighted at dusk and left burning all night. The insects, which are attracted by 
the light, dash against the glass of the lamp-frame and fall into the tray of oil and water below this and are suffocated by the oil. Very large numbers of insects are sometimes caught in this way, especially on still, warm, dark, moonless nights. It is usually not worth while to put out a lamp-trap on bright moonlight or windy nights.

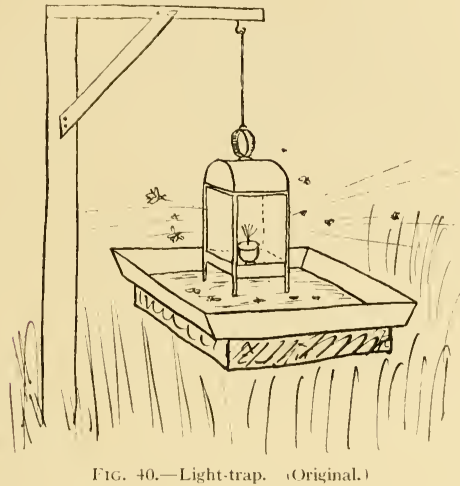

Baits and traps for the attraction and capture of crop-pests are so numerous and various that no complete account can be attempted here. Many nocturnal caterpillars, crickets and other insects which hide away in the daytime are often difficult to track down and deal with but they may sometimes be trapped by laying down fresh sods of turf, planks, etc. in likely places and these may if required be baited towards evening with tender shoots $(c, g$. lucernc) and examined next morning for the presence of insects. Special traps for the attraction and destruction of certain noctuid moths by the dissemination of the smell of a lifuid have been introduced of late years and have been found highly successful in Northern India in one special case; but such means are not with the reach of the ordinary agriculturist.

The trenching of fields and smaller areas such as seedbeds is a simple and efficient method for assisting in the exclusion of creeping insects, such as caterpillars, which may otherwise invade crops. A small furrow of even a few inches breadth and depth will often check the inroads of such insects if the inside edge of the trench is vertical and composed of fairly loose soil. A few 
small steepsided pits dug at short intervals along the bottom of such a trench will serve as further traps, as the insects will generally wander some distance along the bottom of the trench and are therefore likely to tumble into the pits. In the case of Kumblihulas, if sufficiently wide and deep trenches are available, a few fresh branches may be strewn in them to provide a certain amount of food and shelter and these may be examined and renewed daily and all the caterpillars found in hiding killed; but care must be taken that such branches do not provide a bridge up the sides of the trench. In cases where a ditch of standing water forms the boundary of a field, a little oil spread over the surface of the water will form a barrier against invasion by caterpillar pests.

Burning is sometimes a practicable method of dealing with crop-pests, especially in the case of many of the hairy caterpillars which gather gregariously and often form large patches on trectrunks. A bundle of straw soaked in oil and fastened to the end of a bamboo makes an efficient torch for such purposes. The burning of stubble has already been dealt with.

Fires may also be used sometimes in the control of crop-pests which are attracted and killed by the flames at night and insects may also in some cases be driven out of crops at critical times by the judicious use of smoke. Mango Hoppers, for example, may sometimes be diven temporarily out of the trees by kindling smoky fires beneath the branches at the blossoming period when the flowers would otherwise be spoilt by the "honeydew" exuded by the Hoppers.

In the casc of trees the access of pests may often be prevented by banding the trunk with a sticky or oily mixture either painted directly on to the tree or applied on a band of cloth or paper fastened around the tree. A mixture of Tar and Crude Oil Emulsion, in equal parts, may be recommended as efficacious and harmless to trees; but no mixture of this sort can be expected to last more than a short time in India. Wide bands of tin may be nailed on to the stems of Coconut Palms to prevent the access of rats.

The screening of choice fruits and vegetables to guard them against the attack of fruit-flies and other pests is a simple and obvious method of protection.

Many trees are subject to the attack of large boring caterpillars, the larvæ of beetles and moths, which pierce galleries through the living wood and in bad cases may even kill the tree or bush so attacked. A simple remedy is to cut out the larvæ with a knife and to paint the wound over with tar to prevent access of other 
insects or of the spores of fungi or bacteria. The use of the knife in such cases, though apparently drastic, is usually quite successful. Nlango-trees especially are subject to attack by a common treeboring beetle larva (Batocera rubus) and Orange trees also are often affected by the grub of a nother species. Sometimes the grub can be killed or pulled out with a piece of wire but usually it is better to cut down to it and clean out the gallery which is otherwise likely to give access to other diseases later on. A piece of wire with a barbed point is used for destroying palm beetles (Oryctes rhinocros) in their burrows in the tender shoots of paims, the beetles being transfixed on the barb and withdrawn and the burrow tarred over.

A tree or portion of a tree which is dying or dead at once becomes a suitable breeding-place for innumerable insects, mostly beetles, which feed upon dead or decaying wood, and some of these may be a source of danger to living trees if no more dead wood is available for them. All dead trees and branches should therefore be removed and used for fuel or other purposes and not be left standing or lying about the fields. This is especially the case with rotting stumps of palms and aloes which are usually found to be swarming with the fat white grubs of Oryctes which will presently emerge as beetles to attack the palms in the vicinity.

Cereals, such as sugarcane, cholam and paddy, generally exhibit signs of attack by stemborers by a withering of the central shoot which is frequently completely detached so that it comes away from the plant at the least pull. Such a withered central shoot is called a "deadheart" and its presence almost invariably shows that a caterpillar is boring inside the sten of the plant. A watch should be kept for the first appearance of such deadhearts, especially in a valuable crop such as sugarcane, and they should be rigorously cut out and the caterpillar killed to prevent the attack from spreading. Shoots so attacked are in any case quite useless; whereas, if they are cut back as soon as noticed, new shoots will generally be thrown up and little loss result. But the importance of pronipt cutting out of deadhearts lies in the prevention of further damage by later broods of the insects concerned.

\section{INSECTICIDAL METHODS.}

Insecticides, as their name implies, are substances which are used to kill insects. As a rule, they are only used when an insect has attained such numbers as to be a pest. Some insecticides, it is true, may be and are used as deterrents or repellents, to drive insects away temporarily from particular areas, but as a rule it 
only pays to use insecticides when damage is imminent or actually being done. The conditions of agricultural holdings in the Plains of India are so special that insecticidal methods for the control of crop-pests are hardly within the means or reach of the ordinary cultivator, but even at present there is large scope for their employment by Zamindars, Agricultural Stations and Associations, and by all owners of garden and orchard property, whilst in the Hill Districts the more permanent plantations of tea, coffee, etc., have mostly found by experience the economic utility of insecticides.

Insecticides are usually applied in the form of powders, licuids or gases, but only the first two of these will be considered here, as gaseous insecticides are not applicable to crops under ordinary conditions in India and will therefore be dealt with in the next section under the heading of "Special Methods." Broadly speaking, insecticidal substances may be divided into Stomach Poisons and Contact Poisons, and it is with respect to their correct usage that some knowledge of the insects concerned is requisite. Stomach Poisons are applied to the plant which is attacked in order that they may be eaten by the insect and kill it when taken into the system through the alimentary tract; they can therefore only be used for insects which eat solid food, such as leaves or stalks of plants, or in other words insects which have biting mouthparts. Insects with sucking mouthparts obtain their food by thrusting their mouthparts into the plant and sucking its juices; therefore they cannot be poisoned by substances applied only to the outside surfaces of the plant and it is impracticable to inject poisons into the plant which will kill the insects without harming the plant. For sucking insects we therefore use Contact Poisons which kill them either by blocking their spiracles and so asphyxiating them or by direct poisonous action or by evolving poisonous gases; so far, however, as the cultivator is concerned, the insect is killed by suffocation. Contact insecticides can of course be used to kill insects with biting mouthparts, but it is more economical to use Stomach Poisons for these. To sum up, Stomach Poisons are applied to the plant in order that they may be eaten by those insects which have biting mouthparts ; Contact Poisons are applied to the insects themselves, and only incidentally to the plant, in order to suffocate insects with sucking mouthparts.

Before considering the insecticides themselves, a few general remarks on their application will not be out of place here. In the first place it must be noted that no exact scale of dosage can be laid down as universally applicable, although for ordinary practical work an approximately correct dosage may be 11 sect. Too large a quantity of an insecticicle may kill the plant as well 
as the insect, whilst too weak a dose may have no effect on either. What is required is a quantity strong enough to kill the insect but not strong enough to harm the plant, and this must vary according to the kind and age of both plant and insect. If a particular strength of insecticide is found to fulfil these conditions, there is no object in using a stronger dose; such will not kill the insect ăny " deader," whilst the extra quantity used will represent a waste of money and may harm the plant. But a super-lethal dose is usually preferable on the whole to a sub-lethal one, as the extra cost of labour in repeating the latter is generally greater than the difference between the two; in other words, it does not pay to apply an ineffective dosage, as both insecticide and labour are wasted without result. In the following pages are given general average quantities in which the various insecticides referred to should be used and the minimum quantity stated should be tried at first on a small scale and only increased if found inefficacious. It must be remembered also that different makes of insecticides may vary considerably in purity.

Secondly, an appropriate insecticide must be chosen with regard not only to the insect but to the plant also. It would, for example, be criminal folly to apply an arsenical poison to culinary vegetables or fodder cholam just before these were intended to be cut for food of man or beast.

Thirlly, due regard must be paid to weather conditions. It is useless, as a rule, to apply insecticides cluring periods of heavy rain, as they are rapidly washed off by showers before any good is accomplished. Nor is it usually a good thing to apply liquid insecticidles to leaves under the hot noonday sun; such are best applied in the early morning, which is also the best time to apply powders, whilst the dew is still on the leaves. Poisons for nightfeeding insects should be applied in the evening. Many insecticides are decomposed by the action of sunlight and weather and the use of some, such as sulphur, is based on this fact ; the application of an insecticide cannot, therefore, be expected to protect a plant for more than a limited period-probably two or three weeks at the most during dry weather and considerably less if rain occurs.

\section{Stomach Poisons.}

Of this class of insecticides the arsenical preparations known as "Paris Green " and "London Purple" were first tried in India some twenty-five years ago, but their use has now been practically abandoned. Lead Arsenate was introduced ten years ago and Lead Chromate of quite recent years and both are used extensively, 
whilst Naphthaline Emulsion is also used for special crops such as vegetables, where only a temporary poison is required. Other insecticicles of this class include Zinc Arsenite, Dry Paints, and several others which are more rarely used.

Lead Chromate is an insoluble yellow substance which is usually sold in the form of a paste containing about 33 per cent. or as a powder containing about 50 per cent. of Lead Chromate. The paste mixes better with water and is easier to use, three ounces of this being taken to represent two ounces of the powder, one-quarter to one-half of an ounce of powder, and half as much again of paste, being the standard dosage for one gallon of water. If Lead Chromate itself is not obtainable it may be prepared by dissolving separately in water one part by weight of Potassium Bichromate and two parts by weight of Lead Acetate or Lead Nitrate and mixing the two solutions, when two parts by weight of Lead Chromate will be precipitated, and this may be diluted with water to the required strength and used in the sprayer.

Lead Chromate possesses these advantages, that its yellow colour makes it readily perceptible on the plants to which it has been applied and that it is a comparatively weak poison to larger animals such as cattle. It is not, however, absolutely non-poisonous to cattle, as has been claimed, and on the other hand, it has not always proved effective against insect-pests; on the whole it does not seem to be sufficiently poisonous to be really effective, but may for the present be recommended as a readily accessible and moderately efficient insecticide for use by those in whose hands it might be dangerous to place arsenicals.

Lead Arsenate is usually sold in the form of a greyish paste but is also obtainable as a white powder; in either case it should first be mixed with a little water to make a thin paste before dilution to the strength required for spraying. The advantages of Lead Arsenate are the facts that it does not burn foliage as a rule owing to its insolubility in water, that it remains in suspension in the sprayer with a moderate (legree of agitation, and that it sticks well to the surfaces of plants. The powdered form can be dusted onto plants when the white colour shows up well, but this insecticide is usually applied more economically as a liquid spray. It is considerably cheaper than Lead Chromate and a much more violent poison, but does not kill insects so quickly as Paris Green or the more soluble arsenicals. Lead Arsenate in the form of paste should not contain more than 50 per cent. of water, it should contain more arsenic than is equivalent to $12 \frac{1}{2} 2$ per cent. of Arsenic Pentoxide and should not contain arsenic in water-soluble form 
equivalent to more than 075 per cent. of Arsenic Pentoxide. The paste is generally used at a strength of 4 to 8 pounds to 100 gallons (roughly one-half to one ounce per gallon), the powder at 2 to 6 pounds to $\mathrm{I} 00$ gallons of water. If not obtainable directly it may be prepared from Lead Acetate (Sugar of Lead) and Sodium Arsenate, 44 ounces of the former being dissolved in four gallons of water in a wooden or earthenware container, and sixteen ounces of Sodium Arsenate being dissolved separately in two gallons of water; these two solutions on mixing will provide Lead Arsenate sufficient for dilution to I00 gallons.

The Arsenites of Lead and other metals are about twice as poisonous as the corresponding Arsenates, owing to their greater solubility in water and the gastric juices of insects and other animals. For spraying, therefore, as soluble a form of Arsenic is required as can be safely applied to plants without burning them. Sodium Arsenite cannot be so used as it injures foliage and hence is often applied as a weed-killer. Lead Arsenite may be prepared by dissolving separately in water six ounces of Sodium Arsenite (which is itself prepared by boiling together White Arsenic and Caustic Soda) and thirty-two ounces of Lead Acetate ; these solutions are mixed and made up to $62^{\mathrm{I}} / 2$ gallons for spraying. But, on account of the extra solubility of the Arsenite, it is better to use Lead Arsenate.

Zinc Arsenite has been used to some extent in America to replace Lead Arsenate, and is claimed to be more toxic, or at least more rapidly poisonous to insects, one pound of Zinc Arsenite being taken as of equivalent toxicity to three pounds of Lead Arsenate. Zinc Arsenate has also been used as an insecticidal spray at the rate of about four pounds to 100 gallons of water. As the action of Zinc salts on animals usually induces vomiting it is probable that Zinc compounds may find a special use in preference to Lead salts in the particular circumstances found in India where it is especially desirable to avoid the poisoning of cattle which may accidentally feed on sprayed plants.

Paris Green, usually sold as an emerald-green powder, is a double acetate and arsenite of copper and may be called Copper AcetoArsenite, although its actual composition is not fixed. It is a violent poison and may be applied dry but is better used as a liquid spray ; in either case it should be mixed with Lime in order to neutralize any soluble arsenic which may be present and which would burn the foliage. When applied dry, three to four times the same weight of air-slaked Lime is added and the mixture dusted lightly over the plants in the early morning by means of a muslin bag. 
When used as a spray, eight to ten ounces of Paris Green are used in 100 gallons of water to which have been added two pounds of lump Lime to neutralize any soluble arsenic. The advantages of Paris Green are its cheapness and powerful poisonous action ; amongst disadvantages may be noted the fact that it is not properly held in suspension in the sprayer without constant agitation and there is therefore risk of uneven application, that it sometimes burns the plants, and that it is liable to be washed off them very easily. If not obtainable, it is readily made by dissolving separately $4 \mathrm{lb}$. of white arsenic in 5 gallons of water and $5 \mathrm{lb}$. of Verdigris in 5 gallons of water and mixing the two liquids, which are then boiled for some time and a little Acetic Acid added. Commercial Paris Green should contain not less than 55 per cent. of arsenic $\left(\mathrm{As}_{2} \mathrm{O}_{3}\right)$, of which only about 5 per cent. should be soluble in water, and about 27 to $3 \mathrm{I}$ per cent. of Cupric Oxide.

London Purple is simply Calcium Arsenite, and derives its name from the fact that the arsenite of lime formerly used was the residue from the manufacture of magenta and was therefore tinted with colouring matter, which, it is needless to add, is not necessary for its efficacy. Calcium Arsenite is readily prepared by dissolving one pound of white arsenic in two gallons of water and mixing with a solution containing two pounds of lime. The mixture is then heated for half-an-hour and diluted to make 100 gallons. Calcium Arsenite is insoluble in water and therefore will not burn foliage, but care should be taken to see that the lime is in excess. The original London Purple, however, was variable in composition and this insecticide is not much used at the present day.

When the foregoing insecticides are not available, ordinary metallic paints are usually obtainable locally in a finely powdered state and may be clusted on dry mixed with lime, flour, or roaddust; such paints as red lead, white lead, iron oxide, yellow ochre, red ochre, lemon chrome, burnt sienna, etc., may be used in this way, being simply clusted on to the crops whilst these are wet with dew by means of a cloth bag.

In some cases it is necessary to spray vegetables or fruits which are required for consumption within a short period and under such conditions it would obviously be extremely dangerous to use arsenicals or other poisons which might remain on the crop and poison the consumer. In such cases, a temporary insecticide, such as Naphthaline Emulsion, may be used, as this acts as a stomach-poison to any caterpillars which may be doing damage and all evaporates away within about twenty-four hours so that the sprayed material may safely be eaten afterwards. It is prepared by dissolving six 
ounces of concentrated size in half a gallon of hot water and adding one pound of soft soap. Two gallons of kerosine are then warmed carefully in the open air over a small fire-it is scarcely necessary to remark that no attempt must be made to boll kerosine over a fire-or by placing the container in a vessel of boiling water and as much naphthaline is added as will dissolve in the kerosine (about eight pounds as a rule). The two solutions are then mixed together whilst hot, half a gallon of water is added and the whole thoroughly stirred or churned up together.

Lime-Sulphur, at a strength of 3 gallons of concentrated solution to I00 gallons of spray material, has also been found effective as a stomach-poison for caterpillars although its action is very slow. Lead Arsenate may be nixed with it if required. Lime-Sulphur, however, is generally used as a Contact Insecticide, especially for Mites. (Sec page I03.)

\section{Contact Poisons.}

Contact Poisons, although actually effective against almost all insects, are practically only used in the case of sucking insects as it is usually more economical to apply a stomach poison in the case of insects with biting mouth-parts. The Contact Poisons include various Emulsions and Washes based on the use of Oils, Soaps, Rosin, Sulphur, Lime, Tobacco, Phenyle and various other substances.

Crude Oil Emulsion is a very satisfactory insecticide which is largely used in India. It contains 20 per cent. of soft (fish-oil) soap and 80 per cent. of crude kerosine-oil. When properly made, it forms a homogeneous mixture and emulsifies well with water, but care should be taken to see that the oil has not separated out from the soap. If a thick black liquid is found floating freely on the surface of the contents of drums or packages, the emulsion should not be accepted or used for spraying plants. It is obtainable ready-made and is usually put up in five-gallon drums which cost about seven rupees in Calcutta. It is used at a strength of about one part by volume to sixty-four of water (half a pint to a kerosine tin). Care must be taken to see that it is properly strained before placing the mixture in a sprayer. If no strainer is available the emulsion may be placed in a bag or cloth and kneaded by hand until it has passed through and mixed with the water, which should then be churned up by means of the sprayer. Crude oil emulsion may be used against all sucking insects except those which are protected from wetting by hairs or scales; for such a rosin compound must be used. A bag of crude oil emulsion placed in the water-channel when fields are being irrigated will drive 
away subterranean insects, such as termites, ants and root-feeding Aphids, temporarily at any rate, and this will sometimes give crops a chance of recovery in cases where they would otherwise have been seriously affected.

Linsecd Oil Emulsion is sometimes useful, especially as it is easily prepared from materials readily obtainable. One pound of hard soap is shaved up into fine slices and dissolved in one gallon of boiling soft water, which is then taken off the fire and two gallons of raw linseed oil added to the hot solution. The mixture is then churned up violently by the aid of a bucket sprayer to form a smooth, yellowish, creamy emulsion, from which no free oil should separate out on cooling. Diluted with water to a strength of one part in ten, this emulsion is especially useful for scales and similar insects on the trunks of trees; it is not aclapted for use on foliage.

Kerosinc Emulsion is made in a similar manner to Linseed Oil Emulsion, kerosine being used instead of linseed oil. In both these emulsions, whale-oil soap or fish-oil soap may be used instead of hard soap and more soap must be used if the water is hard.

Rosin Componnd is especially suitable for Scales and Mealy-bugs which are protected by their coverings against the action of nonwetting oily sprays. It is made by powdering two pounds of common fir-tree rosin and boiling one pound of ordinary washing soda with one gallon of water; the powdered rosin is added to the boiling solution which is continued to be boiled, adding small quantities of cold water at intervals, until the liquid (now about three gallons) becomes clear and thin, like clear coffee. This is diluted to about one part of rosin compound in seven of water for ordinary spraying, but may be used at a strength of one in five if required.

Rosin Wash is only useful against young Scales, Aphids and similar soft-bodied small insects. Ten pounds of rosin, and oneand-a-half pounds of fish oil are heated with one gallon of water in an iron kettle until the rosin is softened; three pounds of Caustic Soda, dissolved in a little water, is then added and stirred thoroughly, and the mixture diluted with water to make fifty gallons of spraying material.

Carbolic Acid Emulsion is sometimes useful for Aphids, Soft Scales and for use against ants. One pound of whale-oil soap or fish-oil soap is entirely dissolved in about half a gallon of hot water and one pint of crude carbolic acid is added and the mixture boiled for twenty minutes adding another half-gallon of water in small quantities to prevent boiling over. The stock solution so prepared is diluted with twenty parts of water for use as a spray. 
Various forms of crucie carbolic and creosote commonly sold for use as disinfectants are also useful as contact insecticides when used as a strength of about one in eighty of water.

Tobacco Decoctions give excellent killing results against softbodied insects without harming foliage. One pound of Tobacco leaves or stems is steeped in four gallons of hot water and the mixture_applied directly when cool. If soap is addled, at the rate of one pound to twenty gallons, the mixture is made much more efficient. Tobacco stems and dust applied at the roots of bushes and to the surface of the soil around vegetables will often drive away and destroy grubs, worms and small pests.

Sulphur, in the finely-divided form known as Flowers of Sulphur is valuable against Mites of all sorts. It may be used dry, being dusted onto the plants by itself or mixed with lime, flour or roaddust, or may be sprayed on at the rate of one pound in two to four gallons of water. As the insecticidal action of sulphur is due to its oxidation under the influence of warm sunlight, it must be applied in the early morning.

Lime-Sulphur, a chemical combination of lime and sulphur and which kills insects by its caustic properties, has lately come into extensive use in America as a spray for use on dormant trees in the winter-time. It has not been used in India but may perhaps be found useful at considerable dilution. It may be prepared by heating three gallons of water in a barrel or vessel, which must not be made of copper, and adding four pounds of unslaked lime and immediately adding three pounds of flowers of sulphur previously made into a thick paste with water. After the lime has all slaked another three gallons of hot water is added and the heating continued for an hour after which another four gallons of water is added and the whole thoroughly stirred and strained. At this strength the mixture will burn foliage and requires five or six times dilution before use; it may be used undiluted for painting boles of trees to prevent the attacks of porcupines, rats, etc.

Self-boiled Lime-Sulphur may also be prepared and used as a spray for foliage and is especially useful, if lead arsenate be added, as a combined insecticide and fungicide. To make it, twenty pounds of quicklime are placed in a barrel or other suitable receptacle-copper vessels must not be used-and three gallons of cold water are poured over it; as soon as the slaking is well started, sift in twenty pounds of flowers of sulphur, and stir the mixture well. The violent heat generated by the slaking of the lime will bring about a chemical combination between the lime and the sulphur. More cold water is added until the mass has a paste-like 
consistency. Immediately the boiling begins to subside, more cold water must be added at once to prevent further action taking place, as, if the boiling is continued too long, the resultant liquid will burn foliage. This solution is diluted to form 100 gallons.

Flour-Paste is a very simple and cheap spray-liquid which is effective against small insects without any injury to vegetation. It peels off after a day or two and leaves the growing surfaces of the plants free and healthy. It is made simply by making an ordinary flour-paste of one pound of flour in one gallon of water; for use as a spray this is diluted to a strength of about eight to ten parts in one hundred of spray-material. Mixed with Flowers of Sulphur at the rate of about a pound and a half to ten gallons, flour-paste is an excellent remedy against Mites but does not always kill the eggs so that a second application is necessary after an interval of about a week.

Flour-Paste is also very effective for use with Lead Arsenate, Lead Chromate, etc., as a spreader, ensuring that the poison is applied evenly over the foliage.

Potassium Cyanide is too poisonous a substance for direct application to plants as a spray, but is useful for checking ants, which may be nesting in fields and bunds and cherishing Aphids and Scales. Poured into their nests at a strength of one ounce to the gallon of water, it either kills off the nest or at least disables it for sonse time.

Soap, simply dissolved in water, is sometimes valuable as a contact insecticide, especially against small and soft-bodied insects. Ordinary bar soap, obtainable in any bazaar, can be used if no more nauseous brand be available. At a strength of one pound to one gallon of water it acts as a contact poison, and at one pound to ten gallons it may be used for watering lawns or flower-beds to drive down grubs which are eating the roots of grass or plants ; but the amount of dilution must depend largely on the composition of the soap.

Fish Oil Soap, or Whale Oil Soap is far preferable to ordinary hard soap for use against insects. It may be made by adding six pounds of caustic soda to one and one-fifth gallons of boiling water and, when the soda is dissolved, pouring in twenty-two pounds of fish-oil, stirring and boiling slowly, after which the mixture is allowed to cool, when the soap separates out.

Fish Oil Soap and Tobacco Extract is excellent against Aphids and small soft-bodied insects. It is prepared by dissolving one pound of fish-oil soap in ten gallons of water and adding one pint of good tobacco extract. 


\section{Repellents.}

Besides insecticides, which actually kill the insects against which they are used, it is often useful to employ substances which act as repellents; that is to say, they drive insects away and keep them from attacking the plants or areas so treated. Although the action of repellents is necessarily only temporary it is often important to give plants, and particularly young plants, an opportunity of tiding over a critical period, such as transplantation, and it is under such circumstances that repellents may be used.

Bordeaux Mixture, though more often used as a fungicide, makes the parts of plants sprayed with it temporarily distasteful to insects. It is made by dissolving one pound of Copper Sulphate (blue stone) and one pound of quicklime separately in water, mixing the two cold solutions gradually in a third vessel and diluting to ten gallons for use. The mixture must be well strained. It should be tested for any excess of copper by dipping in a knife-blade; if this acquires a brown deposit of copper, more lime must be added until the excess is all neutralized; the final mixture should be as nearly neutral as possible, without excess of either lime or copper. The Copper Sulphate should not be dissolved in a tin or iron vessel, but vessels of wood, copper, glass or stoneware are all suitable.

Dry Slaked Lime, dusted onto and around plants, especially vegetables, sometimes drives away insect pests. It may be prepared by placing a little quicklime in a metal vessel and pouring on hot water; the lime will slake and crumble to a very fine powder. Flowers of Sulphur may be added to the lime when this is dusted onto plants.

Calcium Carbide Residuc, as removed from Acetylene Gas generators, may also be used for protecting vegetables, mixed with earth or sand in the proportion of one in five, or one in ten in the case of seedlings or young plants.

Tobacco Dust, or refuse of stems or leaves chopped up fine, may also be dusted onto leaves as a repellent, but is more valuable when placed in a small ring around the stems of plants attacked by root-borers or subterranean Aphids or Scales, the top layer of soil being removed and afterwards replaced.

Such insecticides as crude oil emulsion, soap, and phenyle, when added to the irrigation water at a strength insufficient to kill insect-pests, sometimes act as repellents to drive them away temporarily.

Copper Sulphate Solution is used especially for the dipping of cane setts before planting to keep away termites until the young 
canes have become established. A saturated solution in cold water does not harm the setts if these are healthy; but if they have been brought from a distance or are not quite freshly cut a solution at half the above strength should be used.

Whitcwash by itself, when applied to the trunks and limbs of trees, has some value as a repellent and fungicide and also prevents sun-scorch. Quicklime is slaked with water, thoroughly mixed, and strained before use. In the case of permanent crops such as coffee and rubber, the scraping (if necessary) and whitewashing of the bases of the stems helps to repel boring beetles, and an admixture of Lead Arsenate or similar stomach poison with the whitewash would probably check the attacks of porcupines on young rubber trees.

\section{Spraying Machinery.}

For the application of insecticides, use is generally made of some form of machine which delivers the insecticidal substance under pressure as a fine mist or spray. Such machines are therefore called "sprayers" in the case of those which are used with

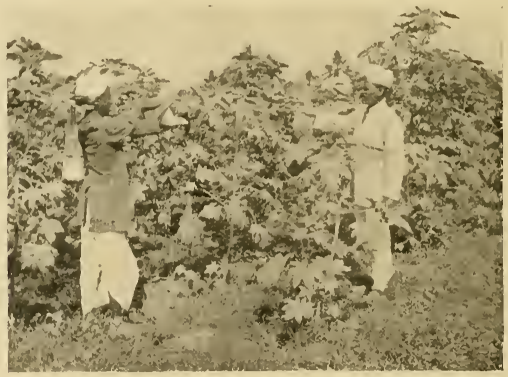

F1G. +1.-Applying powdered insecticides by hand with the aid of cloth bags.

Note the light colour of the powdered leaves in foreground as compared with the unpowdered leaves on the right. (Anthor's original photo.)

liquid insecticides, and "blowers," "bellows " or " powder guns" in the cases of machines which are used for the distribution of dry insecticides in powder form. The latter type of machine is not much used in India, except in the case of a few special permanent crops, such as tea, and for ordinary agricultural work powders can usually be distributed onto plants quite satisfactorily with the 
help of a cloth bag. Liquid insecticides may, at a pinch and in the absence of a sprayer, be sprinkled on to plants by the aid of a branch, palm-leaf or brush, but this method is wasteful and unsatisfactory and a proper sprayer should always be used if it is desired to do satisfactory work.

There are many different types of sprayers on the market, to meet different requirements and priced at various rates from about ten rupees to over one thousand rupees.

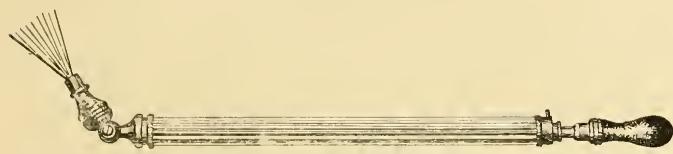

Fig. +2.-Spraying Syringe. (Orisinal.)

The Spraying Syringe is the simplest and cheapest form of sprayer, but it is of course only suitable for very small areas such as gardens. It is simply an ordinary garden syringe fitted with a spraying nozzle. As a rule, an ordinary nozzle is also supplied so that the syringe is available for general work in a garden as well

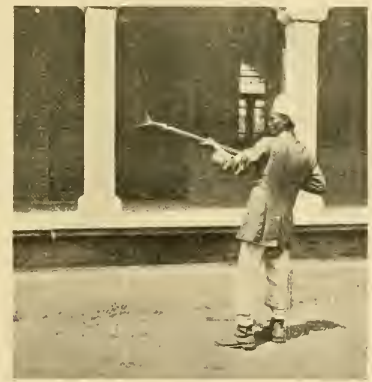

Fig. +3.-Spraying Syringe in action, showing comparative size and shape of jet. (Author's original photo.)

as for special work as a sprayer. As it is often desirable to be able to spray the under surface of leaves, the syringe should be so adapted that the jet of spray-liquid may be thrown out, when 
desired, at right angles to the axis of the barrel of the syringe as well as in a straight line. This end is secured either by the provision of a bent collar which can be screwed on between the barrel and the nozzle or by a jointed nozzle which can itself be fixed at any desired angle. In the case of the "Four Caks" syringe the barrel is protected by a longitudinallyribbed outer metal cover so that it is tolerably secure from indentation by rough usage. A Spraying Syringe of good quality costs from ten to twenty rupees and is suitable for work in small gardens for spraying a few plants which may be attacked by pests.

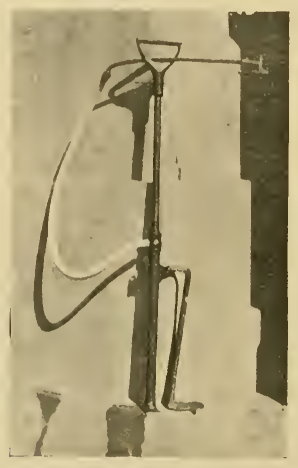

Fig. 4t.-Bucket Pump of old pattern without pressure-chamber. (Author's original photo.)

The Bucket Sprayer, as its name implies, is suitable for use in connection with a bucket or other receptacle for the spray liquid. A kerosine tin makes a very convenient vessel and holds a known quantity of liquid (four gallons) The Bucket Sprayer is simply a pump, usually of brass, fitted with an adjustable footrest and a length of rubber tubing for delivery of the spraymaterial. In the best types there is an air-chamber, seen as a pearshaped expansion at the upper end of the barrel of the pump, which keeps up the pressure during the up-stroke, thus ensuring continuity in the spray. Bucket Sprayers are available in India at a cost of 
about fifteen to twenty rupees each and are suitable for small areas, such as gardens, small fruit-gardens or small areas of crops. If a longer hose is fitted and the nozzle fastened to a bamboo it is possible to spray small trees with one of these pumps, but the waste of time and labour incurred in noving the bucket from one tree to another and the difficulty of working the pump and directing the spray at the same time renders this type unsuitable for work on any large scale. For use around a house, however, the Bucket Sprayer is very suitable and it may of course be used for such purposes as the application of whitewash or disinfectants. As these sprayers have no agitator care must be taken that the spraymaterial is kept properly mixed and this end may be achieved by pumping it back on itself occasionally; this applies to spraying syringes also.

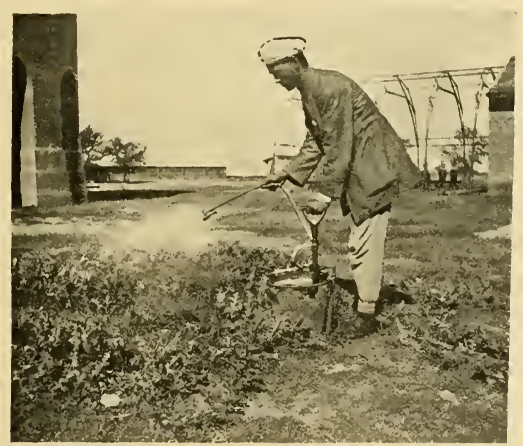

Fig. 45.-Bucket Pump in use. (Anthor's original photo.)

Knapsack Spraycrs are so called because they are usually fitted with straps and are intended to be hung over the shoulders like a knapsack. In this type the spray-material is contained in the sprayer itself which is provided with a pump, delivery-tube and nozzle, and also with an agitator in all efficient patterns. The tank contains a variable amount of liquid, usually from one to four gallons. The patterns usually imported from Europe or America *

* Note.-It should be noted, in connection with American machines and formule, inat the American gallon is only five-sixths of the Imperial gallon. 
generally hold four gallons of liquid but, as these when full weigh upwards of fifty pounds, they are too large and heavy for the physique of the ordinary cooly, in Southern India at all events, where the weight of a fully-charged sprayer should not exceed forty pounds.

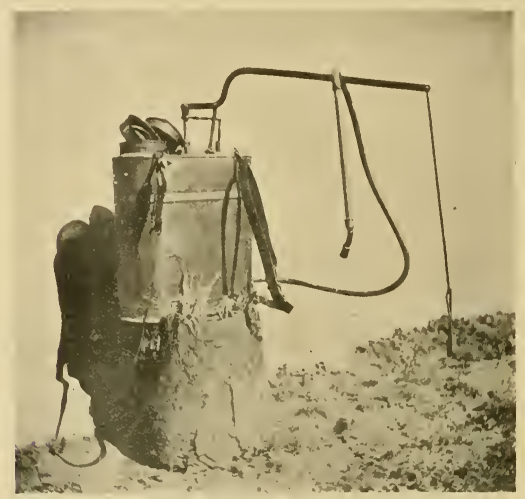

F1G, +6.-Gould's Knapsack Sprayer. Note agitator connected to handle-lever and strainer fitting below cap of filler hole. (Anthor's original photo.)

In Knapsack Sprayers the pump may be outside the reservoir or may be enclosed within it; the latter type is preferable, as the pump is less liable to injury and is better protected from clust and grit. The straps should be wide so as not to cut into the carrier, and this is particularly necessary in India where these straps come into direct contact with the bare skin of a cooly. In the best types two handles are provided, one for use when the sprayer is carried on the back and the other, working up and down like a bucket sprayer, for use when the sprayer is used on the ground. For the latter purpose a footrest is necessary and is usually provider. A good mechanical agitator is essential and is usually provicled in the form of a metal frame or sheet which moves with each motion of the pump, to which it is attached. A strainer is an essential fitting and is usually provided in the form of a detachable metal sieve. 


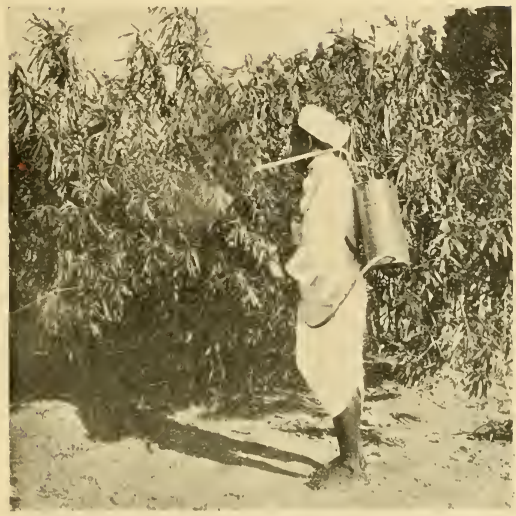

Fic: 47.-Knapsack Spraver in use. (Author's original photo.)

Knapsack Sprayers are suitable for general work in gardens, fruit-gardens, and on crops in moderately small areas up to about five acres. They are also used extensively in the case of permanent and valuable crops, such as tea and coffee, which are grown on hillsicles where it would be impracticable to use larger machines.

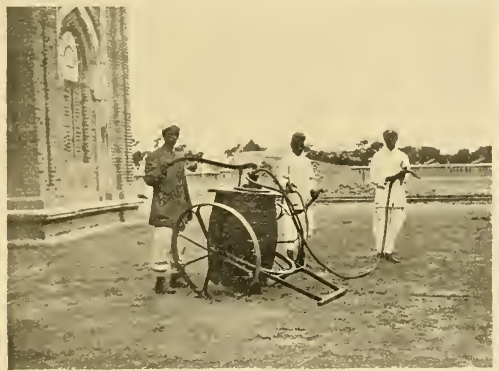

Fig. +8.- Barrel Pump. IAuthor's original photo.' 
For the ordinary cultivator, a Knapsack Sprayer or Pressure Sprayer (see page II3) will fulfil all ordinary requirements. It may be used for spraying all ordinary crops and, with a suitable nozzle or extension rod, for small trees up to twelve or fifteen feet high. Various patterns are obtainable in India at a cost of about thirtyfive to fifty rupees each.

Barrel Sprayers, so called because they are usually mounted in a barrel which acts as the tank for the spray-material, are larger pumps which are specially adlapted for spraying on a moderately large scale. The barrel usually holds about fifty gallons and is mounted on a detachable frame supported on wheels so that it may be transported easily, the whole apparatus when full weighing some six hundred pounds; a larger tank is not practically useful uncler ordinary conditions in India. The pump should supply at least two nozzles at 80 to 100 pounds pressure with ordinary pumping,

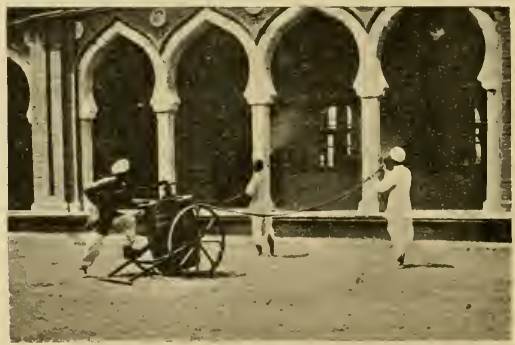

FIG. +9.-Barrel Pump in action. (Author'soriginal photol.

and it should have a large air-chamber within the pump-barrel in order to maintain a constant pressure. The air-chamber should not project above the barrel, as such an arrangement makes the pump top-heavy and exposed parts are especially liable to breakage. For the same reason the handle and similar parts should be made of malleable or galvanized iron and not of cast iron. A good mechanical agitator is an essential fitting and this should be of the paddle type (i.e., a metal frame or sheet attached to and working with the pump). Some machines are fitted with agitators of the " jet " type in which a current of air is driven into the spray-liquid from the bottom of the pump-barrel ; this method is unsatisfactory in practice as it allows a loss of pressure without sufficiently agitating the liquid. The pump should be readily removable from the barrel 
for purposes of cleaning or repair, and the valves should also be removable and so made that they wear lown evenly.

Barrel Sprayers are suitable for field-work on the level and for special work such as is required for orchards or experimental crops. They cost about one hundred rupees each. On large holdings and experimental stations a Barrel Sprayer is very useful for coping with outbreaks of crop-pests but for the ordinary small holdings a smaller type of machine is generally sufficient.

Forms of Barrel Sprayers (as also of Knapsack and Bucket Sprayers) have been placed on the market in India in which oil and water are contained in separate tanks. It is claimed that these may be mixed and sprayed in definite proportions as a mechanical mixture, but such machines have in practice been found unreliable in practical work and their use is now generally abandoned.

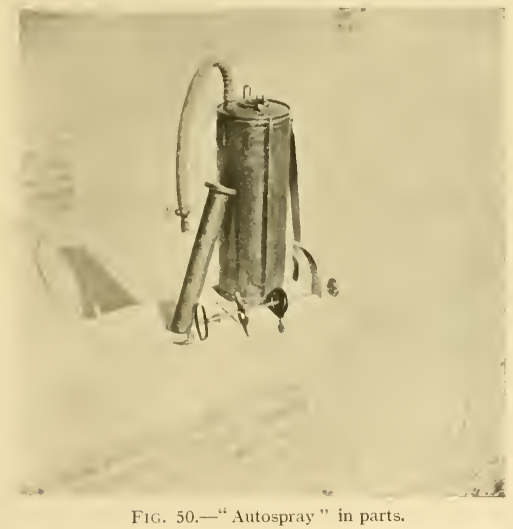

On the left is the pump barrel and in the foreground the piston with locking arrangement fitting into the clips seen on top of the tank. (Author's original photo.)

Pressure Sprayers of various types have been introduced of late years and it seems probable that these will oust the old patterns, especially of Knapsack Sprayers, from the markets of the future. In these sprayers the spray-liquid is placed in the tank and air is then pumped in until a considerable pressure is obtained and this compressed air is used for the expulsion of the spray-material. No pumping is required therefore whilst the spray is being applied 
to the plants, so that the whole attention can be given to the application of the spray and both hands are free to direct it properly. This is a very important point, as thoroughness in spraying is absolutely essential to success, and if most of the energy and attention of the operator is occupied with the physical labour of pumping, it is obvious that a really satisfactory application of the spray can hardly be expected. For this reason alone, Pressure Sprayers have a very considerable advantage over the old patterns of hand sprayers. The pump, by which the necessary pressure is attained, may be contained in the sprayer or may be separate. In the latter case a saving in weight is claimed but against this must be placed the greater risk of breakage or mislayal of the pump and the weight of this is very trifling in comparison with the weight of the tank and other necessary parts. For this reason, preference

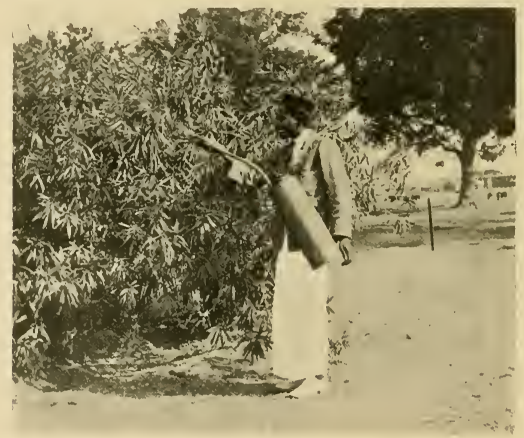

F1G. 51.- "Autospray" in use.

Note that only one hand is required to direct and control the spray.

(Author's original photo.)

may be given to those patterns in which the pump is self-contained. Some models are provided with pressure-gauges to indicate the correct amount of pressure to which the air should be pumped; although such gauges are of course useful it is cloubtful whether they are worth paying much extra for in India where the ordinary cooly is not likely to work up too great a pressure. In those types which are not fitted with a gauge it is usually fairly easy to tell when the pressure is sufficient as the increased difficulty in pumping in more air acts as a commonsense indicator. 
In filling Pressure Sprayers it must be remembered that space must be left for the air to be compressed and at least one-quarter of the capacity of the tank must therefore be left unfilled.

Amongst the advantages of the use of Pressure Sprayers are the facts that they are easily portable, do not leak (as is often the case with a Knapsack Sprayer) and only one hand is required to direct the hose, leaving the other free, so that a tree may be climbed, or

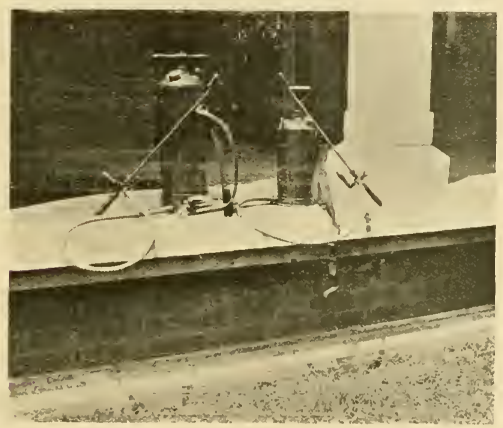

FIG. 52.- "Holder" Pressure Sprayers, +-gallon and 1-gallun types. (Author's original photo.)

spraying may be done from a step-ladder, under conditions in which the use of a knapsack hand-sprayer would be impracticable. For this last reason "Holder" Sprayers of the one-gallon type are in fairly extensive use in Southern India for the spraying of palmtrees for control of fungus diseases, as the operator can climb the tree with the fully charged sprayer slung over his shoulder, either by a strap or in a small canvas bag, and can then carry on spraying with the aid of one hand only. Larger patterns of the "Holder" type are also available for use with ordinary field crops and trees whilst a wheeled ten-gallon pattern is suitable for fruitgardens and similar aleas. Pressure Sprayers of the "Autospray" pattern, obtainable in Calcutta at from Rs. 30 to 35 , contain three gallons of liquid, weigh 40 pounds when fully charged and have been used very successfully in India. Such sprayers are suitable for spraying small areas of crops and for use around houses. We have also found them peculiarly suitable for the spraying of cattle for insect parasites, as a fine spray is delivered on simply turning a 
tap without any motion or noise to scare the animals. A disadvantage of the smaller patterns of Pressure Sprayers lies in the absence of an agitator, but, as there is no risk of spilling the spray liquid, it is comparatively simple to give them a good shaking by hand before commencing to spray.

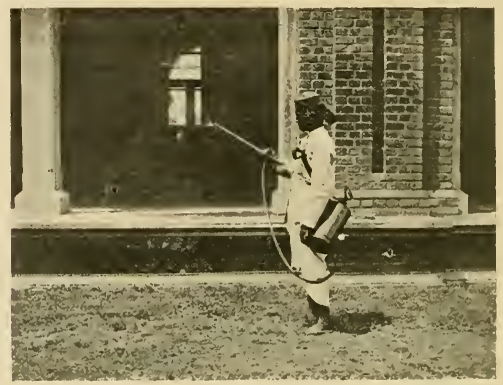

F1G. 53.- "Holder " Pressure Sprayer of 1-gallon type in use. Note that only one hand is required to control and direct the spray.

(Author's original photo.)

Poiver Sprayers, in which there is a large tank mounted on a cart and eight or ten nozzles are worked at once at high pressure by means of a petrol or oil motor, are in extensive use in America, but are not likely to find much scope in India except in special cases, such as large fruit orchards or experimental stations where it may be necessary to spray large areas. Machines of this type are not available in India and would require to be ordered specially. They cost from Rs. I,000 to Rs. 2,000 .

\section{The Selection of Sprayers.}

Before obtaining spraying machines it is as well to have a clear idea of the work which will be required of them in order that suitable patterns may be obtained. It is useless to attempt to cover large areas with a small machine and it is equally wasteful to buy a large machine to do work which could be performed as efficiently by a small one. It is poor economy to save a few rupees in purchasing a spraying outfit and to spend a far larger amount in extra time and labour in applying the sprays. Syringes and Bucket Sprayers are quite suitable for use in and around the house or in a small garrlen. Knapsack Sprayers are used in small areas of field 
crops of I to 5 acres and for small orchards and gardens and for larger areas under permanent crops, such as tea and coffee, in districts which are impracticable for larger machines on account of the unevenness of the ground. For the spraying of field crops over large areas it is more economical to use Barrel Sprayers or Power Sprayers in all cases where the ground is sufficiently even to enable such machines to cover it properly.

After deciding on the size of machine required it is necessary to select one of the various patterns obtainable on the market and in doing this attention should be paid to their relative merits in order to secure the best value for money. It is impossible here to advertise or recommend particular makers or patterns, but information on any points will always be given to inquirers as far as possible.

The material of the tank and of all working parts which come into contact with the spray-liquid should be of heavy brass or bronze or similar alloy. Many spray solutions (c.g. Bordeaux mixture) have a corrosive action on iron, and copper is attacked by Lime-sulphur. Not only the tank, but the working parts of the pump itself (the valves and their seatings, the piston, and interior of the pumpcylinder) must therefore be made of suitable material, as it does not pay to buy cheap machines of inferior metals which corrode rapidly.

A sufficiently large air-chamber should be insisted on, as its presence has a considerable effect on the efficiency of the spray. If the chamber is too small there will necessarily be considerable variation in pressure between successive strokes of the pump, particularly in small machines, and the spraying will therefore tend to be uneven. This item is of course eliminated in the case of pressure sprayers.

Accessibility of the working parts of the pump is a matter to which due attention should be given. In some of the older patterns of machines the pump is enclosed in a tight case and is practically inaccessible without great waste of time. As grit and dirt are sure to find their way into the pump and valves, these must occasionally be removed and cleaned and therefore their accessibility is a necessity. In this respect some of the pressure sprayers are very satisfactory as the whole pump is easily removed for inspection.

The packing of the piston must on no account be made of rubber but should be of some material which is readily replaceable, such as leather.

Strainers are important parts of all self-contained machines as it is essential to see that the spray-liquid is freed from all particles of grit which will otherwise soon wear down the valves and clog the nozzle. All spray-liquids therefore must be strained before they 
are placed in the tank. If nostrainer is provicled with the machine, or if this becomes lost or worn out, a metal funnel should be made, provided with brass wire-gauze of twenty-five meshes to the inch; or the liquid may be strained through a cloth.

Nozzles of many scores of different types have been introduced and used for special or general spraying and it is impossible to attempt to describe all the various patterns. Those principally used in India are of the Bordeaux and the Vermorel patterns or modifications of these. Both of these are quite satisfactory for general work and as a rule spraying machines as supplied are fitted with efficient nozzles. In the Bordeaux nozzle the spray is produced by the stream striking the edges of a metal lip which breaks it up into a fan-shaped spray, the size of the outlet being regulated at will and governing the fineness of the spray; by regulation of a tap in the nozzle the spray may be varied from a very fine mist to a solid stream. In the Vermorel nozzle the spray issues from a small chamber through a hole as a fine cone-shaped mist; the hole is provided with a pin, ordinarily held back by a spring, which can be thrust forward through it to clear it if it becomes stopped with sediment.

Hose of three-eighths of an inch diameter is generally supplied with Bucket and Knapsack Sprayers and of half-inch size for larger machines. The best quality is the cheapest in the long run but in any case hoses will not last long in India and require renewal every two or three years. For fastening the hose to the machine and nozzle clamps are more satisfactory than wire bands.

Extension Rods of light metal tubing are very useful for the spraying of trees and tall crops. A disc of metal attached around the extension rod helps to protect the operator from drip. If, however, extensive spraying of trees is contemplated, as in mango groves, it is better to build up a light tower on a cart for the operator to work from.

\section{The Upkecp of Sprayers.}

To obtain the best results from a spraying outfit, it must be kept in good condition and working order. It is often the case that sprayers are not required for months on end, generally in the dry hot season when no crops are on the ground, and if they are neglected at this time they will be found to be out of order and useless just when they are wanted, the hoses cracked and the valves and nozzles clogged with dust and grit. To keep sprayers in gool condition they must be overhauled and worked regularly, at least once a month, and water pumped through them. Barrels or other wooden tanks should be kept full of clean water when not in use, 
care being taken to see that mosquitos cannot breed in them. After use, the whole machine should always be thoroughly cleaned out and washed through with clean water; this is especially necessary with regard to hose after using kerosine washes, as kerosine attacks rubber and will quickly rot the hoses if these are not washed clean. When in use rubber hose should not be bent at a sharp angle nor should it be left lying about in the sun when the machine is not actually working. As noted above, all insecticides must be well strained before they are placed in the machine, to avoid unnecessary wear of valves and the clogging of nozzles. It is useless to keep a spraying equipment if it is not in efficient order when required for use, but by attention to the above points it should be found ready whenever wanted at short notice.

\section{SPECIAL METHODS.}

Under the heading of special methods may be included various means for the control of crop-pests which are, as a rule, only applicable by entomological experts or at least under their lirect control and which are therefore scarcely within the reach of the ordinary cultivator because they require special knowledge or precautions or apparatus. Of such methods reference is made here to the fumigation of living plants, the control of termites and burrowinganimals by poisonous gases pumped into their galleries by special machines, and the control of insect-pests by fungal and bacterial diseases and by means of parasites. Legislative measures may also be included here.

Finmigation of living plants and trees for the control of pests, such as Scales, which are very resistent to insecticidal sprays, is used extensively in other countries especially in the case of fruittrees and has been applied in India with successful results. The only reason why this method has not been used more extensively in India appears to lie in the fact that Scale-insects do comparatively little damage to fruit-trees in India. In some cases, however, it is a useful method for the treatment of a small number of affected plants or trees to prevent extension of attack. The fumigant commonly used is Hydrocyanic Acid gas, produced by the action of Sulphuric Acid on Potassium Cyanide, and this is found very satisfactory if reasonable precautions are taken. Plants should never be fumigated when the foliage is wet ; the best time to fumigate is in the early evening, so that the gas may act whilst the leaves are dry and during the night. In the case of small plants they may be covered with any gas-tight shade, such as a light framework covered with paper tiglitly pasted over. For treesa tent of some sort is generally used and, if the work is being done on 
any large scale, it is more convenient to have proper tents which are clearly marked on the outside so that the cubic capacity may be seen exactly when they are erected, in order that the proper dosage of gas may be given. If the capacity of the tent is not known the following rough rule may be followed:- Multiply the distance around by the distance over the top of the tented tree and divide by 133 , the result being the number of ounces of Potassium Cyanide required for ordinary work." Thus, the distance around the tented tree being 35 feet and the distance over (from ground to ground) being 20 feet, the cyanide required will be $35 \times 20 \div 133=$ $5 \% 26$, or five and one-quarter ounces. For every ounce of Potassium Cyanide there are required one fluid ounce of Sulphuric Acid and three fluid ounces of water to liberate the gas. The acid is added to the water in a deep wide-mouthed earthenware vessel; the water must never be poured into the acid, as the acid and water combine violently and in the latter case the acid will probably be spattered about and do damage. The tent or box being ready over the plants to be fumigated, the water and acid, ready mixed in the earthenware vessel, are slipped inside and the weighed quantity of cyanide, loosely wrapped in clean paper, is dropped into the acid and the box or tent immediately closed down and earthed up around the bottom and left overnight. Next morning the tent is opened up, or the box lifted, and, after an interval to allow the escape of any gas remaining, may be removed. It must be clearly remembered that Hydrocyanic Acid gas is one of the most poisonous substances known and for this reason alone it should only be used under strict supervision. Potassium Cyanide is also a violent poison if taken into the system, although it is fairly safe to handle if there are no cuts or sores on the hands; but it is always better to use gloves if any quantity is being dealt with. Sulphuric Acid will burn violently into the skin and flesh and the vessels containing it must be handled with great care. For these reasons fumigation of trees and plants in the field should never be carried out except under competent personal supervision.

Besides its use for the control of insect-pests already attacking plants, fumigation with Hydrocyanic Acid gas has also an important use in checking the spread into hitherto unaffected localities of pests, especially Scale-insects, which would otherwise be brought in with growing plants. That there is actually great clanger of this may be realized from even a casual inspection of most of the plants, such as young mangoes, so commonly seen being carried

* Note - In calculations of this sorl, it is always assumed that the cyanide is of 98 per cent. purity. Ordinary commercial eyanide is often of only about 45 per cent. purity and the amount nust consequently be increased pro rala. 
by Rail from one district to another. The invasion of the Coffee Districts by the destructive Green Scale-bug should prove an objectlesson regarding the dangers of importation of insect-pests from one district to another. In all cases, therefore, when living plants are obtained from a distance, the consignee should insist that they are properly fumigated before despatch ; otherwise he may afterwards find to his regret, when it is too late, that he has received more than he ordered.

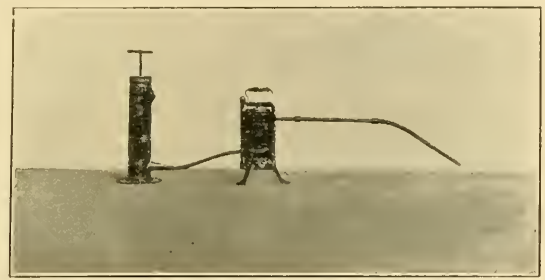

FIG. 5t.--" Universal" Ant Exterminator. (Author's original photo.)

"Ant Exterminators."-Several machines have been placed on the market which are intended to pump hot poisonous gases into the subterranean burrows or galleries of insects such as termites and ants. Whilst these are quite efficient in destroying the inmates of Termites' mounds and of similar nests, they possess this initial disadvantage that, as a general rule, it is not the mound-building termites which do damage and such machines therefore are comparatively of little use in controlling the real culprits whose nests are extremely difficult to discover. It is true that an instrument is available combining a microphone and a pointed iron rod, the idea being that the rod is thrust into the ground so that, when it approaches a nest, the sound produced by its inmates becomes audible by means of the microphone. But in actual practice, in India at all events, such an instrument is found to be quite useless.

As noted above, the species of termites which throw up mounds seem to be harmless as a general rule, those which attack houses, woodwork and crops belonging to distinct species; but the mound builders often make their nests in the middle of roads, lawns, gardens and similar places where their presence is objectionable, and in such cases the nests are readily destroyed by the use of a special machine. The "Universal" Ant Exterminator consists essentially of an air pump connected to a small furnace from which 
leads a flexible metal pipe. For lestroying a nest, a charcoal fire is kindled in the furnace and air pumped through until the fire is thoroughly hot and the metal tube is warmed through by the hot blast driven through the furnace by the pump. The tube is then thrust into one of the main galleries, previously opened up, of the

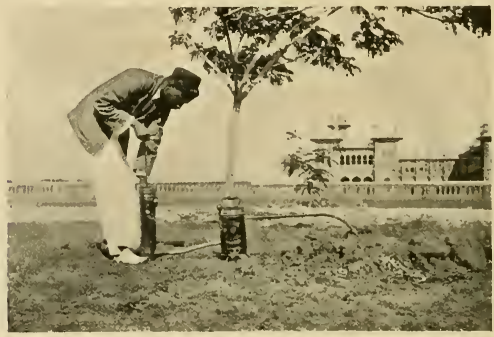

FIG. 55.-Destroying a Termites' Mound with the "Universal" Ant Exterminator. (Author's original photo.)

nest and a small quantity of a mixture of sulphur and white arsenic is dropped into the furnace, which is immediately closed and the pump worked vigorously. The sulphur and arsenic enter into chemical combination and are expelled from the metal tube as dense yellowish fumes which are pumped into the nest, any apertures by which these are seen to escape being promptly plugged with wet clay. The pump is worked for ten or fifteen minutes, nore sulphur and arsenic being added to the furnace from time to time, and the pipe is then withdrawn and the nest left plugged up. If opened up after an interval of not less than three days the nest will be found to have been killed off if the fumes have penetrated properly. If opened up too soon, the effect of the fumes seems to pass off and the nest may recover, the main effect of the fumes being visible in the fungus-combs on whose culture the well-being of the colony apparently depends. Care must be taken not to breathe the fumes, as these are poisonous ; but their dense yellowish-white colour and noxious odour renders them easily avoided. The exit pipe must be hot before the poison is added or the fumes will condense on its interior surface without penetrating into the nest.

Another machine, in principle similar to the "Universal" Exterminator, is one made in America by the George L. Squire Company. In this, however, the current of air is produced by a fan 
and the furnace is much larger and is placed directly over the top of the nest to be treated. Provision is also made for the application of the sulphur mixture through a door, closed with a screw-bolt, in the metal pipe joining the fan and the furnace. The possibility of introduction of the poison without opening the furnace and the use of a fan instead of a pump are decided advantages but these are rather outweighed by the excessive weight of the apparatus and particularly of the furnace. If the rotary fan could be fitted to a light steel pipe, provided with a sliding door for insertion of the sulphur, and this latter connected to a smaller furnace whose fumes were led out by a flexible metal piping, a more useful and portable machine would be produced.

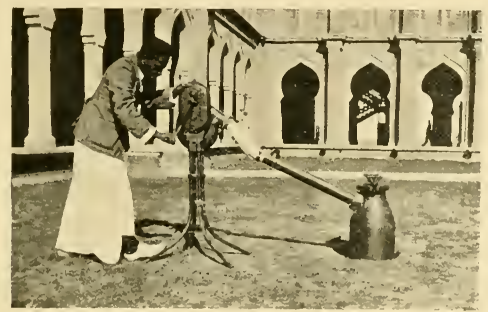

FIG. 56.-" Squire" Ant Exterminator. (Author's original photo.)

Fungal and Bacterial Diseases.--The control of insect-pests artificially by means of fungal or bacterial diseases which attack them and reduce their numbers under natural conditions is at first sight a very promising and easy method. The idea of simply scattering amongst his crops a small quantity of some culture of such diseases and leaving this to do all the work of protecting his fields from damage is one that appeals intensely to the common run of cultivator who expects to obtain great results without any trouble or exertion on his own part. The success which has attended the use of fungal enemies of some scale-insects in the West Indies is held up as an example of what may be done in India where the conditions are entirely different. Green Scale-bug (Lecaninm viride), for example, in Southern India is heavily attacked by several fungi which kill off perhaps ninety per cont. of the insects during the intensely wet weather experienced in the Coffee Districts. These fungi are well distributed, almost every bush attacked by the scales showing them in large numbers. And yet the rate of increase of this insect is so vast that it is not killed out but merely checked temporarily 
at the most. As soon as the dry weather sets in, when the conditions are unfavourable for the growing of the fungi, the scales increase and spread and actually do most damage at this time of year probably largely because they drain the juices of the bushes just when moisture is most deficient. Endeavours to spread the fungus artificially during the wet season would seem a waste of time, because it is able at that time to spread by itself practically wherever the scale is, and during the dry season the conditions are unfavourable to the growth of the fungi unless perhaps these were actually placed artificially in contact with the scales, and in this latter case it would be less trouble to use an insecticide and kill the scales directly. One case only has been quoted, and this under as favourable conditions as are likely to be found in Southern India for the control of an insect pest by a fungus, and it may be seen that these conditions are not suitable or comparable with those in other countries in which no really dry season is experienced. And this is quite apart from the practical difficulties of manufacturing cultures of such diseases on a large scale, although this is a point of importance especially in the case of bacterial diseases. Experiments with a Bacterial Disease of Locusts, caused by Coccobacillus acridiorum, have apparently been successful in South America, but in South Africa Lounsbury's experiments appear to show that this method is of comparatively little use on a field scale (Agricultural Journal of South Africa, April I9I3).

Insect Parasites.-The use of insect parasites is, however, a method which is not only useful and practical but is to some extent within the reach of all cultivators. When eggmasses of pests, for example, are found affixed to leaves of crops, instead of destroying them forthwith, they may be removed and placed in receptacles surrounded by water or oil in such a way that any caterpillars which hatch out may be unable to escape, whilst any parasitic flies which emerge from the eggs may be free to fly away to continue their beneficial task of egg-destruction. Similarly, shoots or stems attacked by caterpillars, or pupæ, may be placed in chatties or similar tight receptacles and covered over with a piece of mosquito netting or moderately fine wire-gauze, so that any moths which emerge may not escape whilst any small parasites may do so; but it must be remembered that not every parasite that emerges is beneficial, as some are hyperparasites or superparasites which do harm and not good. Some account of beneficial insects and parasites is given in a later chapter.

Legislative Enactments for the control of Insect Pests aim as a rule at prevention of the importation of new pests rather than at 
control of those already present. The experience of all countries is that it is the imported pests which do most damage once they obtain a footing in a new country, as they increase at enormously rapid rates without the checks provided in their native land by their various parasites and enemies which usually fail to accompany them to their new settlement; and modern rapid transit and the extension of imports to include all kinds of living plants have greatly increased the danger of the introduction of living insects which may become very serious pests when thus introduced into a new locality. Legislation for the control of all such plant imports into India is at present under consideration and it is to be hoped that we shall shortly be in a position to close our doors to such undesirable aliens from overseas.

In many countries also laws have been enacted for the control of indigenous pests, usually by regulation of the crops which they attack or by requiring the owner to destroy or treat infected plants or areas. Dead or dying coconuts attacked by boring beetles, for example, may be ordered to be cut and destroyed to prevent the pest from spreading and the owner of the trees may be punished if he neglects to do this, or the growing of certain crops may be prohibited at a particular time of the year to prevent its pests being carried over from one season to another. These are practical propositions, actually in use in many countries, and the time is near at hand for consideration whether legislation on these lines would not be beneficial to the general body of cultivators in India also. 


\section{APPENDIX TO CHAPTER XI.}

The following list of Weights and Measures may be found useful for the application of Insecticides :-

I tola $=6.5_{5}^{8}$ drachms $=$ weight of one silver rupee.

16 drachms $=1$ ounce $(\mathrm{oz})=.2 \frac{1}{2}$ tolas nearly.

16 ounces $=I$ pound (lb.) $=8$ chittaks.

${ }_{2} 8 \mathrm{lb} .=\mathrm{I}$ quarter (qr.) $=\mathrm{I} 4$ seers.

4 qrs. $\left(\begin{array}{llll}1 & 1 & 2 & \mathrm{lb}\end{array}\right)=1$ hundredweight (cwt.) $=1$ maund, 14 seers.

$20 \mathrm{cwt}$. $=1$ ton $=27.222$ maunds.

Io tolas $=1$ chittak.

8 chittaks $=$ I seer.

to seers $=1$ maund $=82 \frac{2}{7} \mathrm{lb}$.

I Madras maund $=40$ seers of 24 tolas each.

5 fluid ounces of water $=1$ gill.

4 gills $=1$ pint $=$ Io chittaks.

2 pints $=\mathrm{I}$ quart $=\mathrm{I}$ seer, 4 chittaks.

4 quarts $=I$ gallon $=5$ seers.

I fluid ounce weighs one ounce, nearly.

1 pint of water weighs $x^{\prime} \cdot 25 \mathrm{lb}$.

I gallon of water weighs ro lb.

One American gallon is only five-sixths of an English gallon.

An ordinary kerosine tin contains four gallons of fluid, an ordinary whiskey bottle one-sixth of a gallon.

$\mathrm{I}$ gramme $={ }^{1} 5^{*} 43^{2}$ grains $=\cdot{ }^{\circ} 3^{2}$ ounces.

1,000 grammes $=1$ kilogramme $=2.20 \mathrm{lb}$.

I ounce $=28.35$ grammes.

I pound $=453^{\circ} 5^{8}$ grammes $={ }^{*}+5+$ kilogrammes.

$\mathrm{I}$ litre $=35^{\frac{1}{2}} \mathrm{fl} . \mathrm{oz} .=\mathbf{I}_{1}^{3}$ pints $={ }^{2} 22$ gallons.

1 gallon $=454$ litres.

I cubic metre of water $=220$ gallons.

25 millimetres $(\mathrm{mm})=$. one inch, approximately.

10 millimetres $=1$ centimetre $(\mathrm{cm})$.

1,000 millimetres $=100 \mathrm{~cm} .=\mathrm{I}$ metre $=39^{\circ} 37$ inches $=\mathrm{r}^{\circ} 093$ yards.

1 yard $=914$ metres.

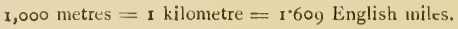

1 mile $=.621$ kilometres.

I square metre $=\mathbf{I}$ centiare $=10.764$ sq. feet.

$100 \mathrm{sq}$. metres $-\mathrm{I}$ acre $=\cdot 024$ acres. 
$10,000 \mathrm{sq}$. metres $=1$ hectare $=2.47$ acres.

I acre $=* 405$ hectares.

$144 \mathrm{sq}$. inches $=\mathrm{I}$ sq. $\mathrm{ft}$.

es $\mathrm{sq} . \mathrm{ft} .=\mathrm{I} \mathrm{sq}$. yard.

$3 \circ \frac{1}{4}$ sq. yds. $=$ I sq. pole.

to sq. poles $=\mathrm{I}$ rood.

4 roods $=\mathrm{I}$ acre $=4, \delta_{40} \mathrm{sq}$. yds.

6 to acres $=1$ sq. mile. 


\section{ChAPTER XII.}

\section{THE CLASSIFICATION OF PESTS.}

\section{"Full nature swarms with life ; one wond'rous mas} () animals."

THOMSON,

IN dealing with the various facts concerning Insect Pests it is convenient to be able to arrange them in some definite method with the object of facilitating reference to the information available about any particular insect, its occurrence, life-history, relationships, or control. Such information may be classified in various ways, the particular method adopted being adapted to the special requirements in view. We may, for example, divide insect-pests firstly into those that are noxious to man himself and his domestic animals either by direct attack or indirectly by conveyance of disease or causing loss, and secondly into those which cause loss by attacking his growing or harvested crops or other inanimate possessions.

Those insects included in the first category may again be subdivided according to-

(a) the animals attacked,

(b) the diseases carried, or

(c) whether the insect is an adaptive or a casual carrier.

It is, however, chiefly with insects of the second category that we are more immediately concerned and these may be livided according to-

(a) the object of damage, e.g., (i) Pests of growing crops, (ii) Pests of stored crops, (iii) Household pests, etc. ;

(b) the extent of damage, i.e., whether a major pest regularly causing considerable loss of the crop or other object attacked, or a minor pest of regular occurrence but causing relatively inconsiderable damage, whilst either of these may be sporadic or local or, in other words, may occur occasionally but not regularly or may only do damage in a limited area.

The above headings may be still further subdivided, so that pests of growing crops may be considered under the head of cereals, pulses, tobacco, coffee, etc., and pests of cereals, for example, may be considered separately as pests of paddy, cholam, cumbu wheat, etc.

Finally, all injurious insects, whether causing disease or clamaging crops or stored products, may be classified according to 
their own natural affinities and the various Orders, Families, Genera and Species to which they belong. This method has the great merit of conciseness, because many of the commonest and most important crop-pests attack several different crops and it would entail a large amount of repetition if an account of each of these pests were to be given under the heading of each different crop. The list of crops (pages 240-263), however, shows the various insects which attack each and will serve as an index to the insects known to attack such crops and reference to these insects in the systematic list of crop-pests will, it is hoped, facilitate their recognition and assist in their control. In order to help still further in this, the succeeding chapters contain brief notes on the more common and important crop-pests classified simply as Caterpillars, Beetles, Grasshoppers, etc. 


\section{CHAPTER XIII. \\ CATERPILLAR PESTS OF CROPS \\ ". . . . . . . . . . bereaves, \\ As caterpillars do the tender leaves," \\ SHAKESPEARE-Sonnets. \\ "Thus are mi blossoms blasted in the bud, And caterpillars eat my leaves away."}

SHAKESPEARE.

THE great Order of Lepidoptera, comprising the butterflies and moths of which upwards of ten thousand different species occur in Southern India, is the most important of all groups of insects from an economic point of view and includes about forty per cent. of all our insect pests of crops and stored prorluce. With rare exceptions it is only in the larval stage that these insects do damage, the adults feeding on the juicy excretions of plants, although a few groups especially amongst the butterflies have depraved tastes for animal

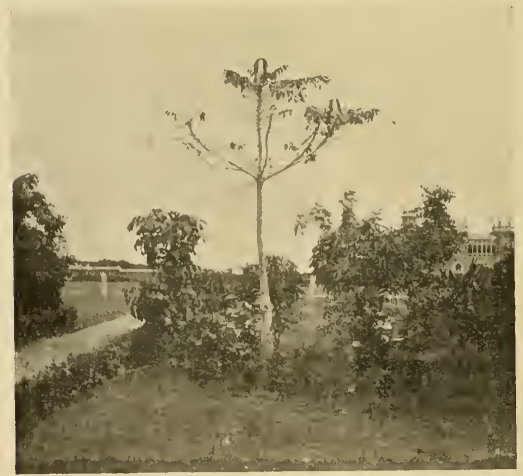

F1G. 58.-Ailanthus cxcelsa defoliated by caterpillars of Eligma narcissus, Coimbatore, December 1912. (Author's original photo.)

food and in some moths the mouth-parts are rudimentary, the adult insect not feeding at all. A few moths (Ophidercs) have the tip of the tongue provided with teeth by means of which they are able to penetrate the outer skin of fruits whose juices they suck, and both the Indian Deaths-head moths (Acherontia styx and A. lachesis) are 


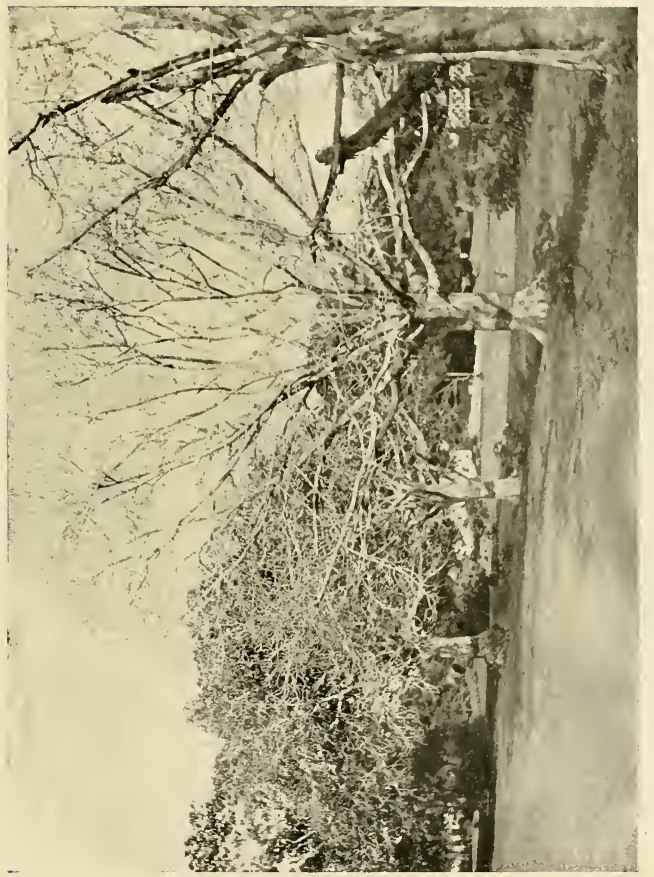

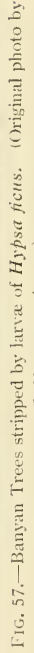



persistent robbers of honey and are often found inside bee-hives. But, with these few exceptions, it is only in the larval or caterpillar stages that the Lepidoptera require consideration as crop-pests.

A caterpillar is easily recognizable as such by the presence of prolegs or false legs, stout fleshy legs situated in pairs on the seventh and succeeding segments of the body, the head being reckoned as the first segment. Except in the case of a few of the more generalized Microlepidoptera, of no economic importance, more than five pairs of prolegs are never present and the number is frequently smaller. This point immediately distinguishes caterpillars from the larvæ of beetles, wasps and flies, in which no prolegs are present, and from those of the leaf-eating sawflies,

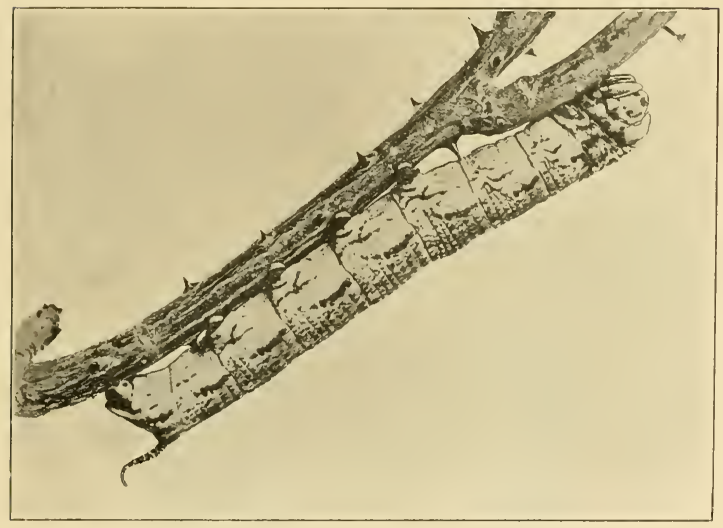

F1G. 59.-Caterpillar of Death's-head Moth (Acherontia), life-size.

This caterpillar may do considerable damage to Erythrina and other plants merely by its large size. (From an original photo.)

which are superficially very like caterpillars but which possess more than five pairs of prolegs. In some cases the number of prolegs may be reduced to two pairs when the caterpillar progresses by reaching forward and grasping an object with its thoracic (true) legs and then, arching up its intermediate segments, brings forward its hinder end and grasps the resting surface; the two extremities are therefore alternately approximated and separated by the whole length of the body. Such a structure and method of progression is 
especially characteristic of the Geometride (literally "earth-measurers"), commonly called "Loopers" or "Spanworms; " but in many Noctuid larvæ (c.g., Plusianc, Catocaliua) some of the anterior prolegs may be absent or little developed so that the caterpillar progresses partly by walking in the ordinary way and partly by arching the segments on which the legs are ineffective, such caterpillars being called "Semi-loopers." In some cases the prolegs, though present, may be greatly modified; in the case of the lobster caterpillar (Stanropus alternus, see figure 279) the posterior legs, or anal claspers, are modified into long slender filaments, and in many case-bearing caterpillars, e.g., Psychide and Enblemma scitula (see figure 242) the prolegs, not being used for purposes of progression, may be obsolescent or much modified. In the case of leaf-miners, (c.g., Phyllocnistis citrclla) the legs and prolegs may be entirely absent, when the larva is said to be apodous (footless); but such larvæ are necessarily so minute that they are not likely to come under common observation.

The structure and habits of caterpillars, sometimes even within the same families, are often so modified or specialized in accordance with food or habitat that it is difficult to classify them as a whole in any satisfactory manner. But, if attention is confined solely to those which do damage to growing crops, they may be placed in groups of which the most important are borers in the stem, shoots and roots, fruit-borers, leaf-eaters and leaf-miners.

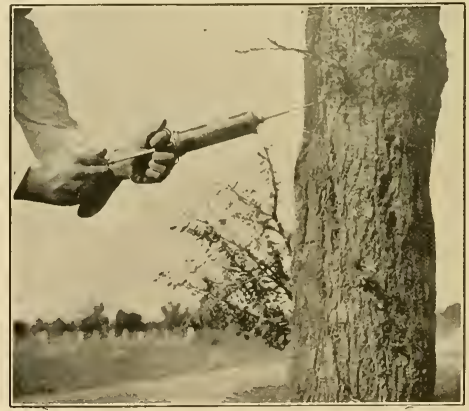

F1G. 60.-Injection Syringe for wood-boring larvæ. (Author's original photo.)

Boring caterpillars are found in almost every kind of crop and attack various parts of the plant, although as a rule each different 
insect has its own peculiar method of attack and bores into similar parts of plants even when these belong to different crops. A tunnel may be bored in the interior of the main stem, whether the plant attacked is a temporary crop such as paddy or a large tree such as a mango, or the caterpillar may attack the roots or the growing shoots, but the seat and method of injury are usually characteristic of each species of caterpillar.

Stem-borers, from the very nature of their attack, are often difficult to control because it is usually impossible to reach them either with a contact or a stomach poison. In the case of those forms (c.g., Arlola, Azygophleps and Zivira), which bore into the main stem of permanent crops (mango, agathi, coffee, tea), the presence of a caterpillar is usually marked by an accumulation of fragments of gnawed wood below the burrow, whose entrance may then be located and a mixture of two parts of chloroform and one part of creosote injected into the gallery by means of a syringe. Where temporary crops, such as cereals, are attacked by stem-borers, the only remedy is to pull out and burn the attacked plants, if these are only a few, to prevent extension of the attack; but, as a rule and in the case of all our important pests of cereals, the damage is so wide-spread that a remedy of this nature is out of the question and means of control must aim at prevention rather than cure. It is possible that the destruction of the adult female moths by means of light-traps or similar methods may be found practicable in the case of the stem-borers of paddy, cholam and ragi. In the case of a semi-permanent crop such as sugarcane it certainly does pay to cut out promptly all dead-hearts which indicate the attack of stemborers, as this practice, if thoroughly carried out, will help to check the attack and will at the same time increase the yield because new shoots will be thrown up to replace those attacked which are very deficient in sugar-content.

Of root-borers we may quote Phassus malabaricus as an example, but there are few true caterpillars which attack plants below groundlevel in India. Pests of this class are particularly difficult to check and the uprooting and destruction of affected plants seems to be the only practical remedy. Many caterpillars bore into the growing shoots of plants. One of the commonest in Southern India is Terastia meticulosalis which bores into the tender shoots of Erythrina and seriously stunts the growth. The only remedy in such cases is to cut back the shoots beyond the larval burrow and to paint the rut end with Crude Oil Emulsion or other repellent to prevent the moths from ovipositing. Bored shoots generally have a withered appearance which is characteristic and are therefore easily recognizable. The Cotton Boll-worms (Earias spp.) often bore into 
the shoots of young cotton-plants before any bolls are put forth and the collection and destruction of all such attacked shoots at this period of the year is a very important measure of control for these moths in order to prevent their increase later on and consequent destruction of the bolls; the removal of these affected shoots not only controls the Boll-worms but often induces extra production of new shoots and flowers on the part of the plant, so that the subsequent crop is not only saved from attack but is actually larger than it would otherwise have been. Under the general heading of "Fruit-borers" may be included all caterpillars which feed on the fruit or seeds of plants. Of this class the Lycænid butterflies provide several examples, the caterpillar of Virachola isocrates feeding in Pomegranates and those of Catochrysops cnejus and Polyommatus baticus boring into the pods of leguminous crops and devouring the seeds. The last-named butterfly may in this manner be a very serious pest in localities where Crotalaria is being grown for seed, as much as thirty por cent. of the crop being destroyed sometimes. Catching the female butterflies by means of hand-nets is practicable in the early stages of an outbreak, but little can be done if the attack is really serjous. The caterpillar of Chlorided obsolcta (Hcliothis armigeral) is a well-known and destructive pest of Gram, the larva eating a hole through the pod into which it thrusts its head to devour the seeds; in this case spraying with a Stomach Poison is practicable because the caterpillar does not remain on one pod but eats its way into several.

Cotton seed in Southern India is extensively attacked by the pink caterpillar of Gelectia gossypiclla; this pest seems to be encouraged by the leaving of old bolls on the cotton-bushes and prompt and regular removal of all ripe bolls will probably keep it in check. Pyroderces coriacella, a minute red-brown moth which has also been reared from cotton-bolls, may feed on the seeds also but is apparently an unimportant pest and perhaps only a scavenger.

Several fruits are attacked by various caterpillars. Litchis commonly contain larvæ of Argyroploce illepida, which bore in the stone, and peaches are sometimes bored by the caterpillar of Dichocrocis punctiforalis, which is a very general feeder in fruits, stems and shoots of many plants. The destructive Codling Moth, Cydia (Carpocapsa) pomondla, which has been recorded from Kashmir, is not known to occur in Southern India, although it may very possibly be found in the Nilgiris.

The number of leaf-eating caterpillars is so vast that only a very general account can be attempted here. Many feed exposed on the leaves whilst others feed within the rolled or folded leaves. Owing to their feeding habits they can be controlled fairly readily by 



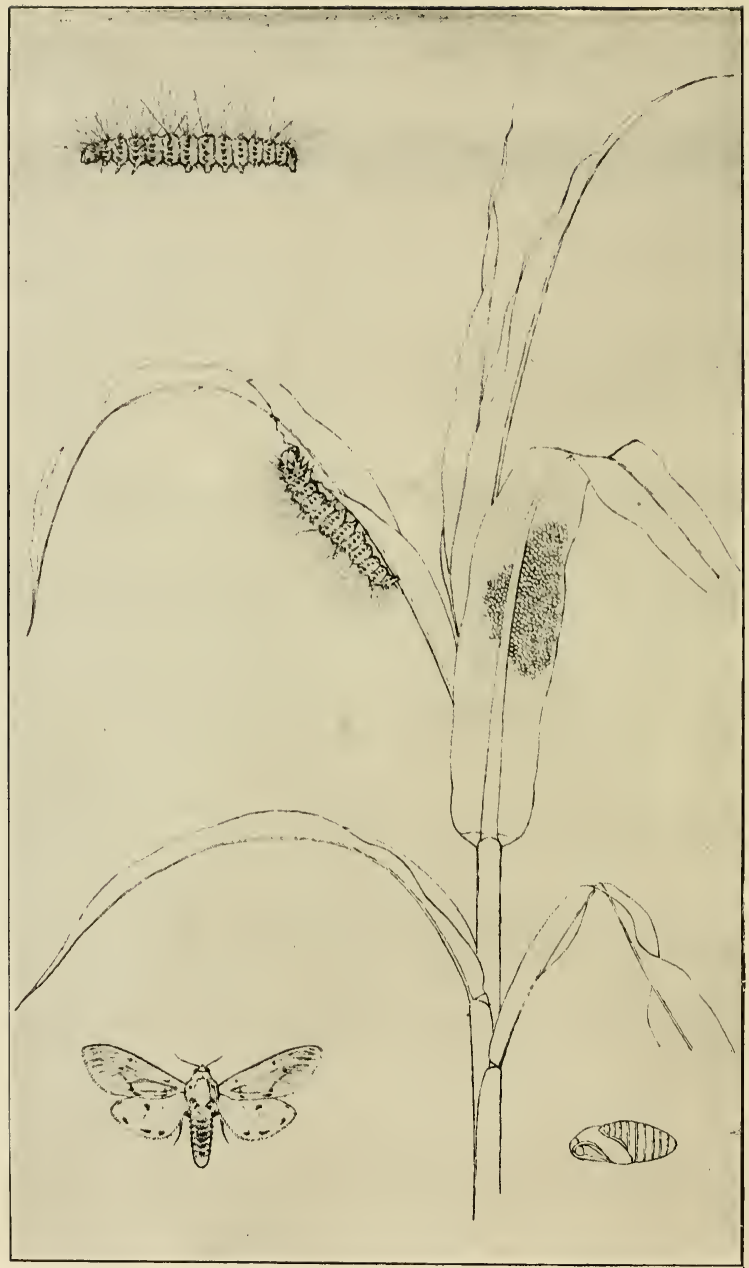

Fig. 61.-Kumbli-puchi (Amsacta albistriga). (Madras Agricultural Department illustration.) 
means of a Stomach Poison when found feeding on crops, but, as in all pests, foresighted prevention is the best remedy.

The Loopers and Semi-loopers already mentioned belong to this group and the latter include Achca (Ophinsa) melicerta whose greyish caterpillar is a common pest of Castor; it is best controlled by hand-picking in the early stages of an attack.

The Hairy Caterpillars or "Woolly Bears" are well known in Southern India under the names of "Kumblihula " or "Kumblipuchi," terms which are applied loosely and indifferently to many very different species. Those of the greatest economic importance are the larvæ of several of the Arctiadce (Amsacta spp, Estigmene lactinea and Utctheisa pulchella), most of which feed rather inclifferently on almost any low-growing crop, although Utetheisa is a specific pest of Sann-Hemp.

In the case of the species of Amsacta, which are often very destructive to crops especially in North and South Arcot, the moths generally emerge from the pupal state after the first heavy showers of rain received in July-August and there may be two or three generations before the end of the year, the pupæ remaining in the soil from about December until the next July; but the emergence of the moths is often irregular and may be spread over a prolonged period. The brownish, hairy caterpillars feed normally on lowgrowing weeds but readily invade and attack crops of almost all kinds, causing great damage. When they are already in large numbers, little can be done except to keep them out of the cropped areas as far as possible by trenching; as usual, the best means of control is by prevention and this may be done by a vigorous attack on the moths themselves when they first emerge and before they have time to lay eggs. The first emergence of the moths is fairly uniform and they are sluggish and conspicuous, so that they may be collected and destroyed in large numbers, thus directly checking subsequent increase. The eggs are laid in batches and hand-picking of the caterpillars, immediately these are seen, should also be done.

Cutworms is the term applied to the caterpillars of certain moths of which Euxoa Agrotis (segetum) is a common and destructive pest in the Hills. These caterpillars hide during the day under stones or clods or in the soil itself and only issue forth at night to feed, when they cut through the stems of young plants at ground-level and feed on the leaves, the destruction done by them being greatly increased by their habit of cutting through many more plants than they actually consume. These Cutworms are extremely difficult pests to control. As they hide by day, they are difficult to find and it is by no means easy to kill them with a Stomach Poison, as they 
avoid the sprayed portions of plants and, rather than eat such. burrow down and feed on the roots.

Swarming Caterpillars or Army Worms are so called because they sometimes appear in immense numbers and, having eaten all the food available in one locality, migrate $c n$ masse into crops which they ravage from their mere numbers. Paddy Seed-beds and Grasslands are especially liable to attack by these caterpillars. The best remedy, as a rule, is to keep them out by trenching. In the case of Paddy Seed-beds these may be flooded if possible and ducks placed in them to eat up the caterpillars.

Leaf-miners are of little economic importance in themselves. They live between the upper and lower surfaces of leaves, eating out the green matter and often leaving a tortuous track which shows as a white "mine" on the leaf. The commonest lepidopterous leaf-miner is perhaps Phyllocnistis citrclla, whose legless caterpillar mines in young leaves of Citrus. In the case of many Stem-borers, c.g., Chilo simplex in Cholam, the young larvæ may at first burrow into leaves, but these are hardly leaf-miners in the strict sense.

Many caterpillars confine themselves to one plant or at least to species of plants which are naturally allied to one another and in dealing with such we can therefore assist control by judicious rotation of crops. But some caterpillars feed on many different plants and are therefore called "polyphagous" (lit. many-eating).

In the control of caterpillar pests it is necessary to consider the conditions in which the pupal state will be passed. Many caterpillars (Kumblipuchis, Cutworms, Army Worms) pupate in the soil and ploughing or suitable disturbance of the ground after they have pupated may sometimes be used in order to destroy the pupæ, either by exposing them to the sun or to birds or by burying them so deeply that the moths will not be able to escape. Other caterpillars pupate in rolled leaves, either on the plant or in old dead leaves which have dropped to the ground, and the collection and destruction of these will help in reducing the numbers of the succeeding broods. Stem-borers usually pupate in the stem of the attacked plant, often low down at about ground-level, so that the pupæ are left behind in the stubble when the crop is cut ; destruction of the stubble is indicated as a remedial measure in such cases. 


\section{CHAPTER XIV. \\ GRASSHOPPERS, CRICKETS AND TERMITES.}

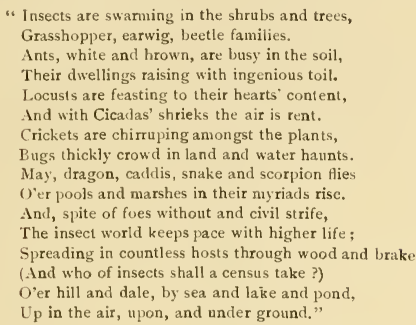

KN1PE-Nebula to Man.

THE idea of Grasshoppers as crop-pests usually calls up recollections of descriptions of hordes of locusts flying in vast swarms from one district to another, darkening the sky during their flight and instantly making a barren wilderness of the places where they alight. Such flights of locusts are well known in many parts of India and occasionally the Bombay locust (Cyrtacanthacris succincta) migrates from its breeding-grounds in the Deccan into the districts of Bellary, Kurnul and Anantapur in large flights which would be very destructive were it not for the fact that they usually take place in June when there are practically no crops on the ground in those parts. So far as Southern India is concerned, therefore, locusts are only occasional and rather minor pests, but the damage done by Grasshoppers of various kinds is very large in the aggregate, because some species at least are active at all times of the year, and their accumulated damage throughout the year all over the Presidency probably totals to considerably more than more striking loss caused by locusts in a more limited area.

The Bombay Locust itself occurs regularly throughout Madras, not, however, as a swarming locust but as solitary individuals. Another commoner and closely-allied form is Cyrtacanthacris ranacea which is the common large spotted grasshopper of cotton-fields. In Bellary and Kurnul a wingless grasshopper (Colemania sphenarioides) has achieved notoriety of late years as a pest of cereals and 
pulses in the period from July to October, in some places destroying practically the whole of the crops. A large greenish grasshopper (Hicroglyphus banian) is a special pest of paddy, particularly in Malabar and South Kanara, and often does considerable damage to this crop and more rarely to sugarcane and maize. A brown grasshopper (Epacromia tamulus) occurs commonly throughout the plains, feeding on a variety of crops amongst which we may specify ragi, cholam, cumbu and daincha, and is especially a pest of these crops in Madura and Tinnevelly. A small narrowlybuilt green species (Atractomorpha cremulata) occurs commonly all over the low-country on varions plants and is especially a pest of tobacco, brinjal and Amaranthus. A small, slender, greenish grasshopper (Oxya velox), often with reddish forewings, is found throughout the plains as a minor pest of paddy, cholam and

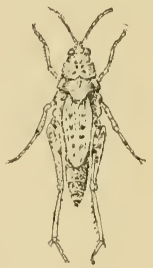

F1G. 62.-Chrotogonus. (Original.)

sugarcane. Finally, a stoutly-built, flattened, short-winged, earthcoloured grasshopper (Chrotogomus spp.) is found commonly on the ground everywhere and is a minor pest of almost all low-growing crops.

Detailed descriptions and figures of these various grasshoppers will be found further on. For the ordinary cultivator it is not necessary to know more than that the insect doing damage is a grasshopper-a fact easily verified by noting that the hindlegs are much larger than the others and formed for leaping-as the habits are much the same in all, as are also the methods to be adopted.

Except for their quiescent period whilst in the egg-state, grasshoppers do damage throughout their lives, for they eat vegetable matter throughout all their periods of growth and also during their adult condition. The eggs are always laid in masses in the ground and often remain there during definite seasons for months at a time before hatching, so that agricultural methods such as ploughing (see Chapter XI) at such seasons may offer a chance of destroying them before they emerge at all. If, however, the grasshoppers 
have hatched out and are found actually doing damage, the only practical method of control is to catch them in bag-nets or hopperdozers (see Chapter XI). Spraying with a stomach-poison is only possible in very small areas.

Under natural conditions, grasshoppers are kept in check by various natural enemies of which the most obvious are birds. Mynahs, as their generic name (Acridotheres) implies, are great hunters of grasshoppers and each bird must destroy dozens of these insects every day. Kites and crows also are often very useful by feeding on grasshoppers, especially if these latter are present in large numbers, when the birds often make a concerted attack and devour very large quantities of the insects. Birds of this useful character are obviously invaluable to the farmer. The Blisterbeetles, which in their adult state are themselves crop-pests, during their larval stages seek out and attack the egg-masses of grasshoppers in the soil and destroy them, and these beetles form a very important check on the increase of grasshoppers in some districts. The endoparasitic enemies of grasshoppers have been little studied in India, but several flies of various species are known to attack them and destroy them.

Crickets are of little importance in Southern India except as (quite local pests. Those species (Brachytrypes, Gryllotalpa) which do damage to crops differ from grasshoppers by their habit of living in burrows in the soil during the day and only coming out to feed at night. As their attack is often very localized, it is sometimes practicable to spray the plants around their burrows with a stomach-poison, but as a rule the simplest plan is to flood them out, where this can be done, when they are perforce driven from their burrows to fall a prey to crows and other birds which quickly congregate during all irrigation operations.

Termites, commonly but incorrectly called "White Ants," are in nowise related to the true ants, nor are they always white. To the popular imagination there is only one kind of "White Ant," which throws up the well-known mounds and attacks indiscriminately growing crops and living and dead wood, but as a matter of fact there are numerous different species whose habits are entirely distinct. Forty or fifty different species occur in Southern IndiaI have found a dozen distinct kinds within the limits of the Agricultural Farm at Coimbatore-some of which attack growing crops and trees, others bore into the solicl wood of living trees, others confine their attentions to dead wood and other vegetable matter, whilst yet others feed only on grasses or lichens and are hence of little economic importance. It will therefore be seen that, when Termites are found to be doing damage, it is first of all necessary 
to distinguish the guilty species in order to apply appropriate remedies; it is, for instance, of no use to set to work and destroy all the mounds in the vicinity, if the guilty variety is not the mound-builder at all.

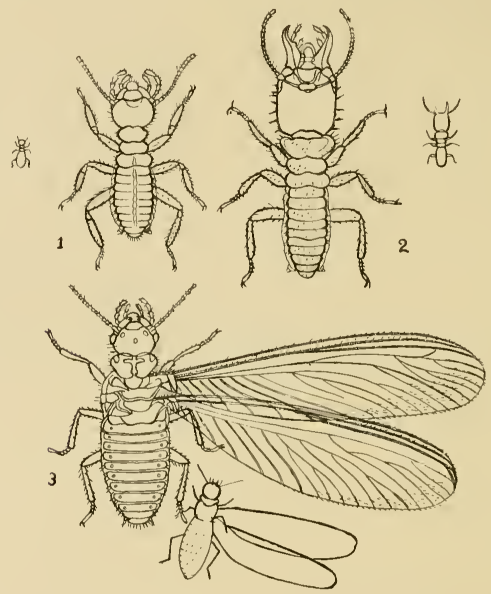

FiG. 63.-Castes of a Termite Odontotermes horni.

1, Worker ; 2, Soldier; 3, Winged Adult. The smaller outline figures show the natural sizes. (After Bugnion.)

To understand anything about Termites it is necessary to consider briefly the main facts in their social economy. Apart from immature forms, we can distinguish in each colony three distinct social states or castes - workers, soldiers, and sexually adult individuals. In the case of the workers and soldiers, of each of which castes there may be two or more sizes according to the species concerned, the individuals are distinguishable as males and females, but their sexual development is arrested at an immature stage. The workers are so called because they are the labourers of the community, foraging for food, tending and feeding the young, and excavating and building up the nest; they are readily recognizable by their vertically-carried heads with small broad jaws. The soldiers derive their name from the fact that they act as defenders of the colony, accompanying the foraging parties of 
workers as guards and running out to repel any attack on the nest by grasping, or at least threatening, the intruder with their jaws, which are large, curved, pointed, and carried horizontally in front of the head; in many species the soldiers also discharge a sticky liquid from a special gland in the head. The sexually mature Termites are most familiar as the winged individuals which swarm out of the nests, usually during the onset of the monsoon; these are males and females and may often be observed to pair off in couples, the male following the female in single file, both running rapidly over the ground in search of some convenient chink or hole in which to hide. As soon as a couple has paired off in this way, and sometimes sooner, the wings are thrown off by an apparently voluntary muscular action, breaking off transversely near the base across the line of a natural suture and leaving the stump of each as a small triangular scale attached to the thorax. Birds, frogs, lizards, ants and insects of all sorts, even cockroaches and muscid flies, clevour the winged Termites as they issue from the nest and very few escape; but a few pairs do burrow into the ground or into trees according to the species, and excavate a small chamber in which they probably pair and certainly do lay a small batch of eggs which presently develop into workers and soldiers. The colony gradually grows until there are enough workers to go out foraging and sufficient soldiers to defend the nest and in the meantime the original foundress grows larger and larger until, in the case of some of the mound-building species, her body becomes as long and stout as a human finger, and at this stage she is nothing but a vast reservoir of eggs, which she extrudes at the rate of at least 30,000 a day, and this probably during a period of several years. The original male also remains in the nest but scarcely increases in size beyond that attained when the royal pair originally took to wing; he is generally found in the royal cell, in which the female or "queen" is enclosed, although he often escapes and is overlooked in opening up a nest. It is not correct to say, arguing from analogy with bees, that the queen Termite is only fertilized once, after which the male dies, for a male is always found if the nest is opened up carefully; occasionally there may be two, rarely three or more, females, but I have never found more than one male. In the case of some of the more primitive species, which live in wood, it is known that the ultimate caste assumed by an individual can be modified by special feeding whilst it is still young, so that an individual which would have become a soldier can be made to become a sexual female, and in this manner colonies of such Termites are able at will to replace their queen, if she should perish by any accident, by a substitute which is called 
a "neoteinic " queen. In the case of the Indian species of Termites, however, there is no evidence that this can be done; in fact, there is a considerable balance of evidence against this and, in the case of some Termites at least (Entermes), it has been shown that the caste of the young individual, i.e., whether it is to be a soldier or a worker, is already fixed before its emergence from the egg, although this does not necessarily prove that, by special feeding or other means, the ultimate form cannot be modified. Still, in the case of all ground-living species of Indian Termites, it is fairly safe to assume in practical work that the queen of a nest, once removed, cannot be replaced and that a colony deprived of its queen will dwindle and die out. In this connection it must be noted that nests, and especially mounds, often contain two or more species of Termites living in close contiguity and care must be taken to see that a queen which may be found and destroyed, belongs to the species which it is required to check.

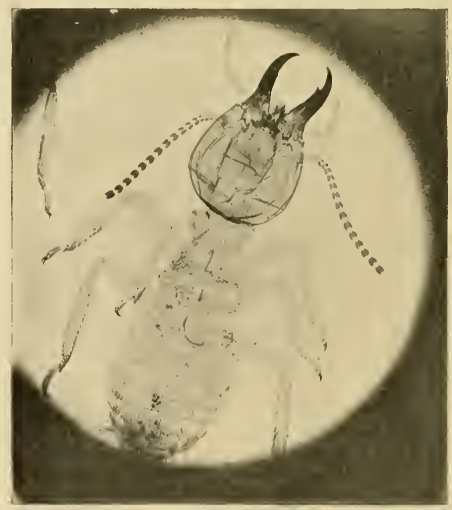

Fig. 64.-Soldier of Odontotermes obesus. (Micro-photo by W. H. Harrison from a specimen determined by Professor N. Holmgren.)

In the case of damage by Termites, therefore, the first requisite is a definite knowledge of the species concerned. This known, endeavour must be made to locate its nest and to destroy this. In the case of nests in beams or trees it may be possible to inject poisonous gases with the help of a pumping machine and this may also be used in the case of mounds or nests in the ground where 
these can be located. In the case of mounds it is usually practicable to dig down and find and remove the queen, or one or two dynamite cartridges may be exploded in the mound, all the openings into which have previously been well closed with wet clay.

If the nest cannot be located, the only thing is to endeavour to prevent attack by the use of some deterrent. For example, if the Termites are attacking the bark of trees, these may be painted or ringed to prevent the access of the Termites; a mixture of Crude Oil Emulsion and Tar, half and half, has been found satisfactory, and various mixtures can be made from materials locally available. In the case of sugarcane setts, which are often attacked when newly planted out, it is useful to dip them before planting in a strong solution of Copper Sulphate, which usually wards off attack

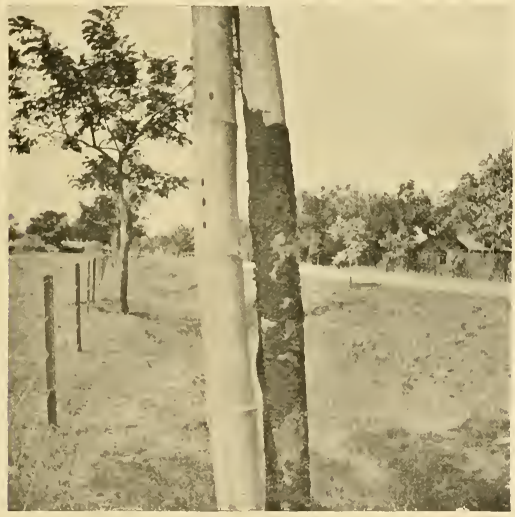

F1G. 65.-.II Casing deposited by Termites (Odontotermes sp.) on Rain-tree (Pithecolobium Saman).

Note that the bamboo support, though dead, is not attacked. (Author's original photo.)

until they have established themselves. When growing crops are attacked and these are irrigated or irrigable, the placing of a bag of Crude Oil Emulsion in the water channel will sometimes drive the Termites away temporarily. In the case of garden plants, watering the roots with a weak solution of Phenyle will usually have a 
similar effect. Kainit is also said to act as a deterrent, although there seems to be little actual evidence on this point. If irrigation is not practicable, shallow trenches may be dug and filled with any dead vegetable matter (e.g., branches, dead leaves, old cholam stalks) to attract the Termites from the adjacent crops as far as possible and, when this object is effected, the contents of the trenches may be set on fire to destroy the Termites wholesale. But, as a rule, very little can be done unless the nests can be located and destroyed, and this is very rarely possible, as they may be ten or twelve feet below ground and give no indication whatever of their presence. In the case of buildings, constructional timber which will be exposed to attack should be treated before it is placed in position, either with one of the various specifics advertised in the market or by soaking in a solution of Sodium Arsenite for a couple of days followed by a good coat of tar when quite dry. If Termites make their way into a house, as they often do when the bricks are of poor quality or badly laid, the only thing is to open up their galleries and to endeavour to inject poisonous fumes with a special machine so as to reach and poison the queen if possible. It is of very little use, in all cases, to kill a small number of the foraging parties, workers and soldiers, and to expect a remission of attack thereafter; unless the nest can be reached and the queen killed, no permanent results will be achieved; but by the use of deterrents, it is sometimes possible to get crops over a critical period after which they are less or not at all liable to attack. 


\title{
Chapter XV.
}

\section{B L G PESTS.}

\author{
"Why, shameless shepherd, pluck me \\ From the branches wet with dew? \\ I am but a poor Cicala, \\ And ne'er did harm to you. \\ The forest lawns, I love them, \\ And I love a lonely nuok; \\ But the one thing that I love not \\ Is a shepherd's finger-crook. \\ lour fruit-tree filchers, catch them, \\ 'Tis right, and kill them too \\ But why my green leaf grudge me, \\ And ny tiny drops of dew ?"
}

BAYLEY-Sabrina Corolla.

BUG PESTS are characterized by the possession of a long sucking tube which they thrust into plants or other food and suck up the juices on which alone they live. This sucking tube is plainly visible as a long slender jointed rod whose base is attached to the lower surface of the head and whose tip is generally carried along the lower surface of the body between the pairs of legs; it may be noted that the tube, as seen, is only a sheath for the very slender setæ enclosed therein and which are the true suctorial organs. No bugs have biting jaws and therefore they are not able to eat leaves and for this reason Bug Pests cannot be controlled by stomach poisons.

For purposes of economic entomology, plant bugs may conveniently be divided into three classes, (I) active bugs, which fly or run actively over foliage and from one plant to another, (2) semi-active bugs, such as the Aphids, which are always small in size, sof t-bodied and gregarious, occurring in masses, the individuals being active but not in practice moving about to any extent, and (3) fixed bugs, such as the Scale-insects, which attach themselves more or less permanently to particular parts of the plants they attack and which are usually protected by a hard or filamentous waxy shield. Speaking very generally, this last class contains insects which are especially pests of permanent crops, such as coffee, tea, mango, rubber and coconut, whilst the first class contains insects which are particularly pests of temporary crops (cereals, pulses, oilseeds, cotton, etc.). 
From the point of view of control-measures the above divisions, though artificial, possess a real importance, because different methods of control have to be practised in regard to each of these classes. The active bugs, which are sometimes quite large insects and which are rarely minute in size, are as a rule too large and active to render feasible the operation of spraying even with a contact insecticide, but on the other hand their size and habits admit of the satisfactory use of mechanical measures such as catching them by hand or in hand-nets or bag-nets.

The second class, of semi-active bugs, contains insects such as Aphids, Psyllids and Aleurodids, which are minute in size, softbodied, and gregarious in habit. They are therefore best dealt with by means of contact sprays such as crude oil emulsion or tobacco wash.

The third class, comprising the fixed bugs, includes practically only the Scale-insects, which are often found in large numbers within a small area-and this is so, not because they are gregarious by habit, but simply because their radius of spread is circumscribed--, and which are often protected by a filamentous or shieldlike waxy covering which secures them from the wetting effects of rain and hence of ordinary aqueous solutions of spray-material. On account of this waxy covering, therefore, it is usually advisable to apply a spray which contains rosin, this substance having a peculiar wetting effect on the waxy covering of the Scale-insects.

The insects themselves are described and figured further on in this book and we can only mention here a few of the more important

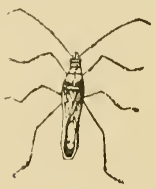

F1G. 66. -Rice-bug / Leptocorisa varicornis). (From Madras Agricultural Citlendar, 1913-14. of the Bug Pests of crops. Of the active bugs, the most injurious is probably Leptocorisa varicornis, a long slender greenish bug which attacks paddy, sucking out the milky juice of the grains just as these are formed; it is easily caught by means of handnets and is also attracted to light at night whilst its numbers should be checked as far as possible in the first place by due attention to the clean condition of the bunds surrounding paddy-fields, as this bug will breed on wild grasses and invade the paddy when this is ripening. Dysdercus cingulatus, a brick-red bug with a black spot on each forewing and peculiar whitish edges to the segments on the underside of the body, is a common and destructive pest of cotton, piercing the bolls with its beak and sucking the contents of the young seed, staining the lint and spoiling the seed either for oil-extraction or for sowing ; 
it is often accompanied by Oxycarenus latus, a very small brownish bug which is found chiefly in old bolls which have been left unplucked after they are ripe : both of these bugs are easily collected by hand and shaken into a pan of oil-and-water.

Garden Crops are particularly attacked by Coptosoma cribraria, a small rounded brownish-green insect which looks at first sight like a beetle and which feeds particularly on beans and other Leguminosæ; it is very active on the wing and cannot be collected by hand, but it is generally rather gregarious and can be caught in large numbers by means of hand-nets. Aspongopus jams, a large red-and-black insect, is sometimes a pest of vegetable plots; it is easily caught by hand.

In the Hills the most important of the active bugs are (I) Antcstici cruciata, an occasional serious pest of coffee which it damages by sucking the berries, (2) Helopcltis antonii, the well-known "Mosquito Blight" of tea, cacao and cinchona, (3) Cyclopelta siccifolia, a stoutly-built dull black bug which is sometimes a serious pest of Erythrina but is usually gregarious and easily collected by hand, and (4) Anoplocnemis phasiana, a very large dark bug with curiously-shaped hindlegs, which is sometimes a serious pest of young Erythrina when these are planted out as shade-trees.

One bug, which deserves mention here because of its curious habits, is Aphanus sordidus, an elongate dull dark-brownish insect which sometimes congregates in large numbers on threshing floors and similar places where oil-seeds or cereals, such as gingelly, groundnut or cumbu, are collected, the bugs, which may be present in very large numbers, running off with the seeds, which they suck, in such quantities as to constitute a serious loss unless they are constantly swept back with the aid of a broom or branch.

In the second class, of semi-active bugs, reference must be made to the various species of Psyllidæ, Aphidæ and Aleurodidæ described further on ; but it may here be noted that some of the Aphids or plant-lice live on the roots of the plants they attack and special methods nust be adopted against these.

Of the fixed bugs, the Green Scale (Lecaninm viridc) of coffee is the most notorious, and incidentally it provides an excellent example of the danger of the introduction of insect pests from abroad. It is believed to have been originally a native of Brazil whence (whether direct or via Africa) it was carried to Ceylon and then into Southern India where it has now spread practically into all the coffee-growing districts in some of which it has absolutely destroyed the whole of the coffee. In appearance it is a small, inconspicuous, light-green, oval, flattened scale, which is found as a rule clustered along the veins and mid-rib on the underside of leaves 
and on young twigs. The only control method which can be advised at present is a vigorous attack on this scale immediately it is noticed, to endeavour to keep it at least within bounds; rosin compound is probably the best insecticide to apply. The shadetrees of coffee estates suffer from various scales, which may affect the coffee as well as the shade-trees; the only satisfactory controlmethod is to eliminate all varieties of trees which are subject to such attacks. Cotton is attacked by three or four Scale-insects, sometimes very heavily indeed, but the attack is usually quite localized, often confined to a single plant, and such plants are best pulled out and burnt, their neighbours being examined at the same time to see whether they have been infected also. Except in the case of permanent crops, such as coffee, tea, rubber, fruittrees and palms, Scale-insects are of comparatively little importance in Southern India, but in the case of such permanent crops they may do great damage and every endeavour should be made to check outbreaks of Scale-insects at the very beginning, as soon as they are noticed, and before serious damage has occurred; for the rate of increase of these little insects is so rapid that, by sheer numbers, great damage may be done in spite of their minute size individually. In particular, great care should be taken that, when fruit-trees or garden plants are brought from a distance, they have not brought any of these insects with them, and this end can only be achieved by insistence on proper fumigation of the plants by the sender before despatch. 


\section{Chapter XVI.}

\section{BEETLE PESTS OF CROPS.}

"The annual loss suffered by agricultural communities through ignorance of entomologi. cal faets is very great. Every plant has its insect enemies, or, more correctly, its insect lover, which feeds upon it, delights in its luxuriance, but makes short work, it may be of leaves, it may be of flowers, it may be of fruit. It has been estimated that every known species of plant has five or six species of insects which habitually feed upon it. Where the plant is one that is valuable to man and is grown for his use, the horticulturist or the farmer finds himself confronted, preseutly, by the ravages of these creatures, and unless he has correct information as to the best manner in which to combat them, he is likely to suffer losses of a serious character."

HOLLAND-The Butterfy Book, pp. 256-257.

THE Coleoptera or Beetles include a greater number of insects than any other Order but, so far as the insect-pests of crops are concerned, they are less important than Lepidoptera and on the whole probably do no more damage than the Orthoptera or Rhynchota. This is due largely to the fact that Beetles have a complete metamorphosis, the larva being very different from the adult in appearance, habits, and usually in food also, so that beetles as a rule only damage crops for a portion of their life-cycle, whilst bugs and grasshoppers feed in a similar manner and on similar food for their whole life after emergence from the egg.

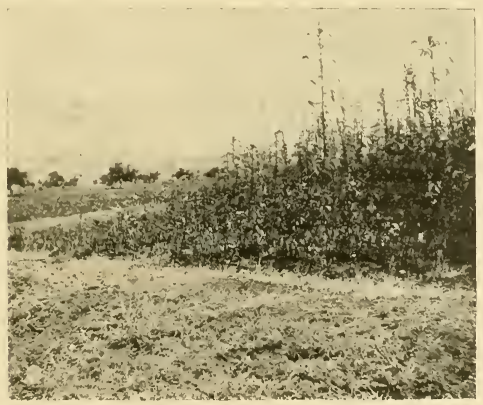

F1G. 67.-Gogu Plants attacked by Beetles.

The plants on the left hand were attacked and their growth stunted in com. parison with the healthy, unattacked plants on the right. (Author's original photo. 
Beetles, it may be as well to repeat here, are provided with biting mouth-parts both in their immature and adult stages, and this fact immediately distinguishes them from bugs some of which somewhat resemble beetles in external appearance.

Cockchafers of various kinds are common in all districts, usually appearing at definite times of the year, often in enormous numbers, and flying in to light at night, though rarely seen in the daytime. They are heavily-built beetles, with short legs and stout, rounded bodies usually coloured in a uniform shade of brown or grey, with short antennæ terminated by an expansile fan of elongate-oval, flattened plates. The beetles themselves fly by night and may do considerable damage by feeding on leaves of plants, especially of ornamental plants in gardens, such as roses. In such cases they may either be collected by hand at night by shaking the plants over trays or sheets, or the plants attacked may be sprayed with Lead Arsenate sireetened with a little treacle or jaggery. A lighttrap, made by suspending a lantern over a tray of oil-and-water, will often attract the beetles in large numbers and may be used as a control-measure supplementary to either of the above, but lighttraps by themselves will not usually afford protection. It is not, however, only the beetles that are destructive, for the larvæ live in the soil and do considerable damage by feeding on the roots of plants. They are white, fleshy grubs, with three pairs of thoracic legs and with the tip of the curved body usually swollen into a bluntly rounded extremity. These grubs usually live just at the roots of grass, coming closer to the surface in wet weather and retreating further down during dry spells. They are very difficult to control, as ordinary flooding will not drown them and the application of insecticides is impracticable on any large scale, though in gardens, where flower-beds or grass-lawns are attacked, watering with soap-solution or phenyle or any similar deterrent will drive them away temporarily. Ploughing will often bring them up to the surface when they are eagerly preyed on by crows and other birds, and as their life-history is usually very definitely limited by seasons, lasting at least a year as a rule, it is possible to arrange an operation such as ploughing to take place during a period when these insects are in the grub stage, with the express purpose of destroying as many as possible at that time. In the Nilgiris especially these larvæ are well known under the name of "Whitegrub," and at certain times of the year the whole countryside, gardens, fields, plantations and grassy downs, is infested by these grubs, which live just below the ground and feed upon the roots of plants. The gardens at Ootacamund are much troubled by these pests, whose ravages commence in August and cease in the dry 


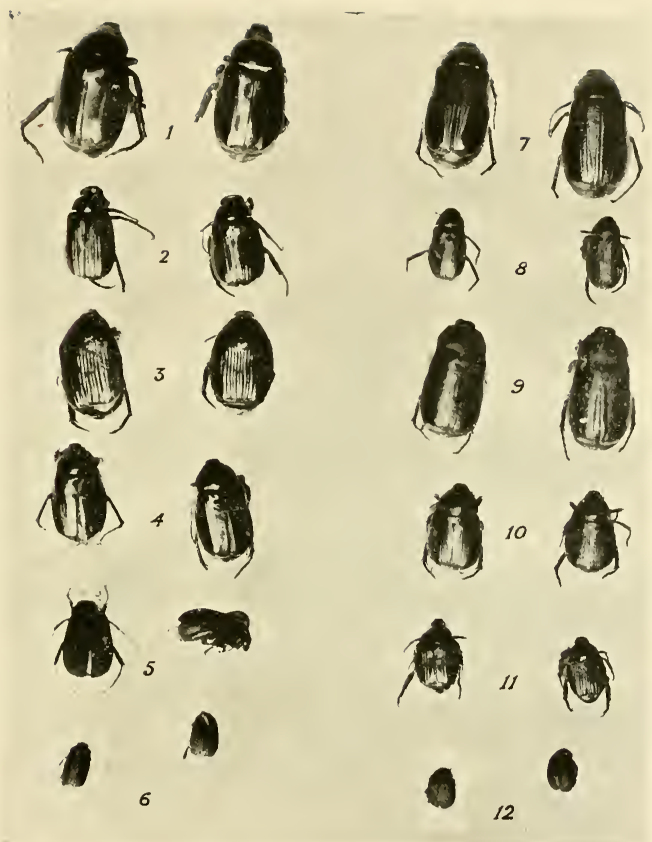

Fig 6s. Nilgiri chafers.

1. Anomala olvicri. Shp.: 2. A. pallicla: 3, A. regina. Newm.: t. ILnidentified): 5, Mclasina barbori, shp.: 6. Serica nilgirensis. Shp. : 7, Holotrichia repetita. Shp.: S. Adoretus ovalis, B1.: 9. Holotrichia conferta, Shp.: 10. Anomala ignicolles: 11. Popillia clelorion: 12. Scrica pilula, Shp. (Originalsphoto by Dr. C. A. Barber.) 

weather after January, the beetles flying in the early evenings immediately after the first rains in April and May. As the flights of the various species concerned are apparently extremely local, the destruction of the beetles in April-June, by light-traps, by handcatching, and by the use of poisoned sprays, will usually lessen considerably the damage done by the grubs in the later months of the year.

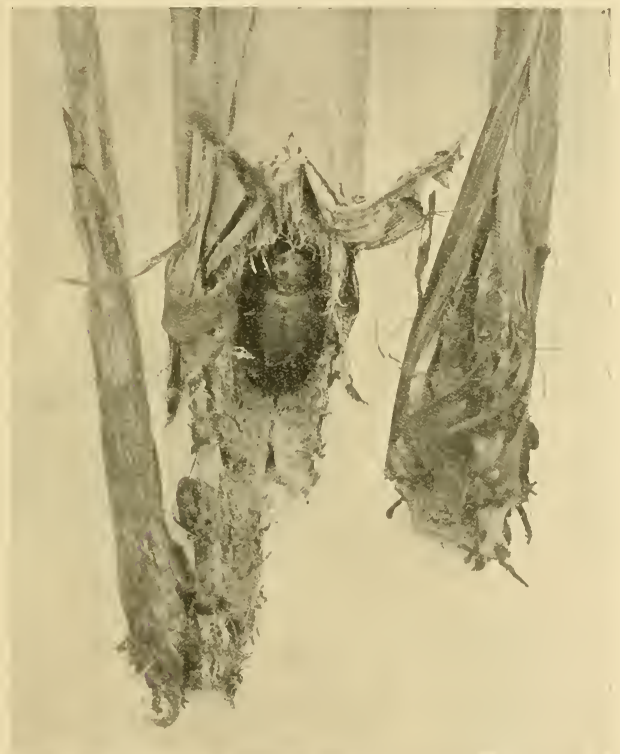

F1G. 69.-Oryctes rhinoceros boring into sugarcane. (Original photo. by Murugesan from a specimen found at Coimbatore, October 1913.)

Closely allied to the cockchafers are the Rosechafers (Cetoniada), differing by their more flattened shape, their brighter colours and their diurnal habits. They attack flowers rather than leaves and are often a serious pest of cereals, such as cholam and cumbu, devouring the flowers so that no grain is formed. Their 
life-histories are practically unknown but they are believed not to do so much damage as cockchafers in their early stages; they are, however, of similar habits in appearing at definite seasons of the year. Collection by hand in hand-nets or by picking the beetles or shaking them into trays of oil-and-water is the best method of control.
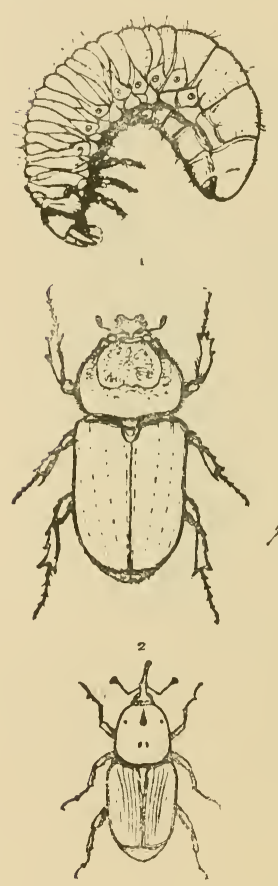

6

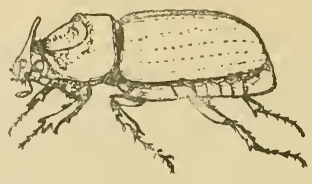

3
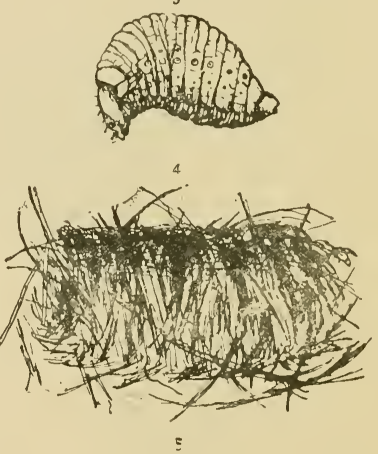

Fig. 70. - Bectle Pests of Palms.

1, Oryctes rhinoceros, larva; 2, 3, O. rhinoceros, beetle; 4, Rhynchophorus ferrugineus, larva; 5 , Cocoon of same; 6, 7, Rh. ferrugincus, beetle. (From Madras Agricultural Department Leaflet.) 
Another ally of the cockchafers is the Palm Beetle (Oryctes rhinoceros) which bores into the tender shoots of palms, aloes, and occasionally into sugarcane. In this case it is only the adult beetle which does damage, the larva living a harmless existence as a fat, white grub which is found commonly in dlecaying vegetable matter - dead leaves, manure pits, rotten wood, dead aloe or palm stems, etc. The beetle itself not only does considerable damage by boring through the tender unexpanded leaves of palms, but its tunnel provides a suitable entrance for the still more destructive Red Palm Weevil (Rhynchophorus ferrugineus) which is thus enabled to lay its eggs in the tender growing parts of the palm from which its larvæ burrow downwards into the stem and, when in large numbers, may kill the tree, whose rotten stump presently becomes a suitable nidus for the larvæ of the palm beetle. So that it will be seen that these two beetles are to some extent mutually interdependent and that the damage done by one is completed and amplified by the other.

Many beetles bore into the solid wood of growing trees or bushes in their larval stage and do very serious damage to the plants so attacked. The longicorn beetles in particular have white woodboring larvæ which are usually long, stout, cylindrical, with distinct segments and well-developed jaws. In the case of the larger grubs which bore into trees, of which Batocera rubus in mango and rubber and the coffee borer (Xylotrcchus quadripes) in coffee are well-known examples, the larva may be cut out and the wound painted over with tar, a drastic remedy which is usually quite successful. But the best method of control is prevention by handcollection of the beetles when these emerge before they have opportunity of laying their eggs; one coffee-borer killed at this time may save twenty bushes bored by grubs later on.

Some at least of the Buprestidæe are also wood-borers in the grub stage, their white larvæ being usually elongate and with a curiously dilated thoracic region. Sphenoptera gossypii is a local pest of cotton in Bellary whilst $S$. arachidis attacks groundnut and Leguminosæe practically throughout the plains, being an especially serious pest of groundnut in South Arcot. The only thing to be done in the case of these small borers is promptly to pull out and destroy all the plants attacked by them.

Though a true longicorn and wood-borer in its early stages, Sthenias grisator deserves special mention, as the beetle has the curious habit of girdling twigs of Erythrina, rose, etc., by seizing them in its jaws and ringing them completely by biting through the bark so as to arrest all flow of sap. In the end of the branch thus killed the eggs are laid and the larva tunnel and live, the 
object of girdling the twigs in this way being to provide a suitable amount of food free from sap, for the larvæ to feed on. The larvæ of most longicorn beetles, it may be noted, feed on dead wood.

Blister Beetles of various species often do great damage to crops by devouring the flowers and tender shoots. Cereals and leguminous crops, such as gram, are especially subject to attack and there seems to be some special attraction for these beetles in flowers of a yellow colour; the common red-barred black Zonabris pustulata, for example, feeds indifferently on yellow flowers such as those of red gram, cotton and prickly-pear. Whether these beetles are to be ranked as pests or beneficial insects is at present, however, an open question. In the adult state they certainly do harm to crops. The

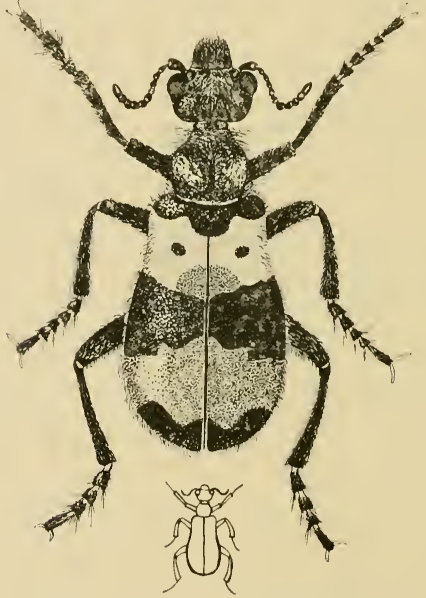

F1G. 71.-A Blister-beetle (Mylabris indica).

The small outline figure shows the natural size. (Original.)

life-histories of very few species are known at all but the larvæ of most of those that are known are parasitic on the eggmasses of grasshoppers; and we have bred two distinct species of blisterbeetles (one of which is apparently Guathospastoides rouxi, Cast) from eggmasses of the destructive Deccan grasshopper (Colcmania sphenarioides). If therefore the larva of a blister-beetle destroys even one eggmass containing (say) forty eggs of a grasshopper, the 
good it accomplishes by so doing at this stage must be offset against any damage it may do later on as an adult, and the question we have to answer is whether the daniage that would have been done by the grasshoppers is greater than that done by the beetle which has destroyed them. And for the present this must remain an open question and we can give the blister beetles the benefit of the doubt.

The vast army of leaf-feeding beetles cannot be considered here in any detail and the ordinary methods for control of biting crop-pests are applicable to them as a whole. Catching them in hand-nets or by shaking the plants over trays or cloths is generally more practicable on a large scale than spraying with stomachpoisons. As a rule it is only the perfect insects which do damage to crops, but to this there are a few exceptions. The Epilachna beetles, which look much like lady-birds but have a curious bloom on the wing-cases, lay their eggs in batches on solanaceous and cucurbitaceous plants on whose leaves the larve feed and may do considerable damage; as the plants attacked are usually those grown in gardens, spraying with a stomach-poison is practicable. The Hispina (Leptispa pygmaa, Phidodonta modesta, and Hispa armigera), small elongated shining blue or black beetles, the two latter thickly covered with long branching spines, have larvæ which are leaf-miners in grasses, the first and third of those named above attacking paddy and the second being a minor pest of sugarcane. As the larva mine inside the leaves they cannot be reached by a spray, which in any case would be out of the question in the case of crops such as sugarcane or paddy. The only remedy which can be suggested at present is the catching of the adult beetles in hand-nets and the burning of all stubble immediately after harvest.

The Tortoise Beetles (e.g., Aspidomorpha miliaris) are leaf-feeders in their early stages and their larvæ are easily recognizable by their extraordinary habit of curving their long forked tails over their bodies and depositing on them a covering composed of cast larval skins and excrement. One species is commonly found on ber (Zizyphus jujuba) but those of economic importance are all minor pests of sweet potato. Remedial measures are not required as a rule but, as this crop is usually grown in small areas only, the plants may be sprayed with a stomach-poison and gone over with a band-net or bag-net to collect the adult beetles.

The habits of the various Weevils which are pests of crops are very varied but all may be recognized by the long curved snout of the adult beetle. The larvæ are short, fat, white, legless grubs with very small heads, and they are as a rule borers in stems, 
leaves, fruits or roots of plants, although the life-histories of very few are known in India.

The Cotton Stem Weevil (Pempheres affinis) lays its eggs on stems of young cotton-plants at about ground-level and the larva makes a spiral burrow inside the stem which produces a characteristic gall-like swelling, inside which it lives and pupates. In the case of badly-attacked plants the whole plant may be snapped off by the wind. No successful remedy, applicable on a field-scale, has been found hitherto, but in the case of experimental plots painting the stems with crude oil emulsion may be recommenderl.

The Sweet Potato Weevil (Cylas formicarins) bores into the tubers of sweet potato which it utterly ruins, every tuber being bored and rotten in the case of a bad attack. No direct remedy is applicable. The beetles are easily collected by hand-nets or bagnets as they sit on the leaves of the food-plant but the damage has usually been done by the time that they are noticed. Abandoning the cultivation of sweet potato for at least a year after an attack, and the use of deeply-rooted varieties of plants, will help to prevent attack. The infected tubers may be fumigated or may be boiled and fed to cattle.

The Mango Weevil (Cryptorhynchus mangiferal) which passes its life-cycle inside the stone of a mango fruit, is very common, probably ninety per cent. of niangoes being infected in some years, although as a rule the presence of the beetle passes unsuspected and no damage is clone to the fruit itself. If the stone of a ripe fruit is cut open, the beetle itself, or its larva or pupa, will generally be found.

Many weevils are leaf-eaters as adults and may do damage, usually of a minor nature, to crops. They are generally easily collected by shaking the plants over cloths or pans of oil-andwater; it should be noted that weevils, when disturbed, frequently drop to the ground and "sham dead" and this death feint should not be mistaken for the real article. Many weevils also have such an extremely tough and thickly chitinized integument that they are not killed by treading on them with the foot on ordinary soft soil and care must be taken to see that they are really squashed. 


\title{
ChAPTER XVII.
}

\author{
FLY PESTS OF CROPS. \\ -The fresh young tie . . . . . \\ . . joy'd to range abroad in fresh attire, \\ Through the wide compass of the ayrie coast : \\ And, with unwearied wings, each part t'inquire \\ Of the wide rule of his ren.,wned sire."
}

SPENSER.

VERY few Fly Pests of crops are known in Southern India as yet, although it is probable that further research will bring to light many more cases of damage by these insects. In all cases it is only the larva or maggot of the fly which does damage, the adult insect itself being harmless.

The Fruit Flies comprise the most numerous and important of the Fly Pests and, as their name implies, they attack various species of fruits, both wild and cultivated. The eggs are usually thrust into the fruits whilst these are still unripe and the maggots tunnel into the pulp and utterly spoil the fruits which may be turned into nothing but a crawling mass of maggots. The fruits most subject to attack in this way are oranges, mangoes, peaches, guavas, and almost all cucurbitaceous vegetables such as pumpkins, melons, etc.

The prompt collection of all fruit seen to be attacked, as soon as the attack is noticed, and of all wind-fallen or rotting fruit lying on the ground, is an obvious course to take in case of attack by these flies, in order to prevent them from breeding as far as possible; such fruit should be boiled or thoroughly burnt or buried deeply underground with at least two feet of well-beaten earth over it. In the case of valuable fruits, such as those intended for Exhibitions, they may be protected by enclosure in muslin bags, but these must be applied whilst the fruit is still small. If it is known that fruit-trees are likely to be attacked they may be protected to some extent by spraying them with a mixture of $3 \mathrm{lb}$. sugar, 3 oz. Lead Arsenate in 4 gallons of water. This spraying should be started when the earliest fruits are about two-thirds grown and should be continued until all are ripe, being renewed at least once a week and promptly after every shower of rain. The object of this spraying is to attract and poison any female flies which may be present and which would otherwise lay their eggs 
in the fruit. Certain strong-smelling oils, such as Citronella and Kerosine, are known to exercise a powerful attraction for the males of certain species of fruit-flies and exposure of pans of water or fly-papers baited with these oils will destroy the males in large numbers; but in practice it is not found that the quantities so destroyed have much influence on the oviposition by the females.

Young cholam plants are sometimes attacked by a fly-maggot which bores in the stem just about ground-level and which may do considerable damage. It is believed that this pest, whose exact identity is not known, attacks healthy plants, but it may possibly prove to be only a follower of an attack by stemborer (Chilo simplex). No remedy can be recommended except increase of seecl-rate and subsequent thinning out and burning of all young plants seen to be attacked, the attack being marked by a characteristic yellowness and drooping of the young plant. Sometimes more than one maggot may be found in the same stem; the brownish pupa is found in the larval burrow.

The Red-gram Agromyza, whose exact name is not known, attacks red-gram, the female fly piercing the pods with its sharp ovipositor and laying eggs singly inside their skin. The maggot on hatching feeds on the seeds inside the pod. Sometimes more than one maggot is found in a single pod, the only outward sign of attack being the minute and almost invisible hole through which the egg was thrust. When full-fed the maggot pupates inside the pod and after a few days emerges as a minute shining black fly. This pest is kept in check by parasites, and no remedial measures can be suggested at present. Another species of Agromysa attacks cowpea, lablab and green gram, the larva boring into the stem and the plants so attacked withering. This fly is sometimes a serious pest of young plants.

The Cecidomyiadæe form a fanily of flies comprising a large number of minute species, many of which have earned notorious reputations in other conntries as crop-pests, but few have been noted hitherto to do damage in India. Two species, however, have lately been discovered at Coimbatore, one of which (a species of Contarinia apparently very near the West Indian C. gossypii, but distinct) attacks the buds of cotton-plants into which the larva bores so that the buds drop off and fail to mature; the other, which may be called the Gingelly Gall-fly in the absence of an exact determination, attacks young gingelly capsules and prevents their proper formation in a similar way, a wrinkled twisted gall being produced instead of a fruit. It is probable that further work will bring to light many more destructive species of 
Cecidomyiada whose minute size has hitherto allowed them to escape notice.

A Blue-bottle fly (Pycnosoma fluiceps) has proved a local pest of toddy in South Kanara, the flies being naturally carrion feeders in their early stages and being bred in immense numbers from the fish offal and other refuse of the Fishing Industry on the WestCoast. The flies have been found to fly inland as far as forty miles and to congregate around the spathes of toddy-palms in such numbers as to suck up all the juice as fast as it exudes, besides fouling the toddy-pots with their excrement. Fuller details will be found in Leaflet No. IV. of I9I3 issued by the Madras Agricultural Department.

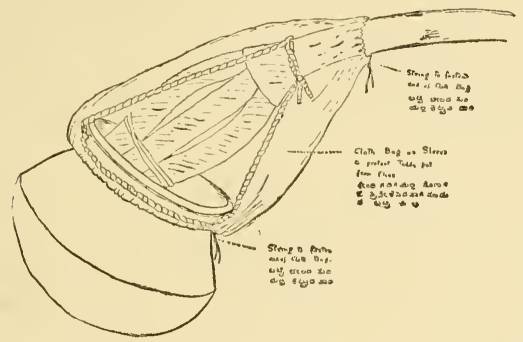

FIG. 72.- Protective device against toddy flies. (From Madras Agricultural Department Leaflet No. IV of 1913.)

Flies are extremely important, both to man and animals, as carriers of diseases (see Chapter XX). So far as crops are concerned, however, they are of comparatively little importance in India. 


\title{
Chapter XVIII.
}

\section{PESTS OF STORED PRODUCTS.}

\begin{abstract}
"To the terrible utilitarian a bushel of peas preserved from the weevil is of more importance than a volnme of observations bringing no immediate profit. Yet who has told you, O man of little faith, that what is useless to.day will not be useful to-morrow. If we learn the customs of insects or animals we shall understand better how to protect our goods. It is by the accumulation of ideas, whether immedialely practical or otherwise, that humanity has done, and will cuntinue to do, betler to-day than yesterday, and better to morrow than to-day. If we live upon peas and beans, which we dispute with the weevil, we live also by knowledge, that mighty kneading trough in which the liread progress is mixed and leavened."

FABRE,
\end{abstract}

EVEN after the agriculturist has grown and harvested his crops and paid his toll to the innumerable insect-pests which attack his produce in the field, he is by no means freed from the undesirable attentions of yet another class of insects which now proceed to levy their clues upon his outturn, whether this be stored for food of man or beast or retained for the sowing of next season's crop. Not only are cereals attacked but seeds of all sorts, and indeed scarcely any manufactured products of vegetable or animal origin are free from destruction, for some of these pests of stored products are not only voracious but also almost omnivorous, so that it has aptly been said of one of them that its food is "everything except cist-iron."

These insects have been very little investigated in India; most of them are beetles, but there are also a few small moths which do damage of this nature. The following is an incomplete list of the destructive species so far as these are known:-

Colcoptera: Siltanus surinamensis (see p. 290), Lamophlams minutus, Athriostoma undulata, Tencbroides mauritanicus (see p. 289), Lophocatcres pusillus, Carpophilus dimidiatus (see p. 288), Rhisopertha dominica (see p. 294), Gibbium psylloides (scotias), Sitodrcpa panicca (see p. 295), Lasioderma serricorne (see p. 295), Tribolium castaneum (see p. 300), Latheticus oryza, Calandra granaria, C. oryze (see p. 34I), Caryoborus gonagra (see p. 308), Pachymerus chincnsis (see p. 306), and various other Bruchidæ.

Lepidoptera: Sitotroga cerealella (see p. 456), Ephestia cautclla (calivitella), E. ficulclla (desuctclla). Phthorimata operculclla (see p. 455).

Of the above-named insects the Rice Weevil (Calandra oryza) is at once the commonest and the most destructive. It attacks cereals of all sorts in the field to a slight extent, feeding on the 



\section{EXPLANATION OF PLATE I. \\ HOUSEHOLD AND GRANARY PESTS.}

Fig. r. Pulse seed eaten by Bruchid Beetle, with eggs deposited on it.

" 2. Bruchid Beetle.

.. 3. Lasioderma serricorne, larva.

. 4. " " beetle.

15. Anthrenus vorax. larva.

,. $6 . \quad$ ", beetle.

,7. Sitotroga cerealella, larva.

" 8. " " moth.

" 9. Calandra oryza, beetle.

"ro. Silvanus surinamensis, beetle.

" Ir. " "

" 2 . " " larva.

.13. Tribolium iastaneum, beetle.

" 14 . Caloclytus annularis, larva tunnelling in bamboo.

"I5. " , beetle.

(The lines alongside the figures show the natural sizes.) 

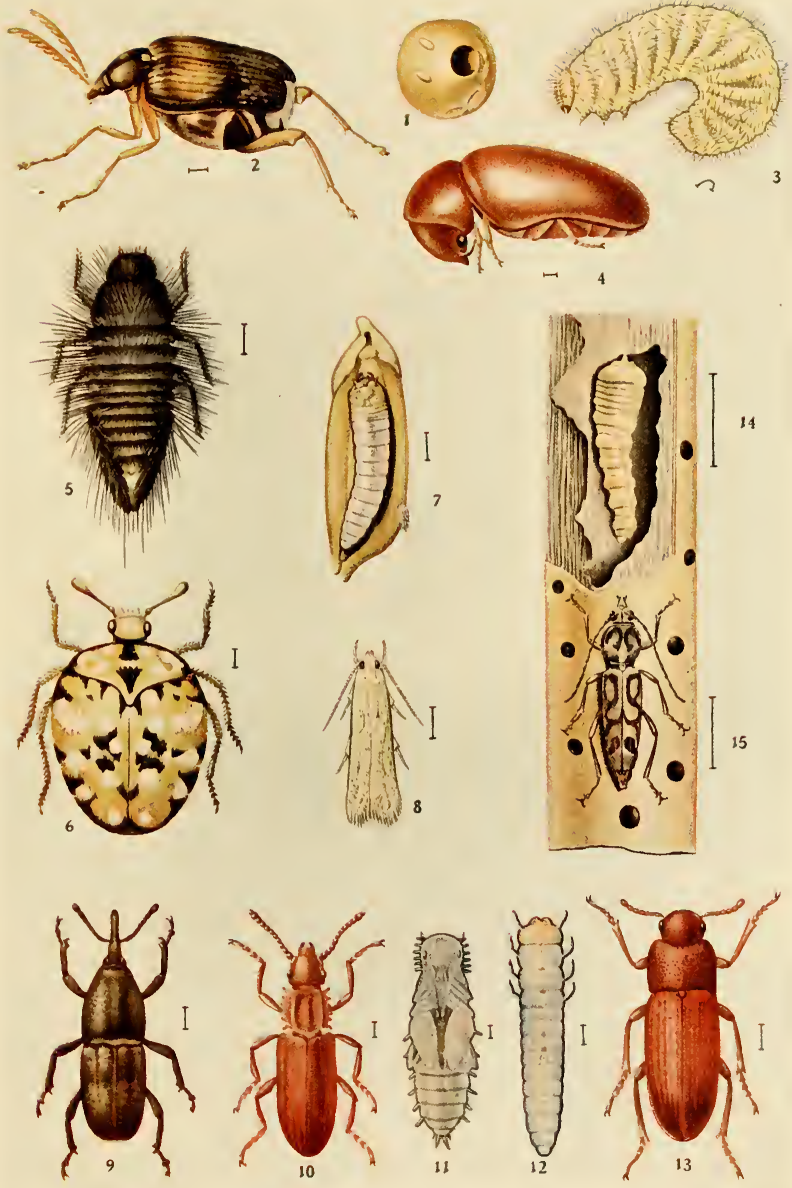

HOUSEHOLD \& GRANARY PESTS. 

ripening grain, but it is an important pest of stored grain, especially of rice, but also of maize, wheat, cholam, etc., and at a moderate estimate may be said to clestroy 5 per cent. of all stored grain which is kept for more than a couple of months after harvest. The whole life-history is passed in a single grain in which the egg is laid, but the adult beetles live for a long time and wander about freely, biting into many grains, so that they probably do more damage as adults than when immature. It has been found by experiment that a certain minimum (about 8 per cent.) of moisture in their surroundings is necessary to the successful existence and breeding of these weevils, so that, if grain can be well dried in the sun to reduce its moisture-content as much as possible and then stored in insect-proof receptacles in a dry place, it will be as secure from attack as is possible under practical conditions. In districts where paddy is stored in jars there should be little difficulty in having the grain sun-dried before storage and then fastening up the jars so as to exclude weevils; for jars not in use an earthenware cap, luted on with clay, might be used, and those in daily use could be covered simply with a fine cloth tied around the neck of the jar. Care should of course be taken that the jars are thoroughly cleaned out and free from weevil or old infected grain before filling them afresh and also that all fastenings are really sufficiently tight to be weevil-proof. If the grain is kept in baskets these should at least be plastered over with mud or cowdung to make them tight if possible.

Tribolium castaneum (ferrugineum) is a small elongate red-brown beetle which attacks stored grains and oilseeds and more especially dried provisions, such as biscuit and flour. It also feeds on dried animal matter and seems to have a special predilection for dried specimens of insects if these are left exposed in ill-fitting boxes. Not only does this beetle do damage by actual consumption of provisions such as flour, but its presence communicates a peculiarly repulsive taste to the substances on which it feeds, so that whole cases of flour and biscuits often have to be condemned as unfit for human consumption on this ground alone.

Silvanus surinamensis, so called because it was first described from Surinam, is a small elongate brown beetle with the sides of the thorax produced into sharp saw-like teeth. It is a common insect in stored products generally but a minor pest in comparison with the two preceding species.

The Bruchidæ, or Pulse Beetles, are short thick-bodied species of the characteristic shape seen in figure 155 . They attack especially pulses such as the various grams, lablab, beans and peas, the larva burrowing inside the seed and destroying it and leaving a 
characteristic large round hole of exit. Owing to their comparatively large size these beetles may do very considerable damage t) stored pulses. A few species attack growing plants in the field and may be found in ripening pods of grams and of some wild leguminous plants such as Crotalaria, but the species which attack living plants are apparently distinct from those which damage stored products. There are numerous species of these beetles, all very similar in general appearance and difficult to distinguish from one another, although differences of habit may prove that their discrimination is of practical importance.

Sitodrepa panicea is an insect of truly catholic tastes, feeding indifferently on almost any substance of animal or vegetable origin and even having been recorded as biting holes through sheet lead. Even the most pungent substances, such as red pepper, do not come amiss to it and it is therefore scarcely a matter for surprise that this little beetle is often found as a serious enemy of dried products, especially of dried roots and similar dried vegetable substances commonly found in bazaars. It is also a very serious enemy of books, boring a long tunnel which may often run straight through several volumes in a row; an annual painting with book solution (see Chapter XIX) will avert such damage.

The Cheroot Beetle (Lasioderma serricorne) needs no introduction as its ravages are sufficiently well-known in Southern India. To the ordinary smoker it is sufficiently annoying to find a cheroot reduced to a combination of holes and dust, but to the manufacturer this beetle may be a cause of heavy loss by riddling bales of tobacco leaves of good quality which are used for the making of outer wrappers of cigars. The only reliable method of control in these cases is by careful fumigation and subsequent storage of the bales in rooms or receptacles which are proof against the entrance of the beetles, though this is by no means easy on a large scale, and probably frequent and regular fumigation of all unmanufactured stock will prove the best safeguard as a rule. If the made cigars are fumigated with Hydrocyanic Acid gas or Carbon Bisulphide and boxed immediately afterwards, so that the beetles have no opportunity of ovipositing in them, they should be and remain free from attack, as the beetles are unable to penetrate into the boxes if these are properly sealed up with strips of paper. The present wholesale losses are quite preventable if the manufacturers will take reasonable precautions, and it may be added that the slight cost of treatment will be more than recouped by saving in clamage.

If stocks of stored grain, such as paddy or maize, are examined and turned over, numbers of small greyish moths will generally be seen flying and running over the grains. These are the adult 
insects of Sitotroga ccrcalella, a small moth whose larva feeds inside grains of cereals. The precautions recommended under the heading of rice weevil are applicable to this pest also-thorough drying and exposure of the grain in the sun and subsequent storage in dry, tight receptacles being generally effective in controlling the damage.
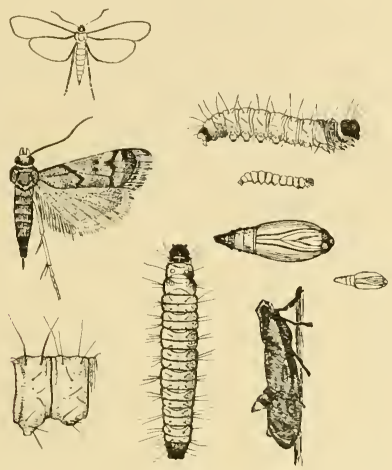

FIG. 73. Ephestia kuehniella. (After Chittenden.)

Several Pyralid moths of the genus Ephestia feed commonly in flour, grain and dried vegetable matter, the caterpillars living in a silken gallery which is run throughout the food so that loose substances, such as flour, are often found to be webbed together in a continuous matted mass. Fumigation is the only remedy as a rule.

Potatoes kept for seed are generally found to be attacked by the Potato Moth (Phthorimalea operenlclla), the larva of which burrows in the tubers and not only spoils them by its tunnels but causes them to rot. This moth is found in practically all potato-growing districts up to about 6,000 feet; it does not appear to be known as yet in Ootacamund (though found at Downham Farm a thousand feet lower down) but will doubtless obtain a footing there in the near future. In other countries it is known to attack growing plants of both potato and tobacco, the larva mining in the leaves, but in India it is only known as yet as a pest of stored potatoes. If these are picked over before storage, all unsound ones being rejected, and the rest stored under layers of dry sand, so as to be 
out of reach of the moths which would otherwise lay eggs in them, a sufficiency of seed can generally be kept; the potatoes should be picked over frequently, once or twice a month, and all rotten ones rejected. Those which are found to contain larvæ of this moth should not of course be simply thrown away, thus enabling the moths to emerge, but should be boiled or buried deep underground under at least two feet of well-beaten earth.

Bamboos and dry timber of all sorts are frequently bored by beetles of various kinds. Painting or varnishing is usually a sufficient preventive of attack but if the wood is already infected the beetles will bore their way out and continue to do damage. In such cases painting with Kerosine, which should be forced into the holes if possible, and subsequent painting with unboiled linseed oil, will generally check the clamage. Small articles of furniture, such as chairs, may be fumigated in a large box. Bamboos are often soaked in water before use for building, and the water perhaps removes some of the sugary contents of the wood and thus makes them less attractive to insect pests of this description.

Grains and stored products, such as are attacked by the insects mentioned above, are usually intended either for food or for sowing. In the former case it is obviously impossible to treat them with any poisons which would be deleterious to the consumer and in the latter any treatment must not impair the vitality of the seed. These limitations prevent us from making use of any method of treatment which would render these articles permanently secure from insect attack by the use of stomach-poisons and the only methods which we can adopt are (I) temporary fumigations at such frequent intervals that any insects which may obtain access will be unable to increase sufficiently to cause serious loss, or (2) one temporary fumigation and subsequent storage in receptacles to which the insects cannot obtain access. On a small scale also it is possible to mix a deterrent substance, such as Naphthaline, with the grain in order to keep out insects, the naphthaline being subsequently sieved out and the residue evaporated in the open air; this does not affect either taste or vitality of seeds if all the naphthaline is carefully evaporated. The naphthaline may be wrapped in pieces of thin cloth for subsequent convenience of removal.

If, therefore, grain cannot be protected from access and renewed infection by insects, the only method of protection is frequent fumigation to prevent the insects breeding and increasing to destructive numbers. On a small scale, as in the ordinary village and bazaar, grain may be exposed to the sun instead of being fumigated. When it can be stored in receptacles (rooms, special bins, or jars) where it will be safe from subsequent infection, one fumigation or 
thorough drying should be sufficient to kill off all insect life and the subsequent storage to maintain it free of pests. It must be remembered that, in drying grain in the sun, it must be spread out evenly and thinly so that every grain may be exposed to the sun's rays and heat; it is of little use to pile grain up in heaps, as the individual grains at the bottom of the pile will not be exposed to the sun, so that the insects in them will not be killed and will subsequently infect the rest. For the storage of grain in villages, the use of large glazed earthenware jars, which can be tightly closed with a stopper and this thickly and tightly luted with clay, will be found most satisfactory; if the grain is thoroughly dried in the sun before placing it in the jars and sealing it up, which will normally be done in dry weather, not only should it remain free from insect attack, but danger of damage by mould should be eliminated to a large extent.

Fumigation, which is only recommended in the case of godowns or stores on a fairly large scale, may be accomplished by the aid either of Carbon Bisulphide or Hydrocyanic Acid gas. Both are dangerous and poisonous substances and should only be used under strict and competent supervision. The former is inflammable and violently explosive; the latter is inert in these respects.

Carbon Bisulphicle is a heavy, colourless, oily liquid, which rapidly evaporates into a colourless gas heavier than air, both liquid and gas exhaling an extremely unpleasant and characteristic smell, and being poisonous if inhaled. The liquid is inflammable and the gas is violently explosive when mixed with air in the presence of fire. The liquid must be kept in stoppered (not corked) bottles and should not be exposed to direct sunlight or stored in any place where it is liable to be heated or to leak or to be upset or spilt. Carbon Bisulphide must never be opened or taken near a light or fire of any sort, not even a lighted pipe, cheroot or cigarette, nor should it ever be stored or used in a place to which unauthorized persons may have access. For fumigation it is simply poured on to the grain to be treated at the rate of about one ounce for every fifteen cubic feet or, in the case of large bins full of grain, about one-and-a-half pounds of fluid to each ton of grain. As the gas is heavier than air, if the liquid is poured onto the grain, it will soak down and through it. After twenty-four hours, during which no light or fire must be allowed anywhere near the place where the treatment is being carried out, the receptacle may be opened, again in the complete absence of fire in any shape, any gas which may be present allowed to escape, and the grain removed and at once transferred to permanent storage. It must be clearly understood that treatment by fumigation in this way will 
only kill the insects already present in the grain and will not prevent insects from entering and attacking it subsequently if access is open to them.

For fumigating small articles or quantities of grain, etc., use may be made of a tight wooden box provided around the top of the sides with a metal gutter into which fits a flange attached to the lid of the box. The gutter being filled with water (allowing for clisplacement of water by the flange) the substances for fumigation are placed in the box, the requisite quantity of Carbon Bisulphide poured in and the lid applied, when the flange of the lid, dipping into the gutter of water, makes a gas-tight fitting. A box of this pattern may also be used for fumigation with Formalin, etc., but is hardly suitable for Hydrocyanic Acid Gas, which is soluble in water, and for which a tightly fitting top, pasted down with strips of paper, is better.

Hydrocyanic Acid Gas, usually liberated by the action of Sulphuric Acid on Potassium Cyanide, is a colourless, highly volatile, and nearly odourless gas, which is one of the most powerful poisons known. For this reason it must be used with great care, although it is a most useful insecticide and absolutely safe in competent hands. It is generally used at a strength of one ounce of Potassium Cyanide (98 per cent. grade) to every one hundred cubic feet of space, the gas being evolved by the help of one ounce of Sulphuric Acid in three fluid ounces of water. It is especially useful for the fumigation of entire buildings, such as godowns or mills, which are infested with insect-pests, and may of course be used for the funigation of living-houses also if these can be evacuated during treatment. For ordinary purposes on a large scale, one pint of Sulphuric Acid and three pints of water are used for every pound of cyanide; it may be useful to note that commercial Potassium Cyanide is usually only of about 45 per cent. strength and the quantities to be taken must be based on the quantities given of 98 per cent. grade.

For fumigations with Hydrocyanic Acid Gas, as with all fumigations, the first requisite is to measure off accurately the cubic capacity of the building or vessel which is to be fumigated; if this is of irregular shape it is often of great assistance to plot its shape to scale on squared paper and to count the number of squares, which will give an approximately correct idea of the capacity of any section, which can then be multiplied by the length to give cubic capacity. All outside doors, windows, or other openings, are then tightly closed and if necessary pasted over with paper. The requisite amount of cyanide, at the rate of one ounce to each 100 cubic feet, is then taken and put up in paper packets of suitable size 
of not more than two pounds weight each, and placed ready in each room, the packets being allotted to different parts of the room if more than one is required for each room. The water is then measured out and poured, for each packet, in to suitable generators which should be sufficiently deep and be made of earthenware and not of metal. The acid, also measured in each case, is then slowly and earefully poured into the water. The acid must always be added to the water and never the water poured into the acid, as in the latter case violent action takes place and the acid is almost certain to spatter about with possibly dangerous results to the operator. For it must be remembered that sulphuric acid is a strong corrosive. The water and acid may be mixed in the rooms where they will be required finally if these have cement or stone floors; otherwise it is better to mix elsewhere to avoid damage to flooring should the acid spill or boil over on being added to the water. The acid and water and the packets of cyanide being all ready, and all doors except those actually required for access to the rooms being closed, and all persons except the operator being outside the building, the operator commences at the top of the building, drops the packets of cyanide gently into the generators and immediately leaves that room, repeating the operation on the next floor below and so working downwards, carefully and rapidly, to the groundfloor and out by the door which is then carefully closed and locked from the outside. If there are two or more rooms on each floor it is useful to have one or more intelligent assistants so that all the rooms on each floor may be treated simultaneously. If the cyanide is made up in paper packets the acid will take a short time to get through the paper, thus giving a few seconds interval between the dropping of the packets into the generators and the ebullition of the gas, which will be enough to secure a safe retreat. Fumigation by Hydrocyanic Acid Gas, if properly carried out, is a radical cure for all living animals (beetles, larvæ, bugs, flies, fish-insects, rats and mice) in the building treated, but it should only be carried out under strict supervision of a competent operator. The building should be left closed for twenty-four hours, after which doors and windows may be opened from the ontside as far as possible and left open for at least an hour to permit the gas to escape. No attempt must be made to enter the building if any smell of gas is still perceptible; this smell is faint and something like that of peach-kernels or of some metals when these are struck together.

In colder countries successful results in the control of grain pests in flour mills, etc., have lately been attained by the use of heat, steam-pipes being laid down in the rooms affected and steam 
turned on under pressure. A temperature of II8 to 125 degrees Fahrenheit is claimed to be sufficient to destroy all insect life and this may be so in countries where, even though the kinds of insects concerned may be identical with Indian ones, the average temperatures to which the individual insects have been exposed for generations are considerably lower than the limits given above. In India, where temperatures run much higher, it is probable that the insects would only be killed off by the temperatures considerably in excess of $120^{\circ}$ even if methods of heating were available. The treatment of stored products by cold so as to prevent insect pests from breeding and doing damage is not practicable in India in the case of grains which are attacked on a large scale, though perhaps possible in the case of cigar factories and similar industries where the products are of considerable value and small bulk. 


\title{
Chapter XIX. \\ HOUSEHOLI PESTS.
}

\begin{abstract}
"()n every dish the booming beetle falls, The cockroach plays, wr caterpillar crawls : A thousand shapes of variegated hues l'arade the table and inspect the stews. To living walls the swarming hundreds stick, Or court, a dainty meal, the oily wick:

Heaps over heaps their slimy: bodies drench, Out go the lamps with suffocating stench. When hideous insects every plate defile, The laugh how empty, and how forced the smile :
\end{abstract}

Calcutta-A Poem. wool."

"The moth shall eat them up like a garment and the worm shall eat them like ISAIAH-li-8.

OF all the numerous insect pests which afflict the dwellers in Indian bungalows the housefly is an easy first both in numbers and really noxious qualities. Its misdeeds have been noted elsewhere, but it cannot be emphasized too strongly that the so-called " poor harmless little fly," which buzzes so cheerfully over our food and drowns itself in our drink, was born and bred amongst filth, preferably night-soil, that it has probably just flown into the bungalow after enjoying itself on some indescribable nastiness outside and that it is generally swarming, inside and out, with pathogenic organisms which it distributes impartially as it walks along. Enteric fever, dysentery, cholera and intestinal worms are all carried commonly by flies, which are also capable of carrying tuberculosis, anthrax, yaws and various other diseases. Strict attention to sanitary conditions around the bungalow, especially as regards disposal of stable manure, will usually bring about a great reduction in the fly population. A small quantity of fresh horsedung, exposed in open boxes, will attract most of the female flies to lay their eggs and the larvæ can then be destroyed by burning, boiling, or treating them with insecticides; but it is of course important that the traps should be cleared regularly, daily or at least every other day. Milk with a few drops of formalin added 
attracts flies in the dry weather, and is a simple means of poisoning them without danger to domestic animals. A small piece of wire gauze or leather fastened to a handle makes a very effective implement to "swat that fly," as the Americans say, and a chokra armed with a weapon of this kind should have little difficulty in dealing with any flies that find their way on to the premises.

Cockroaches are insects which are not only disgusting in appearance and by reason of their powerful odour but they are also animals which are liable to contaminate food where this is accessible to them. The large brown cockroaches /Periplancta australasiac and $P$. americana) are common throughout Southern India and of ten fly about in bungalows just before rain, though at other times they keep out of sight. Several smaller species are also of common

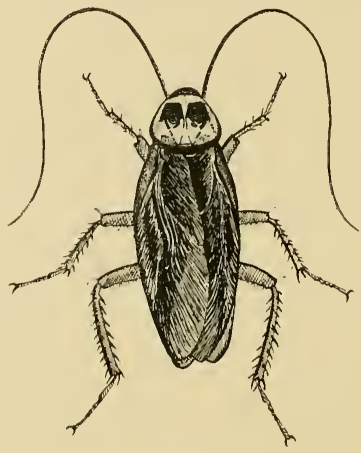

FIG. 74.--Periplaneta americana, the common House-cockroach of India. (Original.)

occurrence and all have much the same habits. Besides attacking food, which they contaminate with their peculiarly nauseous smell they do considerable damage by gnawing the binding of books, corks, etc., and sometimes damage clothes by depositing their eggcapsules amongst such, the fluid extruded with the eggs having an acrid effect which rots the cloth with which it comes into contact. The larger cockroaches may also be very unpleasant housemates by gnawing the hair and toes and sipping liquid refreshment from the lips of sleepers unprotected by a net. Borax mixed with thin syrup, or made into a paste with chocolate, is a good remedy a gainst cockroaches. 
Bedbugs and similar human parasites are included in the chapter on "Insects and Disease" and need not be further referred to here as they are not usually inmates of any well conducted bungalow. Should they gain a footing in a building, however, it is often difficult to get rid of them without fumigating the building or at least the affected portion.

Ants are often a nuisance in houses. If the nest can be found it may sometimes be destroyed by pouring in kerosine or any similar liquid and the holes then stopped up with solid crude oil emulsion or tar. Small ants may often be trapped in large numbers by laying down old sponges soaked in syrup (sugar and water or jaggery) and dropping these at frequent intervals into hot water, then rebaiting and putting them down again. Small ants may also be killed off by attracting them to tins with pierced covers containing a sponge or similar absorbent soaked with a sweetened arsenical mixture prepared by dissolving one-quarter ounce of Sodium Arsenite in hot water and adding it to a syrup composed of $5 \mathrm{lb}$. sugar and $\mathrm{I} / 2 \mathrm{lb}$. water previously heated for about three hours in a water-bath. The ants enter the tin through the holes and carry off the poisoned syrup to their nest, thereby poisoning the young brood, whilst the tin keeps domestic animals from eating the poisoned bait. Crude oil emulsion rubbed on to the legs of tables, etc., will keep ants from running up. The waterreceptacles often applied around legs of meat safes, etc., to keep ants away should have a little oil added to the water periodically to prevent mosquitos from breeding there.

Wasps and bees are often a source of annoyance in bungalows by filling up keyholes, etc., and by daubing mud-nests on to books, pictures, clothing or any suitable surface. A wasp or bee of this sort, which has once determined to make its nest in one particular place, is most persistent in returning even when its nest is destroyed and it is often difficult to dissuade it from its purpose without killing it. Social bees and wasps sometimes build inside houses and the smaller wasps (Polistes) which make hanging nests are generally quite inoffensive and very useful as destroyers of caterpillars, but the larger wasps and the Rock Bee may make a house uninhabitable and require drastic repression by burning at night or by fumigation. The big blue Carpenter Bee (Xylocopa) sometimes damages buildings by boring holes in beams but can generally be discouraged by the application of tar, crucle oil emulsion, or similar substance to the entrance of its burrow.

Termites, commonly but inaccurately called "White Ants," often do considerable damage in bungalows especially when these 
are unoccupied for a short period. Contrary to popular belief, there are several different species with entirely different habits, and those found in houses are not as a rule the same as those which throw up mounds outside. Some termites make their nest in the walls or under the foundation and these often do damage by running out mud galleries and eating matting, carpets, books and furniture. Other species make their nest wholly inside dead wood such as roof-beams which they excavate leaving only a thin exterior, so that an apparently substantial beam proves to be nothing but a shell of mud and dust. Termites in a building are usually difficult to deal with and no exact rules can be laid down because the habits differ in the different species; as a rule, however, it is necessary to destroy the nest and this is best clone by pumping poisonous fumes into the galleries. Crucle oil emulsion, Copper Sulphate solution, or similar repellents may sometimes prove of temporary assistance for protective purposes, but good construction in the first instance, and the creosoting or other protective soaking of all woodwork is the best guarantee against injury to buildings by these insects. A thorough soaking in Sodium Arsenite and subsequent painting over with coal tar will be found effectual for most constructional timber.

Crickets are often a nuisance by their shrill chirping and by their habit of biting holes in clothing. They may sometimes be trapped in tins or basins into which they jurnp during the night, but their omnivorous tastes make them difficult to destroy by poisons and it is not always easy to locate them exactly by their chirruping. However, they may often be dislodged in the daytime by moving furniture and hunted down and killed by hand.

Fish-insects do considerable damage to books, papers and pictures by gnawing holes in the paper. It is supposed that they extract nutriment from the size and in confinement they thrive on paper covered with a thin layer of flour-paste. Books kept in open shelves should be painted over at least once a year with Book Solution made by dissolving half-an-ounce each of Corrosive Sublimate and Carbolic Acid in one pint of methylated spirit; the liquid is a deadly poison and care should be taken not to get it on the hands; it should be painted with a long-handled brush over the outside and inside of the covers of the books and is an effectual preservative against all attacks of insects which would otherwise gnaw the binding. Books and papers kept in closed almirahs or boxes may be effectually preserved by keeping flake Naphthaline with them; Naphthaline evaporates fairly rapidly and requires renewal regularly, as it is of course merely a deterrent whose efficacy depends on the fact that it is volatilizing. To preserve pictures 
the best method is to paint over the back with Naphthaline Emulsion or simply to strew on powdered Naphthaline and then close the back of the frame tightly with tin to keep out the fish insects as far as possible. It must be remembered that the Naphthaline is volatile and will not last for ever. Book Solution painted carefully

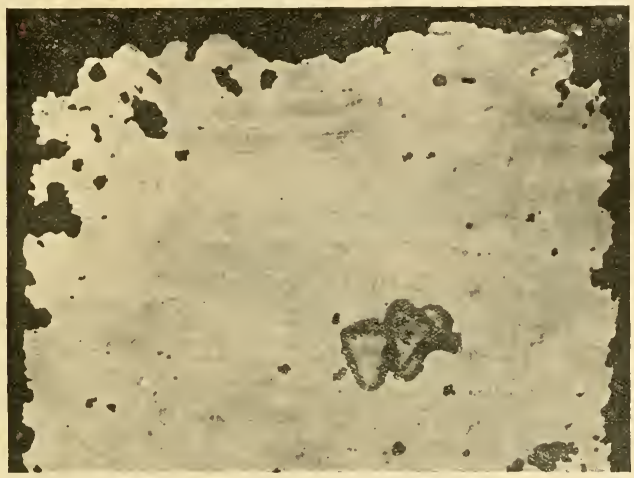

F1G. 75.-Paper eaten by Fish Insects. (From an original photo.)

around the blank edge of the picture before framing may give more permanent results, but care must be taken that the spirit does not run onto the painting itself or the colours may be altered.

Clothes-moths of several different species occur in Southern India, but the habits of all are very similar, the larvæ making little cases of fragments of wool and cloth in which they live. If flake Naphthaline is sprinkled libcrally amongst the clothes before they are put away, all danger of clothes-moths will be avoided; naphthaline balls should be broken up to give a larger surface for evaporation. After airing the clothes in the sun for a few hours all trace of the Naphthaline will disappear. To those to whom the smell of Naphthaline is objectionable camphor may be recommended, but this is more expensive and no more efficient. Trophies, such as heads of game, which are attacked by clothes-moths, may be painted over with a weak solution of Corrosive Sublimate in Alcohol, but it must be remembered that this is a deadly poison and care taken that it is only used for trophies which are hung up out of reach of domestic animals and children. 

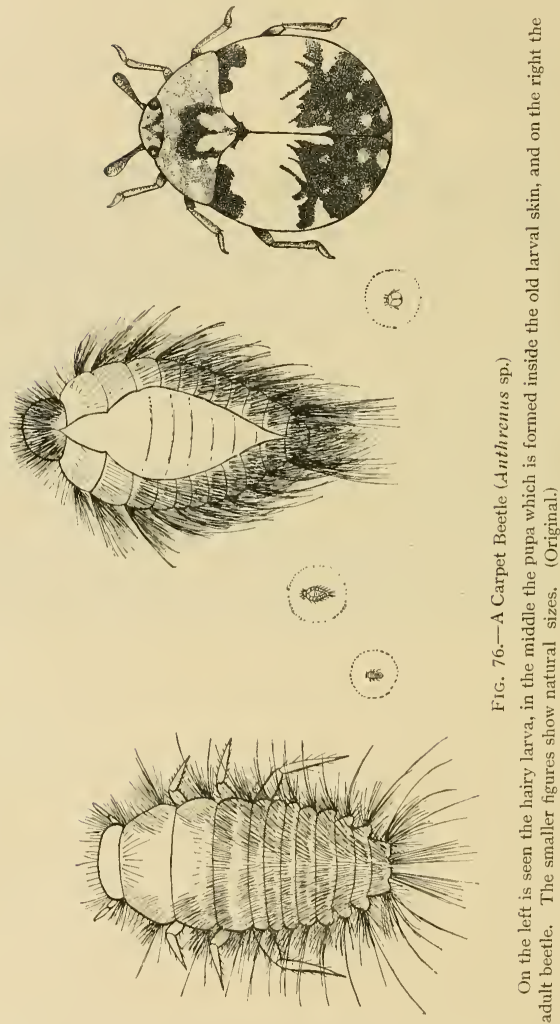

Carpet Beetles frequently attack not only carpets but also woollen clothes, blankets, baize linings of gun-cases and similar articles. When possible all such articles should be protected by a liberal supply of flake Naphthaline when they are put away. Articles in daily use are not attacked as a rule, but carpets may 
sometimes suffer. A liberal supply of flake Naphthaline (5 to I0 lb.) spread over them and left on for twenty-four hours with the room totally closed up (jalousies and all holes pasted over with paper) will often effect a cure and the Naphthaline may afterwards be swept up again and kept for future use; or the carpet may be taken up and fumigated in a tight box or room.

Beetles of various kinds often bore holes in furniture especially when this is made of cane. Painting on kerosine or almost any oil, or even soaking the affected parts in oil, is a simple cure. If a fumigation chamber is available the furniture may be fumigated by hydrocyanic acid gas or carbon bisulphide.
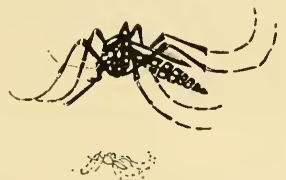

Fig. 77.-Stegomyia fasciata, a common Household Mosquito. (After Goeldi in Brumpt.)

Eye-flies, Sand-flies and Mosquitos are not essentially household pests although they often cause great annoyance in houses. As the breeding-habits of Eye-flies are as yet unknown, we can only deal with the adult insects; these are in the habit of settling gregariously on some hanging support-a cobweb, lamp-hook, piece of string, rope, or straw, etc.--and may be marked down and slain wholesale after nightfall by burning them off with a torch. Sandflies pass their early stages in dark, damp (not wet) places containing decaying organic matter, and it is very difficult as a rule to discover where they are coming from. To reduce the number of Sand-flies in a house all rooms should be kept as free as possible from any dark places for them to rest in during the daytime (e.g., behind pictures, almirahs, writing-tables, hanging clothes, etc.), and all dark corners should be sprayed daily with a weak (about one per cent.) solution of formalin. It is a good plan to paint the backs of almirahs, writing-tables and the under sides of tables, etc., with white paint, or simply to whitewash them, to recluce any dark corners in which Sand-flies and Mosquitos rest during the daytime.

The use of a small hand-net is a simple and efficacious method for reducing mosquitos in a house where this is not fitted-as all Indian bungalows should be-with mosquito-proof screens. It is, however, as a rule much better to attack them in their breedingplaces, which will always be found to be collections of water in or 
near the bungalow. All wells in the compound should be screened over and fitted with a pump, and the mali's water-tanks should be oiled at least weekly. All old tins, jars, bottles, coconut husks or similar articles which may hold water and breed mosquitos should be rigorously cleared away and all holes in trees, cut bamboostumps, etc., should be filled in with plaster or mud. Leaves of aloes and similar plants often hold water in wet weather and breed mosquitos; a small drainage-hole cut in the leaf will usually suffice to prevent this. The saucers beneath flower-pots and watercoolers, the water-dishes beneath legs of tables and meat-safes, and the earthen water-jars on which ferns are often grown, will all be found to be frequent breeding places for mosquitos, which will breed freely in the smallest collection of water. Flower-vases which are not properly emptied and cleaned before refilling are often full of "wrigglers" which are the early stages of mosquitos. 


\section{Chapter XX.}

INSECTS AND DISEASE.

"Ring out old shapes of foul disease."

TenNysox-In Memoriam.

"As when a swarme of gnats at erentide

Out of the fennes of Allan doe arise,

Their murmuring small trumpets sownden wide, Whiles in the air their clust'ring army flies,

That as a cloud doth seem to dim the skies :

Ne man nor beast may rest or take repast

For their sharp wounds and noyous injuries.

Till the fierce northern wind with blust'ring blast

Doth blow them quite away, and in the ocean cast."

\section{SPENSER-Facry Quccu.}

TWENTY or more years ago a man who seriously devoted his time to the study of insects such as mosquitos would have been regarded almost universally as a trifler who was wasting his time with little benefit to himself and none at all to anyone else. At the present time no one with any pretensions to possession of medical or sanitary knowledge can afford to disregard the study of this group of apparently insignificant insects. The extension of their study in India alone may be gauged roughly by comparison of these two facts, that twenty years ago only four different species of mosquitos were known to occur in the Indian Region whereas to-day we know of upwards of two hundred different kinds and have at our disposal elaborate monographs regarding their structure, lifehistories and habits, whilst every year sees the issue of more comprehensive and detailed publications on these insects and others of a similar importance. It is not because of their intrinsic beauty or commercial value that such a cult has suddenly arisen but solely on account of the recognition of the fact that certain mosquitos are responsible for the occurrence in man of various diseases, of which malaria is to-day probably the most important in India. As its name implies, malaria was for long supposed to be due directly to the inhalation of poisonous exudations from marshy places, but it is now certain, as the result of prolonged and careful experiments, that the real connection of marshy places and malaria is that pools and other collections of water serve as breeding-grounds for certain kinds of mosquitos which carry the malarial parasite.

It is not too much to say that the discovery of the fact-for it is no longer a mere theory-of the transmission of diseases by the 
agency of insects has thrown an entirely new light on the study of Tropical Medicine which bids fair to become to a very large extent merely one branch of Applied Entomology. The modern systems of treatment of Tropical Diseases tend more and more to resolve themselves into the control of the insects which act as transmitters of these diseases. In most cases (e.g., Malaria, Yellow Fever, Filariasis, Nagana, Surra, etc.) the problem becomes an entomological one. In the first stages of the investigation of such a disease, in considering the species of insect which is likely to prove the transmitting agent, it is primarily the entomologist who, from his knowledge of the insects found under the necessary conditions, is likely to be best able to indicate the species to be suspected and investigated. Later on, when this investigation is being carried out, it is again the entomologist who knows where to look for such an insect and how to capture it and who has the best knowledge of methods of breeding it and what are its natural enemies and the conclitions favourable or otherwise to its occurrence. Finally, when the investigations have been crowned with success and a definite relationship established between a particular insect and a disease, the control of the disease is often attained most simply by the control of the insect and this again falls primarily into the province of Entomology.

To cite a specific instance, the case of Malaria may be considered briefly. The term malaria is used to cover three distinct specific fevers, quartan, tertian and subtertian malaria, caused by invasion of the blood of man by three different protozoan parasites which are called respectively Plasmodium malaria, $P l$. vivax, and Laverania malaria, the attack of the first two causing a comparatively mild type of malaria, that of the last-named usually giving rise to a severe form of infection. These parasites, which are not known to occur in any other vertebrate animal, are introcluced into the blood of man by the bite of an infected Anopheline mosquito and may either ( $\mathrm{I}$ ) be killed off by the blood on entry into the body or (2) remain dormant in the spleen and develop later on when opportunity is offered by any diminution of vitality on the part of the subject attacked, as by a chill, or (3) develop forthwith and give rise to an attack of malaria. In the last case, it generally takes about nine to twelve days for the parasites to increase sufficiently to be able to produce sufficient toxic (poisonous) substances to give rise to fever. Plasmodinm malarice (the parasite of quartan malaria) and $P$. vinux (the cause of tertian malaria) go through their developmental stages in the circulating blood, whilst Laverania malario (the parasite causing subtertian malaria) sporulates to a 
large extent in the internal organs. The number of days between attacks of "fever" depends, of course, upon the fact of whether the infection took place at one time or on successive days; in a case of simple infection by quartan malaria, for example, the attacks recur after every seventy-two hours (the period of time which the parasite takes to complete its life-cycle in the human bociy), but if infection occurred on two successive nights the patient develops fever on two successive days, because the parasites are of different ages and each lot takes seventy-two hours to complete its life-cycle, and remains free from fever on the third day of each period of three days. Tertian malaria, characterized in simple cases by a recurrence of the attack every forty-eight hours, is the commonest and most widely-distributed form; the interval without feverish symptoms is about thirty-six hours. Subtertian malaria is usually very prolonged and severe; the incubation period, i.e., the interval between first infection and first attack of fever, is 9-10 days; the duration of each attack is twenty-four hours or more, the interval between attacks twenty-four hours or less according to the prolongation of the attack. Chronic malaria is usually caused by infection with the subtertian parasite and is accompanied by repeated slight attacks of fever, enlargement of the spleen and liver and pigmentation of the skin and mucous membranes.

The treatment of malaria cannot be entered into here but, on the principle of prevention being better than cure, we may note briefly that the lessening of (I) the Anopheline mosquitos and (2) their capacity to bite man in any locality must help to reduce the total number of cases infected or reinfected. Draining and oiling of pools and the introduction of larvivorous fish into them, the screening of wells, the prevention of standing water near houses and various other methods, will all help to prevent the mosquitos from breeding, whilst the use of mosquito-proof houses or rooms and nets and the application of repellents will considerably reduce the chance of being bitten and infected even when malaria-carrying mosquitos are prevalent. The use of quinine as a preventive, to kill off any malarial parasites which may obtain access into the body in spite of other precautions, is also an obvious measure to take as a matter of routine when in a "feverish" locality.

The number of deaths due to malaria every year is officially estimated at one million for the whole of India. I have no information regarding the annual mortality from this cause in Southern India but it may be placel at 100,000 on a conservative estimate. The mere money loss to the State may be imagined rather than calculated when it is remembered that, in addition to the actual mortality, the productive capacity of nillions of the population is 
very seriously impaired by this one disease which, it may be emphasized, is entirely carried by insects. It is not every kind of mosquito that is able to carry the malarial parasites from one man to another. There is now a large mass of evidence on the subject and, so far as is known at present, only certain species of the Anopheline group of mosquitos are implicated in the transmission; broadly speaking, they all belong to the genus Anopheles although this has been split up into numerous small groups (Myzomyia, Nyssorhynchus, etc.) on trivial characters which would rarely be recognised as of generic importance in any other group of insects. The early stages of all the species of Anopheles, as in the case of other mosquitos, are passed in water in which the whole life-cycle is passed except in the adult stage. The eggs are usually deposited singly, whereas in ordinary mosquitos (Culicines) they are often cemented together to form little rafts which float on the surface of the water; the larvæ are often found in slowly-running streams and are generally recognisable by their habit of resting just below and parallel with the surface-film of the water, whilst on the contrary Culicine larvæ usually hang down at a considerable angle with the water-surface.

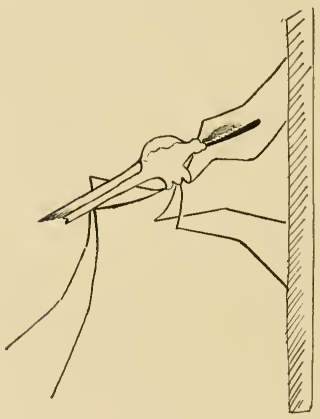

FiG. 78.-Resting attitude of Anopheline Mosquito. (Original.)

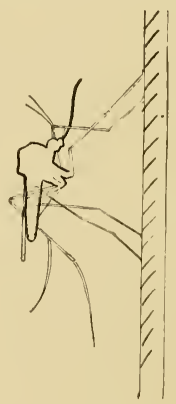

F1G. 79.--Resting attitude of Culicine Mosquito. (Original.)

Both types are air-breathers and usually obtain their air-supply by thrusting their delicate breathing tubes through the water-film into the atmosphere; hence the applicability of oiling the surfaces of infected accumulations of water, as the oil spreads ont over the surface as a thin film and clogs the breathing tubes of the larvæ and so suffocates them. The adult Anopheline mosquitos are 
recognisable as a rule by their spotted wings, long narrow abdomen, long palpi, and especially by their characteristic attitude when at rest, when the head and body are held in an approximately straight line, the head held down towards the resting-surface and body held well away at a considerable angle from the resting-surface. ${ }^{*}$ The Culicine mosquitos, on the contrary, may usually be distinguished by their unspotted wings, short thick abdomen, short palpi and resting attitude in which the head is bent down but the abdomen held parallel with the resting surface, so that the head and body are not held in one plane.

The following list includes most of the Anopheline mosquitos known to occur in Southern India, those which have been incriminated as malaria-carriers under natural conditions being marked with a, * those capable of infecting man with Filariabancrofti being marked $\ddagger$ :-

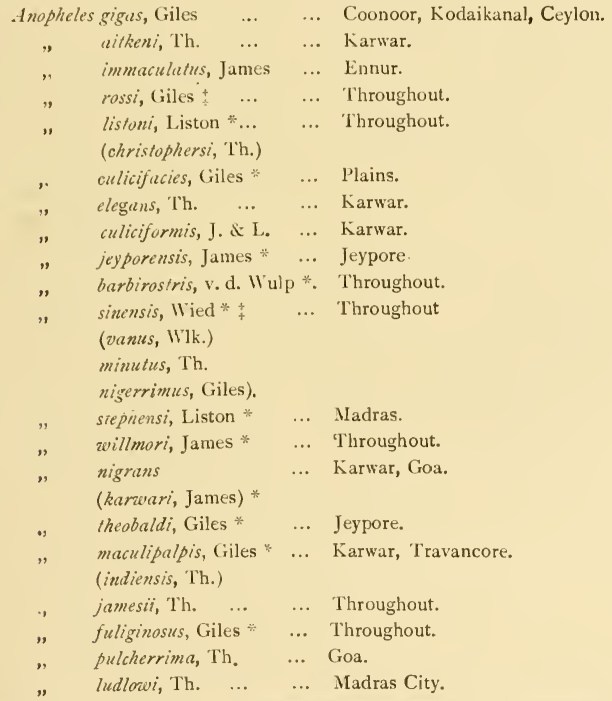

- Anopheles culicifacics, however, is an exception and rests like a Culicine with its abdomen held parallel with the resting surface. 
Here it may be as well to point out that there is a definite relationship between the malarial parasites and $(a)$ the transmitting mosquito and (b) the human host and that in each of these the parasite passes through a distinct portion of its development. Briefly speaking, a malarial parasite in the human body occurs as a pale amoboid organism in the red blood corpuscles, at whose expense it grows and which it destroys and then sporulates, or breaks up into many spores or little organisms (merozoites) which are liberated in the blood, where they may be destroyed by the white corpuscles (leucocytes) or may invade other red corpuscles and develop as before, destroying the red corpuscles and producing the pallid (anæmic) condition seen in sufferers from malaria. Besides the asexual merozoites, sexual forms of the parasite are produced

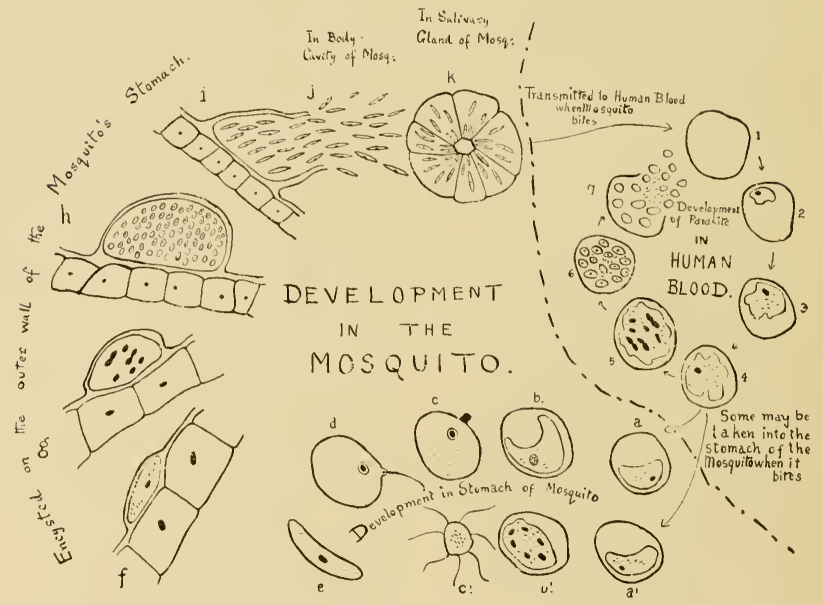

FiG. 80.-Life-cycle of Malarial Parasite. (After Doane.)

after some time and may be sucked up with the blood into the stomach of a mosquito which now bites the malarial patient. After fertilisation, the female cell penetrates the wall of the stomach of the mosquito and becomes a resting cell or cyst (oocyst) which grows and divides ultimately into spindle-shaped motile organisms 
(sporozoites) which make their way into the body-cavity of the mosquito and thence to the salivary glands whence they may be carried with the salivary fluid into the body of a human being bitten by the mosquito. The period occupied by the development of the parasite in the mosquito is from eight to twelve days or more, whence it follows that a mosquito which has become infected by biting a malarial patient is not itself infective and cannot transmit the parasite until after this interval of time, which is practically not before the tenth night after having ingested the parasite. But, after this, one infected mosquito may bite and infect more than one subject during the rest of its life.

In comparison with the above method of infection may be noted the case of a House-fly which first settles and feeds on excrementitious matter contaminated with the "germs" of Typhoid Fever and then flies into a house and crawls over food which it infects with the germs carried on its feet and in its alimentary canal, with the result that those eating the food afterwards ingest the germs and may develop Typhoid Fever. In this case the fly carries the infection only more or less casually and the parasite does not undergo any special cycle of development on or in the carrier nor is the parasite entirely dependent on the fly as a means of access into the human body, as it may also be carried by eating or drinking food which has been contaminated directly.

It is convenient to differentiate between these two classes, that is, cases in which the parasite causing the disease in man or animals is intimately adapted to the insect-carrier in which it undergoes part of its life-cycle, and cases in which the parasite is merely carried more or less mechanically by the insect-carrier from one host to another. In the former case the insect-carrier is a true or adapted carrier, in the latter case it is a more or less casual porter. It will readily be understood how easily a blood-living parasite may be carried directly from one host to another by transfer on the mouthparts of a blood-sucking insect which is disturbed from one host and at once proceeds to bite another of the same kind of animal. The term "Miastor" (Greek miastor, a carrier of pollution) has been proposed by Alcock as a term applicable to insects which by mainly mechanical means spread abroad any kind of hardy pathogenic "germs," under which term we may include not only bacteria but organisms such as eggs of intestinal worms.

Besides the carriage of pathogenic parasites to man and beast many insects and similar animals may cause direct annoyance or damage by their bites, stings, poisonous hairs or spines or similar means, or by direct invasion of the tissues of the body. The irritation caused by the bites of blood-sucking insects, such as 
mosquitos, fleas and bed-bugs, is perhaps hardly to be classed as a disease, but it is often a serious source of annoyance, and abrasion of the skin due to scratching or rubbing such bites may give entrance to germs and thus set up blood-poisoning. The irritation caused by such bites varies considerably in individuals and as regards the bites of different classes of insects. In the case of mosquito-bites the resultant irritation is usually most pronounced in the case of new-comers into the tropics, a partial tolerance being acquired as a rule after a more or less brief period of residence, but the immunity acquired against the bites in one locality is not always effectual in another. Some people appear to be naturally or partially immune from the irritant effects of bites, while others never become so. The irritation is caused by a liquid injected, before the mosquito actually commences to suck blood, not from the salivary glands as would be expected, but from the osophageal diverticula which Schaudinn has shown to contain bubbles of Carbon Dioxide and bacteria or moulcls. Besides the irritation caused by single bites of insects and their individual attacks on man and animals it is often necessary to consider the serious effects wrought by the combined effects of these attacks. Such a combined effect is called "mass infection " and its results, by mere loss of blood and irritation, may cause very serious effects on the health of the host even in the absence of infection by pathogenic organisms.

It is impossible within the limits of a single chapter to attempt any adequate description of the organisms which are the true causes of many diseases or the insects which carry them to man and animals, but a short account of a few of the more important of such insects will be found further on (see pages $346-367,486-487$, $521-524)$. But before discussing the diseases, it may be as well to give here a short account of some of the non-hexapod carriers.

Ticks are distinguished from Hexapods by possessing four pairs of legs in the adult state, although the newly-hatched inmature tick has only three pairs of legs but subsequently develops the fourth (posterior) pair. Ticks belong to the group Acarina, which also includes Mites and these latter are probably important as disease-carriers also, although at present they have been little studied and very little is known about them-indeed, practically nothing in Inclia.

The true Ticks form the superfamily Ixodoidea, subdivided into the families Argasidæ and Ixodidæ. The feeding-habits, which are very important from a control view-point, are very varied in the different groups; in some the tick remains attached to the host, whilst in others it merely gorges itseif with blood and then drops off and hicles until it again requires to feed. In different groups of 
Ticks the following distinct cycles of habits may occur:- (a) all stages drop off the host to moult and the female also drops off to lay her eggs, $(b)$ the larvæ do not drop off but remain attached and moult on the host, the nymph dropping off and also the females for oviposition, (c) both larvæ and nymphs remain attached to the host throughout all their stages, only dropping off as replete femates. A knowledge of the actual life-cycle of the particular species concerned is of the first importance in devising measures for the control of that species. Some ticks can live for years without a meal.

The Blister Beetles (Meloidæ or Cantharidæ) neither suck blood nor actually invade the tissues, but in many places various species are strongly attracted by lights at night and fly into houses. The liquid exucled from the joints of the legs can raise large and painful blisters if it touches the tender human skin-a fact which is well known to most residents in Southern India.

Lice of various kinds infest most domestic and wild animals. Human lice are treated more fully further on but it may be useful to give here a list of the lice found most commonly in Southern India ; they are:--

On pig, Hamatopinus suis, L., var, adventicius, Neumann.

" goat, $\quad$ stenopsis, Burm.
" calf, $\quad$ vituli, L.
" buffalo, "
", monkey, Pclicinus curygaster, Gerv.

Besides these, Hamatopinus spinulosus, Burm., is found on rats (Mus decumanus, $M$. alexandrinus and $M$. sylvaticus) and acts as the transmitter of Trypanosoma lewisi from rat to rat, whilst $H$. stephensi, Christ. and Newst., is found on the Indian Jumping Rat or Gerbille (Tatera indica) and probably transmits a hæmogregarine (Hamogregarina gerbilli) commonly found in the blood of this animal. All lice must be looked on with suspicion as possible or probable vectors of disease from one animal host to another.

The animals which actually invade the tissues belong as a rule to two groups, the mites and flies, the diseases which they cause being known respectively under the general terms of Acariases (i.c., Diseases due to Acari, or mites) and Myiases (Diseases due to flies, Greek myia, a fly). Of the true mites occurring in India very little is known, but a few attack man and domestic animals; sulphur ointment provides the best treatment as a rule. Scabies or itch is caused by a tiny mite, Surcoples scabici, which burrows in the skin; very similar forms occur on the horse in which they sometimes cause a form of mange due to the rubbing off of the hair by the 
animal owing to the irritation caused. "Coolie itch," a disease commonly found in the feet of Indian coolies, is caused by Rhizoglyplus parasiticus, whilst Demodex folliculorum, a peculiar elongate eight-legged mite, is found commonly in the sebaceous glands of the human face; this latter species, however, is of doubtful importance as a pathogenic agent. Pediculoides ventricosus occurs as a rule in cereals in India but sometimes (.$g$. ., when infested straw is used to stuff mattresses, etc.) it attacks man and causes severe urticaria; much the same may be said of Tyroglyphus longior var. iastellanii, which normally occurs in large numbers in copra and produces "copra itch" by invasion of the skin of those handling this substance.

Acariases usually cause more or less temporary annoyance but an attack of myiasis may produce very severe and even fatal results. The attack of the fly may be more or less casual, eggs being deposited on the raw surfaces of wounds or sores, or even taken into the intestine with food, or the fly may normally exist by feeding on living animal tissues during its immature stages. To the former category belong cases such as those of the "cheese hopper," the larva of a fly (Piophila casci) whose immature stages may be ingested with food and cause intestinal myiasis, and various " bluebottle" and other flies which sometimes cause external myiasis in man by infesting ulcers and especially syphilitic erosions of the nose. Rhinal myiasis, or the invasion of the nasal cavities, etc., by the larvæ of muscid flies, is indeed probably the most common form of myiasis affecting man in India. Many of the brilliantlycoloured green "blue-bottle" flies (Pycnosoma, Lucilia, etc.) seen commonly on excrement are attracted by any purulent discharge from the mucous membrane of the nasal cavity and readily deposit eggs (or even living larvæ) on such membrane whilst the subject is asleep in the daytime when the flies are active. Sarcophaga ruficollis has also been recorded as causing human myiasis in India. The larvæ bore into the soft parts and even into the bone and may cause very grave injury or death. Such flies may, and commonly do, deposit eggs or larvæ in neglected sores or wounds in cattle. Such wounds should therefore always be kept dressed with tar or grease to repel the flies. There are, however, some flies which belong to the second category noted above and of these the commonest in Southern India is probably Estrus ovis, whose larva lives in the frontal sinus of the sheep, and these animals may often be seen huddled together or holding their noses in the dust in an endeavour to avoid the attack of a fly which is trying to oviposit in their nostrils. The Jigger or Chigoe (Dermatopliilus penetrans), a flea which usually affects the feet in man, burrowing into the skin 
especially under the toe-nails) and in bad cases causing extensive sores or even permanent crippling, was probably originally a native of South America, whence it was carried to West Africa and thence to East Africa, and was brought to India in I 899 but has apparently not spread beyond Bombay; however, it is quite likely to be brought in at any time by returned Indian emigrants and to get a footing in sandy places.

Returning now to the diseases caused directly in man by pathogenic organisms carried by insects we have already seen how malaria is carried by Anopheline mosquitos and may now proceed to notice briefly some of the other diseases known to be insectborne:-

Relapsing Feiter is caused by Spiroschandinnia carteri, Manson, but it is possible that several distinct forms of disease may be confused under the one term. The Head-louse (Pcdiculus capitis) is probably one carrier, but bed-bugs and mosquitos are not wholly free from suspicion.

Indian Kala Azar, caused by Lcishmania donovani, is endemic in Madras and is perhaps carried by bed-bugs, possibly by Conorlinus rubrofasciutus.

Pappataci Fever, Tliree days' Fover, or Sandfly Fear is an acute fever, lasting three days, whose actual cause is unknown but the infection is carried by sandflies (Phlchotomus spp), the blood of the patient being infective up to the end of the second day of the fever.

Dcuguc, an acute fever whose cause is also unknown, is occasionally epidemic and is supposed to be carried by Culcr fatigans.

Yellew Fever is not as yet known in India but it is important to note that its carrier (Stcgomyia fasciata) occurs commonly in India and that the infection can be carried by the eggs of an infected mosquito.

Plaguc, caused by Bacillus pestis, is a disease of rats from which it spreads to man by the agency of fleas which desert the dead rats and bite man incidentally carrying the infection. In I896 it spread from China to Bombay, whence it has extended almost allover India. It is commonly spread by Xcnopsylla cheopis, because this is the commonest flea found on rats, but may also be carried by other fleas, such as Ccratophyllus fasciatus and Pulcx irritans (the Human flea); it has also been transmitted experimentally from man to rat by the Indian bed-bug (Clinocoris hemipterus). Plague has unfortunately made itself too well known in Madras, the Fort St. Gcorgc Gazctte of 20th May 1913 giving the number of Plague seizures in Madras only from August I898 to I7th May I9I3 as I26,654 whilst the deaths in this period totalled 98,398 . 
Enteric Fever is a term generally used to include Typhoid Fever and two Paratyphoid Fevers. It is commonly carried by House-flies and sometimes also by Drosophila, a small fly which is equally at home on excrement and on ripe fruit. Enteric fever may of course be carried by milk, water, ice, fish, etc., which easily become contaminated directly, but the agency of flies in carrying germs on their feet or in their intestines, from infected excrement on to food (especially milk) is usually much under-rated. In this connection it is noteworthy that Europeans are most liable to enteric in the dry season when the infection is carried on to food by dust and flies, and Natives in the monsoon owing to the pollution of watersupplies by surface drainage.

Filuriasis, in its commonest form of Elephantiasis, is caused by a minute Nemathelminth worm, Filaria bancrofti, which is carried by various mosquitos (e.g., Culex fatigans, Mansonia uniformis, and the Anophelines marked* in the list on page $18 \mathrm{I}$ ), and which when in numbers blocks the lymphatic vessels of the body.

Leprosy is perhaps insect-borne although the exact means of transmission is as yet unknown.

Yaws or Frambasia tropica, caused by Treponema pertenue, is very common in Ceylon but apparently rarer in India. It is probably carried by flies sucking the open sores of patients and carrying the infective organisms to ordinary ulcers or sores which are thereby infected.

Epidemic Dropsy has occurred in Southern India as an epidemic, especially in $1876-77$ when there was a great famine. The exact cause is unknown but it is suspected to be an organism spread by bed-bugs.

Cholera is usually carried by water, milk, fruit, etc., which may be contaminated directly by flies which have previously visited the discharges of cholera patients.

Dysenteries, caused by various organisms, are also due to infection of the intestinal tract with drinking-water, milk, green vegetables, etc., which have been contaminated either directly or by means of flies or similar insects.

Guinea-Worm is the infection of man with Dracunculus modinensis, a Nemathelminth worm which passes the first portion of its life-cycle in the body of Cyclops, a minute crustaccan which is commonly called a "water-flea." If an infected Cyclops is swallowed with drinking-water it is killed in the stomach but the contained worm is liberated and makes its way into the tissues of its new host. The individuals of Cyclops mostly live near the bottoms of wells and pools and are therefore most 
likely to be dipped up during the dry season when the water-level is low.

Oricntal Sore, otherwise called "Delhi boil" and known under various other local names, is a disease found in North-western India, not South of Cambay nor East of Delhi. According to Patton's investigations, it is not communicable by species of Musca or by blood-sucking flies, but is apparently carried only oy immature bed-bugs and by them only when the temperature is below $25^{\circ} \mathrm{C}$. It is thus only carried in the cold weather, developing two or three months later on. Cases of this disease seen in Madras are usually the result of infection further north but the disease has occasionally been introduced and spread in the colder climates of Hill Stations in Southern India (c.g., Bangalore). Tropical Ulcer is also carried similarly by insects and perhaps by leeches.

Conjunctivitis of the eye, usually caused by a Bacillus, is undoubtedly spread to a large extent by means of Eye-flies (Siphonella funicola).

The diseases of domestic animals carried by means of insects are on the whole very similar to those found in man and caused by pathogenic organisms which are carried by similar kinds of insects, but usually both organism and carrier are specifically distinct and peculiar to each particular host.

Trypanosomiases, or diseases caused by infection by minute Protozoa called Trypanosomes, have acquired notoriety by including the two African diseases, Sleeping Sickness and Nagana or Tsetse-fly disease, the former of which attacks man in West Africa, Uganda and Rhodesia, whilst the latter is fatal to the horse, ass and dog. In some parts of India and Burma "Surra," a disease caused by Trypanosoma cvansi, attacks horses, mules, camels and cattle, and is carried by Tabamus and probably other biting flies; later researches, however, seem to show that this Trypanosome may be spread by hæmatophagous muscid flies which are unable to puncture the skin of an animal by themselves but which suck up the blood exuding from the bite inflicted by flies such as Philamatomyia. 7rypanosoma theileri is only known to occur in cattle but is apparently non-pathogenic ; it occurs in South Africa, Transcaucasia and India and is spread by the bite of the cattle fly (Hippobosca). Rats in India and Ceylon are commonly attacked by Trypanosoma lewisi, another non-pathogenic organism, which is probably carried from one host to a nother by the rat-louse and rat-flea. In Madras the striped palm squirrel (Funambulns palmarum, L.) harbours Trypanosoma indica, which is apparently very closely related to $T$. lewisi of the rat. The bandicoot rat (Nesokia bandicotti) is the host of Trypanosomabandicotti, 
which is pathogenic to guinea-pigs, but apparently little known, whilst $T$. vespertilionis is found in various bats. Even reptiles are not exempt from attack by these parasites, for Tryp. vittata is found in the pond tortoise (Emyda vittata), being carried from host to host by a leech, and the common pond snake (Tropidonotus piscator) is attacked by Tryp. primcti. At least two trypanosomes also are known to occur in common wall-lizards or Geckos. The importance of the parasites of this group warrants all necessary precautions for keeping diseases such as Sleeping Sickness and Nagana out of India, although the particular biting flies (Glossina sDD.), which carry these diseases in Africa, are not known to occur in India. By no means an uncommon disease of dogs in the tropics is malignant jaundice, caused by a minute protozoalorganism (Babesia or Piroplasma camis) which is carried by the common Dog-Tick (Rhipicephalus sanguincus). Another similar parasite which has earned a certain notoriety in Madras by its effects on jackal-hounds is Piroplasma gibsoni, which causes intense anæmia and enlargement of the spleen and liver. Slackness of the hound in cover and inability to keep her usual place in the field when the pack is running are the first symptoms noticeable to the huntsman and these are soon followed by rapid loss of condition. This parasite is common in the blood of the jackal and is transmitted by ticks. It is also possible that rabies may occasionally be spread amongst dogs by the agency of biting flies but this is probably an unimportant method of dispersal.

The various forms of Anthrax are sometimes spread amongst cattle, and occasionally carried to man, by the agency of biting flies and it seems obvious, especially in a country such as India, where the agriculture and hence the very livelihoor of the whole people depends on cattle, that every effort should be made to investigate the subject of the transmission of disease amongst cattle by biting flies and other blood-sucking insects. Yet very little appears to be on record either as regards the diseases or the insects by which they are or may be transmitted. There are few if any countries in the world in which the subject of Veterinary Entomology and Protozoology would better repay research than in India, but hitherto investigators have confined their attention almost wholly to the subject of human diseases and there is a vast field for exploration as regards the diseases of donesticated aninuls in the tropics.

It may be useful to give a summary of the principal diseases of man and animals which are known to be carried by insects in India. This list is exclusive of diseases (Scabies, Myiases, etc.), caused directly by insects. 


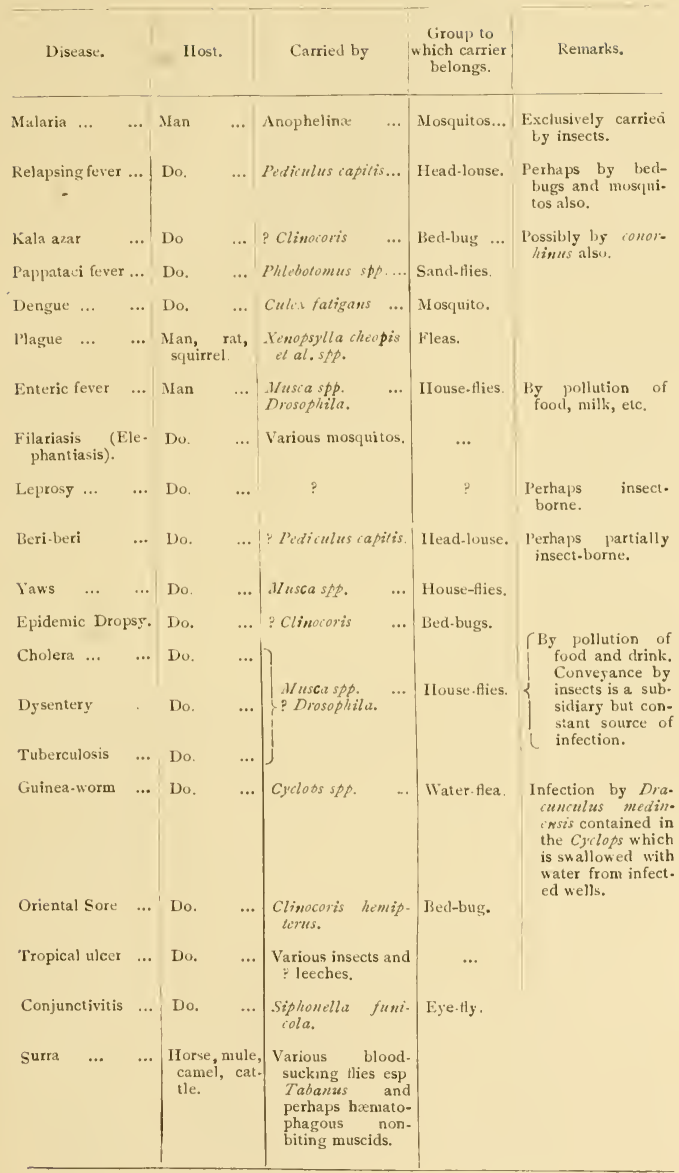




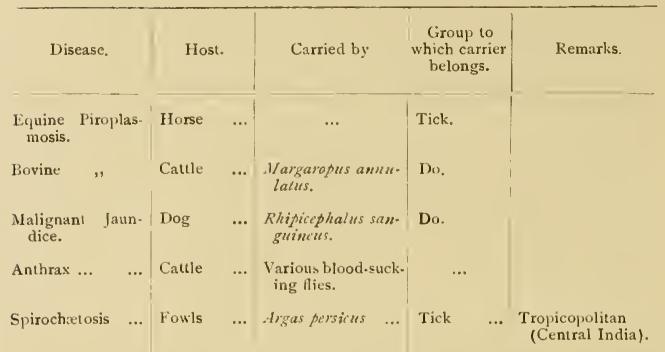

It will be readily seen by merely casual inspection of the foregoing list that many of the most serious diseases are carried by insects, of which house-flies, mosquitos and bed-bugs are probably the most noxious to man. It is not within the scope of this book to enter into the treatment of the various insect-borne diseases but, on the principle that "prevention is better than cure," the following recommendations may be added:-

(i) Avoid the bites of all blood-sucking insects as far as possible. Mosquito- and fly-proof rooms should be as necessary adjuncts of an Indian bungalow as verandahs, but are rarely seen. The use of mosquito-boots in the evening and invariable use of mosquito-nets at night will, however, largely help to reduce risk of infection. It is unfortunately often the case that the new arrival in the tropics is looked down on with scorn simply because he is naturally at first intolerant of the many insect-plagues of every day life and that many dispense with mosquito-nets and such safeguards from an ignorance which passes for bravado. When travelling it may sometimes be impossible to sleep under a net and in such circumstances a supply of some repellent, such as mosquito-oil, should always be carried and used.

(ii) A little systematic attention to the sanitary conditions of the bungalow, outbuildings and compound will usually bring about a vast reduction in disease-carrying insects. A Sunday morning round of inspection will often reveal a hitherto unsuspected accumulation of old tins and other receptacles for water lying about the compound, flower-pots, water-cans, hollow trees, cut bamboo-stumps, etc., all merrily breeding mosquitos, whilst the hordes of flies invading the bungalow and kitchen may be traced to the manure thrown down outside the stable and perhaps also to a pile of kitchen-refuse. A very little regular attention to such details will work wonders. 
(iii) Avoid eating any uncooked vegetables and make sure that all milk and drinking-water is invariably boiled as a matter of routine and thereafter kept protected from flies.

(iv) Ordinarily cleanly persons do not suffer from attack by bed-bugs, lice, etc., as a rule, but it is not always possible to avoid such when travelling. When in camp and after returning from camp therefore, it is not a bad plan to have all bedding spread out for a few hours in the blazing sun on a bare patch of ground.

It is simply not worth while to risk infection by insect-borne diseases when a very little care and common-sense will go a long way to avoid such risk. 


\section{Chapter XXI.}

\section{BENEFICIAL INSECTS.}

"The first step towards vanquishing an enemy is to ascertain currectly is habits; the next to be so certain of his appearance as not to mistake one party for another ; and a third and no less important object is to be well acquainted with our allies and friends.".

CURTIS-Farm Insects.

AFTER bitter experience of the ravages of insect-pests amongst his crops the cultivator is apt to come to the conclusion that his only safety lies in the prompt destruction of every form of insectlife wherever met with. But indiscriminate slaughter of this sort will do almost as much harm as good for it will result in the clestruction not only of pests but of the innumerable insects of all kinds which help to keep the pests in some control. For, as already pointed out (chapters VIII-X), the possible rate of increase of any insect, in the absence of enemies, is so enormous that in the short space of a few months its numbers would be so vast as to devour every scrap of its foodplant in any given district.

The insect enemies of crop pests, which keep these latter within bounds, may be called the farmer's friends, and indeed they are more than this - they are indispensable allies. Insects of this class are generally divided into predators and parasites, predators being animals which are predaceous on others, i.e., which devour other animals which they capture, whilst parasites have already been defined as organisms which live at the expense and to the detriment of other organisms. The distinction between these two groups is not always very sharply defined but in practice it is convenient to keep the two classes distinct. Perhaps the difference may be brought out more clearly by the introduction of a time factor, in which case we may say that predators devour their prey forthwith whilst parasites devour it slowly and gradually and may not always kill it. A beetle or bug which catches a caterpillar and feeds on it forthwith is a predator; a fly which lays its eggs in the caterpillar, in and on which the fly's grubs feed at leisure, is a parasite. Parasites may be considered under various headings (hyperparasites, superparasites, etc.), as already indicated in chapter VIII.

Predaceous insects occur in almost all groups, many insects feeding entirely on others and some which feed normally on dead animal or vegetable matter occasionally devouring living prey ; 
cockroaches, for example, have often been observed to catch and eat winged termites when these swarm out of the nest. Earwigs also are generally rather mixed feeders of the scavenger type but are often found to be predators and are sometimes important checks on the breeding of flies in rubbish-heaps. Ants again as a whole are decidedly mixed feeders, usually eating dead vegetable matter and subsisting largely on the sugary "honey-dew " excreted by various sucking insects (Aphids, Membracids, Coccids, etc.), but observation of a string of ants (e.g., Ecophylla smaragdina, the Red Tree-ant) returning to the nest will reveal abundant spoil brought in by foragers in the shape of small flies, beetles and caterpillars.

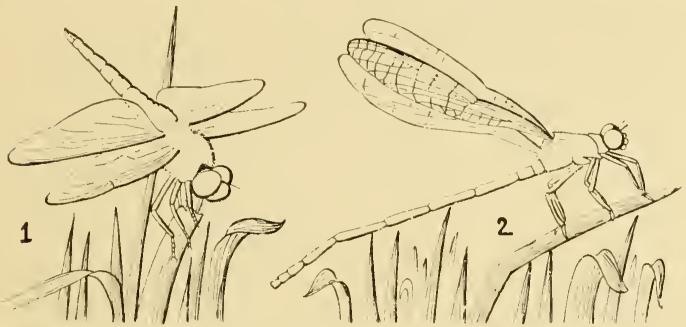

F1G. 81.-Dragonflies; (1) Eshnine and (2) Agrionine. (After Lefroy.)

The Odonata, or Dragonflies, are exclusively insectviorous, hawking small insects on the wing, and also leading an entirely predaceous aquatic existence in their early stages. It is often very difficult to make out exactly what dragonflies are catching even when their numbers and actions leave no doubt that they are actually capturing small insects, and as a rule these latter probably consist of minute midges, winged ants, etc. In cases where winged ants and termites have been flying in numbers out of a nest, I have often seen a swarm of dragonflies hawking backwards and forwards overhead and capturing them, and it is interesting to note that on such occasions the dragonflies usually only bite off the bodies of their victims which continue to fly along apparently quite happily.

The Mantidæ are familiar to all students of insect life in India. Some are comparatively small whilst others are giants of the insect tribe, but all are coloured procryptically in order to secure concealment at once from their enemies and their prey. One of the most curious and striking of South Indian Mantids is Gongylus, whose portrait appears on the cover of this book in its natural 
attitude when at rest amongst foliage, head downwards and with its long sharp-spined front legs doubled together in readiness to strike at its prey, which are usually butterflies. The head, being separated from the body by an attenuated thorax which resembles an elongated neck, seems to be something apart and does not resemble an insect at all; in some specimens the inner surfaces of the raptorial legs are coloured bright pink in life and the head then resembles a papilionaceous flower which may allure butterflies to approach within striking distance. The deceptive appearance is often accentuated by the adoption of a gentle sideways swaying motion of the whole insect, which not only gives an impression of a flower swaying in a gentle breeze but at the same time brings into action yet another device in the reflection of light from the lower surfaces of the prothoracic lobes which flash out like spots of sunshine finding their way through the foliage. Finally, the insect occurs in two different shades, green and brown, resembling living or lead leaves respectively, and exhibits strong sexual dimorphism, the male having pectinated antennæ and well-developed wings whilst in the female the antennæ are simple and the wings abbreviated. It may be added that males are relatively scarce because the female sometimes eats the male prior to pairing and invariably does so afterwards.

Raptorial legs, especially suited for the capture and retention of prey by the development of an armature of spines, as seen typically in the Mantids, are found in many widely different groups of insects, such as the Manticlæ, the Mantispidæ and the Reduviidæ, and the parallel development of such similar structures is an excellent example of convergence in evolution which may be commended to the student. The possession of a long slender rostrum, as seen in the plant-feeding bugs, may be compared with the short, stout beak found in predaceous groups, but the possession of raptorial legs is often a surer mark of distinction; in the Pentatomidæ, for example, the rostrum is always long and slender, whether the bug is a plant-feeder or a predator, but in cases of doubt as to feecling habits a good guess can usually be made after examination of the fore-tibia, which is always provided with spines in predaceous species (e.g., Andrallus, see figure 356).

Many Wasps are predaceous on other insects and the various species which search out and destroy caterpillars are highly beneficial. Some wasps, such as the social species of Polistes which commonly build small open hanging nests in bushes and buildings, either eat the caterpillars themselves or feed them to their larvæ, but many of the solitary cell-building wasps collect 
and store up caterpillars as food for their young. Of this latter class the large long-waisted species of Eumenes are common visitors to almost every bungalow, building neat mud-cells, provided with a regular neck and lip like a water-jar, in which caterpillars are stored, the egg deposited, and the cell sealed and left. It is remarkable with what regularity and consistency the wasp hunts for and succeeds in capturing caterpillars of the same species and size, and it seems probable in some cases that all the caterpillars brought and stored are members of one brood which have been systematically hunted down and destroyed; so that the good accomplished by these wasps is far greater than is generally
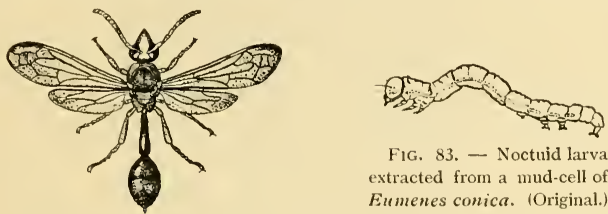

Fig. 83. - Noctuid larva extracted from a mud-cell of Eumenes conica. (Original.)

F1G. 82.-Eumenes conica, a common Cell-building Wasp.

(Original.)

realized. The caterpillars are stung before they are placed in the cell and as a result they remain practically helpless, alive but incapable of co-ordinated motion. A great deal has been written regarding the "wonderful instinct which always impels the wasp to deliver its sting in one and the same and most effective portion of the nervous system of the caterpillar," but this is largely an effort of the imagination, and every gradation can be found in stung larvæ between complete paralysis and ineffective and transient results; sometimes, inleed, the caterpillar may even pupate and emerge as a moth. The wasp's egg is suspended from the top of the cell by a slender filament, so that it is less exposed to danger by any convulsive movements of the stored caterpillars; on hatching it devours these, still living, until they are all eaten, when it pupates in the cell and ultimately emerges. The number of caterpillars stored depends upon their size; in the case of moderatesized ones (e.g., Plusia) about seven are stored in each cell as a rule and one wasp may build and store eight or ten cells in one cluster and probably builds and stores several clusters. So it will be seen that every single one of these wasps may be calculated as a potential destroyer of at least one hundred caterpillars, and such wasps should, therefore, be protected and encouraged as much as possible. Wasps are peaceable creatures if they are left undisturbed and 
even the social species, the smaller ones at any rate, are usually quite unobjectionable inmates of a bungalow.

Amongst the flies, the Asilida or Robber-flies are entirely predaceous, being provided with a stout horny beak which can

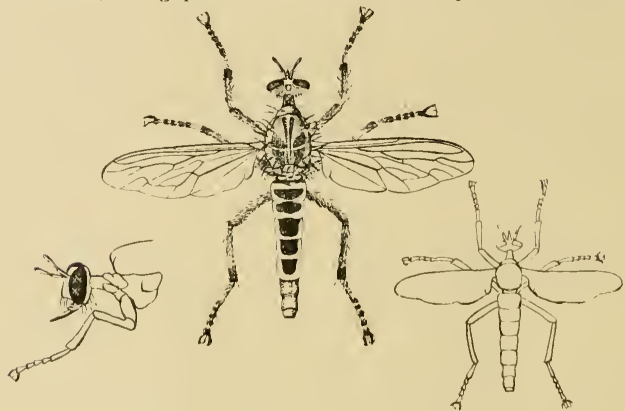

F1G. 84.-Asilid Fly: On the left is a side-view of the head, showing the stoutly-built beak; the outline figure on the right shows the natual size. (Original.)

inflict a nasty poisoned wound in the case of the larger species. These flies are all extremely rapid flyers and capture their prey on the wing. Of the various other groups of predaceous Diptera the Syrphida are of the greatest practical importance, although these are only predaceous in the larval stage at which period of life they live entirely upon Aphids; the flies themselves, many of which superficially resenble bees and wasps, frequent flowers and leaves and may often be seen hovering motionless in the air, whence they are sometimes called "Hover-flies." The eggs are laid on plants infested by Aphids, which the larvæ seize and devour, sometimes, as in the case of the Ragi Root Aphid, even following their prey below-ground.

The Chrysopidæ, or Lace-wing Flies, have habits somewhat similar to the Syrphidx, their eggs also being laid on plants and their larvæ feeding on Aphids. The eggs are very characterisitic, being laid in groups, each egg deposited at the tip of a long slender stalk; it is possible that this arrangement preserves the remaining eggs from the cannibal propensities of the first-hatched larvæ.

The Myrmeleonida, or Ant-lions, are not commonly noticed as adults, in which state they look like weak-winged dragonflies, as their flight is apparently nocturnal, but they are sometimes attracted to light at night. The larval pits, however, are familiar objects in 
all dry sandy or dusty places as little circular funnel-shaped depressions in the ground, at the bottom of which lurks the larva ready to seize and devour any small insect which may tumble into the pit or be brought down into it by the volleys of sand flicked upwards by the concealed larva.

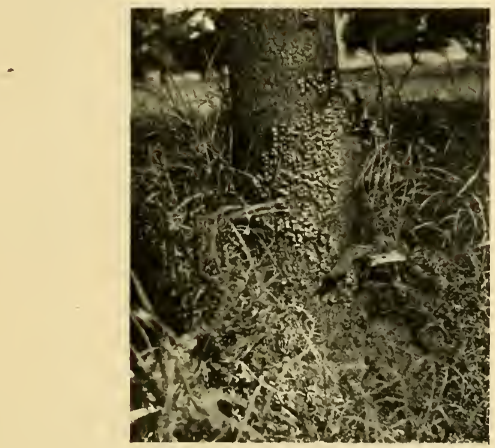

Fig. 85.-Larva cases of Eublcmma scitula massed on stem of Babul IAcacia arabical at Coimbatore. (Author's original photo.)

Amongst the Lepidoptera, which seem to form so typically a vegetarian group, a few species are predaceous in their larval stages. Of these the commonest in Madras is probably Eublemma scitula (sce figure 242) whose curious larva, enclosed in a tough shell-like case, feeds on scale insects and is commonly found on babul (Acacia arabica); frequently masses of these cases are seen on the trunks of trees, the larvæ apparently reacting to a thigmotropic impulse at the time of pupation. Several other species of Enblemma are known to be predaceous on scale-insects, whilst others of this same genus are plant-feeders. In districts where lac is grown these larvæ may do very serious damage by devouring the lac-insects.

The Coleoptera, or Beetles, contain numerous groups of predators. The Cicindelida, or Tiger Beetles, a re predaceous both as larva, which tunnel in the ground and as adults which swiftly run and fly in search of prey. One species (Cicindela sexpunctata) is known to attack the Rice-bug (Leptocorisa) in Northern India and hence is a most useful ally of the farmer, but in Madras this species appears to be scarce or absent, being known only from the Northern districts and from Mysore. Many of the water-beetles 
(Dytiscidac, Gyrinidae, etc.) are entirely predaceous, as indeed are most of the Bugs which live in the water or run along its surface.

The Coccinellidæ, or Lady-bird Beetles, are familiar and extremely beneficial insects, feeding on scale-insects, Aphids and various other pests both in their larval and adult stages. They are generally of very characteristic shape and colour (sce plate V) and every cultivator should make himself familiar with their appearance. The adults have, as a rule, red wing-cases spotted with black but the markings are variable and may be wholly red or black, occasionally yellow or dark blue. A very large blackspotted red species is found in the Hills attacking the large Aphid found on pear-trees, and at least one lady-bird (see figure 133) is known to be an enemy of Green Scale-bugs. The mite so common on cholam is attacked by a minute species (Scymnus sp.) which does not apparently touch the mites themselves but devotes all its attention to devouring their eggs.

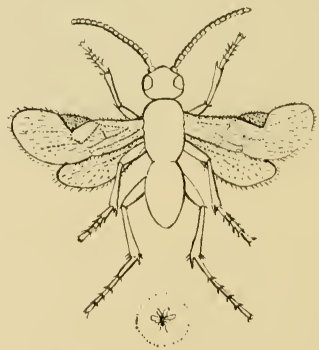

F1G. 86.-Parasite of Diatraa sp. The small figure shows the natural size. (Original.)

Parasites undoubtedly play a much more important part than predators in the reduction of the numbers of any species of insect, and this is largely because parasites as a rule only lay their eggs so that their larvæ can feed on their victims, and they are therefore able to destroy a large number of these latter. It must here be emphasized again that it is by no means every parasite that is beneficial. Probably every species of insect, without exception, is parasitized by one or more other insects and it is obvious therefore that some parasites must be injurious by their destruction of beneficial insects. Even when an injurious insect is attacked it may be parasitized by two or more different parasites, only one of which is likely to survive, and it frequently happens that this survivor is destructive to a really beneficial parasite and its survival 


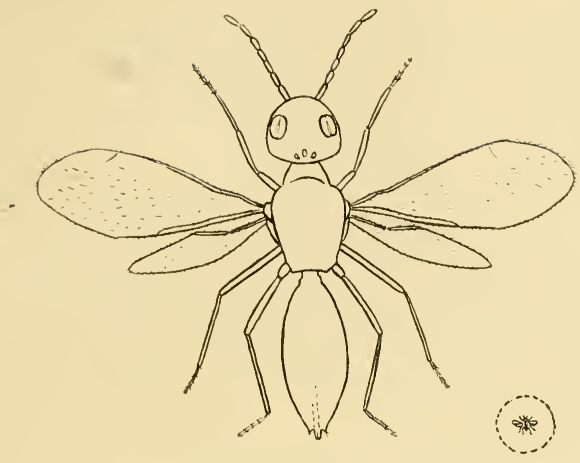

FIG. 87.-Parasite of Aproarema nerteria. The small figure shows the natural size. (Original.)

is therefore advantageous to the injurious pest. On the whole, however, the activities of parasites are decidedly beneficial.

Parasites are found amongst the members of most of the larger Orders of Insects but the parasitic Hymenoptera and Diptera are the most important. Amongst the Hymenoptera, several very extensive families (Ichneumonidæ, Chalcididæ, Proctotrypidæ, etc. ") are entirely parasitic as are also the Tachinidæ and Bombylidæe amongst the Diptera. Animal parasites (Hippoboscidæ, Nycteribiadæ, etc.) are not included here.
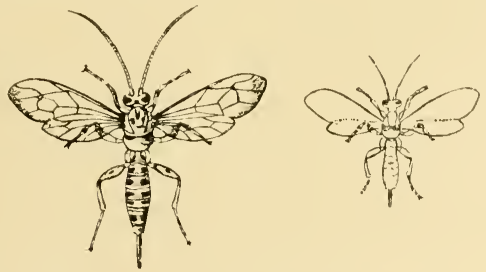

FiG. 88.-An Ichneumon Fly, Xanthopimpla pedator. The smaller ontline figure shows the natural size. (Original.)

* It must again be pointed out that it is impossible to give more than a very small selection of facts in a book of this character. In the present chapter the consideration of whole families and groups must necessarily be omitted. 
The Ichneunonidæ, or Ichneumon Flies, are large to moderatesized slender, waspish Hymenoptera, their females armed with an exserted ovipositor which may be several times the length of the whole body, especially in the case of species which are parasitic on larvæ living in dead wood, into which the ovipositor may be thrust to a great depth in order to oviposit in the concealed larvæ. The members of this group are often parasitic on lepidopterous larvæ, which are hunted down and eggs deposited in, or occasionally on, them by means of the ovipositor. The eggs presently hatch into small white grubs which feed inside the stung larva eating the fat and non-vital portions until they are full-grown, by which time the larva has generally ceased feeding and pupated, when the grubs consume the remainder and then themselves pupate in the pupal shell of their host, afterwards biting their way out and emerging as adult flies to continue their beneficial labours of destroying caterpillars.

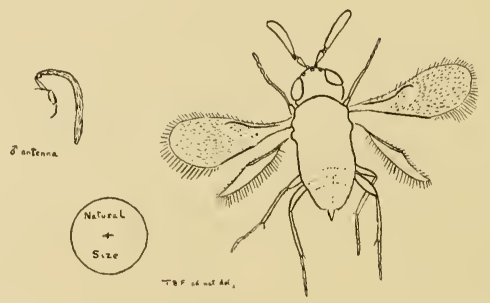

Fig. 89.-A Chalcid Fly, Eretmocerus sp., parasitic on the Castor Aleurodid; Coimbatore, May 1913. The natural size is shown by the small figure within the Circle. (Original).

The Chalcididæ or Chalcid Flies are small to minute Hymenoptera, often brilliantly shining or metallic in colour, which parasitize insects of almost all Orders, many being themselves hyperparasites on Ichneumonids or other Chalcids. As an example of this group we figure an undescribed species, apparently belonging to the genus Eretmocerus, which parasitizes the Castor Aleurodid. Many insects of this family, it may be noted, are highly important as checks on Scale-insects and some have been imported from one country to another expressly to check the attacks of Scale-insects, in which success has been attained in several cases.

The Proctotrypidæ, or Proctotrypid Flies, are the only other family of parasitic Hymenoptera that can be noticed here. They are all minute insects, sometimes wingless and are mostly important 
as being egg-parasites, that is to say, they hunt out and oviposit in batches of eggs laid by the insects which serve as their hosts. A few insects of this group, which has not been studied at all in India as yet, are known to be aquatic and to use their wings for propelling themselves along under water. The unnamed and undescribed species which we figure is parasitic on the eggs of Tettigoniella spectra, a small white Jassid bug which is sometimes very-abundant in paddy-fields and which lays its eggs on paddyleaves which often become submerged in the water, and in this case the parasite walks under-water in search of them. Eggparasites of this kind may be encourged, when egg-masses of pests are found, by placing these eggs in an open vessel surrounded with oil-and-water, so that any flies which emerge may be able to fly away whilst any caterpillars which hatch out will be unable to escape.

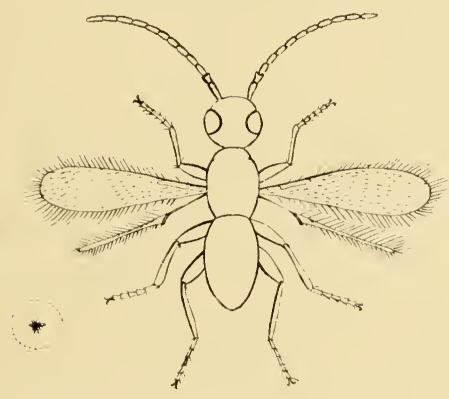

F1G. 90.-Proctotrypid Parasite of Tettigoniclla spectra. The smaller figure shows the natural size. (Original.)

The Tachinida, or Tachinid Flies, in general appearance much resemble rather hairy house-flies or flesh-flies and are parasitic on caterpillars, grasshoppers, etc., on which the eggs are laid as a rule, the white maggots feeding inside their victim in much the same way as ichneumonid grubs, but generally killing it off just as it is full-grown, then emerging and changing on its collapsed remains into characteristic small brown puparia, from which the adult flies presently issue forth.

The Bombylidæ, which are usually hairy, bee-like two-winged flies, extremely swift on the wing and often hovering stationary in one place during flight, are parasitic on various insects, chiefly Hymenoptera, and several species of these flies, which parasitize 
the solitary wasps, are commonly seen in bungalows. A few species, however, are known to parasitize grasshoppers, their larvæ feeding on the egg-masses, and are therefore beneficial. We have bred an undetermined species from the egg-masses of the Deccan Grasshopper (Colemania sphenarioides).

Amongst other parasites of grasshoppers must be reckoned the Blister Beetles, whose larvæ feed on and destroy the egg-masses of grasshoppers, and these beetles are therefore highly beneficial in their early stages, whatever damage they may do as adult insects.

Besides doing good as predators and parasites, insects may be beneficial indirectly in other directions, as in checking the growth of weeds, breaking up of dead wood and acting as scavengers of clead animal matter. As regards the checking of weeds, there are few if any plants which are not subject to attack by insects of some or many kinds and weeds are no exception to this rule. But, whilst insects may do a little good by checking the growth of weeds, this is hardly a factor to be relied on by the agriculturist to supersede the necessity of weeding, and on the other hand many insect pests breed freely on weeds and thereafter invade the adjacent crops and damage them. In forest regions especially, where there is always a quantity of dead wood present, this has a regular and characteristic fauna of its own which feeds upon it and rapidly reduces the dead wood to a state in which it can again form part of the soil, and in such cases the action of these insects is undoubtedly beneficial under natural conditions. Dead animal matter has also a special fauna of its own, various insects feeding on it and laying their eggs on it so that it is rapidly consumed. The Dung Beetles of numerous kinds are common and well-known examples, the beetles separating small pieces of dung which they form into a ball and roll along the ground to a suitable spot, where it is buried and either eaten by the beetle itself or an egg laid on it and the ball left for the food of the future larva. In the case of some of the larger species, such as Heliocopris bucephalus (sec figure I2I), the ball may be very large and solid, as much as six inches in diameter, and may be buried at a depth of several feet. The dispersal and reduction of dead animal matter by insects in this way is obviously beneficial by ensuring its more rapid blending with the soil. 


\section{CHAPTER XXII.}

\section{USEFUL INSECTS.}

"The study of entomology is one of the most fascinating of pursuits. It takes its votaries into the treasure-houses of Nature and explains some of the wonderful series of links which form the great chain of creation. It lays open before us another world, of which we have been hitherto unconscious, and shows us that the tiniest insect, so small perhaps that the unaided eye can scarcely see it, has its work to do in the world, and does it."

J. G. Woop.

UNDER the heading of Useful Insects we may consider the comparatively small number of species which are applied directly to supply the requirements of man, either as food or drugs, or as ornaments, or on account of the products which they yield.

Silk is the best-known and most valuable of such products and forms the staple industry of many whole districts in India and other countries, amongst which we may mention especially Japan, China, Italy and France. Most caterpillars, and various other insects, and of course spiclers, spin silk, and we have already seen that the cocoon-making instinct is widely found amongst insects, the basis of all such cocoons being silk, but it is only in two families of moths that these cocoons are suitable for practical use on account of the strength, quality and quantity of silk fibre contained in them. These two families, the Saturniadæ (or Attacidæ) and Bombycidæ, comprise a number of species of wild silk-moths which occur more or less commonly in Indian jungles and which are constantly being exploited unsuccessfully by promoters of wild-cat schemes for their commercial utilisation, but the only three species which are of actual value in Southern India are the Mulberry, Eri and Tasar Silkworms. In all cases it is of course only the cocoon, or silken case spun by the larva for the protection of the insect during its resting pupal stage, that is of any value.

The Mulberry Silkworm (Bombyx mori) is only cultivated on any scale in Southern India in Mysore and in the Kollegal taluq of the Coimbatore district, this latter area being geographically, if not politically, part of Mysore. As its name implies, this silkworm is fed on the leaves of mulberry, which is generally grown from cuttings as a field crop, the bushes being plucked of leaves and regularly cut back when they grow too high. The caterpillars are reared in open basket-work trays made of split bamboo and when full-fed are placed to spin their cocoons in chandrakhis or splitbamboo frames containing a spiral maze in which the caterpillars 
wander about and select a suitable corner for spinning up. As the silk is spun in one single reelable thread, which is broken by the emergence of the moth, those cocoons which are intended for silk must be stifled (i.e., the encloscd insect must be killed) to prevent their being spoilt in this way. Stifling is done by exposure to the hot rays of the sun or by artificial heat. The cocoons which are intended for silk are placed in water which is nearly boiling, one end of the silk thread teased out and thrown on to a compound thread from four or five other cocoons and the whole reeled on to a

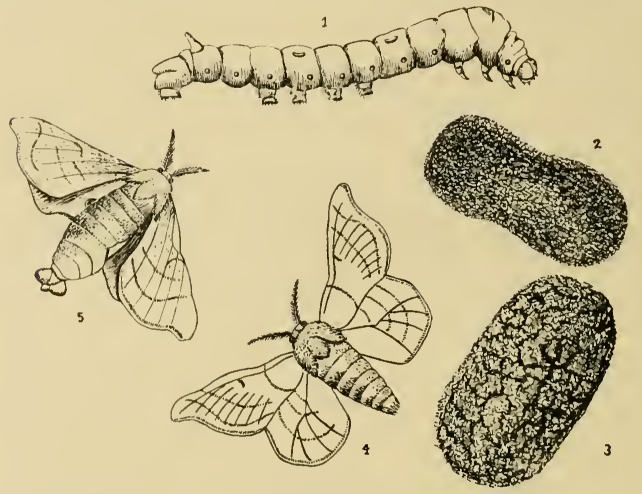

IiG. 91.-The Mulberry Silkworm (Bombyx mori.) 1, Larva; 2, 3, Cocoons : 4, Male Moth; 5, Female Mtoth. (After Indian Museum Notes.)

spool, other cocoons being attached as one comes to an end. Those cocoons which are intended to be kept for rearing purposes are retainer and the moths allowed to emerge, pair and oviposit in due course. As the silkworms are very subject to numerous diseases which are transmitted hereditarily, each female moth is confined over a sheet of paper under a tin funnel whilst laying her eggs; when oviposition is concluded, the body-juices of the parent are examined microscopically to see whether disease is present and, if so, that batch of eggs is destroyed. Scrupulous cleanliness in the rearing-trays and proper disinfection of these trays and the chandrakhis are essential for success in rearing these, as in all other, insects.

The Eri Silkworm (Attucus ricini) feeds on the leaves of castor and is normally an inhabitant of Assam and Bengal but has been 

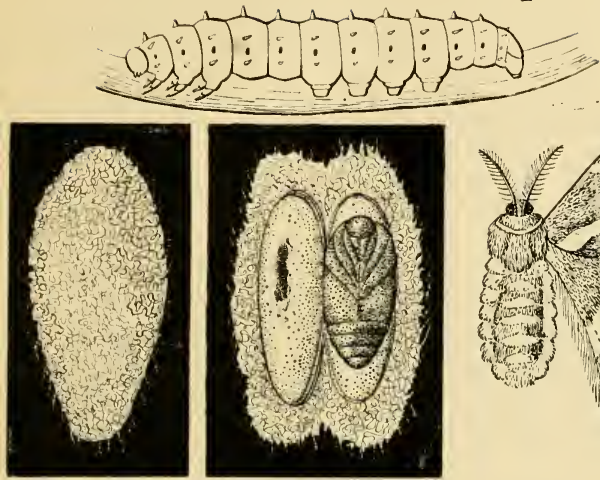

2

FIG. 92.-The Eri Silkworm (Attacus ricini). 1, Larva or Worm; 2, Cocoon ; 3 , Cocoon cut open to show the structure and enclosed Pupa : 4. Female Moth. (Original.)

introduced all over India in a domesticated condition. This insect requires a warm, damp climate and cannot therefore be expected to do well in the plains of Southern India except on the West Coast. In a wild state most of the cocoons are of a dark red-brown colour but, by constant inbreeding of specimens producing only white cocoons, the brown ones are eliminated in the domesticated races. These cocoons are not reelable and must be spun and there is consequently no necessity to kill the insect to obtain its silk. Not only, therefore, can all the cocoons reared be converted into threacl, but all the moths can be allowed to emerge and be used for breeding, so that large broods can be built up rapidly without wasting cocoons for seed. The silk is spun by hand and woven like cotton, the cloth being extremely durable and improving after a little use, becoming more lustrous and soft and also stretching a little. If mill-spun, very fine and even thread can be made and excellent fine cloth prepared from this. Either hand-spun or mill-spun thread, or cloth made from these, can be dyed to any colour required. Further particulars regarding this silk will be found in Pusa Bulletin No. 29, "Directions for the Cultivation of Eri Silk." 
The Tasar Silkworm (Antheraa paphia) is chiefly found in the North of the Presidency, the caterpillars occurring wild or semidomesticated in jungle tracts on various trees of which the more common and important are Shorea robusta (Sal), Zizyphus jujuba (Ber), Terminalia tomentosa and T. arjuna. The cocoons are collected in the jungle, being the produce of wild caterpillars, or from particular trees on which eggs have been placed by rearers. The caterpillars cannot be reared in confinement on a commercial scale, nor will the moths pair readily, and the bred female moths are

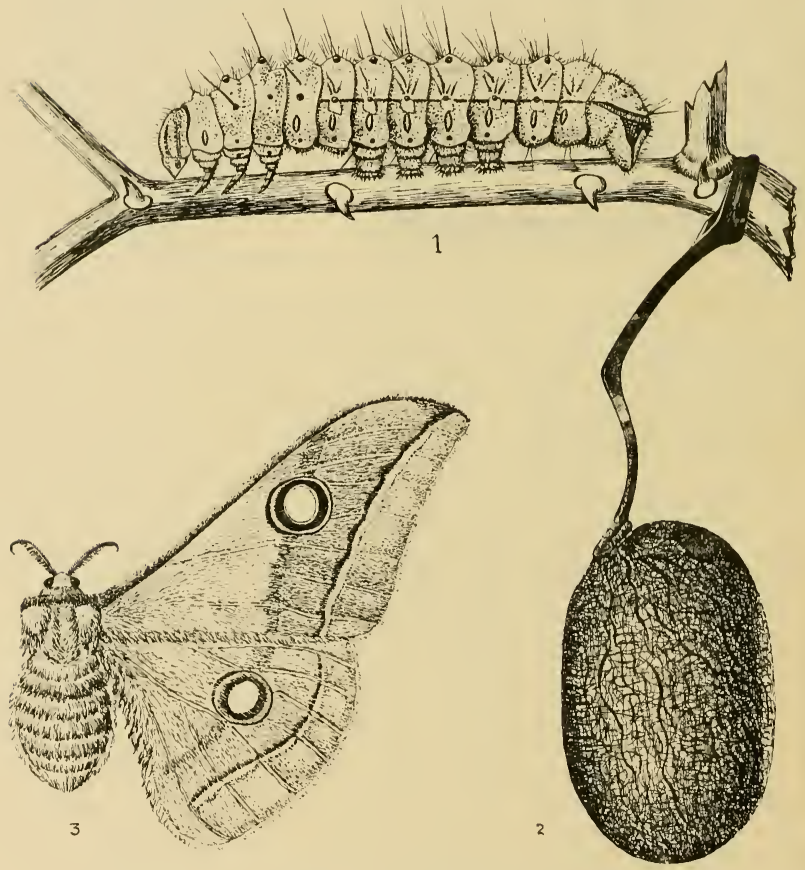

Fig. 93. -The Tasar Silkworm. 1, Larva ; 2, Cocoon ; 3, Female Moth. (1 and 2 after Lefroy.) 
therefore paired with wild males which are attracted to them, the females being usually tied to a twig. Owing to the facts that there is thus no real control over pairing, so that it is impossible to be certain of retaining any particular quality of silk, and that the caterpillars feed in the open exposed to the attacks of innumerable enemies, tasar silk is not an industry which is capable of much development in face of the competition of well-organized sericultural industries in other countries. The cocoon is reelable and the moth must therefore be killed and not allowed to emerge as the thread is spoilt and unreelable after the moth has eclosed.

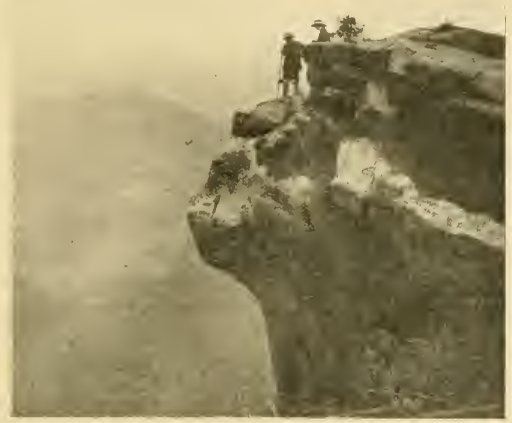

Fig. 94.-Where Apis dorsata builds its comb. The Kadiar Rocks in the Shevaroy Hills. The bees build below the overhanging rock shown here and the honey-gatherers are lowered over the precipice by ropes. (Author's original photo.)

Bees are found throughout Southern India in a wild state and produce a considerable quantity of honey and wax, the right of collecting these in the jungle being usually leased out by the Forest Department to jungle tribes, many of whom make a regular business of raiding bees' nests at particular tinses of the year. There are three kinds of true honey-bees, all of which occur commonly both in the plains and in the hills. They are-

(I) the large Rock Bee (Apis dorsata, see figure II 7 ),

(2) the Indian Bee (Apis indica, see figure II8), and

(3) the Little Bee (Apis florea, see figure II9).

Of these Apis dorsata usually occurs in colonies composed of several or many nests each of which builds a large single comb 
suspended from a cliff or from the horizontal branch of a tall jungle tree. Frequently the same tree or clump of trees or cliffs are used by these bees year after year and in most districts there seems to be a semi-annual migration of the colonies from the Hills to the Plains during the rainy months and vice versâ. When disturbed these bees are apt to be irritable and very vicious, sometimes attacking all who approach their colonies and making roads impassable for traffic. They are not therefore adapted for domestication. The honey and wax are collected in a very crude manner by men of jungle tribes who climb the "bee-trees" or are lowered over cliffs to the nests, protected by a blanket and a torch with which they burn the bees off the comb and cut this away bodily. Enormous numbers of these bees are destroyed annually in this way in certain districts.

The Indian Bee (Apis indica) is similar to, but smaller than, the European honey-bee (Apis mellifica) and, like the latter, builds several parallel combs. This bee varies very considerably in colour according to locality, specimens in the Plains being pale and those fron the Hills dark. It builds its nest as a rule in hollow trees, more rarely on bushes in shady places, the nests being found singly and not gregariously as in Apis dorsata. They are commonly robbed when found, the entrance being chopped open as a rule and the combs cut out without any special precautions, although this bee can sting smartly. Apis indica can be, and of ten is, kept in a more or less domesticated state in hives, in which, however, it rarely remains more than a few months, thereafter swarming off to found a new nest, and this vagrant disposition is one difficulty in keeping these bees, as new colonies have to be obtained frequently or at least the old ones recaught and rehived. The honey of this bee is good but not plentiful, probably only about six pounds being obtainable from each hive annually, so that it is hardly a profitable kind to keep on a commercial scale for honey-production, though very valuable in gardens and orchards as a pollinator.

The Little Bee (Apis florea) is especially a dweller in the Plains, hanging its small single comb in bushes and shady places. The honey is excellent but small in quantity. The nests are commonly robbed when found, the comb being squeezed in the hand and the honey eaten forthwith, the skins of low caste natives being apparently impervious to the sting of this bee. Owing to the small size both of individual bees and of colonies this species is not adapted to domestication.

Besides producing honey and wax, bees are extremely useful to man indirectly by pollinating plants and this is an aspect of 
their activities which must not be overlooked, especially in districts where large areas of crops are required to be fertilized by these insects for the attainment of successful crops later on. In places such as coffee estates and all fruit gardens it will probably be found profitable to keep bees, not so much for the production of honey as for the successful pollination of crops; or at least to protect the bees where these occur in a wild state.

.The only native Indian bee which offers any chance of domestication is Apis indica which, as already noted, can be hived with

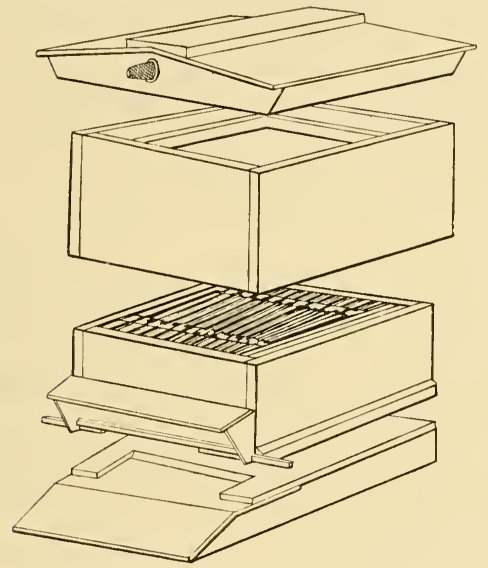

F1G. 95.-Diagrammatic sketch of a Bar-frame Beehive, showing construction. (Original.)

some success. Proper wooden hives should be used, with moveable wooden frames of standard size and provided with wax foundation to save the bees as much as possible from the necessity of making wax. For it must be remembered that the production of wax is a great strain on the activities of bees and that it takes about fifteen pounds weight of honey to repair the wear and tear caused by the production of every pound weight of wax. If, therefore, bees are kept for honey, this should always be extracted in a proper machine *

* For description of a simple hones-extractor see Agricultural /ournal of India for October Igir. 
and the empty combs returned to the bees to clean and refill. It is a most wasteful procedure to remove the wax with the honey.

Lac, which is the resinous excretion of a Scale-insect, is an important industry in some parts of India, but is little grown in Madras where the climatic and other conditions appear unsuitable for its successful cultivation. It is used in India principally by jewellers for filling gold ornaments, bangles and bracelets, and for making toys and ornamental ware, and outside of India in the manufacture of gramophone records, varnishes, furniture polishes and sealing wax. A full account of the cultivation and preparation of lac is given in Pusa Bulletin No. 28, "The Cultivation of Lac in the Plains of India," to which the reader may be referred for fuller information.

Analogous to lac is the white waxy substance produced by another Scale-insect, Cerococcus ceriferus, found commonly in Madras. It has been tried for making candles, but without much success. It is also said to be eaten.

A few insects are of direct use to man as a source of food and of these we may mention especially Termites of various kinds, particularly the winged forms of some of the mound-builders. Not content with the capture of these insects at their normal time of emergence from the nest, in many parts of Madras members of certain castes anticipate their flight and build a small domed hut of twigs and branches over the nest, the top of which is sliced off, and a chatty of water is sunk in this or a hole dug and filled with water. A lighted lamp is now placed in the hut and the emergence hastened by blowing into the nest a mixture of certain powdered roots and seeds, whereupon the termites fly out and fall into the water whence they are collected and sold in the bazaars for food amongst the lower castes.

Locusts are well-known articles of food in most of the various countries which they ravage. I am not aware that they are regularly eaten in Madras but this is probably the case as we read in Kirby and Spence's "Introduction to Entomology" that when a "cloud of locusts . . visited the Mahratta country, the common people salted and ate them." There is probably little reason except prejudice why many insects should not be eaten and, if this seems repugnant to any readers, they may be reminded that the majority, even the most fastidious, have probably devoured with relish many small insects such as cheese-hoppers, which are merely the maggots of a fly, and that Cochineal, a colouring matter derived from a small Plant-bug, is extensively used for colouring fancy sweets.

Besides their use as food, many insects are utilized as drugs of various kinds. Probably the best known in this connection are the 
Blister-beetles, many of the Indian species of which are sufficiently plentiful to repay collection and which contain a considerable percentage of Cantharidin. For veterinary purposes especially these beetles will probably prove worth collecting and using. The supposedly stimulating properties of queen Termites are well known and need not be more than alluded to; when found by coolies during digging, etc., they are usually swallowed alive forthwith.

Finally, insects must be added to the replete armoury of attractions by which the fair sex endeavours to render itself still fairer and more attractive. The brilliantly-metallic wing-cases of many Buprestid beetles in particular are often used for the ornamentation of fans and brooches and the embroidery of cloths and dresses, whilst glow-worms are sometimes enclosed in gauze and used as hair-ornaments. 


\title{
CHAPTER XXIII.
}

\section{SOME OTHER ANIMALS.}

\author{
"The art of seeing, so useful, so universal, and yet so unconmon, is one of the most \\ valuable a man can possess." \\ KIRBY and SPENCE.
}

INNUMERABLE animals other than insects, from elephants to minute organisms invisible to the naked eye, must be included amongst the farmer's friends and foes. Some destroy crops and hence are injurious, some feed on crop-pests and so are themselves beneficial, whilst others do neither harm nor good to man or his possessions and are therefore of neutral value.

Elephants occur in most uncultivated tracts both in the Plains near and in the Hills, though commoner in the latter. In districts where they occur they frequently invade cultivated areas and do an immense amount of damage to crops merely by reason of their size and numbers, a single full-grown elephant consuning between 600 and $700 \mathrm{lb}$. of green fodder daily. In the Hills cardamons seem to be especially attractive, whilst a young tea nursery often seems in the elephantine mind to have been prepared expressly as a most desirable spot to wallow in, to the total destruction of the planters' hopes of young plants. Elephants usually avoid enclosed areas, apparently in fear of traps, and, as they are quite unable to jump, a comparatively narrow ( 7 feet) ditch forms an impassable barrier.

The Gaur (Bos gaurus), commonly miscalled "Bison," occurs in most of the Hill tracts and occasionally does some damage in estates, whilst the Wild Buffalo (Bos bubalus) occurs in the Plains to the north of the Godavari and often does great damage to crops, a herd or solitary bull sometimes taking possession of a paddy-field and driving away the true owners. The Nilgai (Boselaphus tragocamelus) is also common in scrubby localities in the Plains as far south as Mysore and often does much damage to crops. Various species of deer also occur commonly and may at times invade cropped areas. Shooting the trespassers, where damage is done, is probably the only practical control-measure.

No animal does more damage to crops than the Wild Pig (Sus (ristatus) which occurs commonly both in the Plains and Hills. Pigs often breed twice in the year, producing four to six young in each litter, so that their prolific rate of increase enables them to compete with most forms of destruction. Under these circumstances the best thing is to protect the crops by fencing, where these are sufficiently valuable to repay such protection. A suitable permanent 
fencing is described by Clouston in the Agricultural Journal of India for April I9I3.

On the other hand the curious Pangolin, or Scaly Ant-Eater (Manis crassicaudata), found sparingly throughout the Plains though rarely seen, is beneficial as feeding entirely on insects, principally on termites whose mounds it tears open with its powerful claws and then thrusts in its long tongue.

Squirrels of many species occur in Southern India, the commonest being the common Striped Squirrel (Fumambulus palmarum), whose diurnal habits and partiality for the neighbourhood of human dwellings renders it one of the most familiar of all Indian animals. The food of most squirrels consists of buds, fruit, seeds and insects, and they are usually of neutral or slightly beneficial value to the agriculturist. Occasionally, however, squirrels may attack fruit, such as mangoes, and do considerable damage. In such cases they are difficult to check unless they can be shot, as their powers of climbing make it difficult to isolate the trees. In the case of valuable fruit, bagging or netting may be tried.

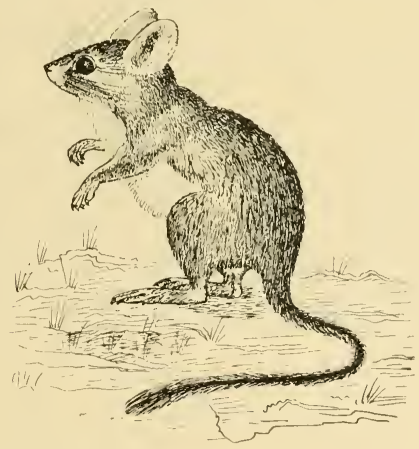

FIG. 96.-The Indian Gerbille (Tatera indica). (After Blanford.)

Rats and mice of numerous kinds are sometimes amongst the most serious pests with which the agriculturist has to contend. In the Anamalai and Travancore Hills, and perhaps in the Nilgiris, the Malabar Spiny Mouse (Platacanthomys lasiurus) is said by Blanford to damage pepper, breadfruit, and jakfruit. The Indian Gerbille (Tatera indica) is common almost everywhere, burrowing in bunds and in the ground, and only venturing out by night. It is a gentle-mannered and pretty little animal, reddish-brown above and 
pure-white below. Normally it probably does some good, because its favourite food is the roots of hariali grass (Cynodon dactylon) which is a most pestilential weed as a rule, but it also does considerable damage by feeding on seeds and grain. Under certain conditions, whether of favourable weather or absence of enemies or both is not exactly known, this little rat increases enormously in numbers and it is probable that this is often the species concerned when complaints are made of damage to standing crops by rats. In $1878-79$ this Gerbille was so plentiful in the Deccan as to ravage the grain-crops over an area of several thousand miles.

The Comnon Indian Rat (Epimys rufescens, or Mus rattus of the "Fauna of India" volume) is common everywhere, burrowing in the ground and climbing well. It is common in houses, living especially in roofs where these are made of suitable materials and is practically omnivorous but feeds chiefly on grain and fruits. It often does considerable damage in coconut topes, destroying the young unripe nuts, and nesting in the crowns of the palms. The Brown Rat (Epimys norvegicus or Mus decumanus) is a typically human parasite which has been carried by shipping all over the World and which is now commonly found in all large towns. It lives in burrows in and under houses, in field-bunds, etc., and sometimes does damage to grain-crops although it is essentially a scavenger. The Indian House-Mouse (Mus manei) is a household pest as a rule, but is occasionally found doing damage near human habitations; in the fields it is replaced by the Southern Field-Mouse (Mus booduga). The Soft-furred Field-Rat (Millardia meltada) lives entirely in cultivated fields, in burrows or simply in cracks in the soil, and sometimes increases "so as to become a perfect plague and to destroy the crops" (Elliot). The Bandicoot (Bandicota malabarica, or Nesokia bandicota (part) of the "Fauna" volume) is common in many parts of Southern Inclia, both in towns and in cultivated tracts, being very destructive to grain and also eating fruits and said to kill chickens. It is of very large size for a rat, the head and body (without tail) measuring I2-I5 inches long, blackish-brown above, grey beneath; it grunts like a pig, whence its name, which is derived from the Telugu "Pandi-koku" (pig-rat) of tank-diggers. The nearly allied Southern Mole-Rat (Gunomys kok) has similar habits, throwing up large piles of earth at the entrances of its burrows, which are often in the bunds of paddy-lands, and storing up grain.

The abovementioned are the commoner and more important of the rats and mice found in Southern India and they are enumerated here in order to emphasize the fact that very various and different species may do damage, a point which is usually overlooked by 
correspondents and others who report damage by "rats" and ask for remedies. The habits of the various species are often lifferent and must be taken into account in devising or carrying out any measures for control. It is, for example, little use to attack a rat, which is burrowing in field-bunds, in order to try and check damage which is actually being done by a different species which is living and nesting in the tops of palm-trees. In selecting a suitable bait for laying down poison or for use in traps, due regard must be paid to the habits and economy of the particular species concerned. In any case the control of damage to crops by rats is by no means easy. Traps are usually out of the question on a

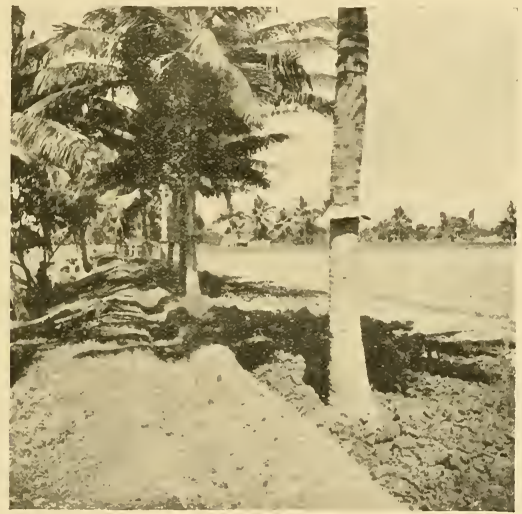

F1G. 97.-Coconut Palms ringed with tin bands to prevent rats from climbing up. (Author's original photo.)

large scale and control methods are consequently limited to exclusion, fumigation and poisons. In the case of trees such as coconut palms it is sometimes possible to exclude the rats from access by nailing downwardly-sloping bands of tin around the trunk, care being taken that access is not possible by way of contiguous or adjacent trees, bushes or buildings. In the case of burrowing species it is sometimes practicable to fumigate the rats by gaseous poisons and in such cases it is as well to go over the ground previously and mark and stop loosely with earth all burrows that can be found, those which are subsequently reopened being presumably 
occupied. In careful hands Carbon Bisulphide is an excellent fumigant but care must be taken to observe the precautions noted in Chapter XVIII; a small quantity is poured into the entrance of the burrow, allowed to evaporate for a second or two and then exploded with a lighted rag on the end of a long pole and a spadeful of earth immediately placed over the hole; the explosion, which drives the gas into the burrow, is very violent and care must be taken to stand well clear of the burrow and to place the bottle of Carbon Bisulphicle well out of range before applying a light. If a machine, such as one of the "Ant Exterminators" (see pages I2I-123), is available the burrows may be fumigated with Sulphur or Sulphur and Arsenic and this is especially useful because the heavy fumes call attention to exit-holes which would otherwise be overlooked; if a regular machine is not at hand a tenıporary makeshift can be manufactured at small cost from a blacksmith's bellows, an earthenware chatty and a few lengths of bamboo, the bellows being arranged to blow fumes of a fire kindled in the chatty through a bamboo or metal pipe into the burrow. Powdered Sulphur freshly made into a paste with Kerosine and wrapped in a piece of paper may also be used, being lighted and pushed with a stick into the burrow which is then closed with earth and left. The indiscriminate use of poisons in cultivated areas may lead to unexpected results and poisoned baits should therefore be placed only in situations where other animals are not likely to reach them; a piece of earthenware drain-pipe or similar covering may be suggested for use in fields. A bait of crusher maize poisoned with Zinc Phosphate has been found successful against Field-Rats in some places. Strychnine also gives good results sometimes, but must of course be used with caution; it is generally given in plantains or sugarcane, the bait being split open, a little strychnine powdered on, and the fruit closed and laid down as required. Several pathogenic organisms, fatal to rats but innocuous to other animals, form the basis of various special cultivations (Danysz Rat Virus, Ratin, Trope Ratin, etc.) which are extensively used in Europe; but these cultures are not readily obtainable in India and seem to deteriorate in the Tropics, so that at present they are hardly within the sphere of practical politics. Most rats, especially semi-domesticated species, it may be noted, are extremely suspicious of baits and traps if these retain any trace of the smell of the human fingers used to prepare them; before sctting or placing baits or traps, therefore, care should be taken to rub a little Aniseed Oil over the hands.

Porcupines are far commoner in most districts than is usually imagined as they are rarely seen owing to their nocturnal habits, 
remaining concealed during the daytime in their burrows, which are generally made amongst rocks where these are available. They feed on vegetable matter, chiefly on roots, and often do great damage to garden crops and to young trees. The latter might be protected to some extent by giving a good thick coat of whitewash mixed with an insoluble arsenical such as Lead Arsenate. Otherwise the treatment for porcupines is much the same as that given for rats. It may, however, be noted that these animals are often inclined to be gregarious and occupy more or less permanent burrows.

Hares are generally common in dry cultivated areas and sometimes do a little damage to crops; but they are unimportant to the agriculturist as a rule.

Flying Foxes (Pteropus giganteus), large fruit-eating Bats, are very common in some districts, feeding normally on wild figs but attacking all fruit and often doing serious damage in orchards. They also drink toddy on occasion and are sometimes found completely "drunk and incapable" under the trees the next morning. They generally rest in the daytime in particular trees to which they resort year after year, sallying out every evening at dusk and ranging over a circle of fifteen or twenty miles' radius. It is remarkable how a tree in fruit is discovered immediately the fruit begins to ripen, attracting the bats from miles around. It is difficult to protect fruit-trees or crops from the ravages of these animals but the following note by Mr. John Still, extracted from "Spolia Zeylanica" (Vol. VI, p. 54), seems to offer a hint as to a method which might be adopted in districts where these bats do damage :-

"In the North-Western Province, near Ganewatta Station, I noticed in a paddy-field a most ingenious method of capturing flying foxes. Great strings of cane are hung across the narrow fields, and from them depend at intervals of 3 or 4 feet long streamers made by tying together several of the whip-like thorny shoots of the common jungle cane. These whips are so thin as to be almost invisible in the dusk, and their thorns are sufficiently tenacious to hold captive any unfortunate flying fox who gets into heir grip."

The Southern Short-nosed Fruit-bat (Cynopterus sphinx; Marginatus of the "Fauna" volume) is also common, roosting by day solitarily or in small parties on leaves of plantains and palms. It flies swiftly in the evening, feeding entirely on fruit and being often extremely destructive to plantains, mangoes and guavas. One which I had in confinement for some time ate a whole plantain nightly but under natural conditions probably several fruits would have been partially eaten and spoilt. 
Most bats are of course well known to be insectivorous and may therefore be considered as beneficial, destroying vast quantities of insects, especially noctuid moths. A few species, however, are carnivorous, at least sometimes, and amongst such we may note especially the Indian Vampire (Lyroderma lyra) which catches and devours small birds, other bats, and frogs, as well as insects.

Various Shrews, often confused with field-rats but distinguishable by their long pointed snout and small eyes, occur commonly and frequently enter houses at night in search of insects which form their main food. They are useful little animals which deserve encouragement.

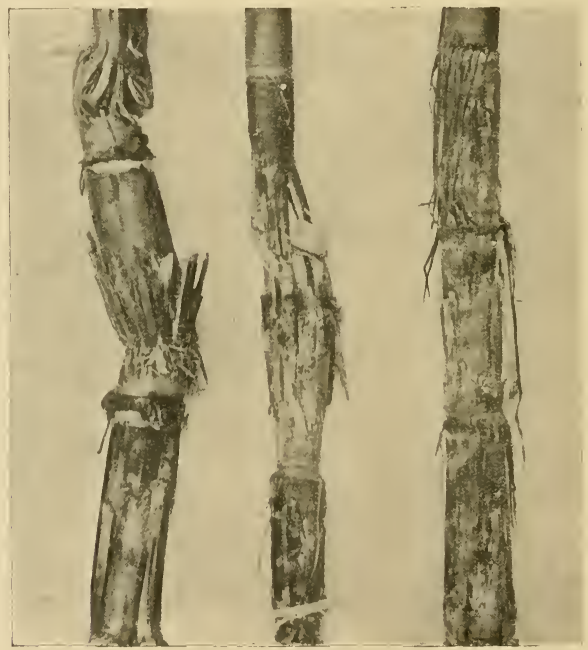

Fig. 98.-Sugarcane gnawed by Jackals, (From an original photo.)

Bears live mostly on fruits and insects, especially on termites whose mounds are clawed open and the inmates sucked up. The only species found in Southern India is the Sloth-Bear (Mclursus ursinus), which sometimes does damage to crops, such as cereals and pulses and especially sugarcane. Toddy-pots also are sometimes robbed of their contents by this animal, which also plunders 
bees-nests when found. On the whole, however, bears are of small importance to the agriculturist.

The Jackal (Canis indicus; aureus of authors) is commonly and widely distributed in all districts, usually occurring in small parties. They are essentially scavengers, feeding on carrion and offal of all sorts, but they are not averse to killing and eating any small animals which they can catch. Chickens are sometimes taken and I have seen a jackal catch a pair of drongos which were squabbling on the ground, striking them down with alternate blows of its fore-paws. Sweet cereals, such as maize and especially sugarcane, are often attacked and considerable damage may be done by these animals in cane-fields. In the Wynaad, it is said by Jerdon that jackals devour considerable quantities of ripe coffee-berries, the seeds passing through, well pulped, and being collected by coolies, as it is asserted that seeds so found make the best coffee, a circumstance due, as explained by Sterndale, to the fact that the jackals select the best fruit. Besides damaging crops the jackal acts as a permanent reservoir of the virus of rabies, so that he cannot be considered either a respectable or desirable member of society.

The use of carefully-stretched wire-mesh fencing, as advocated by Clouston (see p. 215) is said to keep jackals out of areas so protected to some extent. Direct control-methods are difficult, unless burrows can be located; but in the Plains of Southern India the jackal often lies up in bushes in the daytime. Poisons are often difficult to apply; if Strychnine is used, an excessive quantity should not be given, as such often induces vomiting and defeats its object.

Mungos mungo, the common Indian Mongoose, together with several other species, is found throughout Southern India, frequently in the vicinity of houses. All the species feed rather indifferently on any small animals or birds that they are able to catch, whilst their partiality for snakes is well known. Though useful in this respect around houses they often do great damage to fowls or other domesticated birds if they can obtain access to these. As they prey on numerous insectivorous reptiles and birds it is doubtful whether these animals are really so beneficial as is commonly supposed and perhaps their value may be assessed as neutral.

The Indian Palm-civet (Paradoxurus niger) is commonly called the "toddy cat" in many districts on account of its fondness for the contents of toddy-pots, and is often caught by the toddy-drawers asleep in the daytime in palm-trees. Its normal food consists of small animals of all sorts and fruit, so that it is sometimes destructive to poultry and gardens. 
Various small jungle cats, the leopard and tiger need not be more than mentioned here. All are often very destructive to domestic animals of various kinds and the ordinary methods of shikar are the only ones applicable to their control.

Monkeys of various species are also sufficiently familiar and in many districts do considerable damage to crops and gardens, being looked on as sacred and not to be interfered with, although the cultivators, averse to killing the monkeys themselves, sometimes find their pilfering such a loss that they will beg foreigners to do this for them.

Of all vertebrate animals, however, Birds are the most important from an agricultural point of view and it is probable that, if birds were wholly absent in Southern India, it would prove impossible to grow crops on account of the damage by insect pests. It is not generally realized what an enormous number of insects are destroyed in the course of a year by every individual of an insectivorous species of bird, such as a Mynah, which hunts systematically for its food during almost every moment of daylight. On the other hand some birds are distinctly injurious to crops, feeding entirely on fruit or grain, and others, which are beneficial by feeding on insects during part of the year, turn their attention to crops when these are ripe. Not even all the purely insectivorous birds are necessarily useful, as their food may consist of useful or beneficial insects. So that every different kind of bird must be judged on its merits from the point of view of whether it is useful or noxious to the agriculturist, our opinions of the value of each species being based solely on actual records of its food and feeding-habits. A bird that eats injurious insects is itself beneficial and vice versâ, and a bird which does good most of the year is not necessarily to be condemned as injurious because it occasionally does some harm. An occasional lapse from virtue need not be construed as a permanent divergence from the straight and narrow way; the good and the harm have to be balanced tcgether and a general average struck. So far as agriculture is concernerl there are practically only two classes to be considered, birds that feed on insects and those which eat grain, and the beneficial birds in the first class far outweigh in numbers and importance the injurious birds in the second class.

Practically nothing is on record of the actual food of birds in Southern India; what scanty field-notes exist have been collected by Mr. Mason in his memoir on the "Food of Birds in India" (Agri. Dept., Entom. Series, Vol. III), but the original work in this relates solely to one small district in Bihar and the number of observations is too small to be satisfactory. Feeding-habits may 
also vary to some extent in different districts in accordance with the relative abundance of particular kinds of food; at Coimbatore, for example, the Common Mynah is much more of a grasshopperhunter than in Bihar, because the country is more open and there are few fig-trees to provide the fruit on which this bird feeds largely in Bihar.

Amongst the commoner and most beneficial birds we may include the Drongo, Blue Jay, Hoopoe, Babblers, Orioles, Mynahs,

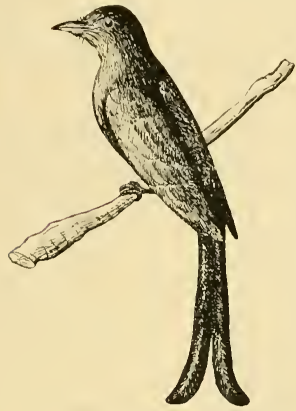

Fig. 99.-The King-crow

(Dicrurus ater). (Original.)

Tree Pie, Grey Tit, Wagtails, Woodpeckers, Nightjars, Crow-pheasant, Spotted Owlet and most owls, Common Pariah Kite, Cattle Egret, and perhaps Crows. Amongst the injurious birds we may mention especially Parroquets, Barbets, Beeeaters, and the House-sparrow.

The Drongo or King-crow (Dicrurus ater) occurs commonly throughout Madras and is exclusively insectivorous, the larger proportion of the insects eaten being of specious injurious to crops. It is fond of resting on any convenient perch from which it can swoop down on its prey and perches may therefore be placed in open fields to encourage and attract this bird.

The Blue Jay or Indian Roller (Coracias indica) is commonly distributed throughout the Plains, preferring localities which are thickly wooded. It feeds mostly on insects, which are largely grasshoppers and caterpillars, occasionally on larger animals such as mice or frogs. This is a most useful bird which deserves every possible protection, especially in the vicinity of towns and cantonments where it is too often shot on account of its gaudy plumage.

The Hoopoe (Upupa indica) occurs throughout Madras but is not very common as a rule. It feeds almost exclusively on insects, of which the greater part are destructive species. The Hoopoe is therefore extremely beneficial from an agricultural viewpoint and deserves protection throughout the year, but especially during the nesting-season, when the young are fed almost entirely on insect larvæ. This bird is particularly useful because its long beak enables it to destroy numbers of insects at some distance underground where they are out of reach of other enemies. 
Babblers of several species occur in Southern India, the Whitehead Babbler (Cratcropus griseus) being indeed confined to an area south of a line drawn from Ellore through Secunderabad to Belgaum. The Jungle Babbler (C. canorus), commonly called "Seven Sisters," is common throughout Southern India. The food of these birds consists for the most part of insects and these latter are all of species which are more or less injurious. A few frogs may be eaten occasionally, but on the whole these birds are distinctly beneficial. They rarely venture far into the open country, such as cultivated fields, but usually remain under the shelter of bushes or trees, where they hunt about amongst dead leaves and undoubtedly do a great deal of good in thinning off noxious insects which would otherwise spread into cultivated areas.

Orioles, of which the Indian Oriole (Oriolus kundoo) and the Black-headed Oriole (O. melanoccphalus) are the commonest, feed partly on insects and partly on fruit, but the vegetable food seems to consist almost wholly of the fruits of wild figs. These birds are not known to damage orchard fruits, and must be considered as distinctly beneficial to agriculture. They therefore deserve encouragement and protection, the more especially because their brilliant plumage has already attracted the undesirable attentions of the feather trade.

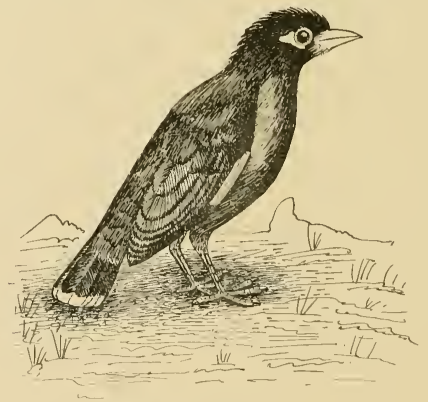

F1G. 100.-The Common Mynah (Acridotheres tristis). (Original.)

Mynahs of several kinds occur in Southern India and the Common Mynah (Acridotheres tristis) may be selected as typical of the group. It is common throughout Madras and feeds mostly on insects, of which grasshoppers form a large proportion. These birds may often be seen following cattle and catching insects 
disturbed from the grass as the cattle move. Occasionally the Mynah may eat a little oats, maize, cholam or paddy grain, but any damage done is insignificant in comparison with the good it does by destroying insects. At Nilambur this bird is reported by the Forest Department as constituting an important check on the caterpillars of Hyblac and Pyransta which defoliate the Teak plantations.

The Tree Pie (Dendrocitta ruf $(a)$ is common in some districts and oecasionally does some harm by eating eggs and young birds, lizards, etc., but the "general average" of its diet shows that the Tree Pie is distinctly beneficial by destroying noxious insects throughout the year.

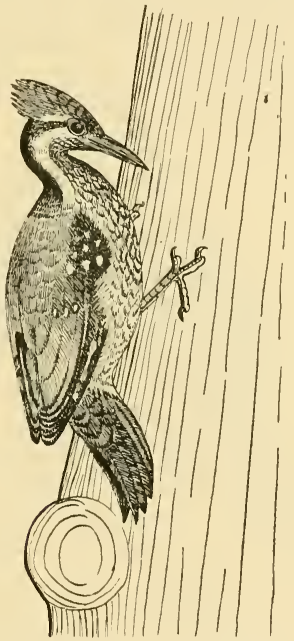

FIG. 101.-The Golden Woodpecker (Brachypternus aurantius).

(After Blanford.)

The Indian Grey Tit (Parus atriceps) and various other Tits common in the Plains feed chiefly on injurious insects, occasionally on fruit; when fruit-buds are plucked, these generally contain injurious insects.

Wagtails, with the exception of the Large Pied Wagtail (Motacilla maderaspatensis), are only winter visitors to Madras, summering and breeding in Northern India and Central Asia. They are, 
however, none the less useful, feeding principally on small insects, especially on flies, which they often catch around cattle.

Woodpeckers of various species occur in all wooded and forest regions. They feed entirely on insects, mostly on wood-boring species which they dig out of the trees affected, thus being especially beneficial in checking these pests of forest areas. Brachyptermus aurantins is said to be very partial to toddy palms, probably attracted by the palm beetles and weevils which bore into the trees when cut by the toddy-tappers.

Night-jars, being nocturnal or at least crepuscular in their habits, are not commonly recognized although they occur not infrequently in most localities. Their food consists of insects which they capture on the wing as a rule, occasionally on the ground. They must be classed as beneficial birds.

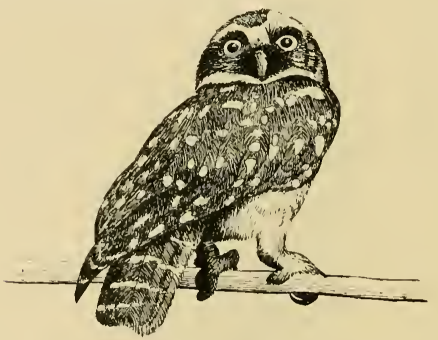

Fig. 102.-The Spotted Owlet (Athene brama). (After Dewar.)

The Spotted Owlet (Athene brama) is probably the most familiar of the owls, because it is common and often ventures out early in the evening. It seems to have a special predilection for the neighbourhood of man and sometimes even ventures into houses in search of prey, whilst a bungalow roof or an adjacent tree is a favourite perch, whence its shrill chattering constantly advertises its presence throughout the night. It feeds chiefly on insects, particularly crickets, and also on any small mice, shrews, or lizards it can catch. On the whole this little owl is distinctly beneficial, and the same may be said of all owls as a class.

The Crow-pheasant or Coucal (Centropus sinensis) does a great deal of good by destroying insects and occasional harm as a poacher of small birds-eggs and nestlings. From an agricultural standpoint it is beneficial and deserves protection in districts where it is" killed for food. 
The Common Pariah Kite (Milins gotinda) feeds largely on insects, particularly on grasshoppers and especially when these are present in large and destructive numbers. In the Bellary district this bird has proved most useful in the control of the Deccan Grasshopper, and in towns and villages it acts as a scavenger, clearing up offal and garbage and thus helping to reduce flies and disease. An occasional chicken taken now and again must not be regarded as a off set to its beneficial qualities. Much the same remarks apply to the Brahminy Kite (Haliastur indus).

The Cattle Egret (Bubulcus coromandus), as its name implies, may often be seen attending cattle and picking off leeches and other pests and also catching grasshoppers and other insects which are disturbed as the cattle walk along. In the stomachs of three birds examined by Mason, out of I66 insects no less than I60 belonged to injurious species; these figures speak for themselves. This bird also feeds to a small extent on fish, frogs and tadpoles, but it is distinctly beneficial from an agricultural standpoint.

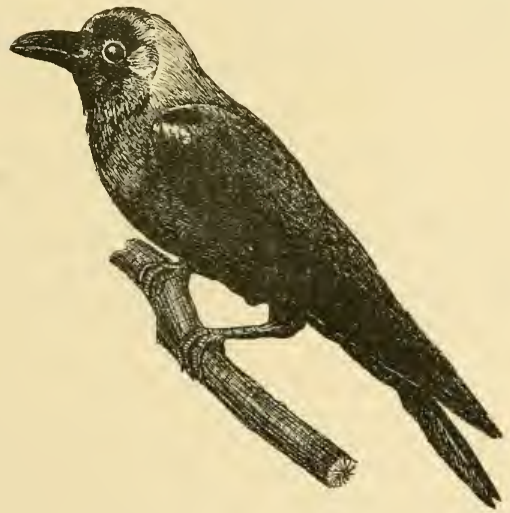

Fig. 103.-The Grey-necked Crow (Corvus splendens). (After Dewar.)

Crows have often been regarded as of neutral or negative value, but these opinions are perhaps tinged by observations on these birds in towns, where their morals have doubtless degenerated as a result of association with human society. Under such conditions the crow becomes a mere scavenger and parasite. But in the country, where the crow has to work for his own living, his habits 
are necessarily rather different and, in common with the cultivator, he has to look to the fields for his livelihood.

There are of course two common species of crows, the Greynecked Crow (Corvus splendens) and the Jungle Crow (C. macrorhynchus). The scientific name of the latter refers to the large size of its beak; that of the former was perhaps bestowed in irony and always reminds one of the Latin Grammar tag "splendide mendax." The habits and manners of both birds are similar, but the Greynecked Crow is generally found more commonly around houses, the Jungle Crow in the fields. Crows probably do some good in towns and villages which are sufficiently insanitary to provide them with a livelihood on garbage, but in the mofussil crows have to eke out an existence otherwise and it is under such circumstances that they may do either good or harm to the farmer. When cereals, and especially cholam, are ripe, crows are always amongst the first to discover the fact and to congregate in dozens in such fields, so that

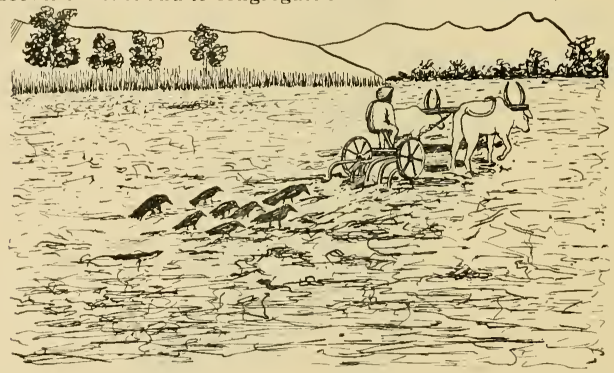

F1G, 104.-Crows following a Harrow and devouring the insects exposed.

(Redrawn from Author's original photo.)

in most districts it is customary to build a platform in the middle of the field and to station there a small boy armed with a whip or an old tin, which he cracks or beats to scare away the birds. At such times crows may certainly do considerable damage. But there is another side to the picture which is to be seen when ploughing or harrowing is taking place, the crows following the plough in numbers on these occasions and eagerly searching for any insects which may be turned up. Similarly, when fields are being irrigated, crows almost always make it their business to be present, hunting assiduously along the edge of the advancing water and picking up insects such as crickets which have been flooded out of cracks in the soil. At times, also, when caterpillars have increased to 
destructive numbers, crows discover them and devour them wholesale, and may under these circumstances do inestimable good in checking pests. On the whole, therefore, the general average of the crow's diet shows that this bird is beneficial from an agricultural point of view, the Jungle Crow being probably the more useful bird of the two. If crops can be protected by watchmen when ripe, the crows may be looked on as the farmer's allies during the rest of the yéar. Occasional damage to seedlings or grass lawns is usually more apparent than real and merely incidental to a search for grubs which are attacking the roots.

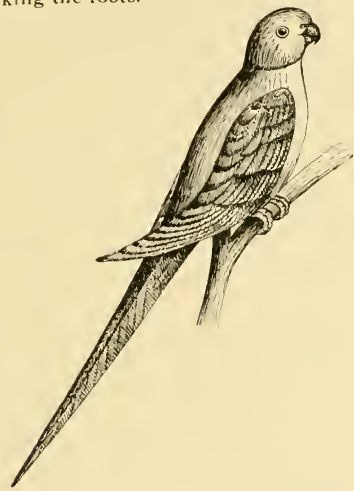

Fig. 105.-The Rose-ringed Parroquet (Palaornis torquatus). (After Cunningham.)

Of birds which are injurious to crops, the Parroquet (Palcornis torquatus) is the most pernicious. It feeds wholly on fruit and grain, usually associating in small flocks, which ravage all cereal crops whenever these are ripe and destroy far more than they eat. It does no good whatever but is, in fact, an unmitigated nuisance, and a reduction of its numbers, whether at the hands of plumagehunters or otherwise, cannot fail to benefit the cultivator.

The common Indian Green Barbet (Thereiceryx zeylonicus) is a pest of all fruit and often does considerable damage to loquats, peaches, etc., feeding in the early morning and evening as a rule. In the Coffee Districts Barbets sometimes do considerable damage by feeding on coffee-berries just as these are ripening. A few insects may be eaten occasionally, but these birds are normally ugivorous and must be regarded as injurious. 
On the other hand the Bee-eaters are exclusively insectivorous; yet they are destructive, especially where bees are kept, by feeding on these insects, and are especially noxious when queen-bees are being reared as they are almost invariably snapped up by these birds on their marriage-flight. The commonest species of bee-eater is Mcrops viridis, a small green bird with a long tail and slender beak, which is often seen perched on telegraph-wires, whence it swoops down on insects and then returns to its perch. These birds appear to be migrants to some extent, though little seems to be on record regarding their movements. Besicles honey-bees, these birds catch and eat various other species of bees, wasps and dragon-flies, and the bulk of their food is composed of beneficial insects, so that bee-eaters must certainly be ranked as injurious birds so far as agriculture is concerned.

The House-sparrow, which has been well named the "Avian rat," is essentially a human parasite and seems unable to establish itself except in towns or at least in the neighbourhood of large pucca buildings, where its incessant shrill cheeping makes it an intolerable nuisance all through the day. The young nestlings are fed at first on insects, chiefly caterpillars, but by the time they are three weeks old their food is composed exclusively of grain, and the adults feed almost wholly on grain, grass, and weed seeds and incidentally probably do some damage by distributing weeds. So far as the farmer is concerned, the sparrow seems to be as injurious in India as in most other countries, and would undoubtedly do more damage if not checked outside of towns by hawks, kites, crows and other enemies.

Allied to the birds are the Reptiles and Amphibians, the former class including tortoises, lizards and snakes, the latter frogs and toads.

Lizards are largely insectivorous and therefore beneficial on the whole, though there is little exact information on record regarding their food, and it is probable that the insects taken are of more or less neutral value on the whole. The common "bloodsucker" (Culotes versicolor) sometimes catches butterflies but probably feeds mostly on ground-living beetles of little importance. The geckos, or wall-lizards, which so commonly take up their station alongside the bungalow-lamps in the evening, feed on almost any moving insect not too large to tackle, whether it be beneficial or not; I have seen a gecko catch and eat a large Mantis and conversely I have seen the same individual catch and reject unharmed an injurious moth (Estigmene lactinea). Lizards undoubtedly do figure prominently amongst the enemies of insect pests of crops and to that extent do some good, but they also do some harm by feeding on 
beneficial and useful insects also, and to that extent must be reduced any benefit derived from them.

Some of the smaller Snakes feed on insects and it is said that young cobras will catch and eat butterflies, but snakes are of no direct importance as insect-eaters. They have, however, some indirect importance, because all the larger snakes feed on other animals, such as mice, rats, birds, lizards and frogs, which may themselves be insectivorous; and if their prey be useful the snakes which devour them must be injurious, and vice versâ. Judged by this standard the fact appears that almost all the smaller colubrine snakes are harmful and that the useful species are the larger colubrines, vipers, and the python, all of which feed on small mammals, and the kraits which feed on other snakes. We arrive then at the seeming paradox that, on the whole, the non-poisonous species not directly harmful to man are injurious indirectly and that the poisonous snakes are really useful. A Russell's Viper in the fields, apart from its potential danger to the farmer himself and to his animals, passes an extremely useful existence, living wholly on rats and mice of which each individual snake must eat several dozens every year, as it is rare to open one of these vipers without finding tolerably recent remains of such a meal.
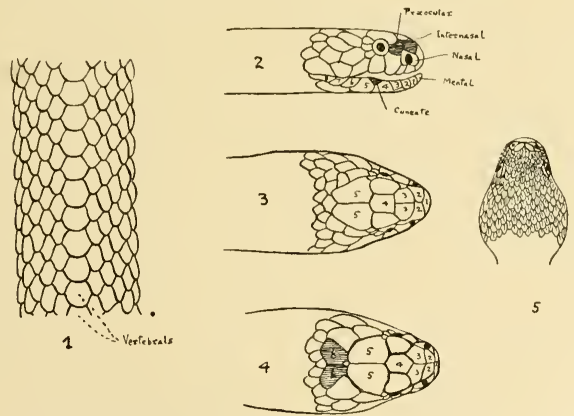

5

F1G. 106.- Key to common Poisonous Snakes of Sonthern India (Original.)

1. Portion of body of Krait, showing enlarged vertebrals; 2 . Side-view of head of Cobra-the numbered scales below the mouth are the infra-labials; 3 . Head of Cobra from above-the numbered scales are 1. Rostral, 2. Internasals, 3. Præfrontals, 4 . Frontal, 5. Parietals ; 4 . Head of King-Cobra or Hamadryad seen from above-figures as in 3 but the scales marked 6 are Occipitals; 5 . Head of Echis earinata from above, showing small scales-compare with the large plates seen in 3 and $t$. 
The mere fact that some snakes are venomous renders them of great direct importance to an agricultural population which walks about barefooted in the fields and the discrimination of the poisonous species is frequently necessary in cases of snake-bite. A few species, such as the Cobra and Russell's Viper, may be well-known, but to the ordinary man one snake is much the same as another and all are poisonous. There are, however, few venomous snakes which are at all common in Southern India and their identification is comparatively easy. The only ones which need be noticed here are the Krait, Cobra, King Cobra or Hamadryad, Echis and Russell's Viper. The Pit-vipers, so called from the curious pit-like depression in the head between each nostril and eye, are common in the Hills, the green species being frequently found on coffee-bushes; they are all poisonous, but rarely or never fatal.

The Krait (Bungarus candidus) is quite a common snake but seldom seen, as it lives a retired life in chinks and cracks of old walls and similar situations, only venturing abroad at night. It feeds solely on other snakes and is of a sluggish, peaceful disposition and loath to bite as a rule although the poison is twice or thrice as virulent as cobra venom and death has been known to occur in less than six hours after a bite from a specimen only I8 inches long. In colour it is of a glistening black, with paired white lines or narrow bands across the back, these white markings being less evident towards the head. The vertchrals, or row of scales along the middle of the back, are hexagonal (six sided) and greatly enlarged, at least twice as large as the other bodyscales, and the subcaudals, or scales beneath the tail, are single (i.e., not divided along the middle line to form two rows). If attention is paid to these points, there should be no difficulty in identifying a specimen as a krait; but it may be observed that there is no snake in India for which the ordinary man is more liable to mistake a harmless species, such as Lycodon anlicus, merely because the general shape and colour-pattern are similar. It may be noted, however, that in Lycodon and other harmless snakes the white cross-bands are more evident behind the head and fade away posteriorly, whilst the opposite is seen in the krait; in Lycodon and similar snakes also the vertebral scales are not enlarged.

The Cobra (Naja naja; tripudians of the "Fauna" volume and authors generally) is usually easily recognisable in life by the characteristic "hood," on which the markings are usually binocellate (two-eyed, spectacle-like), sometimes monocellate (singleeyed, O-shaped), rarely absent. In dead specimens, however, in which the hood is shrunk and the markings obliterated, this 
character is not available and several harmless suakes inflate their necks very considerably. Scale characters are therefore of importance and the cobra carries a uniquely characteristic identification-mark in the shape of a small wedge-shaped (cuneate) scale between the fourth and fifth infralabials (the row of scales bordering the lower lip, counted from the front backwards, remembering that the anterior, unpaired scale is the mental and not an infralabial). The scales bordering the front of the eye on each side are also in direct contact with the pair of scales lying between those in which the nostrils are placed. If neither of thesc characters occur, the snake cannot be a cobra.

The King Cobra or Hamadryad (Naja bungarus) occurs in all the Hill Districts and may reach a length of over 15 feet. It has a small hood but is best recognised by the presence of a pair of large occipital shields in contact with one another and forming a sixth set of large head-scales counting from the nose along the middle line. The anterior subcaudals are undivided, the posterior ones divided into two rows, whilst the vertebrals are not enlarged.

The Echis (Echis carinata) is common throughout the plains, often abundant in sandy places. The Trichinopoly District and the Guindy Race-Course are well-known localities and I have found it in Bellary and seen it brought in at Bangalore. This small viper rarely exceeds a length of 2 feet, but it is extremely poisonous and fatalities from its bite are numerous in districts where it is common. When disturbed or discovered it has a curious habit of throwing itself rapidly from one side to another, whilst remaining in a loose coil, so that the scales rub over one another and procluce a loud hissing sound. This snake is easily recognised by the facts that (I) the top of the head is covered with small scales similar to those found on the body, and (2) the subcaudals, or scales beneath the tail, are entire and form only a single row.

The Russell's Viper (Vipera russellii), so named in honour of Dr. Patrick Russell whose work on South Indian Snakes, published

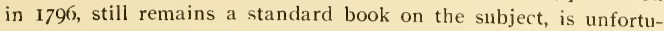
nately only too common throughout Madras. Its coloration, with a triple row of light-edged spots down the back, is distinctive, but it is better identified by the facts that, as in Echis, the top of the head is covered with small scales, whilst unlike Echis, the subcaudals, or scales beneath the tail, are divided down the middle to form a double row. The bite of this snake is fatal to man and domestic animals; otherwise the Russell's Viper is a most useful snake, feeding entirely on rats and mice. It is a sluggish a nimal, as a rule, hissing loudly when disturbed but slow to wrath, but when it does strike it darts like a flash and often retains its grip. 


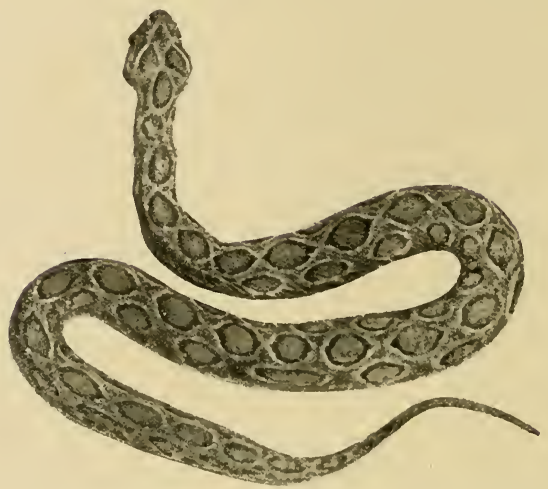

F1G. 107.-The Russell's Viper (Vipera russellii), useful on account of its value as a destroyer of rats but dangerously poisonous to man. IAuthor's original photo.'

A great deal of rubbish has been written on the treatment of snake-bite, a subject which seems to appeal strongly to the credulity of the general public, and the most extraordinary methods of cure are vaunted in blind faith; unfortunately many of these are tried in cases where either the snake is non-venomous or a lethal dose of poison has not been injected and cures are consequently claimed in cases in which the patient would have recovered in any case. Snake-stones, Tanjore pills, the use of ammonia or alcohol, may all be cited as examples of this. If poison has really been injected, the only effective cure is by injection of an appropriate anti-venene prepared by gradually inoculating an animal, usually a horse, to withstand increasing dosages of the poison of that particular kind of snake. A bivalent anti-venene prepared to counteract the poisons of the Cobra and Russell's Viper is prepared and available, but for other snakes no such cure is at present possible as their venoms cannot be obtained in sufficient quantity for the preparation of anti-venenes. Once in the tissues the poison spreads with such extreme rapidity that ligaturing, incision with or without the application of oxydising agents such as potassium permanganate, or even amputation, are of little practical use unless applied with a promptitude which is usually impracticable; deep incision, making several deep parallel cuts along the length of the 
limb, and the application of permanganate crystals may, however, help to neutralize sufficient venom to reduce a lethal dose into a sublethal one, the wound being carefully dressed aseptically. In cases of cobra-bite, if the breathing ceases, artificial respiration should be employed and continued for as long as possible--some hours at least; this may give time to procure anti-venene if this is not already at hand.

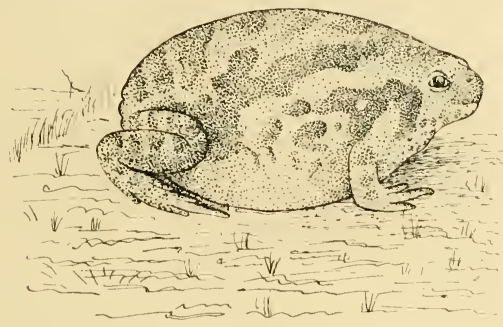

Fig. 108,--Cacopus systoma. (Original.)

The Amphibia include the Frogs and Toads whose eggs as a rule are deposited in water, hatching out into tadpoles which develop legs, reduce their tails, and change into young frogs. In the case of the Chunam Frog (Rhacophorns maculatus), a common tree-frog with little toe-discs by means of which it enabled to cling to walls and leaves and even to panes of glass, the eggs are laid in a curious frothy mass which is suspended over water into which the young tadpoles drop when they hatch out; these eggmasses may often be seen attached to the edges of cement-lined tanks at the commencement of the rainy season. The commonest pond-frog is probably Rana cyanophlyctis which is usually found along the edges of all small accumulations of water; it seems to feed principally on such insects as fall into the water. The Bullfrog (Rana tigrina), a very large frog with a yellowish stripe down the back, is also found around ponds and often, in wet weather, in grass well away from water; it is capable of giving prodigious leaps and is therefore by no means easy to catch. It is largely carnivorous in habit, feeding on other frogs, even other individuals of its own species, and it is not uncommon to find one of these cannibals dead with another individual half his own size wedged firmly in his throat. Several frogs are burrowers, living underground as a rule and only coming up in wet weather; of this group Rana breviceps is a common example in some localities, but 
Cacopus systoma is probably better known, by sound at least. In many districts in the Plains, notably around Madras, this frog is common and its loud drumming note, so difficult of exact location, is frequently heard at night during heavy rain at the commencement of the North-east Monsoon, although the extraordinarily bloated frog itself is seldom seen and quite unfamiliar to most people. The commonest Toad, both in the Plains and Hills, is Bufo melanostictus, which often enters bungalows in search of insects attracted to the lights.

The main food of frogs and toads is well known to be insects and consequently these animals are always regarded as beneficial, as no doubt they are as a class and on the whole. We have, however, few exact records of their food and feeding habits and it is probable that these are so casual as to reduce their value very largely. A frog which snaps up every insect which falls into a pond, or a toad which will engulph any insect which moves, may do actual harm by destroying useful species, whilst many of the real pests, being protected by nauseous odlours or sharp spines, are avoided; a hungry toad, for example, will snap up a specimen of Dysdercus cingulatus but immediately rejects it unharmed. Exact records of the actual food of frogs and toads under natural conditions in India are at present desiderata, whilst the field of inquiry is large and ready at hand to any observer.

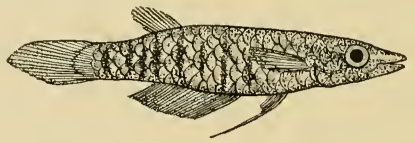

FIG. 109.- Haplochilus lineatus, a mosquito-eating fish. (After Day.)

The main utility of Fish in India is as a source of food, but it must not be overlooked that many fish, especially amongst the smaller species, are of the utmost utility in reducing the number of mosquitos present as larvæ in the ponds and other waters in which such fish live, and this fact is often of the greatest importance in determining the malarial factor in any locality. Several small fish, especially the species of the genus Haplochilus, feed greedily on mosquito-larvæ and may easily be introduced into ponds and wells in order to prevent mosquitos from breeding in such places; at Coimbatore we have also found that young individuals of Macrones vittatus are extremely useful in this respect, but larger individuals would probably require larger prey and do harm by eating smaller fish. For it must be remembered, in stocking water with small fish to reduce mosquitos, that all large fish must be 
removed first of all, for otherwise the large fish will probably eat the smaller ones and be useless themselves as mosquito-destroyers. Crabs are found in most streams both in the Plains and Hills and occasionally do a little harm by burrowing into bunds of paddyfields, etc. It is possible that they may also do some clamage at times to young paddy, whilst crab-holes are often utilized as breeding places by mosquitos, Ceratopogon, and other blood-sucking flies. In most districts, however, they are sought after and used as food, a dead Calotes being a favourite bait.

The Arachnida include the mites, which are treated elsewhere, and the scorpions, spiders and ticks. Scorpions of various kinds are common, and we may mention here the large blackish-green Palamnans found commonly under stones in the Hills, the large brown Butho which occurs in the Plains, and the little grey housescorpion; this last, which frequently shams death when discovered, forms a useful check on household pests. The "Jalamandalam" or "Jerry Munglum" (Galeodes indicus), common in Bellary and other districts, also belongs to this group. Spiclers are so extremely varied in structure, appearance and habits that it is impossible to attempt any account of the group here and the student may be referred to the "Fauna" volume which contains some account of the larger forms. Allusion may, however, be made to the social nests of Stegodyphus which sometimes cover whole bushes and are inhabited by numerous individuals which live in common-a very unusual habit amongst spiders, where it is the general rule for the female to eat her own husband. In South Africa, where a similar Stegodyphus occurs, the caterpillars of a little moth (Batrachedra stegodyphobius), live in the nest with the spiders and feed on the rejected fragments of the food of the latter; I have found empty pupa-cases of a snall moth in these nests in Madras and further search will probably reveal a similar symbiotic arrangement.

The Diplopoda include the Millipedes, animals with long, round, segmented bodies, with two pairs of short legs on each segment. One species has been found under suspicious circumstances in a case of damage to ground-nuts but it is probable that these animals may occasionally do a little damage by feeding on growing plants. Normally their food seems to consist of dead vegetable matter and lichens. They are preyed on by some Reduviid bugs, such as Physorhynchus, but seem rather exempt from attack by vertebrate enemies.

The Chilopoda or Centipedes have a long, many-jointed, flattened body, each segnient bearing only one pair of legs, of which the first pair is usually modified to form a formidable pair of poisonfangs. Centipedes generally live in cavities and cracks in the soil 


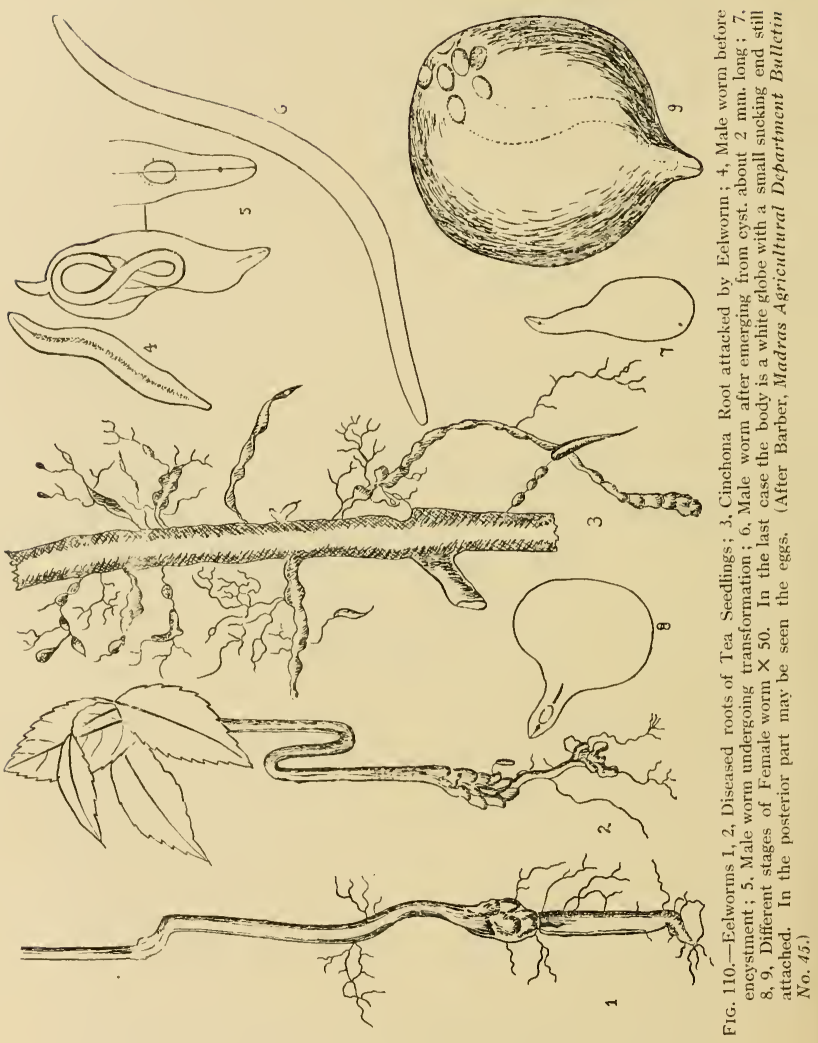


and are nocturnal, preying on insects and small vertebrates and being themselves eaten by many birds, notably crows, when flooded out of their retreats. They are probably of little economic importance, but the large Scolopendras frequently invade bungalows, and arc to be avoided, because they can inflict a highlypoisonous wound with their fangs.

Of the smaller animals the only others which can be mentioned are the Eelworms which frequently attack plants and may do considerable damage in nurseries of young tea plants. Their presence is generally recognizable by the characteristic noclules produced on the roots, the worms themselves being microscopic and barely visible to the naked eye. As a rule they occur in damp or water-logged soil and drainage is indicated as a step towards control, although a patch of ground, once infected, remains so for a long period, and the only thing to do is to discontinue growing on it for a time any crop susceptible to the attack of eelworms. Watering with a weak solution of Formalin has been recommended and Crude Oil Emulsion is also useful sometimes, but as a rule any disinfectant of this nature is useless at a strength insufficient to harm the plants.

Finally, we can only find room for a brief reference to Slugs and Snails which frequently attack young vegetable crops, especially in the Hills. In Ceylon a slug has been noted to do considerable damage to tapped rubber trees by feeding on the exuding latex. They are best checked by taking a bucketful of sawdust and moistening it with a mixture of one or two large cups of phenyle (crude carbolic acid) and ten to twenty cups of water; the sawdust is then spread around the rows or plants to be protected or around single plants, or sprinkled over the surface of the soil if the area is a large one. During wet weather a stronger solution may be employed with safety to the plants as the phenyle is slowly washed out of the sawdust. Ringing the earth around the stems with Lime is also successful sometines, and doubtless the waste Calcium Carbide from Acetylene gas generators could be employed with good results as a deterrent against these animals. Slugs and snails may also be trapped by laying out pieces of board, bark, etc., over fresh baits of succulent leaves, such as cabbage or lettuce; any captures may simply be squashed or dropped into a bucket of salt and water. 


\section{LIST OF CROPS IVITH THE INSECTS WHICH ATTACK EACH.}

IN the following List of the commonly-grown Crops, placed in alphabetical order for convenience of reference, are given under the name of each crop the various insects which are known to attack it, so far as they are included in this book. As all the insects are figured, it is hoped that this list will aid in the identification of at least all the insects more commonly found on these crops.

PAGE

ADRAK :- See Ginger.

Aсатнг (Sisbania grandiftora):--

$\begin{array}{lllllllll}\text { Sphenoptera arachidis (borer) } & \ldots & \ldots & \ldots & \ldots & \ldots & 298\end{array}$

$\begin{array}{lllllllll}\text { Platypria hystrix (leaves) } & \ldots & \ldots & \ldots & \ldots & \ldots & 316\end{array}$

$\begin{array}{lllllllll}\text { Alcides bubo (borer) } & \ldots & \ldots & \ldots & \ldots & \ldots & \ldots & 337\end{array}$

$\begin{array}{lllllllll}\text { Pericallia ricini (leaves) } \ldots & \ldots & \ldots & \ldots & \ldots & \ldots & 370\end{array}$

$\begin{array}{lllllllll}\text { Prodenia litura (leaves) } & \ldots & \ldots & \ldots & \ldots & \ldots & \ldots & 377\end{array}$

$\begin{array}{lllllllll}\text { Catopsilia pyranthe (leaves) } & \ldots & \ldots & \ldots & \ldots & \ldots & 4 \mathbf{r} 3\end{array}$

$\begin{array}{lllllllll}\text { Terias hecabe (leaves) } & \ldots & \ldots & \ldots & \ldots & \ldots & \ldots & 4 \mathbf{r} 4\end{array}$

$\begin{array}{llllllll}\text { Azygophleps scaluris (borer) } & \ldots & \ldots & \ldots & \ldots & \ldots & 447\end{array}$

$\begin{array}{llllllll}\text { Coptosoma cribraria (sucking) } & \ldots & \ldots & \ldots & \ldots & \ldots & 469\end{array}$

Ailantrus (Ailanthus excelsa) :--

$\begin{array}{lllllllll}\text { Solenopsis geminata (leaves) } & \ldots & \ldots & \ldots & \ldots & \ldots & 274\end{array}$

$\begin{array}{llllllll}\text { Eligma narcissus (leaves) } & \ldots & \ldots & \ldots & \ldots & \ldots & 384\end{array}$

$\begin{array}{lllllllll}\text { Attequ fabriciella (leaves) } & \ldots & \ldots & \ldots & \ldots & \ldots & 462\end{array}$

Ikн :-See Calotropis.

Aleizzia spp. :-

$\begin{array}{lllllllll}\text { Xystrocera globosa (borer) } & \ldots & \ldots & \ldots & \ldots & \ldots & 321\end{array}$

$\begin{array}{llllllll}\text { Xyleborus fornicatus (borer) } & \ldots & \ldots & \ldots & \ldots & \ldots & 345\end{array}$

$\begin{array}{lllllllll}\text { Terias hecabe (leaves) } & \ldots & \ldots & \ldots & \ldots & \ldots & \ldots & 4 \mathbf{I} 4\end{array}$

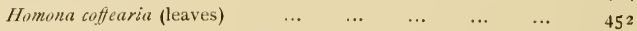

Ali, Low Growing Crops :-

Zonubris pustulatu (flowers)

Itactogaster finitimus (leaves)

Estigmene lactinea (leaves)

Imsacta albistriga (leaves)

Creatonotus gangis (leaves)

Prodenia lutura (leaves) ...

Laphygma exigua (leaves)

$\begin{array}{llllll}\ldots & \cdots & \cdots & \ldots & \ldots & 303 \\ \ldots & \ldots & & \end{array}$

$\begin{array}{llll}\cdots & \cdots & \cdots & 333\end{array}$

$\begin{array}{llllll}\ldots & \ldots & \ldots & \ldots & \ldots & 368\end{array}$

$\begin{array}{llllll}\ldots & \ldots & \ldots & \ldots & \ldots & 369\end{array}$

$\begin{array}{lllllll}\cdots & \ldots & \ldots & \ldots & \ldots & 369\end{array}$

$\begin{array}{llllll}\ldots & \ldots & \ldots & \ldots & \ldots & 377\end{array}$

$\begin{array}{llllll}\ldots & \ldots & \ldots & \ldots & \ldots & 378\end{array}$ 
PAGE

Cyrtacanthacris succincta (leaves)

Do. ranacea (leaves)

530

Aloe (Agave americana) :-

Oryctes rhinoceros (bores shoots)

${ }_{28} 8_{5}$

Alsi :- See Linseed.

Alu :-See Potato.

Aír :- See Mango.

Amaranthus :-

Lixus brachyrhinus (borer)

Laphygma exigua (leaves)

Hymenia fascialis (leaves)

$43 \mathrm{I}$

Eretmocera impactella (top-shoots)

$46 \mathrm{I}$

Atractomorpha crenulata (leaves)

528

Ambadi :-See Rozelle.

ANAR:-See Pomegranate.

Aniseed (Pimpinella anisum) :-

Agonoscelis nubila (sucking)

472

Annatro (Bixa orellana) :-

Xyleborus fornicatus (borer)

Helopeltis antonii (sucking)

APPLE (Pyrus malus) :- -

Celosterna spinator (twigs)

Schizoneura lanigera (sucking roots and twigs)...

Arand1:-See Castor.

ARHAR :-See Red Gram.

BABUL (Acacia arabica) :-

Psiloptera fastuosa (borer)

Calosterna spinator (borer)

297

Clania crameri (leaves) ...

Badan: - See Country Almond.

BAEL (Egle marmelos) :-

Papilio demoleus (leaves) ...

Bajra :-See Cumbu.

BALLAR :-See Lab-lab.

Bamboo (See also Grasses) :-

Stromatium barbatum (borer)

Telicotu augias (leaves) ...

Oregma bambusa (sucking leaves)

Banana :- See Plantain.

BEET (Beta vulgaris) :-

Monolepta signata (leaves)

Bengal-Gram (Cicer arietinum) :-

Chloridea obsoleta (pods) 
Betel (Piper betle) :-

$\begin{array}{llllllll}\text { Cyclopelta siccifolia (sucking) } & \ldots & \ldots & \ldots & \ldots & \ldots & 476\end{array}$

$\begin{array}{llllllll}\text { Disphinctus politus (sucking) } & \ldots & \ldots & \ldots & \ldots & \ldots & 489\end{array}$

Bhavunchr :-See Psoralea corylifolia.

BHINDI (Hibiscus esculentus) :-

$\begin{array}{lllllllll}\text { Sphenoptera gossypii (borer) } & \ldots & \ldots & \ldots & \ldots & \ldots & 29^{8}\end{array}$

$\begin{array}{llllllll}\text { Zonaliris pustulata } \text { (flowers) } & \ldots & \ldots & \ldots & \ldots & \ldots & 303\end{array}$

$\begin{array}{lllllllll}\text { Earias insulana (fruit) } & \ldots & \ldots & \ldots & \ldots & \ldots & \ldots & 3^{84}\end{array}$

$\begin{array}{llllllllll} & \text { fabia (fruit) } \quad \ldots & \ldots & \ldots & \ldots & \ldots & \ldots & 3^{8} 5\end{array}$

$\begin{array}{lllllllll}\text { Cosmophila erosa } \text { (leaves) } & \ldots & \ldots & \ldots & \ldots & \ldots & 39\end{array}$

$\begin{array}{lllllllll}\text { Oxycarenus latus (sucking) } & \ldots & \ldots & \ldots & \ldots & \ldots & \mathbf{4 8 2}\end{array}$

$\begin{array}{llllllll}\text { Dysdercus cingulatus (sucking) } & \ldots & \ldots & \ldots & \ldots & \ldots & 484\end{array}$

Bilva :-See Bael.

Bitter-Gourd (Momordica sp.) :--

$\begin{array}{lllllllll}\text { Epilachna } 12 \text { 2-stigma (leaves) } & \ldots & \ldots & \ldots & \ldots & \ldots & 292\end{array}$

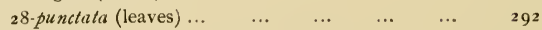

$\begin{array}{lllllll}\text { Aulacophora abdominalis (foveicollis) (leaves) } & \ldots & \ldots & \ldots & 3 \text { II }\end{array}$

$\begin{array}{lllllllll} & \text { " atripennis (leaves) } & \ldots & \ldots & \ldots & \ldots & \ldots & 3 \mathrm{I} 2\end{array}$

$\begin{array}{lllllllll} & \text { stevensi (leaves) } & \ldots & \ldots & \ldots & \ldots & \ldots & 3 \mathbf{r} 2\end{array}$

BLACK-GRAM (Phaseolus mungo ridiatus) :-

$\begin{array}{lllllllll}\text { Azazia rubricans (leaves) } & \ldots & \ldots & \ldots & \ldots & \ldots & 3^{89}\end{array}$

$\begin{array}{llllllll}\text { Nacoleia indicata (leaves) } & \ldots & \ldots & \ldots & \ldots & \ldots & 434\end{array}$

$\begin{array}{llllllll}\text { Riptortus pedestris (sucking) } & \ldots & \ldots & \ldots & \ldots & \ldots & 480\end{array}$

BotTLE-Gourd (Lagenaria vulgaris) :-

$\begin{array}{lllllll}\text { Aulacophora abdominalis foveicollis (leaves) } & \ldots & \ldots & \ldots & 3 \text { II }\end{array}$

$\begin{array}{llllllll}n & \text { atripennis (leaves) } & \ldots & \ldots & \ldots & \ldots & \ldots & 3 \mathbf{I 2}\end{array}$

$\begin{array}{lllllllll} & \text { stevensi }(\text { leaves) } & \ldots & \ldots & \ldots & \ldots & \ldots & 312\end{array}$

$\begin{array}{lllllllll}\text { Sphenarches caffer (leaves) } & \ldots & \ldots & \ldots & \ldots & \ldots & 443\end{array}$

Brinjal, (Solanum melongena):-

$\begin{array}{lllllllll}\text { Solenopsis geminata (buds) } & \ldots & \ldots & \ldots & \ldots & \ldots & 274\end{array}$

$\begin{array}{llllllll}\text { Epilachna } \text { г 2-stigma (leaves) } & \ldots & \ldots & \ldots & \ldots & \ldots & 292\end{array}$

$\begin{array}{lllllllll} & 28 \text {-punctata (leaves) } & \ldots & \ldots & \ldots & \ldots & \ldots & 292\end{array}$

$\begin{array}{lllllllll}\text { Prodenia litura (leaves) } & \ldots & \ldots & \ldots & \ldots & \ldots & \ldots & \ldots & 377\end{array}$

$\begin{array}{llllllll}\text { Laphygma exigua (leaves) } & \ldots & \ldots & \ldots & \ldots & \ldots & 379\end{array}$

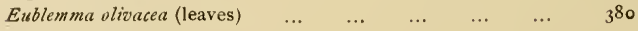

$\begin{array}{llllllll}\text { Brinjal Sarrothripine (leaves) } & \ldots & \ldots & \ldots & \ldots & \ldots & 3^{8} 3\end{array}$

$\begin{array}{lllllllll}\text { Acherontia sty } x \text { (leaves) } & \ldots & \ldots & \ldots & \ldots & \ldots & \ldots & \ldots & 402\end{array}$

$\begin{array}{llllllll}\text { Euzophera perticella (borer) } & \ldots & \ldots & \ldots & \ldots & \ldots & 428\end{array}$

$\begin{array}{llllllll}\text { Leucinodes urbonalis (borer) } & \ldots & \ldots & \ldots & \ldots & \ldots & 436\end{array}$

$\begin{array}{llllllll}\text { Pachyzancla agrotalis (leaves) } & \ldots & \ldots & \ldots & \ldots & \ldots & 440\end{array}$

$\begin{array}{llllllll}\text { Pterophorus lienigianus (leaves) } & \ldots & \ldots & \ldots & \ldots & \ldots & 445\end{array}$

$\begin{array}{llllllll}\text { Aspongopus janus (sucking) } & \ldots & \ldots & \ldots & \ldots & \ldots & 476\end{array}$ 

PLATE II
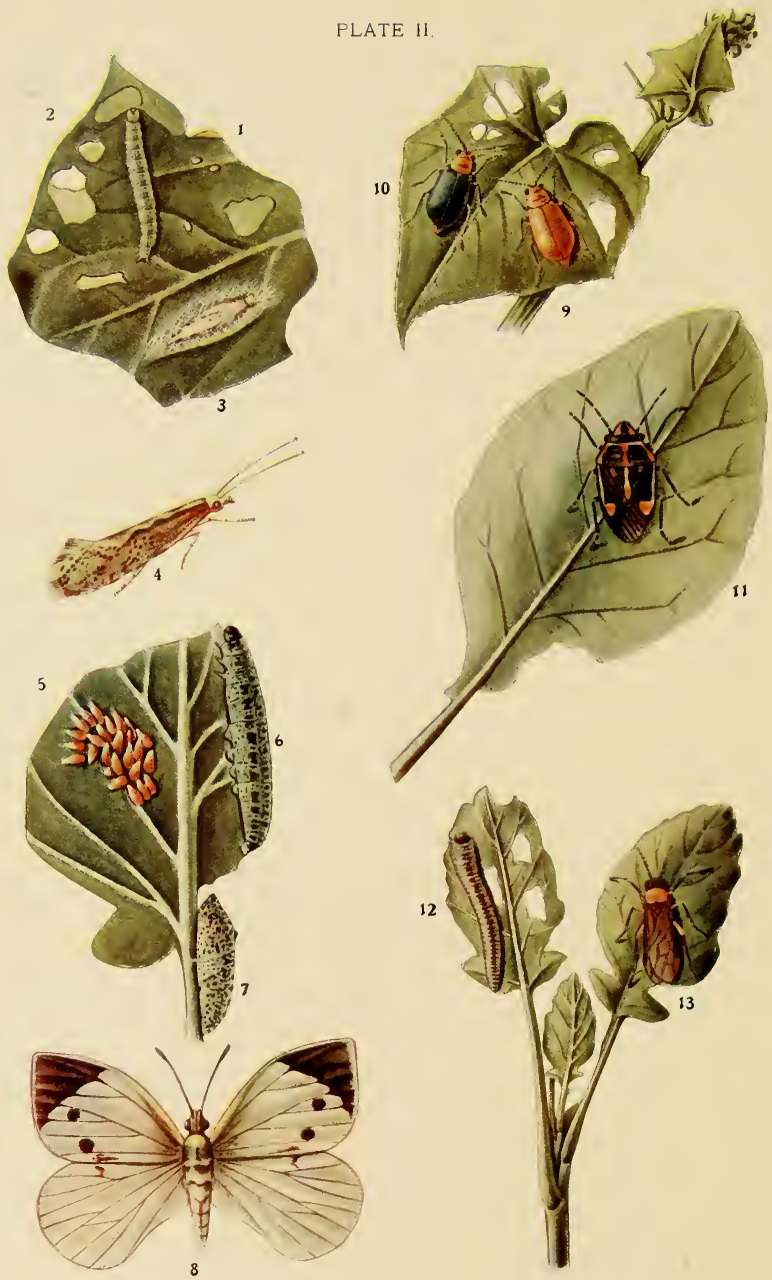

PESTS OF CABBAGE, RADISH, etc. 


\section{EXPLANATION OF PLATE 11. \\ PESTS OF CABBAGE, RADISH, ETC.}

Frg. 1. Plutell. maculipennis, eggs, magnified.

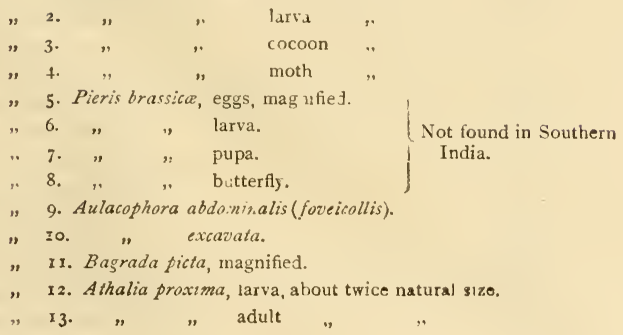




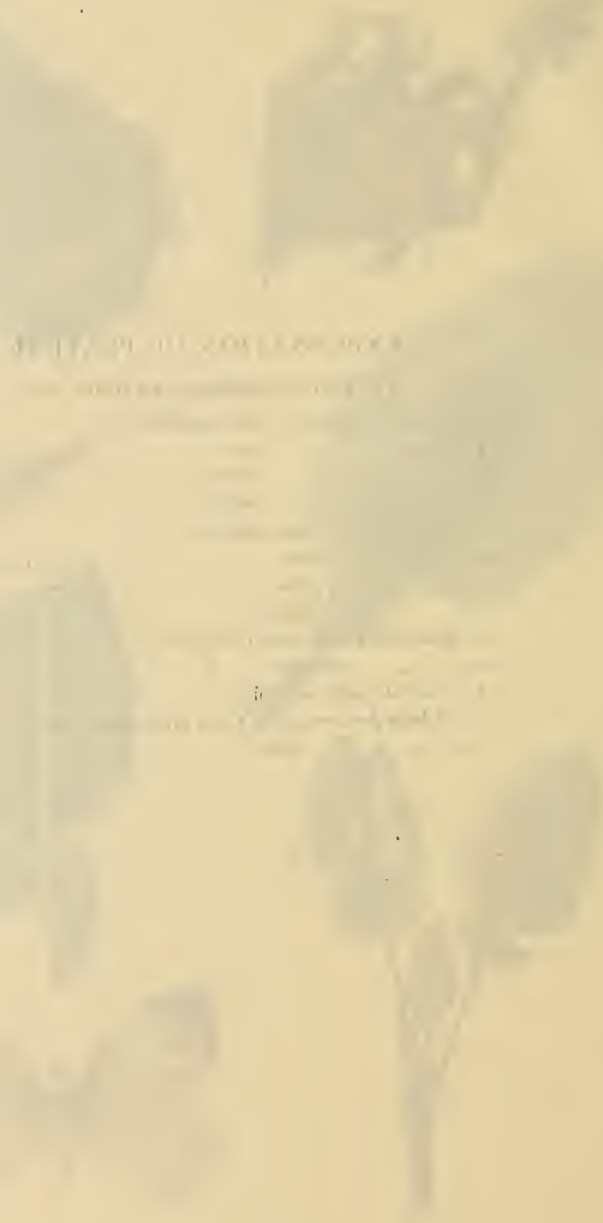


Anoplocnemis phasiana (sucking)

PAGE.

Urentius echinus (sucking)

Orthacris sp. (leaves)

485

Atractomorpha crenulata (leaves)

Bukul:-See Mimusops.

CabBage (Brassica oleracea) :-

Athalia proxima (leaves)

$28 \pi$

Monolepta signata (leaves)

310

Euxoa segetis (stem)

375

Prodenia litura (leaves) ...

$\begin{array}{llllllll}\text { Crocidolomia binotalis (leaves) } & \ldots & \ldots & \ldots & \ldots & \ldots & 437\end{array}$

$\begin{array}{llllllllll}\text { Hellula undalis (leaves) } & \ldots & \ldots & \ldots & \ldots & \ldots & \ldots & \ldots & 43^{8}\end{array}$

$\begin{array}{llllllll}\text { Plutella maculipennis (leaves) } & \ldots & \ldots & \ldots & \ldots & \ldots & 464\end{array}$

$\begin{array}{llllllll}\text { Bagrada picta } \text { (sucking) } \ldots & \ldots & \ldots & \ldots & \ldots & \ldots & 473\end{array}$

$\begin{array}{lllllllll}\text { Orthacris sp. (leaves) } & \ldots & \ldots & \ldots & \ldots & \ldots & \ldots & 527\end{array}$

C.ACAo (Theobroma cacao) :--

$\begin{array}{lllllllll}\text { Yyleborus forniatus } \text { (borer) } & \ldots & \ldots & \ldots & \ldots & \ldots & 345\end{array}$

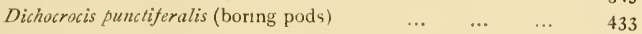

$\begin{array}{llllllll}\text { Helopeltis antonii (sucking) } & \ldots & \ldots & \ldots & \ldots & \ldots & & 488\end{array}$

Calotropis (Calotropis gigantea) :-

$\begin{array}{lllllllll}\text { Paramecops farinosa (leaves) } & \ldots & \ldots & \ldots & \ldots & \ldots & 332\end{array}$

$\begin{array}{lllllll}\text { Pericallia ricini(leaves) } \ldots & \ldots & \ldots & \ldots & \ldots & \ldots & 332 \\ \end{array}$

$\begin{array}{llllllll}\text { Tarache nitidula (leaves) } & \ldots & \ldots & \ldots & \ldots & \ldots & 382\end{array}$

$\begin{array}{llllllll}\text { Lygaus pandurus (sucking) } & \ldots & \ldots & \ldots & \ldots & \ldots & 48_{\text {I }}\end{array}$

$\begin{array}{lllllll}\text { Eurybrachys tomentosa (sucking) } & \ldots & \ldots & \ldots & \ldots & 492\end{array}$

$\begin{array}{llllllll}\text { Pacilocerus pictus (leaves) } & \ldots & \ldots & \ldots & \ldots & \ldots & 527\end{array}$

CARDanom (Elettaria cardamomum) :-

Cardamom Scolytid (seeds)

344

$\begin{array}{llll}\text { Dichocrocis punctiferalis (stem and capsules) } & \text {.. } & \ldots & 433\end{array}$

$\begin{array}{llllllll}\text { Hilarographa caminodes (roots) } & \ldots & \ldots & \ldots & \ldots & \ldots & \ldots & 464\end{array}$

$\begin{array}{llllllll}\text { Stephanitis typicus (sucking) } & \ldots & \ldots & \ldots & \ldots & \ldots & 48_{4}^{4}\end{array}$

Cashew (Anacardium occidentale) :--

$\begin{array}{lllllllll}\text { Cricula trifenestrata (leaves) } & \ldots & \ldots & \ldots & \ldots & \ldots & 406\end{array}$

CASSIA spp. :-

$\begin{array}{llllllll}\text { Sphenoptera arachidis (borer) } & \ldots & \ldots & \ldots & \ldots & \ldots & 298\end{array}$

Biston suppressaria (leaves) $\quad \ldots \quad 409$

$\begin{array}{llllllll}\text { Catopstia pyranthe (leaves) } & \ldots & \ldots & \ldots & \ldots & \ldots & 4 \mathrm{r} 3\end{array}$

$\begin{array}{lllllll}\text { Terias hecabe (leaves) } & \ldots & \ldots & \ldots & \ldots & \ldots & 4 \mathrm{r} 4\end{array}$

$\begin{array}{llllllll}\text { Argyroploce illepida (seeds) } & \ldots & \ldots & \ldots & \ldots & \ldots & 449\end{array}$

Castilloa Rubeer :-

$\begin{array}{lllllllll}\text { Lecanium olea }(\text { scale) } & \ldots & \ldots & \ldots & \ldots & \ldots & \ldots & 5 \text { I5 }\end{array}$

I $6-\mathrm{A}$ 
('ASTOR (Ricinus communis):-

PAGE

Xyleborus fornicatus (borer)

Amsacta albistriga (leaves)

Pericallia ricini (leaves)

370

Prodenia litura (leaves) ...

Achaa melicerta (leaves)

Orgyia postica (leaves)

Olene mendosa (leaves) ...

395

Euproctis fraterna (leaves)

scintillans (leaves)

396

398

399

Parasa lepida (leaves)

Altha nivea (leaves)

4 II

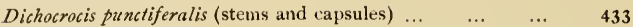

$\begin{array}{lllllllll}\text { Clania crameri (leaves) } & \ldots & \ldots & \ldots & \ldots & \ldots & \ldots & 448\end{array}$

$\begin{array}{llllllll}\text { Nezara viridula (sucking) } & \ldots & \ldots & \ldots & \ldots & \ldots & 473\end{array}$

$\begin{array}{lllllllll}\text { Empoasca flavescens (sucking) } & \ldots & \ldots & \ldots & \ldots & \ldots & 498\end{array}$

$\begin{array}{llllll}\text { Aleurodes ricini (sucking) } & \ldots & \ldots & \ldots & \ldots & 508\end{array}$

$\begin{array}{llllllll}\text { Cyrtacanthacris ranacea (leaves) } & \ldots & \ldots & \ldots & \ldots & 53^{1}\end{array}$

Casuarina (Casuarina equisetifolia) :-

Calosterna spinator (borer)

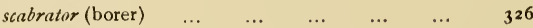

$\begin{array}{llllllll}\text { Arbela tetraonis (borer) } & \ldots & \ldots & \ldots & \ldots & \ldots & \ldots & 453\end{array}$

$\begin{array}{lllllll}\text { Brachytrypes portentosus (seedlings) } & \ldots & \ldots & \ldots & \ldots & 53^{6}\end{array}$

CAuliflower (Brassica oleracea cauliftora):-

Athalia proxima (leaves

Monolepta signata (leaves)

$28 \mathrm{I}$

$\begin{array}{llllllll}\text { Parasa lepida (leaves) } & \ldots & \ldots & \ldots & \ldots & \ldots & \ldots & 4 \mathbf{4} \mathbf{I}\end{array}$

$\begin{array}{llllllll}\text { Plutella maculipennis (leaves) } & \ldots & \ldots & \ldots & \ldots & \ldots & 464\end{array}$

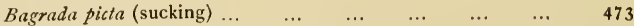

Ceara Ruber (Manihot gluziovii) :-

Lecanium nigrum (scale)

Cereals (See also Paddy, Cholam, Ragi, Wheat, etc.) :-

Anatona stillata (flowers)

282

$\begin{array}{llllllll}\text { Oxycetonia versicolor (flowers) } & \ldots & \ldots & \ldots & \ldots & \ldots & \mathbf{2 8} 3\end{array}$

$\begin{array}{llllllll}\text { Chiloloba acuta (flowers) } & \ldots & \ldots & \ldots & \ldots & \ldots & \mathbf{2 8 4}\end{array}$

$\begin{array}{llllllll}\text { Gnathospastoides rouxi (flowers) } & \ldots & \ldots & \ldots & \ldots & 302\end{array}$

Lytta tenuicollis (flowers)

$3 \circ 3$

$\begin{array}{llllllll}\text { Zonabris pustulata (flowers) } & \ldots & \ldots & \ldots & \ldots & \ldots & 303\end{array}$

$\begin{array}{llllllll}\text { Cantharis ruficollis (flowers) } & \ldots & \ldots & \ldots & \ldots & \ldots & 305\end{array}$

Chillies-:

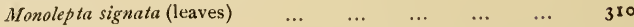

$\begin{array}{lllllllll}\text { Laphygma exigua (leaves) } & \ldots & \ldots & \ldots & \ldots & \ldots & 379\end{array}$ 
PAGE

$\begin{array}{lllllllll}\text { Euzophera perticella } \text { (borer) } & \ldots & \ldots & \ldots & \ldots & \ldots & 428\end{array}$

$\begin{array}{lllllllll}\text { Lygaus pandurus (sucking) } & \ldots & \ldots & \ldots & \ldots & \ldots & 48 \text { I }\end{array}$

Chithagathi (Sesbania egyptiaca) (See also Agathi, Daincha) :--

$\begin{array}{lllllllll}\text { Homoptera glaucinans (leaves) } & \ldots & \ldots & \ldots & \ldots & \ldots & 390\end{array}$

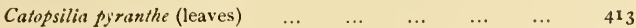

$\begin{array}{lllllllll}\text { Terias hecabe (leaves) } & \ldots & \ldots & \ldots & \ldots & \ldots & \ldots & 4 \mathrm{I} 4\end{array}$

$\begin{array}{llllllll}\text { 'Azygophleps scalaris (borer) } & \ldots & \ldots & \ldots & \ldots & \ldots & 447\end{array}$

Cholam (Andropogon surghum) :--

$\begin{array}{llllllll}\text { Anatona stillata (flowers) } & \ldots & \ldots & \ldots & \ldots & \ldots & 282\end{array}$

$\begin{array}{llllllll}\text { Oxycetoñia versicolor (flowers) } & \ldots & \ldots & \ldots & \ldots & \ldots & { }^{28} 8_{3}\end{array}$

$\begin{array}{llllllll}\text { Chiloloba acuta (flowers) } & \ldots & \ldots & \ldots & \ldots & \ldots & 284\end{array}$

$\begin{array}{llllllll}\text { Gnathospastoides rouxi (flowers) ... } & \ldots & \ldots & \ldots & \ldots & 302\end{array}$

$\begin{array}{lllllllll}\text { Lytta tenuicollis (flowers) } & \ldots & \ldots & \ldots & \ldots & \ldots & 3 \circ 3\end{array}$

$\begin{array}{lllllllll}\text { Zonabris pustulata (flowers) } & \ldots & \ldots & \ldots & \ldots & \ldots & 3 \circ 3\end{array}$

$\begin{array}{llllllll}\text { Cantharis ruficollis (flowers) } & \ldots & \ldots & \ldots & \ldots & \ldots & 305\end{array}$

$\begin{array}{lllllllll}\text { Cholam Fly (stem-borer) } & \ldots & \ldots & \ldots & \ldots & \ldots & 356\end{array}$

$\begin{array}{llllllll}\text { Amsacta albistriga (leaves) } & \ldots & \ldots & \ldots & \ldots & \ldots & 369\end{array}$

$\begin{array}{lllllll}\text { Cirphis unipuncta (boring shoots) } & \ldots & \ldots & \ldots & \ldots & 376\end{array}$

$\begin{array}{lllllllll}\text { Sesamia inferens } \text { (borer) } & \ldots & \ldots & \ldots & \ldots & \ldots & \ldots & 379\end{array}$

$\begin{array}{lllllllll}\text { Psalis securis (leaves) } & \ldots & \ldots & \ldots & \ldots & \ldots & \ldots & 397\end{array}$

$\begin{array}{llllllll}\text { Parnara mathias (leaves)... } & \ldots & \ldots & \ldots & \ldots & \ldots & 417\end{array}$

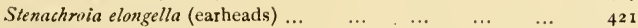

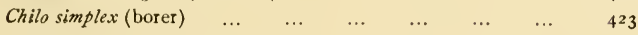

$\begin{array}{llllllll}\text { Marasmia trapezalis (leaves) } & \ldots & \ldots & \ldots & \ldots & \ldots & 43^{2}\end{array}$

$\begin{array}{llllllll}\text { Dolycoris indicus (sucking) } & \ldots & \ldots & \ldots & \ldots & \ldots & 470\end{array}$

$\begin{array}{llllllll}\text { Agonoscelis nubila (sucking) } & \ldots & \ldots & \ldots & \ldots & \ldots & 472\end{array}$

$\begin{array}{llllllll}\text { Nezara virtdula (sucking) } & \ldots & \ldots & \ldots & \ldots & \ldots & 473\end{array}$

$\begin{array}{llllllll}\text { Piezodorus rubrofasciatus (sucking) } & \ldots & \ldots & \ldots & \ldots & 474\end{array}$

$\begin{array}{lllllllll}\text { Menida histrio (sucking) ... } & \ldots & \ldots & \ldots & \ldots & \ldots & 474\end{array}$

$\begin{array}{lllllll}\text { Anoplocnemis phasiana } \text { (sucking) } & \ldots & \ldots & \ldots & \ldots & 477\end{array}$

$\begin{array}{llllllll}\text { Leptocorisa varicornis (sucking) } & \ldots & \ldots & \ldots & \ldots & \ldots & 479\end{array}$

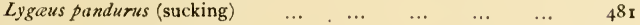

$\begin{array}{llllllll}\text { Calocoris angustatus (sucking) } & \ldots & \ldots & \ldots & \ldots & \ldots & 490\end{array}$

$\begin{array}{lllllllll}\text { Phenice masta (sucking) } & \ldots & \ldots & \ldots & \ldots & \ldots & \ldots & +93\end{array}$

$\begin{array}{llllllll}\text { Pyrilla perpusilla (sucking) } & \ldots & \ldots & \ldots & \ldots & \ldots & 493\end{array}$

$\begin{array}{llllllll}\text { Pundaluoya simplucia (sucking) } & \ldots & \ldots & \ldots & \ldots & \ldots & \ldots & 494\end{array}$

$\begin{array}{llllllll}\text { Epacromia tamulus (leaves) } & \ldots & \ldots & \ldots & \ldots & \ldots & 525\end{array}$

$\begin{array}{lllllllll}\text { Orthacris sp. (leaves) } & \ldots & \ldots & \ldots & \ldots & \ldots & \ldots & 527\end{array}$

$\begin{array}{lllllll}\text { Colemania sphenarioides (leaves)... } & \ldots & \ldots & \ldots & \ldots & 527\end{array}$

$\begin{array}{lllllllll}\text { Chrotogonus sp. (leaves) } \ldots & \ldots & \ldots & \ldots & \ldots & \ldots & 528\end{array}$

$\begin{array}{llllllll}\text { Hieroglyphus nigro-repletus (leaves) } & \ldots & \ldots & \ldots & \ldots & 532\end{array}$

$\begin{array}{lllllllll}\text { Oxya velox (leaves) } & \ldots & \ldots & \ldots & \ldots & \ldots & \ldots & 533\end{array}$ 
Thrips sp. (flowers)

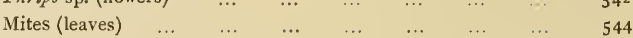

Cinchona :-

$\begin{array}{lllllllll}\text { Xyleborus forincatus (borer) } & \ldots & \ldots & \ldots & \ldots & \ldots & 345\end{array}$

$\begin{array}{lllllllll}\text { Deilephila nerii (leaves) } & \ldots & \ldots & \ldots & \ldots & \ldots & \ldots & 403\end{array}$

$\begin{array}{llllllll}\text { Helopeltis antonii (sucking) } & \ldots & \ldots & \ldots & \ldots & \ldots & 488\end{array}$

$\begin{array}{lllllllll}\text { Lecanium viride }(\text { scale) } & \ldots & \ldots & \ldots & \ldots & \ldots & \ldots & 5^{13}\end{array}$

$\begin{array}{llllllll}\text { Aspidiotus eamelluce }(\text { scale) } & & \ldots & \ldots & \ldots & \ldots & \ldots & 517\end{array}$

$\begin{array}{llllllll}\text { Chionaspis biclavis (scale) } & \ldots & \ldots & \ldots & \ldots & \ldots & 520\end{array}$

CITRUS spp. (See also Lemon and Orange):-

$\begin{array}{lllllllll}\text { Papilio demoleus (leaves) } \ldots & \ldots & \ldots & \ldots & \ldots & \ldots & 44^{12}\end{array}$

$\begin{array}{lllllllll}\text { Tonica zızyphi (leaves) } & \ldots & \ldots & \ldots & \ldots & \ldots & \ldots & 459\end{array}$

$\begin{array}{llllllll}\text { Phyllocnistis citrella (leaf-miner) } \ldots & \ldots & \ldots & \ldots & \ldots & 465\end{array}$

Cluster-Bean (Cyamopsis psoralioides):-

$\begin{array}{llllllll}\text { Coplosoma cribraria (sucking) } & \ldots & \ldots & \ldots & \ldots & \ldots & 469\end{array}$

Coconut (Cocos nucifera) :-

$\begin{array}{llllll}\text { Dorylus orientalis (roots of seedlings) } & \ldots & \ldots & \ldots & \ldots & \mathbf{2 7 4}\end{array}$

$\begin{array}{llllllll}\text { Oryctes rhinoceros (borer)... } & \ldots & \ldots & \ldots & \ldots & \ldots & 285\end{array}$

$\begin{array}{lllllllll}\text { Rhynchophorus ferrugineus (borer) } & \ldots & \ldots & \ldots & \ldots & 3+3\end{array}$

$\begin{array}{llllllllll}\text { Parasa lepida (leaves) } & \ldots & \ldots & \ldots & \ldots & \ldots & \ldots & \text { +II }\end{array}$

$\begin{array}{llllllll}\text { Gangara thyrsis (leaves) } \ldots & \ldots & \ldots & \ldots & \ldots & \ldots & 417\end{array}$

$\begin{array}{lllllllll}\text { Suastus gremius (leaves) } \mathbf{2} \ldots & \ldots & \ldots & \ldots & \ldots & \ldots & 410\end{array}$

$\begin{array}{llllllll}\text { Nephantis serinopa (leaves) } & \ldots & \ldots & \ldots & \ldots & \ldots & 460\end{array}$

$\begin{array}{lllllll}\text { Coconut Aphis (sucking leaves) } & \ldots & \ldots & \ldots & \ldots & 506\end{array}$

$\begin{array}{llllllll}\text { Aspidiotus destructor (scale) } & \ldots & \ldots & \ldots & \ldots & \ldots & 518\end{array}$

$\begin{array}{llllllll}\text { Aularches miliaris (leaves) } & \ldots & \ldots & \ldots & \ldots & \ldots & 526\end{array}$

Coffee (Coffea spp.) :-

$\begin{array}{lllllll}X y \text { lotrechus quadripes (White Borer) } & \ldots & \ldots & \ldots & \ldots & 323\end{array}$

$\begin{array}{lllllllll}\text { Estigmene lactinea (leaves) } & \ldots & \ldots & \ldots & \ldots & \ldots & 368\end{array}$

$\begin{array}{lllllllll}\text { Creatonotus gangis (leaves) } & \ldots & \ldots & \ldots & \ldots & \ldots & 369\end{array}$

$\begin{array}{lllllllll}\text { Euxoa } \text { segetis (seedlings) } & \ldots & \ldots & \ldots & \ldots & \ldots & \ldots & \ldots & 375\end{array}$

$\begin{array}{lllllllll}\text { Olene mendosa (leaves) } & \ldots & \ldots & \ldots & \ldots & \ldots & \ldots & \ldots & 396\end{array}$

$\begin{array}{lllllllll}\text { Parasa lepida (leaves) } & \ldots & \ldots & \ldots & \ldots & \ldots & \ldots & 4 \mathbf{1 1}\end{array}$

$\begin{array}{llllllll}\text { Zeuzera coffea (Red Borer) } & \ldots & \ldots & \ldots & \ldots & \ldots & 446\end{array}$

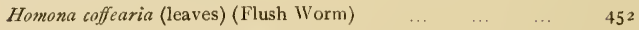

$\begin{array}{lllllll}\text { Antestia cruciata (sucking berries) } & \ldots & \ldots & \ldots & \ldots & 47^{2}\end{array}$

$\begin{array}{lllllllll}\text { Dactylopius citri (scale) } & \ldots & \ldots & \ldots & \ldots & \ldots & \ldots & 509\end{array}$

$\begin{array}{lllllllll}\text { Pulvinaria psidii (scale) } \ldots & \ldots & \ldots & \ldots & \ldots & \ldots & 511\end{array}$

$\begin{array}{lllllllll}\text { Lecanium viride }(\text { scale) } & \ldots & \ldots & \ldots & \ldots & \ldots & \ldots & 5^{1} 3\end{array}$

$\begin{array}{llllllll}\text {,. } & \text { hemispharicusm }(\text { scale) } & \ldots & \ldots & \ldots & \ldots & \ldots & 5 \mathrm{I} 4\end{array}$

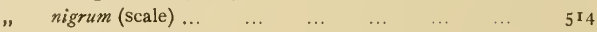

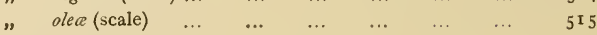


Chionaspis biclaz's (scale)

\section{Colocasia :- -}

$\begin{array}{lllllllll}\text { Monolepta signata (leaves) } & \ldots & \ldots & \ldots & \ldots & \ldots & 310\end{array}$

$\begin{array}{lllllllll}\text { Pericallia ricini (leaves) } & \ldots & \ldots & \ldots & \ldots & \ldots & \ldots & \ldots & 370\end{array}$

$\begin{array}{lllllllll}\text { Prodenia litura (leaves) } & \ldots & \ldots & \ldots & \ldots & \ldots & \ldots & 377\end{array}$

Córal Tree :-See Erythrina.

Cotron (Gossypium spp.) :-

Solenopsis geminata (buds)

Sphenoptera gossypii (borer)

Zonabris pustulata (flowers)

Colosterna spinator (bark)

Atactogaster finitimus (leaves)

Alcides leopardus (borer) ...

Pempheres affinis (borer) ...

$\begin{array}{lllllllll}\text { Acontia graellsi (leaves) } & \ldots & \ldots & \ldots & \ldots & \ldots & \ldots & 385\end{array}$

$\begin{array}{lllllllll}\text { Cosmophila erosa } \text { (leaves) } & \ldots & \ldots & \ldots & \ldots & \ldots & 39 \text { I }\end{array}$

$\begin{array}{lllllllll}\text { Euproctis fraterna (leaves) } & \ldots & \ldots & \ldots & \ldots & \ldots & 398\end{array}$

$\begin{array}{lllllllll}\text { Phycita infusella (top-shoots) } & \ldots & \ldots & \ldots & \ldots & \ldots & 428\end{array}$

$\begin{array}{llllllll}\text { Sylepta derogata (leaf-roller) } & \ldots & \ldots & \ldots & \ldots & \ldots & 434\end{array}$

$\begin{array}{lllllllll}\text { Zeuzera coffea (borer) } & \ldots & \ldots & \ldots & \ldots & \ldots & \ldots & 446\end{array}$

$\begin{array}{llllllll}\text { Gelechia gossypiella } \text { (seeds) } & \ldots & \ldots & \ldots & \ldots & \ldots & 454\end{array}$

$\begin{array}{llllllll}\text { Pyroderces coriacella } \text { (seeds) } & \ldots & \ldots & \ldots & \ldots & \ldots & 45^{8}\end{array}$

$\begin{array}{llllllll}\text { Clavigralla horrens (sucking) } & \ldots & \ldots & \ldots & \ldots & \ldots & 479\end{array}$

$\begin{array}{llllllll}\text { Lygaus pandurus (sucking) } & \ldots & \ldots & \ldots & \ldots & \ldots & 48 \mathbf{r}\end{array}$

$\begin{array}{lllllllll}\text { Oxycarenus latus (sucking) } & \ldots & \ldots & \ldots & \ldots & \ldots & 482\end{array}$

$\begin{array}{llllllll}\text { Dysdercus cingulatus (sucking) } & \ldots & \ldots & \ldots & \ldots & \ldots & +84\end{array}$

$\begin{array}{llllllll}\text { Eurybrachys tomentosa (sucking)... } & \ldots & \ldots & \ldots & \ldots & 492\end{array}$

$\begin{array}{lllllllll}\text { Aphis gossypii (sucking) } & \ldots & \ldots & \ldots & \ldots & \ldots & \ldots & \ldots & 499\end{array}$

$\begin{array}{lllllllll}\text { Cerococcus hilisci (scale) } & \ldots & \ldots & \ldots & \ldots & \ldots & \ldots & 508\end{array}$

$\begin{array}{llllllll}\text { Dactylopius virgatus (scale) } & \ldots & \ldots & \ldots & \ldots & \ldots & 510\end{array}$

$\begin{array}{llllllll}\text { nipa }(\text { scale }) & \ldots & \ldots & \ldots & \ldots & \ldots & \ldots & 5 \circ 9\end{array}$

$\begin{array}{lllllllll}\text { Lecanium nigrum }(\text { scale }) & \ldots & \ldots & \ldots & \ldots & \ldots & \ldots & 514\end{array}$

$\begin{array}{lllllllll}\text { Chrotogonus sp. (leaves) } & \ldots & \ldots & \ldots & \ldots & \ldots & \ldots & 528\end{array}$

$\begin{array}{lllllllll}\text { Catantops sp. (leaves) } & \ldots & \ldots & \ldots & \ldots & \ldots & \ldots & 529\end{array}$

$\begin{array}{llllllll}\text { Cyrtacanthacris ranacea (leaves) } & \ldots & \ldots & \ldots & \ldots & 53 \text { t }\end{array}$ 
Country Almond (Terminalia catappa) :-

PACE

$\begin{array}{lllllll}\text { Apoderus tranquebaricus (leaves) } \ldots & \ldots & \ldots & \ldots & \ldots & 335\end{array}$

$\begin{array}{lllllll}\text { Metanastria hyrtaca (leaves) } & \ldots & \ldots & \ldots & \ldots & \ldots & 410\end{array}$

Cowpea (Vigna catiang) :--

$\begin{array}{llllllll}\text { Sphenoptera arachidis (borer) } & \ldots & \ldots & \ldots & \ldots & \ldots & 298\end{array}$

$\begin{array}{lllllll}\text { Zonabris pustulata (flowers) } & \ldots & \ldots & \ldots & \ldots & \ldots & 3 \circ 3\end{array}$

$\begin{array}{lllllll}\text { Green-Gram Weevil (seed) } & \ldots & \ldots & \ldots & \ldots & \ldots & 33^{6}\end{array}$

$\begin{array}{llllll}\text { Cow-pea Agromyza (boring seed) } & \ldots & \ldots & \ldots & \ldots & 35^{8}\end{array}$

$\begin{array}{llllllll}\text { Laphygma exigua (leaves) } & \ldots & \ldots & \ldots & \ldots & \ldots & 379\end{array}$

$\begin{array}{lllllll}\text { Azazia nul ricans (leaves) } \ldots & \ldots & \ldots & \ldots & \ldots & \ldots & 389\end{array}$

$\begin{array}{llllllll}\text { Plusia orichalcea (leaves)... } & \ldots & \ldots & \ldots & \ldots & \ldots & 393\end{array}$

$\begin{array}{lllllll}\text { Riptortus pedestris (sucking) } & \ldots & \ldots & \ldots & \ldots & \ldots & 480\end{array}$

$\begin{array}{lllllll}\text { Colemania sphenarioides (leaves) } \ldots & \ldots & \ldots & \ldots & \ldots & 527\end{array}$

Crotalaria spp. (See also Sann Hemp) :-

$\begin{array}{lllllllll}\text { Sphenoptera arachidis (borer) } & \ldots & \ldots & \ldots & \ldots & \ldots & 298\end{array}$

$\begin{array}{llllllll}\text { Zonabris pustulata (flowers) } & \ldots & \ldots & \ldots & \ldots & \ldots & 303\end{array}$

$\begin{array}{lllllll}\text { Polyommatus beticus (pods) } & \ldots & \ldots & \ldots & \ldots & \ldots & 4 \mathrm{r} 5\end{array}$

$\begin{array}{lllllll}\text { Laspeyresia tricentra } \text { (stem-borer) } & \ldots & \ldots & \ldots & \ldots & 45 \text { I }\end{array}$

Crucifere (See also Cabbage, Mustard, Radish, Cauliflower, etc.) :-

$\begin{array}{llllllll}\text { Atkalia proxima (leaves) } \ldots & \ldots & \ldots & \ldots & \ldots & \ldots & & 28 \mathrm{r}\end{array}$

$\begin{array}{llllllll}\text { Plusia orichalcea (leaves) } \ldots & \ldots & \ldots & \ldots & \ldots & \ldots & 393\end{array}$

$\begin{array}{lllllll}\text { Crocidolomia binotalis (leaves) } & \ldots & \ldots & \ldots & \ldots & \ldots & 437\end{array}$

$\begin{array}{lllllll}\text { Plutella maculipennis (leaves) } & \ldots & \ldots & \ldots & \ldots & \ldots & +64\end{array}$

$\begin{array}{llllllll}\text { Bagrada picta (sucking) } & \ldots & \ldots & \ldots & \ldots & \ldots & \ldots & 473\end{array}$

CUCURBITACE: :-

$\begin{array}{lllllll}\text { Epilachna 12-stigna (leaves) } & \ldots & \ldots & \ldots & \ldots & 292\end{array}$

$\begin{array}{lllllll}\| & 28 \text {-punctata (leaves) } & \ldots & \ldots & \ldots & \ldots & 292\end{array}$

$\begin{array}{llllllll}\text { Zonabris pustulata (leaves) } & \ldots & \ldots & \ldots & \ldots & \ldots & 303\end{array}$

$\begin{array}{lllll}\text { Aulacophora abdominalis (foveicollis) (leaves) } & \ldots & \ldots & \ldots & 3 \mathrm{II}\end{array}$

$\begin{array}{lllllll}\text { " } & \text { atripennis (leaves) } & \ldots & \ldots & \ldots & \ldots & 312\end{array}$

$\begin{array}{llllllll} & \text { stevensi (leaves) } & \ldots & \ldots & \ldots & \ldots & \ldots & 312\end{array}$

$\begin{array}{lllllll}\text { Apomecyna pertigera } \text { (borer) } & \ldots & \ldots & \ldots & \ldots & \ldots & 327\end{array}$

$\begin{array}{llllllll}\text { Dacus cucurbita (fruit) } & \ldots & \ldots & \ldots & \ldots & \ldots & \ldots & 354\end{array}$

$\begin{array}{lllllll}\text { Plusia peponis (agramma) (leaves) } & \ldots & \ldots & \ldots & \ldots & 394\end{array}$

$\begin{array}{llllllll}\text { Glyphodes indica (leaves) } & \ldots & \ldots & \ldots & \ldots & \ldots & 43^{6}\end{array}$

Cumbu (Pennisetum typhoideum) :-

$\begin{array}{llllllll}\text { Anatona stillata (flowers) } & \ldots & \ldots & \ldots & \ldots & \ldots & 28_{2}\end{array}$

$\begin{array}{lllllll}\text { Oxycetonia versicolor (flowers) } & \ldots & \ldots & \ldots & \ldots & 28_{3}\end{array}$

$\begin{array}{lllllll}\text { Chiloloba acuta (flowers) } & \ldots & \ldots & \ldots & \ldots & \ldots & 284\end{array}$

$\begin{array}{lllllll}\text { Gnathospastoides rouxi (flowers) } & \ldots & \ldots & \ldots & \ldots & 302\end{array}$

$\begin{array}{lllllll}\text { Lytta temu icollis (flowers) } & \ldots & \ldots & \ldots & \ldots & \ldots & 30 \text { ? }\end{array}$

$\begin{array}{lllllll}Z_{\text {onabris pustulata (flowers) }} & \ldots & \ldots & \ldots & \ldots & \ldots & 303\end{array}$ 
PAGE

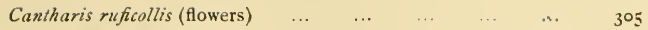

$\begin{array}{llllllllll}\text { Cholam fly (Stem-borer) } & \ldots & \ldots & \ldots & \ldots & \ldots & \ldots & \ldots & 356\end{array}$

$\begin{array}{lllllllll}\text { Estigmene lactinea (leaves) } & \ldots & \ldots & \ldots & \ldots & \ldots & 368\end{array}$

$\begin{array}{llllllll}\text { Amsacta albistriga (leaves) } & \ldots & \ldots & \ldots & \ldots & \ldots & 369\end{array}$

$\begin{array}{lllllllll}\text { Chilo simplex (borer) } \quad \ldots & \ldots & \ldots & \ldots & \ldots & \ldots & 423\end{array}$

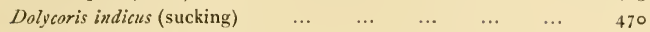

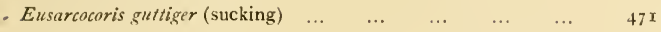

$\begin{array}{lllllllll}\text { Agonoscelis nubila (sucking) } & \ldots & \ldots & \ldots & \ldots & \ldots & 472\end{array}$

$\begin{array}{llllllll}\text { Nezara viridula (sucking) } & \ldots & \ldots & \ldots & \ldots & \ldots & +73\end{array}$

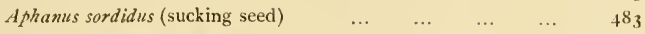

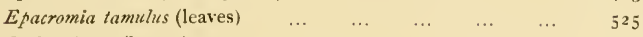

$\begin{array}{llllllll}\text { Orthacris sp. (leaves) } \quad \ldots & \ldots & \ldots & \ldots & \ldots & \ldots & 527\end{array}$

$\begin{array}{lllllllll}\text { Colemania sphenarioides (leaves) } & \ldots & \ldots & \ldots & \ldots & 527\end{array}$

Curry-Leaf Plant (Murraya kanigi) :-

Papilio demoleus (leaves)

412

DAINCHA (Sesbania aculeata)

$\begin{array}{llllllll}\text { Alcides lubo (borer) } & \ldots & \ldots & \ldots & \ldots & \ldots & \ldots & 337\end{array}$

$\begin{array}{llllllll}\text { Catopsilia pyranthe (leaves) } \quad \ldots & \ldots & \ldots & \ldots & \ldots & 4{ }^{1} 3\end{array}$

$\begin{array}{lllllllll}\text { Terias hecabe (leaves) } \quad \ldots & \ldots & \ldots & \ldots & \ldots & \ldots & 414\end{array}$

$\begin{array}{llllllll}\text { Azygophleps scalaris (borer) } & \ldots & \ldots & \ldots & \ldots & \ldots & 447\end{array}$

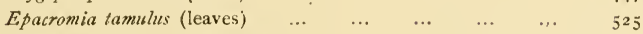

DATE-PALM (Phanix syluestris):-

$\begin{array}{llllllll}\text { Oryctes rhinoceros (borer) } & \ldots & \ldots & \ldots & \ldots & \ldots & 285\end{array}$

$\begin{array}{lllllll}\text { Rhynchophorus ferruginews (borer) } & \ldots & \ldots & \ldots & \ldots & 343\end{array}$

DHAN :- See Paddy.

Draksha :--See Grape-Vine.

Egg-Plant : - See Brinjal.

ERrukam:-See Calotropis.

ERYTHRINA (Erythrina indica) :-

Platypria hystrix (leaves)

$\begin{array}{lllllll}\text { Sthenias grisator (girdles twigs) } & \ldots & \ldots & \ldots & \ldots & 325\end{array}$

$\begin{array}{llllllll}\text { Xyleborus fornicatus (borer) } & \ldots & \ldots & \ldots & \ldots & \ldots & 345\end{array}$

$\begin{array}{lllllllll}\text { Orgyia postica (leaves) } & \ldots & \ldots & \ldots & \ldots & \ldots & \ldots & 395\end{array}$

$\begin{array}{llllll}\text { Terastia meticulosalis (shoot-borer) } & \ldots & \ldots & \ldots & \ldots & 439\end{array}$

$\begin{array}{llllllll}\text { Cyclopelta siccifolia } \text { (sucking) } & \ldots & \ldots & \ldots & \ldots & \ldots & 476\end{array}$

$\begin{array}{lllllll}\text { Anoplocnemis phasiana (sucking) } & \ldots & \ldots & \ldots & \ldots & 477\end{array}$

$\begin{array}{lllllll}\text { Dactylopius citri (scale) } & \ldots & \ldots & \ldots & \ldots & \ldots & 509\end{array}$

$\begin{array}{llllllll}\text { Lecanium olea }(\text { scale) } & \ldots & \ldots & \ldots & \ldots & \ldots & \ldots & 515\end{array}$

$\begin{array}{lllllll}\text { Aularches miliaris (leaves) } & \ldots & \ldots & \ldots & \ldots & \ldots & 515 \\ & & & & & & \end{array}$

Eucalveptus spp. :-

$\begin{array}{llllllll}\text { Homona coffearia (leaves) } & \ldots & \ldots & \ldots & \ldots & \ldots & 45^{2}\end{array}$ 
Ficus spp. :-

PAGE

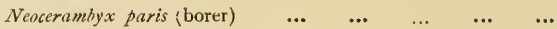

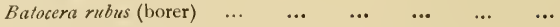

Hypsa ficus (leaves)

Ocinara varians (leaves)

Parasa lepida (leaves)

Phycodes radiata (leaves).

Dactylopius citri (scale)

Pulvinaria psidii (scale)

400

407

411

463

509

5 II

Hemilecanium imbricans (scale)

Pacilocerus pictus (young plants)...

FIgs:-See Ficus.

Ganja (Cannabis sativa) :-

Chloridea obsoleta (leaves and capsules)

Garden-Plants Generally :-

Dorylus orientalis (roots)

274

Adoretus ovalis (leaves) .

Anomala varians (leaves)

287

287

Gingelly (Sesamum indicum) :-

(ingelly Gall-fly (young capsules)

Pericallia ricini (leaves)

Laphygma exigua (leaves)

Acherontia sty $x$ (leaves)

Antigastra catalaunalis (leaves, shoots, pods) ..

Eusarcocoris ventralis (sucking)

Aphanus sordidus (sucking seed)

$\begin{array}{llllll} & \ldots & \ldots & \ldots & \ldots & 364\end{array}$

370

379

402

441

$47 \mathrm{I}$

$4^{8} 3$

GINGER (Zingiber officinalis):-

Calobata sp. (rhizomes) ...

Udaspes folus (leaves)

Dichocrocis punctiferalis (stem and rhizone)

(rogu (Hibiscus cannabinus) :-

Zonabris pustulata (flowers)

Visotra madurensis (leaves)

Alcides leopardus (borer)

Pempheres affinis (borer)

Acontia graellsi (leaves)

Cosmophila erosa (leaves)

Euproctis scintillans (leaves)

Phycita infusella (topshoots

Oxycarenus latus (sucking)

$\begin{array}{lll}\cdots & \ldots\end{array}$

(roukds (See also Cucurbitaceæ, Pumpkin) :- 
Aulacophora atripennis (leaves)

stevensi (leaves)

Dacus cucurbita (fruit)

Glyphodes indica (leaves)

Grape-Vine (Vitis sp.) :-

Adoretus ovalis (leaves)

Gonocephalum hofmannseggi (leaves)

Scelodonta strigicollis (leaves)

Grasses :-

Hispella ramosa (leaves) ...

Prodenia litura (leaves) ...

Spodoptera mauritia (leaves)

Remigia frugaiis (leaves)...

Psalis securis (leares) ...

Melanitis ismene (leaves)

Parnara mathias (leaves)

Ancylolomia chrysographella (leaves)

Leptocorisa varicornis (sucking) ..

Calocoris angustatus (sucking) ...

Phenice mosta (sucking) ...

Tettigoniella spectra (sucking)

Nephotettix bipunctatus (sucking)

Catantops sp. (leaves)

Green-Gram (Phaseolus mungo) :-

Green-Gram Weevil (seed)

Alcides collaris (borer) ... ...

Cow-Pea Agromyza (boring seeds)

Azazia rubricans (leaves)...

Plusia peponis (signata) (leaves) ...

Herse convolvuli (leaves) ...

Nacoleia indicata (leaves)

Maruca testulalis (seeds)

Coptosoma cribraria (sucking)

Anoplocnemis phasiana (sucking)

Riptortus pedestris (sucking)

Colemania sphenarioides (leaves)

\section{Grevillea :-}

Xyleborus forntcatus (borer)

Aspidiotus camellia (scale)

Chionaspis biclavis (scale)

378

$3^{88}$

$+12$

4 I 7

424

$+79$

490

493

$49^{6}$

497

$33^{6}$

337

$35^{8}$

$3^{89}$

394

402

434

440

Groundnut (Arachis hypogaa) :-

Dorylus orientalis (roots) 


\begin{tabular}{|c|c|c|c|c|c|c|}
\hline & & & & & & PAGE \\
\hline Sphenoptera arachidis (borer) & $\cdots$ & $\ldots$ & $\cdots$ & $\cdots$ & $\ldots$ & $29^{8}$ \\
\hline Zonabris pustulata (flowers) & $\cdots$ & $\cdots$ & $\cdots$ & $\cdots$ & $\cdots$ & $3 \circ 3$ \\
\hline Amsacta albistriga (leaves) & $\ldots$ & $\cdots$ & $\ldots$ & $\cdots$ & $\cdots$ & 369 \\
\hline Creatonotus gangis (leaves) & $\cdots$ & $\cdots$ & $\cdots$ & $\cdots$ & $\cdots$ & 369 \\
\hline Chloridea obsoleta (leaves) & $\cdots$ & $\cdots$ & $\cdots$ & $\cdots$ & $\cdots$ & 373 \\
\hline Plusia signata (leaves) ... & $\cdots$ & $\cdots$ & $\cdots$ & $\cdots$ & $\ldots$ & 393 \\
\hline Aproarema nerteria (leaves) & $\ldots$ & $\cdots$ & 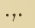 & $\cdots$ & $\cdots$ & 457 \\
\hline Aphanus sordidus (sucking seed) & $\ldots$ & $\ldots$ & $\ldots$ & $\ldots$ & $\ldots$ & $4^{8} 3$ \\
\hline Orthacris sp. (leaves) $\quad \ldots$ & $\cdots$ & $\cdots$ & $\cdots$ & $\cdots$ & $\cdots$ & 527 \\
\hline Chrotogonus sp. (leaves) ... & $\cdots$ & $\cdots$ & $\cdots$ & $\cdots$ & $\cdots$ & 528 \\
\hline Cyrtacanthacris ranacea (leaves) & )... & $\cdots$ & $\cdots$ & $\cdots$ & $\cdots$ & 531 \\
\hline Thrips sp. $\quad \ldots \quad \ldots$ & $\cdots$ & $\cdots$ & $\cdots$ & $\cdots$ & $\cdots$ & 542 \\
\hline UAVA (Psidium guyava) :- & & & & & & \\
\hline Xyleborus fornicatus (borer) & $\cdots$ & $\cdots$ & $\cdots$ & $\cdots$ & $\cdots$ & 345 \\
\hline Fruit-fly (fruit) $\quad \ldots \quad \ldots$ & $\cdots$ & $\cdots$ & $\cdots$ & $\cdots$ & $\cdots$ & 354 \\
\hline Virachola isocrates (fruit) & $\cdots$ & $\cdots$ & $\cdots$ & $\cdots$ & $\cdots$ & 416 \\
\hline Dichocrocis punctiferalis (fruit) & $\cdots$ & $\cdots$ & $\cdots$ & $\cdots$ & $\cdots$ & 433 \\
\hline Pulvinaria psidii (scale) ... & $\cdots$ & $\cdots$ & $\cdots$ & $\cdots$ & $\cdots$ & 5 II \\
\hline Lecanium viride (scale) $\quad .$. & $\cdots$ & $\ldots$ & $\ldots$ & $\ldots$ & $\ldots$ & $5^{1} 3$ \\
\hline
\end{tabular}

Gum Trees:--See Eucalyptus.

Haldi :--See Turmeric.

HeMp, I)eccan :--See Gogu.

HEMP, Indian :-See Ganja.

Hevea Rubrer :- See Para Rubber.

Hibiscus (See also Gogu, Bhindi, Rozelle, etc.) :-

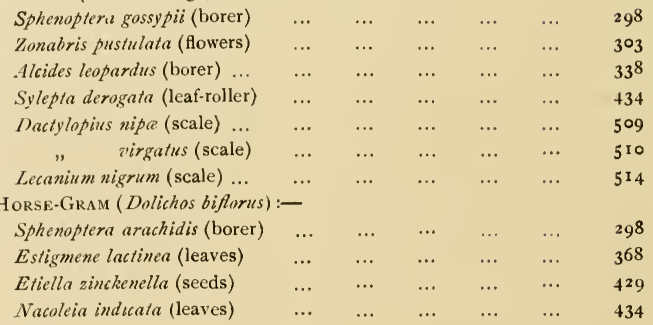

Horse-Radish Tree :-See Moringai.

Ilarch1:- - See Cardamom.

INdian Hemp :--See Ganja

INDiGo (Indigofera arrecta) :-

$\begin{array}{lllllllll}\text { Alcides bubo (borer) } & \ldots & \ldots & \ldots & \ldots & \ldots & \ldots & 337\end{array}$

$\begin{array}{llllllll}\text { Prodenia litura (leaves) } & \ldots & \ldots & \ldots & \ldots & \ldots & \ldots & 377\end{array}$ 
JAK :-

$\begin{array}{lllllll}\text { Glyphodes cesalis (buds and young fruits) } & \ldots & \ldots & \ldots & 435\end{array}$

$\begin{array}{lllll}\text { Cosmoscarta relata (sucking shoots and young fruits) } & \ldots & \ldots & 495\end{array}$ JAM:-See Guava.

Jor.A :-See Cholam.

JuAR :--See Cholam.

JUTE (Corchorus capsularis) :-

$\begin{array}{llllllll}\text { Nisotra madurensis (leaves) } & \ldots & \ldots & \ldots & \ldots & \ldots & 310\end{array}$

$\begin{array}{lllllllll}\text { Jute Apion (borer) } & \ldots & \ldots & \ldots & \ldots & \ldots & \ldots & 33^{\text {I }}\end{array}$

$\begin{array}{lllllllll}\text { Perigea capensis (leaves)... } & \ldots & \ldots & \ldots & \ldots & \ldots & 377\end{array}$

$\begin{array}{lllllllll}\text { Prodenia litura (leaves) } & \ldots & \ldots & \ldots & \ldots & \ldots & \ldots & 377\end{array}$

$\begin{array}{lllllllll}\text { Cosmophila sabulifera (leaves) } & \ldots & \ldots & \ldots & \ldots & \ldots & 390\end{array}$

$\begin{array}{lllllll}\text { Graptostethus servus (sucking capsules) } & \ldots & \ldots & \ldots & \ldots & 482\end{array}$

Kaju :--See Cashew.

Kanguni :--See Tenai.

Khorasani :--See Nigerseed.

Kulthi :-See Horse Gram.

Kusumb :---See Safflower.

LAB-LAB (Dolichos lab-lab):-

$\begin{array}{llllllll}\text { Zonabris pustulatu (flowers) } & \ldots & \ldots & \ldots & \ldots & \ldots & 303\end{array}$

$\begin{array}{llllllll}\text { Platypria hystrix (leaves) } & \ldots & \ldots & \ldots & \ldots & \ldots & 316\end{array}$

$\begin{array}{lllllllll}\text { Cow-Pea Agromyza (boring seed) } & \ldots & \ldots & \ldots & \ldots & 35^{8}\end{array}$

$\begin{array}{lllllllll}\text { Chloridea obsoleta } \text { (pods) } & \ldots & \ldots & \ldots & \ldots & \ldots & \ldots & 373\end{array}$

$\begin{array}{lllllllll}\text { Acherontia sty.x (leaves) } & \ldots & \ldots & \ldots & \ldots & \ldots & \ldots & 402\end{array}$

$\begin{array}{llllllll}\text { Catochrysops cnejits (pods) } & \ldots & \ldots & \ldots & \ldots & \ldots & 4 \mathrm{r} 4\end{array}$

$\begin{array}{lllllllll}\text { Maruca testulalis (pods) } & \ldots & \ldots & \ldots & \ldots & \ldots & \ldots & 440\end{array}$

$\begin{array}{llllllll}\text { Sphenarches caffer (pods) } & \ldots & \ldots & \ldots & \ldots & \ldots & 443\end{array}$

$\begin{array}{lllllllll}\text { Exelastis atomosa (pods) } \ldots & \ldots & \ldots & \ldots & \ldots & \ldots & \ldots & 444\end{array}$

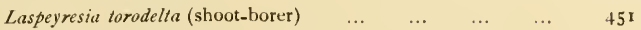

$\begin{array}{lllllllll}\text { Coptosoma cribraria (sucking) } & \ldots & \ldots & \ldots & \ldots & \ldots & +69\end{array}$

$\begin{array}{lllllllll}\text { Aspongopus janus (sucking) } & \ldots & \ldots & \ldots & \ldots & \ldots & 476\end{array}$

$\begin{array}{llllllll}\text { Clavigralla gibbosa (sucking) } & \ldots & \ldots & \ldots & \ldots & \ldots & +78\end{array}$

$\begin{array}{llllllll}\text { Riptortus pedestris (sucking) } & \ldots & \ldots & \ldots & \ldots & \ldots & 480\end{array}$

Ladies' Fingers:- See Bhindi. 
LANTANA (Lantana aculeatu):-

PAGE

$\begin{array}{lllllll}\text { Xyleborus fornicatus (borer) (doubtful) } & \ldots & \ldots & \ldots & \ldots & 345\end{array}$

$\begin{array}{lllllll}\text { Platyptilia pusillidactyla (flowers) } & \ldots & \ldots & \ldots & \ldots & 444\end{array}$

$\begin{array}{lllllll}\text { Puezodorus rubrofasciatus (sucking) } & \ldots & \ldots & \ldots & \ldots & 474\end{array}$

Legumrnosa: (See also Pulses, Crotalaria, Lucerne, Indigo, etc.) :-

$\begin{array}{lllllllll}\text { Sphenoptera arachidis (borer) } & \ldots & \ldots & \ldots & \ldots & \ldots & \mathbf{2 9} 8\end{array}$

$\begin{array}{lllllll}\text { Dichomeris ianthes (leaves) } & \ldots & \ldots & \ldots & \ldots & \ldots & 456\end{array}$

$\begin{array}{llllllll}\text { Coptosoma cribraria (sucking) } & \ldots & \ldots & \ldots & \ldots & \ldots & 469\end{array}$

LEMON :- -

$\begin{array}{llllllll}\text { Papilio demoleus (leaves) } & \ldots & \ldots & \ldots & \ldots & \ldots & 4 \mathrm{I} 2\end{array}$

$\begin{array}{llllllll}\text { Tonica zizyphi (leaves) } & \ldots & \ldots & \ldots & \ldots & \ldots & \ldots & 459\end{array}$

J,ILIES :--

$\begin{array}{llllllll}\text { Polytela gloriosa (leaves) } & \ldots & \ldots & \ldots & \ldots & \ldots & 375\end{array}$

$\begin{array}{lllllllll}U \text { daspes folus (leaves) } & \ldots & \ldots & \ldots & \ldots & \ldots & \ldots & \mathbf{4}^{20}\end{array}$

LINSEED (Linum usitatissimum) :-

$\begin{array}{llllllll}\text { Chloridea obsoleta } \text { (capsules) } & \ldots & \ldots & \ldots & \ldots & \ldots & 373\end{array}$

$\begin{array}{llllllll}\text { Grammodes stolida (leaves) } & \ldots & \ldots & \ldots & \ldots & \ldots & 3^{87}\end{array}$

$\begin{array}{llllllll}\text { Euproctis scintillans (leaves) } & \ldots & \ldots & \ldots & \ldots & \ldots & 399\end{array}$

Liтchi (Nephelium litchi):-

$\begin{array}{lllllllll}\text { Argyroploce illepida } \text { (seeds) } & \ldots & \ldots & \ldots & \ldots & \ldots & 449\end{array}$

Loquat (Eriobotrya japorica) :-

$\begin{array}{lllllllll}\text { Virachola isocrates (fruit) } & \ldots & \ldots & \ldots & \ldots & \ldots & 416\end{array}$

$\begin{array}{lllllllll}\text { Pulvinaria psidii (scale) } & \ldots & \ldots & \ldots & \ldots & \ldots & \ldots & 5 \text { II }\end{array}$

$\begin{array}{lllllllll}\text { Lecanium viride }(\text { scale) } & \ldots & \ldots & \ldots & \ldots & \ldots & \ldots & 5^{1} 3\end{array}$

$\begin{array}{lllllllll} & \text { hemispharicum }(\text { scale }) & \ldots & \ldots & \ldots & \ldots & \ldots & 5^{\mathrm{r}} 4\end{array}$

LUCERne (Medicago sativa) :--

$\begin{array}{lllllllll}\text { Creatonotus gangis (leaves) } & \ldots & \ldots & \ldots & \ldots & \ldots & 369\end{array}$

$\begin{array}{llllllllll}\text { Prodenia litura (leaves) } & \ldots & \ldots & \ldots & \ldots & \ldots & \ldots & 377\end{array}$

$\begin{array}{llllllll}\text { Laphygma exigua (leaves) } & \ldots & \ldots & \ldots & \ldots & \ldots & 379\end{array}$

$\begin{array}{llllllll}\text { Nacoleja indicata (leaves) } & \ldots & \ldots & \ldots & \ldots & \ldots & 434\end{array}$

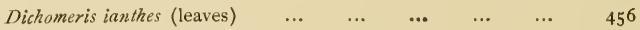

Luffa acutangula (Strainer Vine, Ribbed Gourd; Tam.

Pirkan):-

$\begin{array}{llllllll}R \text { Lptortus pedestris (sucking) } & \ldots & \ldots & \ldots & \ldots & \ldots & 480\end{array}$

MADAR :--See Calotropis.

MAIze (Zea mays):-

$\begin{array}{llllllllll}\text { Chloridea oỏsoleta }(\mathrm{cob}) & \ldots & \ldots & \ldots & \ldots & \ldots & \ldots & 373\end{array}$

$\begin{array}{llllllll}\text { Cirphis unipuncta (boring shoots) } & \ldots & \ldots & \ldots & \ldots & 376\end{array}$

$\begin{array}{lllllllll}\text { Prodenia litura (leaves) } & \ldots & \ldots & \ldots & \ldots & \ldots & \ldots & 377\end{array}$

$\begin{array}{lllllllll}\text { Sesamia inferens } \text { (borer) } & \ldots & \ldots & \ldots & \ldots & \ldots & \ldots & 379\end{array}$

$\begin{array}{lllllllll}\text { Chilo simplex (borer) } \quad \ldots & \ldots & \ldots & \ldots & \ldots & \ldots & 423\end{array}$

$\begin{array}{llllllll}\text { Marasmic trapezalis (leaves) } & \ldots & \ldots & \ldots & \ldots & \ldots & 43^{2}\end{array}$

$\begin{array}{llllllll}\text { Leptocorisa variornis (sucking) } & \ldots & \ldots & \ldots & \ldots & \ldots & 479\end{array}$ 
Calocoris angustatus (sucking)

PAGE

Pyrilla perpusilla (sucking)

490

Pundaluoya simplicia (sucking) ...

493

Hieroglyphus banian (leaves)

494

$53^{\mathrm{I}}$

Mango (Mangifera indica) :-

Adoretus ovalis (leaves) ...

287

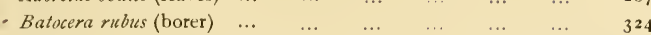

$\begin{array}{lllllll}\text { Eugnamptus marginatus (leaves) } & \ldots & \ldots & \ldots & \ldots & 329\end{array}$

$\begin{array}{llllllll}\text { Mango Leaf-boring Weevil (leaves) } & \ldots & \ldots & \ldots & \ldots & 334\end{array}$

$\begin{array}{lllllll}\text { Apoderus tranquebaricus (leaves) } & \ldots & \ldots & \ldots & \ldots & 335\end{array}$

$\begin{array}{llllllll}\text { Cryptorhynchus mangifere (seeds) } & \ldots & \ldots & \ldots & \ldots & 34 \text { I }\end{array}$

$\begin{array}{llllllllll}\text { Fruit-fly (fruit) } & \ldots & \ldots & \ldots & \ldots & \ldots & \ldots & \ldots & 354\end{array}$

$\begin{array}{lllllllll}\text { Bombotelia jocosatrix (leaves) } & \ldots & \ldots & \ldots & \ldots & \ldots & 3^{82}\end{array}$

$\begin{array}{llllllll}\text { Euproctis scintillans (leaves) } & \ldots & \ldots & \ldots & \ldots & \ldots & 399\end{array}$

$\begin{array}{llllllll}\text { Cricula trifenestrata (leaves) } & \ldots & \ldots & \ldots & \ldots & \ldots & 406\end{array}$

$\begin{array}{lllllllll}\text { Parasa lefida (leaves) } & \ldots & \ldots & \ldots & \ldots & \ldots & \ldots & 4 \text { II }\end{array}$

$\begin{array}{llllllll}\text { Macalla moncusalis (leaves) } & \ldots & \ldots & \ldots & \ldots & \ldots & 430\end{array}$

$\begin{array}{llllllll}\text { Idiocerus niveosparsus (sucking) } & \ldots & \ldots & \ldots & \ldots & 496\end{array}$

$\begin{array}{llllllll}\text { Pulvinaria psidii (scale) } \ldots & \ldots & \ldots & \ldots & \ldots & \ldots & 5 \text { II }\end{array}$

$\begin{array}{llllllll}\text { Aspidiotus destructor (scale) } & \ldots & \ldots & \ldots & \ldots & \ldots & 5^{18}\end{array}$

$\begin{array}{lllllllll}\text { Odontotermes sp. (bark) } & \ldots & \ldots & \ldots & \ldots & \ldots & \ldots & 54^{I}\end{array}$

Manjal :-See Turmeric.

Millets :- -

Cholam Fly (stem-borer)

356

Millet, Italian :-See Tenai.

MIIUSOPS ELENGI:-

Metanastria hyrtaca (leaves)

410

Mrrch :--See Pepper.

Monkey Face :- See Mimusops.

MORINGaI (Moringa pterygosperma) :-

Pericallic ricini (leaves) ..

Eupterote mollifera (leaves) Actias selene (leaves)

Noorda blitealis (leaves) ...

IUllaxgI :-See Radish.

Mung (See Green-Gram).

MUstard (Brassica spp.):-

Athalia proxima (leaves)..

281

$\begin{array}{llllllllll}\text { Crocidolomia binotalis (leaves) } & \ldots & \ldots & \ldots & \ldots & \ldots & +37\end{array}$

$\begin{array}{lllllllll}\text { Hellula undalis (leaves) } & \ldots & \ldots & \ldots & \ldots & \ldots & \ldots & 43^{8}\end{array}$

$\begin{array}{lllllllll}\text { Plutella maculipennis (leaves) } & \ldots & \ldots & \ldots & \ldots & \ldots & 464\end{array}$

$\begin{array}{lllllllll}\text { Bagrada picta (sucking) } \ldots & \ldots & \ldots & \ldots & \ldots & \ldots & 473\end{array}$

Navane:--See Tenai. 
Nigerseed (Guizotia abysinica) :-

Perigea capensis (leaves) ... ...

Chrotogonus sp. (leaves) .

Oleander (Nerium odorum) :-

Pericallia ricini (leaves) ...

Deilephila nerii (leaves) ...

ONion (Allium cepa):-

Laphygma exigua ...

Thrips sp....

URANGE :-

Chloridolum alcmene (borer)

Fruit-fly (fruit)

Papilio demoleus (leaves)

Virachola isocrates (fruit)

Tonica zisyphi (leaves)

Phyllocnistis citrella (leaf-miner)

Cappiea taprobanensis (sucking) ..

Aleurodes citri (sucking) ... ...

PADDY (Oryza sativa) :-

Epicauta sp. (leaves)

Oides affinis (leaves)

Leptispa pygmaa (leaves)

Hispa armigera (leaves) ...

Calandra oryza (ripe grain)

Cirphis unipuncta (borer)

Spodoptera mauritia (seedlings) ...

Sesamia inferens (borer) ...

Remigia frugalis (leaves)

Psalis securis (leaves)

Melanitis ismene (leaves) ...

Parnara mathias (leaves)

colaca (leaves) ...

Telicota augias (leaves) ...

Chilo simplex (borer) ....

Ancylolomia chrysographella (leaves)

Scheenoblus bipunctifer (borer)

Nymphula depunctalis (leaves) ...

Cnaphalocrocis medinalis (leaves)

Menida hastrio (sucking)

Tetroda histeroides (sucking)

Leptocorisa varicornis (sucking)

Tettigoniella spectra (sucking) ..

Nephotettix bipunctatus (sucking)

323

354

412

416

459

465

$+70$

508

306

3I 3

3I 3

3I 5

341

376

378 
$\begin{array}{lllllll}\text { Hieroglyphus banian (leaves) } & \ldots & \ldots & \ldots & \ldots & \ldots & 531\end{array}$

$\begin{array}{lllllllll}\text { Oxya velox (leaves) } & \ldots & \ldots & \ldots & \ldots & \ldots & \ldots & 533\end{array}$

$\begin{array}{lllllllll}\text { Thrips sp. (flowers) } & \ldots & \ldots & \ldots & \ldots & \ldots & \ldots & 542\end{array}$

PALMYRa (Borassus flajellifer):-

$\begin{array}{llllllll}\text { Oryctes rlinoceros (borer) } & \ldots & \ldots & \ldots & \ldots & \ldots & 285\end{array}$

$\begin{array}{llllllll}\text { Rhynchophorus ferrugineus (borer) } & \ldots & \ldots & \ldots & \ldots & 3+3\end{array}$

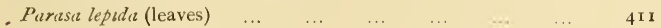

$\begin{array}{lllllllll}\text { Suastus gremius (leaves) } & \ldots & \ldots & \ldots & \ldots & \ldots & \ldots & \ldots & +19\end{array}$

$\begin{array}{lllllllll}\text { Nephantis serinopa (leaves) } & \ldots & \ldots & \ldots & \ldots & \ldots & 460\end{array}$

PAN :-See Betel.

Para RubeER (Hevea brasiliensis) :-

$\begin{array}{lllllllll}\text { Batocera rubus (borer) } & \ldots & \ldots & \ldots & \ldots & \ldots & \ldots & 324\end{array}$

$\begin{array}{lllllllll}\text { Lecanum nigrum } \text { (scale) } \ldots & \ldots & \ldots & \ldots & \ldots & \ldots & \ldots & 514\end{array}$

PEA (Pisum satizum) :-

$\begin{array}{lllllllll}\text { Prodenia litura (leares, etc.) } & \ldots & \ldots & \ldots & \ldots & \ldots & 377\end{array}$

$\begin{array}{llllllll}\text { Plusic orichalcea (leaves, etc.) } & \ldots & \ldots & \ldots & \ldots & \ldots & 393\end{array}$

$\begin{array}{llllllll}\text { Polyommatus baticus (pods) } & \ldots & \ldots & \ldots & \ldots & \ldots & 415\end{array}$

PEAR (Pyrus communis) :-

$\begin{array}{llllllll}\text { Lach uus pyri (sucking young twigs) } & \ldots & \ldots & \ldots & \ldots & 5 \circ 3\end{array}$

Pepper (Piper spp.) :-

$\begin{array}{llllllllll}\text { Parasa lepida (leaves) } & \ldots & \ldots & \ldots & \ldots & \ldots & \ldots & 41 \mathrm{II}\end{array}$

$\begin{array}{lllllllll}\text { Lecanium marsupiale (scale) } & \ldots & \ldots & \ldots & \ldots & \ldots & 516\end{array}$

$\begin{array}{llllllll}\text { Aspidiotus destructor (scale) } & \ldots & \ldots & \ldots & \ldots & \ldots & 5\end{array}$

$\begin{array}{llllllll}\text { Mytiluspis piperis (scale) } & \ldots & \ldots & \ldots & \ldots & \ldots & 519\end{array}$

Phaxas :- See Jak.

Pimaram:- See Ailanthus.

Pinnai (Tam.):-See Country Almond.

Pryaz :-See Onion.

Plantain (Musa sapientium) :-

Cosmopolites surdidus (root-borer)

$\begin{array}{lllllllll}\text { Pericallia ricini (leaves) } & \ldots & \ldots & \ldots & \ldots & \ldots & \ldots & \ldots & 370\end{array}$

$\begin{array}{lllllllll}\text { Prodenia litura (leaves) } & \ldots & \ldots & \ldots & \ldots & \ldots & \ldots & \ldots & 377\end{array}$

$\begin{array}{lllllllll}\text { Stephanitıs typicus (sucking) } & \ldots & \ldots & \ldots & \ldots & \ldots & 4{ }_{4}\end{array}$

Pomegranate (Punica granatum):-

Calosterna spmator (borer)

325

$\begin{array}{lllllllll}\text { Achan melucerta (leaves) } & . . & \ldots & \ldots & \ldots & \ldots & \ldots & \ldots & 386\end{array}$

$\begin{array}{lllllllll}\text { Parasn lepida (leaves) } & \ldots & \ldots & \ldots & \ldots & \ldots & \ldots & 4 \text { II }\end{array}$

$\begin{array}{llllllll}\text { Virachola isocrates (fruit) } & \ldots & \ldots & \ldots & \ldots & \ldots & +16\end{array}$

Ротато (Solauum tuberosum) :-

$\begin{array}{lllllll}\text { Gonocephalum hofjmannseggi (stems) } & \ldots & \ldots & \ldots & \ldots & 299\end{array}$

$\begin{array}{lllllllll}\text { Euxoa segetis (stems) } & \ldots & \ldots & \ldots & \ldots & \ldots & \ldots & 375\end{array}$

$\begin{array}{lllllllll}\text { Plusia urichalcea (leaves) } & \ldots & \ldots & \ldots & \ldots & \ldots & 393\end{array}$

$\begin{array}{llllllll}\text { Eusophera perticella (borer) } & \ldots & \ldots & \ldots & \ldots & \ldots & 428\end{array}$ 
Phthorima a operulella (stored tubers)

PAGE

Dactylopius nipa (stored lubers)

455

PSORALEA CORYLIFOLIA:

509

Aproarema nerteria (leaves) ..

Prickly Pear (Opuntia) :- -

Zonabris pustulatu (flowers)

Pulses (See also Black-Gram, Cow-pea, Green-Gram, Horse-Gram, Red-

Gram, etc.) :-

Episomus lacerta (roots)

Alcides collaris (borer) ...

Amsacta albisiriga (leaves)

Chloridea obsoleta (pods)

Azazia rubricans (leaves)

Herse convolvuli (leaves) ...

Catochrysops cnejus (pods)

402

Polsommatus beticus (pods)

$4 \mathrm{I} 4$

Etiella zinckenella (pods)

415

Agonoscelis nubila (sucking)

Piesodorus rubrofasciatus (sucking)

Menida histrio (sucking)

....

Pumpkins (Cucurlita spp.) :- See also Gourds, Cucurbitacea.

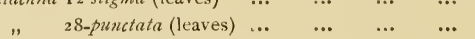

Aulacophora abdominalis (foveicollis) (leaves) $\quad \ldots \quad \ldots$.

\begin{tabular}{|c|c|c|c|c|c|c|}
\hline atmpennis (leaves) & $\cdots$ & $\cdots$ & $\cdots$ & $\cdots$ & $\cdots$ & 312 \\
\hline " stevensi (leaves) & $\cdots$ & $\cdots$ & $\cdots$ & $\cdots$ & $\cdots$ & 312 \\
\hline Apomecyna pertigera (borer) & $\cdots$ & $\cdots$ & $\cdots$ & $\cdots$ & $\cdots$ & 327 \\
\hline Dacus cucurbita (fruit) $\quad \ldots$ & $\cdots$ & $\cdots$ & $\cdots$ & $\cdots$ & $\cdots$ & 354 \\
\hline Pericallia ricini (leaves) ... & $\cdots$ & $\cdots$ & $\cdots$ & $\cdots$ & $\cdots$ & $37 \circ$ \\
\hline \multicolumn{2}{|l|}{ Plusia peponis (agramma) (leaves) } & $\ldots$ & ... & ... & $\cdots$ & 394 \\
\hline Glyphodes indica (leaves)... & $\cdots$ & $\cdots$ & $\cdots$ & $\cdots$ & $\cdots$ & $43^{6}$ \\
\hline Aspongopus janus (sucking) & $\cdots$ & $\cdots$ & $\cdots$ & .. & $\cdots$ & 476 \\
\hline \multicolumn{7}{|l|}{ RADIsH (Raphamus satizus) :- } \\
\hline Athalia proxima (leaves)... & $\cdots$ & $\cdots$ & $\cdots$ & $\cdots$ & .. & 281 \\
\hline Monolepta signata (leaves) & $\cdots$ & $\cdots$ & $\cdots$ & ... & $\cdots$ & 310 \\
\hline Laphygma exigua (leaves) & ... & $\cdots$ & ... & $\ldots$ & $\ldots$ & 379 \\
\hline Crocidolomia binotalis (leaves) & $\ldots$ & $\cdots$ & $\cdots$ & $\cdots$ & $\cdots$ & 437 \\
\hline Hellula undalis (leaves) ... & $\cdots$ & $\cdots$ & $\cdots$ & $\cdots$ & $\cdots$ & $43^{8}$ \\
\hline Plutella maculipennis (leaves) & $\cdots$ & $\cdots$ & $\cdots$ & $\cdots$ & $\cdots$ & 464 \\
\hline Bagrada picta (sucking) ... & $\cdots$ & $\cdots$ & $\cdots$ & $\cdots$ & $\cdots$ & 473 \\
\hline \multicolumn{7}{|l|}{ RAG1 (Eleusine coracana) :- } \\
\hline Anatona stillata (flowers) & $\cdots$ & $\cdots$ & $\cdots$ & $\cdots$ & $\cdots$ & 282 \\
\hline Estigmene lactinea (leaves) & $\cdots$ & ... & ... & .. & .. & 368 \\
\hline
\end{tabular}


PAGE

$\begin{array}{lllllllll}\text { Amsacta albistriga (leaves) } & \ldots & \ldots & \ldots & \ldots & \ldots & 369\end{array}$

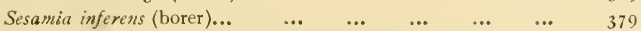

$\begin{array}{lllllllll}\text { Psalis securis (leaves) } & \ldots & \ldots & \ldots & \ldots & \ldots & \ldots & 397\end{array}$

$\begin{array}{lllllllll}\text { Chiln simplex (borer) } & \ldots & \ldots & \ldots & \ldots & \ldots & \ldots & 423\end{array}$

$\begin{array}{llllllll}\text { Saluria inficita (root-borer) } & \ldots & \ldots & \ldots & \ldots & \ldots & 427\end{array}$

$\begin{array}{llllllll}\text { Murasmia trapezalis (leaves) } & \ldots & \ldots & \ldots & \ldots & \ldots & +32\end{array}$

$\begin{array}{llllllll}\text { Nezara viridula (sucking) } & \ldots & \ldots & \ldots & \ldots & \ldots & 473\end{array}$

$\begin{array}{llllllll}\text { Leptocorisa varicornis (sucking) } & \ldots & \ldots & \ldots & \ldots & \ldots & 479\end{array}$

$\begin{array}{llllllll}\text { Ragi Root Aphis (sucking) } & \ldots & \ldots & \ldots & \ldots & \ldots & 502\end{array}$

$\begin{array}{llllllll}\text { Epacromia tamulus (leaves) } & \ldots & \ldots & \ldots & \ldots & \ldots & 525\end{array}$

$\begin{array}{lllllllll}\text { Orthacris sp. (leaves) } & \ldots & \ldots & \ldots & \ldots & \ldots & \ldots & 527\end{array}$

$\begin{array}{llllllll}\text { Cyrtacanthacris ranacea (leaves) } & \ldots & \ldots & \ldots & \ldots & 53 \mathrm{I}\end{array}$

RalN TrEe (Pithecolobium saman):-

$\begin{array}{lllllllll}\text { Arbela tetraonis (borer) } & \ldots & \ldots & \ldots & \ldots & \ldots & \ldots & 453\end{array}$

RED CEDAR (Erocarpus fraxinifolius) :-

Hemilecanium imbricans (scale)

517

Red-Gram (Cajanus indicus) :-

$\begin{array}{lllllllll}\text { Sphenoptera arachidis (borer) } & \ldots & \ldots & \ldots & \ldots & \ldots & 298\end{array}$

$\begin{array}{lllllllll}Z \text { Zona! ris.pustulata (flowers) } & \ldots & \ldots & \ldots & \ldots & \ldots & 3 \circ 3\end{array}$

$\begin{array}{llllllll}\text { Pachymeries chinensis (boring seeds) } & \ldots & \ldots & \ldots & \ldots & 306\end{array}$

$\begin{array}{llllllll}\text { Centhorrhynchus asperulus (flowers) } & \ldots & \ldots & \ldots & \ldots & 328\end{array}$

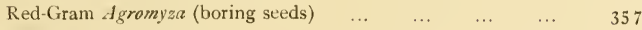

$\begin{array}{lllllllll}\text { Chloridea obsoleta (pods) } & \ldots & \ldots & \ldots & \ldots & \ldots & \ldots & \ldots & 373\end{array}$

$\begin{array}{llllllllll}\text { Olene mendosa (leaves) } & \ldots & \ldots & \ldots & \ldots & \ldots & \ldots & \ldots & 396\end{array}$

$\begin{array}{lllllllll}\text { Euproctis fraterna (leaves) } & \ldots & \ldots & \ldots & \ldots & \ldots & 39^{8}\end{array}$

$\begin{array}{lllllllll} & \text { scintillans (leaves) } & \ldots & \ldots & \ldots & \ldots & \ldots & 399\end{array}$

$\begin{array}{lllllllll}\text { Stauropus alternus (leaves) } & \ldots & \ldots & \ldots & \ldots & \ldots & 408\end{array}$

$\begin{array}{llllllll}\text { Catochrysops cnejus (pods) } & \ldots & \ldots & \ldots & \ldots & \ldots & 4 \mathrm{I} 4\end{array}$

$\begin{array}{llllllll}\text { Etuella zinckenella (seeds) } & \ldots & \ldots & \ldots & \ldots & \ldots & 429\end{array}$

$\begin{array}{lllllllll}\text { Waruca testulalis (seeds) } & \ldots & \ldots & \ldots & \ldots & \ldots & \ldots & \ldots & 440\end{array}$

$\begin{array}{lllllllll}\text { Exelastis atomosa (seeds) } & \ldots & \ldots & \ldots & \ldots & \ldots & 444\end{array}$

$\begin{array}{lllllllll}\text { Eucelis critica (leaves) } & \ldots & \ldots & \ldots & \ldots & \ldots & \ldots & 450\end{array}$

$\begin{array}{lllllllll}\text { Aproarema nerteriu (leaves) } & \ldots & \ldots & \ldots & \ldots & \ldots & 457\end{array}$

$\begin{array}{llllllll}\text { Cyclopelta siccifolia (sucking) } & \ldots & \ldots & \ldots & \ldots & \ldots & 476\end{array}$

$\begin{array}{lllllll}\text { Anoplocnemis phasiana (sucking) } & \ldots & \ldots & \ldots & \ldots & 477\end{array}$

$\begin{array}{llllllll}\text { Clatigralla gibbosa (sucking) } & \ldots & \ldots & \ldots & \ldots & \ldots & & 478\end{array}$

$\begin{array}{llllllll}\| & \text { horrens (sucking) } & \ldots & \ldots & \ldots & \ldots & \ldots & 479\end{array}$

$\begin{array}{llllllll}\text { Lygicus pandurus (sucking) } & \ldots & \ldots & \ldots & \ldots & \ldots & 48 \mathrm{r}\end{array}$

$\begin{array}{llllllll}\text { Graptostethus servus (sucking) } & \ldots & \ldots & \ldots & \ldots & \ldots & 4^{82}\end{array}$

$\begin{array}{lllllllll}\text { Ceroplastodes cajani (scale) } & \ldots & \ldots & \ldots & \ldots & \ldots & 512\end{array}$

$\begin{array}{llllllll}\text { Colemania sphenarioides (leaves) } & \ldots & \ldots & \ldots & \ldots & 527\end{array}$

RibBed Gourd (See Luffa acutangula). 
RrCe :-(See Paddy).

PAGE

Rose (Rosa spp.) :-

$\begin{array}{lllllll}\text { Adorctus l:angalorensis (leaves) } & \ldots & \ldots & \ldots & \ldots & \ldots & 286\end{array}$

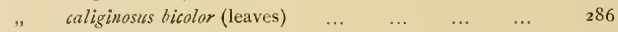

$\begin{array}{lllllllll}, & \text { ovalis (leaves) } & \ldots & \ldots & \ldots & \ldots & \ldots & \ldots & \mathbf{2 8 7}\end{array}$

$\begin{array}{lllllll}\text { Zonabris pustulatu (flowers) } & \ldots & \ldots & \ldots & \ldots & \ldots & 303\end{array}$

$\begin{array}{llllllll}\text { Celosterna spinator(twigs) } & \ldots & \ldots & \ldots & \ldots & \ldots & 325\end{array}$

$\begin{array}{llllllll}\text { Sthenias grisator (girdles twigs) } & \ldots & \ldots & \ldots & \ldots & \ldots & 326\end{array}$

Rozelle (Hibiscus sabdariffa) (Sce also Hiliscus, Bhindi, Gogu,

Cotton) :-

$\begin{array}{lllllll}\text { Phycita infusella (topshoots) } & \ldots & \ldots & \ldots & \ldots & \ldots & 428\end{array}$

SAFFLOWER (Carthamus tinctoria) :--

$\begin{array}{llllllll}\text { Chloridea oosoleta (capsules) } & \ldots & \ldots & \ldots & \ldots & \ldots & 373\end{array}$

$\begin{array}{llllllll}\text { Perigea capensis (capsules) } & \ldots & \ldots & \ldots & \ldots & \ldots & 377\end{array}$

$\begin{array}{llllllll}\text { Dolycoris indicus (sucking) } & \ldots & \ldots & \ldots & \ldots & \ldots & 470\end{array}$

$\begin{array}{lllllll}\text { Monanthie glolulifera (sucking) } & \ldots & \ldots & \ldots & \ldots & \ldots & 486\end{array}$

SANDal (Santalum album) :-

$\begin{array}{llllllll}\text { Zenzera coffece }(\text { borer }) & \ldots & \ldots & \ldots & \ldots & \ldots & \ldots & 446\end{array}$

SANN-HEMP (Crotalaria juncea) :-

$\begin{array}{llllllll}\text { Utetheisa pulchella (leaves) } & \ldots & \ldots & \ldots & \ldots & \ldots & 371\end{array}$

$\begin{array}{llllllll}\text { Plusia signala (leaves) } & \ldots & \ldots & \ldots & \ldots & \ldots & \ldots & 393\end{array}$

$\begin{array}{lllllll}\text { Euproctss scintillans (leaves) } & \ldots & \ldots & \ldots & \ldots & \ldots & 399\end{array}$

$\begin{array}{llllllll}\text { Argina cribraria (leaves) } \ldots & \ldots & \ldots & \ldots & \ldots & \ldots & 40 \mathrm{I}\end{array}$

$\begin{array}{llllllll}\text { " syringa (leaves)... } & \ldots & \ldots & \ldots & \ldots & \ldots & 4 \text { Or }\end{array}$

$\begin{array}{lllllll}\text { Polyommatus baticus (pods) } & \ldots & \ldots & \ldots & \ldots & \ldots & 415\end{array}$

$\begin{array}{lllllll}\text { Etiella zinckenella (seeds) } & \ldots & \ldots & \ldots & \ldots & \ldots & 4^{29}\end{array}$

$\begin{array}{llllll}\text { Laspeyresia tricentra (stem-borer) } & \ldots & \ldots & \ldots & \ldots & 45 \text { I }\end{array}$

$\begin{array}{lllllll}\text { Ragmus importunitas (sucking) } & \ldots & \ldots & \ldots & \ldots & \ldots & 49 \mathrm{I}\end{array}$

Sesbania spp (See also Agathi, Daincha, etc.) :-

$\begin{array}{llllllll}\text { Alcides bubo (borer) } & \ldots & \ldots & \ldots & \ldots & \ldots & \ldots & 337\end{array}$

$\begin{array}{lllllll}\text { Homoptera gluucinans (leaves) } & \ldots & \ldots & \ldots & \ldots & \ldots & 390\end{array}$

$\begin{array}{llllllll}\text { Catopsilla pyranthe (leaves) } & \ldots & \ldots & \ldots & \ldots & \ldots & 4 \mathrm{I} 3\end{array}$

$\begin{array}{llllllll}\text { Terias hecabe (leaves) } & \ldots & \ldots & \ldots & \ldots & \ldots & \ldots & 4 \mathbf{I} 4\end{array}$

SESBANIA .EGYPTIACA :-(See Chithagathi).

Silk-Cotton (Bomliax) :-

$\begin{array}{lllllll}\text { Acanthophorus serraticornis (borer) } & \ldots & \ldots & \ldots & \ldots & 320\end{array}$

$\begin{array}{llllllll}\text { Batocera rubus (borer) } & \ldots & \ldots & \ldots & \ldots & \ldots & \ldots & 324\end{array}$

Silver OAK :-See Grevillea.

SNAKE-GouRd (Trichosanthes anguina) :-

$\begin{array}{lllllll}\text { Epilachna } \mathrm{r} \text { 2-stigma (leaves) } & \ldots & \ldots & \ldots & \ldots & \ldots & 292\end{array}$

$\begin{array}{llllllll} & \text { 28-punctata (leaves) } & \ldots & \ldots & \ldots & \ldots & \ldots & 292\end{array}$

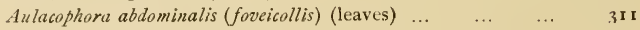

$\begin{array}{lllllllll} & & \text { atripennis (leaves) } & \ldots & \ldots & \ldots & \ldots & \ldots & 3 \mathbf{2}\end{array}$ 
Aulacophora stevensi (leaves)

P.IGE

Pulsia peponis (agramma) (leaves)

312

Solanacre:-

Epilachna i 2-stigma (leaves)

"28-punctutu (leaves)

292

Eublemma olivacea (leaves)

292

Brinjal Sarrothripine (leaves)

380

Pachyzancla agrotalis (leaves)

$3^{s_{3}}$

$4+0$

Sorghum :-See Cholam.

Straiser vine:-See Luffu acutungula.

Sugarcane (Saccharum officinarum) :--

Dorylus orientalis (roots)

Oryctes rhinoceros (borer)

Phidodonta modestu (leaves)

274

$28_{5}$

$\begin{array}{llllll} & \ldots & \ldots & \ldots & \ldots & \ldots\end{array}$

$\begin{array}{llllll}\cdots & \cdots & \ldots & \ldots & \ldots & 379\end{array}$

$\begin{array}{lllllllll}\text { Psalis securis (leaves) } & \ldots & \ldots & \ldots & \ldots & \ldots & \ldots & 397\end{array}$

$\begin{array}{lllllllll}\text { Telicota augias (leaves) } & \ldots & \ldots & \ldots & \ldots & \ldots & \ldots & \text { +1 } 9\end{array}$

$\begin{array}{lllllllll}\text { Diatraa } \mathrm{sp} \text {. (borer) } & \ldots & \ldots & \ldots & \ldots & \ldots & \ldots & 422\end{array}$

$\begin{array}{llllllll}\text { Chilo simplex (borer) } \quad \ldots & \ldots & \ldots & \ldots & \ldots & 422\end{array}$

$\begin{array}{lllllllll}\text { Scirpophaga aurifulu } \text { (borer) } & \ldots & \ldots & \ldots & \ldots & \ldots & +25\end{array}$

$\begin{array}{lllllllll} & \text { monostigma (borer) } & \ldots & \ldots & \ldots & \ldots & \ldots & & 426\end{array}$

$\begin{array}{lllllllll}\text { Phenice mesta (sucking) } \ldots & \ldots & \ldots & \ldots & \ldots & \ldots & 493\end{array}$

$\begin{array}{llllllll}\text { Pyrilla perpusilla (sucking) } & \ldots & \ldots & \ldots & \ldots & & 493\end{array}$

$\begin{array}{llllllll}\text { Aleurodes bergi (sucking) } & \ldots & \ldots & \ldots & \ldots & \ldots & 507\end{array}$

$\begin{array}{llllllll}\text { Hieroglyphus banian (leaves) } & \ldots & \ldots & \ldots & \ldots & \ldots & 531\end{array}$

$\begin{array}{lllllllll}\text { Oxya velox (leaves) } & \ldots & \ldots & \ldots & \ldots & \ldots & \ldots & 533\end{array}$

$\begin{array}{lllllllll}\text { Gryllotalpa africana (setts) } & \ldots & \ldots & \ldots & \ldots & \ldots & 535\end{array}$

$\begin{array}{lllllllll}\text { Odontotermes sp. (setts) } & \ldots & \ldots & \ldots & \ldots & \ldots & \ldots & 5+\mathrm{I}\end{array}$

Thrips sp.

$5+1$

SUNFLOWER (Helianthus anmuus) :--

Dolycoris indicus (sucking)

470

SweEt Potato (Ipomaea batutas) :-

$\begin{array}{lllllllll}\text { Aspidomorpha miliaris (leaves) } & \ldots & \ldots & \ldots & \ldots & \ldots & 317\end{array}$

$\begin{array}{lllllllll}\text { Coptocyla sp. (leaves) } & \ldots & \ldots & \ldots & \ldots & \ldots & \ldots & 317\end{array}$

$\begin{array}{lllllllll}\text { Meiriona sp. (leaves) } & \ldots & \ldots & \ldots & \ldots & \ldots & \ldots & 318\end{array}$

$\begin{array}{lllllllll}\text { Cylas formicarius (tubers) } & \ldots & \ldots & \ldots & \ldots & \ldots & 335\end{array}$

$\begin{array}{lllllllll}\text { Herse convolvuli (leaves) } \ldots & \ldots & \ldots & \ldots & \ldots & \ldots & \ldots & 402\end{array}$

$\begin{array}{lllllll}\text { Omphisa anastomosalis (stem and tubers) } & \ldots & \ldots & \ldots & 439\end{array}$

$\begin{array}{llllllll}\text { Graptostethus servus (sucking) } & \ldots & \ldots & \ldots & \ldots & \ldots & 4 \delta_{2}\end{array}$

TADi :-See Palmyra

TAMARIND ( Tamarindus indicus) :-

Stauropus alternus (leaves) 
Virachola isocrates (fruit)

Argyroploce illepida (seeds)

PAGE

TEA (Camellia theifera) :-

Xyleborus fornicatus (borer

Stauropus altermus (leaves)

Biston suppressaria (leaves)

Parasa lepida (leaves) ..

Zeuzera coffee (borer)

Clania crameri (leaves) .

Heterusia virescens (leaves)

Homona coffearia (leaves) (Flush Worm)

Phassus malabaricus (root-borer)

$\begin{array}{llllllll}\text { Helopeltıs antonii (sucking) } & \ldots & \ldots & \ldots & \ldots & \ldots & 488\end{array}$

$\begin{array}{lllllllll}\text { Empoasca flavescens (sucking) } & \ldots & \ldots & \ldots & \ldots & \ldots & 49^{8}\end{array}$

$\begin{array}{llllllll}\text { Lecanium hemispharicum }(\text { scale }) & . . & \ldots & \ldots & \ldots & \ldots & \ldots & 514\end{array}$

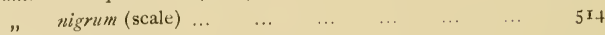

$\begin{array}{lllllllll}\text { Aspidiotus camellice (scale) } & \ldots & \ldots & \ldots & \ldots & \ldots & 517\end{array}$

$\begin{array}{llllllll}\text { Chionaspis biclavis (scale) } & \ldots & \ldots & \ldots & \ldots & \ldots & 520\end{array}$

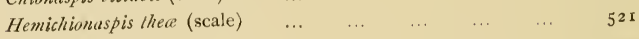

$\begin{array}{llllllll}\text { Tetranychus bioculatus (leaves) } & \ldots & \ldots & \ldots & \ldots & \ldots & 5+4\end{array}$

$\begin{array}{lllllllll}\text { Phytoptus carinatus (leaves) } & \ldots & \ldots & \ldots & \ldots & \ldots & 5+5\end{array}$

TEAK (Tectona grandis) :-

$\begin{array}{lllllllll}\text { Psiloptera fastuosa } \text { (borer) } & \ldots & \ldots & \ldots & \ldots & \ldots & 297\end{array}$

$\begin{array}{lllllllll}\text { Stromatium barhatum } \text { (borer) } & \ldots & \ldots & \ldots & \ldots & \ldots & 3^{21}\end{array}$

$\begin{array}{lllllllll}\text { Hybla puera (leaf-roller) } & \ldots & \ldots & \ldots & \ldots & \ldots & 39^{2}\end{array}$

$\begin{array}{lllllllll}\text { Pyrausta machieralis (leaves) } & \ldots & \ldots & \ldots & \ldots & \ldots & ++^{2}\end{array}$

Tenar (Setaria italica) : (See also Cereals) :-

$\begin{array}{lllllll}\text { Anatona stillata (flowers) } & \ldots & \ldots & \ldots & \ldots & \ldots & 28 \mathbf{2} \\ \text { Gnathospastoides rouxi (flowers) } & \ldots & \ldots & \ldots & \ldots & \ldots & 302 \\ \text { Lytta tenuicollis (flowers) } & \ldots & \ldots & \ldots & \ldots & \ldots & 303 \\ \text { Zonabris pustulata (flowers) } & \ldots & \ldots & \ldots & \ldots & \ldots & 303 \\ \text { Cantharis ruficollis (flowers) } & \ldots & \ldots & \ldots & \ldots & \ldots & 305 \\ \text { Dolycoris indicus (sucking) } & \ldots & \ldots & \ldots & \ldots & \ldots & +70 \\ \text { Colemaniu sphenaroides (leaves) } & \ldots & \ldots & \ldots & \ldots & 527 \\ \text { Hieroglyphus nigrorepletus (leaves) } & \ldots & \ldots & \ldots & \ldots & 53^{2}\end{array}$

TiL :-See Gingelly.

Tobacco (Nicotiana tabacum) :-

$\begin{array}{lllllllll}\text { Chloridea obsoleta }(\text { seed capsules) } & \ldots & \ldots & \ldots & \ldots & 373\end{array}$

$\begin{array}{lllllllll} & \text { assulta (leaves, etc.) } & \ldots & \ldots & \ldots & \ldots & \ldots & 37+\end{array}$

$\begin{array}{lllllllll}\text { Prodeniu litura (leaves, etc.) } & \ldots & \ldots & \ldots & \ldots & \ldots & 377\end{array}$

$\begin{array}{llllllllll}\text { Plusia signata (leaves, etc.) } & \ldots & \ldots & \ldots & \ldots & \ldots & 393\end{array}$

$\begin{array}{lllllll}\text { Gnorimoschema heliopa (stem-borer) } & \ldots & \ldots & \ldots & \ldots & 45+\end{array}$ 
Gallobelicus crassicornis (sucking)

PAGE

Atractomurpha crenulata (leaves)

49 I

Chrotogonus sp. (leaves) ...

528

528

TODDY-PALMS :-

Pycnosoma flaviceps (sucking toddy)

Tomats (Lycopersicum esculentum) :-

- Chloridea obsoleta (fruit) ...

$\begin{array}{lllllll}\text { Prodenia litura } & \ldots & \ldots & \ldots & \ldots & \ldots & \\ \end{array}$

$\begin{array}{lllllll}\text { Tetranychus bioculatus (leaves) } & \ldots & \ldots & \ldots & \ldots & \ldots & 544\end{array}$

Toon (Cedrela toona) :-

Hemilecanium imbricans (scale)

Tulsi (Ocimum sanctum) :-

$\begin{array}{llllllll}\text { Monanthia globulifera (sucking) } & \ldots & \ldots & \ldots & \ldots & \ldots & 486\end{array}$

$\begin{array}{llllllll}\text { Ceroplastodes cajani (scale) } & \ldots & \ldots & \ldots & \ldots & \ldots & 5 \mathrm{I} 2\end{array}$

TUR :-See Red-Gram.

Turueric (Curcuma longur):-

Calobata sp. (rhizomes) ...

Udaspes folus (leaves) ...

Dichocrocis punctiferalis (stem)

Stephanutis typicus (sucking)

Turnip (Brassica sp.) :-

Athalia proxima (leaves)

Bagrada picta (sucking)

URID :-See Black-Gram.

355

420

433

484

WheAT (Triticum vulgare) :-

Sesamia inferens (borer) ...

Dolycoris indicus (sucking)

Agonoscelis nubila (sucking)

Nezara viridula (sucking)

Menida histrio (sucking)

Riptortus pedestris (sucking)

$28 I$

473

WOOd-Apple (Feronia elephantum) :--

Parasa lepida (leaves) ... ...

Argyroploce illepuda (seeds)

4 I I

449 


\section{LIST OF ALLIED PLANTS.}

THE following list, in the preparation of which $I$ have received considerable kind assistance from Rao Bahadur K. Rangachariyar, Lecturing Botanist, shows the commoner plants and trees grouped under their Natural Orders. In view of the fact that many species of Insects are confined to closely allied plants, or at least exhibit a preference for the plants contained in the linits of a Natural Order, it is equally important for the Entomologist and the Agriculturist to know which plants are likely to be attacked by any particular insect, especially in view of control by rotation of crops. For example, an insect which damages mustard is likely to attack cabbage if the two crops are grown near one another in space or time. Many insects are of course polyphagous (i.e., feed on many different plants) but, as a rule, a careful consideration of the relationships of the crops themselves will often avoid considerable loss by Insect Pests.

\section{Papaveracea.}

Papaver somniferum Argemone mexicana

Opium poppy.

$\begin{array}{lll}\ldots & \ldots & \text { Opium poppy. } \\ \ldots & \ldots & \text { Mexican poppy. }\end{array}$

\section{Crucifere.}

\begin{tabular}{|c|c|c|c|c|c|}
\hline Brassica & nigra & $\ldots$ & $\ldots$ & $\ldots$ & Black mustard. \\
\hline , & campestris & $\ldots$ & $\ldots$ & $\ldots$ & Swedish turnip. \\
\hline , & juncea & $\ldots$ & $\ldots$ & $\ldots$ & Indian mustard. \\
\hline , & alba & $\cdots$ & $\ldots$ & $\cdots$ & White mustard. \\
\hline , & oleracea ca & apitata & $\ldots$ & $\ldots$ & Cabbage. \\
\hline , & oleracea bo & otrytis & $\ldots$ & $\ldots$ & Broccoli. \\
\hline$"$ & oleracea ca & auliftora & $\ldots$ & $\ldots$ & Cauliflower. \\
\hline ", & napus & $\ldots$ & $\ldots$ & $\ldots$ & Rape. \\
\hline Raphan & us sativus & $\cdots$ & $\ldots$ & $\ldots$ & Radish. \\
\hline
\end{tabular}

Capparidea.

Gyrandropsis pentaphylla.

Cratava religiosa $\quad . . \quad \ldots \quad \ldots$ Garlic Pear.

Cadaba indica.

Portulaced.

$\begin{array}{lllll}\text { Portulaca oleracea } & \ldots & \ldots & \ldots & \text { Purslane. }\end{array}$

Ternstremiacea.

Camellia theifera Tea.

Sterculiacea.

Theobroma cacao ... ... .. Cacao. 
Abutilon indicum.

Malvacee.

Hibiscus cannabinu

$$
\begin{array}{lllll}
\multicolumn{2}{l}{\text { sibiscus cannabinus }} & \ldots & \ldots & \text { (iogu. } \\
, & \begin{array}{l}
\text { sabdariffa ... } \\
\text { abelmoschus. }
\end{array} & \ldots & \ldots & \text { Rozelle. } \\
" & \text { esculentus ... } & \ldots & \ldots & \text { Bhindi ; Ladies Fingers. }
\end{array}
$$$$
\text { , abelmoschus. }
$$$$
\text { " rosa-sinensis } \quad . . \quad \text {... Hibiscus. }
$$

Gossypium herbaceum

, barbadense

, arboreum

,. hirsutur

, indicum ...

, obtusifolium

Thespesia populnea

Bombax malabaricum

Eriodendron anfractuosum

Tiliacea.

Corchorus capsularis

... .. Jute.

Elæeocarpus otilongus.

Linere.

Linum usitatissimum

Flax; Linseed.

\section{Geraniacece.}

Iverrhoa bilimbi

... Bilimbi.

Averrhoa carambola $\quad \ldots \quad \ldots$ Carambola,

Oxalis spp. $\quad \ldots \quad \ldots \quad \ldots \quad \ldots \quad$ Oxalis.

Impatiens spp. $\quad \ldots \quad \ldots \quad \ldots \quad \ldots$ Balsam.

Pelargonium spp. $\quad \ldots \quad \ldots \quad \ldots$ Geranium,

Rutacea.

Murraya konigi $\quad \ldots \quad \ldots \quad \ldots \quad \ldots \quad$ Curry Leaf Plant.

Atlantia monophylla.

Citrusa medica acida

... Sour lime.

, medica limetta ... ... Sweet lime.

, medica aurantium ... ... Orange.

" decumana ... $\quad . . . \quad \ldots \quad$ Pomelo.

Feronia elephantum... ... ... IVood-apple.

Egle marmelos ... ... ... Bael.

\section{Meliacea.}

Melia azedarach

... Persian Nim.

Melia azadirachta $\quad . . \quad \ldots \quad \ldots \quad \ldots \quad$ Nim ; Margosa.

Cedrela toona $\quad \ldots \quad \ldots \quad \ldots$ Toon. 


\section{Simarubea.}

Ailanthus excelsa ... ... $\quad$... Ailanthus. " malabarica.

Balanites roxburghii.

\section{Rhamnece.}

Zizyphus jujuba $\ldots \quad \ldots \quad \ldots \quad$ Jujube ; Ber.

, glabrata.

, cenoplia.

, rugosa $\ldots \quad \ldots \quad \ldots \quad$ Wild ber bush.

Scutia indica.

Ampelidea.

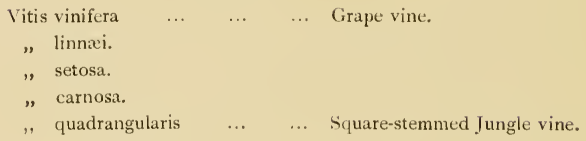

Sapindacea.

Allophyllus cobbe

... Thangot.

Sapindus trifoliatus

... soapnut.

Anacardiacea.

Mangifera indica ...

Mango.

Buchanania latifolia

C.. Cashewnut.

, angustifolia.

Odina wodier

$$
\begin{array}{llll}
\ldots & \ldots & \ldots & \text { John Company tree. } \\
& \text { Leguminosu. } &
\end{array}
$$

Arachis hypogea ... $\quad \ldots \quad \ldots \quad$ Groundnut.

Crotalaria mysorensis.

, verrucosa.

, juncea $\ldots \quad \ldots \quad \ldots$ Sann-hemp.

Trigonella fœnumgroecum _.. Fenugreek.

$\begin{array}{lllll}\text { Medicago sativa } & \ldots & \ldots & \ldots & \text { Lucerne. }\end{array}$

Cyamopsis psoralioides ... ... Cluster bean.

Indigofera linifolia.

, enneaphylla.

, trita.

, tinctoria $\quad \ldots \quad \ldots$ Indigo.

Psoralea corylifolia.

Tephrosia spinosa.

$\begin{array}{lllll} & \text { purpurea } & \ldots & \ldots & \text { Kolinji } \\ & \text { villosa. } & & & \end{array}$


Sesbania agyptiaca

('hitagathi.

" aculeata ... ... ... Daincha.

, grandiflora $\quad . . \quad \ldots \quad$ Agathi.

$\begin{array}{lllll}\text { Cicer arietinum } & \ldots & \ldots & \ldots & \text { Bengal-gram. }\end{array}$

$\begin{array}{lllll}\text { Vicia sativa } & \ldots & \ldots & \ldots & \text { Spring vetch. }\end{array}$

Ervum lens $\quad \ldots \quad \ldots \quad \ldots \quad \ldots \quad$ Lentil.

Pisum sativum $\quad \ldots \quad \ldots \quad \ldots \quad$ Pea.

Glycine hispida.

Erythrina indica $\quad . . \quad \ldots \quad \ldots \quad$ Coral tree; Dadap.

Butea frondosa $\quad . . \quad \ldots \quad$... Whak tree.

Canavalia ensiformis $\quad \ldots \quad \ldots$ sword bean.

Phaseolus trilobus $\quad \ldots \quad \ldots \quad$ Field-gram.

" aconitifolius.

" mungo $\quad \ldots \quad \ldots$ Green-gram; Mung.

$\begin{array}{lllll} & \text { radiatus } \quad \ldots & \ldots & \text { Black-gram. }\end{array}$

Vigna catiang $\quad \ldots \quad \ldots \quad \ldots$ Cow-pea.

Clitoria ternatea.

Dolichos lab-lab ... $\quad \ldots \quad \ldots \quad$ Field bean; Lab-lab.

" biflorus ... $\quad \ldots \quad$... Horse-gram.

Psuphocarpus tetragonolobus ... Goa bean.

Cajanus indicus ... ... ... 1)holl; Red-gram; Tur, Arhar.

Dalbergia sissoo $\quad \ldots \quad \ldots \quad \ldots \quad$ Sissu.

,, latifolia $\quad . . \quad \ldots$ Rosewood.

Pterocarpus marsupium $\ldots . \quad \ldots \quad$ kind tree.

Pongamia glabra.

Derris scandens.

Pterolobium indicum.

Cassia fistula

... Indian Laburnum.

" occidentalis.

,. auriculata

"siamea.

" obovata $\quad \ldots \quad \ldots \quad \ldots \quad$ Country Senna.

" angustifolia $\quad \ldots \quad \ldots$ Tinnevelly Senna.

Cresalpinia pulcherrima ... ... Flower Fence.

Poinciana regia $\quad . . \quad \ldots \quad \ldots$ Gold Mohur.

Hardwickia binata $\quad \ldots \quad \ldots$ Hardwickia,

Tamarindus indica $\quad \ldots \quad \ldots$ Tamarind.

Bauhinia variegata $\quad \ldots \quad$... Mountain Ebony.

Adenanthera pavonina ... ... Red-wood tree.

Acacia arabica $\quad . . \quad \ldots \quad \ldots$ Gum arabic; Babul.

", leucophlcea.

, latronum.

. concinna ... $\quad \ldots \quad$... Soapnut Acacia. 
Albizzia lebbek

Pithecolobium dulce Mimosa pudica
. Siris ; Vagai (Tam.).

.. Korkapilli.

.. Sensitive Plant.

\section{Rosacere.}

Rubus moluccensis.

, ellipticus.

, racemosus.

Eriobotrya japonica

Pyrus malus

, communis ...

Prunus persica

\section{Combretacece.}

Terminalia catappa

$\begin{array}{ll} & \text { belerica } \\ , \quad & \text { chebula }\end{array}$

... $\quad \ldots$ Tropical Alınond.

.. ... Myrobalan.

", arguna.

\section{Myrtaces.}

Psidium guyava ...

... ... Guava.

Eugenia jamboo ...

... Rose apple.

, arnothiana.

, alternifolia.

, jambolana

Punica granatum ...

Eucalyptus globulus

\section{Cucurbitacea.}

Trichosanthes anguina

... Snake gourd.

Lagenaria vulgaris

... Bottle gourd.

$\begin{array}{llllll}\text { Luffa ægyptiaca } & \ldots & \ldots & \ldots & \text { Towel gourd. }\end{array}$

" acutangula $\ldots \quad \ldots \quad \ldots \quad$ Strainer vine ; Ribbed gourd.

Benincasa cerifera.

Momordica charantia

... Carilla fruit; Balsam Pear.

Cucumis trigonus.

$$
\text { , melo } \quad \ldots \quad \ldots \quad \text {... } \text { Melon. }
$$

$\begin{array}{ccccc}\text { sativus } & \ldots & \ldots & \ldots & \text { Cucumber. } \\ \text { Citrullus vulgaris } \ldots & \ldots & \ldots & \text { Water melon. }\end{array}$

Cephalandra indica $\quad \ldots \quad \ldots$ Scarlet gourd.

Cucurbita maxima $\quad \ldots \quad \ldots$ Common gourd.

" $\quad$ pepo $\ldots . \quad \ldots \quad$... Pumpkin.

" moschata ... ... Musk melon.

Ctenolepis garcini.

Passiflorece.

Carica papaya

... Papaya; 1'apaw. 
Cacter.

\begin{tabular}{|c|c|c|c|}
\hline Opuntia dillenii & $\cdots$ & .. & Prickly Pear. \\
\hline 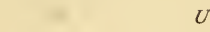 & \multicolumn{2}{|c|}{ Umbellifere. } & \\
\hline \multicolumn{4}{|c|}{ Hydrocotyle asiatica. } \\
\hline Carum caruii $\quad \ldots$ & $\cdots$ & $\ldots$ & Caraway. \\
\hline , copticum ... & $\ldots$ & $\ldots$ & Bishop's weed. \\
\hline Pimpinella anisum & $\ldots$ & $\ldots$ & Aniseed. \\
\hline Coriandrum sativum & $\ldots$ & $\ldots$ & Coriander. \\
\hline Cuminum cyminum & $\ldots$ & $\ldots$ & Cummin seeds. \\
\hline Daucus carota $\quad \ldots$ & $\ldots$ & $\ldots$ & Carrot. \\
\hline Peucedanum graneolens & $\ldots$ & $\ldots$ & Dill. \\
\hline
\end{tabular}

Cornacea.

Alangium lamarckii.

\section{Rubiacere.}

Wendlandia notoniana.

Oldenlandia umbellata

... $\quad$.. Chay-root.

Canthium parviflorum.

Coffea arabica

... ... Coffee.

Morinda citrifolia

, tinctoria

$\ldots \quad \ldots\}$ Indian Mulberry.

" umbellata.

Rubia cordifolia ...

... Indian Madder.

, tinctoria $\quad . . \quad \ldots . \quad \ldots \quad$ Madder.

Cinchona officinalis

, succirubra

Ixora coccinea

$\left.\begin{array}{ll}\ldots & \ldots \\ \ldots & \ldots\end{array}\right\}$ Cinchona.

... ... Scarlet Ixora.

Composite.

Helianthus annuus

Carthamus tinctorius

... $\quad$... Sunflower.

Ageratum conyzoides

Guizotia abyssinica

... ... Safflower.

Cosmos sulphureus

... $\quad$... White weed.

.. ... Niger seed.

... ... Cosmos.

Sapotacea.

$\begin{array}{ccccc}\text { Bassia latifolia } & \ldots & \ldots & \ldots & \text { Mahua; Moha. } \\ \text { " longifolia } & \ldots & & \ldots & \text {. } \\ \text { Mimusops elengi } & \ldots & \ldots & \ldots & \text { Monkey face; Bukul. } \\ \text { Achras sapota } & \ldots & \ldots & \ldots & \text { Sapodilla. }\end{array}$

\section{Oleacer.}

Jasminum spp. $\quad \ldots \quad \ldots \quad \ldots \quad$ Jasmine.

Tabernxemontana coronaria.

\section{Apocynacer.}

Nerium odorum $\ldots, \quad \ldots \quad \ldots \quad$ Oleander. 
Asclepiadacea.

Calotropis gigantea ...

Madar ; Calotropis ; Akh.

Cryptostegia grandiflora.

Pergularia minor.

\section{Convolvulacea.}

Ipomœea batatas

$$
\text { ... } \quad \ldots \quad \text {... Sweet Potato. }
$$

Solanacei.

\begin{tabular}{|c|c|c|c|}
\hline Solanum torvum $\quad \ldots$ & $\ldots$ & $\ldots$ & Turkey berry. \\
\hline " melongena & & $\ldots$ & Brinjal. \\
\hline , tuberosum & & $\ldots$ & Potato. \\
\hline Lysopersicum esculentum & & $\ldots$ & Tomato. \\
\hline Physalis peruviana ... & $\ldots$ & $\ldots$ & Cape Gooseherry. \\
\hline Capsicum frutescens... & $\ldots$ & & Chilli. \\
\hline , $\quad$ grossum $\ldots$ & $\ldots$ & $\ldots$ & Bell-pepper. \\
\hline Nicotiana tabacum ... & $\ldots$ & $\ldots$ & Tobacco. \\
\hline Datura stramonium ... & $\ldots$ & & Thorn-apple ; I)atura. \\
\hline
\end{tabular}

Pedaliacea.

Sesamum indicum .. Gingelly:

Acanthacea.

Adhatoda vasica

$$
\begin{aligned}
& \text {... } \\
& \text { Labiata. }
\end{aligned}
$$

Leucas linifolia $\quad \ldots \quad \ldots \quad \ldots$ Tumbe plant.

$\begin{array}{lllll}\text { Ocimum sanctum } & \ldots & \ldots & \ldots & \text { Tulsi. }\end{array}$

, basilicum ... $\quad \ldots \quad \ldots$ Sweet Basil.

$\begin{array}{llllll}\text { Mentha sp. } & \ldots & \ldots & \ldots & \ldots & \text { Mint }\end{array}$

\section{Verbenacea.}

Gmelina arborea.

$$
\text { , asiatica. }
$$

Tectona grandis

$$
\begin{array}{lllll}
\text { Tectona grandis } & \ldots & \ldots & \ldots & \text { Teak. } \\
\text { Lantana aculeata } & \ldots & \ldots & \ldots & \text { Lantana. }
\end{array}
$$

Amarantacee.

Amarantus spinosus.

, paniculatus.

, gangeticus.

, viridis.

Alternanthera sessilis

Chenopodiacea.

Chenopodium album

... Common Goosefoot.

" ambrosioides

... Hedge mustard; Kathucman. 
Polygonaier.

Rumea vesicarius

Bladder Dock.

\section{Piperacea.}

Piper betle

$$
\text { Betel. }
$$

, nigrum...

.. Pepper.

\section{Myristicacer.}

Myristica fragrans

Nutmeg.

\section{Laurinea.}

\begin{tabular}{ccc|c} 
Cinnamomum zeylanicum & $\ldots$ & $\ldots$ & Cinnamom.
\end{tabular}

Phcebe paniculata.

\section{Euphorbiacea.}

Euphorbia tirucalli Milk Hedge.

, viatorum ...

, pilulifera.

Jatropha curcas

Cactus Euphorbia:

Phyllanthus emblica.

Ricinus communis

Castor.

Hevea brasiliensis

Para rubber.

Manihot glaziovii

Ceara rubber.

.utilissima Tapioca.

\section{Irticaceri.}

Cannabis sativa

Indian Hemp.

Artocarpus integrifolia

Jak.

Morus indica... incisa $\quad \ldots \quad \ldots \quad \ldots \quad$ Bread-fruit.

Ficus bengalensis $\quad \ldots \quad \ldots \quad \ldots \quad \ldots \quad$ Banyan.

$\begin{array}{llllll}\text {, religiosa } & \ldots & \ldots & \ldots & \text { Pipal. }\end{array}$

" glomerata $\quad \ldots \quad \ldots \quad \ldots \quad \ldots \quad$ Country Fig.

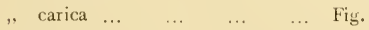

\section{Casuarinea.}

Casuarina equisetifolia

.. Casuarina; Chowkoo

(Tam.).

\section{Scitaminere.}

Curcuma neilgherrensis.

$\begin{array}{lllll}" & \text { longa } \ldots & \ldots & \ldots & \text { Turmeric. } \\ " & \text { angustifolia } & \ldots & \ldots & \text { Arrow-root. }\end{array}$




\begin{tabular}{|c|c|c|c|}
\hline Zingiber officinale & & & Ginger. \\
\hline Elettaria cardamomum & & & Cardamom. \\
\hline Musa sapientumi ... & & • & Banana. \\
\hline " paradisiaca ... & $\ldots$ & ... & Plantain. \\
\hline
\end{tabular}

\section{Bromeliacer.}

Bromelia ananas ... Pineapple

Amaryllidea.

Agave americana ... American Aloe.

Crinum asiaticum ... Asiatic Crinum.

Dioscoreacea.

Dioscorea spp. $\quad \ldots \quad \ldots \quad \ldots \quad \ldots \quad$ Yams.

Liliacee.

$\begin{array}{ccccc}\text { Allium cepa } & \ldots & \ldots & \ldots & \text { Onion. } \\ , \quad \text { sativum } & \ldots & \ldots & \ldots & \text { Garlic. }\end{array}$

Palmece.

Areca catechu $\quad \ldots \quad \ldots \quad \ldots$ Betel nut.

Phoenix sylvestris $\quad \ldots \quad \ldots$ Date Palm.

Arenga wightii.

Caryota urens

$\begin{array}{llll}\ldots & \ldots & \ldots & \text { Malabar Sago. }\end{array}$

Coryphba umbraculifera ... ... Talipot Palm.

Borassus flabellifer $\quad \ldots \quad \ldots$ Palmyra; Toddy Palm.

Cocos nucifera $\quad \ldots \quad \ldots \quad \ldots \quad$ Coconut.

Aroidea.

Typhonium trilobatum $\quad . . \quad \ldots \quad$ Elephant Yam.

Colocasia antiquorum $\quad . . \quad$... Taro ; Kesu.

Amorphophallus campanulatus ... Yam.

Acarus calamus $\quad \ldots \quad \ldots \quad \ldots$ Sweet flag.

\section{Graminea.}

Paspalum scrobiculatum _.. Varagu (Tam.).

Panicum crus-galli.

\begin{tabular}{|c|c|c|c|c|}
\hline " & frumentaceum & ... & $\ldots$ & Kudirai vali (Tam.). \\
\hline , & miliaceum & $\ldots$ & & Pani varagu. \\
\hline$"$ & miliare $\ldots$ & $\cdots$ & $\cdots$ & Samai ; Sawan (Hind.). \\
\hline$"$ & maximum & $\ldots$ & .. & Guinea grass. \\
\hline etaria & italica $\quad \ldots$ & ... & $\cdots$ & $\begin{array}{c}\text { Tenai ; Korra. } \\
\text { Millet. }\end{array}$ \\
\hline " & glauca & $\ldots$ & $\ldots$ & Korali (Tam:). \\
\hline
\end{tabular}


Pennisetum typhoideum ... Cumbu ; Bajra.

Oryza sativa ... $\quad \ldots \quad \ldots$ Rice; Paddy.

Zea mays $\quad \ldots \quad \ldots \quad \ldots \quad$ Maize.

Saccharum officinarum ... Sugarcane.

Andropogon sorghum _.. Cholam; Juar.

Eleusine coracana ... ... Ragi.

Triticum vulgare $\ldots \quad \ldots$ Wheat.

Hordeum vulgare $\ldots \quad \ldots$ Barley.

Bambusa vulgaris

I) arundinacea $\quad \ldots$ ( Bamboos. 


\section{HYMENOPTERA. \\ FORMICID $£$.}

\section{DORYLUS ORIENTALIS, Westwd.}

Dorylus orientalis, Westwd., P.Z.S. (1835), 72 ; Bingham, Faun. Ind. Hym., II, 4-6, ff. 6, 7; Lefroy, Ind. Ins. Pests, p. 231, f. 276, Ent. Mem. Dept. Agri., Ind., I, 128, f. 12, Ind. Ins. Life, p. 227, f. I30; Green, Perad. Circ. III, No. 22, p. 292.
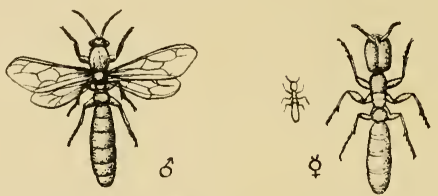

FIG. 111.-Dorylus orientalis, male and worker. (Original.)

Distribution.--Throughout Southern India.

Lifehistory.-Not known.

Foodplants.-Coconut seedlings, groundnut (roots).

Status,--Rather doubtful. Occasionally a pest, attacking growing plants; has been noticed to attack young coco-palms in Southern India and in Ceylon to perforate the pods of groundnuts and consume the contents. Specimens in the Coimbatore collection also are labelled as "attacking roots of groundnut." Other specimens were found at roots of coffee but no damage seemed to have been done. Has also been found damaging sugarcane.

Control.-?

Remarks.-The workers are very similar in habits and appearance to some termites, but the males (which often come in to light at night) are quite different.

\section{SOLENOPSIS GEMINATA, Fb.}

Atta geminata, Fabr., Syst. Piez., p. 423 (1804).

Solcnopsis geminata, Bingham, Faun. Ind. Hym., II, 158-159, f. 64 ; Lefroy, Ind. Ins. Life, p. 229.

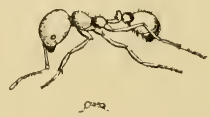

FIG. 112.-Solenopsis geminata, worker. The smaller figure shows the natural size. (Original,) 
Distribution.--Probably throughout Southern India. (Not noted from Bellary or Malabar.)

Lifchistory.-Nest in the ground.

Food.--Sometimes found attacking young cotton seedlings and buds of hollyhock, brinjal, crotons, ailanthus, etc.

Status.-May do damage, even to killing the plant, by biting the tender buds and shoots and growing the leaves.

- Control.-(I) Killing the nest where found.

(2) Ringing of plants with ashes or painting crude oil emulsion on to the stem or branches attacked.

MONOMORIUM GRACILLIMUM, Sm.

Myrmica gracillima, Snith, J. Linn. Soc., VI, 34 (I86I).

Monomorium gracillimum, Bingham, Faun. Ind. Hym., II, 210-2I I.

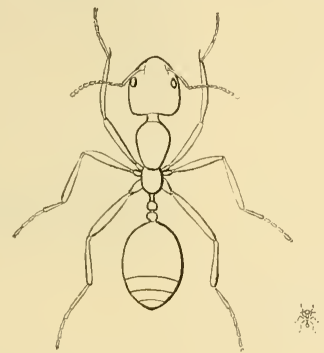

FIG. 113.-Monomorium gracillimum, worker. The small figure shows the natural size. (Original.)

Distribution.-Coimbatore. Probably widely distributed in Southern India.

Lifchistory.-Nest in the ground, in cracks of walls, etc.

Food-A scavenger of dead insects, feeding also on provisions such as sugar, bread, ghi, vegetable oils.

Status.-A common pest of store-rooms and houses.

Control.-(I) Destruction of the nest if it can be found.

(2) Laying down baits (e.g., a sponge soaked in sugar and periodically dropping it in hot water), or permanent poisoned baits which the ants will carry off to their nests and feed to their young.

Remarks.-Bingham (l.c.) states that gracillimum is confined to Ceylon, being represented in India by mayri, Forel, but Coimbatore specimens appear to be gracillimum. 
CECOPHYLLA SMARAGDINA, Fb.

Formica smaragdina, Fabr., Syst. Ent., p. 828 (I775).

Ecophylla smaragdina, Bingham, Faun. Ind. Hym., II, 3 I I ; Lefroy, Ind. Ins. Life, p. 230, ff. I33-I35 ; Dutt, Ent. Mem. Dept., Agri.,'Ind., IV, $254-260$, ff. 2 I-22.

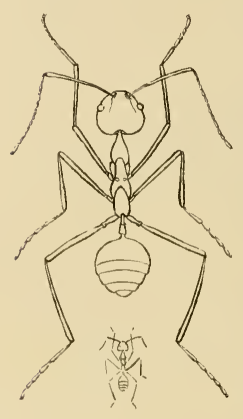

F1G. 114.-Ecophylla smarag. dina, worker. The smaller figure shows the natural size. (Original.)

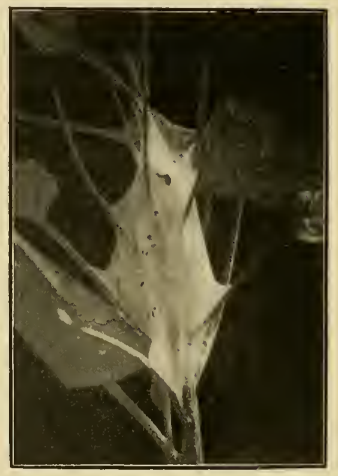

F1G. 115.-Silken chamber spun around branch by E. smaragdina. (After Lefroy).

Distribution.-Throughout Southern India up to about 5,000 feet, occurring most abundantly in regions of heavy rainfall.

Lifchistory.-Forms a nest in trees composed of leaves spun together by silken threads excreted by the larvæ which are held in the jaws of the worker ants and applied to the situations in which the silk is required. Besides the main nest there are usually many subsidiary chambers of spun leaves containing plantsucking insects which are tended and defended by the ants. The males and females of this ant are green, the workers orange-red.

Food-Caterpillars, beetles, flies, ants, etc.

Status.-Beneficial to some extent as predators on small insects of various sorts but harmful as protectors of noxious Scale-insects, etc., which are not only tended but deliberately introduced on to new plants by the ants. In mango garclens also these ants may 
prove a great annoyance by covering the trees with their nests and attaching the mango-gatherers.

Control.-The nests are conspicuous and easily opened and killed by spraying or burning.

\section{CANPONOTUS COMPRESSUS, Fb.}

- Formica compressa, Fabr., Mant. Ins., I, 307 (I787).

Camponotus compressus, Bingham, Faun. Ind. Hym., II, 35 I-352, f. 109; Lefroy, Ind. Ins. Life, p. 233, ff. I25--I28.

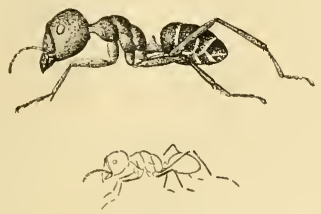

Fig. 116.--Camponotus compressus, worker. The small figure shows the natural size. (Original.)

Distribution.-Throughout the Plains of Southern India (not found in Malabar).

Lifchistory.-Nest in the ground, often at the foot of a tree.

Food.-A general scavenger, feeding in the field on honey-dew, dead insects, etc., and attaching sugar in the house.

Status.-Indirectly a pest as it tends and protects Scale-insects, Aphids, Membracids, etc., which may themselves do considerable damage by sucking the juice of plants.

Control.--(I) The nests are fairly easily found and destroyed.

(2) In the cases of trees badly attacked by Scales which were attended by these ants, it has been found that a band of tar and crude oil emulsion applied around the trunk of the tree keeps the ants from ascending, thus leaving the Scales open to attack by their natural enemies.

Observation.-This ant has been noticed in active defence of a Scale-insect against a small parasitic fly which was attempting to parasitize the Scale.

\section{APID}

APIS DORSATA, Fb.

Apis dorsata, Fabr., Ent. Syst., II, 328 (I793) ; Bingham, Faun. Ind. Hym., I, 557-558, t. 4, f. II. 


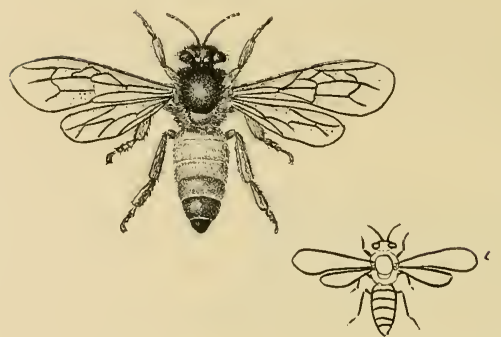

FIG. 117.-Apis dorsata, worker. The small outline figure show's the natural size. (Original.)

Distribution.--Throughout the Hills and sub-montane districts, apparently migrating into the Plains.

Lifchistory.-A large single comb is formed, usually about 3 feet wide and deep, but often much larger; it is suspended under the horizontal branch of a tree or under an overhanging rock or similar situation. The colonies are gregarious and many combs are usually found together, the same locality being resorted to year after year.

Status.-Very beneficial in pollination of flowers and useful as yielding honey and wax.

Remarks-(1) This bee does not appear capable of domestication.

(2) This is the Large or Rock Bee; Tamil, Malanthenee (Mountain Bee).

APIS INDICA, Fb.

Apis indica, Fabr., Ent. Syst. Suppl, p. 274 (1798); Bingham, Faun. Ind. Hymı., I, 558, t. 4, f. 12.

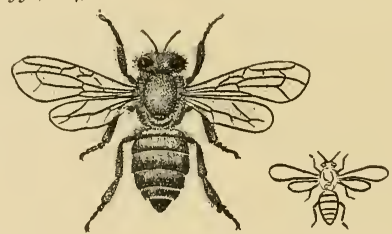

F1G. 118.--Apis indica, worker. The small outline figure shows the natural size. (Original.)

Distribution.-Throughout Southern India.

Lifehistory.--Several parallel combs, each about a foot wide and deep, are suspended usually in a hollow tree or similar more or less protected situation. The colonies are not gregarious. 
Status.-Very beneficial in the pollination of flowers and useful as yieldling honey and wax.

Romarks.-(I) The races of this bee found in the Hills are very much darker than those found in the Plains.

(2) This bee may be domesticated to some extent but will not remain in a hive for more than a few months as a rule. It is very subject to attacks of Wax-moth and does not store any great quantity of honey.

(3) This is the Indian Bee, intermediate in size between the Rock and Little Bees and slightly smaller than the European Bee; in Tamil Thenee (bee).

APIS FLOREA, Fb.

Apis florea, Fabr., Mant. Ins., L, 305 ; Bingham, Faun. Ind.' Hym., I, 559, f. I87.

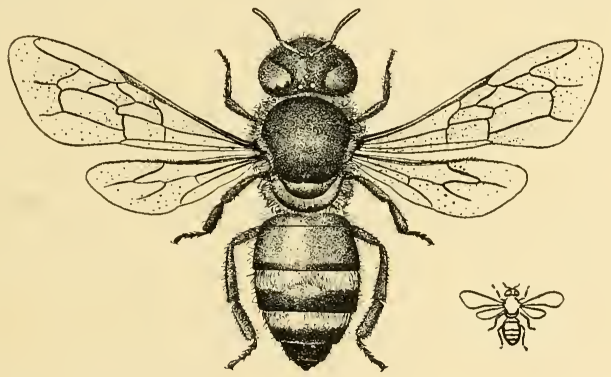

F1G. 119.-Apis florca, worker. The small outline figure shows the natural size. (Original.)

Distribution.-Throughout Southern India.

Lifchistory.-This bee builds a small single comb, usually about six inches broad and deep, which is generally slung from a branch of a bush. Colonies not gregarious.

Status.-Very beneficial as a pollinator of flowers. The honey and wax, though of good quality, are produced in too small quantity to have much commercial value. The nests are commonly robbed when found and the honey eaten.

Remarks.-(I) This bee is not likely to repay domestication.

(2) This is the Little Bee; in Tamil, Siruthence (small bee). 


\section{SPHEGIDÆ.}

OXYBELUS SQUAMOSUS, Sm.

Oxylchus squamosus, Smith, T.E.S. (1875), 38 ; Cameron, Manch. Mem. (4), III, 276 (1890); Bingham, Faun. Ind. Hym., I, 315: Lefroy, Ind. Ins. Life, p. 209.

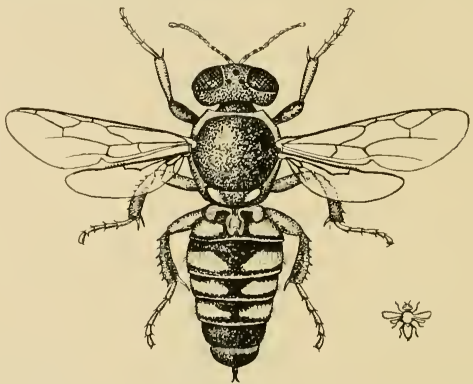

Fig. 120.-Oxybelus squamosus. The small figure shows the natural size. (Original.)

Distribution.-Guindy; Coimbatore. Probably throughout the Plains of Southern India.

Lifehistory.-Not known in detail. These wasps, however, are known to tunnel in sandy banks and to store their nests with Diptera.

Food.-Adult flies of Philamatomyia insignis.

Status.-Highly beneficial as predaceous on the above-named pest of cattle.

Remarks.-This little wasp is found fairly commonly on and around cattle. It stalks Philematomyia insignis when this fly is intent on sucking blood and seizes it, when wasp and fly usually drop to the ground; the fly is stung and carried off by the wasp and, so far as I have been able to observe, it is held by the sting only (and not by the legs) during flight. Sometimes the wasp collects the female flies whilst these are ovipositing in cowclung, at which time the flies are in a rather helpless position, anchored (so to speak) by their ovipositor in the dung. This wasp does not attack Stomoxys or Houseflies, as quoted by Lefroy (l.c.); if it does by error clutch a Stomoxys or hæmatophagous Muscid, both fly and wasp drop to the ground but the former is released immediately the mistake is discovered. As a check on Philamatomyia this little wasp is most efficient and useful. 


\section{TENTHREDINIDE.}

ATHAlia PROXIMA, Klug. (Plate II, FIGS. I2, I3.)

Tcuthredo proxima, Klug, Berlin Mag., VII, I30 (I8I6).

Athalia proxima, Lefroy, Ind. Ins. Pests, p. I52, Ent. Mem. Dept. Agri., Ind., I, 127, 357-370, t. 20, Ind. Ins. Life, p. 165, t. 9.

Distribution.-Coimbatore, Shevaroys, Bellary, Godavari, Bangalore, Bababudins.

Lifelistory.-Eggs are thrust into the tissue of the leaves of the foodplant, being deposited singly during the day-time. The larva hatches out after about a week and feeds on the leaves, eating holes from the edge and in the centre of the leaf. The young larva is greenish grey but it becomes darker as it grows until it is greenish-black when full-fed. It looks much like a Lepidopterous larva, but is easily distinguished by having eight pairs of prolegs besides the three pairs of thoracic (true) legs. When full-grown it constructs a cocoon in the soil ; pupal period from Io days upwards. In some districts (Coimbatore) this insect is only found cluring the cold weather (November-February); in others (Bellary) it has been found during the South-West Monsoon (August).

Foodplants.-Mustard, cabbage, radish, cauliflower, turnips.

Status.-A minor pest of cruciferous plants, sometimes doing considerable damage to young seedlings.

Control.-(I) Handpicking of larvæe.

(2) Protection of plants by spraying Naphthaline Emulsion or dusting with lime (20 pints) and kerosine ( 20 pints).

\section{COLEOPTERA.}

\section{SCARABAIDA.}

HELIOCOPRIS BUCEPHALUS, Fb.

Scarabeus buccphalus, Fab., Syst. Ent., p. 24 (1775).

Heliocopris bucephalus, Lefroy, Ind. Ins. Life, p. 249, f, I4I.

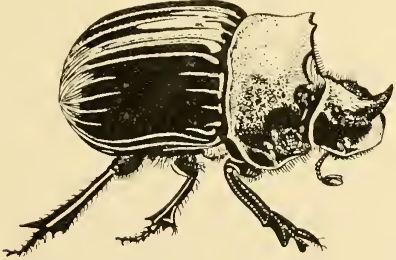

F1G. 121.-Heliocopris buccphalus. (After Howlett. 
Distribution.-Bellary, Coimbatore. Probably throughout Plains of Southern Inclia.

Lifchistory and Food.-The beetles collect animal dung and make it into balls which they roll away and bury in the ground. In some of these balls eggs are laid and the larva feeds on the dung. The exact lifehistory of all species is little known but in some cases it may extend over two years or more.

Status.-Beneficial to some extent.

Remarks.-A very large number of species of these beetles exist in India and are commonly to be seen in dry places. They undoubtedly do a great deal of good by disposing of dung and ordure in the vicinity of habitations.

\section{CETONIADE.}

ANATONA STILLATA, NeWm.

Cetonia stillata, Newm., Ent. Mag., V, I69 (1838).

Anatona stillata, Arrow, Cetoniinæ (F.I.), p. II4 (I9I0).

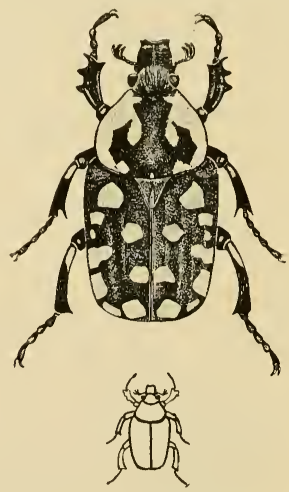

F1G. 122.-Anatona stillata. The small outline figure shows the natural size. (Original.)

Distribution.-Hadagalli (September I9II), Bangalore (Arrow).

Lifchistory.-Eggs are laid in moist places, the beetles burrowing about 2 inches underground and ovipositing there. The larva probably feed at the roots of grasses and miscellaneous plants. 
Eggs are perhaps laid about September, the beetles emerging about June in the following year.

Foodplant.-Beetle on the ears of cholam and cumbu, tenai and ragi, devouring pollen of ear-heads in flower and milk of developing grains. In the case of cholam, the beetles may enter the earhead to the number of a dozen or more in one head and destroy the grains, filling the ear-head with excrement.

- Status.-A local pest of some importance.

Control.-Collection of the beetles by hand-nets.

OXYCETONIA VERSICOLOR, Fb.

Cetonia versicolor, Fab., Syst. Ent., p. 5 I (I775).

Orycitonia versicolor, Lefroy, Ind. Ins. Life, p. 258 (Glvcyphana); Arrow, Faun. Ind. Ceton, pp. I64-I66, ff. 35-36.

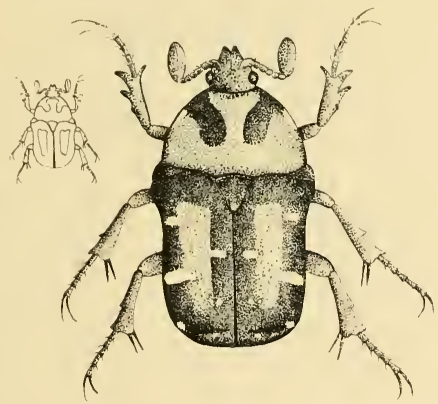

FIG. 123.-Oxycctonia versicolor. The small outline figure shows the natural size. (Original.)

Distribution.-Bangalore, Bellary, Coimbatore, Madras. Probably throughout Southern India. May to October.

Lifchistory.--Not known.

Foodplants. - The beetle feeds on flowers and tender grains of cumbu, cholam, tenai and other cereals. Sometimes on flowers of other crop and garden-plants, such as groundnut and Cosmos.

Status.-Scarcely a serious pest as a rule.

Control.--Collection of the beetles by hand and in hand-nets. 


\section{CHILOLOBA ACUTA, Wied.}

Cetonia acuta, Wied., Zool. Mag., II, i, p. 87 (I823).

Chiloloba achta, Lefroy, Ind. Ins. Life, p) 258 ; Arrow, Faun. Ind. Ceton., p. I72, t. 2, f. 4 .

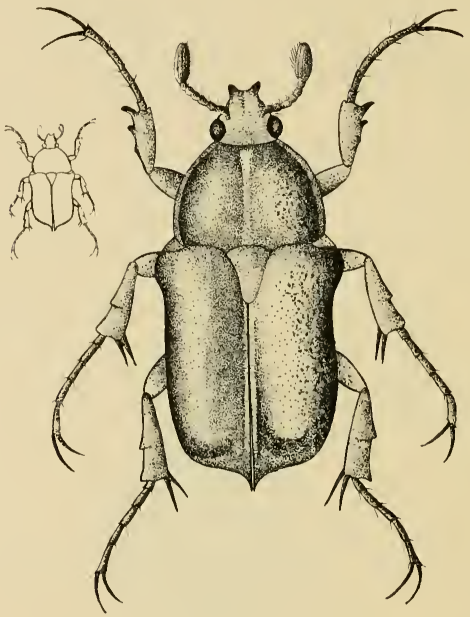

F1G. 12t.-Chiloloba acuta. The stnall outline figure shows the natural size. (Original.)

Distribution.-Bellary, Bangalore, Coimbatore, Shevaroys, South Arcot. In September and October.

Lifehistory.-Not known.

Foodplants.--Ears of cholam, cumbu, etc., the beetles devouring the flowers and tender grains.

Status.-Not a serious pest as a rule.

Control.-Collection of beetles by hand and with hand-nets.

Remarks,-Arrow's coloured figure scarcely gives a sufficient idea of the beautiful brilliant metallic green coloration of this beetle. 

PLATE III.
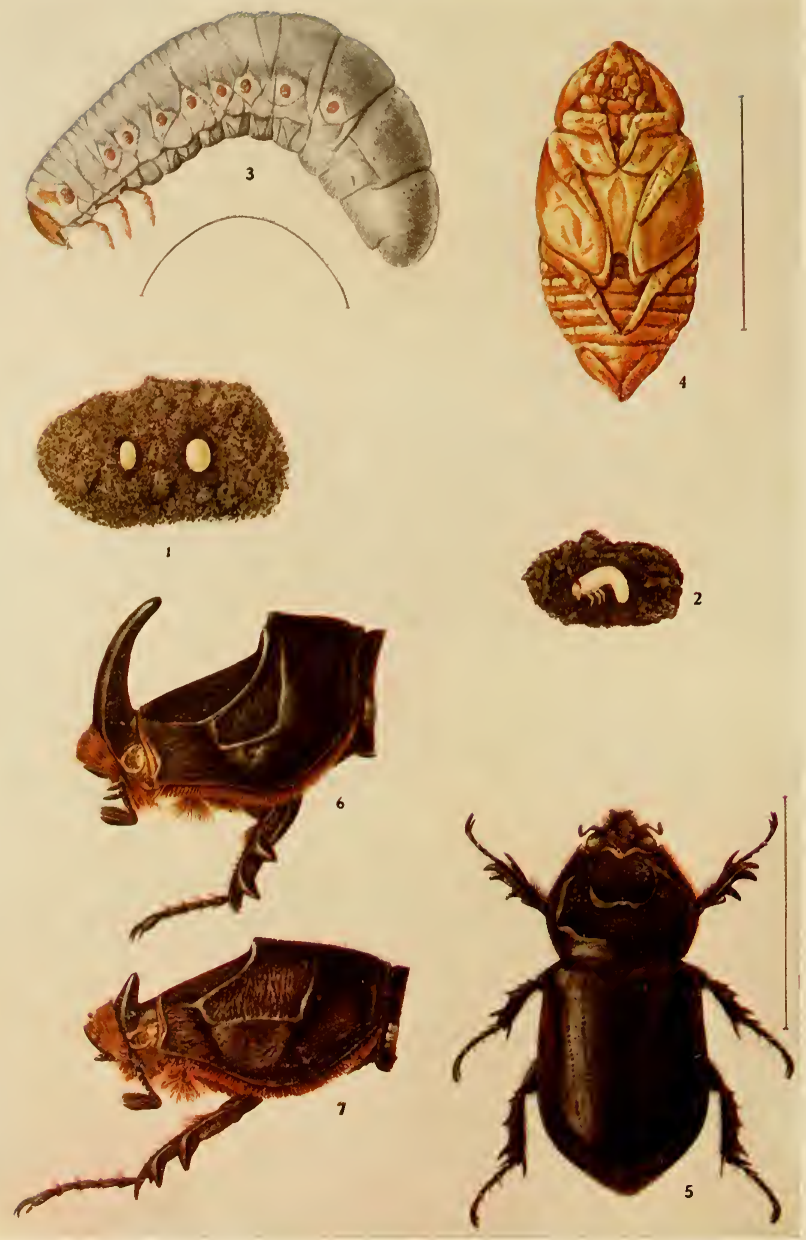

ORYCTES RHINOCEROS. 


\section{EXPLANATION OF PLATE III. ORYCTES RHINOCEROS.}

F1G. 1. Eggs.

2. Young larva.

"3. Adult larva.

1. 4. Pupa.

" 5. Beetle.

"6. Side-view of head of male beetle.

" 7. " " of female ,

(The lines alongside the figures show the natural sizes.; 
DYNASTIDE.

ORYCTES RHINOCEROS, Linn.

Scarabaus rhinoceros, Linn. Syst. Nat. (x), 346 (1758).

Oryctes rhinoceros, Lefroy, Ind. Ins. Pests, pp. 207-208, Ind. Ins. Life, p. 256, figs. I45, I46 ; Arrow, Faun. Ind. Dynast, pp. 278--28I, f. 63 ; Ghosh, Ent. Mem. Agri. Dept., Ind., Vol. II, 193-204, t. 27.

(SEE Plate III.)

Distribution. - Throughout the Plains of Southern India all the year round.

Lifehistory. The eggs are laid in decaying vegetation or rotting trees, often in palm trees attacked by Palm Weevil. The stout whitish grubs live in rotting vegetable matter. The beetle itself does clamage by boring into the soft crowns of palm trees thereby providing a means of entry for the Palm Weevil to lay eggs. The grubs have been noted on decaying date stems, manure heaps, and on the dead top shoots of palmyras dead of bud rot.

Foodplants. Palms of various species; American Aloes (both beetle and grub). The beetle also occasionally bores into sugarcane stems. (See figure 68.)

Status.-A serious pest, principally of palms. Possibly of importance also as a carrier of spores of fungal diseases of palms.

Control.-All dead and rotten palms should be cut and burnt. Heaps of rotting vegetable matter near palm groves should be regularly turned over and the grubs destroyed. The beetle comes to light and may sometimes be attracted by light-traps. In the Chittoor District (Nariambattu) the following method was reported to be adopted to trap the beetles. "Wide vessels of good size filled with kitchen refuse, such as rice-water, etc., are kept among the plants at the rate of one for every ten or twelve palms. The liquid soon begins to ferment and emit a strong smell attracted by which the beetles are said to appear in good numbers and drop in, when they are collected and killed." This method may be tried elsewhere.

\section{RUTELIDA.}

ADORETUS BANGALORENSIS, Br.

Adoretus bangalorensis, Brenske, I.M.N., V, 38, t. 4, ff. I, 2 (I900). Distribution.-Bangalore.

Lifehistory. - Not known. Probablv very similar to that of Anomala varians.

Foodplant and Status.--The adult beetles were found attacking rose-bushes in the Government Botanical Gardens at Bangalore. 
Control.-Collection of the beetles by hand.

Remarks.-This beetle is perhaps identical with A. ovalis, Bl.
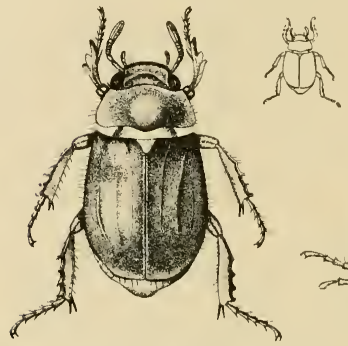

Fig. 125.-Adorctus bangalorensis. The suall outline figure shows the natural size. (From Indian Museum Notes.)

ADORETUS CALIGINOSUS BICOLOR, Br.

Adorctus caliginosus, Burm., var. bicolor, Brenske, I.M.N., V, 38, t. 4 , ff. 3,4 (I900).
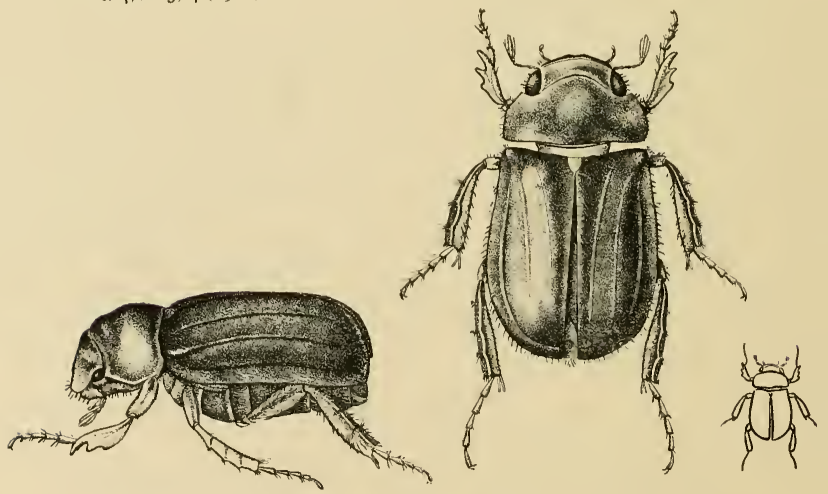

F1G. 126.-Adorctus caliginosusbicolor. The small outlice figure show a the natural size. (From Indian Museum Notes,)

Distribution.-Bangalore.

Lifchistory.-Not known. Probably very similar to that of Anomala varians. 



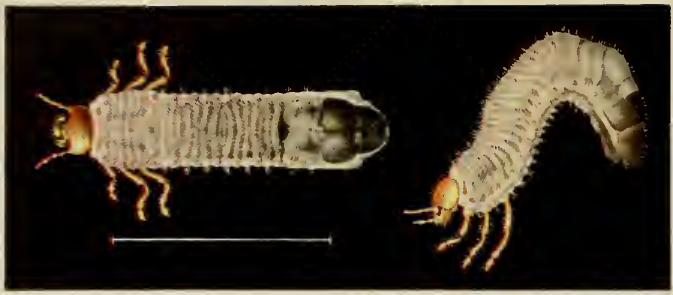

3

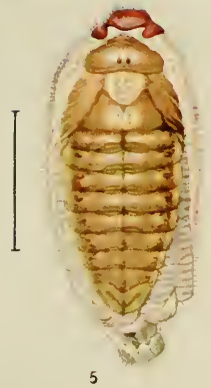

4
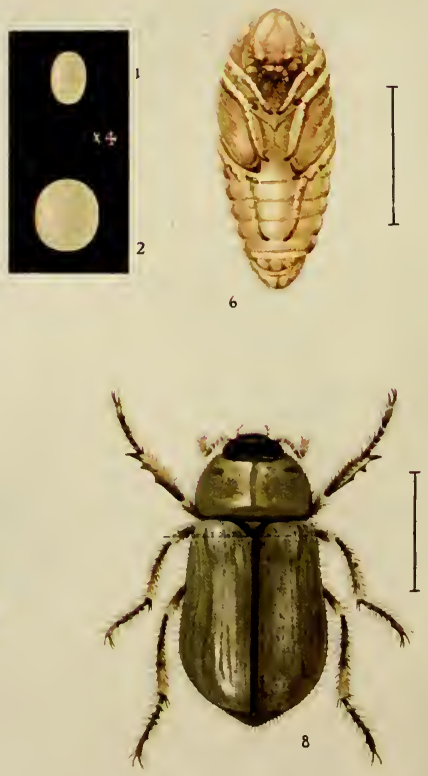


\section{EXPLANATION OF PLATE $\mathbb{N}$,}

\section{ANOMALA VARIANS.}

FIG. 1. Egg, newly laid, $x_{4}$.

" 2. Egg just before hatching.

" 3. Larva, dorsal view.

"4. " lateral ,

" 5. Pupa, dorsal view, partly enclosed in last larval skin.

"6. Pupa, ventral view.

" 7. ", lateral ,

, 8. Beetle.

(The lines alongside the figures show the natural sizes.) 
Foodplant and Status. - The adult beetles were found attacking rose-bushes in the Government Botanical Gardens at Bangalore.

Control.-Collection of the beetles by hand.

ADORETUS OVALIS, Bl.

Adoretus ovalis, Blanchard, Cat. Coll. Ent., p. 233; Sharp, A.M.N.H. (7) XI, 472-473 (I903).
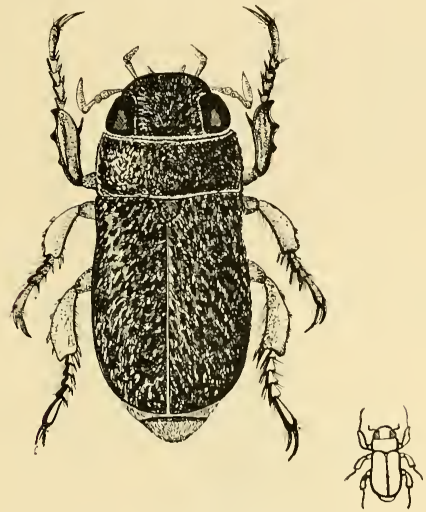

FIG. 127.-Adorctus ovalis. The small outline figure shows the natural size. (Original.)

Distribution.-Coimbatore, Anantapur, Bellary, Godavari, Madras, South Arcot, all the year round. Ootacamund in April.

Lifehistory.-Not known.

Foodplant. - The beetle eats leaves of grape-vine and mango. It feeds on the foliage at night and often does serious injury. During the day numbers of them are often found hidden just under the surface soil around the plant.

ANOMALA VARIANS, Oliv. (Plate IV.)

Anomala varians, Olivier, Ent. I, 5, p. 78, t. I0, f. I23 $a, b$; Lefroy, Ent. Mem. Agri. Dept., Ind., II, I43-I47, t. XIV, Ind. Ins. Life, p. 254, t. XIV.

Distribution.-Coimbatore, Bangalore, Bellary, practically throughout the year. 
Lifchistory.--The comparatively-large white egg is probably laid in the soil in which the grubs live, feeding on roots of various plants. The full-grown grub is about $40 \mathrm{~mm}$. long, dirty whitish with yellow head and legs and the abdomen incurved beneath. The pale-yellowish pupa is partly enveloped in the old larval skin which forms a kind of false-cocoon for it. The life-cycle is about 6-9 months.

Foodplants. - The grubs are bad pests on all garden plants, such as creepers, etc.

In Coimbatore flights of this chafer generally occur when the North-East Monsoon breaks.

Control.- No satisfactory method of dealing with the grubs can as yet be recommended for use on a field-scale. The beetles, when abundant, may be collected by hanil, by hand-nets, and at light.

\section{NITIDULIDA.}

CARPOPHILUS DIMIDIATUS, Fb.

Nitidula dimidiata, Fab., Ent. Syst., I, I, 26I (1792).

Carpophilns dimidiatus, Lefroy, Ind. Ins. Life, p. 297.

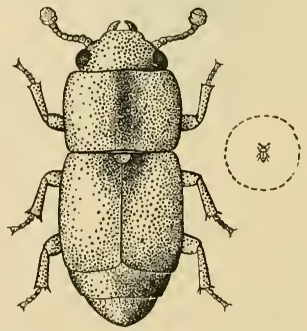

Fig. 128.-Carpoplitus dimidiatus. The small figure show's the natural size. (Original.)

Distribution.-Throughout Southern India all the year round.

Lifchistory and Food. - Not fully worked out. The larva probably feeds in rotting vegetable matter, pupating in the ground. The beetles are found in rotting vegetable matter (rotten fruit, etc.) and some species of this group occur in flowers.

Status.-Not known to be a pest but may prove to be so by carrying fungal and orher diseases from attacked trees, etc., and so infecting healthy ones.

Remarks.-The insects of this group, though numerous in India, are small and inconspicuous. In their habits they are very varied 
most being found on or in rotting animal and vegetable tissues, whilst some live in flowers, and the larva of one species (in Italy) is recorded as predaceous on a Scale-insect.

\section{TROGOSITIDE.}

\section{TENEBROIDES MAURITANICUS, L.}

Tinebrio maturitanicus, Linn., Syst. Nat. (ed. X), I., 417 (1758).

Tinebroides manritanica, Lefroy, Ind. Ins. Pests, 25I-2, f. 302 , Ind. Ins. Life, P. 299, ff. I76 I77; Chittenden, U.S.A. Entom. Bull. 4, Pp. I 22 I24, f. 60 . (I896).
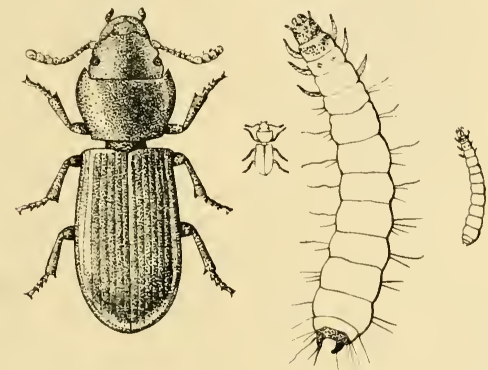

Fig, 129.-Tonthroides manritanicus, beetle and laria. The smatl figures show the natural sizes. (Original.)

Distribution:- Probably throughout Southern India all the year round.

Lifehistory.-The elongate, curverl, pale-white eggs, measure about $2 \mathrm{~mm}$. in length. The full-grown larva is nearly an inch long, stoutly-built, of a dirty whitish colour, with conspicuous smooth brown head and chitinous prothoracic and supra-anal shields, this latter terminating in a pair of short, sharp, projections. A single beetle may lay forty eggs. Exact life-cycle not known.

Food. - This beetle is at times vegetarian in its diet, feeding on stored grain, groundnuts, etc., and is sometimes at least predaceous, feeding on other insects which infest stored produce. Specimens were found in stored tobacco in Madras where they were presumably predaceous in the Cheroot Beetle.

Stutus. Rarely a pest and often beneficial. Includerl here as an insect commonly found in storedlgrain, etc. 


\section{CUCUJIDÆ.}

\section{SILVANUS SURINAMENSIS, L.}

Dermestes surinamensis, Linn., Syst. Nat. (ed X), I, 357 (I758).

Silvanus surinamensis, Lefroy, Ind. Ins. Pests, p. 252, f. 304, Ind. Ins. Life, p. 300, figs. I79, I80 ; Chittenden, U.S.A. Ent. Bull. 4 , p. I2I, f. 59, Bull. 8 , f. 4 .

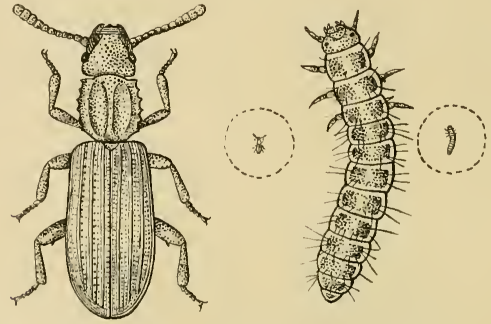

FIG. 130.-Silvanus surinamensis, beetle and larva. The small figures show natural sizes. (Larva after Chittenden.)

Distribution.-Probably throughout Southern India all the year round.

Lifehistory.- Not worked out in South India.

Food.-Dried fruit, flour, etc.

Statns. -Not noted as a pest.

\section{EROTYLIDÆ.}

FATUA LONGICORNIS, Wied.

Languria longicornis, Wied, Zool. Mag., II, 48 (I823).

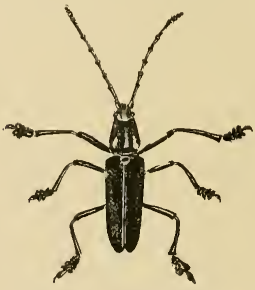

FIG. 131.-Fatua longicornis, Male. (Original.)

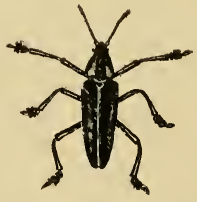

FIG. 132.-Fatuazlongicor. nis, Female. (Original,) 



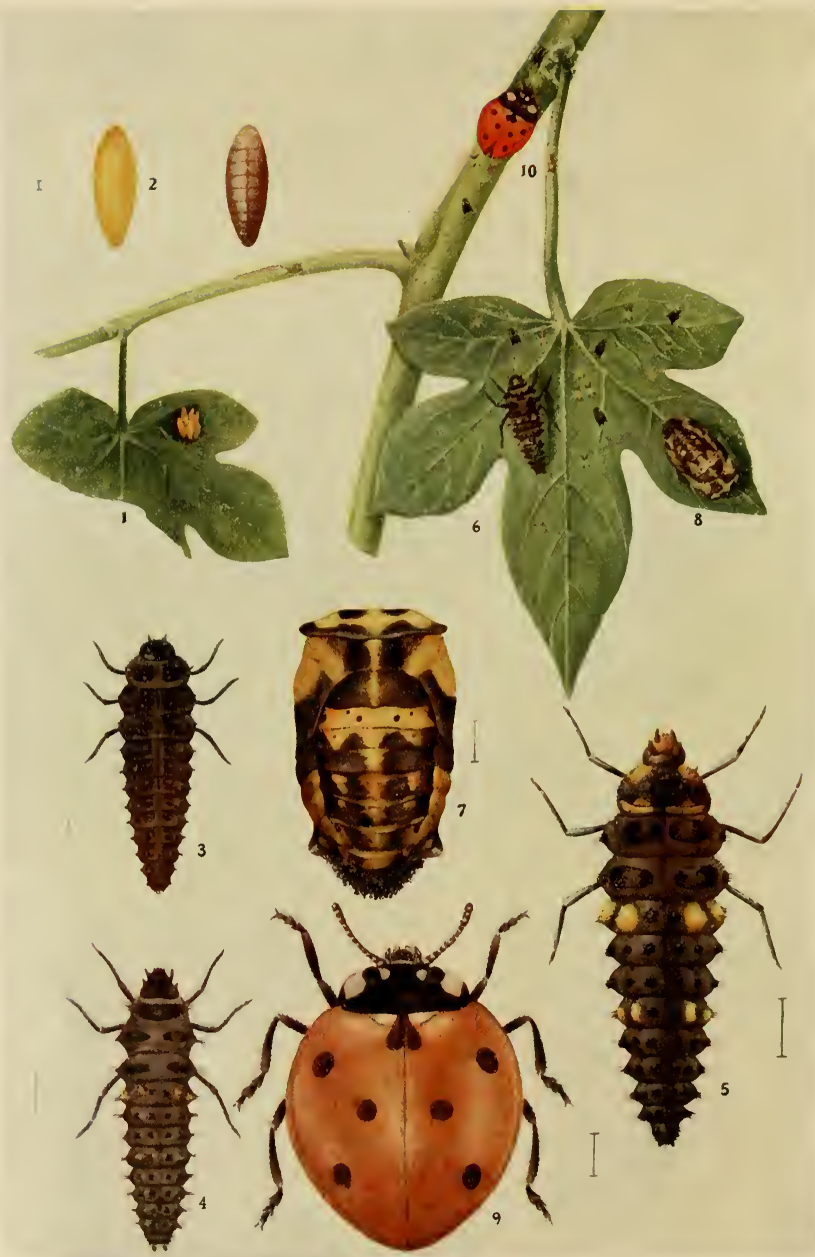

COCCINNELLA SEPTEMFUNCTATA. 


\section{EXPLANATION OF PLATE $V$. \\ COCCINELLA SEPTEMPUNCTATA.}

FIG. I. Cluster of eggs on leaf, natural size.

, 2. Eggs, enlarged.

" $3,4,5$. Larva in various stages, enlarged.

.. 6. Larva, natural size.

. 7. Pupa, enlarged.

" 8. " natural size.

"9. Beetle, enlarged.

" so. ", natural size.

(The lines alongside the figures show the natural sizes,) 

Distribution.--Throughout the dry districts of Southern India.

Lifehistory and Foodplant.-Lifehistory not known in detail.

The beetles are commonly found on Euphorbia antiquorum and larvæ have been found in rotting branches of this plant which had previously been bored by a Phycitid larva.

Status. -Not a pest.

\section{COCCINELLIDA.}

COCCINELLA SEPTEMPUNCTATA, Linn.

Coccinclla scptempunctata, Linn., Syst. Nat. (ed. X), I, 365 (I758) ; Lefroy, Ind. Ins. Pests, p. 273, f. 33I, Ind. Ins. Life, p. 306.

\section{(SEE Plate V.)}

Distribution.- Throughout Southern India all the year round.

Lifelistory and Food.- The yellow elongated eggs are deposited in clusters on plants affected with colonies of Aphids (Green-Fly).

The brownish long-legged larve are active and predaceous on the Aphids which they seek out and devour. The squat, brown, mottled pupa is affixed to leaves.

Status.-- Both larva and beetle are highly beneficial by feeding on Aphids.

Remarks.-This particular species of Coccinclla is found chiefly on wheat and mustard, but sometimes on paddy and other crops. Numerous other species are found in Southern India, the lifehistory in general being very similar.

\section{? COELOPHORA Sp.}

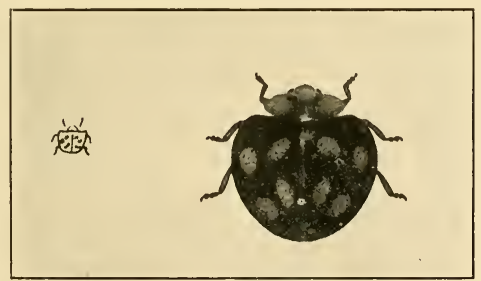

F1G. 133. - Coclophora sp. The smaller figure shows the natural size. (Original.)

(Head and thorax orange-yellow, wing-cases black, each with four elongated orange spots.)

Distribution.-Nilgiris (Hillgrove ; 4,200 feet). 
Lifehistory and Food.--Both larvæ and beetles have been found to be preslaceous on the Green Bug (Lecanium viride) of coffee, on the leaves of which the pupe were also found.

Stutus.-Beneficial as predaceous on Lecunium viride.

$$
\text { ePilachna i2-Stigma, Muls. (Plate Vi.) }
$$

Epilatha dodecastigma, Muls., Spec., p. 789; Lefroy, Ind. Ins. Life, p. 308, f. I88.

Distribution.- Throughout Southern India all the year round.

Lifehistory. - The yellowish eggs are laid in clusters on leaves of the foorlplant on which the stout, spinous, yellow grubs feed, eating the epiclermal layer of the leaf in characteristic patches. The squat, yellow pupe are attached head-downwards to leaves, or more usually stems, of the foodplant. The beetles also eat the leaves.

Foodplants.--Solanaceous and cucurbitaceous plants; especially on Brinjal.

Staths.-Often a serious pest on Brinjal and Bitter Gourd (Momordica).

Control.- Collection by hand of the insect in all stages. Spraying of plants in bad cases.

Natural Enemies. - A small Chalcid was reared from a pupa of E. 12-stigma found in Bellary.

Remarks.-The closely-allied and perhaps commoner species, Epilachna 28-punctata, is also shown on the plate (fig. 5), which depicts the colouring of the beetles as rather too deep a red.

\section{DERMESTIDÆ.}

DERMESTES VULPINUS, Fb.

Dermestes rulpinus, Fab., Spec. Ins., I. 64 (I78I); Lefroy, Ind. Ins. Life, p. 3II, f. I90.

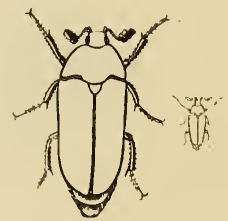

IG. 134.-Dermestes vutpinus. The smaller figure shows the natural size. (Original.)

Distribution.- South Kanara. Probably throughout Southern India. 



\section{EXPLANATION OF PLATE VI. EPILACHNA BEETLES.}

HIG. 1. Epilachna dodecastigma, egg.

$\begin{array}{lllll}\text { " 2. } & \text {. } & \text {, } & \text { larva. } \\ \text {, } & 3 . & \text { 4. } & \text { " } & \text { pupa. }\end{array}$

"5. Epilachna 28 -punclata, beetle.

" 6. Beetles (both species) on plant, natural size, showing eggs, larvæ, pupæ, adults, and damage done.

(The lines alongside the figures show the natural sizes.) 


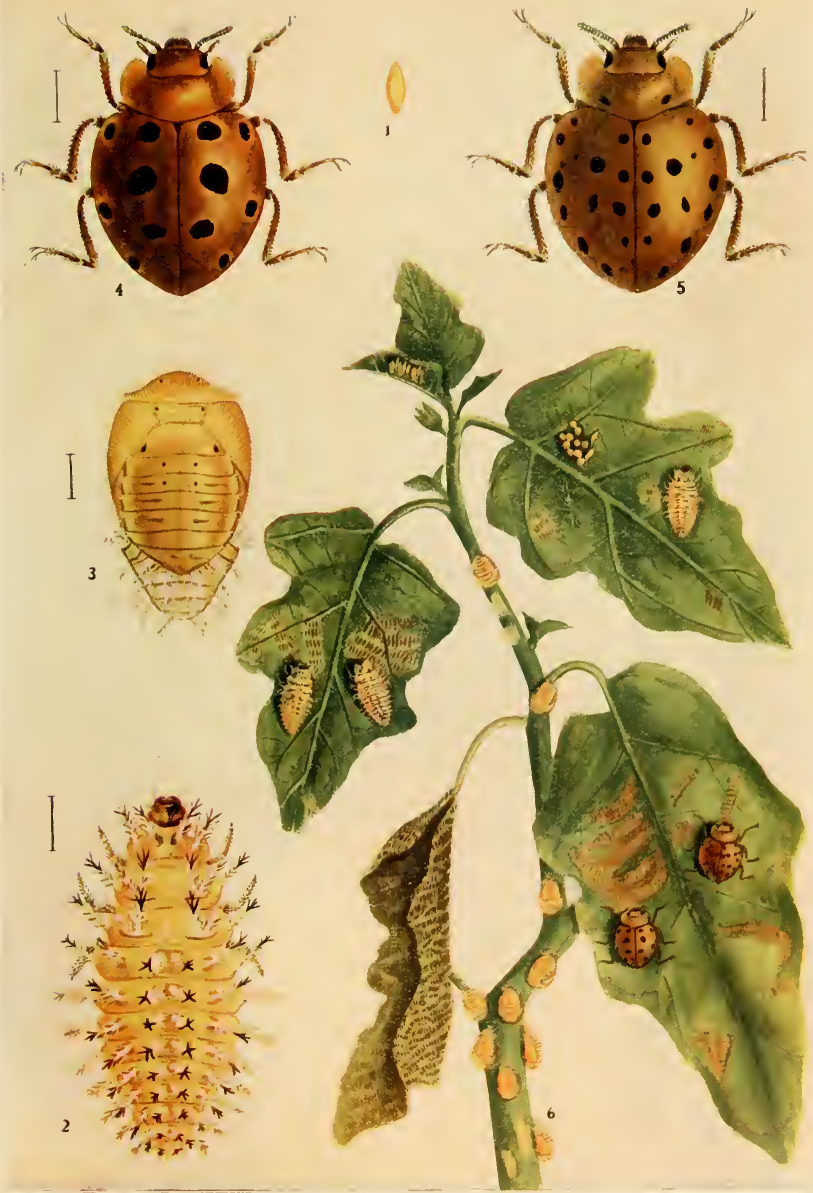



Lifehistory and Fond.--Not worked out in detail in India. The beetles and larvæ usually feed on dead animal matter, such as fish manure.

Status. Scarcely a pest as a rule. Usually rather beneficial as a sravenger and the larva have been found feeding on pupæ of flies breeding in fish manure. At times, however, the beetle is said to be very destructive to silk-worm cocoons.

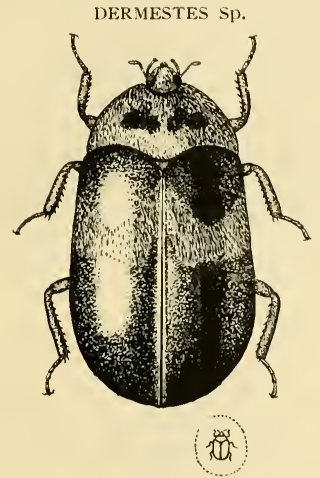

Fic. 135.-Dermestes sp. The smaller figure show the natural size. (Original.)

Distribution.-Coimbatore. Probably throughout Southern India.

Lifehistory and Food.-Not known in detail. The beetle has been bred from larva found feeding on animal refuse in sparrows' nests. Probably on any dead animal matter.

BOSTRYCHIDÆ.

SINOXYLON SUDANICUM, Lesne.

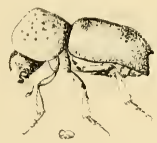

FiG. 136.- Sinoxylon sudanicum. The smaller figure shows the natural size (Original.)

Sinoxylon sudanicum, Lesne, Ann. Soc. Ent. France (1895), 176, (1906), 503-504, f. 534 ; King, 4th Rept. Wellcome Lab., Vol. B. p. I 40 , t. 9 , f. I. 
Distribution.--Bellary, Coimbatore, Chingleput. Probably throughout Southern India all the year round.

Lifehistory. - Not worked out in detail. Eggs are laid in clead wood, probably in galleries tunnelled by the beetles. Larvæ in galleries in dead wood, in which the beetles also feed. Length of life-cycle is not known.

Food. - Dry stems of Agathi, of Cambodia Cotton killed by Stem Weevil, and in almost any dry wood that is not too hard.

Status.-Attacks only dead wood and is hardly a pest as a rule except when it bores into furniture, etc.

\section{RHIZOPERTHA DOMINICA, Fb.}

Synodendron dominicum, Fab., Ent. Syst., I, pt. 2, p. 359 (1792).

Synodcndron pusillum, Fab., Ent. Syst. Suppl., p. I56 (1798).

Rhizopertha dominica, Lesne, Ann. S.E. Fr. (1898), 332 ; Stebbing, I.M.N., VI, 25 26; Lefroy, Ind. Ins. Life, p. 316 ; Chittenden, U.S.A. Ent. Bull. 96, pt. III, pp. $29-47$, ff. 7,8 .

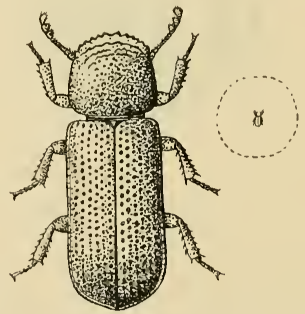

Fig. 137.- Rhizopertha dominica. The smaller figure shows the natural size. (Original.)

Distribution.-Throughout Southern India.

Lifelistory.- The white, elongate, pear-shaped eggs are laid loosely and singly amongst the food of the larvæ, which hatch out after about Io days. The larva when full-grown is slightly less than $3 \mathrm{~mm}$. long, a white, fleshy grub swollen at either extremity but more swollen anteriorly. The whole life-cycle is probably less than two months.

Food.- Stored cholam and cumbu ears; also recorded from stored wheat, paddy, flour, biscuits, etc.

Status.--Apparently a minor pest of stored products.

Control.-Fumigation and keeping stored grain, etc., in insectproof receptacles. 

PLAIE VII.
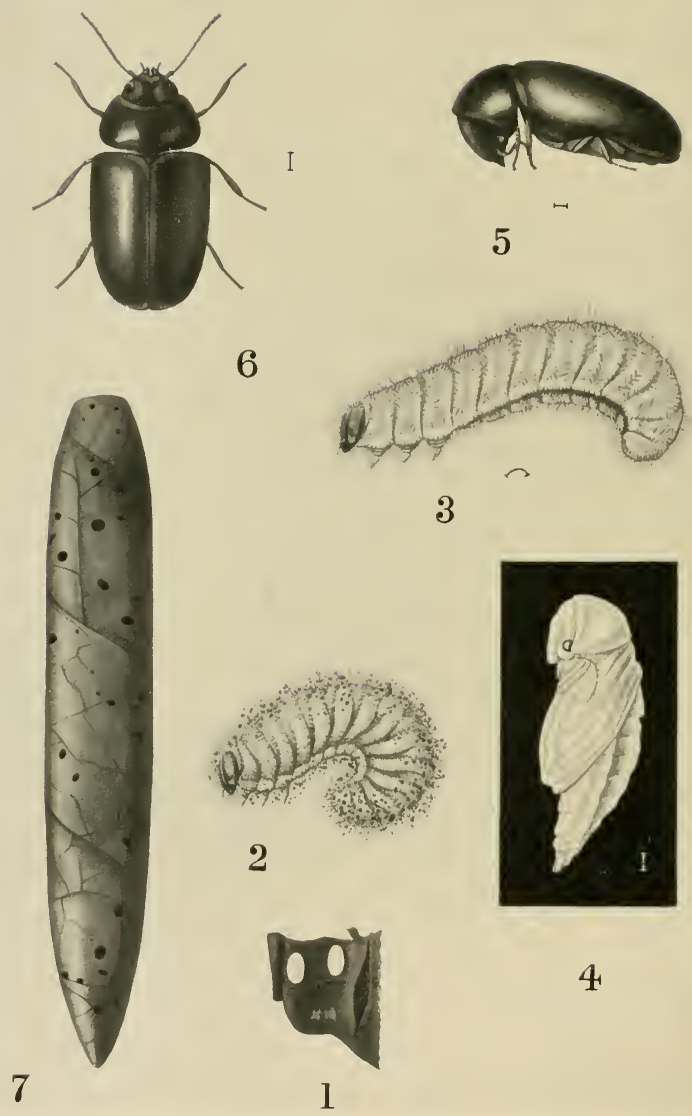

4 


\section{EXPLANATION OF PLATE VII. LA SIOLERMA SERRICORNE.}

Fig. 1. Eggs.

" 2. Larva, covered with particles of tohacco-leaf.

.. 3. Larva freed from pirtules of leaf.

"4. Pupa.

, 5, 6. Beetle.

"7. Cheroot bored by beetles, showing holes of exit.

(The lines alongside the fig rres show the natural sizes.) 


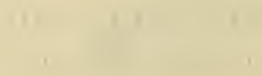




\section{PTINIDA.}

SITODREPA PANICEA, L.

Dermestes paniceus, Linn., Syst. Nat. (ed. X), p. 357 (I758).

Sitodrepa panicea, Chittenden, U.S.A. Bull. No. 4, pp. I24--126, ff. 61, 62; Lefroy, Ind. Ins. Life, p. 3I8, f. 197.

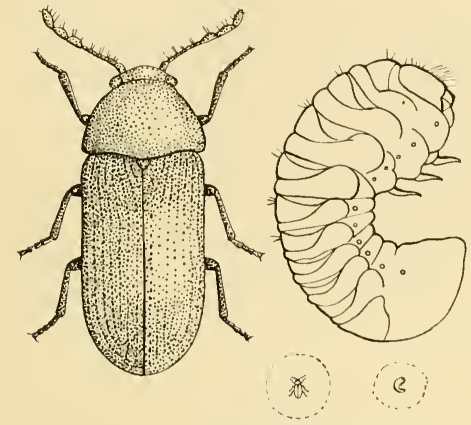

FIG. I38.-Sitodrepa panicea, beetle and larva. The smaller figures show the natural sizes. (Larva after Chittenden.)

Distribution. - Throughout Southern India.

Lifchistory.-Eggs are laid in almost any dry substance of organic origin, the larva, on hatching, tunnelling galleries in which they pupate in small cocoons. The entire life-cycle may be passed in less than two months.

Food.-This species has been said to "eat anything but cast iron," even perforating tin foil and sheet lead. Books, papers, stored grain and drugs of all kinds, boots, sheet cork, etc.

Status. -An important pest of books and papers and hence of great importance in Libraries, Record Rooms, etc.

Control.-Books and papers should be kept as far as possible in closed almirahs or boxes and protected with a plentiful supply of Naphthaline renewed regularly. Books in exposed shelves should be treated at least annually with Book Solution. (See page I72.)

\section{LASIODERMA SERRICORNE, Fb. (PLATE VII.)}

Ptimus serricornis, Fab., Ent. Syst., I, I, 24I (1792).

Lasioderma testaceum, Duftschmid, Faun. Austr., III, 46 (I825); Lefroy, Ind. Ins. Pests, p. 253, f. 305, Ind. Ins. Life, p. 3 I9, t. I9. 
Distribution.- Throughout Southern India all the year round.

Lifehistory. - The minute shining white eggs are laid on dried tobacco, being generally thrust in under a fold of the leaf; in the case of cheroots they are generally laid just under the outer leaf inside the open end. The eggs hatch after four or five days, when the grub emerges and tunnels through the tobacco until it is fullfed, when it spins a small cocoon covered with fragments of leaf in which it pupates. The complete life-cycle occupies about 8 - I0 weeks according to temperature and the beetles live a considerable time after emergence. The beetles are quite active on the wing.

Food.-Dry tobacco as a rule. Occasionally found in other vegetable matter, such as opium leaves (i.c., the poppy petals used for wrapping opium cakes), turmeric, etc.

Status.-A pest of great importance in cigar and tobacco factories.

Control.- The most effective method is fumigation of the finished cheroots by exposing them to the fumes of Hydrocyanic Acid gas for 24 hours, then airing for half an hour, and boxing them immediately afterwards. This treatment cloes not injure the aroma of the tobaeco.

\section{CLERIDÆ.}

NECROBIA RUFIPES, Fb.

Dermestes rufipes, Fab., Spec. Ins., I, 65 (178I).

Necrobia rufipes, Howard, U.S.A Ent. Bull. 4, p. 105, f. 49; Lefroy, Ind. Ins. Life, p. 326, f. 204.

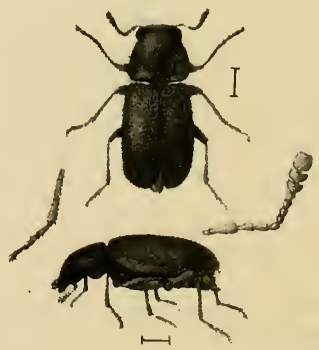

FtG. 139.-Necrobia rufipes. The natural size is indicated by the lines alongside the figures of the beetle. (From Indian Museum Notes,) 
Distribution.- Probably throughout Southern India all the year round,

Lifehistory.- Eggs are laid in or on animal matter on which the larvæ live. These are greyish-white, with a brown head, and a series of brown patches above, separated hy a paler dorsal stripe. Pupation in a glistening, paper-like cocoon.

Food.-Animal matter, especially dried meats such as Hams or Bacon. Found abundantly in Fish manure, both at the place of preparation on the Malabar coast and in Fish Manure distributed intand.

Status. Scarcely a pest.

\section{BUPRESTIDÆ.}

PSILOPTERA FASTUOSA, Fb.

Buprestis fastuosa, Fab., Syst. Ent., p. 216 (1774).

Psiloptera fastmosa, I.M.N., II, 45. III, No. 6, p. 3, fig; Stebbing, ind. Forest. Bull. No. 12, pp. $7-9$, t. 2.

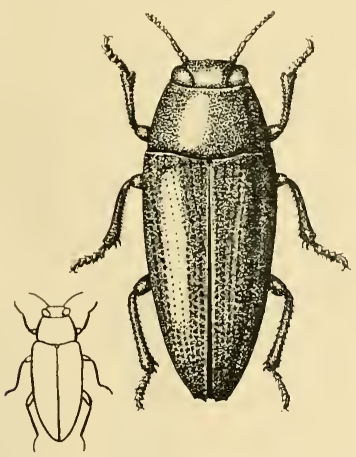

Fig. 1+0.-Buprestis fastuosa. The outline figure shows the natural size. (original.)

Distribution.-Throughout the Plains of Southern India.

Lifehistory.- The larva is a borer in the wood of trees.

Foouplant.-Teak, and probably other trees.

Status.- Stated to have damaged the Government Teak Plantitions at Nilambur in January I 890 .

Coutrol.-? 
SPHENOPTERA GOSSYPII, Kerr.

Sphenoptera gossypii, Kerr., Ann. S.E. Belg. XXXVI, 195 (1892); Lefroy, Ind. Ins. Pests, pp. I00-I03, ff. II4-II9, Ind. Ins. Life, p. 330 , t. 20.

: [Sphenoptera neglecta, Klug; King, J. Ec. Biol., IV, 42-44, t. 4; King, 4th Report Wellcome Lab., Vol. B, p. I34, Plate; Aulmann, Faun. deut. Kolon., pt. iv, pp. I8-22.]

Distribution.-Bellary.

(See Plate VIII.)

Lifelistory.--Eggs laid on the bark generally about midway between base and crown of stem. The larva on hatching bores into the stem, tunnelling a gallery up and down the centre When full-fed it prepares an exit hole, leaving only the bark intact, and pupates in the larval burrow, the beetle emerging through the hole previously prepared by the larva.

Foodplants.-Cotton (especially Egyptian). Hibiscus esculentus.

Status. A bad pest where it occurs but apparently rarely found in southern India.

Control.-Destruction of attacked plants which wither and are easily noticed.

NOTES.--(i) Except in Bellary, this insect has not been noted on Cotton in the Madras Presidency.

(ii) Two parasites (Hymenopterous) have been reared attacking the grub.

(iii) Local cottons were not found to be attacked so much as exotic ones.

SPHENOPTERA ARACHIDIS, Lefroy MS.

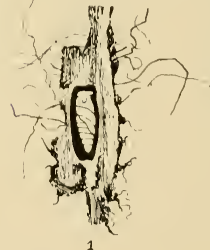

1

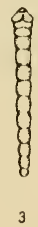

3

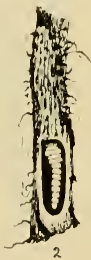

Fig. 1+2.-Sphenoptera arachidis. The small outline figure shows the natural size. (Original.)
Fig. 1+1,-Sphenoptera arachidis.

i, Pupa in cocoon (natural size);

2, Larva in root (natural size);

3, Larva (magnified). (Original.)

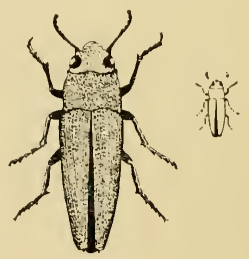

Distribution.-In all Groundnut-growing districts of Southern India, occurring from middle to end of cropping-period. 



\section{EXPLANATION OF PLATE VIII. SPHENOPTERA GOSSYPII.}

FIG. 1. Larva inside stem of cotton-plant.

„2. Larva, magnified.

"3. Pupa in cocoon, inside stem, $x_{3}$.

"4. Pupa, ventral view, magnified.

, 5. Beetle, magnified.

, 6. Beetle.

, 7. Hymenopterous parasite.

(The lines alongside the figures show the natural sizes.) 
2

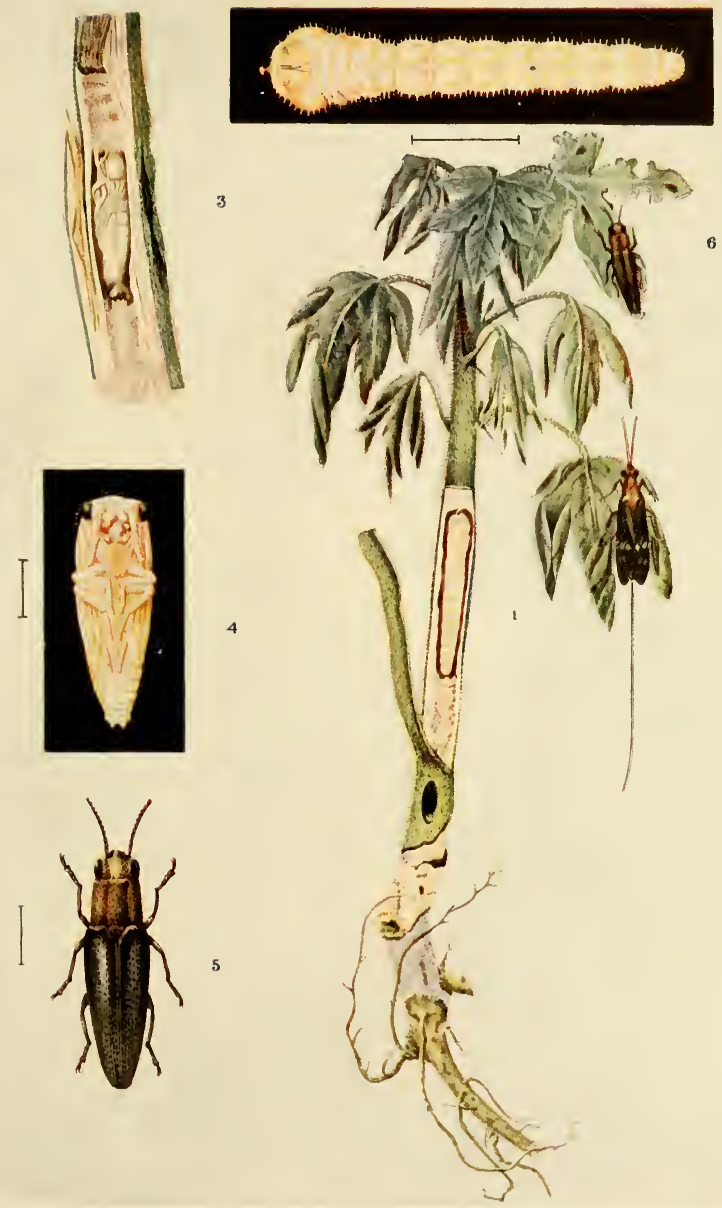



Lifchistory.-Small flattened scale-like elliptical eggs are laid on the stem or on one of the branches of the plant sometimes away from the stem. The grub is $I / 2$ inches when full fed. It bores down along the stem tissue to the roots, devouring the main root. The pupation period lasts to days, the milk-white pupa being formed in the larval burrow.

Foodplants.-Chiefly groundnut (called the Verpuchi of gioundnut) and other leguminous plants such as Cow-peas, Redgram, Horsegram, Agathi, Cassia, etc. Also found in wild sannhemp (Crotalaria striata).

Status.-A serious pest in certain years especially in South Arcot where groundnut is grown extensively.

Control.-Destruction of affected plants is the only remedy that can be advocated at present pending further investigation.

\section{TENEBRIONID Æ.}

GONOCEPHALUM HOFMANNSEGGI, Stev.

hofmannseggi, Steven, Nouv. Nem. Mosc,, I, 96 (I829!.

Opatrum, Lefroy, Ind. Ins. Life, p. 338.

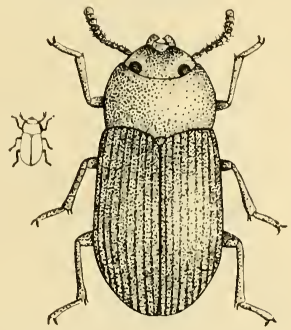

Fig. 143.-Gonocphalum hofmannseggi. The small outline figure shows the natural size. (Original.)

Distribution.-Trichinopoly-probably throughout Southern India all the year round.

Lifchistory and Food. - The larvæ of these beetles are found on the surface of the ground where they feed on dead and decaying vegetable matter. Exact lifehistory not worked out.

Status.- These beetles sometimes occur in enormous numbers and enter houses in such quantities as literally to cover the walls of rooms. Occasionally they do damage to potatoes, grape-vines, etc., but as a rule they are probably rather beneficial as scavengers of dead vegetable matter. 


\section{TRIBOLIUM CASTANEUM, Hbst.}

Colydium castancum, Herbst, Kafer, VII, 282, t. I12, f. I3 (I 797 .

Tribolium castamcum, Macleay (I825) ; Blair, E.M.M. (I9I3), 222 224.

Tribohum ferrugimenm, auct. (nec. Fabr.); Chittenden, U.SA. Ent. Butl. No. 4; Lefroy, Incl. Ins. Pests, p. 253, f. 307, Inct. Ins. Life, p. 338 , f. 215 .

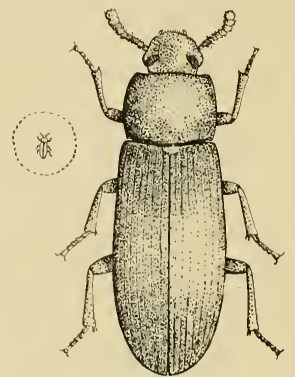

Fin. 1+t.-Tribolinm castancum. The small figure shows the natural size. (() riginal.)

Distrilution.-Throughout Southern India ; all the year round.

Lifchistory. - The minute white eggs are laid, usually thrust into cracks, on the surface of stored.seeds or of the receptacles in which these are contained. The full-fed larva is about $5 \mathrm{~mm}$. long, whitish-brown, with darker legs and a pair of anal spines. The pupa is white and naked and the pupal stage lasts for 4 or 5 days. The beetles atso feed on stored substances.

Food.-Stored pulses, grain, flour, dried insects, etc.

Status. - A serious pest of stored products, not only by the actual quantity eaten but on account of the extremely nauseous smell and taste which it communicates to infected substances.

Control.-Fumigation and subsequent storage in Insect-proof receptacles.

\section{COSSYPHUS DEPRESSUS, Fb.}

Lampyris depressa, Fab., Spec. Ins., I., 254 (I78I).

Cossyplus depressus, Lefroy, Ind. Ins. Life, p. 339, t. 2I, f. 4.

Distrilution.-Godavari, Bangalore, Bellary, Coimbatore. May to July and September to November. Probably throughout Southern India. 


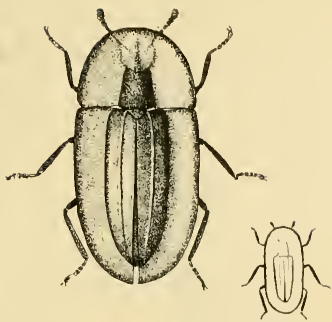

Fig, 145.-Cossyphus depressus. The small figure shews the natural size (Original.)

Lifehistory.--Not known.

Food.-Not known-probably dead vegetable matter.

Remarks. Often comes in commonly to light at night. A very curious beetle on account of its strong resemblance to a seed.

RHYTINOTA IMPOLITA, Fairm.

Rhytinota impolita, Fairm., Ann. S.E. Belg., XL., 8 (1896).

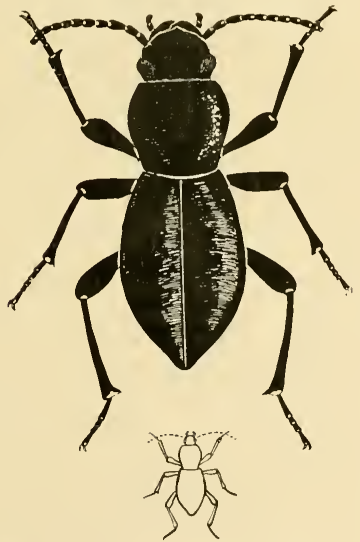

Fig. 1+6. Rhytinota impolita. The snall figure shows the natural size. (1)riginal.) 
Distrihution.-Probably throughout Southern India all the year round.

Lifehistory and Food. - Early stages not known. Probably feeds on dead vegetable matter on or just below the surface of the ground.

Remarks. - A conspicuously common beetle to be seen wandering about over the ground in dry, open places.

\section{MELOIDÆ.}

\section{(CANTHARIDÆ; MYLABRIDÆ.)}

GNATHOSPASTOIDES ROUXI, Cast.

Cunthuris rouri, Cast., Hist. Nat., II, 274 (I840).

Cantharis (Epicauta) rouxi, Lefroy, Ind. Ins. Life, p. 346.

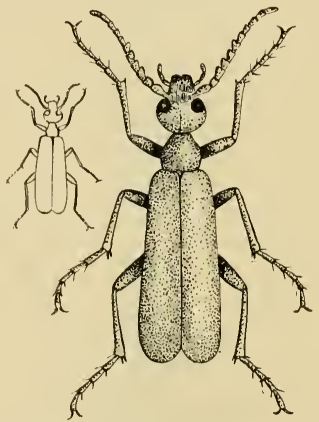

FtG. 1+7,-Gnathospastoides rouxi. The small figure shows the natural size. (Original.)

Distribution.--South Kanara, Kistna, Kurnul, Bellary, Coimbatore-probably throughout the Plains.

Lifehistory. - Eggs were laid in captivity (in October I9II) in groups of 50 to 125 each. The young larvæ hatched out after about fifteen days and were extremely active. In captivity the larva was found to feed freely on egg-masses of the Deccan grasshopper. Further details of lifehistory not worked out, but this beetle has been bred from a pupa found with these egg-masses.

Status.-The beetle itself often does considerable damage to ear-heads of cumbu, cholam and tenai, eating the pollen so that no grain is formed. In its early stages, however, it is probably beneficial by acting as a check on the increase of grasshoppers. 
LYTTA TENUICOLLIS, Pall.

Cantharis tenuicollis, Pall., Ic. Insect., p. I02, t. E, f. 35 ( $178 \mathrm{I}$ 1806 ?) ; Lefroy, Ind. Ins. Pests, pp. 205 206, f. 243, Ind. Ins. Life, p. 346, f. 220 .

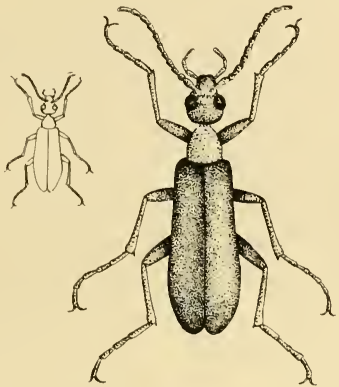

FIG. 148.-Lytta tenuicollis. The small figure shows the natural size. (Original.)

Distribution.-Kurnul, Bellary, Coimbatore, Tanjore, Tinnevelly ; September to November.

Lifehistory.-The whitish-yellow cigar-shaped eggs are laid in the soil in a mass which may contain over 400 eggs; the eggs seem to be deposited at night and one female may lay more than one egg-mass on subsequent nights. The young larvæ hatch after about $12-14$ days. The larvæ probably feed on egg-masses of grasshoppers but the lifehistory is not known as yet.

Status.--The beetle does considerable damage to ear-heads of jola, cumbu, etc.

Control. - The beetles are attracted to light at night or may be collected during the day-time.

$$
\text { ZONABRIS PUSTULATA, Thnb. }
$$

. . . pustulata, Thnb., Diss. Nov. Spec. Ins., VI, I13, f. I3 (1791).

Mylabris pustulata, Lefroy, Ind. Ins. Life, p. . , f. 219.

Mylabris sida, Fab. Ent. Syst. Suppl., p. I20 (I798).

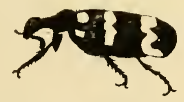

FiG. 149. Zonabris pustutata. (Original.) 
'Meloc cichorii, Linn., Syst. Nat. (ed. X), I, 419 (1758).

J)istribution. - Found very commonly all over South India.

Lifchistory. - Eggs are laid in masses (one mass found to contain I06 eggs). The eggs are bright-yellow, elongate and cylindrical. Further history not known.

Foodplants. - The beetle feeds on the flowers and tender shoots of many plants such as cotton, gogu, redgram, groundnut. cowpea, lab-lab, Cucurbitacex, wild Ipomceas, prickly-pear, garden spp. of llibiscus, rose plants, sometimes found on cereal ear-heads also such as cumbu, tenai and cholam. Especially on yellow flowers.

Control.-Collecting by hand with small nets.

Obscration. The correct name of this extremely common beetle seems to be a matter of doubt. It has for a long time been known as Mylabris pustuluta but specimens very similar in appearance have been returned by Dr. Creighton Wellman under the name of Zoutbris oricntalis, Mars. Probably there are several closely allied forms confused under the name pustulata. Linne's cichorii is perhaps a composite species and probably inculded the beetle here referred to.

\section{ZONABRIS Sp.}

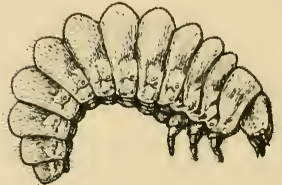

\section{gin}

Fici. 150). - Eltimate stigne of recond fearabidoid) larva.

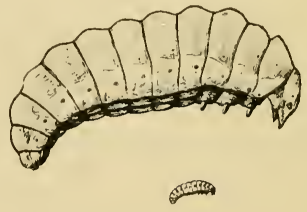

Fig. 151.-Ciaretate larvat.

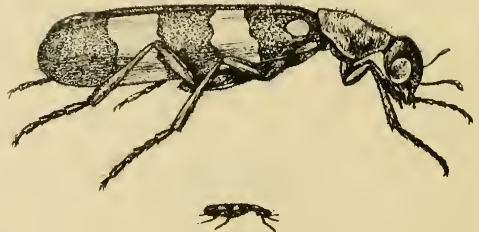

Fici. 152.-Adult Beetle.

Zonabris sp. The smaller figures show the natural sizes. (Original.) 
Distribution.-Bellary (Hadagalli).

Lifehistory.-Eggs are deposited in the soil and the young larvæ, on emerging from the egg, seek out the egg-masses of the Deccan grasshopper and devour these.

Foodplants. - The perfect beetle has been found on flowers of Phascolus aconitifolius (Madiki).

- Status.-This insect is an important check on the Deccan grasshopper in the Hadagalli district.

“CANTHARIS" RUFICOLlis, Oliv.

(dull-grey-blue species with orange-yellow thorax.)

Cautharis ruficollis, Olivier, Ins., 46, t. i, f. 6.

Lytta ruficollis, Fab., Ent. Syst., I, ii, 85 (1792).

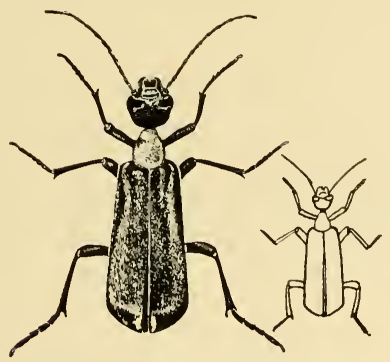

FIG. 153,-Lytta ruficollis. The outline figure shows the natural size. (Original.)

Distribution.-Bellary, Kurnul, Coimbatore, Tanjore, Tinnevelly ; October to December.

Lifehistory.-Not known.

Status. - Beetle does damage to ear-heads of Cumbu and Jola, similarly to other Cantharids.

Control.--May be collected by hand. Is attracted to light at night.

Remarks.-This species seems to agree sufficiently well with Fabricius' brief description, 


\section{EPICAUTA Sp.}
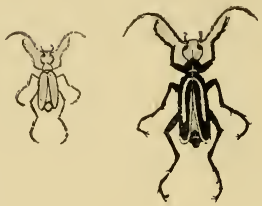

FIG. 154.-Epicauta sp. The smaller figure shows the natural size. (Original.)

Distribution.-South Kanara ; in October.

Lifchistory. - Not known.

Status.-Local pest of paddy, eating flowers and also attacking ripe ear-heads.

Control.-Collection by hand is indicated.

\section{BRUCHIDÆ.}

PACHYMERUS (BRUCHUS) CHINENSIS, Linn.

Curculio chinensis, Linn., Syst. Nat. (ed. X), p. 386 (I758).

Bruchus chinensis, Lefroy, Ind. Ins. Pests, pp. 255-256, ff. 3I I, Ind. Ins. Life, p. 350, f. 223.

Pachymerus chinensis, Chittenden, U.S.A. Dept. Agri. Ent. Bull. 96, pt. 6 (I9I2).
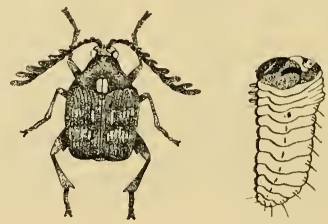

FIG. 155.-Pachymerus chinensis. Magnified; the small figure shows the natural size of the beetle. (Larva after Chittenden.) 
Distribution.-Probably throughout Southern India all the year round.

Lifchistory.-The clear translucent egg is about $.53 \mathrm{~mm}$. long by $.3 \mathrm{~mm}$. broad. The eggs are laid in the field on the outside of a pod of gram and twenty or more eggs may be laid on one pod, green pods being preferred to dry ones. The eggs hatch after seven or eight days and the young newly-hatched grub is slender, darkishcoloured, and hairy, with long slender thoracic legs and a welldeveloped prothoracic plate which is armed with peculiarly sharptoothed edges, which help the grub to bore through the shell of the pod, which the grub at once proceeds to do, and then eats its way into a seed. Soon after entering the seed, the first moult is undergone and the larva now becomes a thickset grub with three pairs of short legs ; in its resting-position inside the seed it assumes a doubled-up attitude. It grows quickly and is full-fed after about ten days when it is plump and pale-white in colour. It then tunnels almost to the outside of the seed, leaving untouched only a thin partition of the outer husk, and prepares an oval chamber whose interior is smoothed off with a soft paste; in this chamber it remains motionless for two days and then assumes the pupal state in which it remains for seven days. But the beetle does not emerge for another couple of days until its integuments are hardened; it then bites through the circular disc previously left in the seed by the grub and then makes its way through the seed-pod. The beetles are inactive during the day-time but fly actively at dusk and at night. One complete life-cycle occupies about 32 days. [Y.R.R.]

Foodplant.-Red-Gram.

Status.-A fairly serious pest to Red-Gram in the field.

Control. - Attempts may be made to catch the beetles with handnets in the evening when they are abundant.

Remarks.-Various species of Bruchida have hitherto been confused in India under the name chinensis; it is believed that the species here referred to is the true chincnsis of Linnæus. So far as observed hitherto in Southern India, this particular species lives only on Red-Gram in the field; Bruchids living on stored seeds belong to other species.

BRUCHUS THEOBROMÆ, Fb.

Bruchus theobromce, Fab., Syst. Ent., p. 65, Spec. Ins., I, 75 (I78I).

Bruchus thcobromatis, Gmelin, Syst. Nat. (Ed. XIII), p. I735.

Distribution.-Coimbatore; Bezwada. 


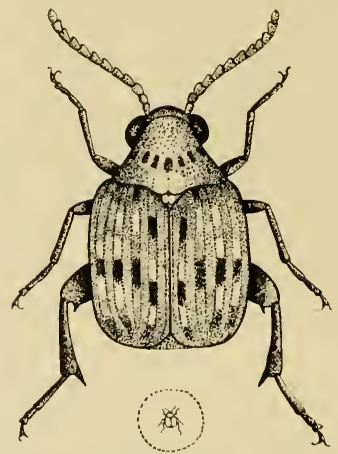

Fig. 156.-Bruchus theobroma. The small figure shows the natural size. (Original.)

Lifehistory.-Not known. Probably in stored seeds.

Remarks.-Specimens from Coinbatore agree with an example received from Pusa under the name of theobroma, $\mathrm{Fb}$.

NOTE.-There are apparently various other species of Bruchids, some of which infest stored seeds and others which live in seeds in the field, but it is not yet possible to give exact names of the various species.

CARYOBORUS GONAGRA, Fab.

Bruchus gonagra, Fab., Ent. Syst. Suppl., p. I59 (1798).

Caryoborus gonagra, Lefroy, Ind. Ins. Pests, p. 255, f. 309, Ind. Ins. Life, p. 35I, f. 224 ; Ind. Mus. Notes, III, I4-I 5.
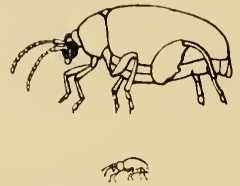

FiG. 157.-Caryoborus gonagra. The small figure shows the natural size. (Original.)

Distribution.-Godavari, Kurnul, Bellary, Coimbatore, Chingleput ; all the year round; generally in February and March on Tamarind. 
Lifehistory.--Eggs are probably laid on the young seed-pods of Cassia and Tamarind. The newly-hatched grub tunnels through the pod-capsule and into a seed. When full-fed the grub spins a cocoon of matted white threads within which it pupates, the beetle cutting its way out through cocoon and outer skin of the fruitcapsule. Length of life-cycle not known.

Foodplants.-Tamarind (Tamarindus indica), Cassia spp., Acacia spp.

Status. - A minor pest of stored Tamarinds when these are stored with the seeds.

Control.-Removal of Tamarind-seeds before storing will avert attack.

\section{CHRYSOMELIDE.}

SCELODONTA STRIGICOLLIS, Mots.

Odontionopa strigicollis, Mots., Bull. Mosc., XXXIX, 409 (1866).

Scelodonta strigicollis, Lef roy, A.J.I., II, 292, I.I.L., pp. 358-359, f. 232 .

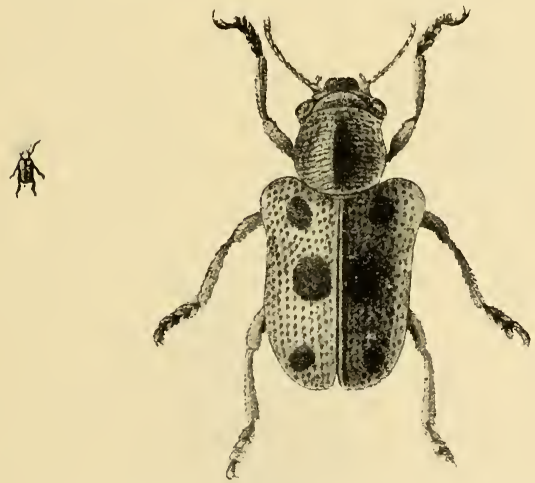

F1G. 155.-Scelodonta strigicollis. The small figure shows the natural size. (After Lefroy.)

Distribution.-Anantapur, Bangalore, Coimbatore.

Lifehistory.-Not known in South India.

Foodplant.-Noted only on grape-vine hitherto.

Status. - A serious pest of grape-vines.

Control.-Collection by hand and spraying. 
MONOLEPTA SIGNATA, Ol.

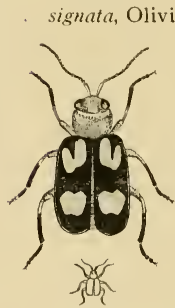

F1G. 159.-Monolcpta signata. The small figure shows the natural size. (Original.)
665 , t. 5 , f. 89 .

Distribution. - Ganjam, Coimbatore, Godavari, Bellary ; throughout the year.

Lifehistory. - Not known.

Foodplants. - Colocasia, chillies, radish, beet, cauliflower, cabbage.

Status.-Often serious on vegetable crops such as radish, etc.

Control.-Catching in small hand-nets and spraying with Naphthaline Emulsion when bad.

\section{NISOTRA MADURENSIS, Jac.}

Nisotra madurcnsis, Jacoby, Ann. S.E. Belg., XL, 267 (1896).

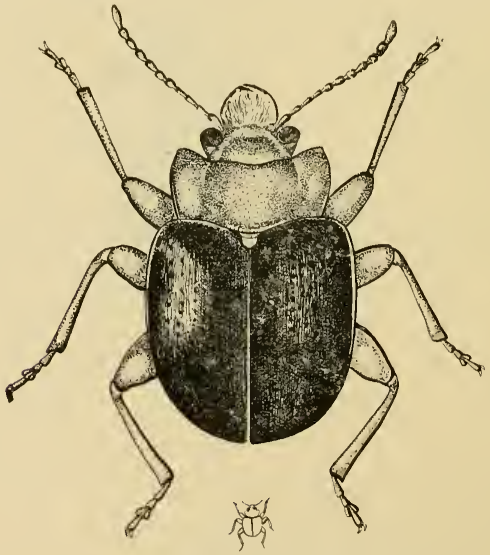

Fig. 160.-Nisotra madurensis. The small figure shows the natural size. (Original.) 
Distribution.-Malabar (Taliparamba), ? Trichinopoly ; in July and August.

Lifchistory.-Not known.

Foodplants.-Gogu, jute.

Status.-The beetle eats the leaves but is not a serious pest.

Control.-Collection by hand.

\section{AULACOPHORA ABDOMINALIS, Fb.}

. . abdominalis, Fab., Sp. Ins., I., I 5 I (I78I).

. . foveicollis, Kust, Kafer Europ., XXVIII, Iоo.

Aulacophora fovcicollis, Lefroy, Ind. Ins. Life, p. 362, f. 236.
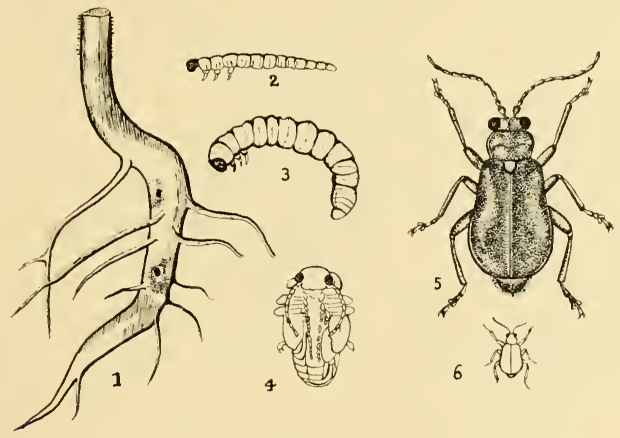

F1G. 161.-Aulacophora abdominalis. 1, Attacked root; 2, Young larva (magnified); 3, Full-grown larva (magnified); + , Pupa (magnified) ; 5, Beetle (magnified) and 6, Natural size. (Figs. $1-$ after Shiraki.)

Distribution.- Throughout Southern India up to at least 4,000 feet.

Lifchistory.- Larva in ground at roots of cucurbitaceous plants, feeding on roots.

Foodplants.-All Cucurbitaceæ.

Status.-Sometimes a pest of some importance; usually occurs in fair numbers and does a good deal of damage on the whole.

Control.--Hand-collection and spraying where bad. 
AULACOPHORA ATRIPENNIS, Fb.

. . atripennis, Fabr., Syst. El., I, 482.

Aulacophora cxiavata, Baly, J. Linn. Soc., XX, I8 (1888;.

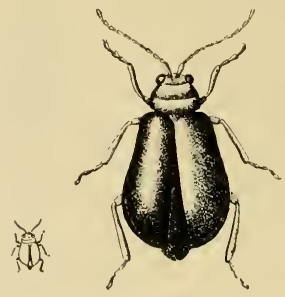

F1G. 162.-Anlacophora atripcunis. The small figure shows the natural size. (Original.)

Distribution.-All over South India.

Lifchistory. -Not known.

Foodplants.-On all cucurbitaceous plants.

Status.-Not usually a bad pest.

Control.-Hand-collection and spraying where bad.

AULACOPHORA STEVENSI, Baly.

Aulacophora stevensi, Baly, E.M.M., XXIII, I02, t. II, f. I ; Jacoby, P.Z.S. (I887), I03, t. II, f. I.

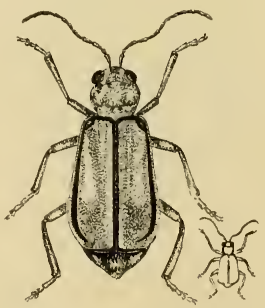

FIG. I63.-Aulacophora stcvcnsi. The small figure shows the natural size. (Original.) 
Distribution.-Chingleput, Godavari, Kistna, Coimbatore; August to December.

Foodplants.-Snake-gourd, Bitter-gourd, Bottle-gourd.

Status. - Not so widely distributed and injurious as the two other species of Aulacophora. It is specially destructive to flowers of gourd (snake gourd chiefly).

Control.-Hand-collection and spraying.

OIDES AFFINIS, Jac.

Oides affinis, Jacoby, P.Z.S. (I883), 400, t. 45, f. 4 .

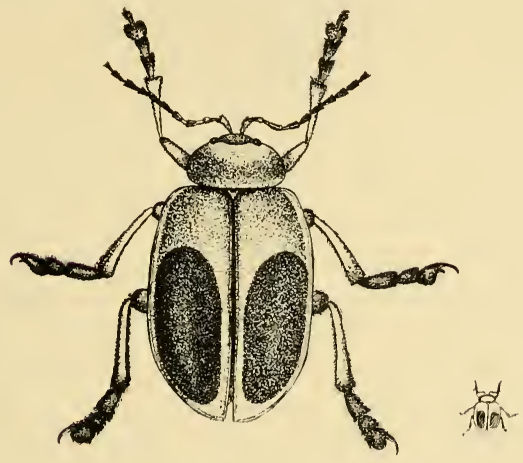

Fig. 16t.-Oides affinis. The small figure shows the natural size. (Original.)

Distribution.-Malabar (Shoranore); July and August. Nilgiris (Jacoby).

Lifehistory.-Not known.

Foodplant.-Paddy.

Status.-Sporadic and local; doubtfully a pest.

LEPTISPA PYGMeA, Baly.

Leptispa pygmaa, Baly, Cat. Hisp., p. 2 (1858); Lefroy, Ind. Ins. Life, p. 364, fig. 240; Weise, Wytsm. Gen. Ins. Fasc. 125, p. 66 (I9II). 


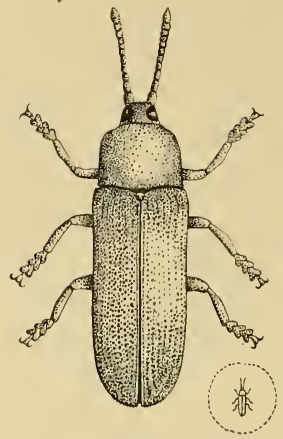

F1G. 165.-Leptispa pygmcea. The small figure shows the natural size. (Original.)

Distribution.-South Kanara, Malabar, Mysore, Cochin ; July to October.

Lifehistory.-The eggs are laid on Paddy leaves and the grubs also feed on the upper surface of the leaves, the attacked leaves usually folding over so as to hide the enclosed grub. The grub, when full-fed, pupates on the leaf, the beetles emerging after about 4 days.

Status.-Three to five larvæ may be present on a single leaf, eating out longitudinal patches. The beetles also eat the leaves, but to a less extent. The insect may be a serious pest. It is said to be worst in wet weather.

Control.-Bagging by hand-nets may be tried.

HISPELLA RAMOSA, Gyll.

Hispa ramosa, Gyllenhal in Schonherr, Syn. Ins., Vol. I, pt. 3, App. p. 6 (1817).

Hispella ramosa, Weise, Wytsm. Gen. Ins. Fasc. 125, p. 93 (1911).

Distribution.-Coimbatore (January to June).

Lifelistory.-Not known.

Foodplants.-Grasses.

Status.--Not found in sufficient numbers to constitute a pest. 


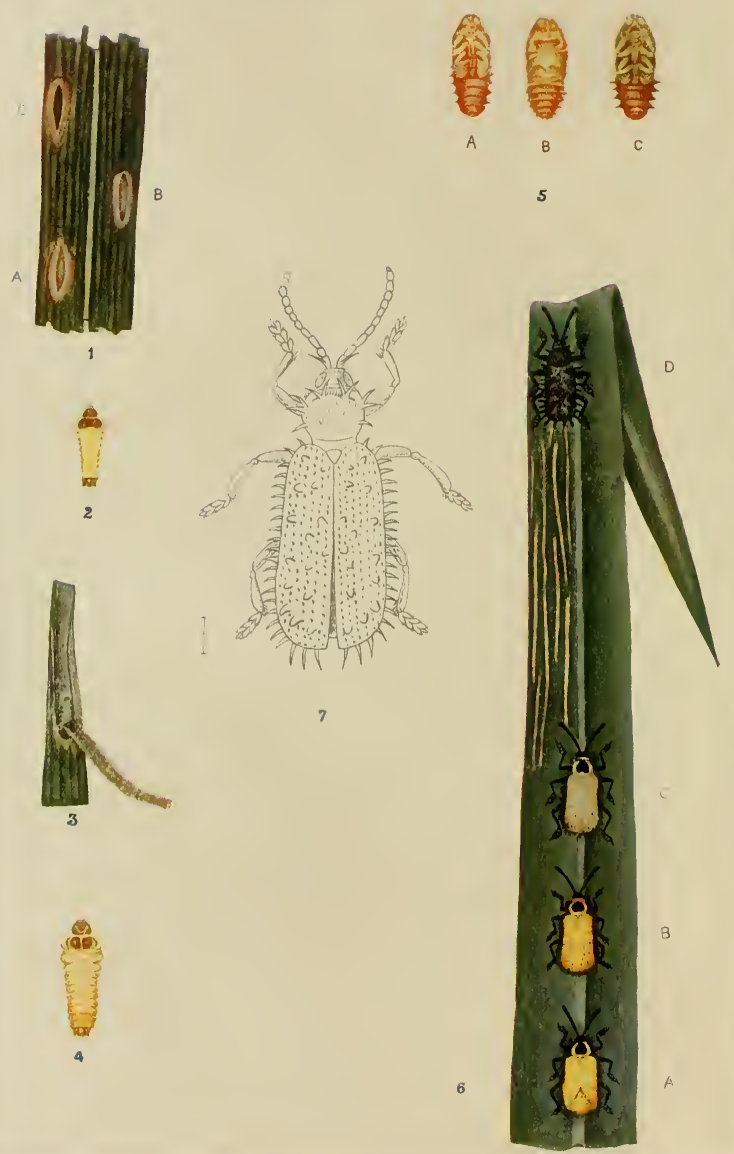

6

PHIDODONTA MODESTA. 


\section{EXPLANATION OF PLATE IX.}

PHIDODON'TA MODESTA.

Fig. t. Eggs $\left\{\begin{array}{l}A, B \text {, one day old. } \\ C, \text { just before hatching. }\end{array}\right.$

, 2. Newly hatched larva $\times 3$.

, 3. Larva in mine in cane-leaf.

"4. Full-grown larva $\times 3$.

. 5. Pupæ $\times 3$.

6. Beetle $\left\{\begin{array}{lll}\text { A. Immediately after emergence from puja } & \times 3 . \\ \text { B. Fifteen minutes after emergence from pupa } & \times 3 . \\ \text { C. Thirty } & , & \times 3 \\ \text { D. Sixty } & , & \times 3\end{array}\right.$.

.. 7 . Beetle showing disposition of spines. 




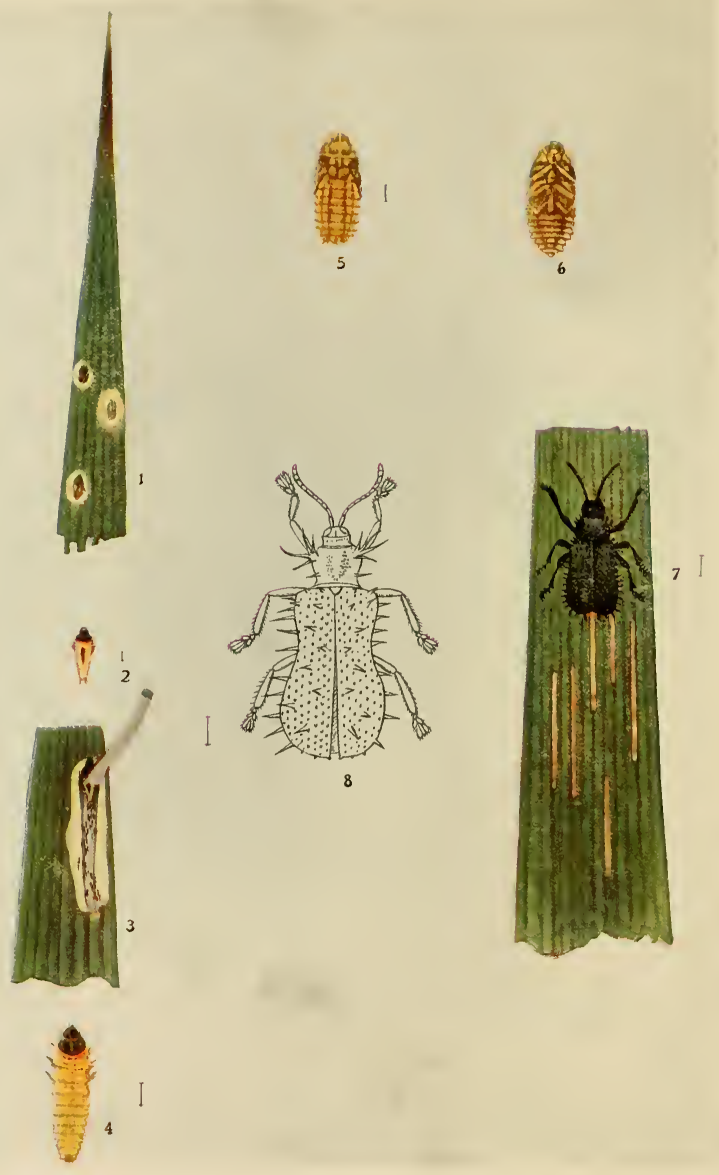

HISPA ARMIGERA (ÆNESCENS). 


\section{EXPLANATION OF PLATE X. \\ HISPA ARMIGERA (ENESCENS).}

FIG. I. Eggs inside leaf.

"2. Young larva, magnified.

"3. Larva burrowing inside leaf; the larval burrow has been cut open.

,4. Full-grown larva, magnified.

" 5, 6. Pupa.

"7. Adult beetle.

" 8. Beetle shoving arrangement of spines.

(The tines alongside the figures show the natural sizes.) 



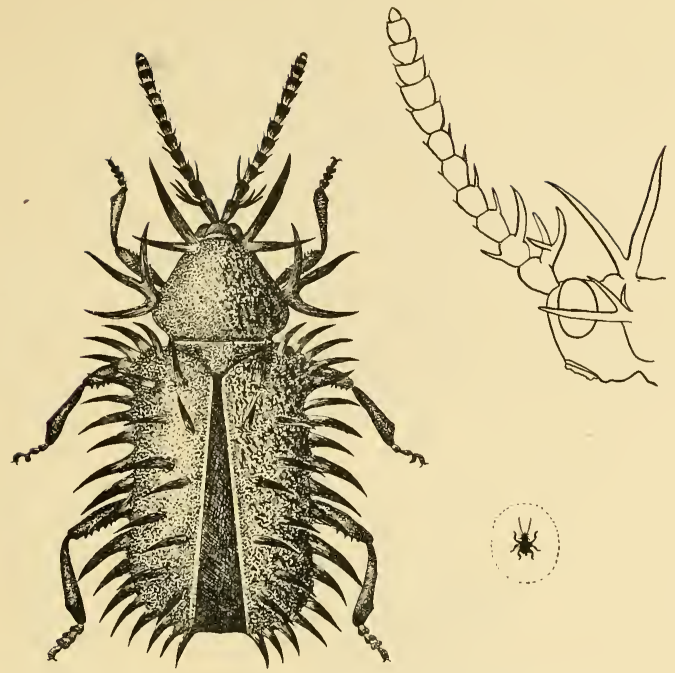

Fig. 166.-Hispolla ramosa. The figure to the right shows a side-view of the head; the small figure indicates the natural size. (Original.)

\section{PHIDOdONTA MOdESTA, Weise. (Plate IX.)}

Phidodonta modesta, Weise, D.E.Z. (I906), 404 ; Lefroy, Ind. Ins. Life, p. 365. Plate XXIII; Weise, Wytsm. Gen. Ins. Fasc. I25, p. 94 (I9II).

Distribution.--Bellary, Godavari, Ganjam ; April to November.

Lifehistory.-Eggs in leaves of Sugarcane, larva burrowing mines longitudinally in cane-leaves, pupa in leaf, beetle also eating cane-leaves.

Foodplant.-Sugarcane.

Status.-Usually a minor pest of Sugarcane.

Control.-Collection of larvæ in their mines and of beetles by hand.

\section{HISPA ARMIGERA, Ol. (PLATE X.)}

Hispa armigcra, Olivier, Entom. VI, 763, t. I, f. 8 (I808); Weise, D.E.Z. (I904), 457, Wytsm, Gen. Ins. Fasc. 125, p. I03 (I9II). 
Hispa cyanipcnnis, Mots., Reise Amur, II, 238 (IS6I).

Hispa ancscens, Baly, J. As. Soc. Beng., LV, 412 (I887) ; Cotes, I.M.N., 37 (I889); Lefroy, Ind. Ins. Pests, pp. II4-II6, Ind. Ins. Life, p. 364, f. 239.

Distribution.--In all rice-growing tracts of Southern India.

Lifchistory. - The eggs are laid on leaves of Paddy in which the grubs tunnel, producing discoloured patches. Pupates in leaf.

Status.-Occurs sporadically as a serious pest of Paddy.

Control.-Bagging by means of nets may be suggested as a remedy.

\section{PLATYPRIA HYSTRIX, Fb.}

Hispa hystrix, Fab., Ent. Syst. Suppl., p. II6 (1798); Weise, Wytsm. Gen. Ins. Fasc. 125, p. 107 (I911).

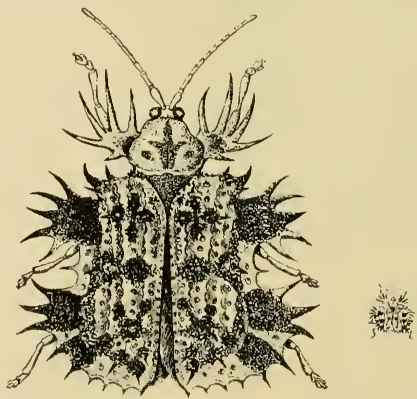

F1G. 167.-Platypria hystrix. The small figure shows the natural size. (Original.)

Distribution.-Coimbatore; Tanjore (March to June).

Lifehistory.-Not known.

Foodplants.-Agathi, Lab-lab. (Also on Erythrina in Ceylon.)

Status.-A minor pest, the larva mining portions of the leaves.

Control.-Only collection by hand can be suggested pending fuller knowledge.

\section{ASPIDOMORPHA MILIARIS, Ol.}

Cassida miliaris, Olivier, Ins., p. 97, t. 2, f 25 ; Fabr., Syst. Ent., p. 91, Ent. Syst., I, 300.

Aspidomorpha miliaris, Lefroy, Ind. Ins. Life, p. 366, f. 243. 


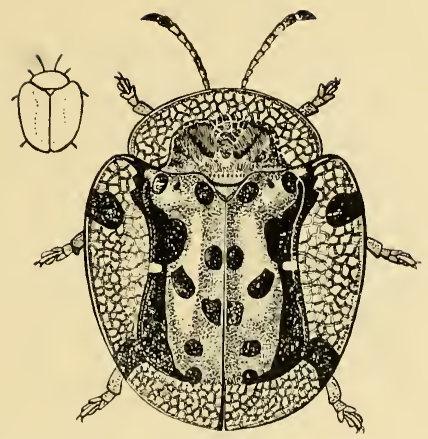

FIG. 168,-Aspidomorpha miliaris. The outline figure shows the natural size. (Original.)

Distribution.-Coimbatore, Bellary, Ramnad. Probably throughout Southern India all the year round.

Lifehistory.-Eggs laid in masses on Convolvulaceæ, on which larvæ feed and pupate.

Foodplants.-Convolvulaceæ.

Status. - Harmless as a rule but may occur on sweet potato as a minor pest.

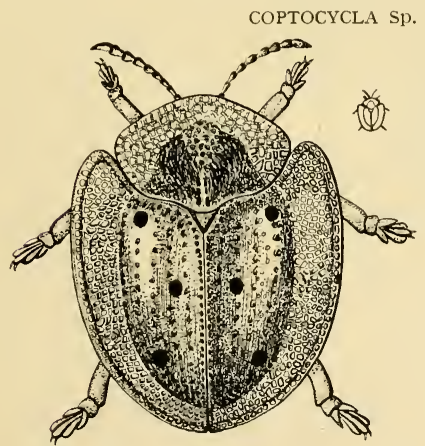

Distribution. - Godavari, Coimbatore, Shevaroys, South Arcot, Tinnevelly ; throughout the year.

Lifehistory. -- Not known.

Foodplant. - Sweet potato.

Status.-Scarcely a pest.

FIG.a169.-Coptocycla.sp.! | The?outline figure shows the natural size. (Original.) 


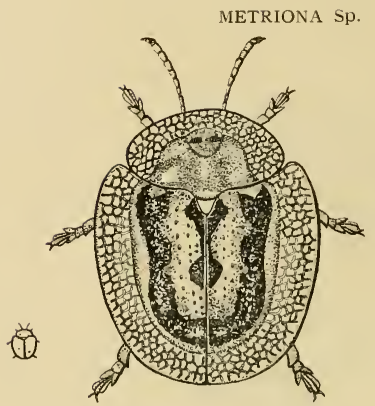

Distribution. - South Arcot, Tinnevelly; throughout the year.

Lifelistory. - Not known.

Foodplant. - Sweet Potato.

Statns.-Scarcely a pest.

Fig. 170.-Metriona sp. The ontline fignre shows the natural size. (Original.)

CERAMBYCID E.

DORYSTHENES ROSTRATUS, Fb.

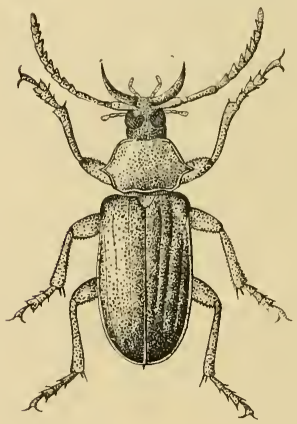

Prionus rostratus, Fab, Ent. Syst., I, 2, p. 243 (I792).

Dorysthenes rostratus, Gahan, Faun. Ind. Ceramb., pp. 6 7, f. I.

Distribution.-Coimbatore. In October and November.

Lifchistory. - Not known.

Foodplant. - Larva probably bores in trees.

Status.-Not known to be a pest.

Remarks. - Often

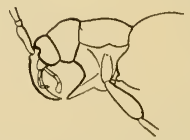
comes in to light in very large numbers at the beginning of the North-East Monsoon.

Fig. 171.-Dorysthenes rostratus, from a living specimen with jaws opened. The lower figure shows the incurved position assumed by the jaws after death ; note also the curious projection below the thorax. (Original.I 
PRIOTYRANNUS MORDAX, White.

Prionus mordax, White, Cat. Col. B.M. Longic, I, I8 (I853).

Priotyrannus mordax, Gahan, Faun. Ind. Ceramb., p. 22, f. 8; Lefroy, Ind. Ins. Life, p. 371, f. 248.
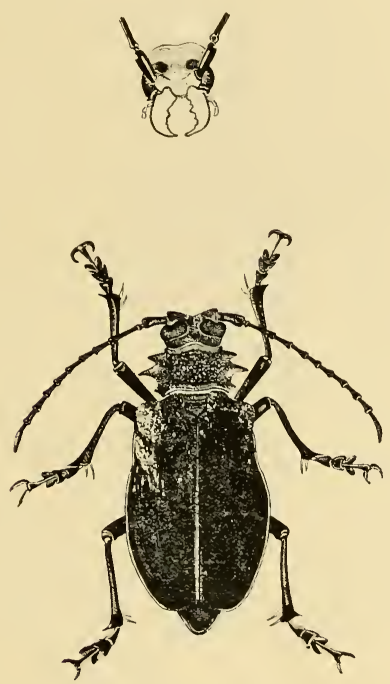

FIG. 172.-Priotyrannus mordax. The upper figure shows the head and jaws as seen from in front. (Original.)

Distribution.--Nilgiris, Anamalais, Kanara, Travancore. In August and September.

Lifehistory. - Not known.

Status. - Not known specifically as a pest.

\section{ACANTHOPHORUS SERRATICORNIS, Ol.}

Prionus serraticornis, Olivier, Ent. IV, p. I4, t. 9, f. 33 (I795).

Acanthophorus scrraticormis, Gahan, Faun. Ind. Ceramb., pp. 23-24. f. 9; Lefroy, Ind. Ins. Life, p. 372 , f. 250. 


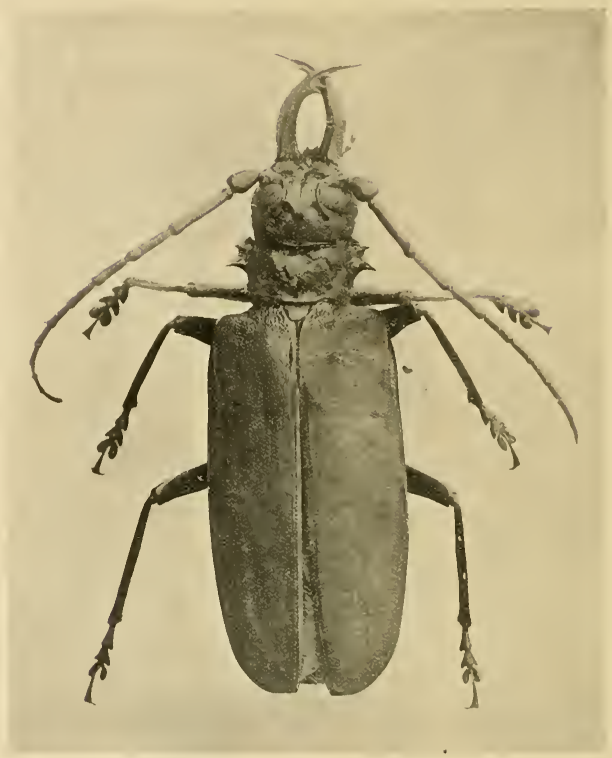

FIG. 173.-Acanthophorus serraticornis. (From an original photo by Murugesan.)

Distribution.- South Arcot, Bangalore, Cochin ; probably throughout Southern India.

Lifchistory.--Not known.

Foodplants,--Larva said to bore in mango. The beetle was found at Bangalore on a silk-cotton (Bombax malabaricum) in which it had probably passed its earlier stages.

-Status.-Not definitely noted as a pest but from its large size the larva is likely to do considerable damage to the trees it attacks.

Control.-Where larval burrows are found, a mixture of two parts chloroform to one"part creosote should be injected by means of a syringe. 
XYSTROCERA GLOBOSA, Oliv.

Cerambyx globosa, Oliv., Entom. IV, p. 27, t. 12, f. 8I (I795).

Xystrocera globosa, Gahan., Faun. Ind. Ceramb., pp. I06-107, f. 42 ; Lefroy, Ind. Ins. Life, p. 372.

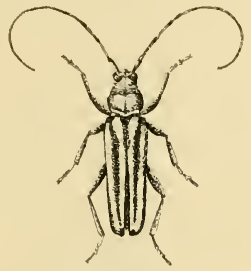

F1G. 17t.-Nystrocera gtobosa. (Original.)

Distribution.-Coimbatore, Anamalais. September to October.

Lifchistory.--

Foodplants. - $\}$ Not known in India.

Status.- Not definitely known as a pest in India.

Remarks. - Recorded as a serious pest of Siris (Albizziat lebbek) in Egypt.

STROMATIUM BARBATUM, Fb.

Callidium barbatum, Fab., Syst. Ent., p. I89 (I775).

Stromatium barbatum, Gahan, Faun. Ind. Ceramb., p. I14, f. 45 ; Lefroy, Ind. Ins. Life, p. 373.
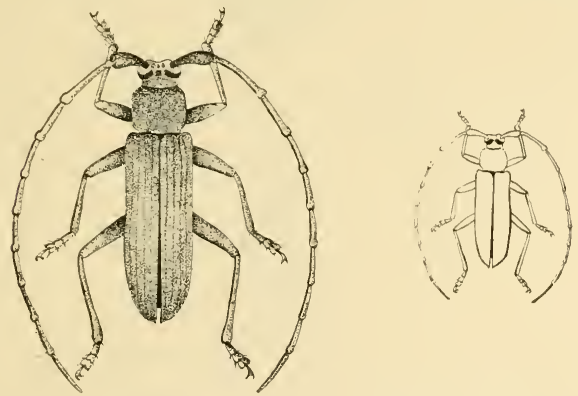

FIG. 175.-Stromatium barbatum. The smaller figure shows the natural size. (Original.) 
Distribution.-Bellary. In June.

Lifehistory.-Not known in detail.

Foodplants. - Found emerging from bamboo at Hagari. Stated by Lefroy to breed in Acacia catechu, Teak, Dalbergia sissu, etc.

Status. - Not definitely recorded as a pest but likely to be so sporadically.

NEOCERAMBYX PARIS, Wied.

Cerambyx paris, Wied, Germ. Mag., IV, 167 (182I).

Neocerambyx paris, Gahan, Fauna Ind. Ceramb., pp. 124 125; Lefroy, Ind. Ins. Life, f. 257.

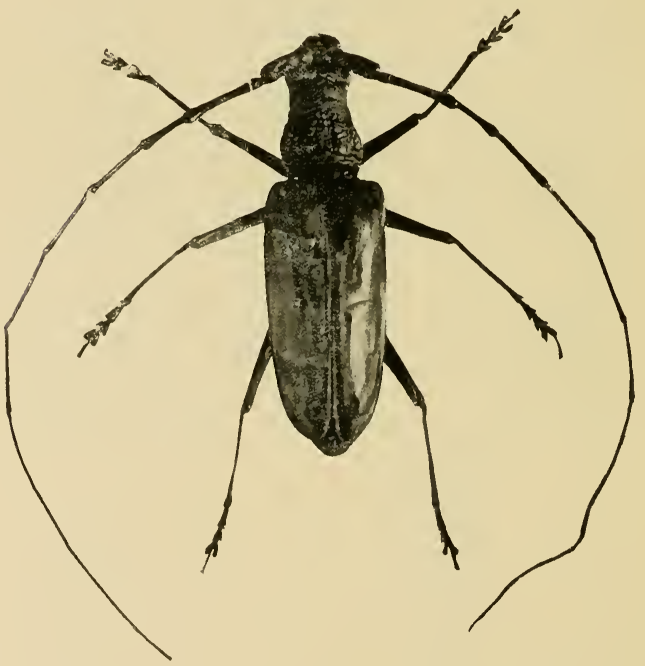

Fig. 176.-Neocerambyx paris. (After Lefroy.)

Distribution.-Bangalore, Kollegal, Coimbatore. June to October. Lifehistory.-Not known.

Status.-Larva probably bores in trees and does damage by its large size. See under Acanthophorus, 
CHLORIDOLUM ALCMENE, Thoms.

Chloridolum alcmene, Thoms., Syst. Ceramb., p. 568 (I865) ; Gahan, Faun. Ind. Ceramb., pp. I99 200; Lefroy, Ind. Ins Life, p. 374, f. 253 .

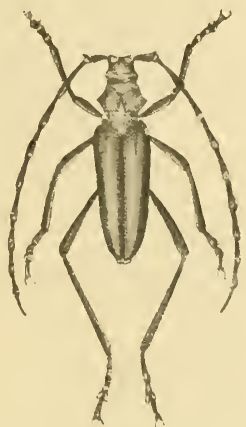

Fig. 177.-Chloridolum alcmenc. IFrom Agricultural Journal of India.)

Distribution.-Coorg, Nilgiris.

Foodplanls, ctc.- Larva boring into Orange-trees in Coorg.

XYLOTRECHUS QUADRIPES, Chevr.

Xylotrechus quadripes, Chevr., Mem. Soc. R. Sci. Liege, XVIII, 315 (I863) ; Gahan, Faun. Ind. Ceramb., pp. 245-246, f. 90 ; Lefrov, Ind. Ins. Life, p. 374 , f. 254.

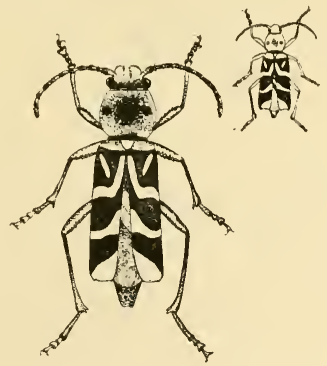

FIG. 178. - Xylotrechus quadripes. The small figure shows the natural size. (Original.) 
Distribution.- Throughout the Hill districts of Southern India. Usually two broods - about March and October.

Lifchistory and Foodplant.- Eggs laid in stems of Coffee-bushes about ground-level. Grubs bore in stems and branches, being well known in Coffee districts as "the Borer."

Status.-A serious pest to Coffee.

Control.- Cutting out of attacked bushes, collection of adult beetles by hand, regulation of shade over coffee, scraping and whitewashing of bushes just before eggs are due to be laid.

\section{BATOCERA RUBUS, Linn.}

Cerambyx rubus, Linn., Syst. Nat., II, 625 (ed. XII) (1767).

Batocera rubra, Lefroy, Ind. Ins. Life, p. 375, f. 245 ; Green, Ceylon Agri. Dept. Bull. No. 3 (Jan. I9I3).

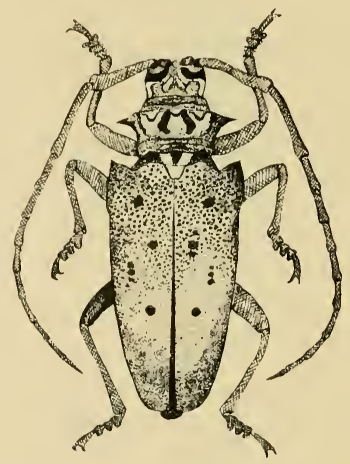

Fig. 179.-Batocera rubus. (Original.)

Distribution. - Throughout Southern India. Seems to emerge at the beginning of rains, in May and October.

Lifchistory.-Eggs are laid in or under bark and the grubs tunnel into the stem or roots of the tree attacked. The larval stage probably lasts over a long time-possibly several years. When full-fed it pupates in its tunnel, the pupal stage lasting about one month.

Foodplant.-Occurs commonly in Mango. Also attacks Duki Fig, Silk Cotton [Bombax malabaricum], Hevea (Para) Rubber. 
Contrel.-Injection of mixture of two parts Chloroform to one part Creosote into larval tunnels where accessible. Collection of adult beetles by hand. The beetles are often attracted to light at night.

NOTE. - The specific name rubus is apparently a proper name.

CCELOSTERNA SPINATOR, Fb.

Lamia spinator, Fb., Ent. Syst. Suppl., p. I+5 (I798).

Colosterna spinator, Lefroy, Ind. Ins. Life, p. 375.

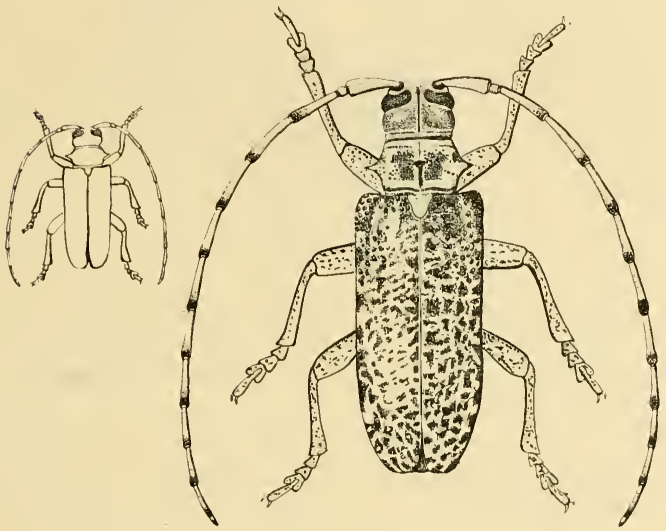

FIG. 180.-Calosterna spinator. The small figure shows the natural size. (O)riginal.)

Distribution.-Bangalore, South Arcot, Tinnevelly ; probably throughout Southern India.

Lifchistory and Foodplants.-Grub bores in Babul (Acacia arabica), Casuarina, and Pomegranate. The adult beetles occasionally eat bark of cotton-plants, twigs of apple, rose, etc.

Status.-A minorpest. Does a good deal of clamage when abundant, as it is sometimes.

\section{CCELOSTERNA SCABRATOR, Fb.}

Lamia scabrator, Fab., Sp. Ins., I. 224 (I78I).

Colosterna scahrata, Lefroy, Ind. Ins. Life, p. 375, f. 246, 255 ; V. S. Iyer, Ind. Forest. Bull. No. II, pp. 7-8, t. 4, ff., 2 a, 2 b. 
Distribution.--Nellore, South Arcot; probably throughout the Plains of Southern India.

Lifehistory.-Larvæ bore into the wood of the roots of Casuarina trees.

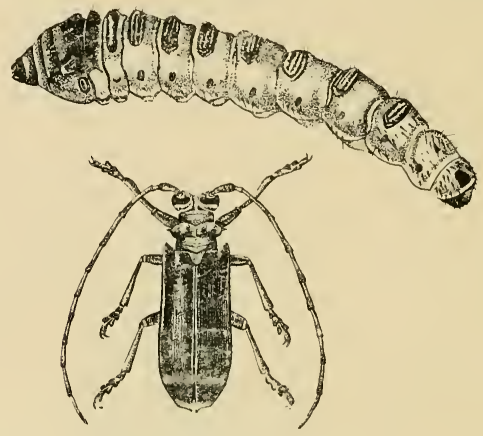

FIG. 181.-Ca'lostcrna scabrator. larva and beetle. (After Lefroy.)

Foodplants.-Casuarina.

Status.--Has been noted as very destructive to Casuarina in Southern India.

Control.- - ?

$$
\text { STHENIAS GRISATOR, Fb. }
$$

Lamia grisator, Fb., Mant. Ins., I., I36-I37 (1787).

Sthenias grisator, Lefroy, Ind. Ins. Life, p. 376.

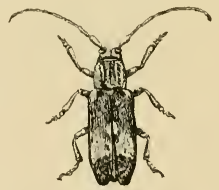

F1G. 182.-Sthenias grisator. (Original.)

Distribution.-Coimbatore, Coorg. August to January.

Lifehistory. - Not known.

Habits.-Girdles twigs of Dadap (Erythrina), Tabernamontana, Croton, Rose-bushes, etc.

Status.-A minor pest.

Control.-Only collection of beetles and destruction by fire of girdled twigs can be suggested at present. 



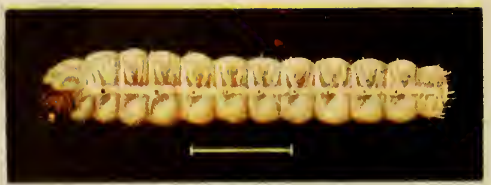

2

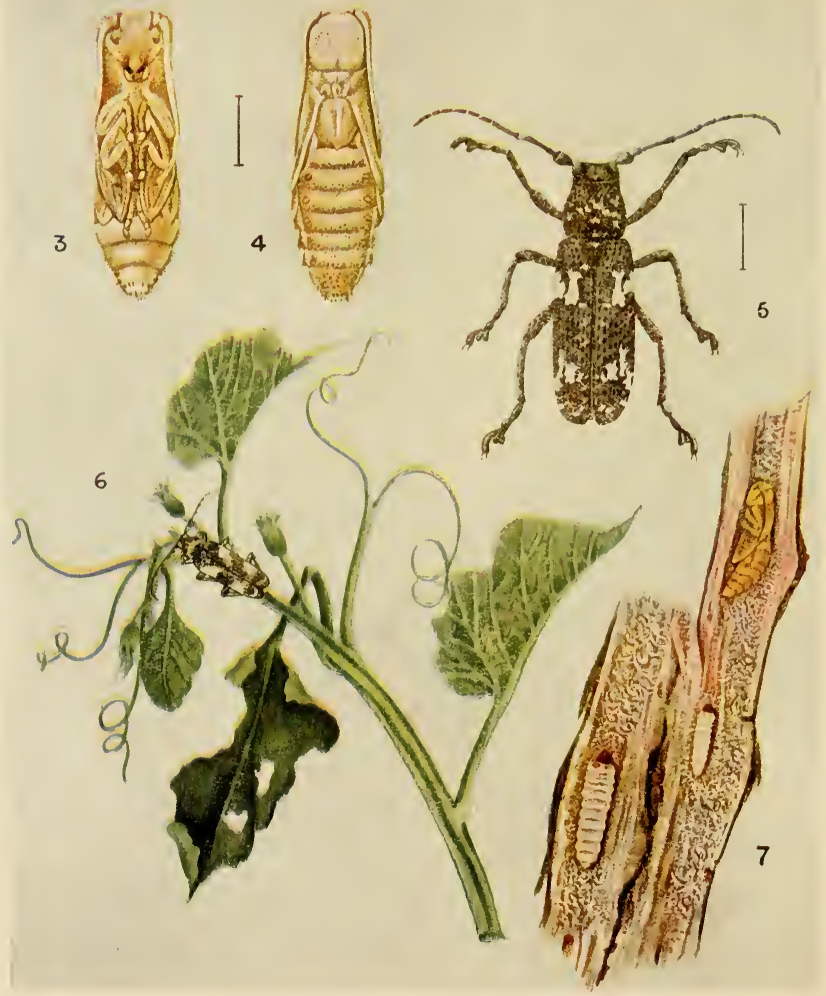




\section{EXPLANATION OF PLATE XI.}

\section{APOMECYNA PERTIGERA.}

Fig. 1. Egg, magnified.

"2. Full-grown larva.

.. 3, 4. Pupa.

"5. Beetle.

, 6. Beetle on plant, natural size.

$" 7$. Stem cut open to show larvæ and pupa, natural size.

(The lines alongside the figures show the natural sizes.) 

A POMECYNA PERTIGERA, Thoms. (PLATE- XI.)

. . pertigera, Thoms., Phys., I., 6, p. I60.

Apomecyna pertigera, Lefroy, Ind. Ins. Life, p. 376, tab. XXX.

Distribution. - Only noted from Coimbatore; probably occurs throughout Southern India.

Lifehistory and Foodplauts. Larva bores in stems of pumpkin and probably other cucurbitaceous plants.

Status. - A minor pest, which sometimes does considerable damage in Northern India.

Control.-Destruction of affected stems and collection of beetles when seen on the plants.

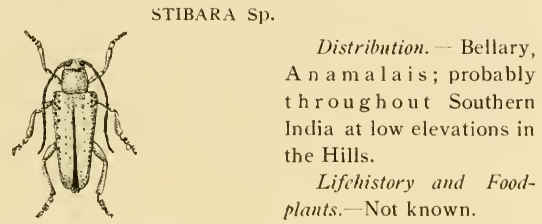

Fig. 183.-Stibara sp. (Original.)

CURCULIONIDA.

EPISOMUS LACERTA, Fb.

Curculio lacerta, Fab., Spec. Ins., I., I98 (I78I).

Episomus lacerta, Lefroy, Ind. Ins. Life, p. 384 , t. 27, f. 6.
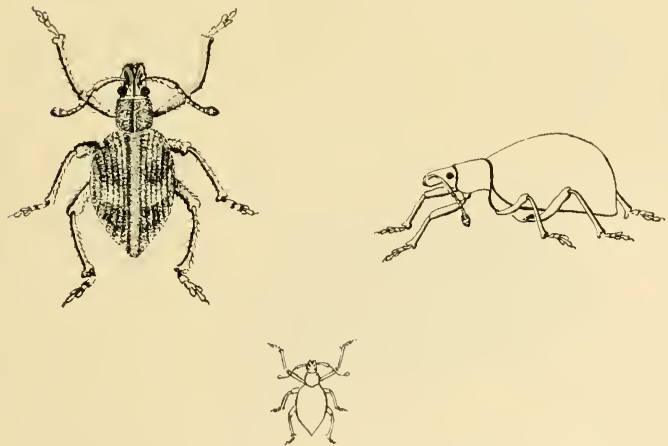

F1G. 18t.--Episomus lacerta. The small figure shows the natural size. (Original.)

Distribution.-Bellary, Coimbatore, South Arcot. June to December. 
Lifehistory.--This weevil has the curious habit of laying its eggs between folded leaves. The tips or other portions of leaves are folded over and kept in position by the legs. The long ovipositor is inserted into the fold, the sides of which are gummed together by a sticky secretion, and from four to twelve eggs are deposited in the chamber thus formed. The egg is oval, pale white and about $\mathrm{r} \frac{1}{2} \mathrm{~mm}$. long. The eggs hatch after $12-14$ days, the resultant white grubs being about $2 \mathrm{~mm}$. long, legless, with a comparatively large head bearing a pair of moderate-sized dark mandibles, with distinct segments covered with numerous delicate hairs, and having the abdomen straightened out and not doubled up. The newly hatched grubs seem to bite their way out of the leafy egg-capsule and drop to the ground where they burrow down and probably feed on rootlets of plants. The eggs are laid on any thick fleshy leaf which will retain sufficient moisture to prevent the eggs from drying up. The complete lifehistory has not been followed through, but full-grown grubs, found at roots of pulses, were palewhite, fairly stout, about $15 \mathrm{~mm}$. (3/5 inch) long, with a comparatively large head and a straightened body. The number of eggs deposited by a single weevil is very large; a female beetle captured in cop. on I2th August I9I I had laid I, II 8 eggs by Ioth November whell it was still living and was liberated. [Y.R.R].

Foodplants.-Usually on pulses; probably feeds on most lowgrowing plants.

Status.-An intermittent pest in local areas where pulses are grown.

Control.-Collection by hand. Attraction to baits. Spraying of attacked areas, which are usually circumscribed.

Natural Enemies.-A minute Chalcid ? parasitizes the eggs.

CEUTHORRYNCHUS ASPERULUS, FSt.

Ceuthorrhynchus asperulus, Faust, Deut. Ent. Zeit. (1898). 323.

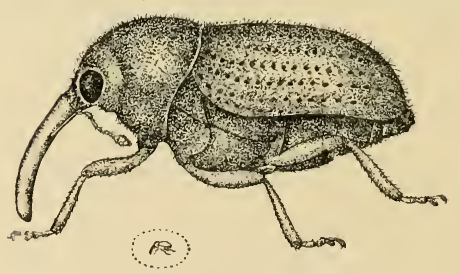

F1G. 185.-Ceuthorrhynchus asperulus. The small figure shows the natural size.

Distribution.Godavari, Kistna, Bellary, Coimbatore. October to February.

Lifehistory.-The egg is laid in a very young flower-bud, being thrust through a hole bored through the side of the 
calyx into the bud; from this hole oozes out a drop of sticky liquid which dries into a conspicuous red spot. The minute oval, creamywhite egg hatches into a tiny grub which eats its way to the pollensacs of the flower and feeds on them. The full-grown grub is about $3 \mathrm{~mm}$. in length, pale-white, head brownish and distinct from body which is stout and somewhat doubled up when in the resting position. As the grub grows the flower also grows so that though originally the egg had been inserted low down through the calyx, the mature grub is to be found on the pollen-sacs at the very apex of the opening flower. The grub devours portions of the petals as well as the pollen. When full-fed it emerges through a round hole cut clear through the base of the flower and drops to the ground, where it probably pupates in the soil. Exact life-cycle not yet worked out [Y.R.R.]. Possibly the grubs pass the period March to October in the soil (as larvæ, pupæ, or beetles mature but not yet emerged from the cocoon), the beetles attacking the next crop in October. The weevil itself also eats the floral anthers.

Foodplant.- Red-Gram.

Status.-A minor pest.

Control.-Collection of the beetles by hand may be tried.

EUGNAMPTUS MARGINATUS, Pasc.

Eugnamptus marginatus, Pisc., A.M.N.H. (5), XI, I 23.

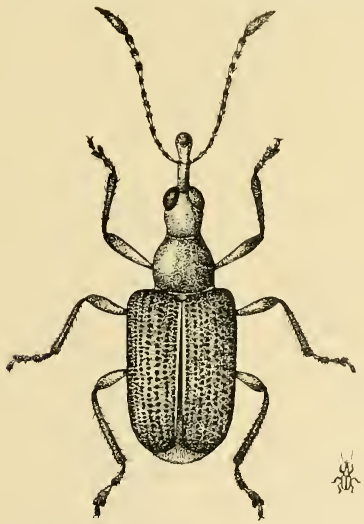

F1G. 186.-Eugnamptus marginatus. The small figure shows the natural size. (Original.) 
Distribution. -Godavari, Malabar. August to October.

Liffhistory.-With its snout the weevil digs deep pouches into the tissues of the underside of a mango-leaf, on either side of the midrib, and lays its eggs singly in these cavities. The translucent oval egg is about $\frac{1}{2} \mathrm{~mm}$. long, and from to to 20 eggs may be laid in a single leaf. The eggs laid in this manner, the weevil now proceeds to cut right through the leaf near the stem, so that the leaf
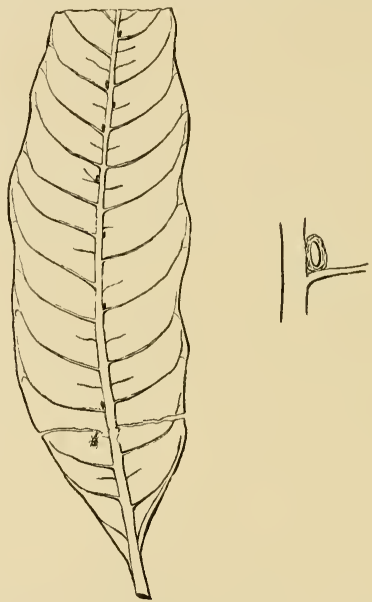

F1G. 187.-Eugnamptus marginatus ovipositing in a mal.go-leaf; about half the natural size. To the right is seen a single egg more highly magnified.

(Original.)

Ialls from the tree. The young grubs, on emergence from the egg, mine into the leaf, eating all that portion between the epidermal layers. The legless full-grown grub is about $4 \frac{\mathrm{T}}{2}$ to $5 \mathrm{~mm}$. long, flattened; dirty green in colour, spiracles at the end of short lateral spine-like projections. When full-grown the grubs emerge from their mines in the leaf and burrow just below the surface of the soil, where they form oval chambers in which they pupate, the weevils emerging after 7 to 8 days. The weevil also eats small holes in the leaves. [Y.R.R.].

Foodplant.-Mango.

Status.-A pest which may attain considerable importance when in large numbers; in badly-infested trees practically all the young 
shoots may have their leaves cut off, so that the trees have to put forth leaves afresh.

Control.-Collection and destruction of freshly-cut leaves containing eggs and young grubs.

APION Sp.

(Jute Apion.)

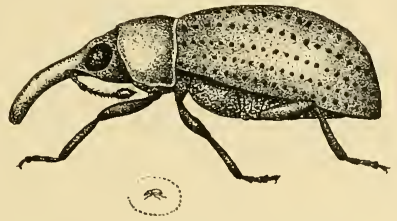

FIG. 188.-Apion sp. The small figure shows the natural size. (Original.)

Distribution.--Godavari, Bellary. In Mlay and June.

Lifchistory and Foodplant.- - The minute, thick-set, dirty white larva bores in the stems and shoots of Jute; the pupa is formed in an oval chamber at the extremity of the larval gallery. Pupal period about four days.

Statns.-An occasional and minor pest, causing withering of side-shoots but not (or rarely) the death or fracture of the mainstem of the plant.

Remarks.-Also found occurring on Wild Jute /Corchoris trilocularis). Parasitized by a small Braconid.

\section{LIXUS BRACHYRHINUS, Boll.}

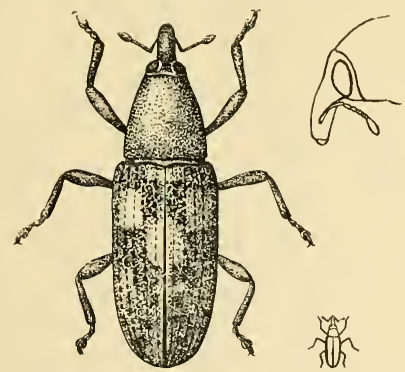

F1G. 189.-Lixus brachyrhinus, beetle and side-view of head. The small figure shows the natural size. (Original.) 
i, p. 464 .

Lixus brachyrhimus, Lefroy, Ind. Ins. Life, p. 385.

Distribution.--Coimbatore, South Arcot, Chingleput; probably throughout Southern India. Occurs all the year round.

Lifehistory.-Larva bores in stems of cultivated Amaranths. The eggs are laid (probably inside the stem) under the axil of a leaf on one of the lateral branches, the newly-hatched grub tunnelling down the branch in an irregular zig-zag mine gradually increasing in size until it reaches the main stem, where it bores down a little and then upwards until reaching the junction of another lateral branch where it forms an elongate chamber in the upper part of the burrow and pupates in this, the beetle emerging after about 44 days.

Stutus.-A minor pest, capable of doing considerable damage to cultivated Amaranths as a single plant may harbour as many as ten or a dozen grubs.

Control.-Destruction of attacked plants and collection of the weevils by hand.

PARAMECOPS FARINOSA, Wied.

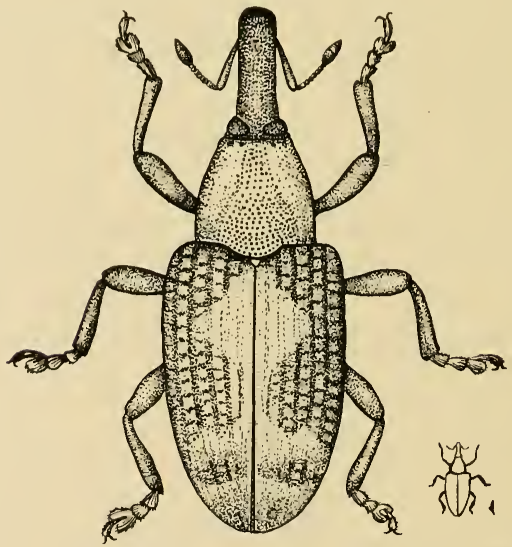

Fig. 190.-Paramecops farinosa. The small figure shows the natural size. (Original.) 
farinosa, Wiedl, Germ. Mag., IV., 157 (1821).

Paramecops farinosa, Lefroy, Ind. Ins. Life, p. 386.

Distribution.--Throughout Southern India all the year round.

Lifchistory and Foodplant. - Eggs are laid in the rind of Calotropi. into which the young larvæ tunnel. The beetle feeds on the leaves of Calotropis making unsightly patches.

Status.- Scarcely a pest, but may do damage to the Calotropis plants where these are collected and used for manure.

ATACTOGASTER FINITIMUS, Fst.

Atactogaster finitimus, Faust., D.E.Z. (1904), 251 ; Lefroy, Ind. Ins. Life, p. 386, f. 263.

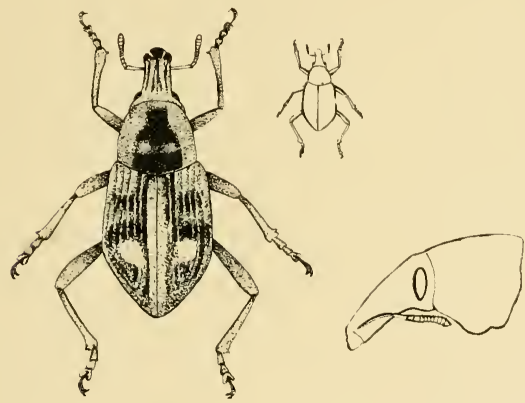

Fig. 191.-Atactogaster finitimus, beetle and side-view of head. The small figure shows the natural size. (Original.)

Distribution.-Bellary, Coimbatore, Madura, Ramnad, Tinnevelly. Mostly found about October. Appears to exhibit a preference for areas of black-cotton soil.

Lifelistory.--Not known.

Foodplants. - The beetle eats most low-growing plants.

Status.-A serious local pest in Ramnad and Tinnevelly in some years in October, the beetles appearing in large numbers and devouring young plants of cotton, etc.

Control.- Collection of beetles by hand and by attraction to baits of fresh leaves placed around edges of fields. Fowls turned ont into the cotton-fields help to keep these weevils in check. 


\section{[MANGO LEAF-BORING WEEVIL.]}

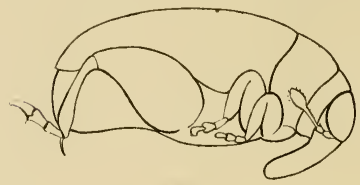

FIG. 192.-Mango Leaf-boring Weevil. The small figure shows the natural size. (Original.

Distribution.-Godavari, Kistna, Guntur ; March and July.

Lifchistory. - The weevil bites into the under-surface of a mangoleaf and hollows out between the epidermal layers a small oval pouch into which is inserted a minute oval egg, about $3.3 \mathrm{~mm}$. long, somewhat flattened and translucent. When the leaf is held up to the light the places of oviposition are distinctly recognisable as shining white dots. The newly-hatched grub begins to feed on and mine in the green matter of the leaf, of which between a quarter and half of one square inch is destroyed by each grub. The fullgrown legless grub is about $3 \mathrm{~mm}$. long, flattened, translucent, whitish, the green matter contained in its intestinal canal showing clearly through the transparent body. The grub cleans out a portion of its tunnel and converts it into a chamber roughly oval in shape, and changes into a pupa of normal weevil type. The beetle emerges four days after pupation and escapes by cutting a round hole in the wall of the pupal chamber. Life-cycle is probably, egg three days, larva five days, pupa four days, total 12 days. [Y.R.R.]

Stutus. - A minor pest of local importance. As many as 20-30 larvæ may be found in one leaf and such leaves are so badly mined that they turn red-brown and dry up completely; in such cases a good deal of damage may be done. The beetles also may cut small holes in the leaves but the damage thus done is inconsiderable.

Rcmarks. - In its general appearance and especially in the dilated hind-femora, this weevil bears considerable resemblance to a flea-beetle. It is very wary and active and jumps off the leaves on the least disturbance.

CYLAS FORMICARIUS, Fab.

Attclahus formicarius, Fb., Ent. Syst. Suppl., p. 163 (1798). 



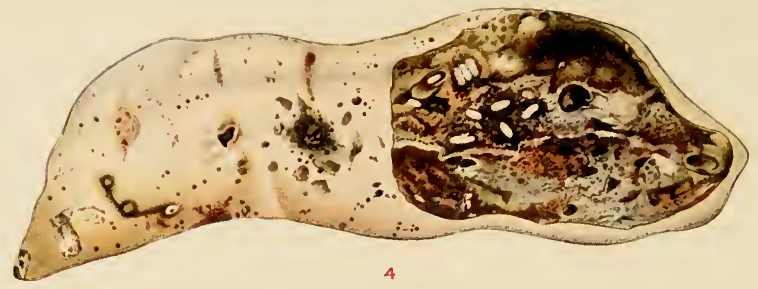

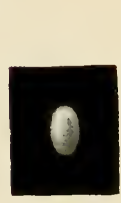

1

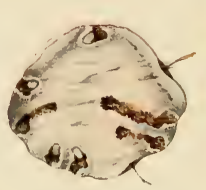

2

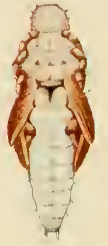

5

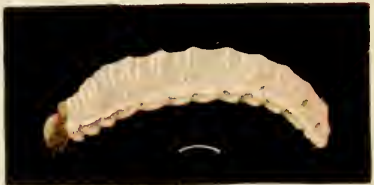

3

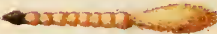

B
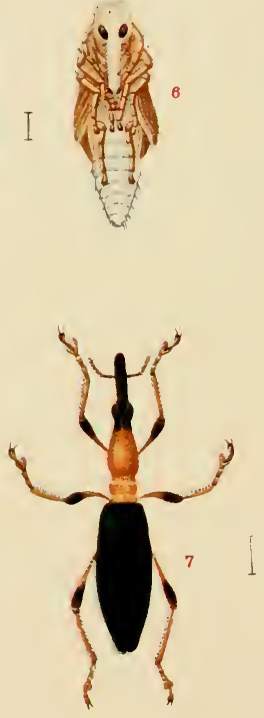

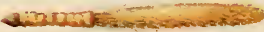

H

CYLAS FORMICARIUS. 


\section{EXPLANATION OF PLATE XII. CYIAA FORMICARIUS.}

FIG. I. Egg, magnified ten times.

" 2. Eggs thrust into potato, twice natural size.

3. Larva.

,$\quad+$ Infected potato.

, 5. 6. Pupa.

, 7 . Adult bectle.

" 8. Antenna of female beetle (above) and of male (below).

(The lines alongside the figures show the natural sizes.) 


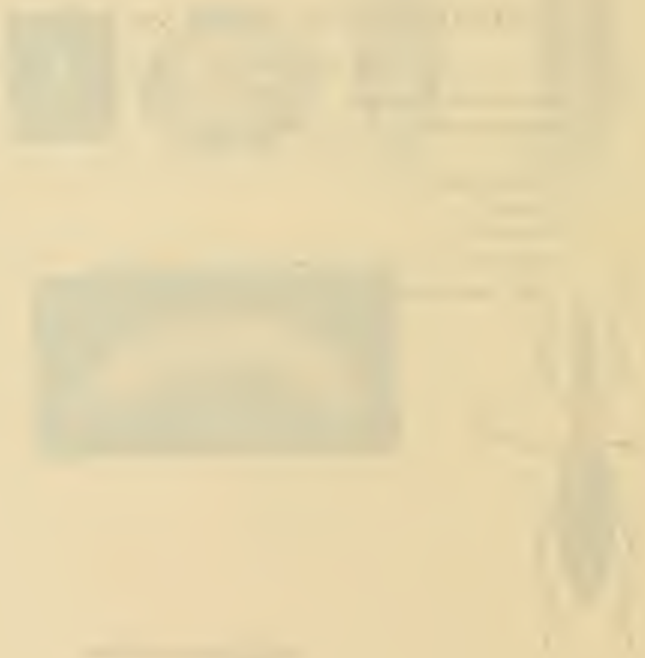


Cylas formicarius, Lefroy, Ind. Ins. Pests, p. I62, Ind. Ins. Life, p. 386, t. 26, Ent. Mem. Dept. Agri., Ind., II., I55-I59, t. XVIII.

(SEE Plate XII.)

Distribution.-Throughout Southern India, in the Hills up to at least 4,000 feet, probably all the year round.

Lifehistory. - The small oval whitish egg is deposited in cavities bitten out by the beetle in the stems or tubers of the foodplant. The legless grub, which is whitish with a pale-yellow head, bores into the stem or tuber, the presence of the grubs often being shown by the development of dark patches around the attacked portions. Pupation in a small chamber at the end of the larval burrow, pupa whitish. The beetle emerges after about a week, the complete lifecycle occupying about one month.

Foodplant.-Sweet potato (Ipomara batatas). Probably also in stems of other species of Ipomaa (e.g., I. pes-capre) though not definitely noted in India.

Status.-This may be a very destructive pest to sweet potato crops.

Control. - Collection of beetles by hand-nets and by attraction to light-traps. Planting of deep-rooting varieties of sweet potato. In bad cases of infection, only complete destruction of the whole crop is of any avail and sweet potatoes should not be grown in the vicinity for at least two years.

APODERUS TRANQUEBARICUS, Fb.

Attclabus tranquebaricus, Fab., Ent. Syst. Suppl., p. I62 (I798).

A poderus tranquebaricus, Lefroy, Ind. Ins. Life, p. 387 , t. 27 , f. 8.
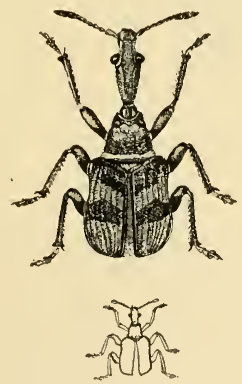

FtG. 193.-Apoderus tranquebaricus. The small figure shows the natural size. (Original.) 
Distribution.-Madras, Chingleput, South Arcot ; January-February ; July-August.

Lifehistory.-The oval yellowish egg, which is about $2 \mathrm{~mm}$. long, is laid at the tip of a leaf which is doubled-up; both sides of the leaf are cut across to the midrib, near the base of the leaf, and this terminal portion is rolled into a tight roll cigar-wise. It is not certain whether the weevil does this before ovipositing or not,--probably before. The egg hatches after four days. The small legless, yellowish grub has a brownish-yellow head with darker manclibles and a few short hairs are scattered over the body. The pupa, which is bright yellow in colour and about $3 \mathrm{~mm}$. long, is enclosed in the folded leafin the midst of black powdery excrementitious matter left by the grub. The beetle emerges through a hole through the side of the leaf-roll. [Y.R.R. and T.V.R.]

Foodplant.-Country almond (Terminalia catappa) (Tam. Pinnai), mango.

Status.-Not a pest.

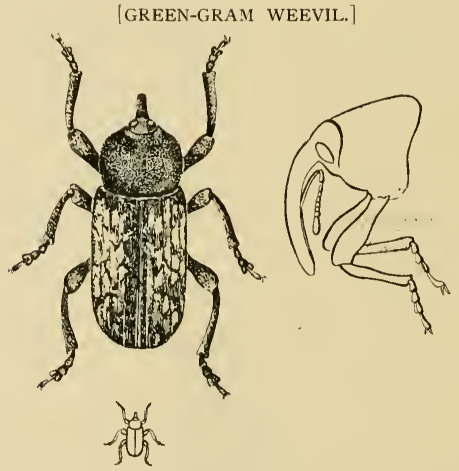

F16. 194.-Green-gram Weevil, beetle and side-view of head. The small figure shows the natural size. (Original.)

Distribution.-Bellary (Hadagalli) and Kurnul; November and December.

Lifchistory and Foodplants. - The eggs are laid in a hole bored in a seed of green-gram (Phascolus mungo) or cow-pea, the female having previously eaten her way inside the pod. Three eggs are usually laid in one pod, one at each end and the third in the middle of the porl. The grub on hatching feeds on the seed, devouring 
three or four seeds before it is full-fed, when it emerges from the pod and drops to the ground in which it pupates.

Status.--A local pest which may at times do considerable damage. Said to occur more commonly on areas of black cotton soil.

Control.-?

ALCIDES COLLARIS, PaSC.

. . collaris, Pascoe, A.M.N.H. (5), XX, 358.

Alcides collaris, Lefroy, Incl. Ins. Life, p. 388.

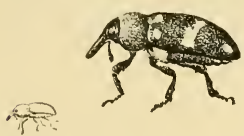

FIG. I95.-Alcides collaris.

The small figure shows the

natural size. (Original.)

Distribution.--Coimbatore ; Bellary.

Lifehistory.-The female weevil gnaws a hole in the stem of the foodplant, deposits an egg and carefully covers it over with fibres of the stem. The grub on hatching bores into the stem but does not seem to tunnel far; a swelling or gall is formed near the point of entry and in this the grub lives until mature, when it is seen to be a legless dirty-white larva usually found inside the gall in a doubled-up posture. The grub when full-grown prepares a thin tough brownish cocoon from which the weevil emerges after about eight days, waiting another three days or so before its integuments are sufficiently hardened for it to emerge into the open air. The total life-cycle, from egg to beetle, is about 35 days.

Foodplants.-Green-gram (Phaseolus mungo) and other pulses. Said by Lefroy to occur in sweet-potato fields but not found on that plant in Southern India.

Status. - A minor pest. When eggs are laid in young plants they may be killed. In older plants the locality of the gall causes a point of weakness which may cause the plant to break off if strong winds occur. Usually one or two grubs occur in one plant but sometimes six or eight may be found.

Control. - Collection of the beetles by hand.

Natural Enemies,-A small blackish Braconicl.

ALCIDES BUBO, Fb.

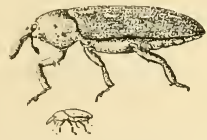

Fig, 196,-Alcides bubo.--The small figure shows the natural size. (Original.) 
. . bubo, Fab., Syst. El., II, 474.

Alcides bubo, Lefroy, Ind. Ins. Life, p. 388.

Distribution.-Coimbatore, Bellary (Hadagalli), Madras (Saidapet), South Arcot (Palur), Trichinopoly, Madura, Tinnevelly.

Lifchistory.-- The pale yellowish egg is laid in small holes in the stem of the foodplant excavated by the mother-weevil. After about five days it hatches into a pale whitish legless grub which burrows into the stem and grows until it reaches a length of $6--7$ $\mathrm{mm}$. ( $\frac{1}{4}$ inch). The larval tunnel is bored, not up and down the stem, but immediately around the point of entry, so that a distinct swelling or gall is often formed around the seat of injury. The insect pupates within the larval burrow, the beetle emerging a week after pupation.

Foodplants.-Agathi and Daincha (Seshania), Indigo (Indigofera arrecta) and Cluster-bean (Cyamopsis psoralioides).

Status. - A major pest of considerable importance in betelgrowing districts.

Control.-?

ALCIDES LEOPARDUS, OI.

- . lcopardus, Olivier, Ent., V, 83, p. 190, t. 22, f. 296.

Alcides leopardus, Lefroy, Ind. Ins. Life, p. 388, f. 26I, c.

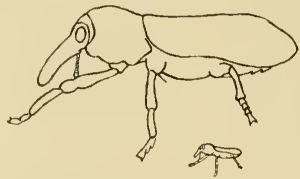

FIG. 197.-Alcides leopardus. The small figure shows the natural size. (Original.)

Distribution.-Coimbatore, Saidapet, South Arcot (Palur). Probably throughout the year.

Lifchistory. The beetle gnaws separate chambers in the leafstalk and deposits a single pale-yellow egg which seems always to be placed in only the second of the chambers excavated. The whitish grub, on emergence from the egg, bores down into the stalk and stem until full-grown, when it is nearly an inch long, stout, pale-white, with a dark head and prothoracic shield; pupation in a chamber at the lower end of larval gallery. Pupa stout, pale-whitish, of general form of the beetle but with wings, legs and snout adpressed ventrally. Length of lifehistory not known.

Foodplant.-Cotton and Hibiscus. 
Status.-A very minor pest, the plants being little injured even when the larval tunnel extends a long way down the stem.

\section{Control-?}

Remarks.--At Palur the grubs of this beetle had apparently been extracted by a bird which had ripped open the affected twigs.

\section{PEMPHERES AFFINIS, Fst.}

Fempheres affinis, Faust, D.E.Z. (I898), 319.

Phylaitis sp., Lefroy, Indian Insect Pests, pp. 103-104, ff. 120, I2I, Ind. Ins. Life, p. 389, t. 27, ff. II-I6.

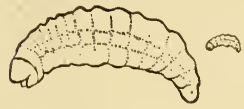

1. Larra.

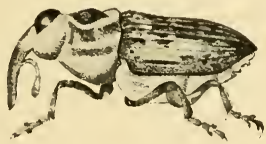

3. Beetle, magnified.

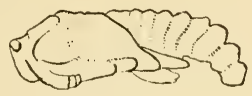

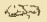

F1G. 198.-Pempheres affinis. (Original.)

Distribution.-Only found hitherto in the Coimbatore District all through season when cotton is in the ground.

Lifehistory.--Eggs are presumably laid in the tissue of the stem at ground-level, where later are found the characteristic gall-like swellings caused by the tunnellings of the whitish grub which forms a spiral burrow within the stem, pupating therein when fullfed. Exact length of life-cycle not yet known; it is probably quite short-three or four weeks. The adult beetles are very active.

Foodplants.-Cotton (especially exotic varieties, such as Cambodia and Tree-Cottons) and Gogu (Hibiscus cannabinus).

Control.-No satisfactory method has yet been found.

Natural Enemies.-None found hitherto. 


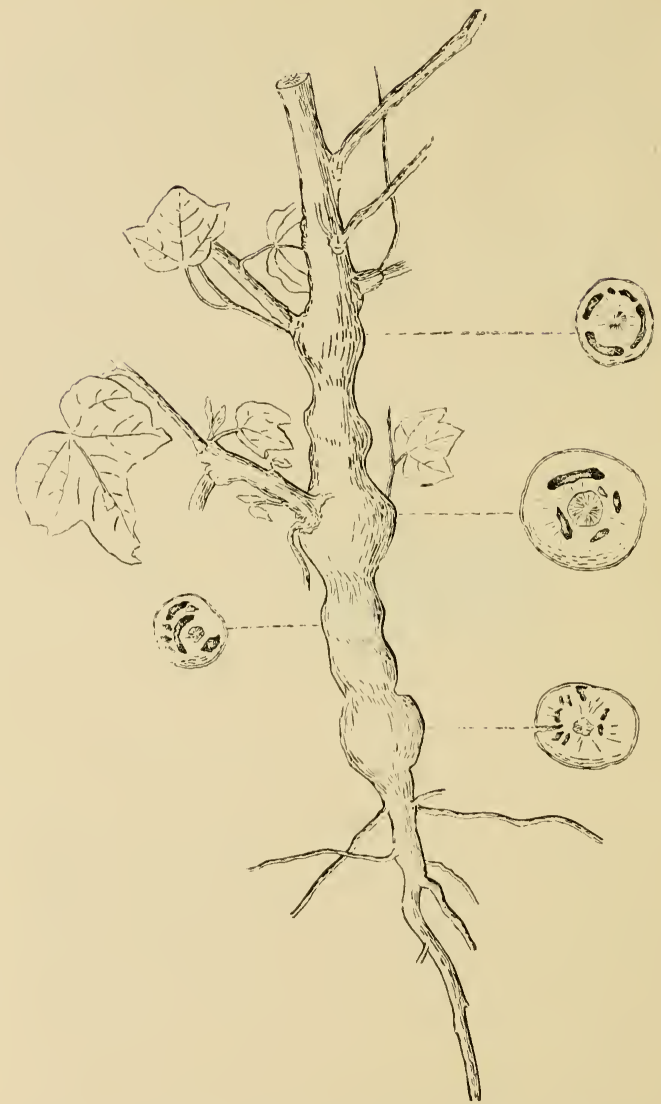

FIG. 199.-Cotton plant attacked by Stem-Weevil (Pempheres affinis). The sections at various levels show the extent of the larval tunnels. (Original.) 

PLATE XIII.

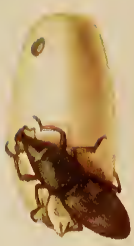

8

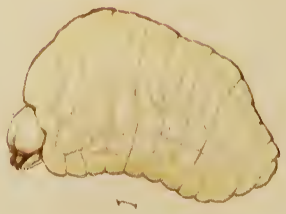

3

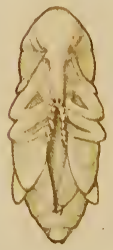

5
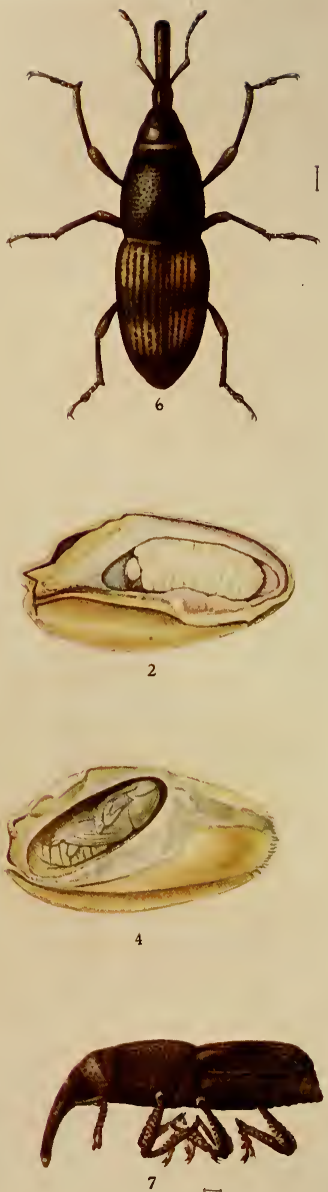


\section{EXPLANATION OF PLATE XIII}

\section{CALANDRA ORYZÆ.}

F1G, I. Eggs laid on and in a wheat-grain $x 8$.

. 2. Larva feeding inside a wheat-grain $\times 8$.

.3. Larva temoved from grain x 16.

1. 4. Pupa in natural position inside grain $x \delta$.

, 5. Pupa removed from grain, ventral view $\mathrm{x}$ I6.

, 6. Beetle, dorsal view x 16.

"7. " lateral view $\times 16$.

" 8. " gnawing into a wheat-grain $\times 8$.

" 9. " inside a wheat-grain $\times 8$.

(The lines alongside the figures show the natural sizes.) 

CRYPTORHYNCHUS MANGIFERE, Fb.

Curculio mangifere, Fab., Syst Ent., I39, 66 (1775), Spec. Ins., I, 177 (I78I).

Cryptorhynchus mangifera.-Lefroy, Ind. Ins. Life, p. 389; Marlatt, U.S.A. Ent. Circ. No. I4I, Figs. (I9II).

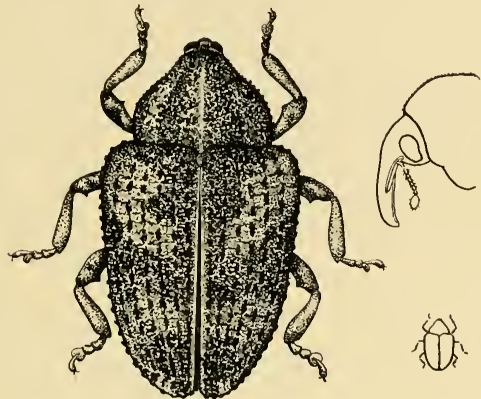

F1G. 200.-Cryptorhynchus mangifere beetle and side-view of head.

The small figure shows the natural size. (Original.)

Distrilution:-Bangalore, Coimbatore, Madras. Probably wherever mangoes are grown in Southern India. Usually in June and July.

Lifehistory. - Not fully worked out. Eggs are probably laid in the young fruit into which the newly-hatched grub bores, taking up its position inside the embryo mango-stone whose interior it devours. When full-fed, the grub pupates inside the stone and the weevil bores its way out. Length of life-cycle not known; probably only one brood annually, the beetles surviving as adults until the next mango-season. A specimen of the adult beetle was found on a coco-palm in Chittur in February I908.

Foodplant.- Mango (chiefly on sweet varieties). No alternative foodplant is known.

Status. - Not a serious pest as a rule. A small proportion of fruit is spoiled by the weevils boring ont of the fruit on exit from pupa.

Control.-?

CALANDRA ORYZÆ, Linn. (PLATE XIII.)

Curculio oryza, Linn., Amoen. Acadl., VI, 395.

Calandra oryzce, Lefroy, Ind. Ins. Life, p. 390 ; Fletcher, A.J.I., October I9II, Plate. 
Distribution.--Throughout Southern India, all the year round.

Lifehistory.-Eggs laid in grain in which the grub passes its whole existence pupating inside and onfy emerging as a perfect beetle. About six broods in the year.

Foodplant.-Stored grain of nearly all descriptions. Particularly wheat, paddy, etc. Occasionalty found in the field on ripe ear-heads.

Status. - A major pest causing great damage and loss.

Control. Fumigation of affected grain. Thorough drying of grain before storage and thereafter storing in insect-proof receptacles. Parasitized to some extent by a small metallic-green Chalcid.

COSMOPOLITES SORDIDUS, Germar.

. . sordidus, Germ.

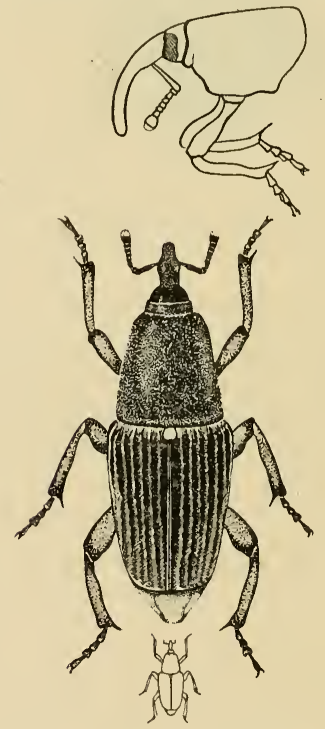

Fig. 201.-Cosmopolites sordidus, beetle and side-view of head. The small figure shows the natural size. (Original.) 

PLATE XIV.
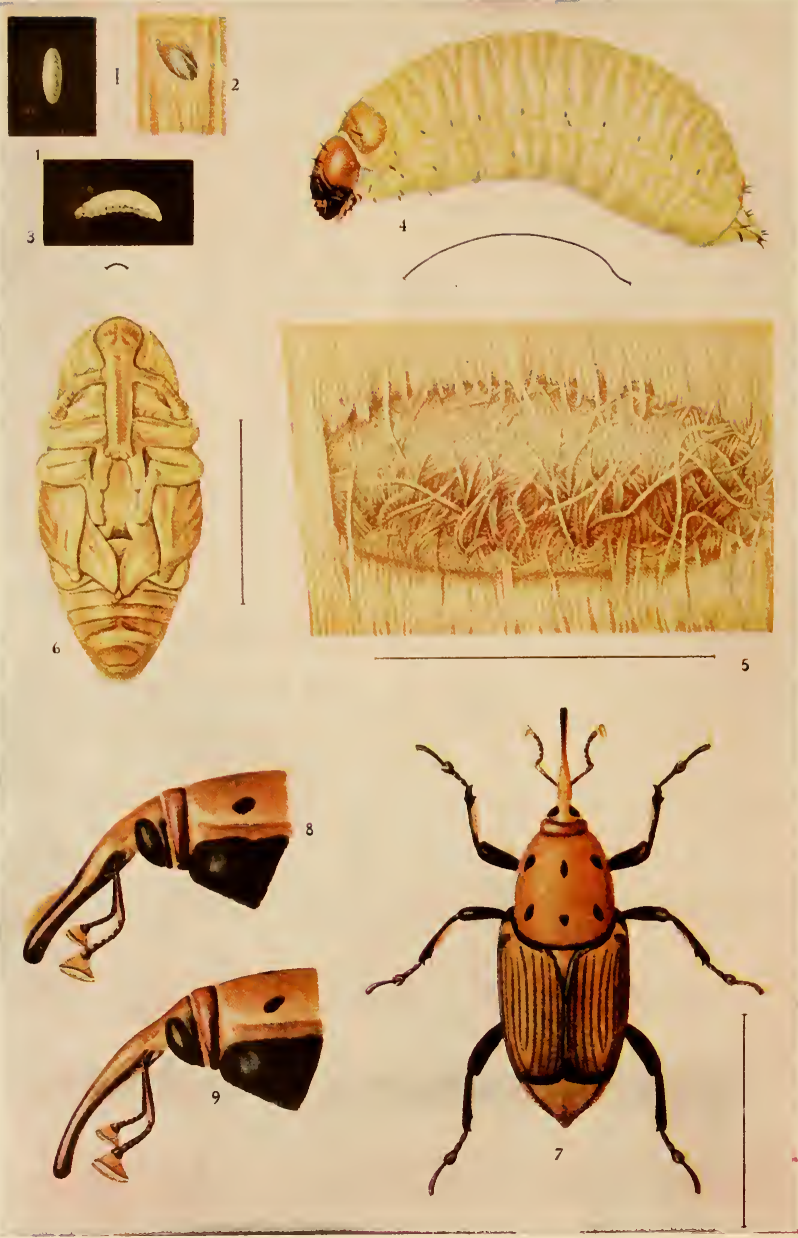

RHYNCHOPHORUS FERRUGINEUS. 


\section{EXPLANATION OF PLATE XIV.}

RHYNCHOPHORUS FERRUGINEUS.

Fig. 1. Egg, magnified.

"2. " as laid in a cavity of palm-stem,

, 3. Young larva, magnified.

" 4. Adult ", ,

, 5. Cocoon inside palm-stem.

, 6. Pupa removed from cocoon.

"7. Beetle, magnified.

, 8. Lateral view of head of male beetle.

" 9. " , female ,

(The lines alongside the figures show the natural sizes) 
Distribution.-Malabar, Coimbatore, Godavari, Ganjam. Probably throughout the year.

Lifehistory. - The eggs have not been noted but are probably laid in the substance of the root-stock of plantain-plants into which the beetles themselves burrow. The legless, dirty-whitish grub is more than half an inch in length, with a reddish-brown head. Usually a number of grubs occur in one root-stock which is tunnelled throughout. The attack is, as a rule, confined to the root-stock but sometimes extends a little distance up the stem. The grub, when full-grown, converts a part of the tunnel into an oval chamber lined with excreta and pupates therein, the beetle emerging from the pupa after about a week but taking three or four days longer for its integument to harden.

Foodplant.-Plantain (Musa sapicntium).

Status. -Usually a pest of minor importance, occasionally and locally doing considerable damage. In cases of slight attack there is little indication of damage, but where the attack is severe, the central shoot may wither or no fruit be produced.

Control.- Care should be taken that all old stumps should be removed and destroyed when the new suckers are planted and these latter should be examined and not used if found to be infected.

RHYNCHOPHORUS FERRUGINEUS, Fb.

. . ferrngineus, Fab., Enc. Meth., V, 473.

Rhynchophorus ferrugineus, Lefroy, Ind. Ins. Life, p. 390, ff. 268269 ; Ghosh, Ent. Mem. Agri. Dept., Ind., Vol. II, No. I0, Plate.

(SEe Plate XIV.)

Distribution.- - Throughout Southern India, probably throughout the year.

Lifehistory.-Eggs are laid in the soft parts of palms, particularly where cut by toddy-drawers or injured by Oryctes. The stout whitish grubs mine through the tissues in all directions and, when full-fed, pupate in a cocoon made of twisted fibres. The complete life-cycle takes about two months, the adult weevils living two or three months more after emergence from the cocoon.

Foodplants.- Palmyra, date and coconut palms.

Status.-A major pest of great importance in all palm-growing districts.

Control.- All cuts and wounds of palni-tissue should be protected as far as possible by smearing with Tar. The control of the Rhinoceros beetle will directly lead to diminution in numbers of the Palm Weevil also. Badly affected trees should be cut down, split up, and burnt. 


\section{BRENTHIDÆ.}

ORYCHODES INDUS, Karsch.

Orychodes indus, Karsch, Mitth. Zool. Mus. Dresd., I, 5 I (I875).
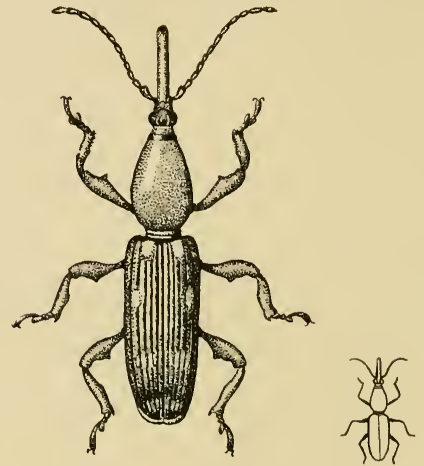

Fig. 202.-Orychodes indus. The small figure shows the natural size. (C)riginal.'

Distribution.-Nilgiris. Probably throughout Hills of Southern India.

Lifehistory.- Not known. The beetles are generally found in or on dead trees and the larvæ probably feed on rotten wood.

\section{IPIDÆ (SCOLYTIDÆ).}

CARDAMOM SCOLYTID.

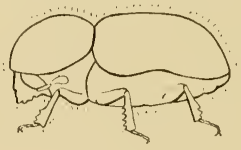

$$
\text { (a) }
$$

FIG. 203.-Cardamom Scolytid. The small figure shows the natural size. (Original.)

Distribution.-Coorg.

Lifehistory.-Not known.

Foodplant--Cardamom. 
Status.-A pest of very considerable local importance, from to to 30 per cent. of the capsules being bored and destroyed by the beetle.

Control.-No definite measures, beyond collection and destruction of attacked capsules, can be recommended pending local investigation of the work.

\section{XYLEBORUS FORNICATUS, Eich.}

\section{(Shot-hole Borcr.)}

Xyleborus fornicutus, Eichhoff, Perl. Ent. Zeits. (I868), I5I; Barlow, I.M.N., IV, 57-58, t. 5, f. 2 ; Green, Perad. Circ. II. No. 9, tab.; Watt and Mann, Pests of Tea, pp. 174-I77, t. 4, f. 2.

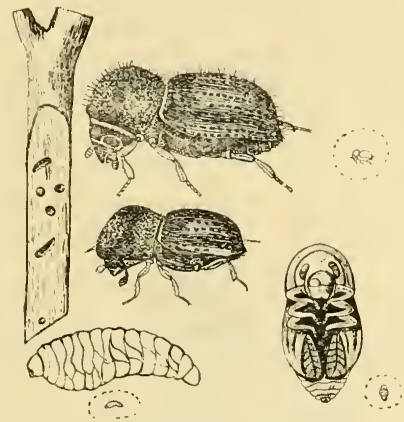

Fig, 20t.-Xyleborus fornicatus. IAfter Indian Museum Notes.।

Distribution.-Travancore (Pirmad and High Range).

Lifchistory.-The beetle bores in stems of living plants and lays its eggs in the galleries. The larva is about $4 \mathrm{~mm}$. long, legless, fleshy, white. Pupa soft, creamy-white, in the galleries, without cocoon. Only the female beetle is provided with wings and able to fly.

Foodplants.-Tea, Annatto (Bixa orellona); also occasionally in Grevillea, Albizzia stipulata and A. moluccana, Cacao (Thcobroma cacao), Guava (Psidium gnyava), Cinchona, Erythrina, Castor, and doubtfully in Lantana. (Green.)

Status.-The Shot-hole Borer, so called because its galleries resemble the effects caused by firing a charge of small shot into wood, is said not to be common in Travancore and presumably does little damage. 
Control.-(I) Destruction by fire on the spot of all infected prunings.

(2) In cases of recent outbreak in a district, rigid cutting and burning of infested bushes.

(3) Good cultivation, by keeping the tea-bushes in a vigorous condition, will help largely to withstand attack.

Remarks. - I am indebted to Mr. Anstead for information regarding the occurrence of this insect in Southern India.

\section{DIPTERA.}

\section{HIPPOBOSCIDÆ.}

HIPPOBOSCA MACULATA, Lch.

Hippobosca maculata, Leach, Mem. Wern. N.H. Soc., II, 553, t. 26, ff. II-I3 (I8I8); Austen, A.M.N.H. (7), XII, 258 (I903); Howlett, Ind. Ins. Life, p. 656, t. 69, f. 7 .

Hippobosca sive, Bigot, Ann. S.E. France (1885), 235.

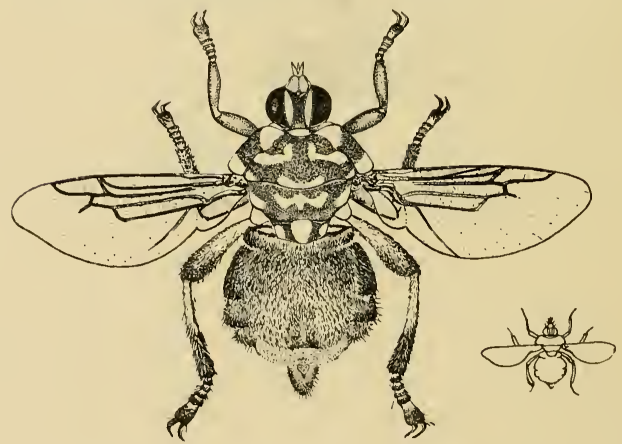

F1G. 205.-Hippobosa maculata. The small figure shows the natural size. (Original.)

Distribution.--Throughout Southern India.

Lifehistory and Food. - The eggs hatch inside the mother-fly and the larvæ are retained until they are full-grown, when they are extruded and at once pupate, the puparia being small round objects, at first whitish but later on turning dark brown.

Status.--A pest of cattle, feeding solely on blood. 
Contrel. - These insects can only be checked in the adult stage and deterrents are therefore indicated.

\section{HIPPOBOSCA CAPENSIS, Olf.}

Hippobosca capensis, Olfers, De Veget. et Anim. Corp., pars I, p. I0I (18I6).

Hippobosca francilloni, Leach, Mem. Wern. N.H. Soc., II, 554, t. 26, ff. 8-I0 (I8I8); Austen, A.M.N.H. (7), XII, 256 (I903).

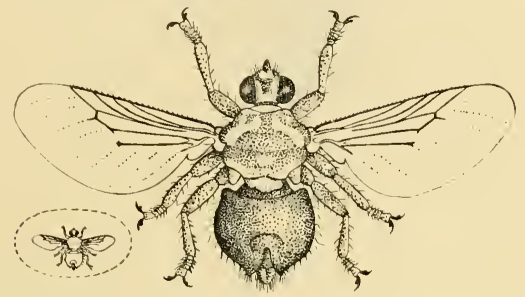

FIG. 206.-Hippobosca capensis. The small figure shows the natural size. (Original.)

Distribution.--Throughout Southern India.

Lifelistory.-Quite similar to that of Hippobosca maculata.

Host.-- Dog.

Status. - Common on dogs and doubtless transmits disease.

Control.--Deterrents such as Crude Oil Emulsion.

Remarks. - This species was first described by Leach, whose paper was read before the Wernerian Natural History on Ioth April 18I0 but, owing to delay in the publication of Leach's paper, Olfers' name for this insect has priority of publication.

\section{CESTRIDAE. \\ CESTRUS OVIS, Linn.}

(Estrus ovis, Linn., Faun. Suec. (I734); Osborn, U.S.A. Ent. Bull. No. 5, pp. I02-I05, f. 48 ; Howlett, Ind. Ins. Life, p. 654, ff. $428-429$, t. 69 , f. 6.

Distribution. - Coimbatore, Madras. Probably throughout Southern India.

Lifchistory and Food.-Eggs or living maggots (the latter almost always) are deposited by the female fly in the nostrils of the sheep and goat. The larvæ at once begin to work their way upwards, causing great irritation, until they effect a lodgment in the frontal sinus where they attach themselves by the hooks present on either 


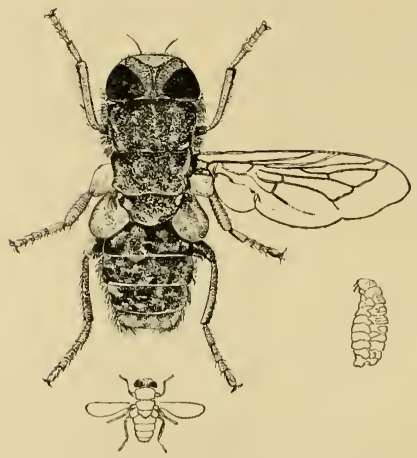

FIG. 207.- Fstrus ovis. Female fly (magnified), Larva (natural size), and Fly (natural size-outline figure). (Original.)

side of the head and feed on the mucus. At this stage the larva is creamy-white with two brown spots (spiracles) on the last segment. When full-fed it makes its way down the nasal passages of its host and clrops to the ground where it quickly buries itself and changes inside a smooth, hard, blackish, oval puparium. Pupal period about a fortnight.

Statns.-A serious pest of sheep. Goats seem little affected.

Control.- Preventive measures seem little practised in India where infestation by this fly is apparently accepted as normal. Frequent dressing of the sheeps' noses with tar, or a mixture of Tar and Crude Oil Emulsion, may be tried to keep the flies from ovipositing. A feather dipped in turpentine, run up the nostril and quickly turned, is sometimes used to dislodge the grubs but in most cases it is impossible to reach them all. Valuable animals may be trephined but this requires skilled veterinary assistance. All grubs and puparia found in sheep-pens should of course be destroyed.

\section{MUSCID Æ.}

PYCNOSOMA FLAVICEPS, Macq.

Lncilia faviceps, Macq., Dipt. Exot., II, 3, I 45 , t. I8, f. I (I842).

Pycnosoma flaviceps, Howlett, Ind. Ins. Life, p. 643, t. 69, f. 2 (I909).

Lucilia dux, Esch.; van der Wulp, Cat. Dipt. S. Asia, p. I 48 (I896). 


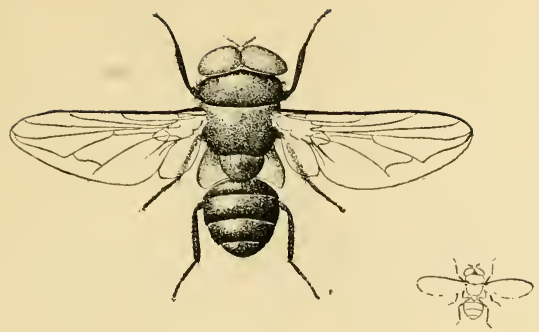

Fig. 20s.-Pycnosoma flaviceps. The small figure shows the natural size. (Original.)

Distribution.-South Kanara, Malabar. Probably throughout Southern India.

Lifehistory and Food.-The grubs feed in rotting organic matter, such as putrefying fish, pupating in the soil when full-fed. The adult flies have brilliant green bodies and red heads and are attracted to animal excrement, decaying organic matter, torddy, etc.

Status.-Has proved a serious pest of Toddy in South Kanara, sucking all the juice exuding from the palm-spathes, fouling the pots, spathes and juice with excrementitious matter, and swarming around the vessels in the Toddy-shops.

Control. - The flies may be kept away by tying a cloth sleeve between the palm-spathe and collecting-pot (see also Leaflet No. IV of I9I3 issued by the Department of Agriculture, Madras, and Fig. 72 on page 159 ).

IIUSCA NEBULO, Fb.

(The Indian House-fly.)

Musca nebulo, Fabr., Ent. Syst., IV, 32I (I794).

Musca domestica, Howlett, Ind. Ins. Life, p. 644 (nec Linn.).

Distribution.- Throughout Southern India.

Lifehtstory and Food.- Eggs are laid on decaying a nimal or vegetable matter, chiefly in night soil and in refuse around slaughterhouses, etc., on which the whitish maggots feed on hatching out, pupating in the soil when full-grown. The length of the life-cyclc varies with temperature but is probably about Io days in the Plains.

Status.- This pest and its allies deserve to be bracketed with the Rat-flea and Anopheline Mosquitos amongst the most common causes of ill-health amongst the inhabitants of India. Bred 


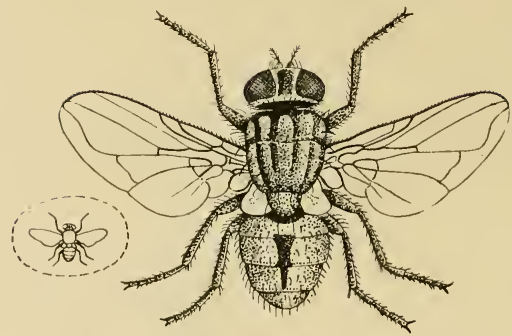

F1G. 209.-IIusca ncbulo. The small figure shows the natural size. (Original.)

amongst filth the adult fly is equally at home on excrementitious matter and on food intended for human consumption and carries on to the latter various disease-germs derived from its frequenting unclean situations. Enteric Fever, Cholera and Intestinal Worms are amongst the more important of the evils carried onto food by the House-fly.

Control.--(I) The most important means of control is proper sanitation in the neighbourhood of all dwellings. This includes proper disposal of all refuse-food, stable-manure, and excrementitious matter of every kind.

(2) Killing the flies by traps, fly-papers, etc.

(3) Screening of all food, bungalows, kitchens, etc.

Remarks.-(I) The House-flies of India include several distinct species which may or may not be identical with Musca ncbulo. The lifehistory and habits of all, however, are likely to be practically identical and all may be looked on as noxious pests of the worst description.

(2) I am indebted to Captain Patton, I.M.S., for information regarding the identification of Musca nchulo, which is apparently the common House-fly of Southern India.

\section{MUSCA PATTONI, Aust.}

Musca pattoni, Austen, A.M.N.H. (8), V, II4-II7 (Jan. 19Io); Patton and Cragg, Ind. J1. Med. Res., I, I7-I8, t. 2 (Aug. I9I3).

Distribution.-Probably throughout the Plains of Southern India.

Lifchistory.-Eggs are laid in piles of cowdung, rarely in isolated patches, the eggs being laid singly, but frequently by large numbers of flies in the same place. The larva is of the shape shown in the figure and about $10 \mathrm{~mm}$. in length. The dirty greyish-white puparium, about $7 \mathrm{~mm}$. long, is found in the dung. 


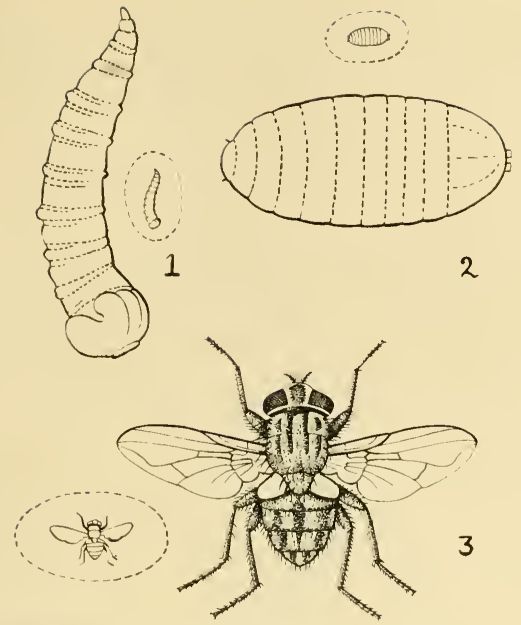

FIG. 210.-Musca pattoni. 1, Larva ; 2, Pupa ; 3, Imago (Fly). The small figures show the natural sizes. (After Patton and Cragg.)

Food.--The blood and serous discharges of cattle and horses.

Status.-Not definitely known to be a pest but quite likely to prove one on account of its feeding habits, whereby it may carry pathogenic organisms from one animal to another.

Control.- Treatment of cowdung with oily sprays or keeping in suitable receptacles.

Remarks.-This species is cited here as an example of the group of non-biting but bloodsucking (hæmatophagous) species of the genus Musca, which also includes $M$. gibsoni (? recte gibsonc), Patton and Cragg, M. convexifrons, Th., and M. beszii, P. and C. These flies are not themselves provided with biting mouth-parts and are therefore unable to pierce the skin of animals to obtain blood, but they rely on other biting flies to draw blood and thereupon endeavour to thrust their proboscides into the wound to obtain the exuding blood, of ten positively worrying and driving away the true biter. It is probable that this and other flies of this group may prove to be important agents in the conveyance of diseases of domestic animals. 
PHILEMATOMYIA INSIGNIS, Aust.

Philamatomyia insignis, Austen, A.M.N.H. (8), III, 298-299 (March 1909); Howlett, Ind. Ins. Life, p. 646 ; Cragg, Sci. Mem. Govt. Ind., No. 54 (I9I2); Patton and Cragg, Ann. Trop. Med., V, 5 I5 520, Figs. (Feb. 1912).

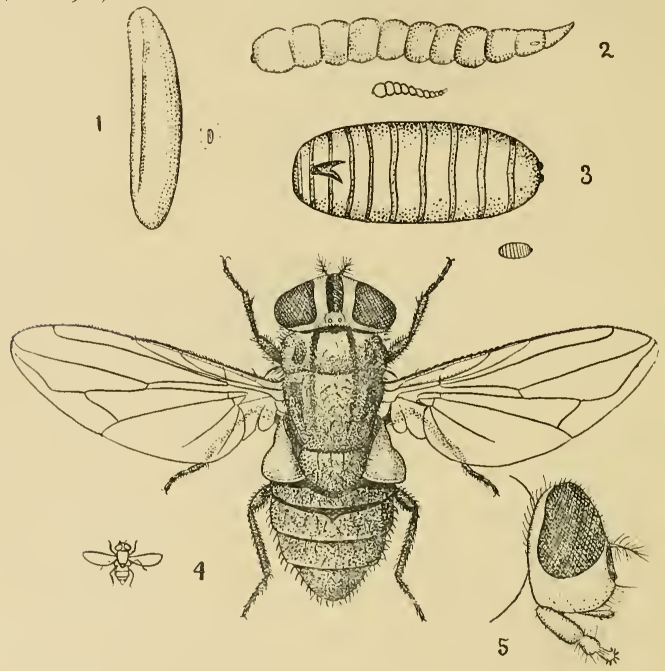

FIG. 211.-Philcmatomyia insignis. 1, Egg ; 2, Larva ; 3, Pupa ; 4, Fly ;

5. Side-view of head of Fly with proboseis extended. The small figures show the natural sizes. ( $1-3$ after Patton and Cragg;,+ 5 original.)

Distribution.-Throughout Southern India:

Lifehistory and Food.--The eggs, which are of relatively enormous size, long, cylindrical, round-pointed at the ends, curved, are laid in a large mass in fresh cowdung, in which the larvæ feed.

Status.- One of the commonest insects found sucking the blood of cattle. Doubtless capable of carrying disease.

Control. - No suggestions can be made, other than application of deterrents and collection and sterilization of cowdung.

Remarks.-In size, colour and general appearance, this fly is almost exactly similar to a House-fly but microscopical examination 
shows that the tip of the proboscis is surrounded by a ring of stout black chitinous teeth.

Natural Enemics.-Oxybclus squamosus (see page 280).

\section{STOMOXYS CALCITRANS, Linn.}

Conops calcitrans, Linn., Syst. Nat. (ed. X), I, 604 (1758).

Stomoxys, Geoffroy, Ins., II, 539, t. I8, f. 2.

Stomoxys calcitrans, Bezzi, Arch. de Parasit., XV, I38 (Oct. I9II) [Synonymy and Distribution]; Howlett, Ind. Ins. Life, p. 646, t. 69, f. 3; Brain, Ann. Ent. Soc. Am., V, 42I-430, t. 33, 34, l.c. VI, I97-20I, t. 22 .
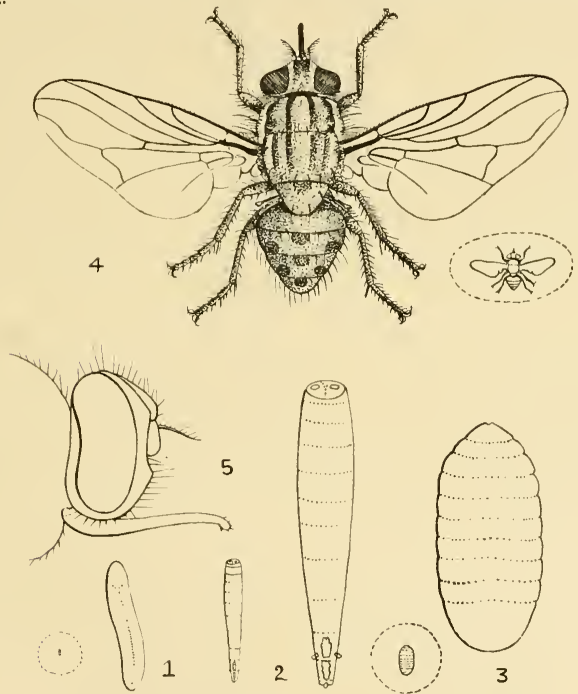

F1G. 212.-Stomoxys calcitrans. 1, Egg ; 2, Larva ; 3, Pupa ; +, Fly ; 5, Side-view of Head of Fly. The small figures show the natural sizes. (Original.)

Distribution.-Throughout Southern India.

Lifchistory and Food.-Eggs are usually laid on horse-dung, damp straw, etc., in damp places in which"the larvæ live. The larvæ are 
superficially similar to those of the House-fly. Life-cycle about 3 weeks, probably less in warm weather.

Status. - A blood-thirsty and annoying pest of domestic animals, often attacking man also. Undoubtedly carries disease.

Control. - This must be based on sanitary disposal of horse-dung and other stable-refuse.

Remarks.-(I) The flies, of which there are several very similar species, are very similar in general appearance to House-flies, but at once recognisable by the long, slender, chitinous proboscis.

(2) Little is known at present of the lifehistories of this and other Indian Muscid Flies and the descriptions here given must be taken as merely indicative of a very few examples from the large number of Muscid Flies noxious to man and animals in India.

\section{TRYPANEIDÆ.}

\section{DACUS CUCURBITÆ, COQ.}

Dacus cucurbita, Coquillet, Ent. News (I899), I29-I30; Lefroy, Ent. Mem. Agri. Dept., Ind., I, 228; Howlett, Ind. Ins. Life, f. 4I8; Froggatt, Fruit Flies, pp. $84-85$, t. 2., ff. 6,7 .

Bactrocera cucurbitce, Bezzi, Mem. Ind. Mus., III, 96-97, t. 8, f. 7 (I9I3).

\section{(See Plate XVI.)}

Distribution.-- Throughout Southern India.

Lifehistory.--Eggs are laid on melons, etc., being thrust just under the skin by the ovipositor of the female fly. The white grubs on hatching burrow into the fruit, tunnelling in it and completely spoiling it. When full-grown they emerge and pupate in the soil. The total life-cycle occupies about 15 days.

Foodplants.- Fruits of Cucurbitaceæ (Nelons, Pumpkins, Cucumbers, etc.).

Status.-A serious pest of cucurbits.

Control.-(I) Prompt destruction of all attacked fruits by boiling, burning or burying them deeply underground. It is not of the slightest use to throw the fruit down on the ground as the maggots will emerge in due course as flies which will attack other fruits.

(2) Protection of fruit in small areas by netting, etc.

Remarks.-This Fruit-fly is given here as a typical example of its class. At least a dozen different species occur and some of them attack Mangoes, Oranges, Peaches, Guavas, Almonds, etc., the general lifehistory, habits and appearance being the same in all. This group of flies badly requires to be worked out and the species properly differentiated. In some the flies may be attracted by 



\section{EXPLANATION OF PLATE XVI}

\section{DACUS CUCURBIT.Æ.}

Fig. 1 . Maggots in fruit, natural size.

"2. A single larva, enlarged.

" 3, 4, 5. Pupa, enlarged, with details of extremities.

$\leadsto$ 6. Adult fly, greatly enlarged. 
PLATE XVI.
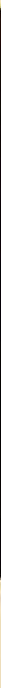

(3)

5
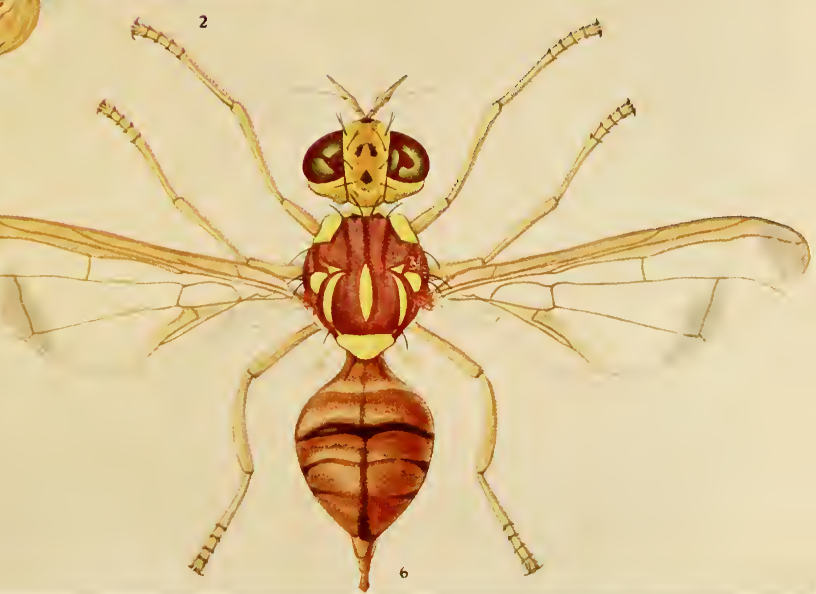

DACUS CUCURBIT E. 

traps containing oils such as Citronella and Kerosine, but this method of control can only be applied to particular species of flies.*

\section{MICROPEZID E.}
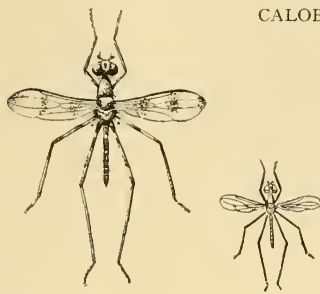

F1G. 213.-Calobata sp. The small figure shows the natural size.

(Original.)

\section{CALOBATA Sp.}

Distribution. - Throughout the Plains of Southern India.

Lifflistory. - The maggots have been found boring into Turmeric rhizomes. Pupation in the larval galleries.

Foodplants.- Turmeric, Ginger.

Status.-Doubtful as a pest. The larvæ have only been found in rotting rhizomes and may merely act as scavengers.

\section{CHLOROPID E.}

SIPHONELLA FUINICOLA, de Meij.

(The Eye-fly.)

Siphonella funicola, de Meijere, Notes Leyden Mus., XXV, I60 (1905).

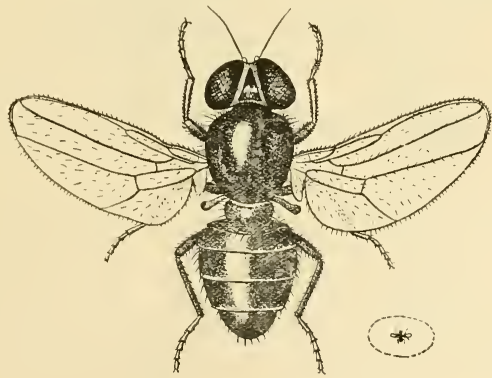

F1G. 21t.- Siphonella funicola. The small figure shows the natural size. (Original.)

* Since this was written, an account by Bezzi of some of the Indian species has been published by the Indian Museum, but practically notning is known as yet regarding the susth Indian Frait-llies. 
Distribution.-Throughout Southern India.

Lifehistory. - Not known.

Food.-Not known. The larva is suspected of feeding on decaying vegetable matter.

Status.-An annoying pest which undoubtedly may convey diseases of the eye.

Control.-The flies may sometimes be attracted in large numbers to a piece of vertically-hanging rough string or tape and may then be killed off in quantity by burning with a torch at night.

\section{AGROMYZID $A$.}

\section{CHOLAM FLY.}

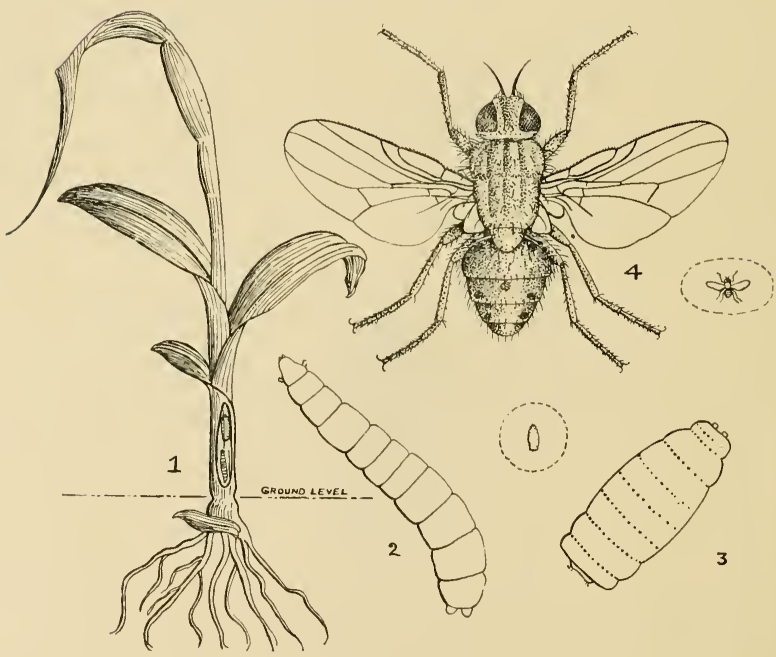

Fig. 215.-Cholam Fly. 1, Attacked Cholam plant cut open to show larva and pupa of natural size; 2, Larva; 3, Pupa; 4, Fly. The small figures show the natural sizes. (Original.) 
Distribuiton.--Throughout Southern India.

Lifchistory. - The larva bores in the young sten of the foodplant, causing a characteristic "cleadheart." The pupa is also found in the stem.

Foodplants. - Cholam, cumbu and millets.

Status.- Sometimes a serious pest of young seedlings.

Control. - Increased seed-rate and prompt removal and destruction of all young plants seen to be attacked.

Remarks. - The name of this fly is not known and its systematic position is doubtful. In general appearance and habits it much resembles the palæarctic Pcgomyia fusciceps (Anthomyiadæ).

\section{RED-GRAM AGROMYZA.}
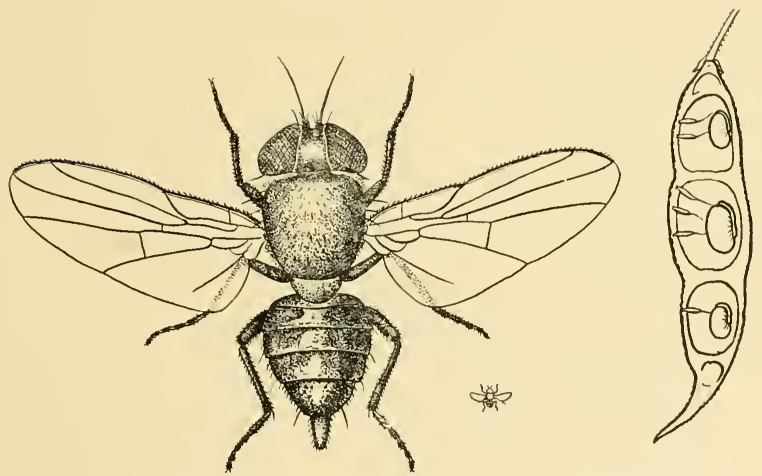

F1G. 216.-Red-Gram Agronyza. Fly, enlarged and natural size; to the right is a Red-gram pod cut open to show the eggs thrust into it. (Original.)

Distribution.-Throughout Southern India.

Lifelistory.-Eggs are thrust through the tender shell of a young pod of Cajanus indicus, the grub on hatching feeding on the seed, pupating inside the pod.

Foodplant.-Red-Gram (Cajanus indicus).

Status. - A minor pest as a rule.

Control.- - ?

Remarks.-This is probably the same as the species called the “Turpod Agromyza " by Howlett (Ind. Ins. Life, p. 622). 


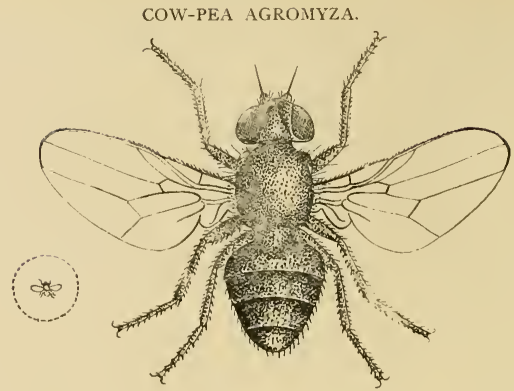

I'Ig. 217.-Cow-pea Agromyza. The small figure shows the natural size (Original.)

Distribution.-Coimbatore; Tinnevelly.

Lifclistory.-The larvæ bore into the stem, a number being found in the same plant, plants thus attacked wilting. Pupa in larval burrow.

Foodplants.-Cow-Pea (Vigna catjung), Lab-lab (Dolichos lab-lab), Green-gram (Phaseolus mungo).

Status.-A serious pest of young plants.

Control.--?

\section{SYRPHIDA.}

\section{SYRPHUS Spp. (PLATE XV.)}

Distribution.-Throughout Southern India.

Lifehistory.-The eggs are laid singly on plants attacked by Aphids, on which the larvæ feed. The larvæ are variable in colour, usually greenish, sometimes with red markings; they feed on Aphids which they seek out and devour greedily. Pupation usually on a leaf, in a sort of cocoon formed by the cast larval skin. The flies themselves have often a wasp-like pattern of markings and fly very rapidly or hover in the air.

Status.-Extremely beneficial as a natural control of Aphids.

\section{TABANIDÆ.}

TABANUS STRIATUS, Fb.

Tubanus striatus, Fab., Ent. Syst., IV, 37I (I794); van der Wulp, Cat. Dipt. S. Asia, p. 58 (I896) ; Kertesz, Cat. Dipt., III, 28I (I908); Howlett, Ind. Ins. Life, t. 42, f. 2 ; Mitzmain, Philipnine Jl. Sci. VIII-B, 197-2I8, tabs. (June 19I3), l.c. 223-229. 


\section{EXPLANATION OF PLATE XV. \\ SYRPHID FLY.}

FIG. I. Egg, magnified.

2. Young larva $\times 45$.

, 3. Full-grown larva $\times 8$.

, 4. Pupa on leaf $\mathrm{x} 6$.

, 5. Adult fly, $\mathrm{x}_{4}$.

, 6. Wheat Plant.

, 7. Egg laid amongst colony of Aphids.

„ 8, 9. Larvæ feeding on Aphids.

, г. Pupa on plant.

(Figs. 7-10 are slightly larger than bife-size. : 


\section{PLATE XV.}
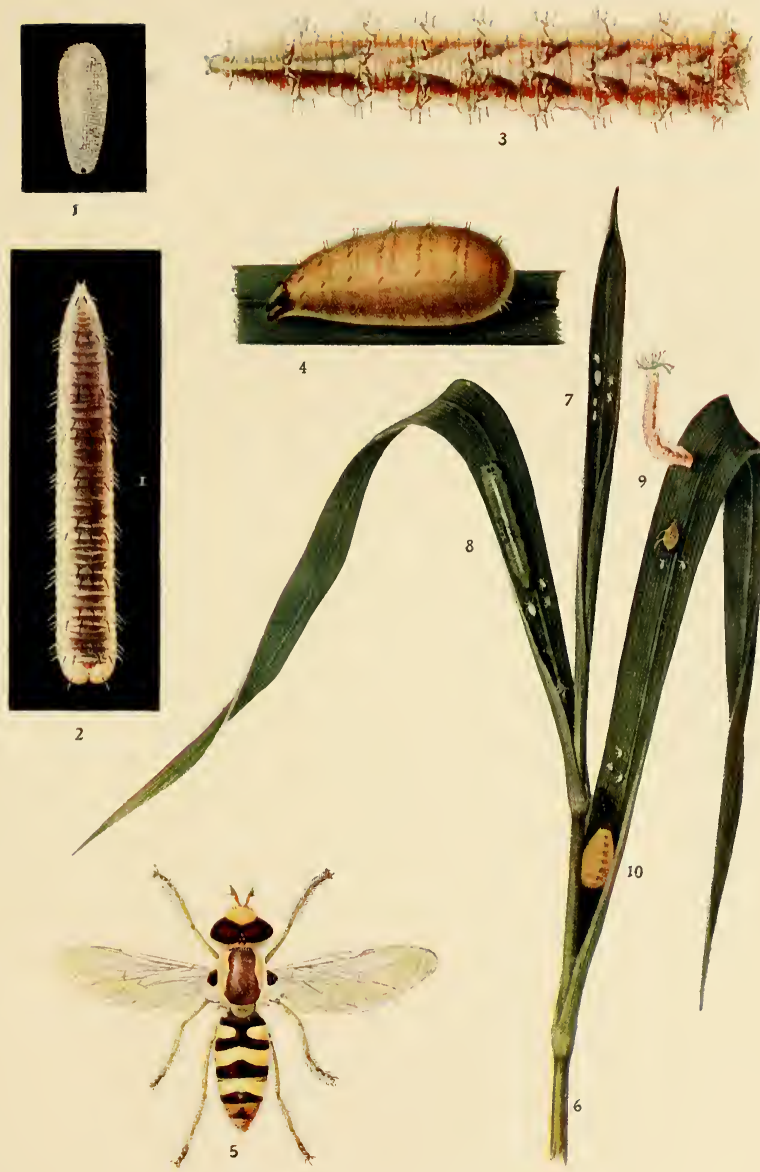



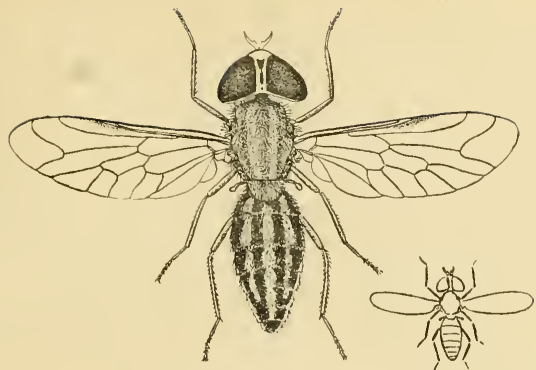

F1G. 218.-Tabanus striatus, female. The small figure shows the natural size. (Original.)

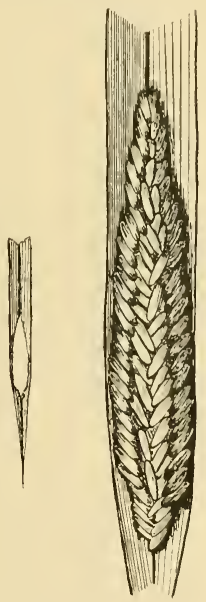

Fig. 219.-Eggmass of Tabanus striatus on paddy leaf, natural size and enlarged. (Original.)

Distribution.-Throughout Southern India.

Lifchistory.-Eggs are laid in a large mass, usually on a leaf or twig overhanging water into which the young larva drop on 
emergence, thenceforward leading an aquatic life burrowing in the mud at the water's-edge and feeding on worms or living or dead insects. The full-grown larva is $40-50 \mathrm{~mm}$. long, dull whitish, elongate, tapering at each end with protuberances at the edges of the segments. When full-fed it leaves the damp mud at the water's-edge and after a quiescent period pupates in the earth above water-level.

Status.-The flies themselves are a pest of cattle and doubtless carry disease. According to Mitzmain's experiments in the Philippines this fly can transmit Surra directly and mechanically.

Control.--(I) Deterrents applied to cattle.

(2) Screening of breeding-places where practicable.

(3) Removal of egg-masses when found to situations where the larvæ on hatching will not be able to find water whilst any parasites will escape.

\section{PANGONIA Sp.}

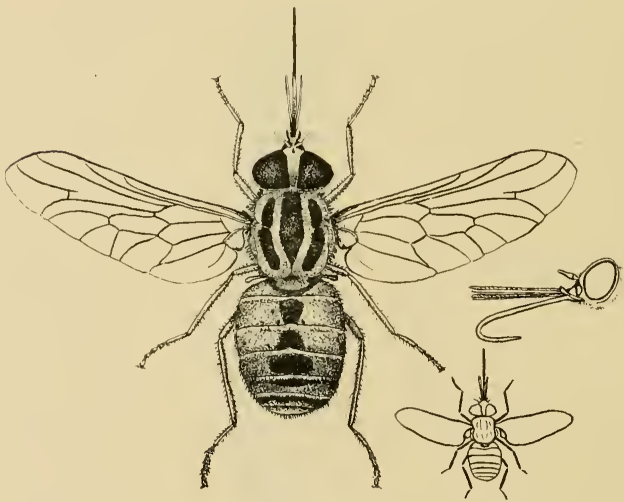

Fig. 220.-Pangonia sp., female. The smaller figure shows the natural sice.

On the right is a side-view of the head showing the mouth-parts separated out. The proboscis itself is naturally straight. (Original.)

Distribution.--Mostly in the Hills between about 2,000 and 4,000 feet.

Lifchistory. - Not known. Probably similar to that of Tabanus.

Status.- The male flies seen to feed largely on flowers but the females are persistent blood-suckers of man and other animals and may serve as carriers of disease. 


\section{Control.- ?}

Obscrvation.- - It is usually stated that these flies suck blood when hovering on the wing; but this is not the case, at least as regards the species figured here. The flies hover with their long proboscides thrust out and probably search for a suitable place with their labella; this found, the fly settles and thrusts the tip of the proboscis against the skin of the animal attacked, pressing firmly forward so that the proboscis is bent arcuately, when the mandibles are brought into contact with the skin and thrust in and the blood sucked. The proboscis itself takes no part in the sucking of the blood and it seems impossible that these flies should suck blood whilst hovering.

\section{ULICID Æ.}

\section{MoSQUiTos.}

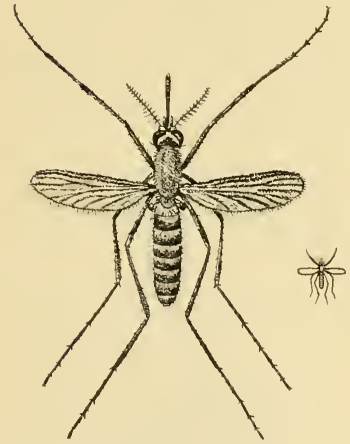

IF1G. 221.-Culcx fatigans, a very common Indian Mosqnito, The small figure show's the natural size. (After Patton.)

It is impossible to give here any but a general account of the various mosquitos found in Southern India. The eggs are laid singly or in masses forming little rafts which float on the surface of the water. The larvæ and pupæ of all species are aquatic and control should therefore aim at elimination of breedingplaces in the vicinity of dwellings. Open wells and cisterns should be screened and fitted with a pump where practicable and empty tins, broken bottles, coconut husks, etc., which may catch rain, should not be allowed

to lie about the compound. Jars of water under legs of tables, etc., should be treated with kerosine oil regularly and all bodies of open water near dwellings should be treated regularly with some larvicide or a supply of a small fish kept in them. An invasion of mosquitos in the house may sometimes be traced to flower-vases, fowls' or dogs' water pans, etc., and all such should be emptied and refilled daily. 
Besides the actual annoyance caused by the mosquitos to man and other animals, they are extremely common carriers of clisease. Malaria is carried solely by various species of Anopheline mosquitos and other diseases may be carried by Culicines. For characteristic differences in resting-attitudes of these mosquitos, see figures 78 and 79 . Anophelines are usually long and slender, blackish in colour, with spotted wings.

Control should aim at prevention rather than remedy and this may be obtained by renclering water unsuitable for the breeding of mosquitos, by methods such as screening, the use of larvicides, fish, draining, etc. Screening of houses and beds by fine netting and use of repellents are also indicated. The treatment of diseases carried by mosquitos cannot be dealt with here.

\section{PSYCHODIDÆ.}

PHLEBOTOMUS MINUTUS, Rond.

Phlcbotomus minutus, Rondani, Ann. S.E. France (2), I, 263 (1843); Annandale, Spol. Zeyl., VII, 203; Newstead, Bull. Ent. Res., II, 62, 69-70, figs.

Phlcbotomus babu, Annand., Rec. Ind. Mus., IV, 49-50, t. 4, f. I, t. 6 , ff. $3,3^{\text {a }}$.

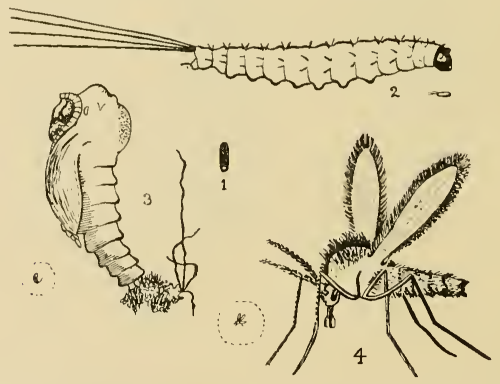

FIG. 222.-Phlcbotomus minutus. 1, Egg; 2, Larva; 3, Pupa; +, Fly. All the figures are considerably magnified, their natural sizes being indicated by the smaller figures inside the dotted lines. (After Howlett.)

Distribution.-Travancore; Coimbatore. Probably throughout the Plains of Southern India.

Lifehistory. - The eggs are laid singly or in small clusters in damp places. The very minute larvæ live in damp places (e.g., 
under heaps of bricks) and are covered with toothed spines and have long anal bristles. Total life-cycle about a month. The flies have been found at Coimbatore hiding during the day-time in the open galleries of Termites' nests and Gerbilles' burrows; possibly the larvæ also live in these galleries, feeding on decaying vegetable matter which falls in.

Status.--This is one of the commonest species of "Sand-fly," a persistent blood-sucker, and suspected to convey "Sand-fly Fever." It feeds naturally on the blood of geckos, chamæleons, toads, etc.

Control.-(I) Cleanliness around houses and avoidance of the creation of damp patches of earth in which the flies may breed.

(2) The flies are attracted to light at night and may be killed in numbers settled on the wall around a lamp.

(3) During the day-time the flies hide in dark corners, behind pictures, etc. Advantage may be taken of this habit to rout them out and kill them.

(4) Protection from bites by use of a deterrent.

CECIDOMYIADE.

CONTARINIA SP.

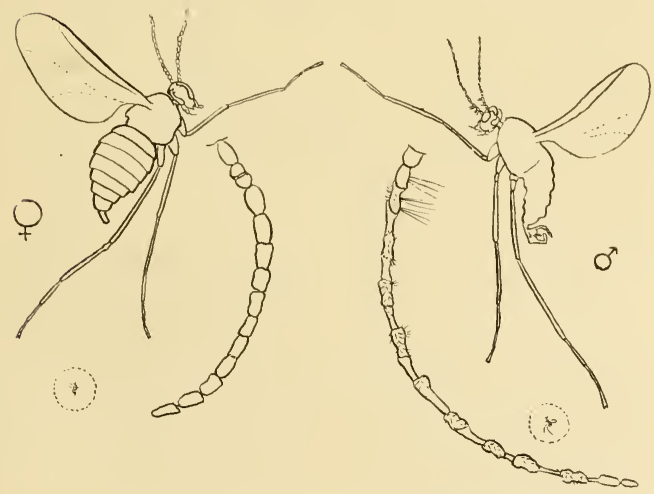

F1G. 223.-Contarinia sp. Male and Female Flies, enlarged, with their antennæ shown more highly magnified. The small figures inside the dotted circles indicate the natural sizes. (Original.)

Distribution.-Coimbatore. 
Lifehistory. - Not known in detail. Eggs are deposited in or on cotton-buds into which the larvæ bore, causing the buds to wither and fail to expand. Pupation in the withered bud.

Foodplants.-- Cotton.

Status.-A minor pest, probably more widely distributed than has yet been noted.

Control.-Collection and destruction of all withered buds is inclicated but is hardly practicable on a field scale.

Remarks.-This insect, in general appearance and habits, seems to resemble very closely $C$. gossypii, described from the West Indies. It is, however, apparently distinct.

\section{GINGELLY GALL-FLY.}
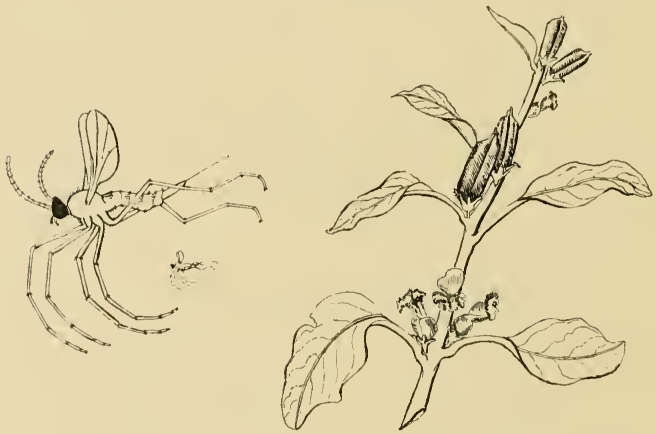

F1G. 22t.-Gingelly Gall-fly, natural size and magnified.

(Original.)

FiG. 225.-Gingelly Capsules damaged by Gall-fly. Those nearer the tip of the stem are normal. (Original.)

Distribution.-Coimbatore.

Lifehistory.-Eggs are laid in flowers or young capsules of gingelly (Sesamum indicum) the small white grubs feeding in the young capsules and stunting their growth so that they become wrinkled withered galls, as shown in the lower part of the figure. When full-grown the larva pupates in the gall.

Foodplants.-Gingelly.

Status.-A minor pest.

Control.-?

Observation.--This insect is almost certainly an undescribed novelty. 


\section{SIPHONAPTERA.}

\section{SARCOPSYLLIDÆ.}

ECHIDNOPHAGA GALLINACEUS, Westw.

Sarcopsyllis gallinacens, Westw., E.M.M., XI, 246 (I875).

Echidnophaga gallinacens, Jord. and Roths., in Thomp. Yates and Johnst. Lab. Rept., VII, p. 52, ff. I, I4, 2I, 27 (I906) ; Nov. Zool., XX, 528; Osborn, U.S.A. Ent. Bull. 5, pp. I44-I46, ff. 76,77 (Sarcopsylla).

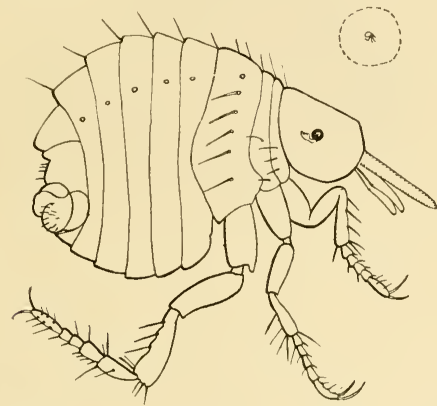

F1G. 226.-Echidnophaga gallinaceus. The small figure inside the dotted circle shows the natural size. (Original.)

Distribntion.-Hill and sub-montane districts of Southern India ; Coimbatore.

Lifehistory.-Not known in detail in Southern India. The eggs are probably dropped in dusty, dry places in which poultry are kept, the minute, wriggling, worm-like, hairless larvæ living in the dust on small particles of organic matter. Pupa in a slight cocoon composed of grains of sand. The adults attach themselves firmly, after the manner of ticks, to their hosts, usually on the bare portions around (and especially under) the beak in the case of young chickens. I have not found the adult females of this flea encysted or buried in the skin, as described by some writers.

Food.-The blood of fowls as a rule; occasionally on dogs, cattle and man, especially on young animals.

Statns.-May be a serious pest of young fowls, attacking also any other animals in the vicinity of the poultry run.

Control.-Brushing the affected parts with crude oil emulsion or sweet oil : the latter is better for fowls. Thorough washing out 
of the fowl-house and run with disinfectants, recollecting that damp localities are unsuitable for these fleas to breed in.

\section{PULICIDÆ.}

XENOPSYLLA CHEOPIS, Roth.

Pulex cheopis, Rothschild, E.M.M. (1903), 85-86, t. I, ff. 3, 9; Howlett, Ind. Ins. Life, p. 658, t. $7 \mathrm{I}$, f. a ; Reports on Plague in Inclia, I, pt. 1, pp. $240-250$, t. 10-12, pt. 2, pp. $486-509$.

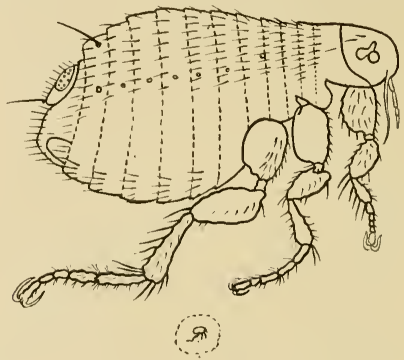

FIG. 227.-Xenopsylla cheopis, female. The small figure inside the dotted circle shows the natural size. (From Reports on Plague in India.)

Distribution.-Throughout Southern India.

Lifchistory.-The white, round eggs are about as large as a small pins-head and are laid on the ground as a rule. After about two days the larvæ hatch out and live amongst and on animal or vegetable refuse; the larva is an elongate, bristly, minute, white grub, rarely seen as it shuns the light. Pupation takes place in a small cocoon of silk covered with particles of dust, etc. Life-cycle, egg about 2 days, larva about 7 days, pupa about 7 diays.

Hosts. - Rats of all sorts as a rule, occasionally on cats and on man.

Status, - A most serious pest as being the carrier of Plague bacilli from rats to man.

Control.-(I) Destruction of rats.

(2) Cleanliness in houses.

(3) Exposure of infested clothing to bright sunshine on a broad flat surface.

CTENOCEPHALUS FELIS, Bouché.

Pulex felis, Bouché, Nova Acta Ac. Leop. Carol., XVII, 505 (1835); Rothschild, Nov. Zool., XII, I92 (1905) and Ent. Rec., XIII, I26, t. 3 [differences between felis and canis]. 
Pulex serraticeps (part), Gerv., Hist. Nat. Ins. Apt., III, 37I (I844); Osborn, U.S.A. Ent. Bull. No. 5, pp. I50 - I52, f. 83.

Pulex felis (part), Reports on Plague in India, I, 495-498.

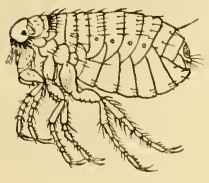

R :

FIG. 228. - Ctenocep. halus felis. The figure inside the dotted circle shows the natural size. (Original.)

Distribution.-Throughout Southern India.

Lifchistory.- Similar to that of $X$. cheopis.

Host.-Normally the cat, tiger, panther, etc. But, in spite of its name, this is the common flea of dogs in Madras, Ct. canis being found only on jackals as a rule. It sometimes attacks man and occasionally the horse.

Control.-As for $X$. cheopis. Dogs may be cleared of fleas by rubbing in crucle oil emulsion and washing it off after 24 hours.

Remarks.-(I) This flea is often confused with Ct. canis (the Dog Flea of Europe), but is distinct.

(2) It is impossible to give here any complete list even of the commoner fleas. The differences between them are minute and only to be seen by microscopical examination.

Pulcx irritans, the true human flea, seems to be rather scarce in India as a rule.

\section{LEPIDOPTERA.}

ARCTIADA.

ASURA CONFERTA, Wlk.

Pitane couferta, Wlk., Cat. II, 533 (I854).

Asura conferta, Hmpsn., Faun. Ind. Moths, II, 106, f. 72, Cat. Phal., II, 428, f. 340 ; Lefroy, Ind. Ins. Life, p. 437.

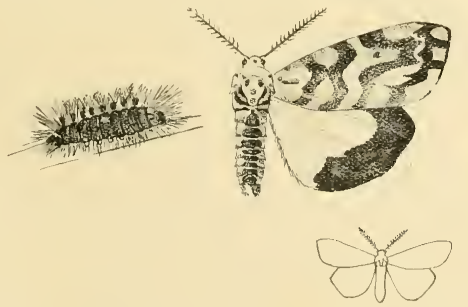

F1G. 229.-Asura conferta, moth and larva. The small outline figure shows the natural size of the moth. (Original.)

Distribution.--Throughout the sub-montane districts of Southern India. 
Lifehistory.-Larva short, stout in middle, brownish-black, thickly covered with tufts of black hair; orange marks on first, seventh and last segments from head and an orange line on back from seventh to last segments. Cocoon slight, with larval hairs interwoven.

Foodplants.-Moss and lichens and perhaps also low-growing plants.

Status.- The larva is not known to do damage to crops but is in itself a peculiarly noxious pest owing to the large numbers in which it often occurs in houses and the irritating nature of its hairs. It is one of the various insects known as "Kumbli-puchi."

Control.--?

ESTIGMENE LACTINEA, Cram.

Bombyx lactinea, Cramer, Pap. Exot., II, t. I33. D. (I777).

Amsacta lactinca, Hmpsn., Faun. Ind. Moths, II, 27-28, f. 9, Cat. Phal., III, 328-329, f. I 47 ; Lefroy, Ind. Ins. Life, p. 438, ff. 302, 303.
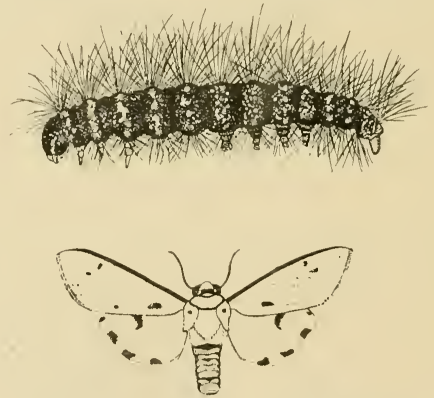

Fig. 230.-Estigmene lactinea, larva and moth. (Original.)

Distribution.- Throughout the Plains of Southern India.

Lifehistory.-Larva black with long blackish or red-brown hairs arising from warts set in a ring a round the middle of each segment, head blackish or red-brown; active in habit. Pupa squat, dark-redbrown, in a cell underground.

Foodplants.-Cumbu, ragi, coffee, horse-gram, and various lowgrowing plants.

Status.-Locally a serious pest of cumbu.

Control--Hand-picking of caterpillars in small areas and protection of crops by a narrow trench around cultivated areas. 

PLATE XVII

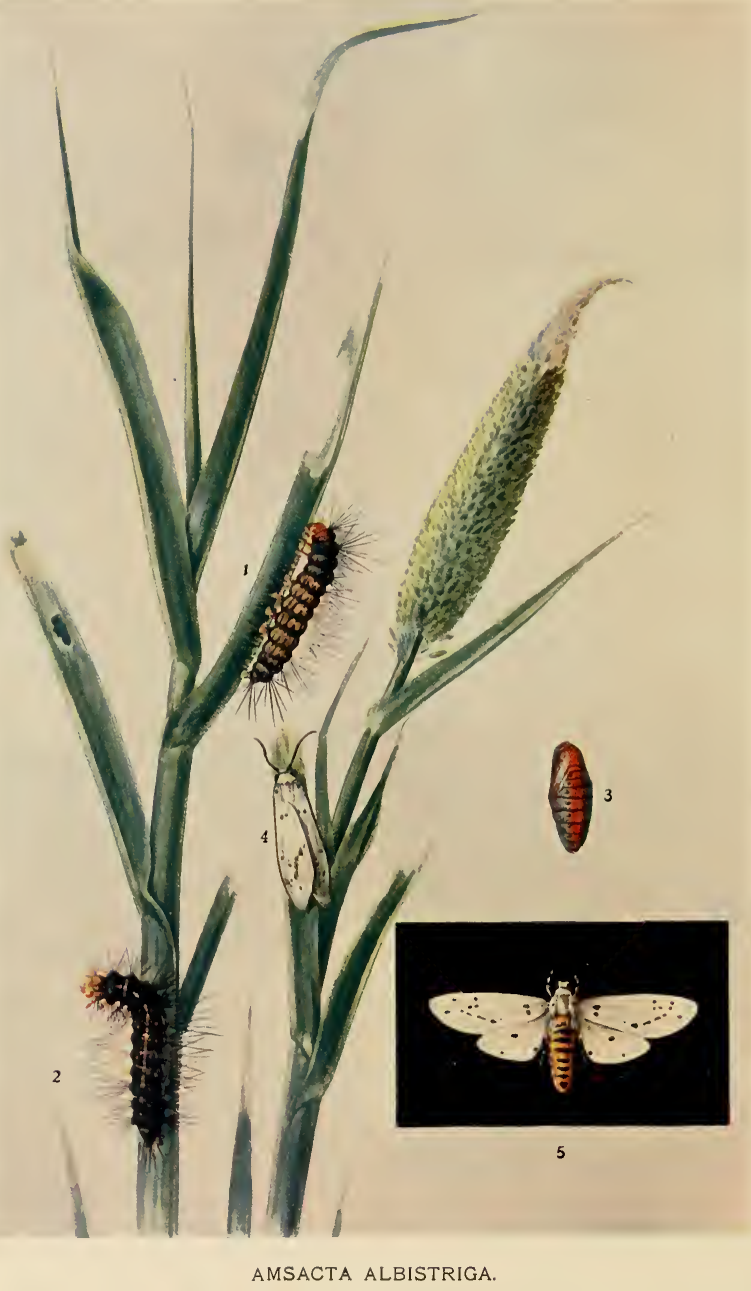




\section{EXPLANATION OF PLATE XVII.}

\section{AMSAC'TA ALBISTRIGA.}

Fig. I, 2. Larvæ.

"3. Pupa.

"4, 5. Moth.

(All these figures are life-size.) 

A.MSACTA ALBISTRIGA, Wlk.

(KUMBLIHULA.)

Aloa albistriga, Wlk., Cat. XXVI, 303 (1864).

Amsacta albistriga, Hampson, Faun. Ind. Moths, II, 28, Cat. Phal., III, $330-33$ I, t. 46, f. I9; Lefroy, Ind. Ins. Life, p. 438, ff. 299-300 ; Coleman, Mysore Ent. Bull. No. 3 (I9I 2).

(SeE Plate XVII.)

Distribution.- Probably throughout the Plains of Southern India, mostly in dry tracts of red soil (not noted from Malabar Coast or extreme North of Madras Presidency).

Lifchistory.-Larva blackish-brown covered with long blackish hairs, head reddish or orange, with a narrow orange stripe down the back, central third of bocly often orange-brown; very active in its movements. Pupa squat, red-brown, in the soil.

Foodplants.-Cholam, cumbu, groundnut, pulses, castor, etc.; on almost all low-growing plants and crops.

Status.-A very serious pest in some localities especially in South Arcot and Salem.

Control.-The moths emerge early in the evening after the early monsoon showers and are sluggish and conspicuous and easily collected by hand, thus preventing eggs being laid to give rise to caterpillars later on. It is difficult to check the caterpillars as they feed on various weeds and are not confined to crops. Narrow trenches may be dug around the cultivated fields and fresh leaves placed in them daily to trap the caterpillars which must be killed and removed regularly. Prevention (by catching the moths by hand or by light-traps) is the best remedy.

NOTE.-Amsacta moore $i$ is very similar in appearance and habits and hybids between the two species probably occur, as crosspairings are not infrequent.

CREATONOTUS GANGIS, Linn.

Phalana gangis, Linn., Amoen., Acad., VI, 4Io (I764) ; Hnipsn., Cat., Phal., III, 333-334 ; Lefroy, Ind. Ins. Life, p. 438.

Creatonotus interruptus, Hmpsn., Faun. Ind. Moths, II, $26-27$.

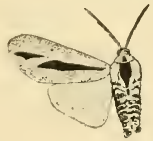

F1G, 231.-Creatonotus gangis. (Original.

Distribution.-Throughout Southern India. 
Bombyx ricini, Fab., Syst. Ent., p. 583 (I775).

Pericallia ricini, Hmpsn., Faun. Ind. Moths, II, I7-18, Cat. Phal., III, 350-35I, f. I55 ; Lefroy, Ind. Ins. Life, p. 438.

Distribution.-Throughout Southern India.

Lifchistory.- - Larva dark-brown or blackish, thickly covered with fine long reddish-brown hairs which arise from bluish warts, head redish or blackish; rather variable in colour; active in habits. Pupa squat, red-brown, enclosed in a rather flimsy white cocoon affixed to objects above ground-level.

Foodplants.-Castor, plantain, pumpkin, gingelly, cotton, agathi, Calotropis, Moringa, oleander, colocasia and various other plants and shrubs.

Status.-A serious pest of garden crops.

Control.-Hand-picking and spraying.

UTETHEISA PULCHELLA, Linn.

Tinea pulchella, Linn., Syst. Nat. (X), p. 534 (I758).

Utetheisa pulchella, Hnupsn., Faun. Ind. Moths, II, 55, Cat. Phal., III, 483-485 (partim), f. 217 ; Lefroy, Ind. Ins. Pests, p. I48, ff. I66-I68, Ind. Ins. Life, p. 438.

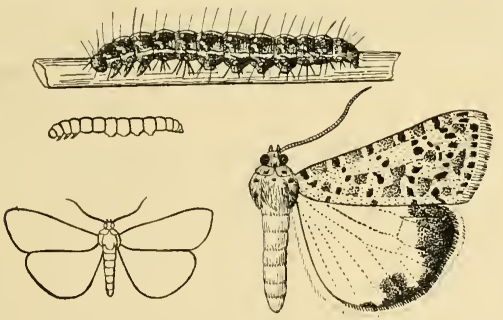

F1G. 233.-- Utetheisa pulchella, larva and moth. The smaller figures indicate the natural sizes. (Original.)

Distribution.-Throughout the Plains of Southern India.

Lifclistory.-Eggs laid singly or in small batches on leaves of the foodplant. Larva when full-grown about $20 \mathrm{~mm}$. long, rather stout, with an irregular pale creamy-yellow line down the back, bordered on either side by a blackish stripe, below which is a series of reddish-orange blotches margined beneath with paleyellow longitudinal spots. A few scattered blackish hairs, longer at either extremity of the larva, arise singly from small warts on the back and sides. Pupation in a rather flimsy cocoon, usually in 
folded leaves, sometimes on the surface of the ground. Life-cyc!e about four weeks.

Foodplants.--Sann-hemp, Heliotropinm and various low-growing weeds.

Status.-A serious pest of sann-hemp.

Control.-Hand-picking of larvæ and spraying in small areas.

Remarks. - The closely-allied $U$. pulchelloides will probably be found to occur all round the coasts of Southern India. The larva feeds on Tournefortia argentea and is not known to be a pest.

AGARISTIDÆ.

EGOCERA VENULIA, Cr.

Noctua vemulia, Cramer, Pap. Exot., II, t. I65 D (I777).

Egocera vemilia, Hmpsn., Faun. Ind. Moths., II, I58, Cat. Phal., III, 597. f. 26I ; Lefroy, Ind. Ins. Life, p. 440, t. 34 f. 5.
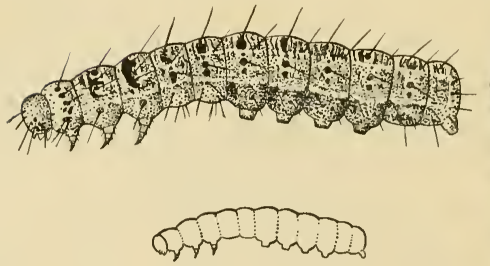

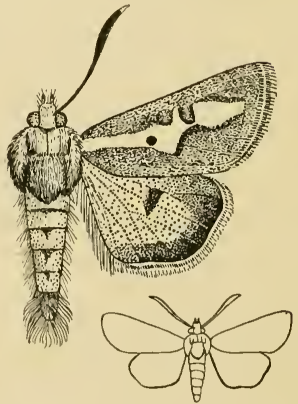

FiG. 234.-Agocera venulia, larva and moth. The smaller outline figures indicate the natural sizes. (Original.)

Distribution.-Throughout the Plains of Southern India.

Lifehistory.-The full-grown caterpillar is about $45 \mathrm{~mm}$. long, rather stout, especially posteriorly; the head is reddish-orange, heavily spotted with black; the body is smooth except for a few short scattered hairs arising from the warts, pale earthy-brown with numerous scattered short transverse black streaks, irregular both in shape and position but which tend to form black bars across the dorsal surface on the anterior half of each segment, on which the dorsal tubercles are broadly ringed with black; spiracles black, with a supraspiracular tubercle heavily ringed with black and a smaller and less conspicuous postspiracular wart; on 
the segments behind those bearing prolegs the warts are ringed with reddish-orange instead of black: legs orange-brown, prolegs pale-brownish. (Description from a preserved specimen kindly supplied by Dr. L. C. Coleman.)

Foodplants.-Trianthema, Barhavia.

Status. - Not a pest.

Remarks.--Fairly common at light. The moth is sometimes seen flying extremely swiftly backwards and forwards over the ground in the evening.

\section{NOCTUIDE.}

CHLORIDEA OBSOLETA, Fb.

Noctua obsoleta, Fab., Ent. Syst., III, i, p. 456 (I793).

Chloride a armigera, Hmpsn., Faun. Ind., Moths, II, I74-I75. f. II 4 , Cat. Phal., IV, 45-46, f. I8; Lefroy, Ind. Ins. Pests, pp. I $44-\mathrm{I} 47$, ff. I6I-I64, Incl. Ins. Life, p. 4I4, f. 305, t. 28, ff. 2, 3 [as obsoleta].

Heliothis obsoleta, Quaintance and Brues, U.S.A. Entom. Bull. No. 50 (1905).

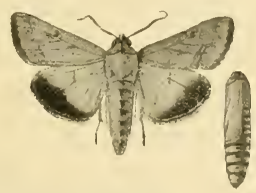

FIG. 235.-Chloridea obsoleta, moth and pupa. (From Indian Museum Notes.)

Distribution.-Throughout Southern India.

Lifchistory. - The eggs are laid singly on leaves or pods, according to the foodplant. The full-grown larva is about $35 \mathrm{~mm}$. long, rather slender, with scattered short hairs ; colour variable, usually pale apple-green with whitish longitudinal lines and with a darker shade along the side narrowly edged below with whitish; the whole body (except clarker side-stripe) sometimes tinged with pinkish, in which case the head may be yellowish instead of the usual green. Pupa brown, usually in a slight cocoon in the soil. When feeding on fruits or seed-pods, the caterpillar bites a hole through the outside and only thrusts its head inside, leaving the body exposed.

Foodplants.-Red-gram, Bengal-gram, groundnut, tomato, maize (cob), tobacco (seed capsules), ganja (Camnabis sativa) (leaves and capsules), linseed "(capsules), safflower (capsules), lab-lab (pods), and many other low-growing plants. 
Status.-An important pest, especially of gram.

Control.-Hand-picking is the only remedy that can be adopted as a rule. Usually spraying is usele'ss because the caterpillars feed chiefly on the seeds and do not therefore ingest sufficient of a poison-spray spread over the outside of the capsule.

Remarks.-(I) The larvæ are highly cannibalistic and will readily eat not only one another, but other caterpillars.

(2) A Pentatomid bug, Andrallus spinidens (see page 475) was found sucking the larva on linseed at Coimbatore in February 1907.

(3) As Meyrick points out [Trans. New Zealand Inst., XLIV, 90 (I9II)] the generic name Heliothis may legitimately be retained by those who prefer it, as the differences between Clloridea and Heliothis are so small as to be negligible in practice.

\section{CHLORIDEA ASSULTA, Guen.}

Hcliotlis assulta, Guénée, Noct., II, I78 (I852).

Chloridea assulta, Hmpsn., Ill. Het., IX, 92, t. I76, f. 22, B.J., XV, 602, Cat. Phal., IV, 47, t. 55, f. 22 ; Lefroy, Ind. Ins. Life, p. 4 I 4.
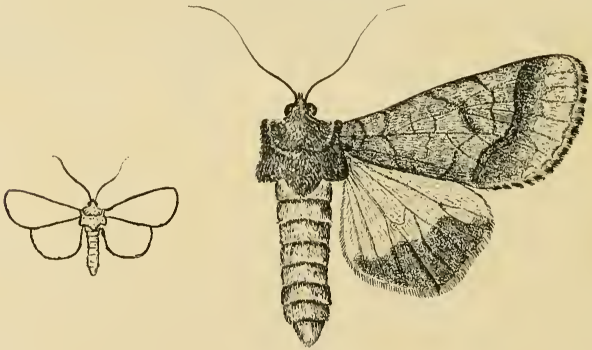

Fig 236.-Chloridca assulta. The small outline figure shows the natural size. (Original.)

Distribution.-Coimbatore. Probably throughout all tobaccogrowing tracts.

Lifchistory.-Not worked out in detail. Stages probably very similar to those of Chl. obsoleta. Larva figured by Hampson (III. Het.).

Foodplant.-Tobacco. Hampson gives Plysalis permviana.

Status.- Not yet noted as a pest in Southern India but it may do considerable damage to tobacco. 
EUXOA SEGETIS, Schiff.

Noctua scgetum, Schiff., Wien. Verz., pp. 8I, 252, ff. 3 a, b (I776). Euxoa segetis, Hmpsn., Faun. Ind. Moths, II, p. I8I, f. II7, Cat. Phal., IV, I67, f. 59; Lefroy, Ent. Mem. Agri. Dept., Ind., II, I67.

Distrilution. - Sub-montane and
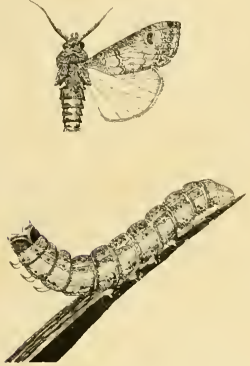

F1G. 237. - Euxoa segetis, male moth and larva. (Original.)
Hill Districts of Southern India.

Lifehistory.--The larva is pale greyish, sometimes with a pinkish tinge, with interrupted darker lines down the back and sides; the body is smooth and greasy-looking. It feeds at roots of various plants, apparently not coming above the surface, or only cutting off plants just above soil level.

Foodplants.-Potato, cabbage, coffee, and various plants of the kitchen and flower garden.

Status. - A serious pest in gardens in the Nilgiris and Shevaroys. It has also been recorded as doing serious damage by ringing young coffeeplants in Mysore.

Control.-?

POLYTELA GLORIOSE, Fb.

Bombyx gloriosa, Fab., Spec. Ins., II, p. 205 ( I78I).

Polytela gloriosa, Hmpsn., Faun. Ind. Noths, II, I68-I69, f. I08, Cat. Phal., V, 457, f. I30; Lefroy; Ind. Ins. Life, p. 445, t. 34, f. I 2.

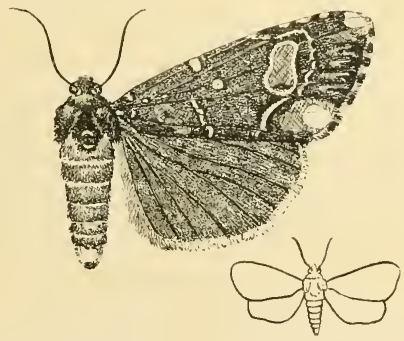

Fig. 238.-Polytcla gloriosce. The outline figure shows the natural size. (Original., 
Distribution.-- Throughout the Plains of Southern India.

Lifehistory.-Length of full-grown larva about $40 \mathrm{~mm}$.; colour purplish-brown with three longitudinal rows of white spots of which the central ones are the largest, and orange black-spotted sub-dorsal patches on the three anterior and posterior segments. The caterpillar is often seen exposed on the leaves in the early morning, retreating into the shelter of the leaf-sheaths later on.

Foodplants.-Gloriosa superba, Amaryllis, and many liliaceous plants.

Status.-Scarcely a pest but often does unsightly damage to ornamental lilies.

Control.-Easily hand-picked in the early morning.

\section{CIRPHIS UNIPUNCTA, Haw. (PLATE XVIII.)}

Noctua unipuncta, Haworth, Lep. Brit., p. I74 (I809).

Cirphis unipuncta, Hmpsn., Faun. Ind. Moths, II, 275-276, Cat. Phal., V, 547-549, B.J., XVII, 464; Lefroy, Ent. Mem. Dept. Agri., Ind., I, I75, Ind. Ins. Pests, p. I38, f. I56, Ind. Ins. Life, p. 446.

Distribution.- Throughout Southern India. In October and November.

Liffhistory.-The rounded, greenish-white eggs are laid in batches, usually in two parallel rows, and thrust into the shelter of a leaf-sheath, curled leaf, etc. The full-grown larva is about $35-40$ mum. long, noclerately stout, smooth, dull-greenish or purplish with a broad longitudinal paler stripe along the side and a narrower lighter stripe below the spiracles; head pale yellow-brown, ventral surface and legs pale-greenish, prolegs with a plate above each sucker-foot. Pupa pale-brown, in an oval cocoon of earth in the soil.

Foodplants.-Cholam, as a rule. Sometimes on rice, maize, ctc.

Status.-A minor pest of cholam, the larvæ burrowing into the central shoots.

Control.

Remarks.-This is the insect usually called the "Army worm" because the caterpillars appear sometimes in immense swarms which invade cultivated ground and devour the crops wholesale. In such cases cultivated tracts may be protected by narrow but steep-sicled trenches.

\section{PERIGEA CAPENSIS, Gn.}

Apamea capensis, Guenee, Noct., I, 213 (1852).

Eupleria conducta, Hmpsn., Faun. Ind. Moths, II, 2 I I ; Lef roy, Ind. Ins. Life, p. 447. 



\section{EXPLANATION OF PLATE XVIII. CIRPHIS UNIPUNCTA.}

F1G. I. Eggs laid in leaf-sheath.

,2. ", inside fold of curled leaf.

"3. Young larvæ feeding on maize-plant.

$" 4$ 4. Full-grown larve, showing colour variation.

"6. Pupa.

, 7. Moth in resting attitude.

(The lines alongside the figure show the natural sizes.) 


$$
\sqrt{x}
$$






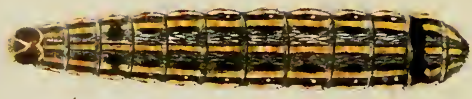

6
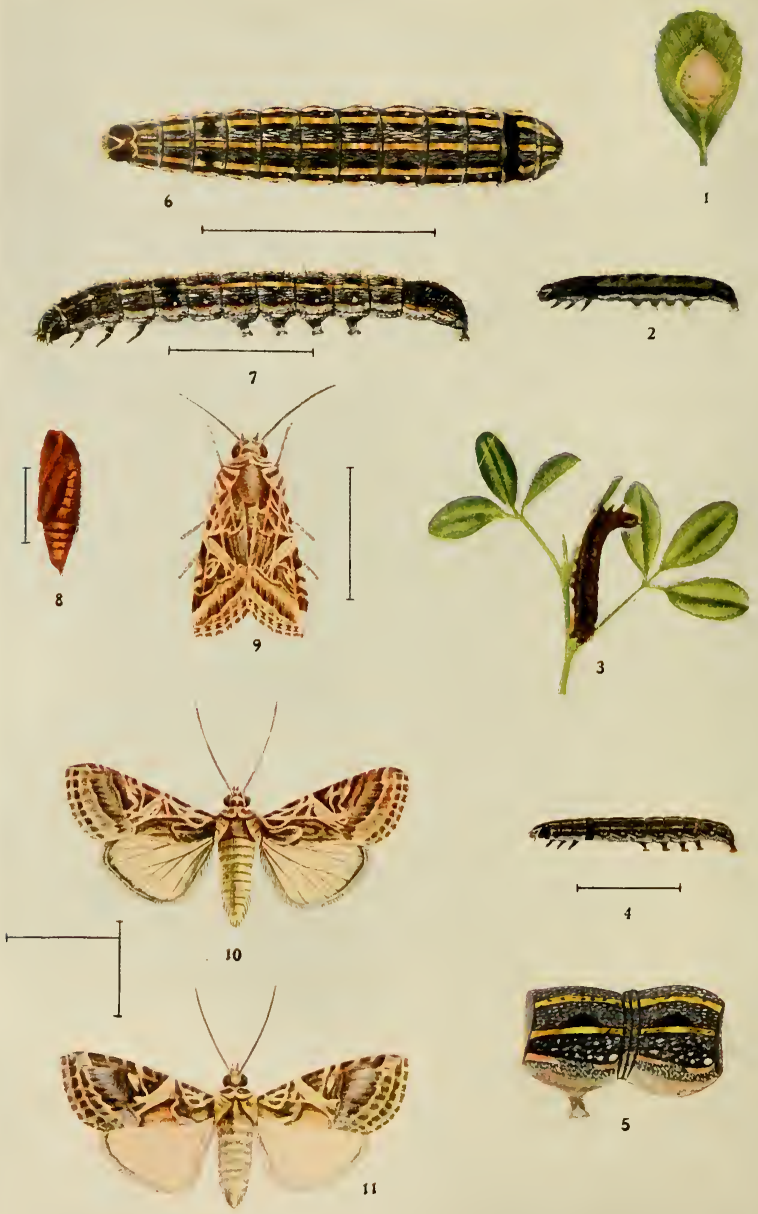


\section{EXPLANATION OF PLATE XIX.}

\section{PROIDENIA LITURA.}

Fis. I. Egg-cluster on leaf.

" $2,3,4,6,7$. Larvæ in different stages of growth.

"5. Details of segments of full-grown larva.

" 8 . Pupa.

,9, 10, 1 r. Moths.

(The lines alongside the figures show the natural sızes.। 

Perigea capcnsis, Hmpsn., Cat. Phal., VII, 332 334, t, II6, f. 20.

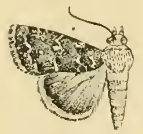

F1G. 239.-Perigea capensis. (Original.)

Distribution.-- Throughout Southern India.

Lifehistory.-Larva smooth, with a conical elevation on last segment, pale-green, with series of white-dotted purple-brown blotches along the back and sides and a row of white dots along the sides lower down.

Foodplants.-Safflower. Probably very various; Acanthads (Hampson), Niger-seed (Khorasani), Jute, Corcopsis, Kakaronda (Blumea balsamifora) (Lefroy).

Status. - A destructive pest of safflower.

Control.--Spraying with Lead Arsenate has been found effective in small experimental plots.

Prodenia litura, Fb. (Plate XiX.)

Noctua litura, Fab., Syst. Ent., p. 60I (I775).

Prodenia littoralis, Boisd. ; Hmpsn., Faun. Ind. Moths, II, 247-248, f. I39; Lefroy, Ind. Ins. Pests, p. I56, ff. I 76-177, Ent. Mem. Agri. Dept., Ind., I, I7I, II, 79- 93, t. 8, Ind. Ins. Life, p. 447.

Prodenia litura, Hmpsn., Cat. Phal., V1II, 245-247.

Distribution.-Throughout Southern India.

Lifehistory.-Eggs laid in clusters on leaves and covered with buff-coloured hairs derived from the body of the female moth. The eggs hatch after three or four days into small blackish-green larvæe which live gregariously for a short time before dispersing. After about 20 days the larva is full fed and is then about $40 \mathrm{~mm}$. long, stout, smooth, except for a few scattered short hairs, dull darkgreyish (almost blackish-green) with a bright yellow stripe down the back and along each side and a rather duller yellow stripe along the lower edge of the body, each yellow side-stripe being bordered above by a black lunule; head and legs dark, the former with a pale $\wedge$-mark. Pupation in an earthern cell about two inches below the soil; pupa red-brown. The moth emerges after about six days. The whole life-cycle occupies about a month.

Foodplants. - Polyphagous. It has been found to attack the following in Madras:-Castor, tobacco, maize, tomato, Colocasia, agathi, jute, indigo, lucerne, brinjal, cabbages, elephant yam, peas, plantain (leaves; Godavari) and grass. It will probably eat almost any low-growing plant. 
Status.-A serious pest of tobacco, castor and agathi. Well known in Tamil districts as Arakkan.

Control.-(I) Hand-picking of egg-masses and batches of young larvæ before these have dispersed.

(2) Surrounding of valuable crops by narrow steep-sided ditches to keep out and trap the caterpillars.

\section{SPODOPTERA MAURITIA, Boisd. (Plate XX.)}

Hadena mauritia, Boisd., Faun. Mad. Maur., p. 92, t. I3, f. 9 (I833).

Spodoptera mauritia, Hmpsn., Faun. Ind. Moths, II, 249, f. I40, Cat. Phal., VIII, 256-258, f. 66; Lefroy, Ind. Ins. Pests, pp. I22, I89, Ent. Mem. Dept. Agri., Ind., I, I72, Ind. Ins. Life, p. 448.

Distribution.-Throughout Southern India.

Lifchistory. - The eggs are deposited, usually on the under surface of blades of grass or paddy, in batches covered by the buff-coloured hairs derived from the body of the female moth. The full-grown caterpillar is $35-40 \mathrm{~mm}$. long, cylindrical, paler or darker green above, greenish-yellow beneath with a reddish stripe along the sides at the junction of the two hues; along the side there is also sometimes a broad pale stripe edged above by black lunules on each segment: when touched, the caterpillar curls up until the head and tail are nearly touching in a characteristic manner. The caterpillar feeds at night, hiding by day under clods, etc. When full fed it pupates in the soil, turning into a brownish pupa, from which the moth emerges after about Io days.

Foodplants.-Grasses of various sorts.

Status.-A pest of paddy and grasslands, sometimes doing considerable damage to seedling rice-plants.

Control.- (I) Protection of seed-beds by surrounding them with narrow steep-sided trenches.

(2) In small areas spraying and collection of egg-masses as far as possible.

(3) Trapping of larvæ by laying down sods, planks, etc., might be tried.

(4) Flooding of seed-beds and turning in ducks to eat the caterpillars. This method is practised successfully in some districts.

LAPHYGMA EXIGUA, Hb.

Noctua exigua, Hübner, Ent. Schmett. Noct., f. 362 (I808).

Caradrina exigua, Hnpsn., Faun. Ind. Moths, II, 259-260 ; Lefroy, Ind. Ins. Pests, p. I87, ff. 2I 4, 215, Ent. Mem. Dept. Agri., Ind., I, I73, fig., Ind., Ins. Life, p. 448.

Laphygma exigua, Hmpsn., Cat. Phal., VIII, 265, f. 68. 



\section{EXPLANATION ()F PLATE XX. SPOIOPTERA MAURITIA.}

Fis, I. Egg-mass as laid on paddy-leaf.

„2. A single egg, magnified.

"3. Young larva in characteristic attitude.

$, 4,5,6,7,8$. Larvæ in various stages of growth.

, 9. Pupa.

"IO, II, I2. Mloths.

(The lines alongside the figures show the natural si<es.) 


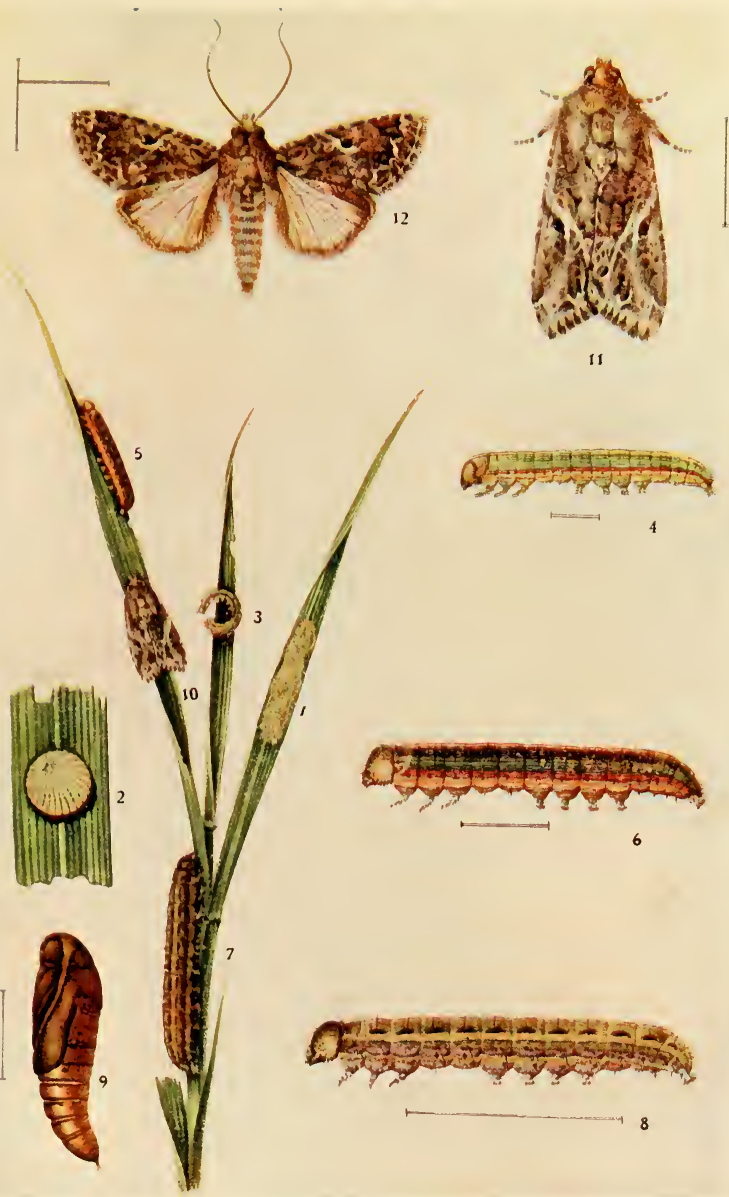

SPODPTERA MAURITIA. 




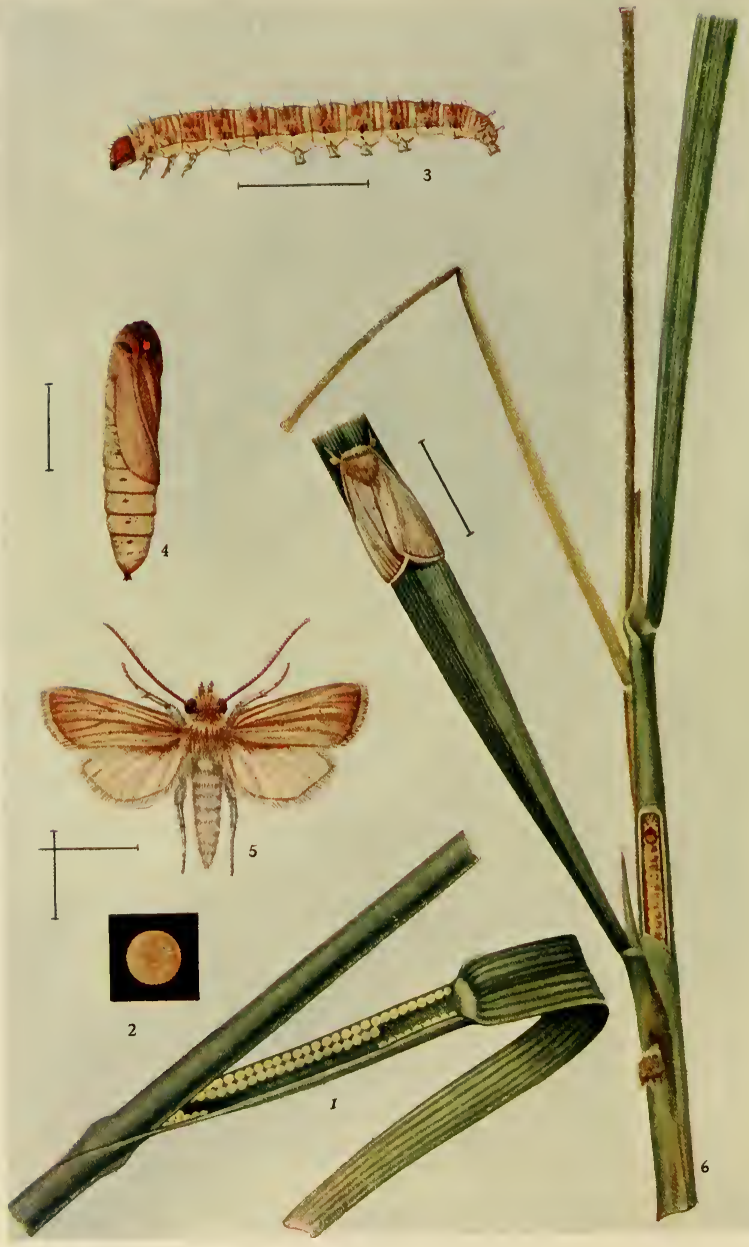

SESAMIA INFERENS. 


\section{EXPLANATION OF PLATE XXI.}

\section{SESAMIA INFERENS.}

Fig. 1. Eggs laid inside leaf-sheath.

, 2. A single egg, magnified.

" 3. Larva, magnified.

,. 4. Pupa, magnified.

"5. Moth, magnified.

"6. An affected plant showing dead-heart caused by the larva inside - the stem, which has been cut open, and a moth in resting attitude.

(The lines alongside the figures show the natural sizes.) 


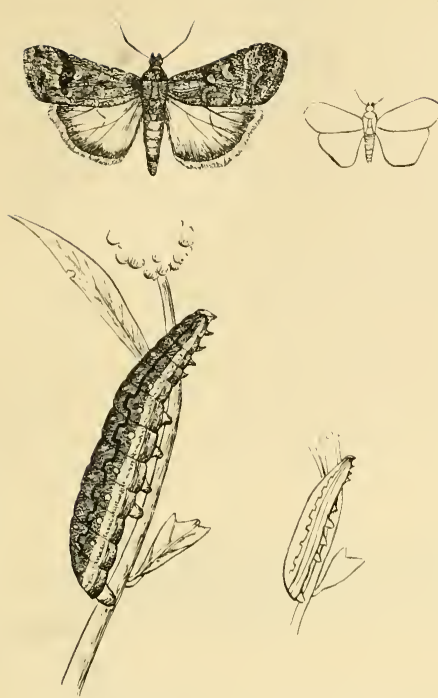

FIG. 240.-Laphygma exigua, moth and larva.

The smaller outline figures show the natural sizes. (Larva after Spuler.)

Distribution.Throughout Southern India.

Lifehistory.-Eggs are laid in batches. Larva very variable in colour, greenish or pinkishbrown,with a narrow darker line down the back and a broader spiracular line which may be yellowish edged with darker above or wholly darker. Pupation in soil. L if eh is t ory very rapid, the whole life-cycle being passed in as short a space as three weeks, so that in suitable circumstances the increase is very rapid and the caterpillars are found in swarms.

Foodplants. - Lucerne, indigo, onions, chillies, gingelly,

cowpea, brinjal, radish, Amaranthus. Polyphagous; probably on almost any low-growing plant. Said to be destructive to cotton in Egypt but not as yet found on cotton in India.

Status.-Occasionally a bad pest particularly of lucerne and indigo, where these are grown, but usually not a serious pest in Southern India.

\section{SESAMIA INFERENS, WIk. (PLATE, XXI.)}

Lincania inferens, Wlk., Cat. IX, I05 (I856); Hmpsn., Faun. Ind. Moths, II, 284, fig. I53.

Sesamia inferens, Hmpsn., Cat. Phal., IX, 327-328, f. I44.

Nonagria uniformis (Nec Ddgn.), I.M.N., V, I78; Lefroy, Ent. Mem. Agri. Dept., Ind., I, I76, f. 5I (part).

Distribution.--Throughout Southern India. 
Lifchistory.-Eggs are laid in clusters usually consisting of several rows of eggs laid within the cover of a leaf-sheath; the egg is rounded, pale yellow-green. The larva on hatching bores into the stem and is a borer all its life; its length when full grown is $2025 \mathrm{~mm}$., its shape cylindrical, rather slender, its general colour usually greyish white, tinged more or less with red or pink, head red-brown. It pupates in the stem itself, the pupa being about $15 \mathrm{~mm}$. long, moderately stout, brownish-yellow. The moth emerges after about ro days.

Foodplants.--Maize, cholam, ragi, paddy, wheat, sugarcane.

Status.-A bad pest of ragi in Madras.

Control. - The plants attacked usually reveal the presence of the borer by development of "deadhearts" and destruction of these is indicated to prevent extension of the attack.

EUBLEMMA OLIVACEA, Wlk.

Acontia olivacea, W1k., Cat. XII, 795 (I857).

Eublcmma olivacea, Hmpsn., Faun. Ind. Moths, II, 342, Cat. Phal., X, II6; Lefroy, Ind. Ins. Pests, p. I66, Ent. Mem. Agri. Dept., Ind., I, I80, Ind. Ins. Life, p. 457.

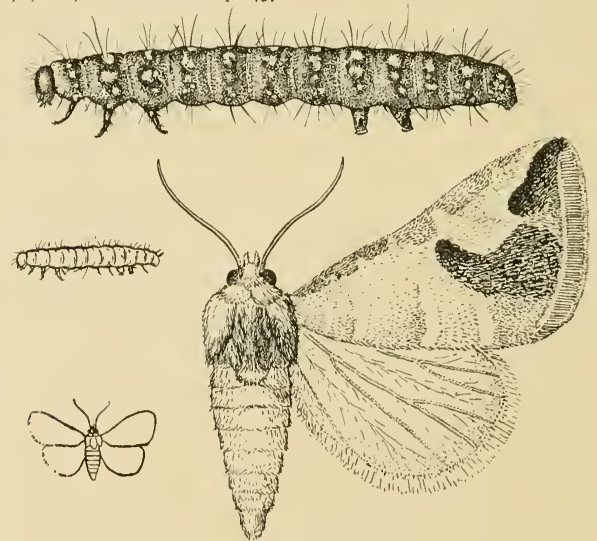

F1G. 241.-Eublemma olivacea, larva and moth. The smaller outline figures show the natural sizes. (Original.)

Distribution.--Throughout Southern India.

Lifchistory.--The full-grown larva is about $20 \mathrm{~mm}$. long, moderately stout, with scattered fine hairs arising from yellow tubercles 
which show up conspicuously against the brown or purplish-brown ground-colour; head reddish-brown. The brown pupa is usually found in a folded leaf, occasionally in the ground. The caterpillar lives within a folded leaf which is usually rolled from the tip upwards, and the caterpillar feeds on the leaf-substance of the roll in which it is contained.

Foodplants.--Brinjal and wild Solanacea.

Status.-A minor pest as a rule but occasionally a very destructive pest of brinjal.

Control.- Hand-picking and spraying.

Romarks. - In Northern India the caterpillar is reported to bore into brinjals but this has not been noticed in the South.

EUBLEMMA SCITULA, Rnbr.

Erastria scitula, Rambur, Ann. S.E. Fr. (I833), 26, 5, t. ii, f. I6.

Eublemma scitula, Hmpsn., Cat. Phal, X, 153.

Eublemma cretacea, Hmpsn., Ill. Het., IX, 96, t. I62, f. I7, Faun. Ind. Moths, II, $34 \mathrm{I}$; Lefroy, Ind. Ins. Life, p. 457. t. 36, f. 9.
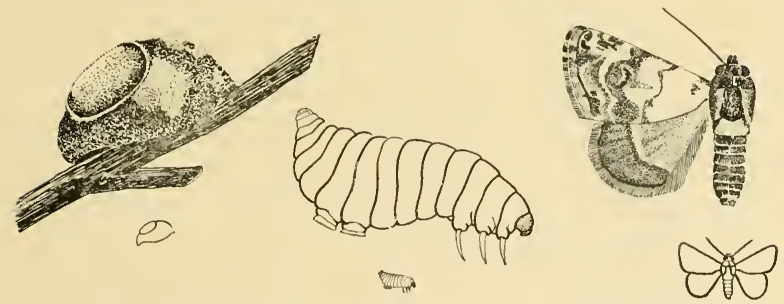

FIG. 242.-Eublemma scitula, larval case, larva extracted from case, and moth. The smaller outline figures show the natural sizes. (Original.)

Distribution.- Throughout Southern India.

Lifchistory.-Eggs are laid on trees infested by Scale-insects on which the caterpillars feed. The larva is short and dumpy and concealed in a case which looks not unlike a large Scale-insect itself; at times thousands of these cases may be seen grouped together on the stems of Babul trees.

Food.-Scale-insects of various sorts.

Status.-An extremely beneficial insect except when it attacks the Lac-insect which, however, is not cultivated to any extent in Madras.

TARACHE NITIDULA, Fb.

Noctua nitidnla, Fab., Mant. Ins., II, I 26 ( 1787 ). 
Tarache catena, Sowerby ; Hmpsn., Faun. Ind. Moths, II, 3I2 ; Lefroy, Ind. Ins. Life, p. 455.

Tarache nitidula, Hmpsn., Cat. Phal., X, 768, t. I72, f. 32.

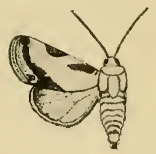

FIG. 243.-Tarache nitidula. (Original.)

Distribution.-Throughout the Plains of Southern India.

Lifchistory. - Not known.

Foodplant.--Cotton and Calotropis.

Status.-A very minor pest of cotton.

TARACHE OPALINOIDES, Gn.

Acontia opalinoides, Gn., Noct., II, 219 (1852).

Tarache opalinoides, Hmpsn., Faun. Ind. Moths, II, 3 I I, Cat. Phal.,

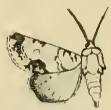

Fig. 24t.-Tarache opali. noides. (Original.)
$\mathrm{X}, 775$, t. I73, f. I3 ; Lefroy, Ind. Ins. Life, pp. $455^{-456}$.

Distribution.-Bellary, Coimbatore.

Lifehistory.--Not known.

Foodplants.-Cotton. Probably many other Malvacea.

Status. - Not known to be a pest.

BOMBOTELIA JOCOSATRIX, Gn.

Penicillaria jocosatrix, Guen, Noct., II, 304.

Eutelia jocosatrix, Hmpsn., Faun. Ind. Moths, II, 393.

Bombotelia jocosatrix, Hmpsn., Cat. Phal., XI, II-I2, f. 6.
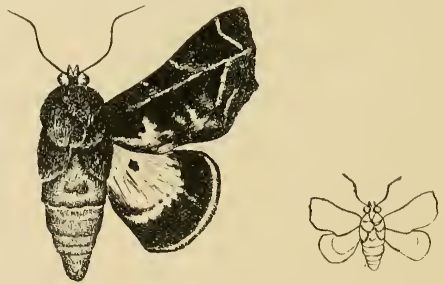

Fig. 245.-Bombotelia jocosatrix. The outline figure shows the natural size. (Original.)

Distribution.-Throughout Southern India. 
Lifchistory.-Caterpillar green, with sub-lateral dark striæ; the segments with small purple spots and a sub-dorsal series of larger spots; a few hairs from the tubercles.

Foodplant.-Mango; Terminalia belerica.

Stutus.-Once noted as a minor pest of mango at Koilpatti, where the caterpillars were eating the young leaves of mango.

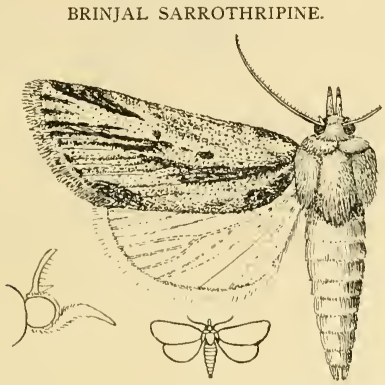

FIG. 246.-Brinjal Sarrothripine. The outline figure shows the natural size.

To the left is a profile view of the head. (Original.)

Distribution.-Bellary, Coimbatore, Malabar.

Lifehistory.-The yellowish hairy caterpillar lives exposed on the leaves which it may reduce to mere skeletons.

Foodplants.-Brinjal (Solanum melongena), Solanum xanthocarpum (a wild Solanaceous plant).

Status.-A minor pest of brinjal.

Remarks. -It is doubtful what the correct name of this moth may be. Possibly it is Cryptothripa occulta, Swinh. (P.Z.S., I885, 46I, t. 27, f. II ; Hmpsn., Faun. Ind. Noths, II, 38I, Cat. Phal., XI, 309, f. I08) with which the moth seems to agree structurally. Its coloration seems variable, unless several species are confused together.

\section{ELIGMA NARCISSUS, Cram.}

Bombyx narcissus, Cramer, Pap. Exot., I, 73 E.F. (1775).

Eligma narcissus, Hmpsn., Faun. Ind. Moths, II, 43, Cat. Phal., Xl, 330-33I, f. I20.

Distribution.-Throughout Southern India. September to February.

Lifchistory.-Young larva pale-greenish or yellowish with large irregular black warts from which arise long slender pale hairs. 
Full-grown larva $40^{--}-50 \mathrm{~mm}$. long, with transverse reddish bands across the back only reaching half way down the sides, these bands being almost completely overlaid by broad transverse black bars

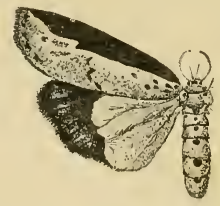

FIG. 247.-Eligma narcissus. (Original.)

which include large raised smooth black warts from which are emitted single long slender hairs about $15 \mathrm{~mm}$. long; head yellowish with a small black triangular mark above the mouth and large black eye-like spots. Pupa moderately slender, red-brown, spiracles more or less surrounded with blackish, in a long narrow boat shaped cocoon formed on the trunk of the tree on which the larva has fed; the cocoon harmonizes wonderfully well with the colour of its environment. Frequently numbers of larvæ pupate alongside one another.

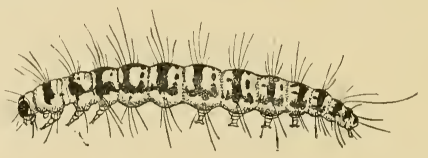

Fig. 248.-Eligma narcissus, larva. (Original.)

Foodplants.-Ailanthus cxcelsa.

Status.-May at times defoliate Ailanthus when grown as an ornamental shrub.

Control.--Spraying with Lead Arsenate, hand-picking of larvæ.

\section{EARIAS INSULANA, Boisd.}

Tortrix insulana, Boisd, Faun. Mad. Maur., p. I2I, t. I6, f. 9 (I833).

Earias insulana, Hmpsn., Faun. Ind. Moths, II, I33, f. 88, Cat. Phal., XI, 502-503; Lefroy, Ind. Ins. Pests pp. 89-93, Ent. Mem. Agri. Dept., Ind., I, I84, Ind. Ins. Life, p. 456, t. 38, ff. I-6.

[SeE Plate XXII.]

Distribution.-Throughout the Plains of Southern India all the year round. 



\section{ENPLANATION OF PLATE XXII.}

\section{EARIAS INSULANA, ETC.}

FIG. 1. Earias insulana, larva.

, 2. Cotton-boll attacked by larva.

, 3. Top-shoot of cotton-plant tunnelled by larva, showing characteristic drooping and wilted appearance.

., +. Earias insulana, moth in resting attitude.

.. 5. . " larra, dorsal view.

"6. . " moth, yellow variety.

,7. Earias iupreoviridis (chromataria), moth.

, 8. Earias fabia, moth.

(The lives alongside the figures show the natural sizes.) 


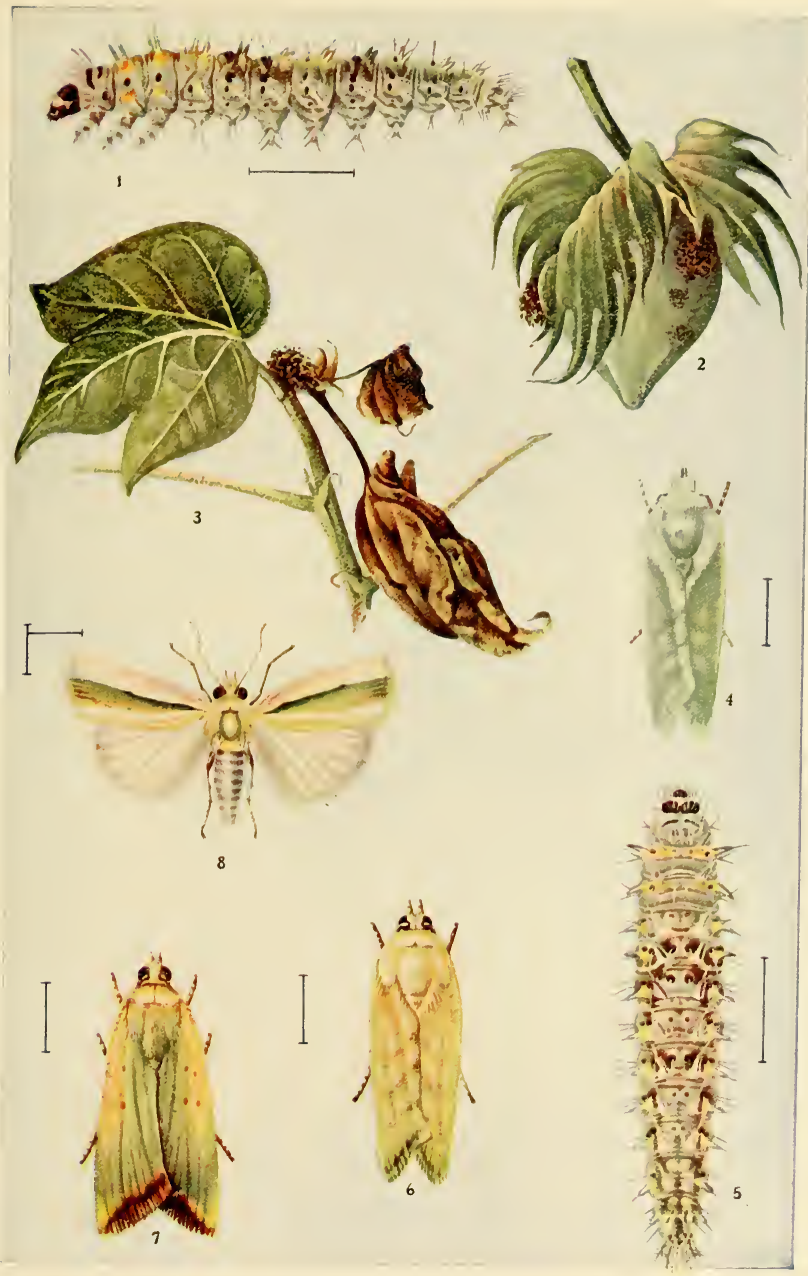



PLATE XXIII.

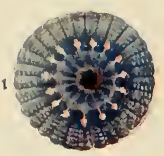

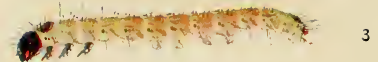

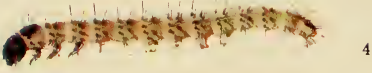

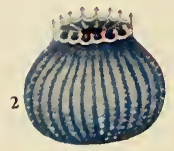

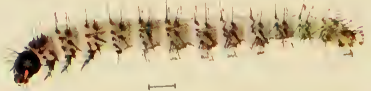
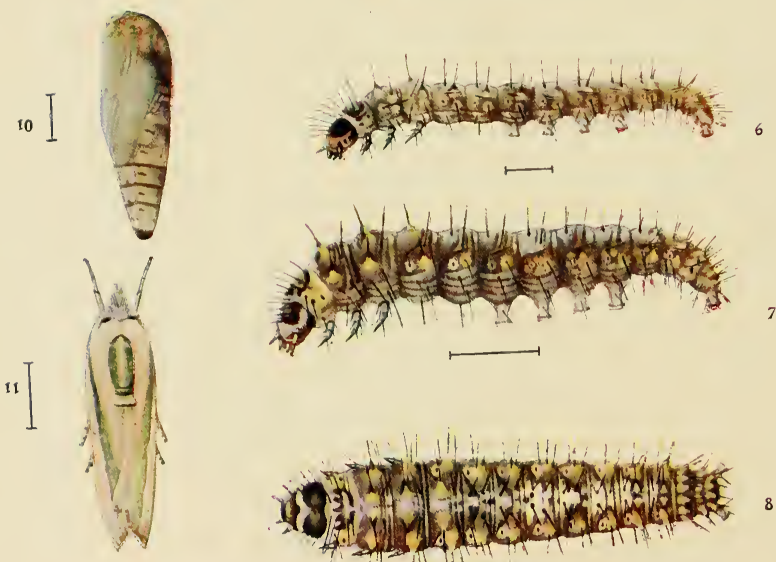

12
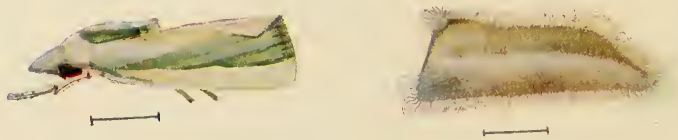


\title{
EXPLANATION OF PLATE XXIII.
}

\author{
EARIAS FABIA.
}

F1G, x. Egg, apical view, greatly magnified.

" 2. Egg, lateral view , ,

, 3-7. Larvæ in different stadia, magnified.

" 8 . Full-grown larva, dorsal view, magnified.

„9. Cocoon, magnified.

" ı. Pupa, magnified.

"x. Moth in resting attitude, dorsal view.

" r2. " , " , lateral view.

(The lines alongside the figures show the natural sizes.) 
Lifehistory. - The eggs are laid singly on shoots, flowers or young bolls. Larva bores in the shoots before bolls are formed but after that is found only in the bolls in which it bores. Larva palegreenish with short spinelike hairs, and dotted with black and with a row of short yellowish spines along either side of the back. Pupa in a tough cocoon of silk spun either on the foodplant or in the soil.

Foodplants.--Cotton, bhindi (Hibiscus esculentus) and other Malvacea.

Status.--A destructive pest of cotton.

Control.-(I) Hand-picking of first-attacked shoots which are easily seen and, later on, picking and destruction of all attacked bolls.

(2) Removal of all cotton-bushes from the field after the crop is picked so that no harbourage may be left for this insect to live over until the next season.

(3) Bhindi and other similar plants should not be grown in the neighbourhood of cotton-fields, at least when cotton is not in the ground.

EARIAS FABIA, Stoll.

Noctua fabia, Stoll, Pap. Exot., IV, t. 355 H (I782).

Earias fabia, Hmpsn., Faun. Ind. Moths, I, I33, Cat. Phal., XI, 507; Lefroy, Ind. Ins. Pests, pp. 89-93, figs. 98-103, Ent. Mem. Dept. Agri., Ind., I, p. I83, figs. 52, 53, Ind. Ins. Life, p. 456, t. 38, f. 8.

(SEE Plate XXIII.)

Distribution.-Throughout the Plains of Southern India all the year round.

Lifehistory.--Quite similar to that of E. insulana. The larvæ are practically identical, those of the present species often a little darker in colour.

Foodplants.-Cotton, bhindi (Hibiscus esculentus), hollyhock and various other malvaceous plants.

Status.-A destructive pest of cotton. It seems rather more common in Southern India than E. insulana.

Control.-Similar to that of E. insulana.

ACONTIA GRAELLSI, Feist.

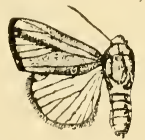

Fig. 249.-Acontia graellsi. (Original.)

Acontia graellsi, Feisthamel, Ann. S.E.Fr., VI, 300, t. I2, f. 3 (1837); Hmpsn., Faun. Ind. Moths, II, 324, Cat. Phal., XI, 660, f. 272.

Distribution.-Throughout the Plains of Southern India. 
Lifchistory.-The larva is about $45 \mathrm{~mm}$. long when full-grown, rather slender, with only two pairs of prolegs, green in colour; along the back on each segment is a pair of black horse-shoe shaped marks, their convex sides directed outwards, and there are also a few scattered black warts from which arise single short hairs. The caterpillar is generally seen on the plants in the early morning or evening, hiding itself during the rest of the day under leaves or on the ground close to the plants. When touched, it wriggles and jumps with great activity. Pupation is effected in a cocoon formed on the surface of the ground of earth and dry leaves.

Foodplants. - Cotton, hollyhock, probably also gogu, bhindi and other malvaceous plants. Lavatera (Hampson).

Status:-A very minor pest of cotton, occasionally doing slight injury by eating the tender leaves and young shoots.

ACHAA MELICERTA, Dr.

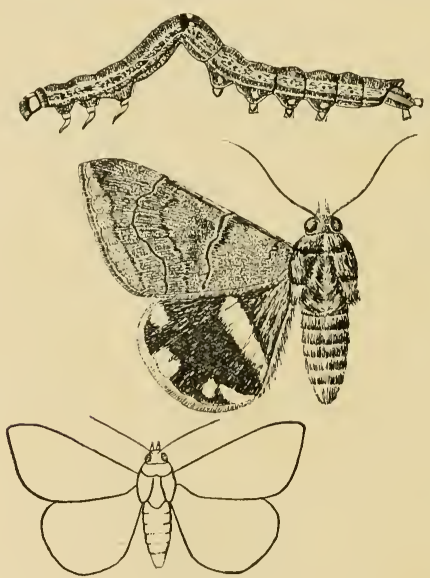

Fig. 250.-Achaa melicerta, larva and moth. The outline figure shows the natural size of the moth. (Original.)

Noctua melicerta, Drury, Ill. Exot. Ins., I, 42, t. 23, f. I (I770).

Opliiusa melicerte, Hmpsn., Faun. Ind. Moths, II, 494-495; Lefroy, Ind. Ins. Pests, p. 158, ff. I78, I79, Ent. Mem. Dept. Agri., Ind., I, I85, f. 54 , II, pp. $59-77$, t. 6, 7 , Ind. Ins. Life, pp. $451-452$. 
Achea melicerta, Hmpsn., Cat. Phal., XII, 536-537, f. I24.

Distribution.---Throughout Southern India all the year round.

Lifchistory.-Eggs are usually laid singly, scattered over the lower surface of the leaves of the foodplants, the larva emerging after two or three days, and making its first meal off part of the empty eggshell. The full-grown caterpillar is about $50-60 \mathrm{~mm}$. long, slender, a semi-looper with the first pair of prolegs aborted, in colour very variable but usually grey or blackish with reddish or whitish side-stripes. The pupa is brown but the colour is concealed under a delicate greyish bloom; pupation usually takes place in the soil, occasionally in a slight cocoon spun between leaves. The whole life-cycle occupies between 3 and 4 weeks.

Foodplants.-Castor, pomegranate, Euphorbia pilulifcra.

Status.-A sporadic but serious pest of castor, the leaves of which may be entirely stripped.

Control.-Hand-picking of larvæ and construction of open spaces around and across castor-fields ; birds attack the larvæ freely when they attempt to cross such open ground. Spraying is impracticable when the castor leaves are grown to feed silkworms. Parasites keep this caterpillar in check as a rule.

GRAMMODES STOLIDA, Fab.

Noctua stolida, Fab., Syst. Ent., p. 599.

Grammodes stolida, Hmpsn., Faun. Ind. Moths, II, 532, Cat. Phal.' XIII, 2I-23.

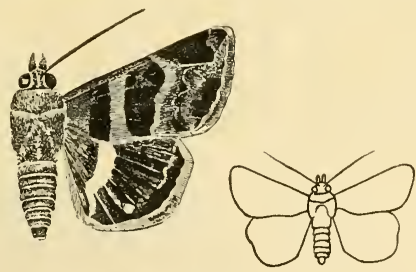

F1G. 251.-Grammodes stolida. The outline figure shows the natural size. ()riginal.)

Distribution,--Coimbatore.

Lifchistory.-Full-grown larva about $25 \mathrm{~mm}$. long, slender, smooth, first pair of prolegs absent ; in colour velvety-black with a row of red spots (one on each segment) along the side, and below these spots an orange-yellow stripe bordered below by dark-grey. Pupation in an oval silken cocoon on the foodplant. 
Foodplant.-Linseed.

Status.-An occasional minor pest of linseed.

\section{REMIGIA UNDATA, Fb.}

Noctua undata, Fab., Syst. Ent., p. 600 (I775).

Noctua archesia, Cramer, Pap. Exot., III, t. 273 F.G. (I780).

Remigia archesia, Hmpsn., Faun. Ind. Moths, II, 526, f. 293 ; Lefroy, Ent. Mem. Dept. Agri., Ind., I, I86, f. 55, Ind. Ins. Life, p. 450, f. 309.

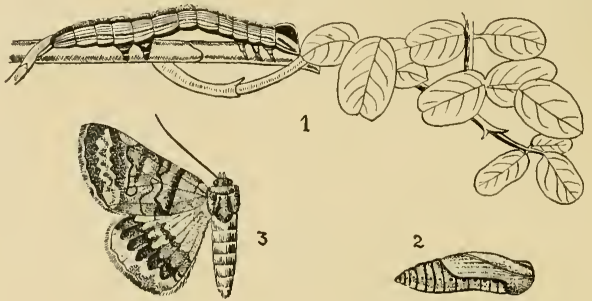

FiG. 252.-Remigia undata. 1, Larva ; 2, Pupa ; 3, Moth. (Larva and Pupa after Moore.)

Distribution.-Throughout Southern India.

Lifehistory.-Not known in detail.

Foodplants.-Indigo.

Status.-A very minor pest.

REMIGIA FRUGALIS, Fb.

Noctua frugalis, Fab., Syst. Ent., VI, 60I (I775:

Remigia frugalis, Hmpsn, Faun. Ind. Moths, II. 527 ; Lefroy, Ent. Mem. Dept. Agri., Ind., I, I87, f. 56, Ind. Ins. Life, p. 45I, f. 310.

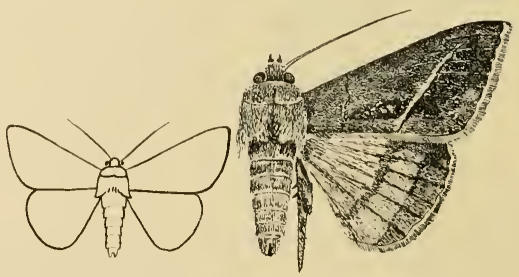

F1G. 253.-Remigia frugalis. The outline figure shows the natural size. (Original.)

Distribution.-Throughout the Plains of Southern India. 
Lifchistory.-The greyish-yellow semi-looping caterpillar feeds exposed on leaf-blades and pupates in a cocoon amongst leaves

Foodplants.-Grasses, including paddy.

Status.-An occasional very minor pest of rice.

AZAZIA RUBRICANS, Bdv.

Ophiusa rubicans, Boisd., Faun. Mad. Maur., p. I06, t. I6, f. I (I833).

Thermesia rubricans, Hmpsn., Faun. Ind. Moths, 11, 534, f. 298; Lefroy, Ind. lns. Life, p. 455.

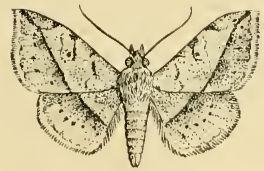

F1G. 254.-Azazia rubricans. (Original.)

Distribution.---Throughout the Plains of Southern India.

Lifehistory.-The caterpillar is slender and loops in walking although all prolegs are present; in colour it is green with markings consisting of ( $\mathrm{I}$ ) an ashywhite band between each segment; (2) a few faint narrow lines along the back and (3) a bright yellowishbrown stripe along the side, but any or all of these may be absent. The pupa is formed in a slight cocoon amongst leaves of the foodplant (usually in wet lands), or just beneath the surface of the soil (in dry areas). The moth has a great resemblance to a dry leaf.

Foodplants.-Green-gram, red-gram, cow-pea, black-gram ; probably on all pulses.

Status.-A minor and sporadic pest of pulses.

Control.-Hand-picking of caterpillars and, where practicable, scraping the surface of the soil with a bullock-hoe to expose the pupæ.

HONOPTERA GLAUCINANS, Gn.

Alamis glaucinans, Guen, Noct., III, 6.

Homoptera glaucinans, Hmpsn., Faun. Ind. Moths, II, 475, f. 263.

Distribution.-Coimbatore. Probably throughout Southern India.

Lifchistory.-Larva elongate, slender, 35-40 $\mathrm{mm}$. long, first two pairs of ventral prolegs absent, pale-green in colour with square white patches along the back of many of the abdominal segments.

(NOTE.-Forsayeth figures it as pale-green with a broad yellow stripe along the side.) Pupa in a slight cocoon.

Foodplant.-Sesbania agyptiaca.

Status.-A minor pest, only once noticed. 


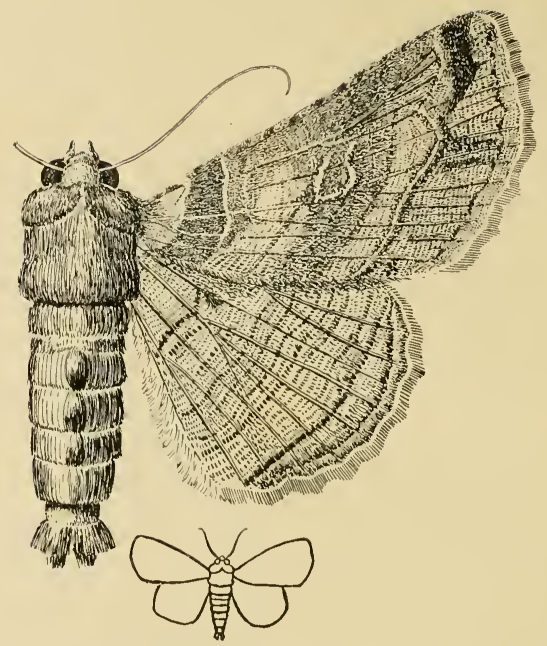

FIG. 255, - Homoptera glancinans. The outline figure shows the natural size. (Original.)

\section{COSMOPHILA SABULIFERA, Gn.}

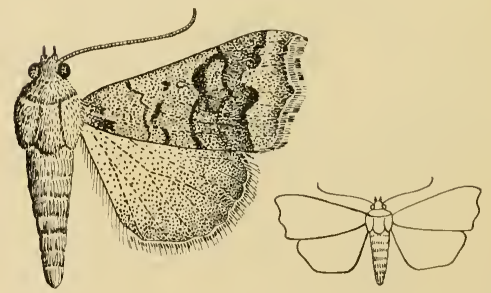

FIG. 256.-Cosmophila sabulifcra. The outline figure shows the natural size. (Original.)

Gonitis sabulifera, Guen., Noct., II, 404.

Cosmophila salulifera, Hmpsn., Faun. Ind. Moths, II, 409; Lefroy, 
Ind. Ins. Pests, p. I5I, Ent. Mem. Agri. Dept., Ind., 1, I82, Ind. Ins. Life, p. 453.

Distribution.-Godavari, South Arcot.

Lifelistory.-The full-grown caterpillar is about $25 \mathrm{~mm}$. long, rather slender, with the first pair of forelegs slightly reduced; in colour it is greenish, with narrow darker-green lines down the back and a wavy dark stripe along the side. Pupa in a cocoon.

Foodplants.-Jute.

Status.-A very minor pest of jute in Southern India.

COSMOPHILA EROSA, Hb.

Noctua crosa, Hb., Zutr., II., I9, ff. 287-288.

Cosmophila erosa, Hmpsn., Faun. Ind. Moths, II, 4II ; Lef roy Ind. Ins. Pests, p. II2, Ent. Mem. Agri. Dept., Ind., I, I8I, Ind. Ins. Life, p. 453 , t. 36 , ff. 7,8 .
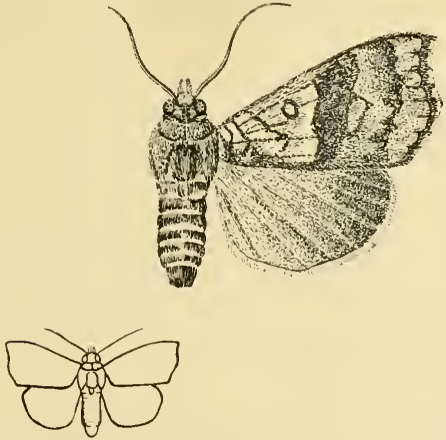

FIG. 257.-Cosmophila crosa. The outline figure shows the natural size. |Original.।

Distribution.-Throughout Southern India.

Lifelistory. - The full-grown caterpillar is $25-30 \mathrm{~mm}$. long, slender, with normal prolegs; in colour it is green with five white lines along the back and sides. Pupates within folded leaves.

Foodplants.-Cotton, bhindi (Hibiscus esculentus), gogu and various other malvaceous plants.

Status.-Occasionally a serious pest of cotton, especially in the case of young plants of exotic varieties.

Control.-In small experimental areas spraying may be done.

Remarks. - Natural enemies include wasps and crows. 
HYBLAA PUERA, Cr.

Noctua pucra, Cramer, Pap. Exot., t. I03 D, E (1777).

Hybla pucra, Moore, Lep. Ceylon, III, t. I54, ff. 2, $2^{\mathrm{a}}$; Hmpsn., Faun. Ind. Moths, II, 37I-372, f. 204; Hole, B.J., XV, 679-697, t. A-E.
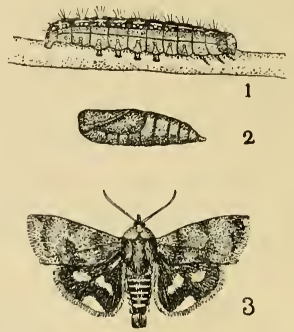

Fig. 258.-Hyblea pucra : 1, Larva ; 2, Pupa; 3, Moth. (Larva and Pupa after Moore.)

Distribution.-Throughout Southern India.

Lifehistory.-The oblong, yellowish or greenish eggs are laid singly on the backs of young leaves, usually in an angle between two veins. The full-grown larva is about $30 \mathrm{~mm}$. long, stout, cylindrical, very variable in colour, usually greenish below and dark-brown or blackish above, with a sub-dorsal white line and lateral spots which may form interrupted lines. It lives in the shelter of a rolled-up leaf in which it usually hides during the daytime, only coming out to feed at night. Pupation in a rolled leaf, amongst dead leaves on the ground, or in the soil. The total lifecycle is about a month.

Foodplants.-Teak (Tectona grandis), Bignoniaceæ and probably many other plants.

Statns.-May be a serious pest of teak.

Control.-Cutting out alternative foodplants in forests; encouragement of insectivorous birds, such as Mynahs which are reported to feed on these caterpillars at Nilambur. In nurseries the young plants may be sprayed but this is not practicable in the open forest.

PLUSIA SIGNATA, Fb. (?)

Noctua signata, Fab., Ent. Syst., III, 2, p. 8I (I794).

Plusia signata, Hmpsn., Faun. Ind. Moths, II, 568-569; Lefroy, Ind. Ins. Pests, p. I55, ff. I72-I74, Ent. Ment. Dept. Agri., Ind., I, I 90, Ind. Ins. Life, p. 452. 


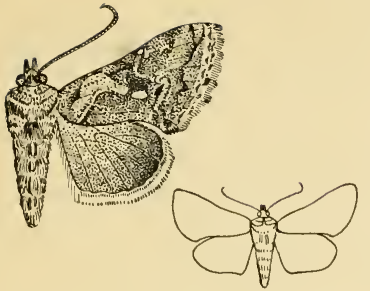

Fig. 259.-Plusia signata. The outline figure shows the natural size. (Original.)

Distribution.-Throughout Southern India.

Lifehistory.--Larva slencler, attenuated anteriorly, only three pairs of prolegs present, including anal claspers ; in colour pea-green with several wavy whitish longitudinal lines and a broader white longitudinal lateral stripe. Pupation in a white silken cocoon; moth emerges after about a week.

Foodplants.-Tobacco, groundnut, green-gram, sann-hemp.

Status.-Scarcely a pest as a rule. Occasionally does some damage to young tobacco seedlings and, in the case of groundnut, etc., the attack seems confined to the tender leaves only.

Rcmarks.-The exact identification of this moth is a matter of doubt. So far as can be judged from the specimens obtained, the species here referred to is $P$. signata but it is possible that the specimens may represent $P$. chalcytes.

PLUSIA ORICHALCEA, Fb.

Noctua orichalcea, Fab., Sp. Ins., II, 227.

Plusia orichalcea, Hmpsn., Faun. Ind. Moths, II, 573; Lefroy, Ent. Mem. Dept. Agri., Ind., I, I93, Ind. Ins. Life, p. 452, t. 37, f. I0.

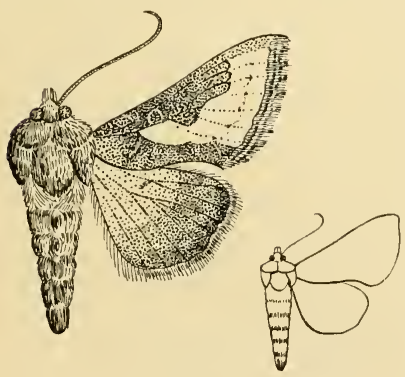

F1G. 260.-Plusia orichalcat. The outline figure shows the natural size. (Original.)
Distribution.-Throughout Southern India.

Lifehistory. - L a $\mathrm{r} v$ a about $25 \mathrm{~mm}$. long, slender, a t te n u a ted anteriorly, in colour pale-green, the head darker-green, the body covered with small whitish tubercles each with a central black dot from which issues a short white hair; along each sicle runs a row of black tubercles bordered below by a white spiracular stripe. Pupation period about 8 days. 
Foodplants.-Cow-pea, potato, pea, indigo, Carum copticum (Bishop's Weed) ; Cruciferæ (Lefroy), Corcopsis (Hampson).

Status.--Occurs fairly commonly on cow-pea, indigo and potato (Nilgiris), but scarcely a pest in Southern India.

PLUSIA PEPONIS, Fb.

Noctua peponis, Fab., Syst. Ent., p. 608 (I775).

Plusia agramma, Guen, Noct., II, 327 ; Hmpsn., Faun. Ind. Moths, II, 574; Lefroy, Ent. Mem. Dept. Agri., Ind., I, I94, Ind. Ins. Life, p. 452 , t. 37 , f. II.

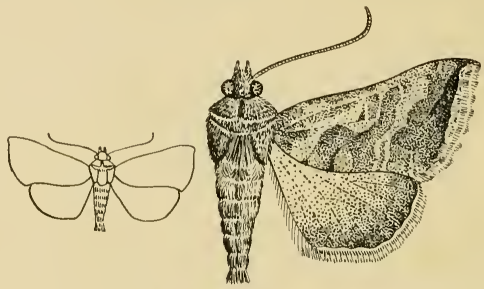

F1G. 261.-Plusia peponis. The outline figure shows the natural size. (Original.)

Distribution.- Throughout Southern India.

Lifehistory.-The greenish-white, globular, beautifully-sculptured eggs are laid singly on the under-surface of the leaves of the foodplant. The newly hatched larva is about I'5 mm. long, head and legs black, body whitish, with scattered dark hairs arising from black warts. After the first moult the larva has on each segment a dorsal and a sub-dorsal black conical wart from which arises a short hair. The full-grown larva is about $30-35 \mathrm{~mm}$. long, slender, segments distinct, covered with whitish conical warts each giving rise to a short hair; head olive-green; body whitish-green with milk-white longitudinal stripes; legs green, only three pairs of prolegs including anal claspers; anal segment humped. The caterpillar remains on the lower surface of the leaf which it cuts so as to make the distal portions bend down and provide a shelter for it. The colour of the caterpillar is extremely like that of its foodplant. Pupation in a tough cocoon of pure white silk spun between folds of the leaf; pupation period about a week [T.V.R.].

Foodplants.-Snake-gourd, pumpkin and other Cucurbitacea.

Status.-Occasionally a rather serious pest of cultivated cucurbits.

Control.-Hand-picking of larvæ and pupæ. 
SIMPLICIA ROBUSTALIS, Gn.

Simplicia robustalis, Guen, Delt., p. 58 ; Hmpsn., Faun. Ind. Moths. JII, 36, f. I6; Lefroy, Ind. Ins. Life, p. 457.

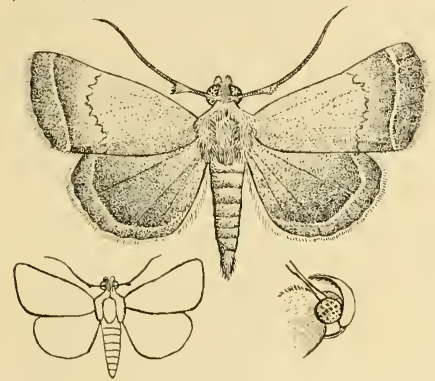

F1G. 262.-Simplicia robustalis. The outline figure shows the natural size.

To the right is seen a profile view of the head. (Original.)

Distribution.-Coimbatore, Kurnul. Probably throughout Southern India.

Lifchistory.-Caterpillar about $20 \mathrm{~mm}$. long, slender, smooth, dirty brown in colour, with faint irregular interrupted whitish longitudinal lines. Pupation in a slight cocoon; pupal period about 10 days.

Food.--Dead leaves, cumbu stalks, etc.

Stutus.--Only noted as doing damage on one occasion when the caterpillars were present in thousands in the thatched roof of a house, devouring the dry coconut leaves and cumbu stalks which composed the thatch.

Control.--The caterpillars were destroyed by spraying the thatch with lead arsenate in the case noted above and the moths on emergence were driven away by smoking with sulphur and spraying with cyllin.

\section{LYMANTRIADA.}

ORGYIA POSTICA, Wlk.

Orgyia postica, Wlk., Cat. IV, 803 ; Hmpsn., Faun. Ind. Moths, J, 436, f. 303; T. V. Ramakrishna Ayyar, B.J., XX, 34I.

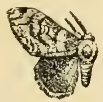

F1G. 263.-Orgyia postica, male moth. (Original.) 
Distribution.--Bellary, Coimbatore.

Lifehistory.--Eggs in clusters; spherical, depressed in centre. The eggs hatch after about 8 days, all hatching at one time, the young caterpillars feeding gregariously at first, but separating later. Full-grown caterpillar I5 $-25 \mathrm{~mm}$. long, cylindrical, yellowish brown, paler beneath; on the first four abdominal segments are dorsal, thick, rounded, brush-like tufts of short yellow hairs, on the prothorax is a pair of long anteriorly divergent black hair-pencils and on the penultimate segment is a stouter posteriorly-directed pencil of orange-brown hairs; all the segments with warts from which arise long fine hairs. Pupation in a tough silken cocoon. The life-cycle is :- egg, 8 days; larva, 25 days; pupa, 8 days. The male moth is winged and very active; the female is wingless and sluggish and often never quits the cocoon after emergence from the pupal condition.

Foodplants.-Castor, Erythrina. Probably polyphagous.

Status.--Occasionally a serious pest on castor.

Control.--The young caterpillars, whilst still gregarious, are easily seen and hand-picked.

OLENE (DASYCHIRA) MENDOSA, Hb.

Bombyx mendosa, Hubner, Zutr., II, I9, ff. 293-294.

Dasychira mendosa, Hmpsn., Faun. Ind. Moths, I, 452-453 ; I.M.N., III, No. 4, p. 22, fig.; Lefroy, Ind. Ins. Life, p. 460.
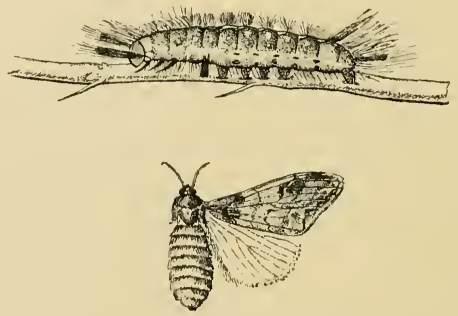

F1G. 26t.-Olene mendosa, larva and moth. (()riginal.)

Distributiou.- Bellary, Coimbatore, Shevaroys.

Lifclistory:- Not known in any detail. The appearance of the caterpillar is shown in the figure. It pupates in a slight silken cocoon.

Foodplants.- Castor, red-gram, coffee.

Status.--A minor pest.

Control.--Hand-picking. 
PSALIS (DASYCHIRA) SECURIS, Hb.

Bombyx securis, Hubn., Zutr., II, I9, ff. 29I, 292.

Dasychira securis, Hmpsn., Faun. Ind. Moths, I, 453-454; Lefroy, Ind. Ins. Life, p. 460 , t. 39, f. 7 .

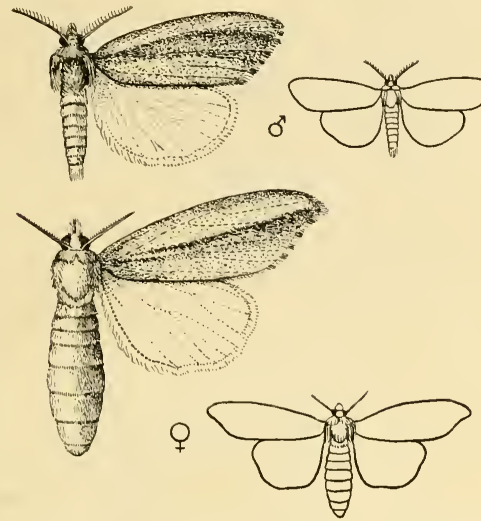

F1G. 265.-Psatis sccuris, male and female moths. The ontline figures show the natural sizes. (Original.)

Distribution.--Throughout the Plains of Southern India.

Lifehistory - Eggs are laid in batches covered with hairs derived from the anal tuft of the female noth. The full-grown caterpillar is $30-40 \mathrm{~mm}$. long, rather stout, in colour bright-yellow with a broad red-brown stripe down the back and a narrow paler stripe along the side; head dull-orange; on either side of the head two long tufts of hair project forward and a single tuft backwards from the anal segment; on the first four abdominal segments are short, thick, rounded brush-like tufts of pale-yellowish hair and on the sixth and seventh abdominal segments two bright-red papules stand on the centre of the back; all the segments with numerous warts from which arise spreading tufts of fine pale hairs. Pupation as a rule on a leaf-blade in a cocoon formed of silk interwoven with larval hairs; the pupal period is about Io days.

Foodplants.-Paddy, cholam, ragi, sugarcane, grasses.

Status. - A minor pest of paddy.

Control.-The caterpillar is conspicuous and feeds exposed and so is easily hand-picked. 
EUPROCTIS FRATERNA, Moore.

Euproctis fraterna, Moore, Lep. Ceylon, II, 85 ; Hmpsn, Faun. Ind. Moths, I, 477; Lefroy, Ind. Ins. Life, p. 46I, ff. 334, 3 I 5.

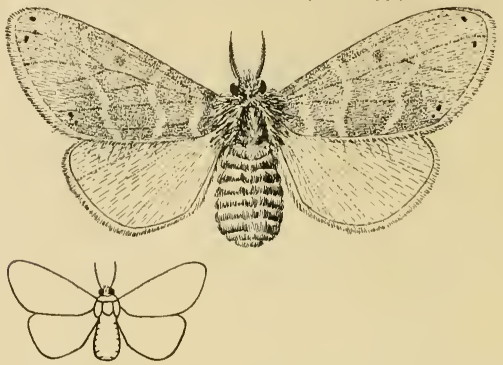

F1G. 266.-Euproct is fraterna. The outline figure shows the natural size. (Original.)

Distribution.- Probably throughout Southern India.

Lifehistory.-Eggs laid on the lower surfaces of leaves in a mass covered with hairs from the anal tuft of the female; the egg is creamy yellow, circular, flattened. The newly hatched larva is about $2 \frac{1}{2} \mathrm{~mm}$. long, slender, hairy, yellowish. The full-grown larva is rather stout, dark reddish-brown, paler along the lower surface, head and prothoracic shield bright orange-red, thickly covered

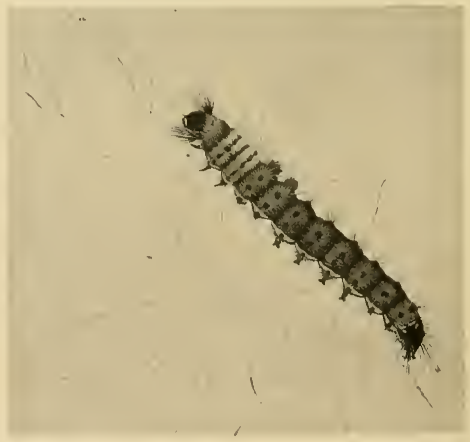

F1G. 267.-Euproctis fraterna, larva. (After Lefroy.) 
with tufts of whitish hair and with a pair of large tufts of darker hair directed forward on either side of the head and a single similar tuft directed backwards from the anal segment. Pupa red-brown, in a slight cocoon interwoven with the larval hairs. Life-cycle: egg, about 7 days; larva, 30 days; pupa, about 4 days.

Foodplants.-Castor, pomegranate, cotton (occasionally), redgram.

Status.-Occasionally a rather serious pest of castor.

Control.-Hand-picking of the caterpillars and moths. The caterpillars are gregarious and easily collected; their hairs are somewhat poisonous and they should not be touched with the bare hand more than is necessary.

EUPROCTIS SCINTILLANS, wlk.

Somena scintillans, Wlk., Cat. VII, I734.

Euproctis scintillans, Hmpsn., Faun. Ind. Moths, I, 483 ; Lefroy, Ind. Ins. Life, p. 461.

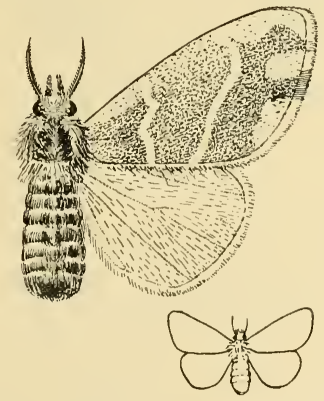

F1G. 268.-Euproctis scintillans The outline figure shows the natural size. (Original.)

Distribution.--Throughout Southern India.

Lifehistory.--Similar to that of E. fraterna. Caterpillar rather stout, dark coloured, with tufts of fine hairs, a pale-yellow stripe down the back and on the first two abdominal segments (the two segments bctwecn the legs and prolegs) a thick tuft of blackish or reddish stout detachable hairs.

Foodplants,--Mango, gogu (Hibiscus camabinus), sann-hemp, linseed, castor, red-gram.

Status.-A minor pest, rarely of much importance.

Control.-As in E. fraterna. 


\section{HYPSID Æ.}

HYPSA FICUS, Fb.

Bombyx ficus, Fab., Ent. Syst., III, 2, p. 27 (1794).

Hypsa ficus, Hmpsn., Faun. Ind. Moths, I, 504 ; Lefroy, Ind. Ins. Life, p. 463 , t. 39 , ff. I, 2.
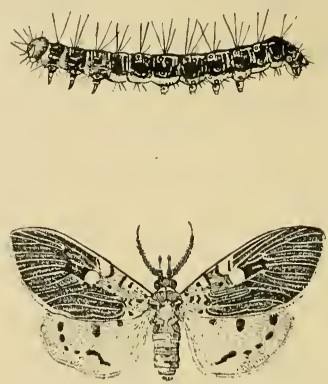

Fig. 269.-Hypsa ficus, larva and moth. (Original.)

Distribution.--Coromandel Coast, Trichinopoly, Coimbatore.

Lifchistory. - The caterpillar is about $25 \mathrm{~mm}$. long, cylindrical, rather flattened posteriorly, its whole body covered with scattered yellow-brown warts from which arise fairly long white hairs; head jet black; the body is black with a white stripe along the back and white dots along the side, sometimes with pale yellow markings on the back and beneath the sides, sometimes with red warts. Pupation in a cocoon usually underground.

Foodplant.-Figs (Ficus glomerata, F. carica, F. religiosa, etc.).

Status.-An occasional defoliator of fig-trees.

Control.-In the case of young trees in small areas, hand-picking and spraying may be done.

\section{ARGINA CRIBRARIA, $\mathrm{Cl}$.}

Phalcna cribraria, Clerck, Icon. Ins., II, t. 54, f. 4 (I764).

Argina cribraria, Hmpsn., Faun. Incl. Moths, II, 5I-52, f. 24 ; Lefroy, Ind. Ins. Life, pp. 463-464, Ent. Mem. Dept. Agri., Ind., p. I59, Ind. Ins. Pests, pp. I48, I93, figs. 


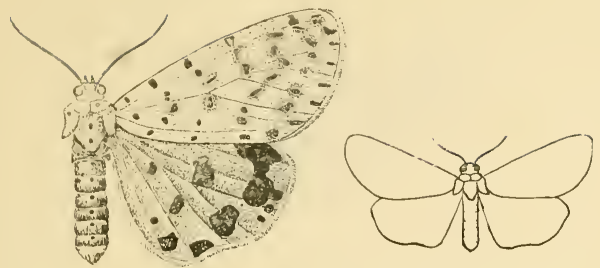

F1G. 270.-Argina cribraria. The outline figure shows the natural size. (Original.)

Distribution. Throughout Southern India.

Lifchistory. Eggs are laid in small clusters on lower surfaces of leaves. Caterpillar $25 \mathrm{~mm}$. long, in colour white with a black line along the side, and irregular black patches, a yellow line along the side developed into an orange spot on each segment; hairs black above, lighter beneath.

Foodplants. Sann Hemp.

Status. A minor pest of Sann Hemp, occasionally abundant.

Control.- In small plots spraying and hand-picking of young larva.

ARGINA SYRINGA, Cr.

Plalena syringa, Cram., Pap. Exot., I, t. 5 c.

Argina syringa, Hmpsn., Faun. Ind. Moths, II, 5 I ; Lefroy, Ind. Ins. Pests, pp. I48, I94. Ent. Mem. Dept. Agri., Ind., I, I58.

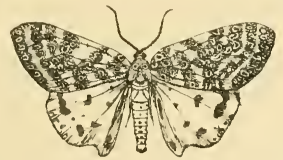

Fig. 271.- drgina syringer. (Original.)

Distribution.- Throughout Southern India.

Lifchistory. Similar to A. cribraria.

Foodplants.-Sann Hemp (Crotalaria juncea).

Status.-A minor pest occasionally abundant.

Controi.- Hand-picking of young larva and spraying in the case of small areats.

$$
\text { SPHINGIDE. }
$$

HERSE CONVOLVULI, Linn.

Sphin.r convoliuli, Linn., Syst. Nat. (ed. X), p. ,98 (I758).

Herse conotiuli, Hmpsn., Faun. Ind. Moths, I, I03, f. 6o; Lefroy, Ind. Ins. Pests, p. I59, Ent. Mem. Agri. Dept., Ind., I, I 55, Ind. Ins. Life, p. 467 . 


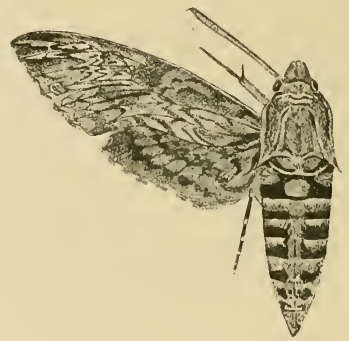

Fig. 272.-Horse convolvuli. (Original.)

Distribution.-Throughout Southern India.

Lifchistory.--Eggs are laid singly on leaves. The full-grown caterpillar is about $100 \mathrm{~mm}$. long, with a sharp down-curved horn on the tail end; colour dark brown with indistinct oblique redbrown blotches on the sides or green with oblique yellow or pink black-elged bars on the sides. Pupa in the soil, in a chamber just below the surface; colour red-brown, tongue-sheath long, projecting, incurved.

Foodplant.-Sweet potato, green-gram and other pulses.

Status.-A minor pest as a rule, occasionally occurring in large numbers when the damage is serious.

Control.--Hand-picking of the caterpillars. Spraying of small areas.

\section{ACHERONTIA STYX, Westw. [PLATE XXIV.]}

Acherontia styx, Westwd., Cab. Or. Ent., p. 88, t. 42, f. 3 ; Hmpsn., Faun. Ind. Moths, I, 67, f. 40 ; Lefroy, Ind. Ins. Pests, p. I60, Ent. Mem. Dept. Agri., Ind., I, I54, f. 40, Ind. Ins. Life, p. 467, t. 40.

Distribution.--Throughout the Plains of Southern India.

Lifehistory.--The large, globular, green egg is laid singly on leaves. The full-grown caterpillar is about $90 \mathrm{~mm}$. long, rather stout, with a rough skin, and a recurved horn on the tail end; in colour it is variable, usually light greenish with oblique darker green stripes along the sides and meeting over the back. Pupa red-brown, in a chamber below the ground. The moth squeaks when disturbed.

Foodplants.--Brinjal, lab-lab, gingelly.

Status.-A minor pest of brinjal and gingelly,

Control.-Hand-picking of caterpillars. 



\section{EXPLANATION OF PLATE XXIV.}

\section{ACHERONTIA STYX.}

Fig. I, 2, Eggs, enlarged.

" $3,4,5,6$. Larvæ in various stages of growth.

"7. Pupa.

" 8. Moth.

(The lines alongside the figures show the natural sizes.) 

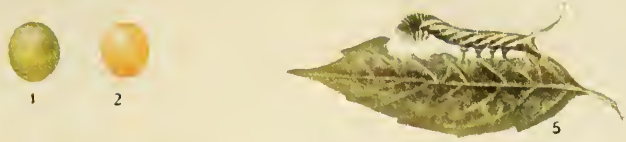

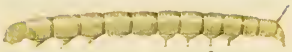

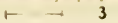

4.

4
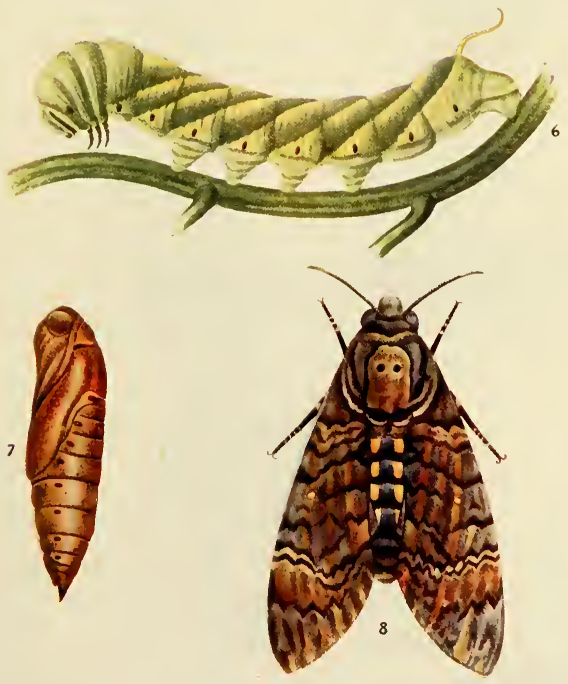

ACHERONTIA STYX. 

DEILEPHILA NERII, Linn.

Sphinx nerii, Linn., Syst. Nat. (ed X), p. 798 (I758).

Deilephila nerii, Hmpsn., Faun. Ind. Moths, I, 94-95, f. 54 ; Lefroy, Ind, Ins. Life, p. 468 , f. 316.

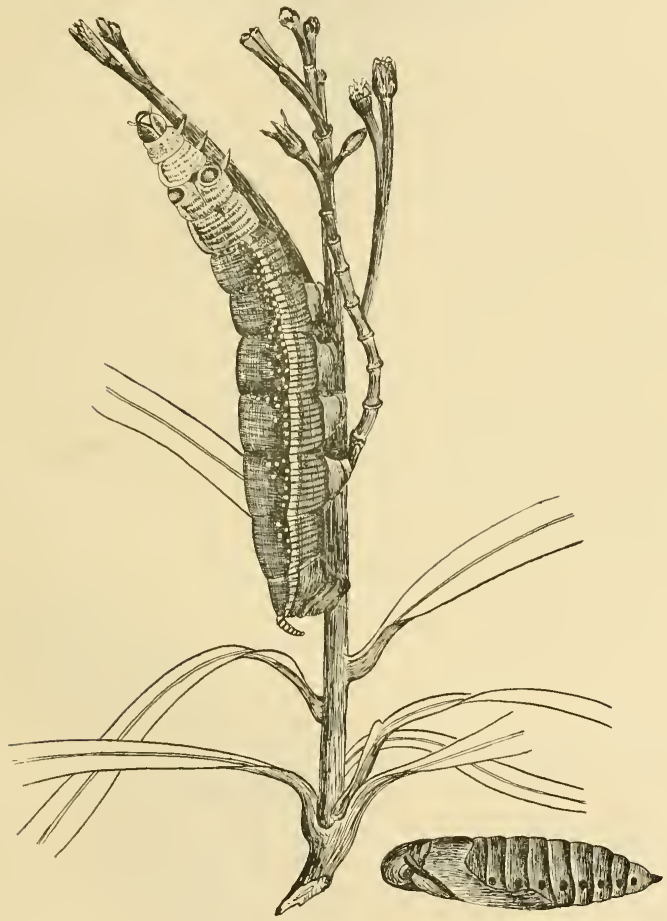

FIG. 273.-Deilephila nerii. larva and pupa. (Original.) $26-\mathrm{A}$ 


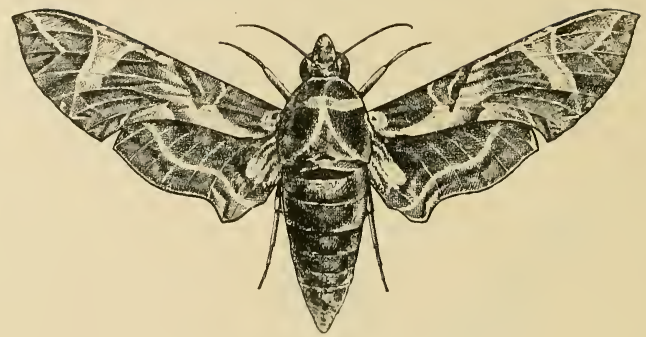

F1G. 27t.-Deilephila nerii. (After Lefroy:)

Distribution.- Throughout Southern India.

Lifchistory. - Egg laid singly. The full-grown caterpillar is about $100 \mathrm{~mm}$. long, attenuated anteriorly, with a short roughened horn on the tail end; colour variable, usually pale-green, with white dots especially evident along the sides and a bright blue eye-spot on either side of the third thoracic segment. Pupa pale-brownish yellow, with black spots; pupation in a cell below ground.

Foodplants.-Oleander (Nerium oleander) and other plants.

Status. - A minor pest of ornamental oleanders which it sometimes strips of their leaves.

Control.- Hand-picking of the larvæ, which rest on the leaves and twigs, although they are by no means easy to see in spite of their large size.

\section{EUPTEROTIDÆ.}

EUPTEROTE MOLLIFERA, Wlk.
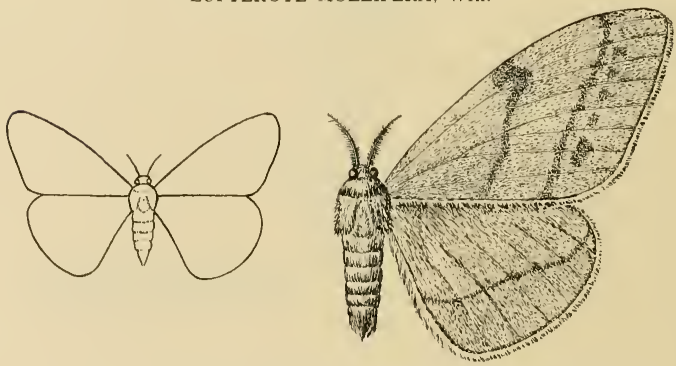

F1G. 275.-Eupterote mollifera, male. The outline figure shows the natural size. (Original.) 



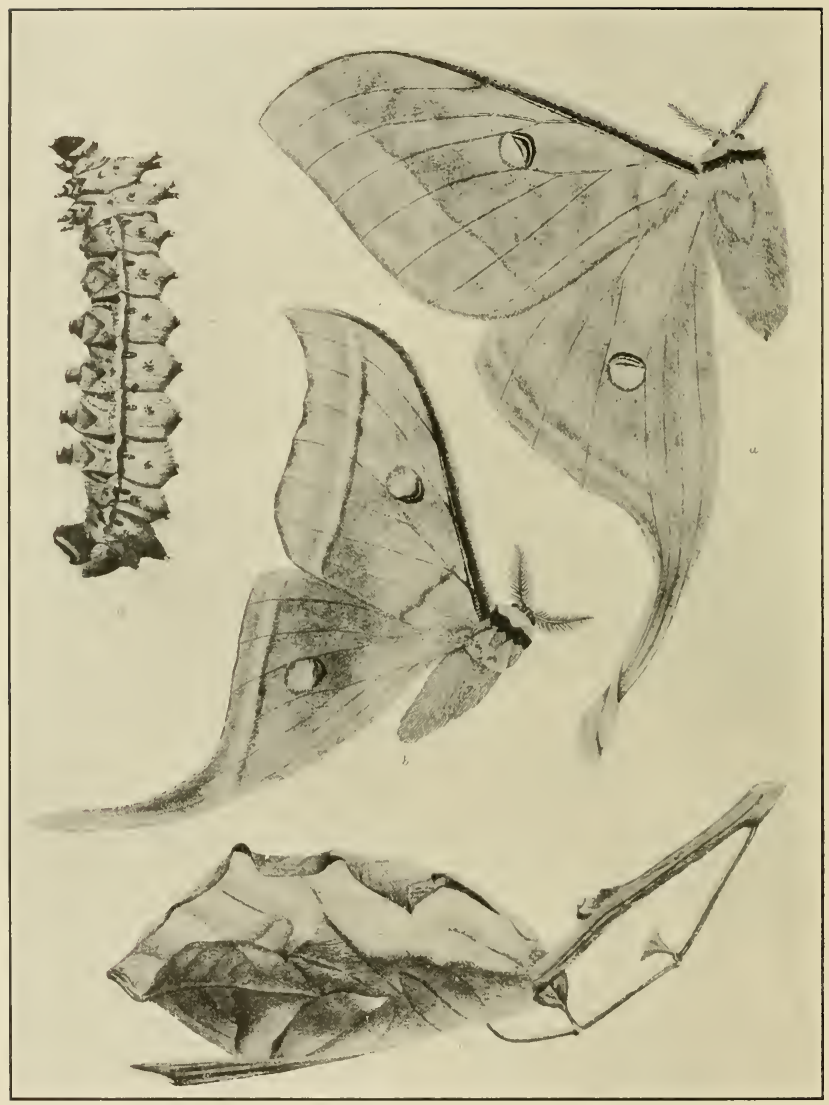

FIG. 276.-Actias Selcn. (From Indian Museum Notes.! 
Eupterote mollifera, WIk., Cat. XXXII, 376; Hmpsn., Faun. Ind. Moths, I, 57-59; Lefroy, Ind. Ins. Life, p. 471.

Distribution. Throughout Southern India.

Lifchistory.-Caterpillar about $40 \mathrm{~mm}$. long, dull brown or redbrown, with a dull whitish line along the side above the spiracles; head and true legs reddish; all the segments with numerous warts from which arise spreading tufts of fine brown hair; on the back of the first and third to sixth abdominal segments are also large thick tufts of short dark-brown hairs.

Foodplant.-Moringa pterygosperma (Tamil, Moringai).

Status. - Occasionally a serious pest, occurring in enormous number and defoliating the trees.

Control.-The caterpillars usually rest on the tree-trunk cluring the day time and may be destroyed by burning with a torch.

NOTE.-The hairs of this caterpillar are poisonous and care should be taken not to touch them or even to approach the trees on which they occur nearer than necessary.

\section{SATURNIADÆ.}

ACTIAS SELENE, Hb.

Attacus selenc, Hubn., Samml. Exot. Schm., I, t. I72, f. 3.

Actias selene, Hmpsn., Faun. Ind. Moths, I, I 3, f. 8 ; Lefroy, Incl. Ins. Life, p. 478 , f. 326.

\section{[SEE FIGURE 276.]}

Distribution.- Throughout Southern India.

Lifchistory.--The full-grown caterpillar is about $75 \mathrm{~mm}$. long, stout, with distinct segments, in colour bright apple-green, with two rows of yellow spinous warts along the back and another row along the side; the fine hairs on the back are yellowish, those on the sides and beneath blackish; pad to anal claspers reddish. Cocoon tough, oval, brown, usually enclosed in a leaf or leaves.

Foodplants.-Moringa pterygosperma and various other shrubs.

Status. - Not very common as a rule.

Remarks.-On account of the large size of the cocoon, inquiries are often made with regard to the value of the silk produced by this insect. It is, however, of no commercial importance.

\section{CRICULA TRIFENESTRATA, Helfer.}

Cricula trifcnestrata, Helfer, J.A.S.B., VI, 45 ; Hmpsn., Faun. Ind. Moths, I, 28, f. I4; Lefroy, Ind. Ins. Life, p. $48 \mathrm{I}$.

Distribution.- Throughout the damper districts of Southern India. 

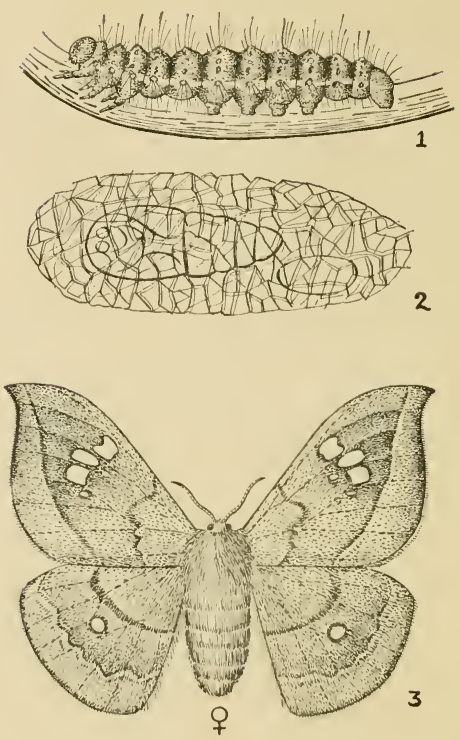

F1G. 277.-Cricula trifenestrata: 1, Larva ; 2, Cocoon enclosing pupa : 3, Female Moth. (Original.)

Lifchistorv.--Full-grown caterpillar about $50 \mathrm{~mm}$. long, segments sharply defined, each with six large warts from which arise tufts of fine hairs; colcur dark brown, with a pale-recldish stripe along the side, prothoracic segment (first segment behind head) and anal claspers crimson. Cocoon spun amongst leaves and twigs, often in masses; conposed of a net-work of bright golden silk.

Foodplants.-Mango; cashew (Anacardium occidentale).

Status.-An occasional pest of mango and cashew, stripping all the leaves.

Remarks.-(I) The hairs of the caterpillars are poisonous and they should therefore not be handled.

(2) The cocoons are often found in large numbers and inquiries are made regarding a possible sale for them. They are, however, of no comnercial value. 


\section{BOMBYCID E.}

OCINARA VARIANS, WIk.

Naprepa varians, Wlk., Cat. V, II 53 .

Ocinara varians, Hmpsn., Faun. Ind. Moths, I, 35 ; Lefroy, Ind. Ins. Life, p. 484 , f. 327.
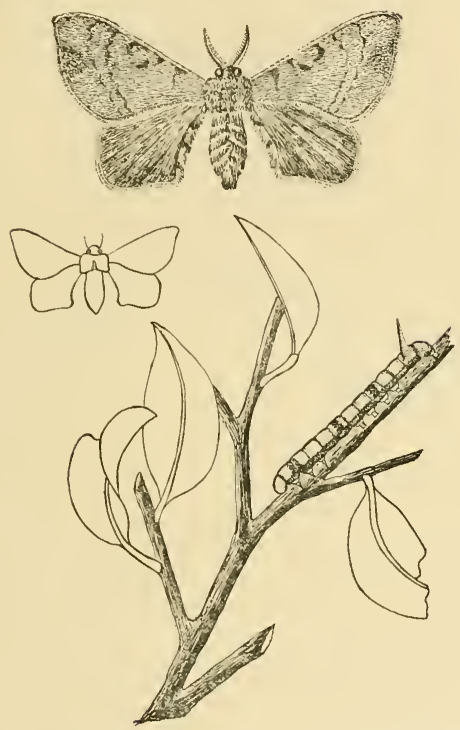

FIG. 278.- Ocinara varians, moth and larva. The outline figure shows the natural size of the moth. (Original.)

Distribution.--Throughout Southern India.

Lifehistory.-The full-grown caterpillar is about $30 \mathrm{~mm}$. long, humped anteriorly and with a slight horn on the tail end; in colour pale grey, matching very closely the twigs on which it rests. The bright yellow cocoon is spun in a rolled leaf as a rule.

Foodplants. - Figs of various sorts.

Status.-A pest of fig-trees, occasionally stripping every leaf. especially in the case of young trees. 
Control.--Spraying with Lead Arsenate or similar poison and hand-picking of small trees. It must be noted, however, that the caterpillars are often very difficult to see especially when resting on the bare twigs after having stripped all the leaves.

\section{NOTODONTID E.}

STAUROPUS ALTERNUS, Wlk.

Stauropus alternus, Wlk., Cat. V, I020; Hmpsn., Faun. Ind. Moths, I, I49-I50, f. 9I ; Lefroy, Ind. Ins. Life, p. 472, f. 321.

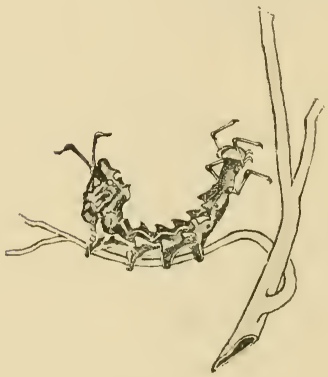

Fig. 279.-Stauropus alternus. larva. (Original.)

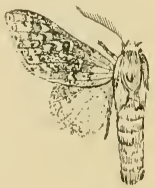

Fici. 280.-Stauropus altermus, malc moth. (Original.)

Distribution. - Coimbatore, Ganjam. Probably throughout Southern Inclia.

Lifchistory.-Full-grown caterpillar about $40 \mathrm{~mm}$. long, with extraordinarily dilated and flattened posterior extremity which is held over the back when alarmed, the anal claspers being reduced to two slender filaments; a row of paired sharp triangular humps down the back; second and third pairs of thoracic legs very long ; colour grey-brown mottled with darker. This caterpillar cannot be mistaken for anything else when once seen. The young caterpillar mimicks an ant; the full-grown one looks not unlike a spider when alarmed. The dark red-brown pupa is formed in a slight cocoon spun amongst leaves, etc.

Foodplants.-Tamarind, Tur (Cajanus indicus), Trewia mudifolia, Tea.

Status.-Rather a scarce insect as a rule, but has once been recorded as a serious sporadic pest of tea in Ceylon. 


\section{GEOMETRID E.}

BISTON SUPPRESSARIA, GN.

Biston suppressaria, Guenee, Phal., I, 210 ; Hmpsn., Faun. Ind. Moths, III, 247; I.M.N., V, I85 I87, t. I3, ff. IO, IOa-c ; Watt \& Mann, Pests of Tea, pp. $225-226$, t. 9. f. 2.

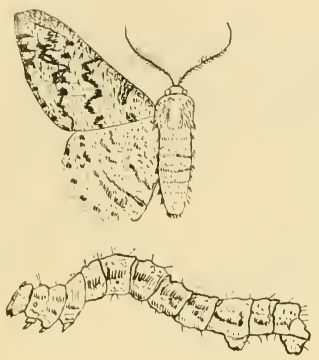

1.16. 281.-Miston suppressaria, moth and larva. IFrom Indian Musenm Notes.t

Distribution.-- Reported to occur in the Tea districts.

Lifelistory.- Not known in detail. The caterpillar may be either dark-brown and twig-like or green with darker bands. Pupation in the soil.

Foodplants.- Tea, Cassia auriculatı.

Status.-Apparently only an occasional and very minor pest of tea in Southern India.

Control.-Hand-picking of caterpillars.

Remarks.-Included here on the authority of Mr. Anstead who informs me that it has once been reported as damaging tea in South India.

\section{LASIOCAMPID E.}

METANASTRIA HYRTACA, Cram.

Phalcna hyrtaca, Cram., Pap. Exot., III, t. 249 F.

Metanastria hyrtaca, Hmpsn., Faun. Ind. Moths, I, 4IO-4II, f. 283 ; Lefroy, Ind. Ins. Life, p. 497, ff. 332, 333.

Distribution.-Coimbatore, Chingleput, Ganjanı. Probably throughout Southern India.

Lifchistory.-- Full-grown larva about $75 \mathrm{~mm}$. long, stout, greyish, covered with stout hairs and with flaps at the sides and tufts of longer hair projecting forward on either side of the head; between the metathorax and first abdominal segments (third and fourth 


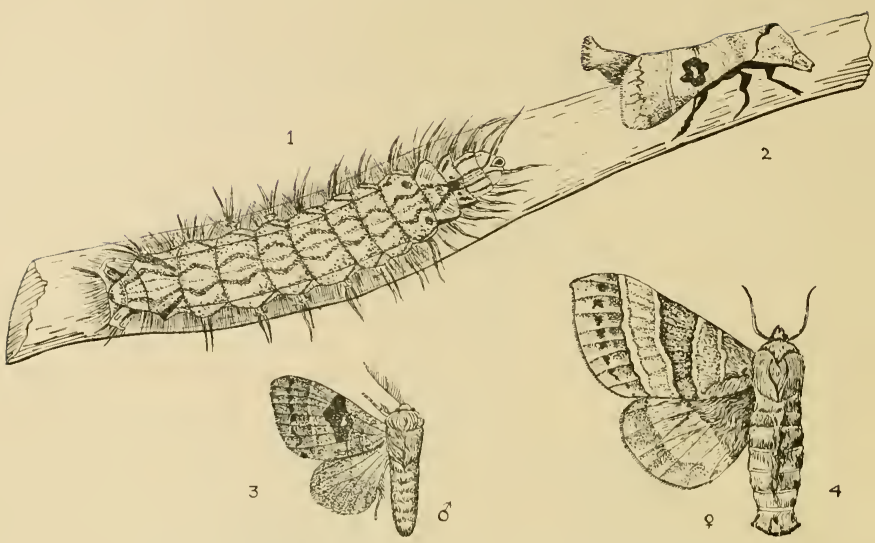

FIG. 282.-Metanastria hyrtaca: 1, Larva (after Moore); 2, Male Moth in resting attitude (after Forsayeth) : 3, Male, and 4. Female Moths.

(O)iginal.)

segment behind head) is a patch of short blackish or reddish hairs, concealed in repose but exposed when alarmed. Pupa brownish-rerl in a long cocoon usually spun on a branch of the foodplant.

Foodplants.-Mimusops elengi, country almond (Terminaliacatappa), Nyctanthes arbortristis (Tamil, Pavazha malli).

Status. - Not a pest as a rule but occasionally appears in large numbers and strips trees.

\section{LINIACODID $\Subset$.}

\section{PARASA LEPIDA, Cr.}

Phalena lepida, Cram., Pap. Exot., II, t. I30 E.

Parasa lepida, Hmpsn., Faun. Ind. Moths, I, 388, f. 264 ; Lefroy, Ind. Ins. Life, p. 500 , f. $33^{6}$; I.M.N., III, No. 4 , p. I3, figs.

Distribution.-- Throughout Southern India.

Lifehistory.-Full-grown caterpillar $15-25 \mathrm{~mm}$. long, squat and stout; in colour bright green with a broad interrupted blue stripe lown the back and a narrower blue stripe along each side; both dorsal and lateral stripes are bordered by a row of warts from which arise thick spreading brushes of short spinous hairs; at each 
extremity the two internal hair tufts are much larger than the rest. In walking, the legs are not visible and the caterpillar moves with a sluglike motion. Pupation in a tough shell-like rounded cocoon, often found in numbers together on tree-trunks. Pupation period three to five weeks or longer.

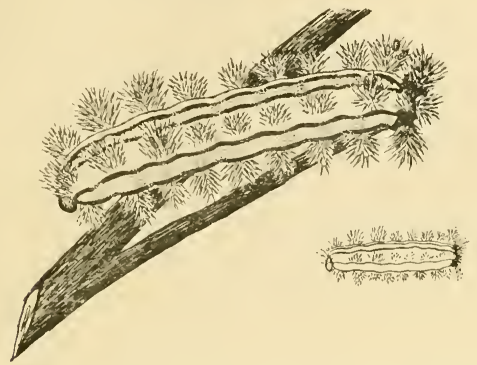

FIG. 283.-Parasa lcpida, larra. The small figure shows the natural size. (Original.)

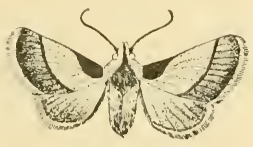

FIG. 2\&4.-Farasa lcpida. moth. IOriginal.।

Foodplants.--Castor, mango, ccccnut, palmyra, wcod-apple, pepper, pomegranate, cauliflower, tea, ccffee. Polyphagcus.

Status.-An occasional serious pest, even of large trees, which it strips entirely of leaves.

Control.-(I) In the case of low-growing trees and shrubs the larvæ, being more or less gregarious, may be hand-picked, care being taken not to touch them with the bare hand as the larval spines are very poisonous.

(2) Spraying with Lead Arsenate or similar poison. Crushing of pupæ in the cocoons on tree-trunks.

ALTHA NIVEA, WIk.

Altha nivea, W1k., J.L.S., VI, I73; Hmpsn., Faun. Ind. Moths, I, 397, f. 273; Lefroy, Ind. Ins. Life, p. 499. 


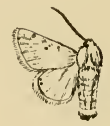

Fig. 285. Altha nivea. (()riginal.)

Distribution.-Bellary, Coimbatore. Probably throughout Southern India.

Lifchistory. - The round shell-like cocoons have been found on the stem of castor-plants, below the surface of the ground.

Foodplants.-Castor (Ricinus communis).

Status.-Not known to do any damage.

NYMPHALIDÆ.

MELANitis ISMENE, Cram. [Plate L, FigS. 7 9.]

Pupilio ismene, Cram., Pap. Exot., I, t. 26, ff. A, B (I775).

Melanitis ismene, Lefroy, Ind. Ins. Pests, p. I22, f. I39, Ind. Ins. Life, p. 4 I0, t. 29; Bingham, Faun. Ind. Butt., I, I58 I59, f. 36.

Distribution.-Throughout Southern India, occurring from sealevel to elevations above 7,000 feet.

Lifchistory.--The round, white eggs are laid on leaves of grasses on which the larva feeds. This latter is pale green with a roughened skin, with a darker head bearing a pair of horn-like processes and with the anal extremity produced into two slender processes; it feeds chiefly at night, remaining immobile during the day-time. The stout, smooth, pale green pupa is slung by the tail from a grass-stem or leaf.

Foodplants.-Grasses.

Status.--A pest of paddy but as a rule does very little dlamage, its numbers being probably checked by parasites and natural enemies.

\section{PAPILIONIDÆ.}

\section{PAPILIO DEMOLEUS, Linn. [PLATE XXV.]}

Papilio demoleus, Linn., Syst. Nat., X, 464 (1758) ; Bingham, Faun. Ind. Butt., II, 39-40, f. 7; Lefroy, Ind. Ins. Pests, pp. I74-I77, ff. I95-I97, Ind. Ins. Life, pp. 422 423, ff. $291-292$.

Distribution.- Throughout Southern India.

Lifehistory.-The rounded greenish-white eggs are laid on leaves of Citrus of various kinds. The young larva is brownish or blackish with an irregular, broad, conspicuous white bar across its back, and is protected by its resemblance to a bird's dropping. The 


\section{EXPLANATION OF PLATE XXV. \\ PAPILIO DEMOLEUS.}

Fig. x. Eggs laid on leaf, magnified.

,. 2-5. Larvæ in various stadia.

.. 7. Larva suspended for pupation.

.. S. Pupa.

, 9, ro, Butterfly. 


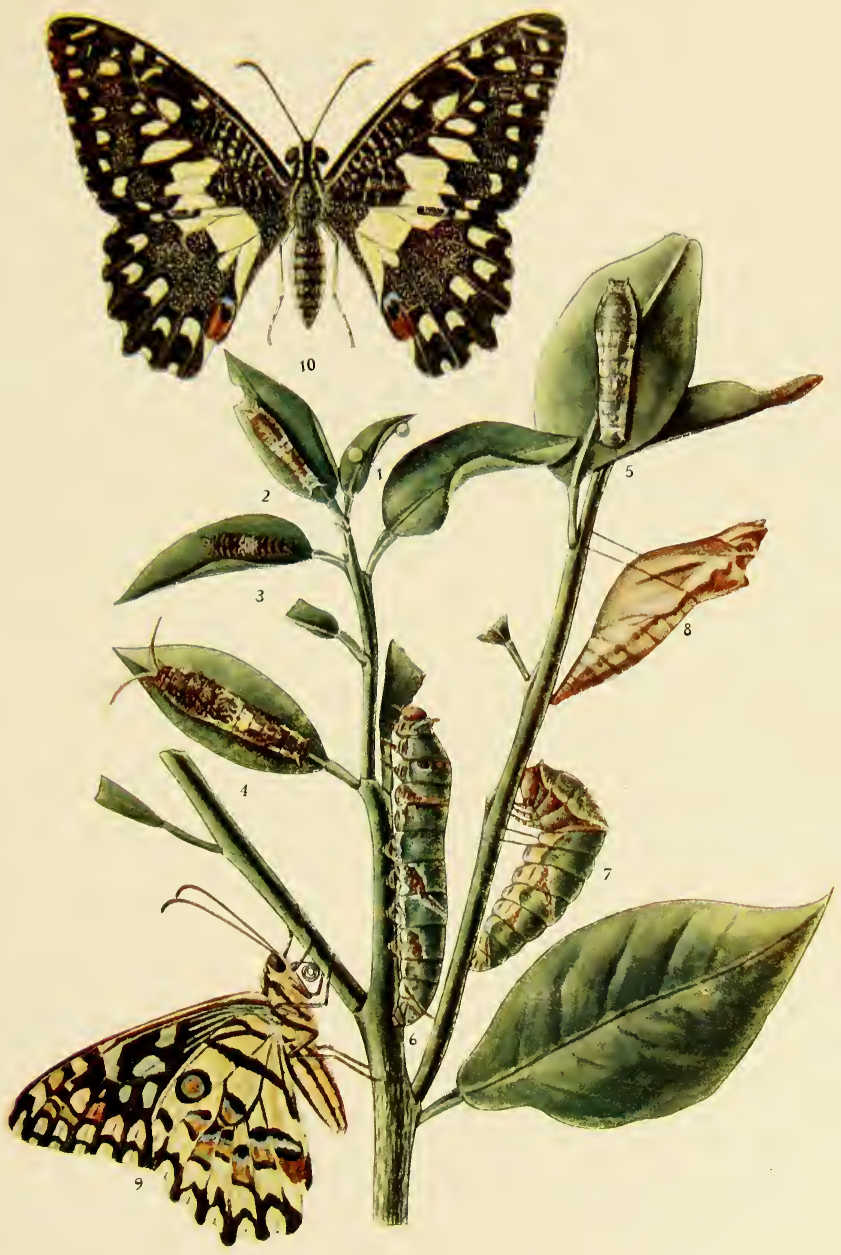



full-grown larva is green with oblique brownish cross-bands. Pupa pale brownish or greenish slung by a girdle and anal pad. The larval and pupal periods are each of about a fortnight's duration.

Foodplants.-Various species of Citrus (Orange, Citron), Bael (Egle marmelos) and other Rutaceæ. Also occasionally on Psoralea corylifolia (Tel. Batunchi) sometimes on curry-leaf plant (Murraya kanigi) (Tam. Karuveppilai).

Status.-Sometimes a serious pest, stripping all the leaves when in large numbers.

Control.-Hand-picking when the attacked bushes can be reached; the eggs and larvæ are fairly easily seen.

\section{PIERID E.}

CATOPSILIA PYRANTHE, Linn.

Papilio pyranthe, Linn., Syst. Nat., X, 469 (I758).

Catopsilia pyranthe, Lefroy, Ind. Ins. Life, p. 418, f. 289; Kershaw, Butt. Hongkong, pp. I00-IOI, t. 7, f. 9, t. II, f. 5, t. I3, f. 9, t.34, ff. 2 I 22 ; Bingham, Faun. Ind. Butt., II, 22I -223.

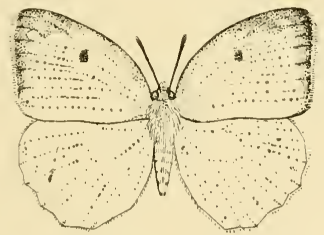

Fig. 286.-Catopsitia pyranthe. (Original.)

Distribution.-Throughout Southern India.

Lifchistory.-The egg is spindle-shaped, white and almost smooth, and is laid singly on the leaves and stems of the foodplant. The larva has a roughened skin and is pale leaf-green in colour with a lateral row of nearly-continuous black dots above a longitudinal pale-yellow stripe. Pupa smooth, pale green, attached to a twig or leaf by a girdle and anal patch of silk.

Foodplants.--Cassia occidentalis and C. auriculata, Sesbania and probably other Leguminosa.

Status.-Rarely a pest though it often occurs in very large numbers. On one occasion, however, the caterpillars of this butterfly were sent as destructive to Sesbania in the Cumbum range, Madura district; but various noctuid caterpillars were also concerned in this case. 
TERIAS HECABE, Linn.

Papilio hecabe, Linn., Syst. Nat. (ed. X), p. 470 (I 758).

Terias hecabe, Bingham, Faun. Butt., II, 250-254, ff. 60-62 ; Swinhoe, Lep. Indica, VII, 50-56, t. 567.

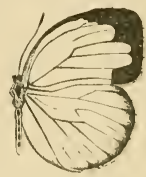

FIG. 287.--Terias hecabe. (Original.)

Distribution. - Throughout.

Lifchistory. - The smooth, white, spindle-shaped egg is attached singly to the upperside of the leaves of the foodplant. Larva rather slender, pale-green with a white stripe along the side, the skin rather roughened and sparsely covered with short hairs which are probably hollow as minute drops of liquid may be seen apparently exuded from their tips, so as to give the larva sometimes the appearance of being irrorated with white. Pupa attached by the tail and slung by a girdle from a stem or leaf of the foodplant; usually pale-green, slender, rather sharply pointed anteriorly. The caterpillar and pupa are usually difficult to see on their foodplants.

Foodplants.-Agathi, Daincha and other species of Sesbania and Cassia.

Statns.-Scarcely a pest as a rule but sometimes strips the leaves of the foodplants especially in the case of young plants. Occasionally a pest of Albizzia planted as shade for tea, etc

Control.-Spraying with Lead Arsenate, Lead Chromate, etc., in the case of localized attacks, young nursery beds, etc.

\section{LYCANID E.}

CATOCHRYSOPS CNEJUS, Fb. [PLATE XXVI.]

Hesperia cuejus, Fab., Ent. Syst. Suppl., p. 430 (1798).

Catochrysops cnejus, Bingham, Faun. Ind. Butt., II, 4I 5 4I6; Lefroy, Ind. Ins. Life, p. 427, t. 32.

Distribution.-Throughout the Plains of Southern India.

Lifehistory. - The rounded highly sculptured egg is laid on flowerbuds. The newly-hatched larva bores into the bud, feeding on the unopened flower and after eating that it attacks another flower or enters a pod where it feeds on the unripe seeds. When full-grown it is about I3 mm. long, flattened, pale-greenish or yellowish, 



\section{EXPLANATION OF PLATE XXVI. CATOCHRYSOPS CNEIUS.}

FI'. I. Eggs laid on a shoot of black gram (Phasenlus radiatus).

"2. Egg, magnified.

" 3. Larva boring into a pod.

,. 4, 5. Larvæ.

"6. Pupa on a pod, at the base of which is seen the hole bored by the larva with pellets of brown excreta around it.

" 7, 8. The butterfly. 


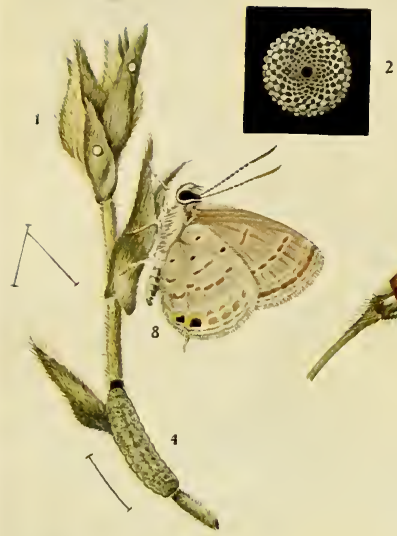

2
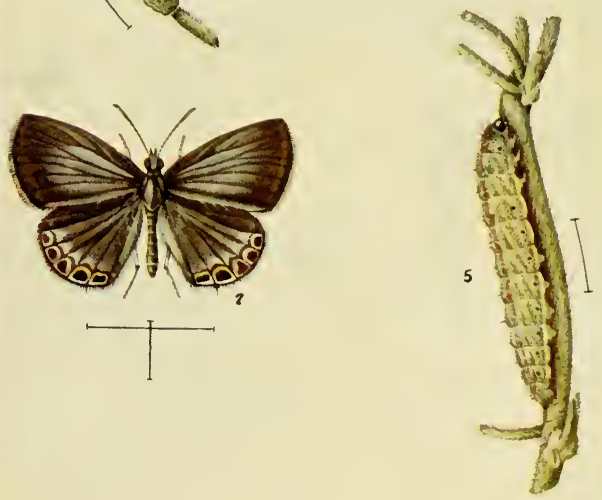

CATOCHRYSOPS CNEJUS. 

covered with short spine-like hairs. "When full-grown the larva descends to the ground, enters the earth at the base of the stem of the foodplant and there constructs a weak cocoon of silk in which it transforms into a dark-coloured rounded pupa provided with a slight silken girdle " [Y.R.R.] but, sometimes at least, pupation is effected on or amongst the leaves of the foodplant.

Foodplants.-Red-gram, Lab-lab and other pulses.

Status.-Serious injury may be done when this insect is in large numbers, a very large proportion of the pods being completely emptied of their contents.

Control.—?

POLYOMMATUS BEETICUS, Linn.

Papilio boticus, Linn., Syst. Nat. (ed. XII), I, 789 (I767).

Polyommatus boticus, Bingham, Faun. Ind. Butt., II, 432-434; Lefroy, Ind. Ins. Life, p. 428; Kershaw, Butt. Hongkong, p. 75, t. 9, ff. 2 , 10 .

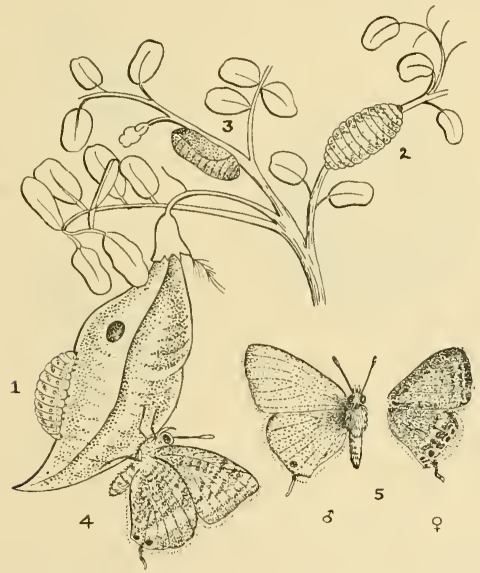

Fig. 285.-Polyommatus baticus: 1,2, Larva ; 3, Pupa; 4, Butterfly in resting attitude showing underside of wings; 5 , Butterfly, left male, right female. (Figs. $1-3$ after Lang, +-5 original.)

Distributiou.-Throughout Southern India.

Lifchistory.-Eggs are laid on flower-buds and pods into which the young newly-hatched larvæ burrow. The full-grown larva is 
about $12 \mathrm{~mm}$. long, pale-green, with a roughened skin. The short squat pupa is pale yellowish-green or greyish, smooth, with a double sub-dorsal series of small blackish spots; pupation usually on a leaf, twig, or pod of the foodplant.

Foodplants.-Crotalaria and Pisum of various species, and probably on most pulses.

Status. - May be a serious pest in localities where Crotalaria is grown for seed.

Control.--?

VIRACHOLA ISOCRATES, Fabr.

Hesperia isecrates, Fab., Ent. Syst., III, i, 266-267 (I 793).

Thecla isocrates, Westw., T.E.S., II, I-8, t. I (I835).

Virachola isocrates, Lefroy, Ind. Ins. Pests, pp. I79-I80, ff. I99-206, Ind. Ins. Life, p. 428, f. 293.
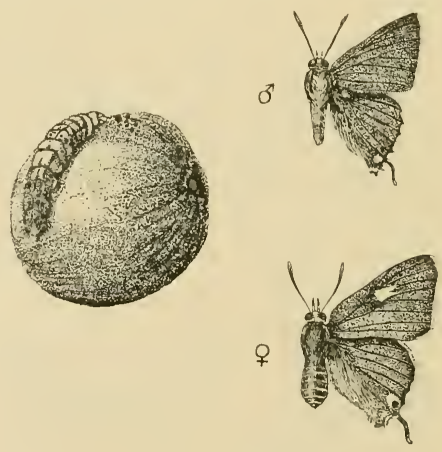

FIG. 289.- Tirachole isocrate's, larva and male and female butterfly. (Larva after Lefroy: other figures original.)

Distribution.--Throughout Southern India.

Lifehistory. - Eggs are laid on the flowers and buds, the larva boring into the fruit until full fed, when it emerges and secures the stalk of the fruit to the stem with a silken binding; this done, it re-enters the fruit and pupates.

Foodplants. - Pomegranate, guava, loquat, tamarind, orange.

Status.-Sometimes a serious pest of pomegranate, but only occasionally attacks other fruits. 



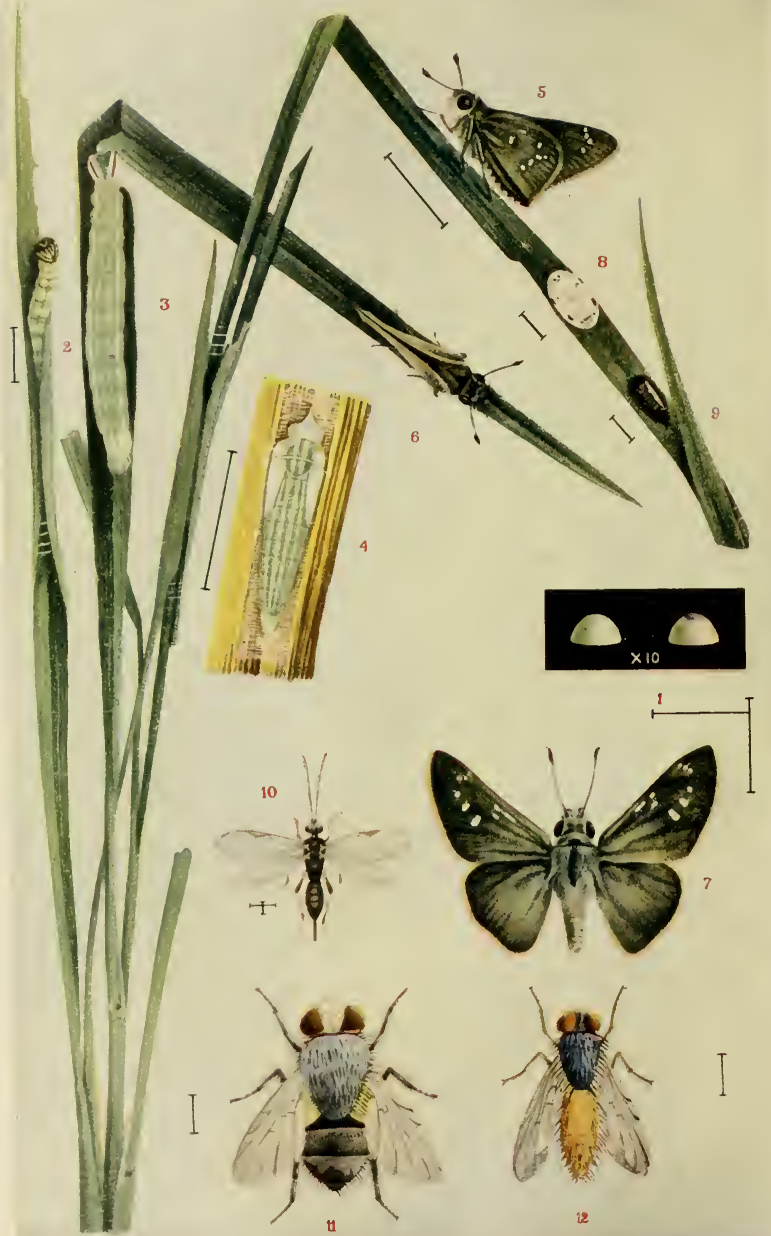




\section{EXPLANATION OF PLATE XXVII.}

\section{PARNARA MATHIAS.}

FIG, r. Eggs, lateral view $x$ ro.

„2. Joung larva rolling a leaf.

"3. Full-grown larva.

" 4. Pupa in rolled leaf.

" 5-7. Butterfly.

" 8, 9. Puparia of Tachinid parasites.

, ro. Hymenopterous parasite.

, rr, I2. Tachinid parasites.

(The lines alongside the figures show the natural sizes.; 

Control.-Destruction of attacked fruits, catching of butterflies by hand-nets, and perhaps covering of valuable fruit in muslin bags.

\section{HESPERIADÆ.}

GANGARA THYRSIS, Moore.

Papilio thyrsis, Fab., Syst. Ent., p. 532 (I775).

Gangar, thyrsis, Lefroy, Ind. Ins. Life, p. 43I, f. 295 ; Distant, Rhop. Malay, p. 394, t. 34, f. I3.

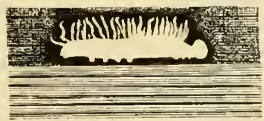

F1G. 290.-Gangara thyrsis. larva about half grown. (Original.)

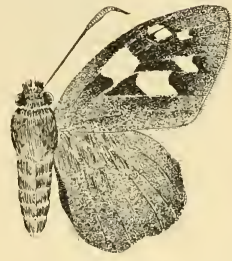

FIG. 291.-Gangara thyrsis. IOriginal.

Distribution.-Coimbatore.

Lifchistory and Foodplant.-The eggs are laid on leaves of various species of palms on which the larva feeds. The larva, when full grown, is pale greenish, reddish in parts, but the colour is concealed under long delicate white waxy filaments which form a fluffy secretion all over the larva ; it lives inside rolled up palm-leaves in which it also pupates. The greenish white pupa is about $27 \mathrm{~mm}$. long and attached by the tail to a stout silken cord spun across the leaf chamber in which it vibrates with great energy when disturbed so that it produces a loud rattling noise. The butterfly is on the wing only at dusk.

Status.-A minor pest which occasionally does some damage to ornamental palms and in nurseries of young coco-palms, etc.

Control.-The larva is easily found and collected by hand. The bitten leaves and fragments of white waxy secretion on the leaves give a good clue to its whereabouts.

\section{PARNARA MATHIAS, Fb. [PLATE XXVII.]}

Hesperia mathias, Fab., Ent. Syst. Suppl., p. 433 (I798).

Baoris mathias, Distant, Rhop. Malay, pp. 380-38I, t. 35, f. Io.

Parnara mathias, Kershaw, Butt. Hongkong, p. I30, t. VIIa, f. I ; Lefroy, Ind. Ins. Life, p. 43I, t. 33. 
Distribution.-Throughout the Plains of Southern India.

Lifehistory. - The larva is pale-greenish with indistinct pale yellowish-white bars across the back and a whitish line along the side; it lives in rolled up leaves of various grasses. The translucent pale-greenish pupa is formed on a blade of the foodplant, attached by the tail and a girdle.

Foodplants.--Grasses of various kinds, especially paddy, and more occasionally cholam, etc.

Status. - A minor pest as a rule.

Control.- - ?

Remarks.-The numbers of this butterfly are usually kept in check by numerous parasites and predators.

PARNARA COLACA, Moore.

Hesperia colaca, Moore, P.Z.S. (I877), 594, t. 58, f. 7 .

Parnara colaca, Lefroy, Incl. Ins. Life, p. 43I, f. 296.
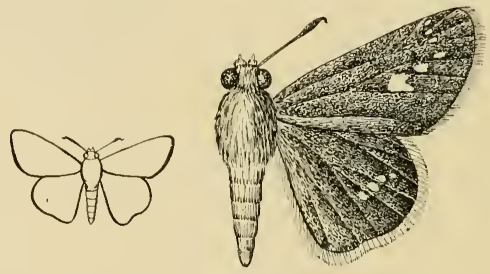

Fig. 292.-Parnara colaca. The outline figure shows the natural size. (Original.)

Distribution.-Chingleput (Saidapet and Madras).

Lifchistory.-Not known in detail.

Foodplant.-Paddy.

Status.- -Scarcely a pest.

\section{SUASTUS GREMIUS, Fb.}

Hesperia gremius, Fab., Ent. Syst. Suppl., p. 433 (I798).

Suastus gremius, Lefroy, Ind. Ins. Life, p. 43I ; Kershaw, Butt. Hongkong, p. 125, t. I4, f. 25, t. 7a, f. II ; Willey, Spol. Zeyl., VI, I25-I30, figs. (I909).

Distribution.--Bangalore, Godavari, Coimbatore. In July and August. (Probably throughout palm-growing districts all the year round.) 


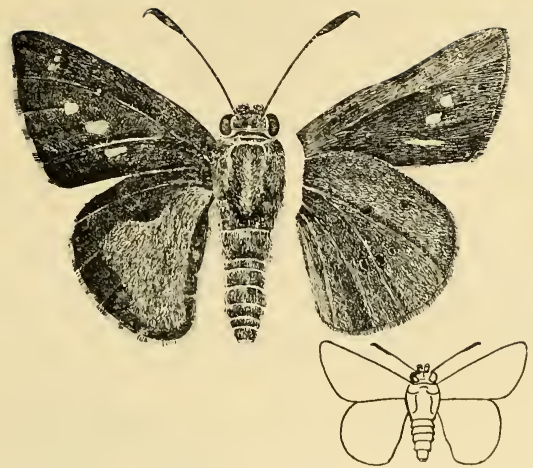

F1G. 293.-Suastus gremius. The ontline figure shows the natural size. (Original.)

Lifchistory.--The larva is pale-green with a narrow blue line down the back; it lives in tubes formed by rolling up portions of palm-leaves. When full fed, it closes the ends of this tubular-cell with silk and changes to a yellowish pupa. Prior to pupation the larval cell is sometimes cut adrift from the palm-leaf, the larva pupating on the ground.

Foodplants.-Palms, mostly palmyra. Also recorded from coconut palm.

Status.-A minor pest.

Control.- - ?

TELICOTA AUGIAS, Linn.

Papilio augias, Linn., Syst. Nat. (ed. XII), I, p. 794 (I767).

Telicota augias, Distant, Rhop. Malay, p. 382, t. 34, f. 23 ; Lefroy, Ind. Ins. Life, pp. $43 I^{-} 432$.

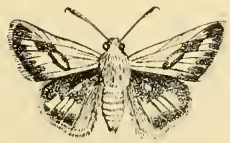

F1G. 294.-Tolicota augias. (Original.)

Distribution.-Vizagapatam, Coimbatore, South Arcot. Probably throughout Southern India all the year round. 
Lifchistory. - The greenish larva folds the leaves of the foodplant into tubular cells in which it lives and pupates.

Foodplants. - Sugarcane. Also saicl to feed on bamboo and paddy.

Status.-A minor pest, rarely doing much damage even when abundant.

Control.-In small cane-plots the larvæ may be hand-picked.

\section{UDASPES FOLUS, Cram.}

Papilio folus, Cram., Pap. Exot., I, t. 74, f. 7 (1779).

Udaspes folus, Davidson and Aitken, B.J., V, 37I-372 ; Lefroy, Incl. Ins. Pests, p. I68; Incl. Ins. Life, p. 432; Kershaw, Butt. Hongkong, pp. I36-I37, t. I4, f. 20.

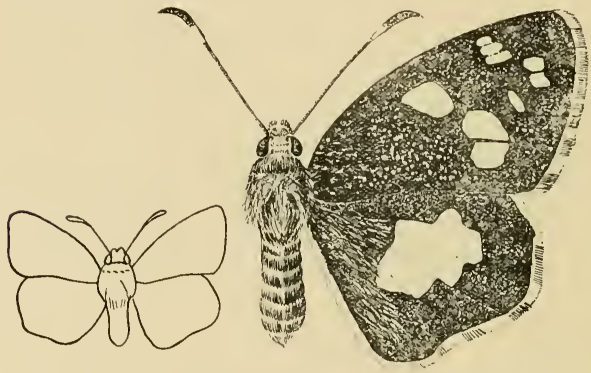

F1G. 295.-Cidaspes folus. The outline figure shows the natural size. (Original.)

Distribution.-Northern Circars and Coimbatore.

Lifchistory. - Larva greenish (either pale or dark) with a darker stripe along the back caused by the digestive tract being visible through the skin; head brownish or blackish. Pupa with the head-end prociticed into a beak, yellowish-white or greenish-white, attached by an anal pad and a girdle; pupation inside a rolled leaf but the pupa is not entirely concealed. Larva in a rolled leaf of the foodplant.

Foodplants--Ginger, turmeric, and probably wild lilies (Kershaw notes the foodplant at Hongkong as Alpinia nutans).

Status. - Rather a scarce insect as a rule but occasionally a serious pest of ginger and turmeric.

Control.- The folded leaves containing the larvæ and pupæ are easily seen and the insects collected by hand. 


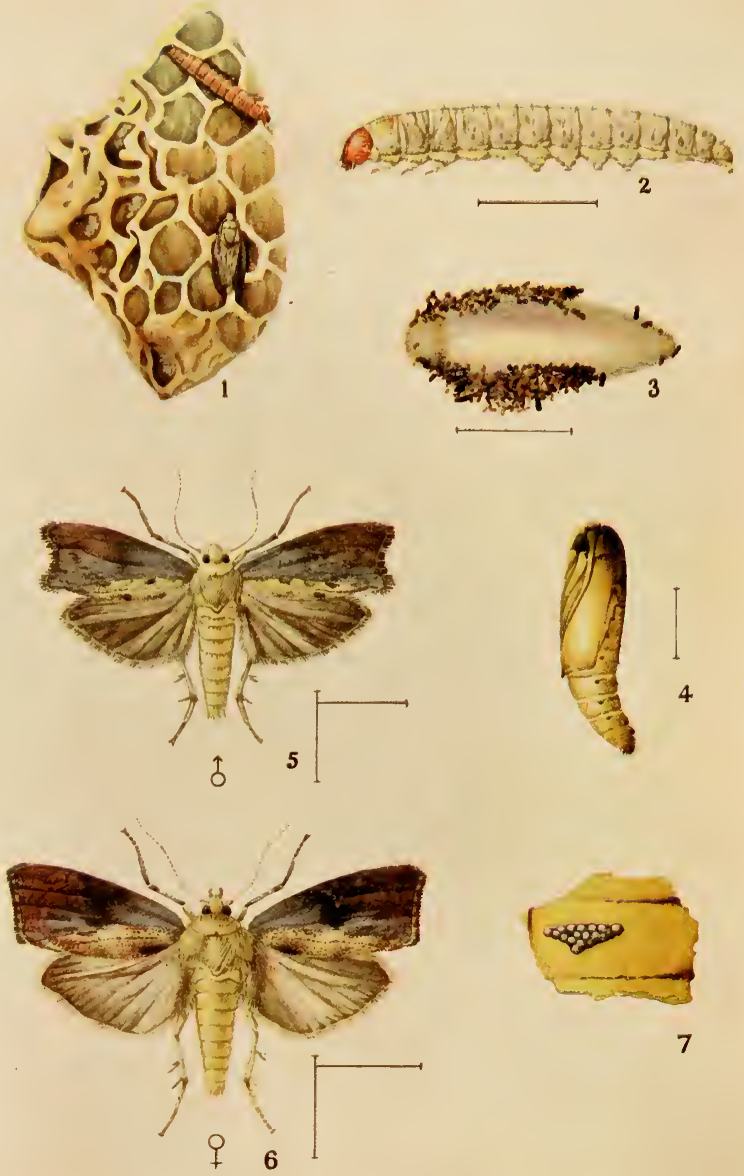


\section{EXPLANATION OF .PLATE XXIIII.}

\section{GAILERIA MELLONELLA.}

Fic. 1. Eggs, laria, and moth on comb, natural size.

. 2. Larva.

.. 3. Cocoon.

. 4. Pupa, removed frum cucuon.

, 5. Male moth.

"6. Female moth.

, 7. Eggs, enlarged.

(The lines alongside the figures show the natural sizes 

PYRALIDÆ.

STENACHROIA ELONGELLA, Hmpsn,

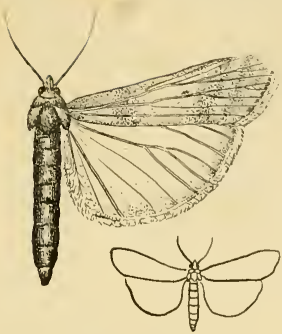

Fig. 296.-Stenachroia clon. gclla. The outline figure shows the natural size. (Original.)

Stenachroia elongella, Hmpsn., B.J., XII, 94, fig. ; Lefroy, Ind. Ins. Life, p. $5 \mathrm{IO}$.

Distribution.-Bellary.

Lifehistory.--Not known. Caterpillar webs over earheads on which it feeds.

Foodplants.-Earheads of cholam. Status.-An occasional but very local pest of cholam, doing consiclerable damage when in large numbers.

Control-Destruction of firstattacked heads.

GALLERIA MELLONELlA, Linn. [PLATE XXVIII.]

Phalcua mellonella, Linn. Syst. Nat. (ed. X), p. 537 (I758).

Galleria mellonella, Hmpsn., Faun. Ind. Moths, IV, 9, f. 8 ; Lefroy, Ind. Ins. Life, pp. 500-50I, f. 338 ; Fletcher, A.J., I, Oct. I9I I, tab.

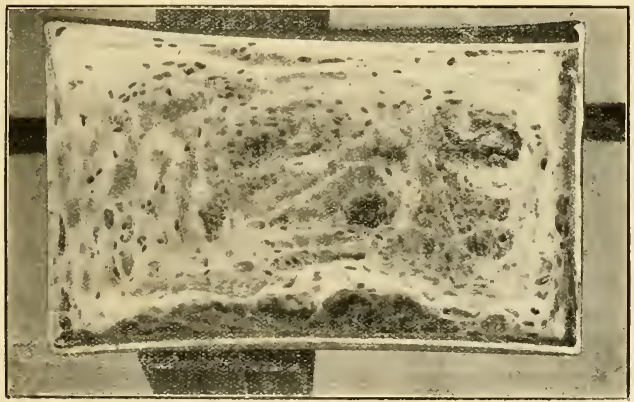

FIG. 297.-Frame of Bee-hive webbed with silk by larvæ of Galleria mellonella. (After Lefroy.)

Distribution.-Throughout Southern India.

Lifehistory.-Eggs are laid singly or in small clusters on wax combs of Bees' nests. The larva tunnel through the wax, on which 
they feed, lining their tunnel with silken webbing. The full-grown caterpillar is about $20-25 \mathrm{~mm}$. long, moderately stout, smooth except for a few short bristly hairs, dirty-white with a yellowish head. The pale-yellowish pupa is enclosed in a tough oval cocoon of white silk, usually spun in a crack or crevice and often covered with larval excreta on the outside.

Food.-Wax of Bees' combs.

Status.-A pest of Apiaries.

Control.-Colonies of bee should be kept strong. The use of bar-frame hives, coupled with regular examination of the combs, will keep this pest in check. Wax foundation should be kept in tight boxes to which the moths cannot obtain access.

\section{DIATRÆA Sp.}
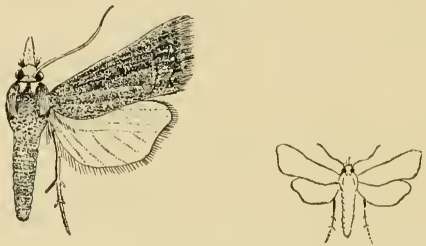

Fig, 298.-Diatrea sp. The outline figure shows the natural size. IOriginal.)

Distribution.- Probably throughout the Plains of Southern India.

Lifehistory.-Not known in detail. Caterpillar, a borer in stalks of cane, whitish with dark warts from which arise bristly hairs. Pupa slender, brown, in larval tunnel.

Foodplant.--Sugarcane. Occasionally (exceptionally) in cholam.

Status.-A serious pest of sugarcane.

Control. - The shoots attacked by the caterpillars wither and show as dead-hearts. These should be cut out and burnt to prevent the moths emerging and spread of the attack. If this is done at once, while the crop is young, new shoots will be thrown up and no loss of crop occur.

Remarks.-This insect has hitherto been confused with Chilo simplex, but is distinct in structure, habits and main foodplants. It is perhaps Diatraa venosata, Wlk., of which striatalis, Snellen, well known as a serious pest of cane in Java, is a synonym.

CHILO SIMPLEX, Butl.

Chilo simplex, Butl., P.Z.S. (1880), 690; Hmpsn.; Faun. Ind. Iloths, IV, 26, f. I7 ; Lefroy (partim), Ind. Ins. Pests, pp. I25-I30, ff. 
I4.3-150 ; Ent. Mem. Agri. Dept., Ind., I, I95, ff. 57, 58 ; Ind. Ins. Life, pp. 5 I0 5II, t. 47 , ff. I, 4. I5, I6 ; Hmpsn., B.J., XXI, I 250.

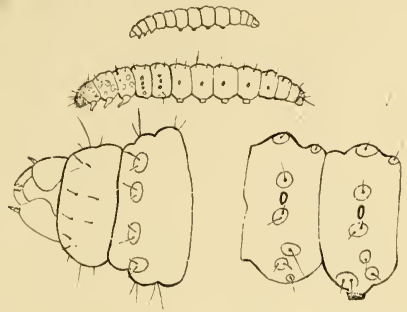

FIG. 299.- Chilo simplex, larva. The outline figure above shows the natural size: the lower figures show details on a larger scale. (Original.)
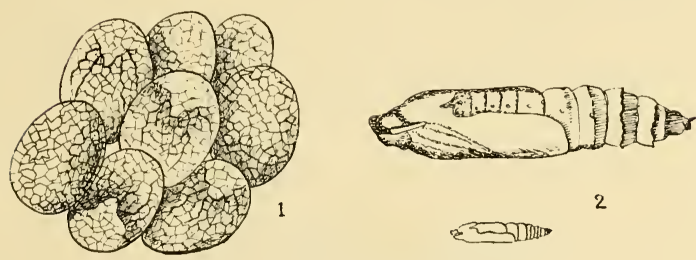

23010
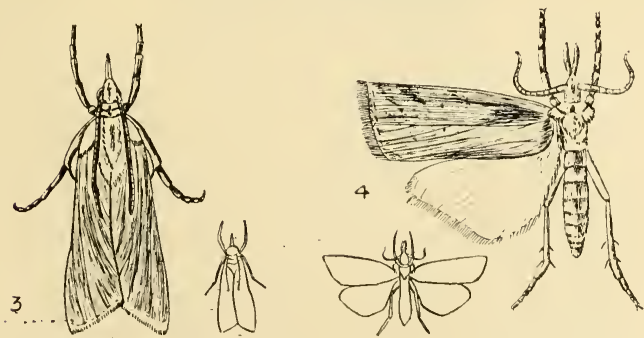

FIG. 300-Chilo simplex : 1. Cluster of Eggs as laid: 2. Pupa; 3, Moth in $\because$ resthy attitude $\because$ f. Xfoth. The smaller figures show the naturál sizes. (Author's original illustration.) 
Distribution.- Throughout the Plains of Southern India.

Lifehistory.-Eggs are laid in masses overlapping one another. Caterpillar dirty-white or pinkish-grey with numerous small dark warts bearing short bristly hairs, head brownish, thoracic plate horny. Pupa rather slender, yellow-brown, in gallery bored by the larva in the stems of the larger cereals.

Foodplants.-Cholam, ragi, maize, occasionally in cumbu and sugarcane.

Status.--A serious pest of cholam, ragi and maize, the larva boring down the stem which it hollows out so that the whole upper part of the stem is filled with rotting excremental matter.

Control.--(I) In large areas it is not practicable to pull out the early affected plants but this can be done in small experimental plots and the like.

(2) The female moths are attracted by light at night and numbers can be caught at times by light-traps placed in and near the affected fields. This is probably the only practical measure on a large scale.

\section{ANCYLOLOMIA CHRYSOGRAPHELLA, Koll.}

Chilo chrysographelhis, Kollar, Hugels Kaschmir, IV, 494.

Ancylolomia chrysographella, Hmpsn., Faun. Ind. Moths, IV, 33 ; Lefroy, Ind. Ins. Life, p. 5I I ; Ent. Mem. Dept. Agr., Ind., I, I98.

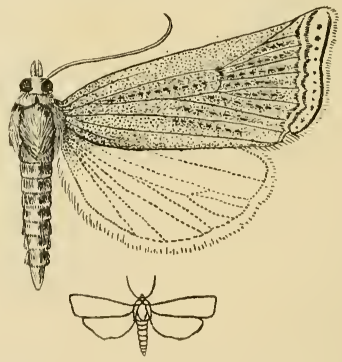

Fig. 301.-Ancyloloma chrysographella. The outline figure show's the natural size. (Original.)

Distribution.--Throughout Southern India.

Lifihistory.-Caterpillar about $20-25 \mathrm{~mm}$. long, cylindrical, slender, smooth, with short prolegs, in colour pale-green with blackish head and plate on prothorax. The caterpillar feeds at night, remaining during the day in hiding underground in long tubular 
galleries lined with silk or may be found at the roots of its foodplant. Pupation in larval gallery; pupal period about ten days. (T.V.R.)

Foodplants.-Paddy, Paspalum dilutatum. Probably on all Gramineæ.

Status.-Only found on one occasion as a serious pest of paddy seedlings. It is, however, liable to occur at any time in dry, sandy localities.

Control.-(I) The moths are strongly attracted to light and lighttraps may be employed.

(2) In paddy seed-beds or small experimental areas, spraying of plants.

(3) Where practicable flooding of affected areas will bring up the larvæ which are greedily devoured by crows, etc.

\section{SCIRPOPHAGA AURIFLUA, Zeller.}

Scirpophaga amriflua, Zeller, Mon. Chil., p. 2 ; Hmpsn., Faun. Ind. Moths, IV, 46; Lefroy, Ind. Ins. Pests, pp. I $30-I 33$, f. I52; Ent. Mem. Agri. Dept., Ind., I, I99, f. 59; Ind. Ins. Life, p. 51 I, t. 47, ff. $2,5,14,17$.

Scirpophaga intacta, Snell, Tijd. v. Ent. (I89I), 343, t. XVIII, ff. I-4; Lefroy, Ind. Ins. Life, t. 47, f. Io.

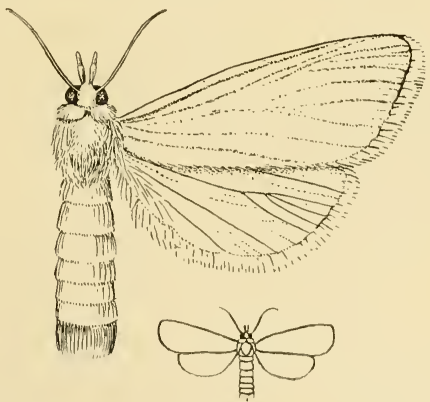

F1G. 302,-Scirpophaga auriflua. The outline figure show's the natural size. (Original.

Distribution.-Throughout the Plains of Southern India.

Lifchistory.-Eggs are laid on a leaf in a cluster covered with the orange hairs from the anal tuft of the female moth. Caterpillar dirty yellowish-white, rather stout, smooth except for a few short 
bristly hairs; burrowing in the stem of young plants, in top-shoots of older ones. The yellowish, elongate pupa in the larval burrow.

Foodplant. -Sugarcane.

Stutus.-A rather minor pest of cane in Southern India.

Control.--(I) Cutting out and destruction of affected top-shoots.

(2) Attraction of moths by light-traps.

SCIRPOPHAGA MONOSTIGMA, Zeller.

Scirpophaga monostigma, Zell., Mon. Chil., p. 3 ; Hmpsn., Faun. Ind. Moths, IV, 46; Lefroy, Ent. Mem. Agri. Dept., Ind.. I, 200, f. 60 ; Ind. Ins. Life, p. 5 II, t. 47 , f. 3 .

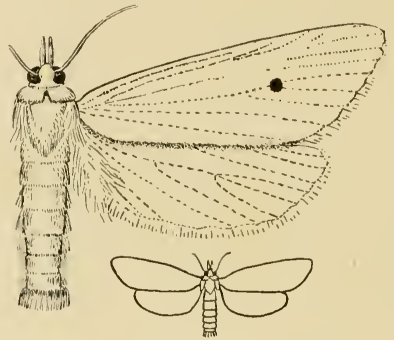

FIG. 303.-Scirpophaga monostigma. The outline figure shows the natural size. (Original.)

Distribution.-Coimbatore; probably throughout the submontane districts of Southern India.

Lifehistory.-Probably the same as in S. auriflua.

Foodplant.-Sugarcane.

Status. - A rather minor pest of cane.

Control.-As in S. auriflua.

SCHCENOBIUS BIPUNCTIFER, Wlk. [PLATE XXIX.]

Schanohins bipunctifer, W1k., Cat. XXVIII, 523; Hmpsn., Faun. Ind. Moths, IV, 48, f. 32 ; Lefroy, Ind. Ins. Life, p. 512.

Distribution.- Throughout the Plains of Southern India.

Lifchistory.-Eggs are laid on leaves in clusters covered with yellowish hair derived from the anal tuft of the female moth. The caterpillar bores in the stems of paddy and perhaps of wild grasses. The full-grown caterpillar is about $20 \mathrm{~mm}$. long, slender, smooth, segments distinct, in colour. dull-whitish or yellowish sometimes with a green tint, head orange-yellow. Pupation-in the larval burrow which is lined with silk. The moth emerges through a hole previously cut by the caterpillar through the side of the stem. 



\section{EXPLANATION OF PLATE XXIX.}

\section{SCHCENOBIUS BIPUNCTIFER.}

Fig. 1. Egg-mass on leaf, natural size.

, 2. Egg-mass on leaf, magnified.

" 3. Larva.

, 4. Pupa.

"5. Stem cut open, showing cocoon.

, 6. Female moth, in resting attitude.

"7. Moth, male.

" 8. " female.

(The lines alongside the figures show the natural sizes. The plant shows a dead-heart characteristic of attack by the larva.) 
PLATE XXIX.

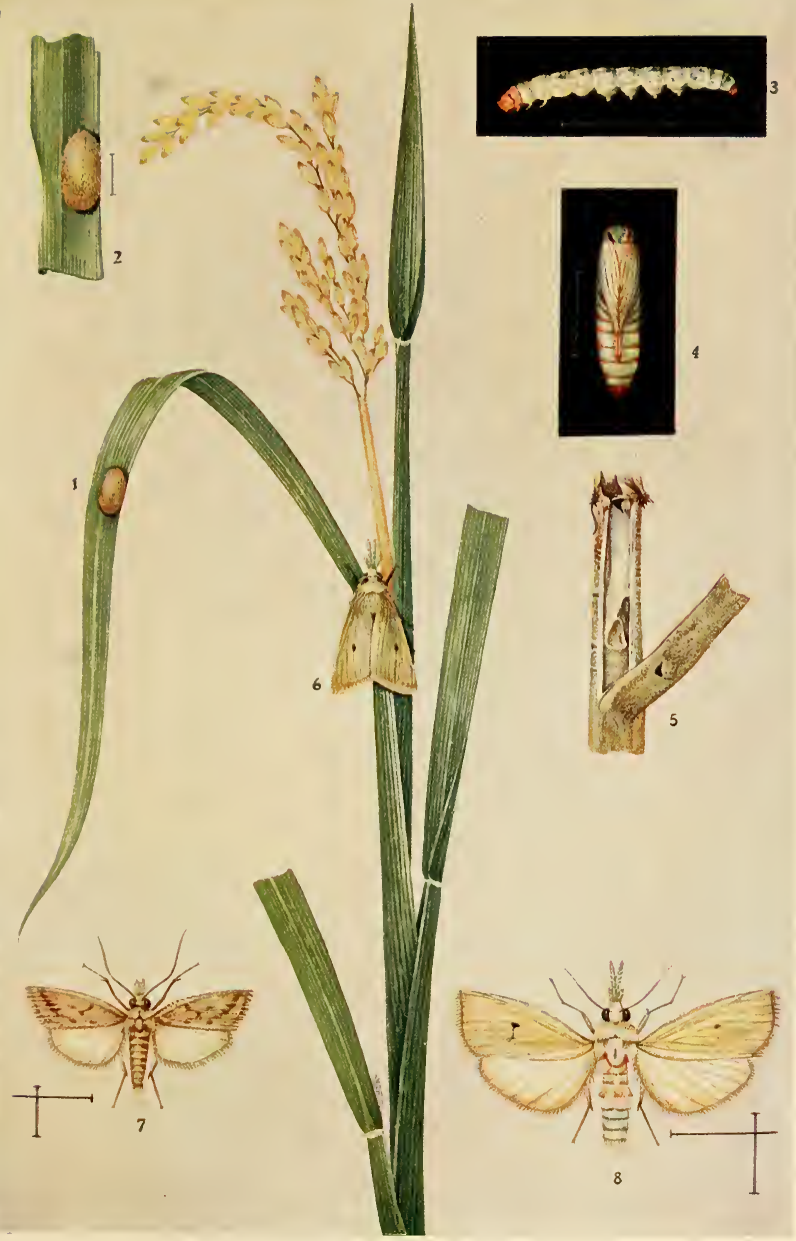



Foodplants.--Paddy.

Status.-A very serious pest of paddy in Southern India.

Control.-(I) The moths are strongly attracted at night to light and may be caught in large numbers by means of light-traps.

(2) The egg-masses are conspicuous and, when plentiful, are easily hand-picked.

(3) Paddy-stubbles should be ploughed up, and if possible burnt after the harvest is gathered.

SALURIA INFICITA, WIk.

Arrobasis inficita, W1k., Cat. XXVII, 30 (1863).

Poujadia inficita. Rag., Mon. Phyc., t. 44, f. 18 ; Hmpsn., Faun. Ind. Moths, IV, 58.

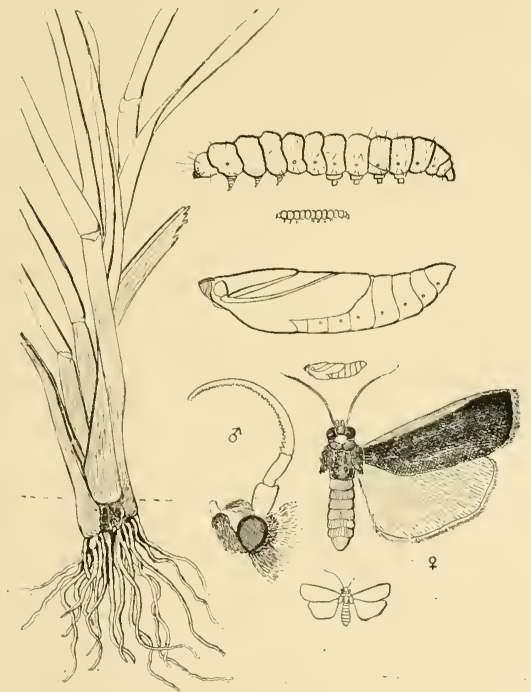

Fig. 304.- Saluria inficita. To the left is.a Ragi plant, cut open to show the larva boring inside just below ground-level, which is represented by the dotted line. The other figures show - the Larva, Pupa, Female Moth, and a profile view of head of Male Moth. The ontline finnures indicate the natural sizes. (Original.) 
Distribution.- Probably throughout the Plains but only actually noticerl at Coimbatore.

Lifchistory. - Not known in detail. The larva is moderately stoutly built, the prothoracic segment large, the next two segments short but projecting; in colour it is pure creamy-white, the head yellowish tinged with blackish around the mouth-parts; there are a few short, white, inconspicuous hairs on all segments. It bores into the stem of the foodplant low down at about or just above ground-level and pupates in the stem or emerges and pupates in a small chamber excavated in the soil.

Foodplants. Ragi.

Stutus. - A minor pest noted on the Central Farm at Coimbatore in August and September in 1908, 1909 and 1913.

Control.- The female moths are attracted to light at night.

\section{EUZOPHER.A PERTICELLA, Rag.}

Euzophra perticella, Rag., Nouv. Gen., p. 32 ; Hmpsn., Faun. Ind. Moths, IV, 73, f. 48; Lefroy, Ind. Ins. Pests, p. I66 ; Ent. Mem. Agri. Dept., Ind., I, 203; Ind. Ins. Life, p. 514, t. 48.

(SEe Plate XXX, Figs. I-4.)

Distribution.- Throughout the Plains of Southern India.

Lifchistory. - The caterpillar is about $20 \mathrm{~mm}$. long, morlerately stout, smooth except for a few bristly hairs, in colour yellowishwhite with an orange brown head. It bores in the stems of its foodplant. Pupa rather stout, red-brown, in a cocoon formed in the larval burrow.

Foodplant.-Brinjal, chillies, potato.

Status.-Sometimes a serious pest of brinjal, especially in gardens.

Control.-Destruction of affected plants which wither and die owing to the boring of the caterpillar in their stems.

\section{PHYCITA INFUSELLA, Meyr.}

Phycita infusella, Meyr., Proc. Linn. Soc. N.S.W., IV, 218 (1879); Lefroy, Ind. Ins. Pests, p. 99, ff. I10-II3 ; Ent. Mem. Agri. Dept., Ind., I, 205, f. 6I ; Ind. Ins. Life, p. 514.

Phycita bipartella, Hmpsn., Faun. Ind. Moths, IV. 90 (1806).

(SEE PLATE XXXI.)

Distribution.-Throughout Southern India.

Lifehistory. The full-grown caterpillar is $10-12 \mathrm{~mm}$. long, rather stout, smooth except for a few scattered bristly hairs, in colour pale- 


\section{EXPLANATION OF PLATE XXX.}

\section{PESTS OF BRINJAL.}

FIG. 1. Euzophera pericella, larva in its burrow in the stem.

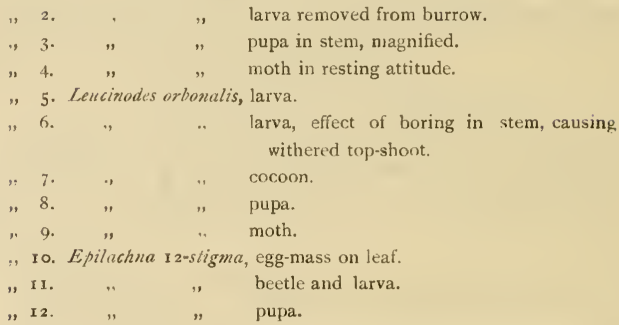




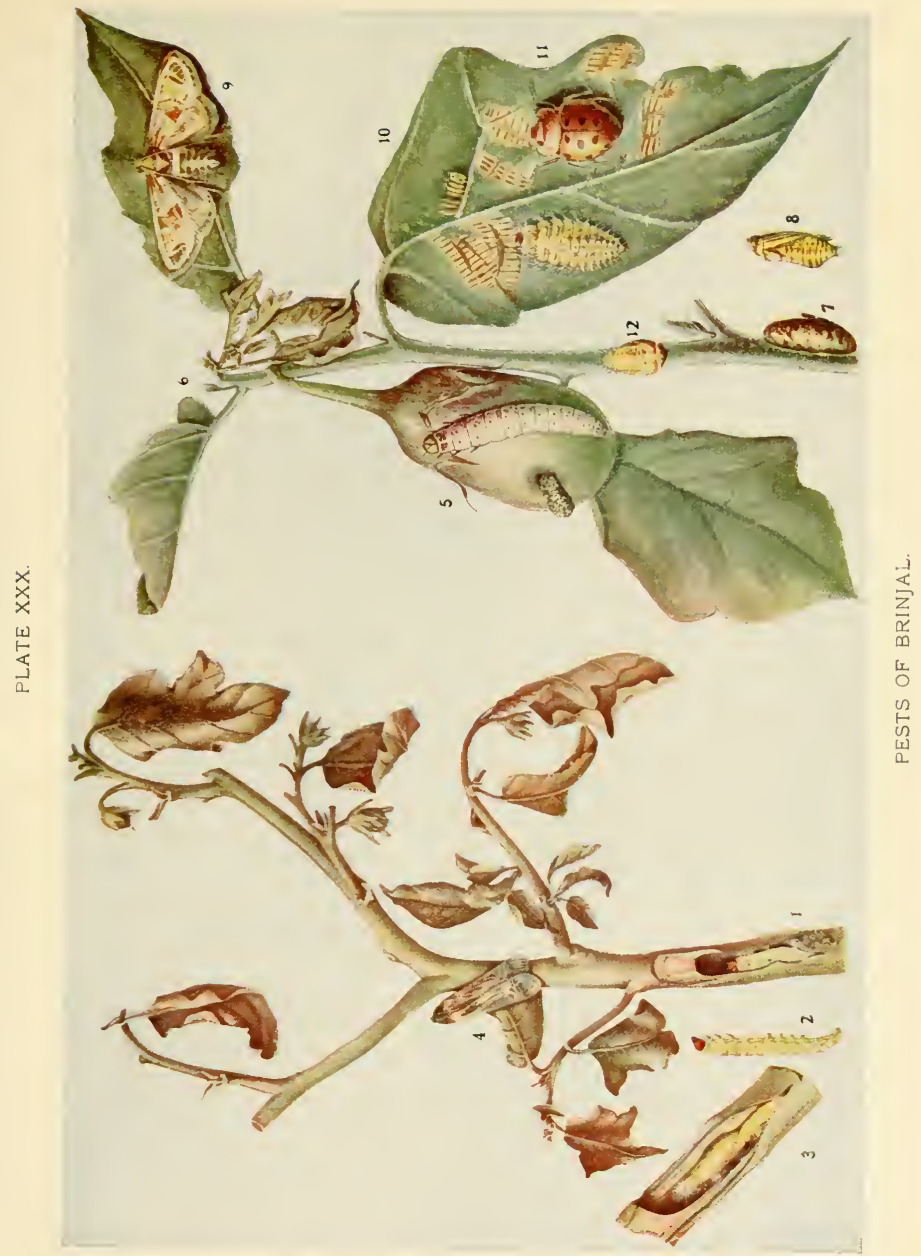






\section{EXPLANATION OF PLATE XXXI.}

\section{PHYCITA INFUSELLA.}

Fig. I. Larva, magnified.

,. 2. Pupa

.. 3, 4. Moth, magnified.

" 5. Top-shoot of cotton-plant webbed by larva showing characteristic brown knot of withered leaves.

(The lines alongside the figures show the natural sizes.) 
PLATE XXXI.

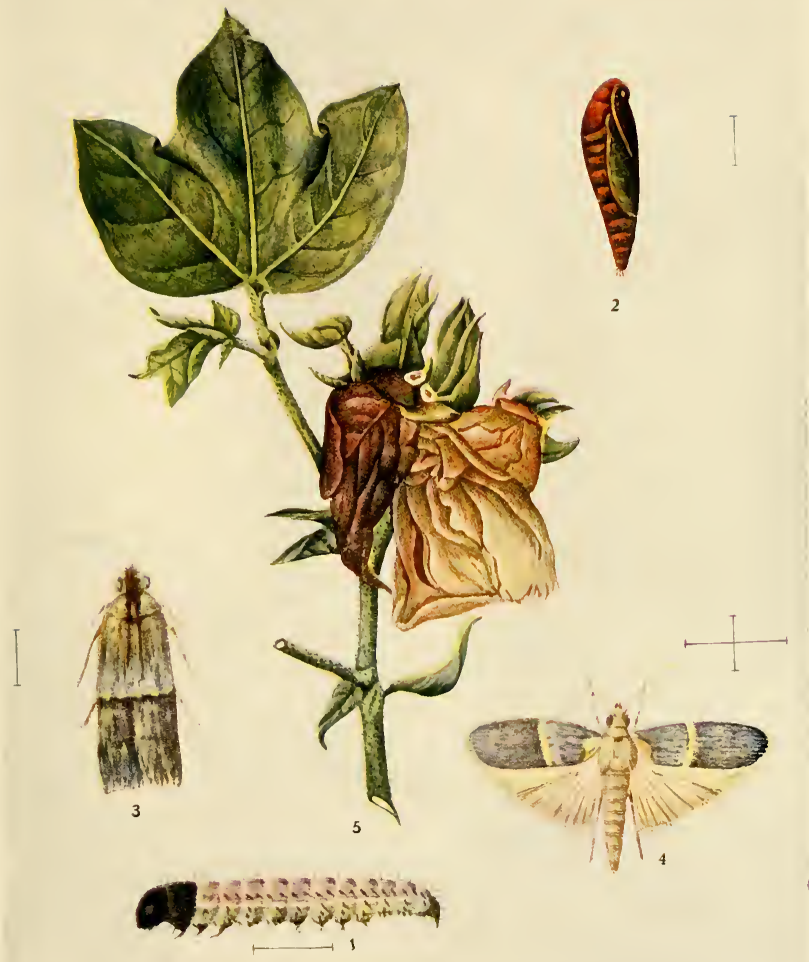

PHYCITA INFUSELLA. 

green with a blackish head and dark prothoracic shield. Pupation in a slight silken cocoon in folcled leaves. Caterpillar in top-shoots, which wither and drop.

Foodplant. - Cotton, Roselle and Gogu (Hibiscus cannabinus).

Stutus. - A minor pest of cotton, occasionally appearing in some numbers on young plants.

Control.--(I) Picking and destruction of affected top-shoots.

(2) Attraction of moths by light-traps.

ETIELLA ZINCKENELLA, Tr.

. . zinckenella, Treitschke, Schm. Eur., IX, p. $20 \mathrm{I}$.

Eticlla sinckcuella, Hmpsn., Faun. Incl. Moths, IV, 108-109; Lef roy, Incl. Ins. Life, p. 515 :

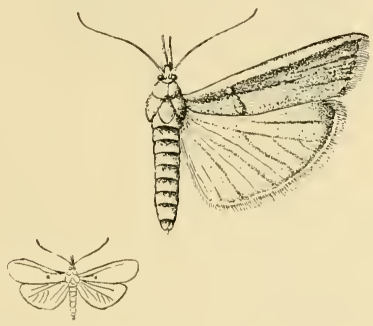

F1G. 305. -Etiella zinckenella. The ontline fignre shows the natural size. iOriginal.

Distribution... Throughout Southern India.

Lifchistory.--Caterpillar green with five black spots on prothoracic shield; when about to pupate it turns pink. Pupation in silken cocoon outside the pod.

Fondplants.-Horse-gram, Cowpea, Red Gram, Sann Hemp.

Status. - A minor pest of pulses as a rule, occasionally doing considerable damage, the whole of the seeds being destroyed in poris entered by the caterpillars.

Control.-?

MACALLA MONCUSALIS, wlk.

Maculla moncusalis, Wlk., Cat. XVI, 252; Hmpsn., Faun. Incl. Moths, [V, I13. 

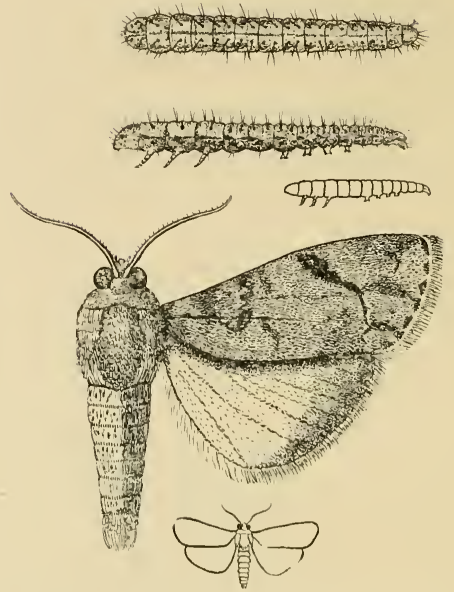

Fig. 306.-Macalla moncusalis, larva (dorsal and lateral views) and moth. The outline figures show the natural sizes. (Original.)

Distribution.--Throughout the Plains of Southern India.

Lifehistory and Foodplant.-The caterpillar webs mango-shoots and devours the young leaves. It is sometimes gregarious, several being found in one web. When full-grown it is about $25 \mathrm{~mm}$. long, rather stout, in colour brown with a paler stripe down the back and with a yellowish lateral stripe edged with dark-brown above; head pale brown, sprinkled with darker. Pupation in a slight silken cocoon ; pupa squat recl-brown.

Status.-A minor pest of Mango.

Control.- The webs are conspicuous and easily collected and the enclosed caterpillars destroyed.

\section{NYMPHULA DEPUNCTALIS, Gn.}

Nymphula depunctalis, Guen., Delt \& Pyr., p. 274; Hmpsn., Faun. Ind. Moths, IV, 195; Lefroy, Ind. Ins. Pests, 121 ; Ent. Mem. Agri. Dept., Ind., I, 207 ; Ind. Ins. Life, p. 515, t. 49.

(SEE Plate XXXII.)

Distribution.-Throughout the Plains of Southern India. 



\section{EXPLANATION OF PLATE XXXII. NYMPHULA DEPUNCTALIS,}

FIG. I. Full-grown larva, magnified.

, 2. Pupa.

"3. Pupa in cocoon, which is cut open to show the pupa.

, 4. Moth.

, 5, 6. Larvæ in their cases feeding on paddy-plant.

"7. Cocoon inside larval case.

. 8, 9, 10. Larval cases floating on the water.

(The lines alongsicle the figures show the natural sizes,) 
PLATE $X X X I I$.

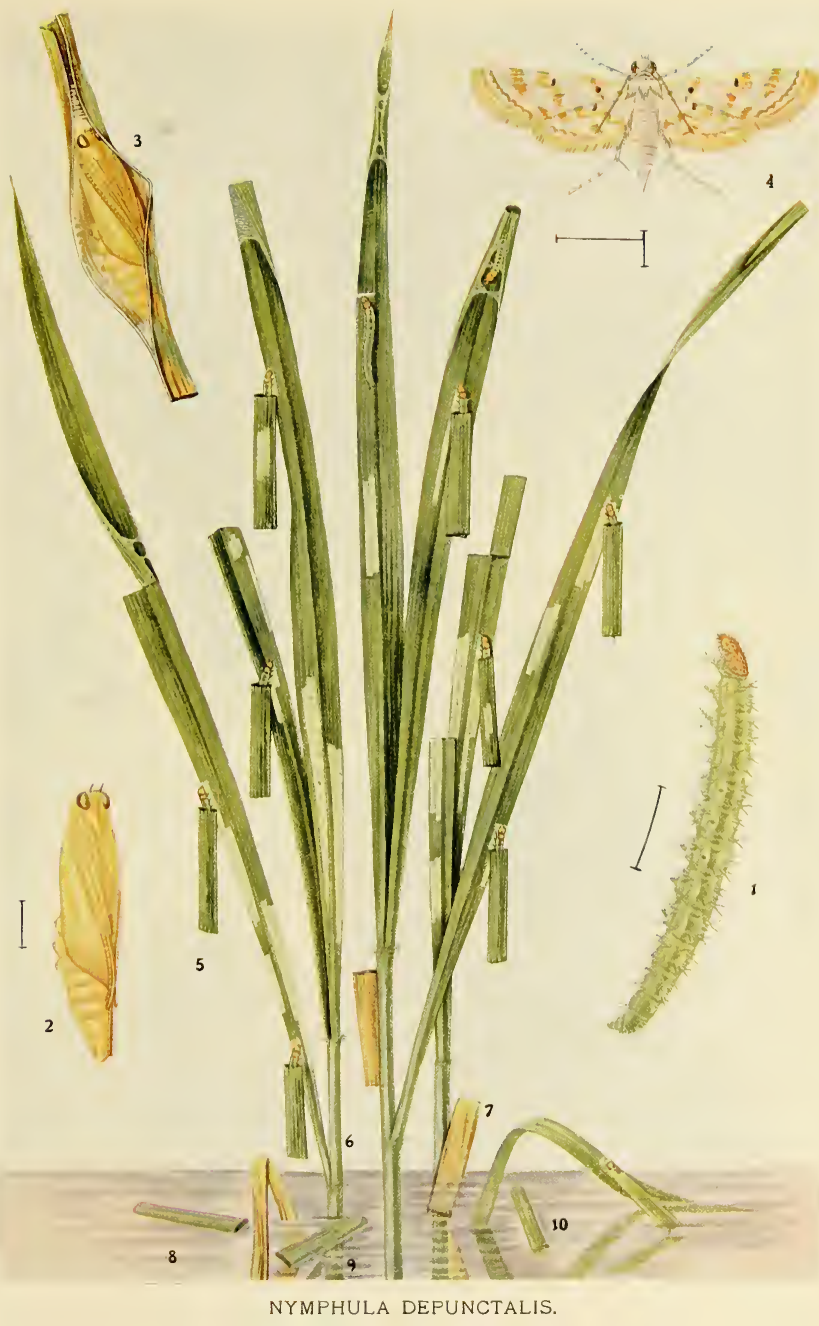



Lifelistory.--The caterpillar is semi-aquatic, living in cases made of rolled pieces of leaf, and is furnished with bunches of slender filamentous gills along the sides. The caterpillar is slender, about $15 \mathrm{~mm}$. long, in colour pale green with an orange head. It feeds on the green tissue of the leaf. Pupation in the larval case.

Foodplant.--Paddy.

Status.- A serions pest of Paddy, sometimes causing great damage.

Control.-Draining the water off the affected fields, when practicable, is indicated, but this is rarely possible. In some districts a thorny bush is dragged over the field to dislodge the larval cases and the water then clrained off; it is difficult to see what is the value of the thorny branch and the draining of the water is evidently the important factor where success is claimed in treatment of this pest.

\section{HYMENIA FASCIALIS, Cr.}

Phalcua fascialis, Cramer, Pap. Exot., IV, t. 398, f.O. (I782).

Phalana recurvalis, Fabr., Ent. Syst., III, ii, 237 (I794).

Zinckenia fascialis, Hmpsn., Faun. Ind. Moths, IV, 262, f. I58; Lefroy, Ind. Ins. Pests, p. I82; Ent. Mem. Agri. Dept., Ind., I, 208, fig. 62 ; Ind. Ins. Life, p. 5 I6.

Hymenia fascialis, Marsh, U.S.A. Entom. Bull. No. I09, Pt. I (I9I I).
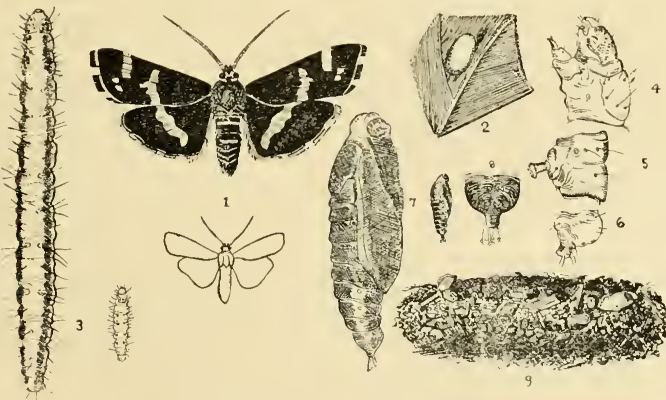

F1G. 307.-Hymenia fascialis. 1, Moth: 2. Esg (magnified); 3, Larva (magnified and natural size): +-6 , Details of Larva: 7. Pupa (magnified and natural size): 8, Anal extremity of Pupa showing cremastral hooks: 9, Cocoon. (Figs. 2-9 after Marsh.)

Iistribution. - Throughout Southern India. 
Lifchistory.--Caterpillar rather flattened, about $15 \mathrm{~mm}$. long with a pair of narrow wavy whitish lines along the back, and with lateral black spots on two of the thoracic segments. The reddishbrown pupa is enclosed in a thin coarse silken webbing between the folds of a leaf. Pupal period $6-7$ days; total lifehistory about four weeks.

Status.--Usually a minor pest of Amaranthus, occasionally doing serious damage in gardens.

Control.-Spraying in small areas. A mixture of Nicotine Sulphate, I fluid ounce; Whale Oil Soap, 4 ounces ; Water, 4 gallons is recommencled by Marsh for use on vegetables intended for consumption and with which it would be unsafe to use arsenical sprays. Care must be taken to apply the spray to both sides oî the leaf.

CNAPHALOCROCIS MEDINALIS, Gn.

. . medinalis, Guenee, Delt \& Pyr., p. 20I.

Cnaphalocrocis medinalis, Hmpsn., Faun. Ind. Moths, IV, 275, f. I66; Lefroy, Incl. Ins. Pests, p. I22; Ent. Mem. Agri. Dept., Ind., I, 209 ; Incl. Ins. Life, p. 5 I6.

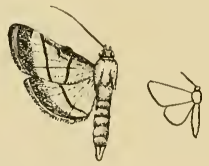

FIG. 308.-Cnaphalocrocis medinalis, male. The outline fisure shows the natural size. (Original.)

Distribution.- Throughout the Plains of Southern India.

Lifchistory.-The slender green caterpillar is about $20 \mathrm{~mm}$. long. It lives in folded leaves, which are not actually rolled but the tip is merely fastened over the broader basal part. Pupation in a brownish cocoon on the leaf; pupal period about 6 dlays. The caterpillars eat the leaf tissue so that the leaves become whitened and sickly.

Foodplants. Paddy. Probably on grasses also.

Status.-A minor pest of Paddy as a rule, occasionally doing consiclerable clamage in the Northern Circars. Not known as a pest in the Southern parts of Madras.

Control. - ?

MARASMIA TRAPEZALIS, Gn.

Botys trapezalis, Guenee, Delt. \& Pyr., p. 200.

Marasmia trapezalis, Hmpsn., Faun. Ind. Moths, IV, 277 ; Letroy, Ind. Ins. Pests, p. I38; Ent. Mem. Dept. Agri., Ind., I, 210, f. 63 ; Ind. Ins. Life, p. $5^{16 .}$ 


\section{EXPLANATION OF PLATE XXXIII.}

\section{MARASMIA TRAPEZALIS.}

Frs. I, 2. Larva, magnified.

"3. Pupa in rolled and damaged leaf.

" 4. Moth in resting attitude, natural size.

.. 5. Moth, enlarged.

(The lines alongside the figures show the natural sices.) 
PLATE XXXIII.

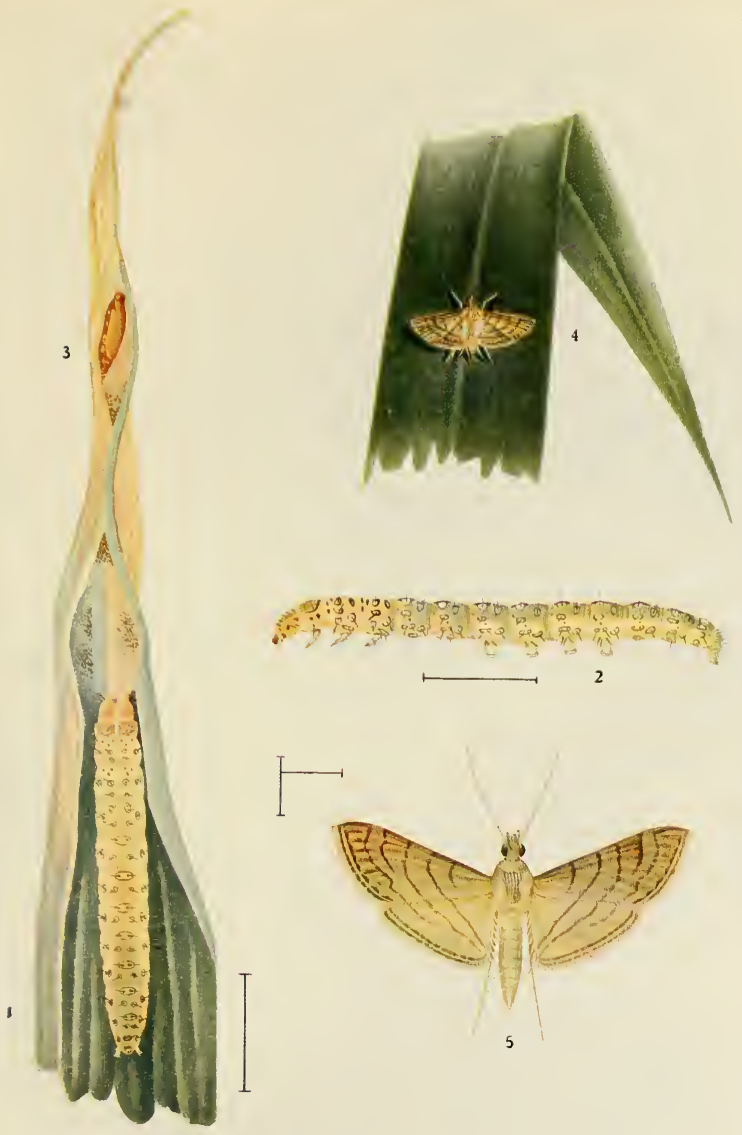

MARASMIA TRAPEZALIS. 



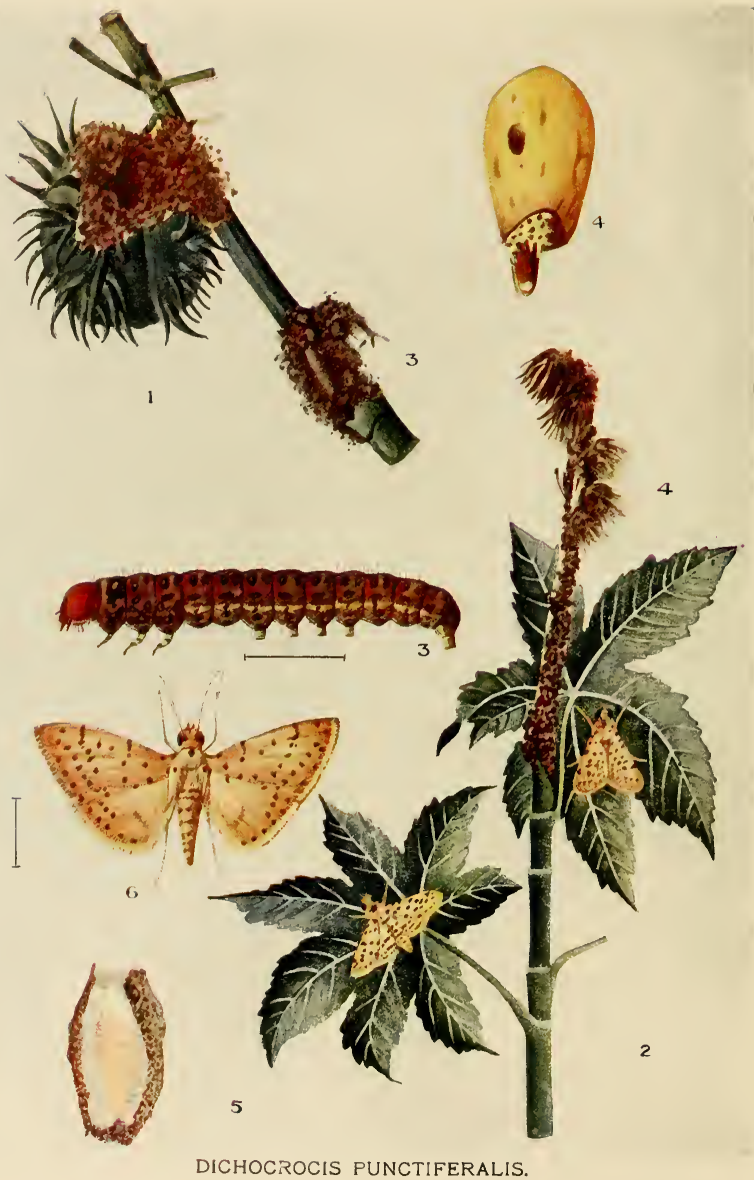


\section{EXPLANATION OF PLATE XXXIV. DICHOCROCIS PUNCTIFERALIS.}

Fic. I. Stalk and capsule of castor-plant showing silk webbing and excrement of larva.

" 2. Shoot of castor, with larval webbing and excrement and two moths in resting attitude.

" 3. Larva, magnified.

" 4. Pupa in castor-seed.

, 5. Pupa in cocoon.

"6. Moth, female, magnified.

(The lines alongside the figures show the natural sizes.) 

Distribution.-Throughout Southern India.

Lifchistory.-The full-grown caterpillar is about $20 \mathrm{~mm}$. long, cylindrical,.segments distinct; its colour is variable, greenish, sometimes pale-yellowish green; scattered over the body are small oval horny patches from which arise stout bristly hairs. It lives in a fold of the leaf, which it rolls over and fastens with silk, only emerging to eat the green matter of surrounding leaves. It is very active when disturbed. The small reddish-brown pupa is contained in a slight cocoon within a folded leaf. The pupal period is about a week.

Foodplants.-Cholam, Maize, Ragi.

Stutus.-A very minor pest of the larger cereals.

DICHOCROCIS PUNCTIFERALIS, Gn.

Botys punctiferalis, Guenee, Delt \& Pyr., p. 320.

Dichocrocis punctifcralis, Hmpsn., Faun. Ind. Moths, IV, 307, f. I8I ; Lefroy, Ind. Ins. Pests, p. I59 ; Ent. Men. Agri. Dept., Ind., I, $21 \mathrm{I}$; Ind. Ins. Life, p. 5 I 7, t. 50.

\section{(SEe Plate XXXIV.)}

Distribution.-Throughout Southern India.

Lifchistory. -Full-grown caterpillar ${ }^{15}-25 \mathrm{~mm}$. long, rather stout, pale or reddish brown with numerous flattened horny warts from which arise short bristly hairs; head red-brown, prothoracic shield large. Bores in stems, seeds and fruits. Pupa in a strong silken cocoon; pupal period 7 - 10 days.

Foodplants.-Castor (stems and seed-capsules), Turmeric (stem), Ginger (stem and rhizome), Guava (fruit). Outside of Southern India it has been reported as attacking Mango flowers, Cholam heads, Peaches, Cacao pods, Cardamom capsules, etc.

Status.-Sometimes a serious pest of Castor and Fruit. Chiefly a castor pest.

Control.-Attacked shoots and seed-capsules of Castor are conspicuous (see plate) and should be collected and destroyed.

Remarks. - In the coloured plate the caterpillar is shown as rather too dark a brown and the moth should be more of a bright orangeyellow colour.

NACOLEIA INDICATA, Fb.

Phalcena indicata, Fab., Ent. Syst., III, ii., 218 (I794).

Botys vulgalis.-Guenee, Delt \& Pyr., p. 202, t. 6, f. 8.

Nacolcia vulgalis, Hmpsn., Faun. Ind. Moths, IV, 3I 5-316; Lefroy, Ind. Ins. Life: p. 517. 


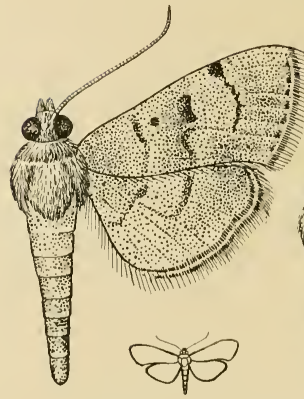

FIG. 309 .

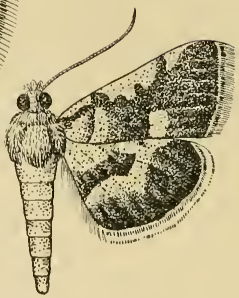

Fìg. 310 .

Nacoleia indicata. two forms of the moth. The outline figure shows the natural size. (Original.)

Distribution.-Throughout the Plains of Southern India.

Lifehistory.-Not known in detail. The caterpillar rolls and fastens together leaves of its foodplant.

Foodplants.-Lucerne, Green Gram, Black Gram (Phaseolus mungo radiatus), Horse Gram (Dolichos biflorus).

Status.-A minor pest of pulses, especially harmful to young plants.

Control.--Not sufficiently serious as a rule to require remedial measures.

\section{SYLEPTA DEROGATA, Fb.}

Phulena derogata, Fab., Syst. Ent., p. 64I ; Ent. Syst., III, ii, 218 (I794).

Sylepta multilinealis, Guen., Hmpsn., Faun. Ind. Moths, IV, 334.

Sylepta derogata, Lefroy, Ind. Ins. Pests, p. 96, ff. 108, 109; Ent. Mem. Agri. Dept., Ind., I, 212; II, 95-II0, t. 9 ; Ind. Ins. Life, p. 517 .

\section{(SEE Plate XXX V.)}

Distribution.-Throughout the Plains of Southern India.

Lifchistory. - The pale-yellowish eggs are laid singly on leaves and shoots of the foodplant, usually on the lower surface of a leaf. The full-grown caterpillar is about $25 \mathrm{~mm}$. long, rather flattened, smooth, with a few short bristly hairs, in colour pale greyish, greenish or yellowish, semi-transparent, with a dull-yellow head. 



\section{EXPLANATION OF PLATE XXXV. SYLEPTA DEROGATA.}

Fig. I. Eggs on cotton-leat.

,2. Young larva.

"3. Adult larva on rolled cotton-leat.

"4. Details of larva.

,. 5, 6. Pupa.

7, 8. Moth.

(The lines alongside the figures show the natural sizes.) 


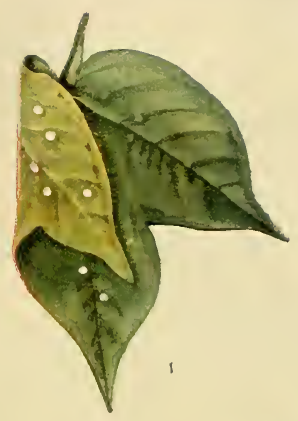

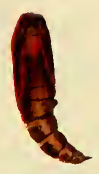

6
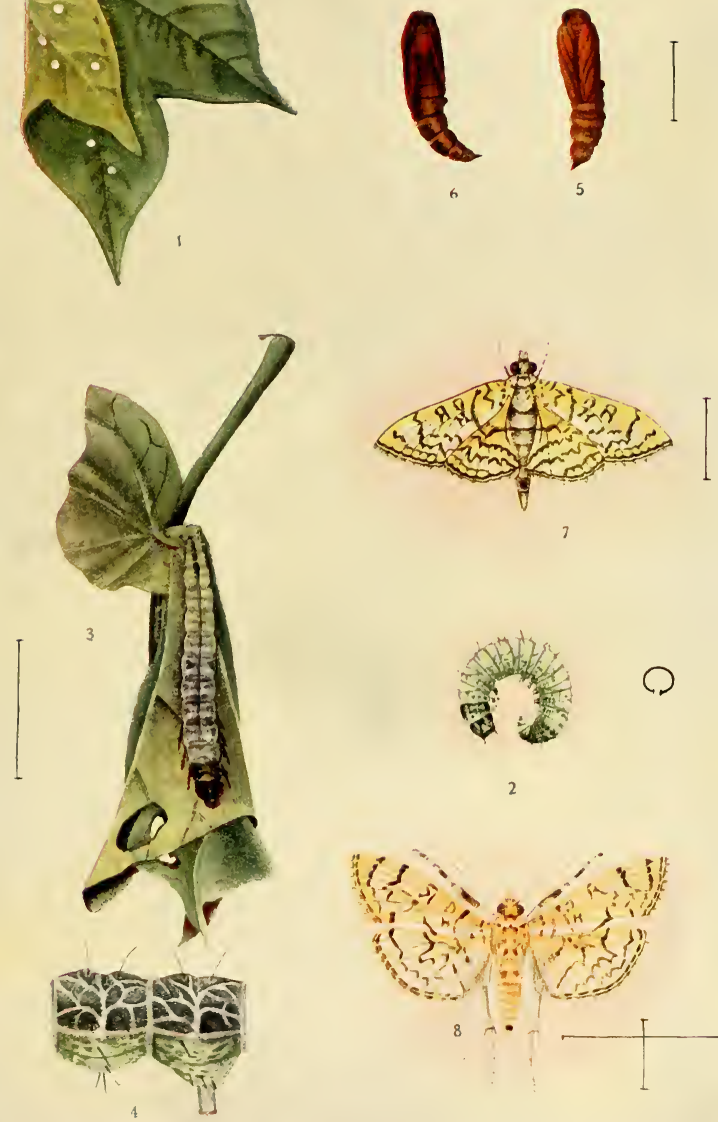

○

2

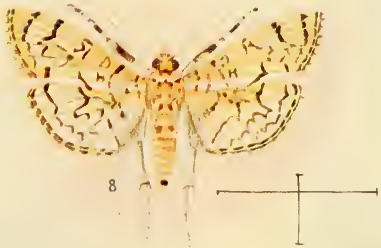



It lives in folded leaves and wriggles very actively when disturbed. Pupa brown or red-brown, in the leaves folded by the larva. Tota: life-cycle, egg 2-3 days, larva 13-18 days, pupa 6--9 days.

Foodplants.-Cotton, Hibiscus spp.

Status. - A minor pest of native Cottons, sometime serious on exotic varieties (Cambodia, Caravonica).

Control. - The folded leaves are easily seen and the caterpillars collected or crushed by hand.

GLYPHODES CASALIS, Wlk.

Glyphodes carstis, Wlk., Cat. XVII, 499; Hmpsn., Faun. Ind. Moths, IV, 356.

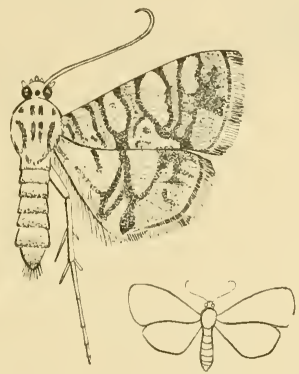

Fig. 311.-Glyphodis cesalis. The outline figure shows the natural size. (Original.)

Distribution.--South Kanara, Godavari.

Lifehistory.-The caterpillar is pinkish, each segment banded with numerous black flattened horny warts from which arise single short bristly hairs; head and prothoracic shield yellow. Pupation in a silken cocoon; pupa red-brown; pupal period about 7 days.

Foodplant. - Jak.

Status.-A minor pest, the caterpillar boring into flower buds and young fruits.

GLYPHODES INDICA, Saund.

Eudioptis indica, Saunders, T.E.S. (1851), 163, t. 12, ff. 5--7.

Glyphodes indica, Hmpsn., Faun. Ind. Moths, IV, 360 ; Lefroy, Ind. Ins. Pests, p. 165, f. 187 ; Ent. Mem. Agri. Dept., Ind., I, 213, f. 64 ; Ind. Ins. Life, p. 518. 


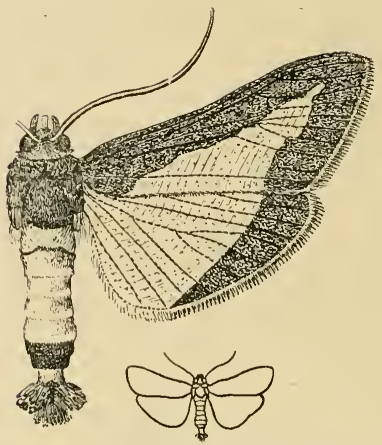

FIG. 312.-Glyphodes indica. The outline figure shows the natural size. (Original.)

Distribution.-Throughout Southern India.

Lifchistory.--The caterpillar is about $25 \mathrm{~mm}$. long, rather slender, with the anterior portion flattened, in colour bright green with a pair of white lines along the back; it is found as a rule on the lower surface of the leaf. Pupa lark brown, in a transparent. coarse, white silken cocoon; pupal period 8-Io days.

Foodplants.-Cucurbitaceous plants of all sorts.

Status.-Minor pest of pumpkins, etc.

Control.-Rarely in sufficient numbers to require remedial measures. If vegetable crops are badly attacked the caterpillars and pupæ may be hand-picked and the plants sprayed.

\section{LeUCinodes orbonalis, Gn. [Plate XXX, FigS. 5-9.]}

Lcucinodes orbonalis, Guenee, Delt. et Pyr., p. 223 ; Hmpsn., Faun. Ind. Moths, IV, 370, f. I98 ; Lefroy, Ind. Ins. Pests, p. I6, ff. 188, I89; Ent. Mem. Agri. Dept., Ind., I, 2I4, f. 65 ; Ind. Ins. Life, pp. 5I8-5I9.

Distribution.- Throughout Southern India.

Lifchistory.-The caterpillar is about $15 \mathrm{~mm}$. long, rather stout, pink or pinkish-brown, with numerous darker smooth warts emitting short bristly hairs. Pupa in a tough dark-coloured cocoon on the stem or fruit.

Foodplant.-Brinjal (Solanum melongena), Solanum xanthocarpum.

Status.-Sometimes a serious pest of brinjal, the caterpillar boring in shoots and fruits.

Control.-Collection and destruction of affected fruits and shoots. 
CROCIDOLOMIA BINOTALIS, Zeller.

Crocidolomia binotalis, Zeller, K. Vet.-Ak. Handl., p. 66 (1852); Hmpsn., Faun. Ind. Moths, IV, 372 ; Lefroy, Ent. Mem. Agri. Dept. Ind. I, 215 ; Ind. Ins. Life, p. 519.

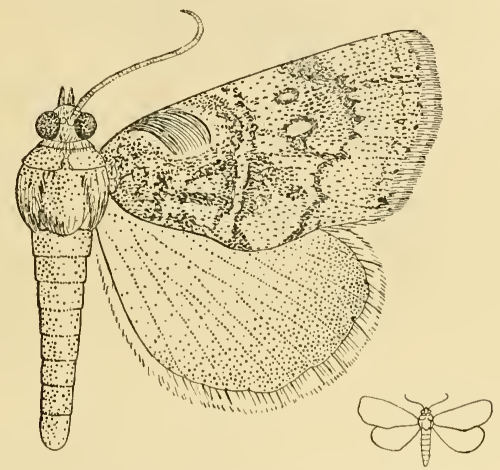

FIG. 313.-Crocidolomia binotalis. The outline figure shows the natural size. (Original.)

Distribution.--Throughout Southern India.

Lifchistory.-Caterpillar $12-15 \mathrm{~mm}$. long, pale green, with a pair of broad dark-green bands on the back bordiered on either side by prominent whitish streaks, and with a faint whitish line down the centre of the back; on the side of each segment is a group of three black tubercles, arranged in a triangle and each emitting a long slender hair. The caterpillar lives and feeds under cover of a web spun on the lower surface of the foodplant. Pupa in a silken cocoon, sometimes formed on the leaf, sometimes in the soil. Pupal period about Io days.

Foodplants.-All cruciferous plants, especially mustard and radish.

Status.-Sometimes a serious pest of mustard and radish, the caterpillar webbing the whole plant.

Control.-Hand-picking and spraying.

HELLULA UNDALIS, Fb.

Phalcna undalis, Fab., Syst. Ent., p. 392 ; Ent. Syst., III, ii, 226 (I794). 
Hellula undalis, Hmpsn., Faun. Ind. Moths IV, 373, f. 200 ; Lefroy, Ind. Ins. Life, p. 519 ; U.S.A. Ent. Bull. No. 19, pp. $5 \mathrm{I}-57$, f. 12, l.c. No. 23, pp. 53-6I, f. I3.

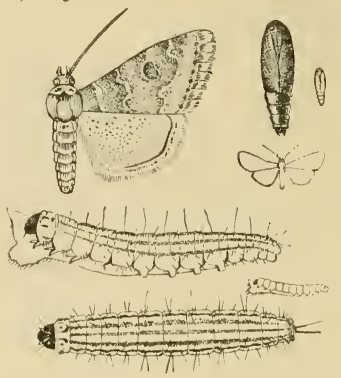

F1G. 314.- Hollula undalis. Larva, pupa and moth. The outline figures show the natural sizes. (After U.S.A. Dept. Agri. Bullctin.)

Distribution. - Throughout Southern India.

Lifclistory.-The creamy-yellow eggs are laid as a rule on the under surface of leaves or on the top-shoot of the foodplant, occasionally on the stem, dry leaves, etc. The newly-hatched caterpillar at first mines the leaves but later on builds covered passages of silk and excrement, at first on the leaves and then on the petioles, until they reach the stem into which they bore and pass the remainder of their larval existence. The full-grown caterpillar is about 12-I $5 \mathrm{~mm}$. long, moderately stout, with a few short hairs scattered over the body ; in colour it is variable, pinkish-white, greyish-yellow or yellowish-grey, with purplish-brown stripes, one down the back and three on each side, of which the lowest is faintest; head black. The pale yellowish-brown pupa in a rather compact cocoon of white silk, spun either amongst leaves, on the ground, or in the larval burrow. Life-cycle, egg about 4 days, larva about 9 days, pupa 6 days, total about 3 weeks.

Foodplants. Cabbage, rarlish, mustard.

Status.-Sometimes very destructive to small garden-plots of cabbages, radish and other cruciferous plants.

Control.- The only practical method seems to be the destruction of all plants first attacked to prevent the increase of the insect later on.

TERASTIA METICULOSALIS, Gn.

Terastia meticulosalis, Guenee, Delt. et Pyr., p. 212 (1854) ; Hmpsn., Faun. Ind. Moths, IV, 38I, f. 206. 
Distribution.-Bellary, Madras, Coimbatore.

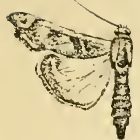

F1G. 3i5.-

Terastia meti.

culosalis.

(Original.)

Probably throughout Southern India.

Lifchistory.--Not known in detail. Caterpillar creamy-white with large flattened shining brownish warts from which arise short hairs. Bores into terminal shoots and unripe seed-pods of Erythrina.

Fnodplant.--Erythrint of various species.

Status.-A minor pest.

Control.-Cutting out caterpillars from terminal shoots, the attacked portions of which wither and die back.

\section{OMPHISA ANASTOMOSALIS, Gn.}

Botys anastomosalis, Guenee, Delt. et Pyr., p. 373.

Omphisa anastomnsalis, Hmpsn., Faun. Ind. Moths, IV, 382, f. 207 ; Swezey, Pr. Hawaii Ent. Soc., I, 76 77 ; Fullaway, Hawaii Expt. Stn. Bull. 22, pp. I6-I9, figs.; Calif. Monthly Bull., I, 242-253, ff. $103-107$.

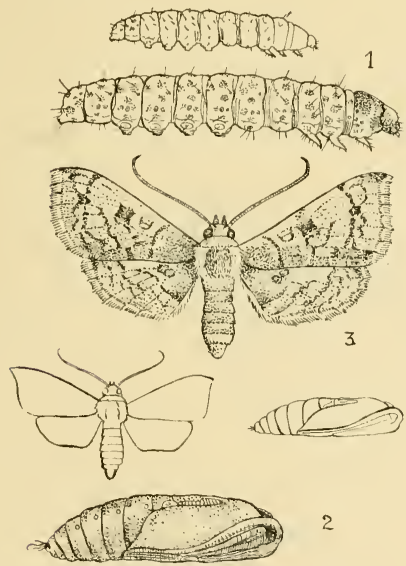

FIG. 316.-Omplisa anastomosalis. 1, Larva :

2. Pupa; 3, Moth. The smaller figures show the natural sizes. (After Fullaway.)
Distribution. - Coimbatore, Saidapet. Probably throughout Southern India.

Lifchistory.-Caterpillar about $25 \mathrm{~mm}$. long, moderately stout, smooth; in colour whitish, each segment rather faintly indicated, with darker smooth flattened warts each emitting a short bristly hair; head yellowish, true legs blackish. The caterpillar bores in stems, the pupæe also being found in the larval tunnels.

Foodplant.--Wild Ipomcea.

Remarks.-This species has not yet been noted as a pest of cultif sweet potato in the 
Hawaiian Islands and in Formosa and will probably be found to attack this crop in India also.

\section{MARUCA TESTULALIS, Geyer. [PLATE XXXVI.]}

Pyralis testulalis, Geyer in Hubn. Samml exot. Schmett, IV, 4. p. I2, ff. 629, 630; Hnpsn., Faun. Ind. Moths, IV, 393-394, f. 2II ; Lefroy, Ind. Ins. Pests, p. I49, f. I69; Ent. Mem. Agri. Dept., Ind., I, 216, f. 66; Ind. Ins. Life, p. 5 I9, f. 342.

Distribution.-Throughout Southern India.

Lifchistory.-Caterpillar about I5 mu. long, rather slender, segments with dark rounded warts emitting single short bristly hairs; in colour pale brownish-green, head olive-brown. It bores into the end of pods and devours the ripening secds one after another. The larval burrow is marked by a mass of brownish excrement at the entrance of the gallery. The yellowish-green pupa in a large oval cocoon. Pupal period about a week.

Foodplants.-Dolichos lab-lab, green gram (Phascolus mungo), red gram.

Status. - A minor pest of pulses.

Control.-Collection and destruction of affected pods.

\section{PACHYZANCLA EGROTALIS, Zell.}

Botys agrotalis, Zeller, K. Vet.-AK. Handl., p. 38 (1852).

Pachyzancla agrotalis, Hmpsn., Faun. Ind. Moths, IV, 405 ; Lefroy, Ind. Ins. Life, pp. 519-520.

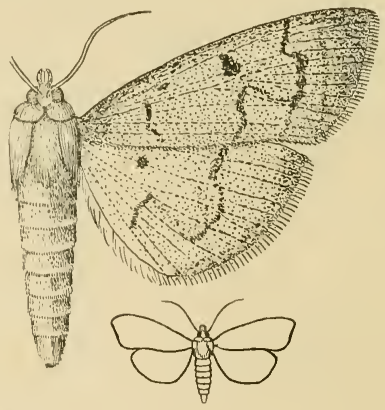

Fig. 317.-Pachyzancla agrotalis. The outline figure shows the natural size. (Original.)

Distribution-Coimbatore; Malabar; S. Kanara. 


\section{EXPLANATION OF PLATE XXXVI.}

\section{MARUCA TESTULALIS.}

FrG. r. Pod of green gram attacked by larva, showing masses of extruded excrement which mark affected pods.

, 2. Larva, magnified.

3. Pupa in cocoon within pod.

4. Pupa, magnified.

"5. Moth, natural size, in resting attitude.

.. 6. Moth, magnified.

(The lines alongside the figures show the natural sizes. 


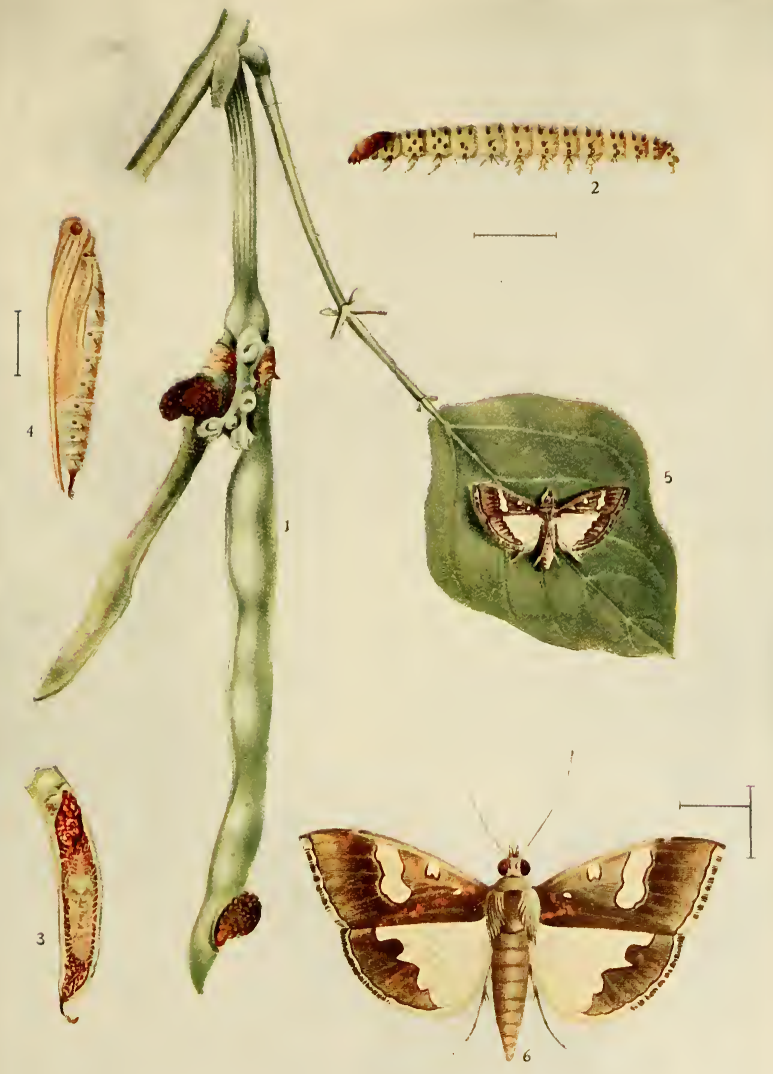

MARUCA TESTULALIS. 


PLATE XXXVII.

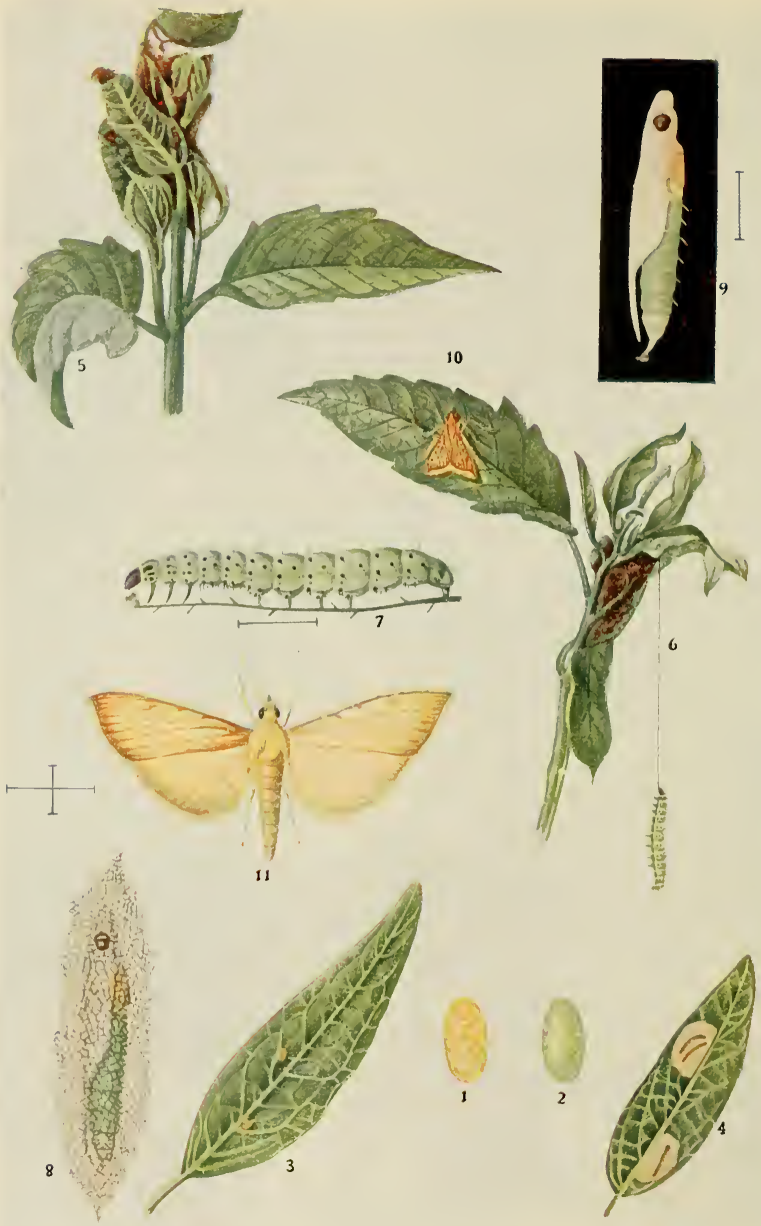




\section{EXPLANATION OF PLATE XXXIII.}

ANTIGASTRA CATALAUNALIS.

FIG. I, 2. Eggs, magnified.

, 3. Eggs as laid on leaf.

"4. Newly-hatched larvæ feeding on green tissue of lear.

, 5. Gingelly shoot rolled by the larva.

6. " " " showing larva hanging by a thread.

"7. Larva, magnified.

, 8. Cocoon with enclosed pupa, magnified.

, 9. Pupa, magnified.

" 1 о. Moth, natural size, in resting attitude.

" II. Moth, magnified.

(The lines alongside the figures show the natural sizes.) 

Lifchistory.--Caterpillar about $25 \mathrm{~mm}$. long, cylindrical, smooth, peagreen in colour with numerous irregularly-oval black smooth flattened warts tending to form bands around each segment. Webs together leaves of the foodplant, feeding gregariously and eating the leaves covered by the web. Pupation in a cocoon covered with particles of leaf and excrement, in the web ; pupa slender, reddishbrown; pupal period about to days.

Foodplants.-Brinjal and wild solanaceous plants.

Status.--A minor pest of brinjal.

Control.- The webs are conspicuous and the caterpillars may easily be destroyed by hand-picking.

\section{antigastra CATAlaunalis, Dup. [Plate XXXVII.]}

Botys catalaunalis, Dup., Lep. France, VIII, 330, t. 232, f. 8.

Antigastra catalannalis, Hmpsn., Faun. Ind. Moths, IV, 412, f. 224 ; Lefroy, Ind. Ins. Pests, p. I6I ; Ent. Mem. Agri. Dept., Ind., I, 218; Ind. Ins. Life, p. 520, t. 51 .

Distribution.--Throughout Southern India.

Lifchistory.-Eggs are laid singly on leaves. Full-grown caterpillar about $15 \mathrm{~mm}$. long, smooth with a few scattered short hairs, in colour green with a few small blackish warts, head dark-brown. The newly-hatched caterpillar eats blotches in the leaves of the foodplant, later on in life it webs together the top-shoots and bores into the shoots and porls. Pupa whitish, with black eye-spot and greenish abdomen, in net-like cocoon of white silk. Pupal period about a week.

Foodplants.-Gingelly (Sesamum indicum).

Status.-Occasionally a serious pest of gingelly.

Control.- (I) Hand-picking of affected top-shoots which are conspicuous, as they wither and turn blackish (see figs. I and 2 on Plate XXXVII.

(2) The moths come fairly freely to light and light-traps may be tried in badly-affected fields.

NOORDA BLITEALIS, wlk.

Noorda blitealis, W1k., Cat. XIX, 979 (I859); Hmpsn., Faun. Ind. Moths, IV, 4I4-4I5, f. 227 ; Lefroy, Ind. Ins. Life, p. 520.

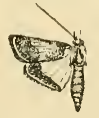

FIG. 318.-Noorda blitealis. (Original.)

Distribution.-Throughout the Plains of Southern Inclia. 
Lifchistory. - The white eggs are laid singly on leaves of the foodplant. The caterpillar is about $15 \mathrm{~mm}$. long, rather slender, in colour pale green, marked with darker at either extremity, and with a few small flattened warts on each segment. The red-brown pupa in an oval cocoon, usually spun in the soil at the base of stem of foodplant. The caterpillar folds or joins the leaves and feeds on the green matter.

Foodplant.- Horse-radish tree (Moringa pterygosperma).

Status.-A minor pest as a rule, occasionally serious.

Control.-?

PYRAUSTA MACHÆRALIS, Wlk.

Pyrausta macharalis, Walker, Cat. XIX, IOI3; Hmpsn., Faun. Ind. Moths, IV, $432-433$; Hole, B.J., XV, 679-697, tabs.

\section{cess}

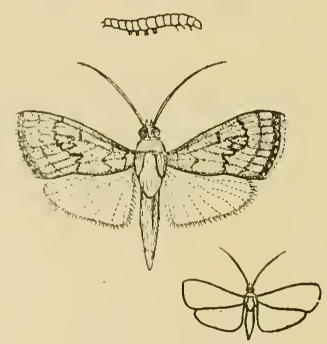

FiG. 319.- Pyrausta macharalis, larva and moth. The outline figures show the natural sizes. (From Indian Museum Notes.)

Distribution.--Nilambur. Probably throughout Plains.

Lifchistory.-The small, round, greenish eggs are laid singly on the backs of young Teak leaves, close to a rib or veinlet. The mature larva is about $24 \mathrm{~mm}$. long, elongate, moderately stout, palegreen in colour with yellow sub-dorsal lines sometimes tinted with reddish-purple and a double series of yellow purple-dotted spots on each abdominal segment along either side of the mid-dorsal line. The larva feeds on the green matter of the leaf, leaving the bare skeleton, and the presence of such skeletonized leaves is highly characteristic of this insect. When full-fed, the larva pupates in a slight cocoon, usually formed inside a shrivelled and rolled leaf. The total life-cycle is about 30 days. (Hole.)

Foodplants.-Teak (Tectona grandis). 
Status.-May be a serious pest of Teak Forests. At Nilambur the larvæ have been noted to be kept in check by Mynahs.

Remarks.- Hole (l.c.) quotes damastesalis, Wlk., as a synonym of this insect, but Hampson (B.J., XV, 22I) had already pointed out that damastesalis, Wlk., is a Pionea and the same species as lewanalis, Swinh. I presume that the Teak defoliator is macharalis, Wlk., and have therefore retained the name in the absence of specimens from Nilambur.

\section{PTEROPHORIDÆ.}

\section{SPHENARCHES CAFFER, $Z$.}

Oxyptilus caffer, Zeller, Linn. Ent., VI, 348.

Sphenarches cafber, W1sm., I.M.N., II, 20 figs. ; Lefroy, Ent. Mem. Agri. Dept., Ind., I, 220 ; Ind. Ins. Life, p. 528, f. 343 ; Fletcher, Spol. Zevl., VI, 2I, t. E., f. 8, I0, t. F., f. I (I909).

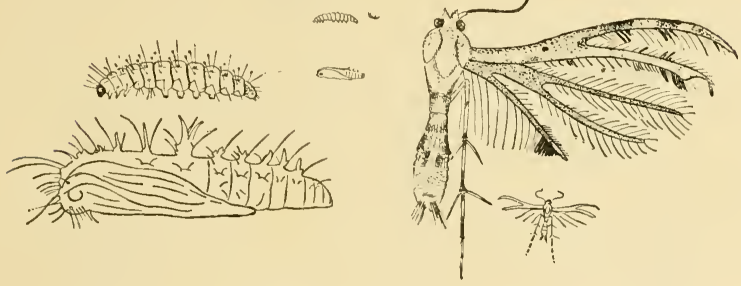

FiG. 320.-Sphenarches caffer. larva, pupa and moth. The outline figures show the natural sizes. (Original,। Hills.

Distribution.-Throughout Southern India, in the Plains and

Lifchistory. - Eggs are laid singly on buds and leaves. The fullgrown caterpillar is about $7 \mathrm{~mm}$. long, rather stout, segments well marked, all legs long and slender, all segments with a few large warts emitting long hairs of which two on each sicle have palmate tips and the whole body also closely studded with short white clubbed hairs; in colour variable, paler or darker green or greenishyellow, with a narrow clarker line along the back and a series of reddish spots forming a stripe along the sides. Pupa pale pink and greenish, covered with complex spines; attached by the tail to the undersurface of the mid-rib of a leaf or to a stem; pupal period about $5-7$ days. 
Foodplants.-Bottle-Gourd (Lagenaria vulgaris), Dolichos lab-lab, and various other plants.

Status. -A minor pest of Bottle-Gourd and Lab-lab.

Control.-Spraying in small areas. Remedial measures are rarely necessary.

PLATYPTILIA PUSILLIDACTYLA, Wlk.

Oxyptilus pusillidactylus, W1k., Cat. XXX, 933 (1864).

Plutyptilia pusillidactyla, Fletcher, Spol. Zeyl., VI, 13, t. A, f. 2, t. E, ff. 5,6 .

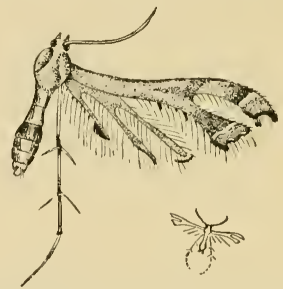

Fig. 321.-Platyptitia pusitlidactyla. The small figure shows the natural size. (Original.)

Distribution.-Throughout Southern India to about 5,000 feet.

Lifehistory. - The very pale greenish-yellow eggs are laid singly on terminal shoots of the flower-bud, into which the caterpillar bores and lives. The caterpillar is about $5 \mathrm{~mm}$. long, stout, pale yellow and without hairs. The pale-yellow pupa is found in a regular cocoon formed of bits of vegetable matter spun together with silk and placed in a cavity gnawed into the side of the fruitreceptacle.

Foodplant.-Lantana.

Status.-Beneficial in Districts invaded by Lantana. Where attacked by this caterpillar bunches of fruit contain only a few shrivelled fruits instead of a dozen or more plump ones. This little moth is therefore a factor of some importance in checking the spread of Lantana through the dispersal of the seeds by Birds.

EXELASTIS ATOMOSA, Wlsm.

Aciptilia atomosa, Wlsm., P.Z.S. (1885), 885 .

Exelastis atomosa, Meyr., B.J., XVII, 730; Lefroy, Ent. Mem. Dept. Agri., Ind., I, 210, ff. 67, 68; Ind. Ins. Life, pp. 527-528, t. 53.

\section{(SeE Plate XXXVIII.)}

Distribution. $\rightarrow$ Throughout the Plains of Southern India. 


\section{EXPLANATION OF PLATE XXXVIII.}

\section{EXELASTIS ATOMOSA.}

Fig, 1. Eggs as laid on pod of red gram.

, 2. Eggs, magnified.

" 3. Larva, magnified.

" 4. Details of larva.

"5. Pupa on portion of pod of red gram, magnificd.

" 6, 7. Moths, magnified.

(The lines alongside the figures show the natural sizes.) 


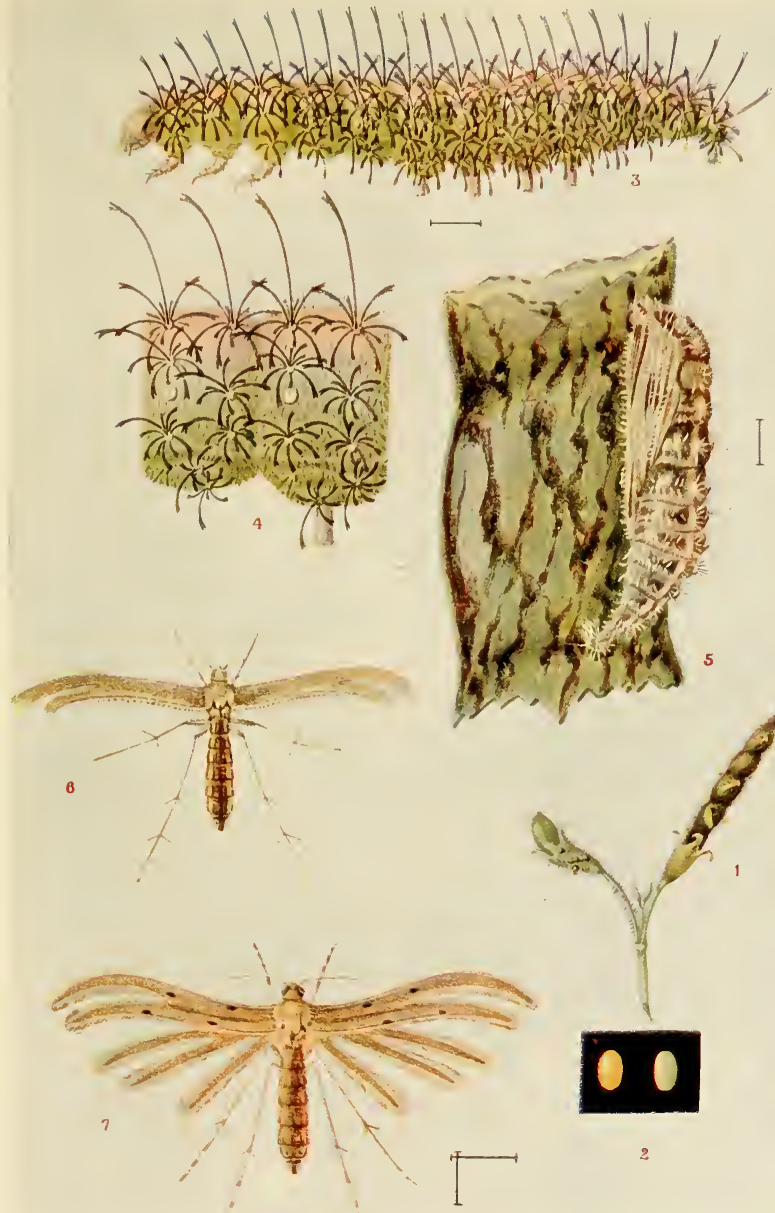



Lifehistory.-The pale-green eggs are laid singly on young pods and leaves of the foodplant, the caterpillar boring into the pod and devouring the seed. The caterpillar is about $10 \mathrm{~mm}$. long, moderately stout, densely clothed with short hairs and with long spines emitted from raised warts ; in colour it is green, usually with a pink or brown stripe down the back. Pupa thickly clothed with spinous hairs, attached by the tail, greenish or pinkish.

Foodplants.-Red Grain (Cajamus indicus), Dolichos lab-lab.

Status.-An important pest of Red Gram and Lab-lab.

Control.-?

\section{PTEROPHORUS LIENIGIANUS, Z.}

Pterophorus lienigianus, Zeller, Linn. Ent., VI, 380 ; Meyr., T.E.S. (1907), 407 ; Fletcher, Spol. Zeylan., VI, 34-35 (I909).

Ptcrophorus serindibanus.-Moore, Lep. Ceylon, III, 527, t. 209, f. I4.

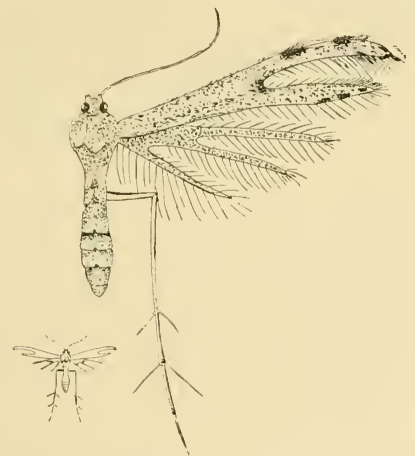

FIG. 322.-Pterophorus licnigianus. The small figure shcus the natural size, (Original.)

Distribution.-Godavari, Coimbatore. Probably throughout Southern India.

Lifchistory.-Caterpillar about 8-10 mm. long, moderately stout, hairy, very pale yellowish, head brown.

Foodplants.-Brinjal(Solunum melongena). [In Europe on Artemisia vulgaris. Doubtless polyphagous.]

Status.-Scarcely a pest. Caterpillars found eating leaves of Brinjal on two occasions.

Remarks. - The moths seem to run much smaller than European specimens but otherwise do not seem to differ. 


\section{ZEUZERIDÆ.}

ZEUZERA COFFEA, Nietn.

(Thi Red Borer of Coffice.)

Zenzera coffec, Nietner, Edin. New. Phil. Journ., XV, 36 (I862); Hmpsn., Faun. Ind. Moths, I, 312 ; Lefroy, Ent. Mem. Agri. Dept., Ind., I, I56, f. 4I ; Ind. Ins. Life, p. 496.

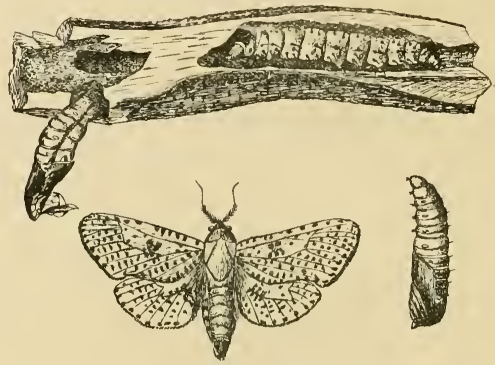

FIG. 323.-Zenzera coffece ; larva inside stem, pupa projecting from larval gallery after emergence of moth, pupa removed from cocoon, and moth. (After Indian Museum Notes.)

Distribution.--Throughout the Hills of Southern India.

Lifelistory. - Caterpillar about $50 \mathrm{~mm}$. long, stout, smooth, in colour red-brown; it bores into stems and branches of Coffee, Tea, etc. Pupa red-brown, provided with bands of hooked spines; in larval burrow.

Fondplants.--Coffee, Tea, Sandal (Santalum album), etc.

Status.-Often does a considerable amount of damage in planting Districts but not looked on as a very serious pest as a rule.

Control.- The entrance of the larval burrow is usually marked by the extrusion of excrement and wood-dust. The caterpillar may be cut out, or the burrow syringed with a mixture of Chloroform 2 parts, Creosote I part.

\section{AZYGOPHLEPS SCALARIS, Fab.}

Hepialus scalaris, Fab., Mant. Ins., II, I35.

Cossus scalaris, Fab., Ent. Syst., III, pt. 2, p. 5 (I794).

Asygophleps scalaris, Hmpsn., Faun. Ind. Moths, I, 3I0, f. 211 ; Lefroy, Ind. Ins. Life, p. 496. 


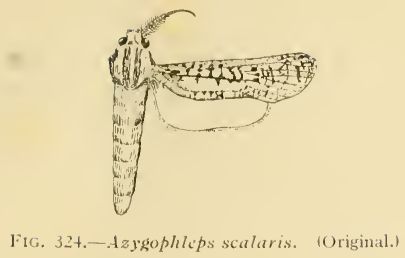

Distribution.-Throughont the Plains of Southern India.

Lifehistory.-The pale-yellowish eggs are laid in a mass which may contain upwards of 2,000 eggs and which is placed between two leaflets of Agathi which have folded together for the night; the egg-mass is cemented together and to the leaves by a sticky secretion which rapidly hardens. The young caterpillars hatch out, usually in the morning, after about six days and lower themselves by slender silken threads by which they swing freely in the air and are dispersed by the wind on to neighbouring plants, which they attack at the growing-point, tunnelling down into the main stem where the rest of their larval life is passed. The newly hatched caterpillar is about $I_{\frac{1}{4}} \mathrm{~mm}$. long, with a black head and greyish body studded with pinkish warts. The full-grown caterpillar is about $60-75 \mathrm{~mm}$. long, slender, with slight transverse humps on the back of the body-segments, in colour opaque white, the head and the large prothoracic plate red-brown. The caterpillar bores down the centre of the stem, its tunnel being filled with frass which is occasionally ejected through holes bitten in the side-walls of the stem. On attaining full growth, the caterpillar bites an exit hole almost through the outer portion of the stem and, after spinning some silken partitions across its gallery, transforms into an elongate blunt red-brown pupa provided with bands of hooked spines almost encircling the segments. The total life-cycle is :- Egg six days, larva 50-80 days, pupa $\mathrm{I}_{4}-\mathrm{I} 5$ days.

Foodplants.-Agathi (Sesbania grandiflora), chithagathi (S. agyptiaca), Daincha (S. aculeata).

Status.-A serious pest of agathi; an especially bad pest of young plants.

Control.-(I) In the case of agathi plants of 6 feet or more in height, the larval burrow may be slit up and the caterpillar killed.

(2) Syringing a mixture of chloroform 2 parts, creosote I part, into the larval burrow, which is marked by the mass of extruded excrement. 


\section{PSYCHIDÆ.}

CLANIA CRAMERI, Westwd.

Oiketicus crameri, Westwd., P.Z.S. (I854), 236, t. 37, f. 4 .

Eumeta crameri, I. M.N., IV, I7-I8, t. 3, f. 2.

Clania crameri, Hmpsn., Faun. Ind. Moths, I, 29I ; Dungeon, B.J., XII, 643 ; Anstead, Planters Chron., VIII, I70; Watt and Mann., Pests of Tea, pp. 188 I89, t. 7 , f. 4 .
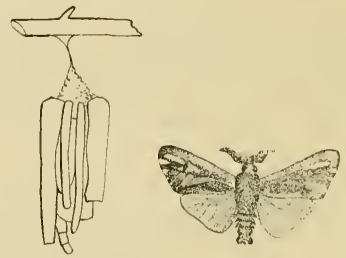

F1G. 325.-Clania crameri, larva case and male moth. (Original.)

Distribution.--Throughout Southern India.

Lifchistory.-Not known in detail. The caterpillar lives in a case composed of silk overlaid with small twigs, grass-stems, etc., laid longitudinally to form a faggot-shaped bundle. Pupation inside the larval case. The male moth is winged, the female a wingless grub, little more than a bag of eggs, which never leaves the case. The caterpillar feeds on both leaves and bark of tea-bushes.

Foodplants.-Polyphagous. Babul (Acacia arabica), Tea, etc.

Status.-Not a pest in the Plains but sometimes does a good deal of damage to Tea.

Control. - The larval cases are fairly easily seen and may be handpicked and burnt.

Remarks. - I have not seen specimens of C. crameri from the tea Districts and the name is given on the authority of Mr. Anstead who informs me that it does a good deal of damage to tea sometimes. It is possible that Clania varicgata is really referred to (See Hmpsn., Faun. Ind. Moths, I, 29I, f. 200; Bell, B.J., XVII, $837-840$, fig.). The habits and general appearance of both insects are almost identical.

\section{ZYGENIDE.}

HETERUSIA VIRESCENS, Butl.

Heterusia vircscens, Butler, Ill. Het. v. 21, t. 83, f. 3 ; Hmpsn., Faun. Ind. Moths, I, 262. 


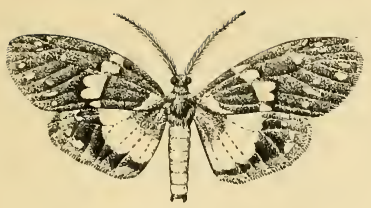

F1G. 326.-Heterusia virescens. (Original.)

Distribution.-Nilgiris, Wynaad.

Lifelistory.-Not known. Probably very similar to that of $H$. cingala.

Foodplants.-Tea.

Status.-An occasional local pest of tea, the caterpillars sometimes stripping the bushes.

Control.-Collection of the caterpillars by hand and of the moths by hand-nets. The moths fly by day.

Remarks.-(I) Apparently only once reported as doing damage in Southern India. The outbreaks in the case of the allied $H$. cingala in Ceylon are usually sporadic and severe in circumscribed areas but parasites soon increase in numbers and hold the moth in check.

(2) I am indebted to Dr. Coleman for the loan of the specimen from which the figure has been drawn.

\section{EUCOSMIDA.}

ARGYROPLOCE ILLEPIDA, Butl.

Teras illepida. Butler, T.E.S. I882, 42.

Cryptophlebiacarpophaga, Wlsm, I.M.N., IV, I06, t. 7, f. I. ; Lefroy, Ind. Ins. Life, p. 53I, t. 28, ff. II-I 2.

Cryptophlcbia illepida, Walsm., Faun. Hawaii, I, 68I, t. I0, ff. 23-25. Argyroploce illepida, Meyr., Rec. Incl. Mus., V, 2 I8.

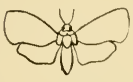

3

apd

1

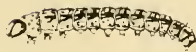

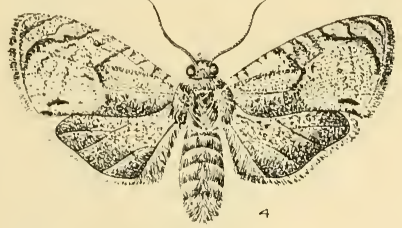

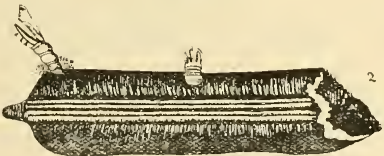

11G. 327.-Argyroploce illepida. 1. Larva: 2, Empty pupa-cases project. ing from pod of Cassia fistula; 3,4 . Moth, natural size and magnified.

(Figs. 1 and 2 from Indian Museum Notes.) 
Distribution.-Probably throughout Southern India.

Lifehistory.-Caterpillar darker or lighter grey with a yellowish tinge on the back, down which runs an interrupted dark line, and there are also broken dark lines along the sides. Pupation in a cocoon.

Food.-Seeds of Cassia fistula and C.occidentalis, Litchi (Nephelinm litchi), Tamarind (Tamarindus indica), and probably of other trees.

Status.-Scarcely a pest.

\section{EUCELIS CRITICA, Meyr.}

Eucelis critica, Meyr., B.J., XVI., 587 ; Lefroy, Ind. Ins. Pests, p. I43 ; Ent. Mem. Dept. Agri., Ind., I, 22I.; Ind. Ins. Life, p. 530, t. 55.

(SEE Plate XXXIX.)

Distribution.--Probably throughout the Plains of Southern India.

Lifchistory.-- The eggs are laid singly, usually on the leaves at the upper part of plants. The caterpillar is about $9 \mathrm{~mm}$. long, moderately stout, smooth except for a few short scattered hairs, in colour yellowish, with a brown head. It rolls and webs together the upper leaves of the food-plant, pupating in a scanty covering of white silk between the folds of a leaf. Pupa reddish-brown, in spun-up shoots of Cajanus indicus; pupal period about a week.

Foodplants.-Red Gram (Cajanns indicus).

Status.-A minor pest.

LASPEYRESIA KOENIGANA, Fb.

Pyralis kocnigana, Fab., Ent. Syst. III, ii, 279 (I794).

Nov. Synon.

Hemerosia aurantiana, Pryer, Cist. Ent., Il, 235, t. 4, f. I2.

Laspeyresia aurantiana, Meyr., P. Linn. Soc. N.S.W., XXXVI, 292-293 (I9II).
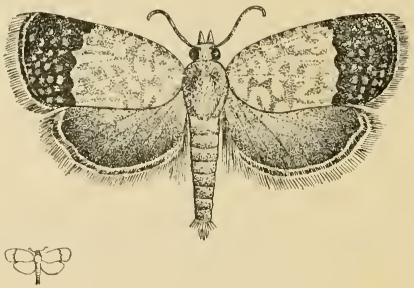

FIG. 328.-Laspeyresia koenigana. The small figure shows the natural size. (Original.)

Distribution,--Coimbatore. Probably throughout Southern India. 



\section{EXPLANATION OF PLATE XXXIX.}

\section{EUCELIS CRITICA.}

Frg. I. Egg, magnified.

, 2. Larva, magnified.

1, 3. Details of larva.

, 4. Shoot of red gram showing rolled leaves and empty pupa-case projecting after the emergence of the moth.

. 5. 6. Moths, magnified.

(The lines alongside the figures show the natural sizes,) 
PLATE XXXIX.

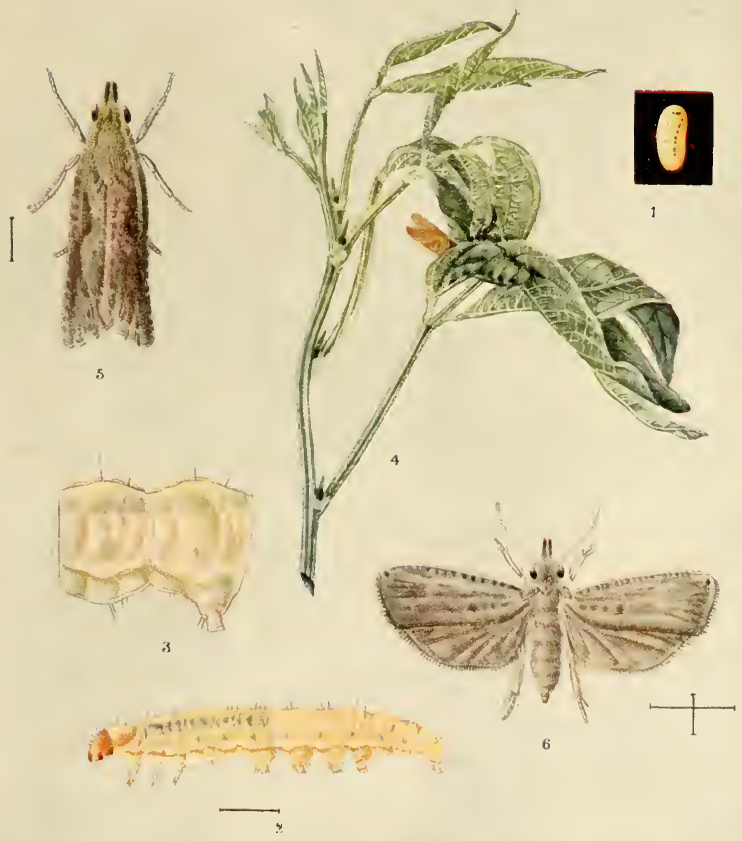

EUCELIS CRITICA. 


PLATE XL.
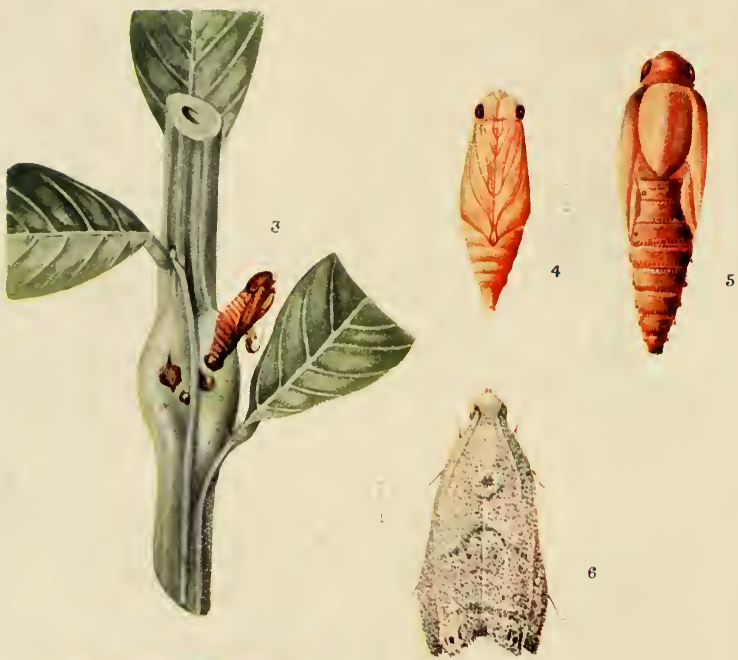

al

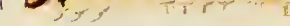

2

ay)

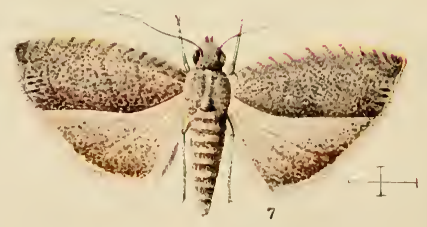

LASPEYRESIA TRICENTRA. 


\section{EXPLANATION OF PLATE XI. LASPEYRESI.I TRICENTRA.}

FIG. I, 2. Larvæ, magnified.

" 3. Affected plant, shoring pupz-case projecting from stem after emergence of moth.

"4, 5. Pupæ, ve itral and dorsal views, magnified.

" 6, 7. Motḩs, mıgnifiet.

(The lines alongside the fignres show the natural sizes,) 
Lifehistory and Foodplants.- Not known. I have seen the moths flying around pomegranate and guava, one of which is perhaps the food-plant.

Status.-Not known as a pest.

Remarks.-(I) A common little moth which may be found to feed on cultivated crops.

(2) Fabricius description, which seens to have been overlooked hitherto, clearly refers to this species and his name should be restored.

\section{LASPEYRESIA TRICENTRA, MEYr.}

Lasperresia tricontra, Meyr., B.J., XVII, 734 (I907) ; P.Z.S. (I908), 721-722; Lefroy, Ent. Mem. Agri. Dept., Ind., 1. 222 ; Ind. Ins. Life, p. $53 \mathrm{I}$.

(SEE Plate XI.)

Distrilution. - Throughout Southern India.

Lifchistory.-Not known in detail. The caterpillar is about 6 $\mathrm{mm}$. long, smooth, in colour dull whitish with dark-brown head and prothoracic shield, turning pinkish-red when full-fed. It tunnels in the stems of Crotalaria, causing a characteristic gall-like swelling, in which it pupates.

Foodplants.-Sann Hemp (Crotalaria juncea) and probably other varieties of Crotalaria.

Status.--A minor pest, only noted as cloing any damage in the Northern Circars.

LASPEYRESIA TORODELTA, Meyr.

Laspeyresia torodelta.--Neyr., B.J., XXII, 772 (19I4).

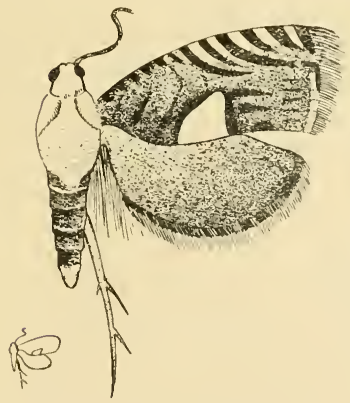

Fig. 329.--Laspcyresa torodclta. The outline figure shows the natural size. (Original.)

Distribution-Coimbatore, Nalabar.

Lifehistory:- The caterpillar is upwards of $10 \mathrm{~mm}$. long, slender, with short hairs scattered over the body, in colour pale green with a redclish head. It bores into the growing tips of the stem of the foodplant, devouring the tissues of the stem so that this droop sand dies. Pupation in the larval burrow; Pupal period about ten clays.

Foodplant.-Lab-lab (Dolichos lab-lab).

Status.-A minor pest. doing most damage to young plants. 


\section{TORTRICIDÆ.}

HOMONA COFFEARIA, Nietn.

Tortrix coffcaria, Nietn., Obs. Enemies Coffee-tree, pp. 4, 24 (I86I).

Homona fasciculana, WIk., Cat. XXVIII, 424 (1863).

Capua coffcaria, I.M.N., V, 187-I88; Green, Perad. Circ. IJ, No. 3. tab. II, No. 17, pp. 237238.
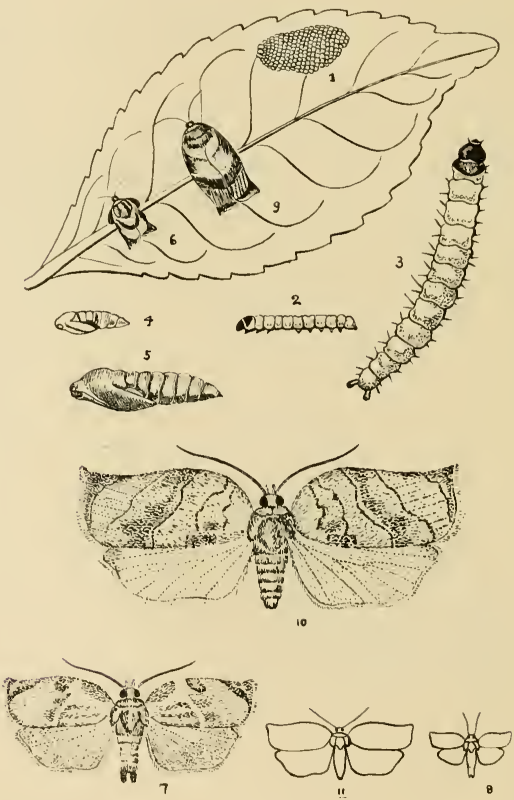

Fig. 330.-Homona cofficaria. 1, Eggmass, natural size, on tea leaf; 2, 3, Larva, natural size and magnified; 4, 5, Pupa, natural size and magnified; 6 , Male moth in resting attitude; 7, 8 , Male moth, magnified and natural size; 9 , Female moth in resting attitude; 10, 11. Female moth, magnified and natural size. (Figs. 1-6 and 9 after Green). 


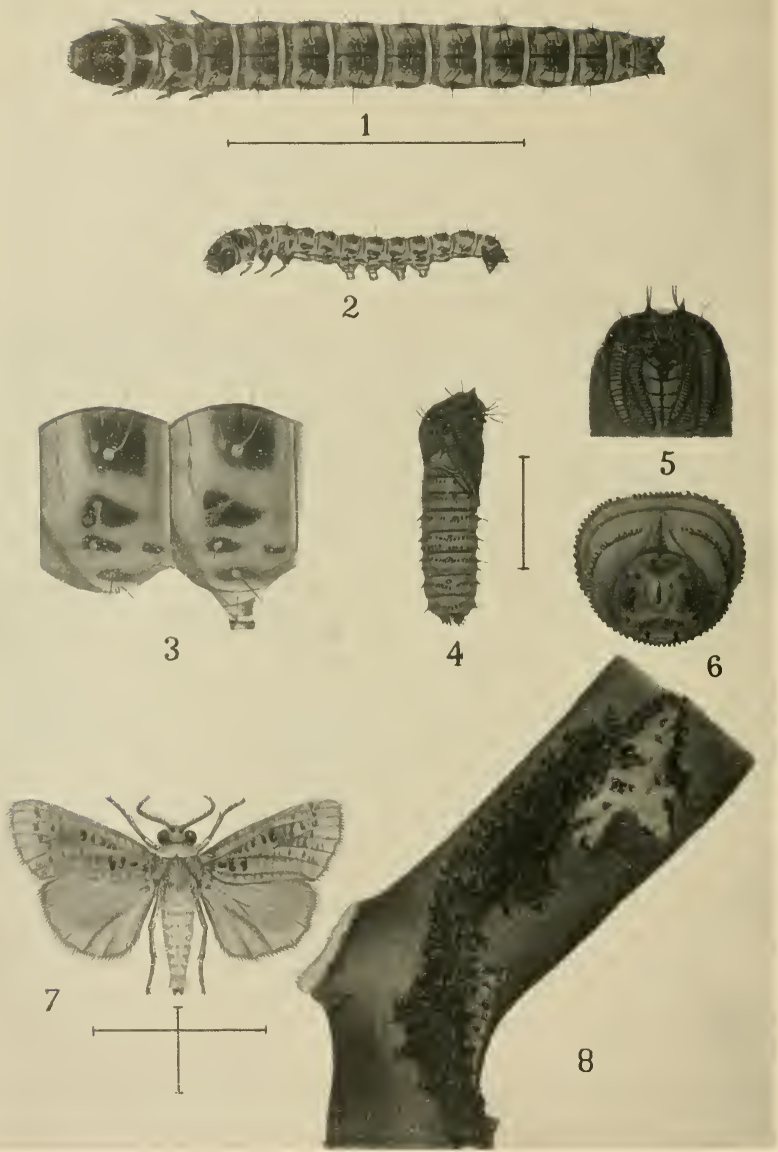

ARBELA TERAONIS. 


\section{EXPLANATION OF PLATE XLI.}

\section{ARBELA TETRAONIS.}

FIG, 1, 2, Larva.

"3. Details of larva.

"4. Pupa.

, 5,6 . Details of pupa.

, 7. Moth.

" 8. Larval gallery, composed of silk and on frass, branch of tree.

(The lines alongside the figures show the natural sizes.) 
Jistribution.-Tea districts.

Lifchistory:-The pale-yellow eggs are laid in compact masses on the upper-side of mature leaves. The young caterpillars are at first more or less gregarious but separate after the first moult. When full-grown the caterpillar is about $20 \mathrm{~mm}$. long, pale green in colour with a shining black head and prothoracic plate. It spins together two or more leaves to form a shelter, often enclosing a young shoot, nibbling the leaves and buds here and there and destroying far more than it eats. The reddish-brown pupa is found in the larval shelter.

Foodplants.-Tea, Coffee, Acacias, Albizzias, Eucalyptus, etc. (Green).

Status.-The "Flush Worm" does considerable damage in all Tea districts of Southern Inclia.

Control.-(I) Collection and destruction of egg-masses.

(2) Collection and destruction of all twisted leaves containing caterpillars and pupæ.

(3) The female moths have been found to be attracted by suspending withered Grevillea branches between the rows of teabushes. The branches are slung from sticks about 40 feet apart so that the bottom of the branch is level with the tops of the teabushes. The dry branches are visited daily and shaken into a sack which is then banged on the ground to kill the moths.

Remarks. $-H$. coffearia has not been definitely recorded from Southern India and is included here on the authority of Mr. Anstead. Particulars of lifehistory, foodplants and control are based on work in Ceylon.

\section{ARBELID厓.}

\section{“ARBELA " TETRAONIS, Moore.}

Arbcla tetraonis, Moore, P.Z.S. (I879), 4II, t. 34, f. 3 ; Hmpsn., Faun. Ind. Moths, I, 315 ; Lefroy, Ind. Ins. Life, p. 493, t. 45 ; V. S. Iyer, Ind. Forest Bull, No. II, pp. 3-7, t. I-2.

\section{(SEE Plate XLI).}

Distribution.-Nellore, North and South Arcot. Probably throughout the Plains of Southern India.

Lifchistory. - The eggs are probably laid singly in crevices of bark. The larva on hatching bores a gallery into the stem or a branch and from this it emerges to feed on the bark under cover of a long gallery of silk overlaid with small fragments of wood. Pupa red-brown provided with rings of hooks on the segments, in the larval gallery in the stem. The life-cycle is probably:- eggs laid June-July, larvæ feed July-April, pupæ May-June, moths June-July. 
Foodplants.-Casuarina, Rain-Tree (Pithecolobium saman), and various soft-wooded trees.

Status. Has been noted as doing serious damage to Casuarina, especially in dry seasons.

Control.- The larval galleries and freshly-eaten bark around them are evidence of the presence of the caterpillar which is readily destroyed by syringing into its burrow a mixture of 2 parts chloroform and one part creosote.

NoTE.-The generic name Arbela, being pre-occuped in Rhynchota, is not available for this genus of Lepidoptera. It seems, however, unnecessary to introduce a new term here.

\section{GELECHIADA.}

GELECHIA GOSSYPIELLA, Saunders.

\section{(Pink Bollworm.)}

Depressaria gossypiclla, Saund., T.E.S., III, 285 (I842).

Gelechia gossypichla, Meyr., B.J., XVI, 592 ; WIsm., Faun. Hawaii. I, 73I 733 ; Durrant, Bull. Ent. Res., III, 203-206. fig. ; Lefroy, Ind. Ins. Pests, p. 93. ff. 104 I06; Ent. Nem. Agri. Dept. Ind., I, 223, f. 69 ; Ind. Ins. Life, p. 534 , f. 344 .

\section{(SEE PLATE XLII.)}

Distribution. - Throughout the Plains of Southern India.

Lifchistory. - The eggs are laid singly on Cotton-bolls, into which the caterpillar bores, feeding on the oily seeds. The young caterpillar is whitish, but when older it assumes a pink tinge until, when full-grown, it is almost of a salmon-red colour. It is then about 15 mm. long, moderately stout, smooth except for a few short scattered bristly hairs, with a brown head and prothoracic shield. Pupa brownish, in a slight cocoon formed on the stem of the foodplant, in or on the soil, or in the expanded boll itself.

Foodplants.-Cotton.

Status. - A serious pest of cotton, sometimes doing great damage, especially to exotic varieties.

Control.-(I) Picking and destruction of first-attacked bolls.

(2) Careful removal from the field of all open but damaged bolls. Leaving these on the bushes, as not worth plucking, invites attack of this and other cotton pests.

GNORIMOSCHEMA HELIOPA, LOWER.

Gelechia heliopa, Low., P. Linn. Soc., N.S.W. (I900), 4 I7.

Gnorimoschtma heliopa, Meyr., B.J., XVI, 592 (I905) ; P. Linn. Soc., N.S.W. (I904), 320-32I ; Lefroy, Ind. Ins. Pests, p. I56; Ent. Mem. Agri. Dept. Ind., I, 224 ; Ind. Ins. Life, pp. 534-535 ; A.J., I., III, pt. I, tab. 



\section{EXPLANATION OF PLATE XLII.}

\section{GELECHIA GOSSYPIELLA.}

Fig. I. Eggs, enlarged.

"2. Young larva.

"3. Adult larva.

" 4. Pupa.

"5. Infested cotton-boll.

"6. Larva inside cotton-seed.

"7,8. Moth.

(The lines alungside the figures show the natural sizes,) 

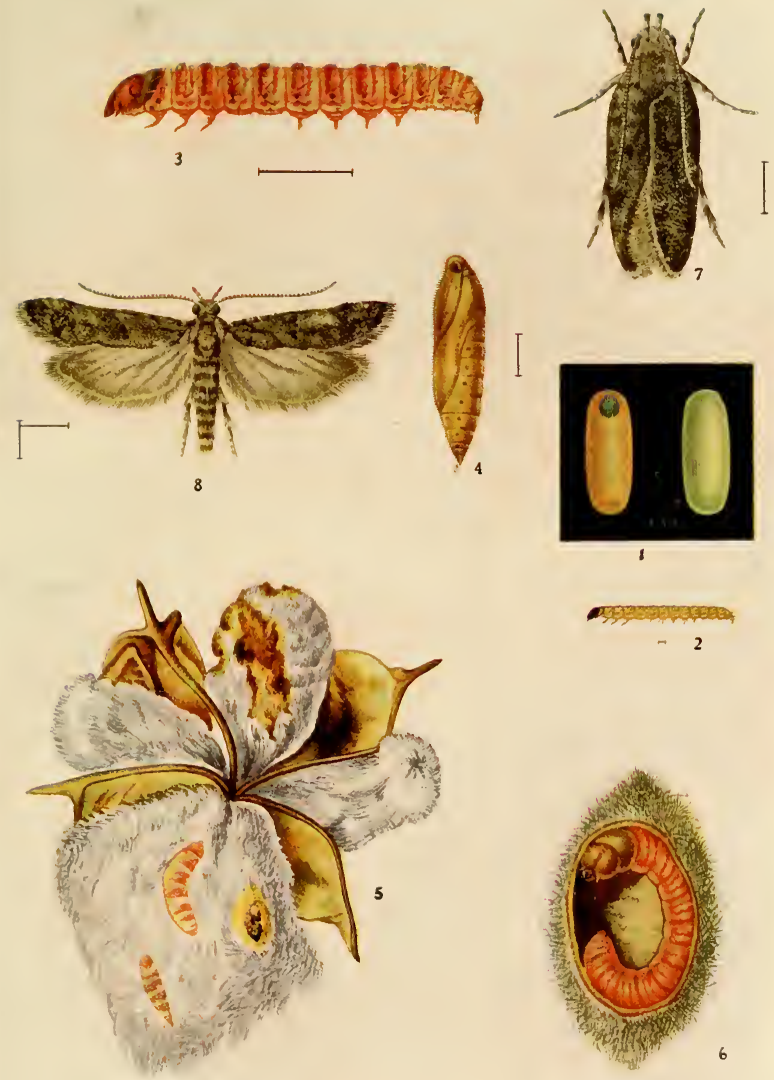




\section{EXPLANATION OF PLATE XLIII.}

GNORIMOSCHEMA HELIOPA.

F1G. 1, 2. Eggs.

"3, 4. Affected tobacco-stems, showing characteristic swelling and mode of entry of larva.

, 5. Larva.

"6. Pupa.

"7, 9. Moth.

" 8. Side-view of head of moth.

(The lines alongside the figures show the natural sizes.) 
PLATE XLIII.

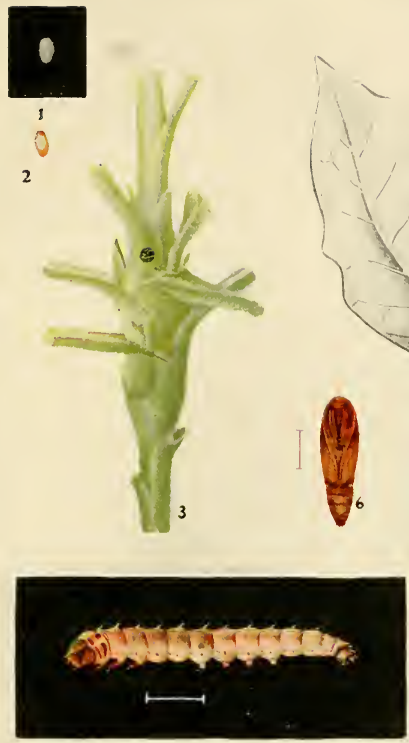

5
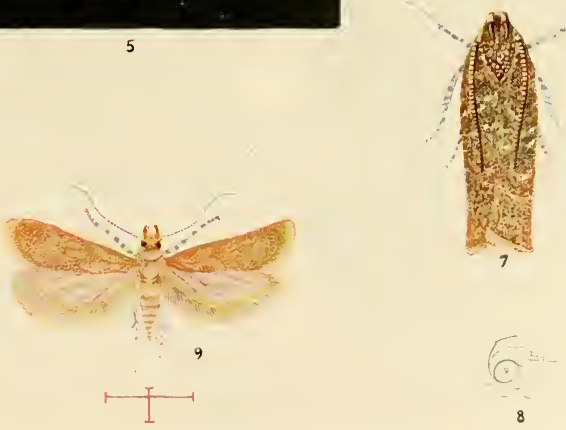

GNORIMOSCHEMA HELIOPA. 


PLATE XLIV.

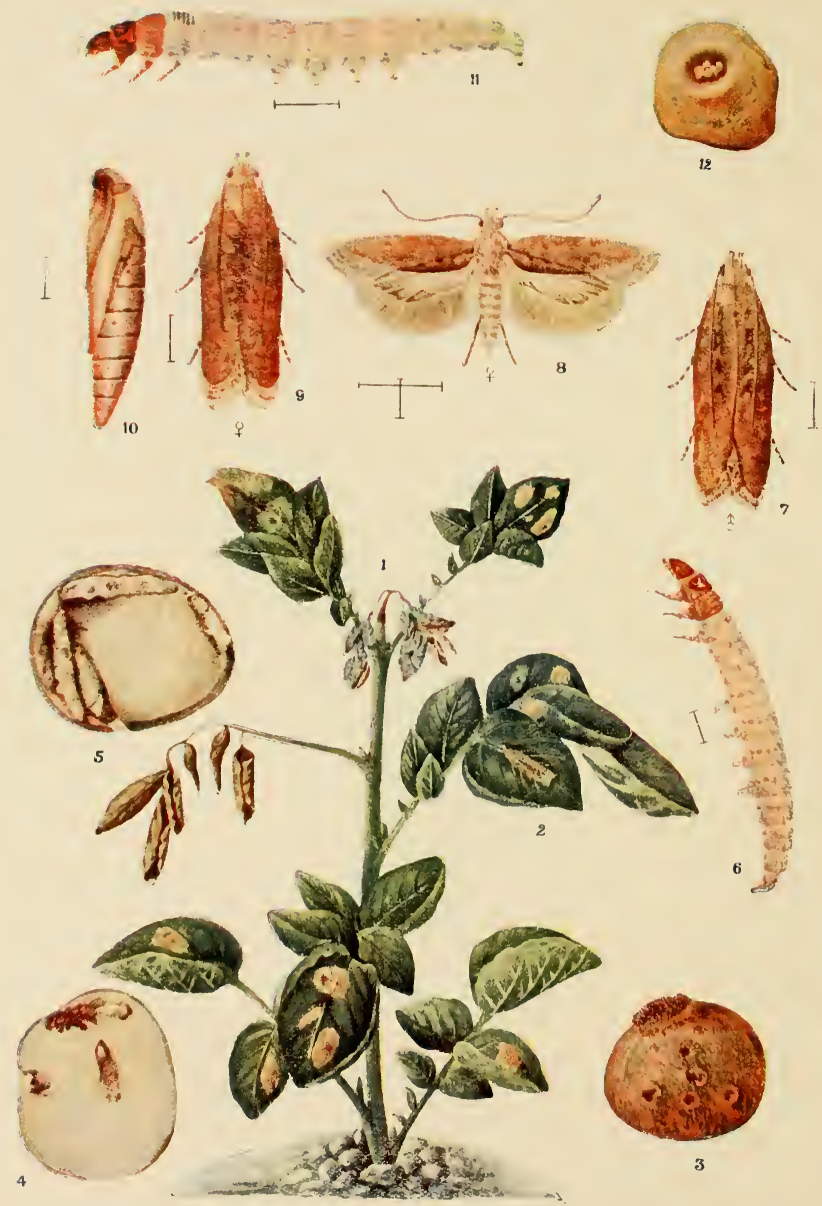

PHTHORIMAA OPERCULELLA 


\section{EXPLANATION OF PLATE XLIV.}

\section{PHTHORIMEA OPERCULELLA.}

Fı. I. Potato plant, showing injury to growing plant caused by larve.

, 2. Moth resting on leaf.

, 3. Potato tuber showing evidence of larval attack in the masses of excrement at the eyes. There is also a cocoon on the tuber.

, 4. Tuber cut open showing damage done by larva.

, 5. Tuber cut open showing larval track and pupa.

,6. Young larva, magnified.

, 7. Male moth, magnified.

, 8, 9. Female moths, magnified.

- Iо. Pupa, magnified.

„, II. Full grown larva, magnified.

" I2. Eggs deposited at the eyes of a potato tuber, magnified.

(The lines alongside the figures show the natural sizes.) 


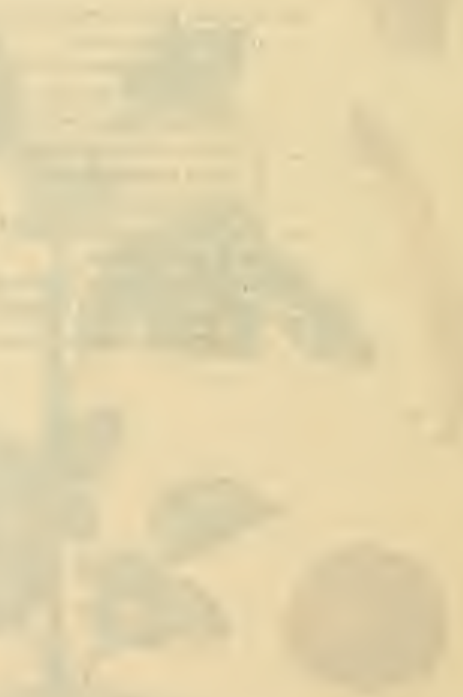


Distribution.--Gōdīvari, Bellary, Anantapur, Coimbatore. Probably throughout the Plains of Southern India.

Lifehistory.-Eggs are laid singly on the stalk or rib of a leaf, the newly hatched caterpillar boring down through the stalk into the stem in which it passes the rest of its immature life, causing a characteristic swelling of the stem. The full-grown caterpillar is about $10 \mathrm{~mm}$. long, whitish or pale pink, with a darker head. When full-fed it changes to a yellowish brown pupa insirle the gall-like swelling.

Foodplant.--Tobacco.

Status.-Usually rather a minor pest of tobacco in Southern India, occasionally doing serious damage.

Control.-(I) Killing the caterpillar by slitting the gall with a sharp knife.

(2) Removal and destruction of all old stumps of tobaccoplants as soon as the crop is harvested.

Rcmarks.--The hindwing of the moth should be more pointed than is indicated on the Plate.

\section{PHTHORIMIA OPERCULELLA, Z.}

Gclechia operculclla, Zeller, Verh., Z-B. Ges. Wien, XXIII, 262-263, t. 3 , f. 17 (1873).

Bryotropha solanclla. Boisd., J.B., Soc. Centr. Hort., XI (I 874).

Phthorimaca operculclla.-Meyr., E.M.Ml. (1902), 103-I04; Busck, Proc. U.S. Nat. Mus. XXV, 82I 822, t. 30, f. I9; WIsm., Faun., Hawaii, 1. $4^{83} 4^{85}$, t. I3. f. 27 ; Lefroy, Ind. Ins. Life, p. 535. t. 57 ; A.J., J., V, $19-28$, t. I (Jan. I910); Chittenden, U.S.A. Entom. Circ. No. 162 (1912).

\section{(SEE PLATE XLIV.)}

Distribution.-Bangalore, Nilgiris up to 7,000 feet.

Lifchistory.-Eggs are laid on stored potatoes into which the caterpillars tunnel. Caterpillar about $10 \mathrm{~mm}$. Iong, smooth, with a few scattered short hairs, in colour white with dark-brown head and prothoracic shield. Pupa pale brown, in a cocoon on the outside of a potato-tuber or in any convenient situation giving a little shelter.

Food.--Stored potatoes.

Status.-A serious pest of stored potatoes.

Control.- Storage of potatoes under dry sand, examining about twice a month and rejecting and destroying all affected tubers.

Remarks.-Outside of India the caterpillar is known to mine in the leaves of potato and tobacco in the field, as shown in the Plate and is sometimes a serious pest of tobacco. But so far, it has only been noted as damaging stored potatoes in Southern India. 
SITOTROGA CEREALELLA, Oliv.

Alucita coralclla--Olivier, Enc. Mcth., IV (Ins. I.), 12I (I789).
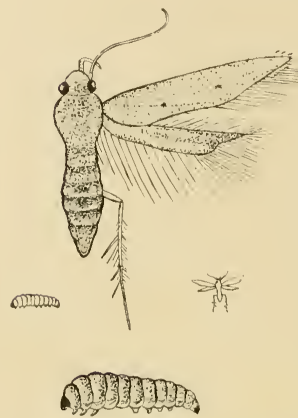

Fig. 331.-Sitotroga cercalclla. moth and larva. The outline figures show the natural sizes. (Original.)
Sitotroga cerealilla.-Meyr., B.J., XVI. 59 I (1905); Busck, Proc. U.S. Nat. Mus., XXV, 782, t. 28, f. 3 .

Distribution. - Throughout South ern India.

Lifolhistory.-Eggs are laid on grain into which the caterpillar bores. This is a short, stout, whitish grub with poorly-developed legs; when full-fed, it is about $4 \mathrm{~mm}$. long. Pupation inside the grain.

Food.-Stored grain (Paddy. Maize, etc.)

Status.-Not noticed much as a rule but a serious pest of stored grain and in the aggregate must do a great deal of damage.

Control.-Fumigation and preservation of grain in insect-proof receptacles.

DICHOMERIS IANTHES, MEyr.

Hypsolophus iumthes,-Meyr., T.E.S. (1887), 273-274.

Ypsolophus ianthes.-Meyr., Rec. Ind. Mus., V, 223 ; T. Linn. Soc.

(2) XIV, 275.

Ypsolophins ochropham's.-Meyr., B.J., XVII, 98I (1907); Lefroy, Incl. Ins. Life, pp. 533-534.

Dichomeris ianthes.-Meyr., B.J. XXII., I72 (19I3).

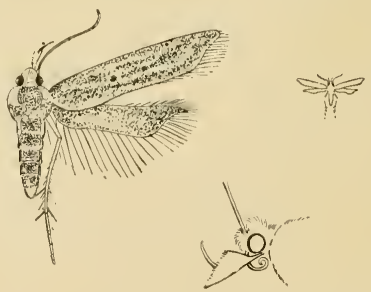

FIG. 332.-Dichomeris iunthes, moth and profile view of head. The small outline figure shows the natural size. (Original.) 
Distribution.- Probably throughout the Plains of Southern India

Lifchistory. - " Larva green, smooth and nearly hairless, with small lateral black spots, and black head and prothoracic shield. It webs together two top leaves and lives within, eating holes in the neighbouring leaves." (Lefroy.)

Foodplants.-Leguminosae of various kinds, especially lucerne, indigo.

Stalus.-Has been noted as an occasional pest of indigo, but not hitherto in Southern India.

APRO.EREMA NERTERIA, MEYr.

(SURUL PUCHI.)

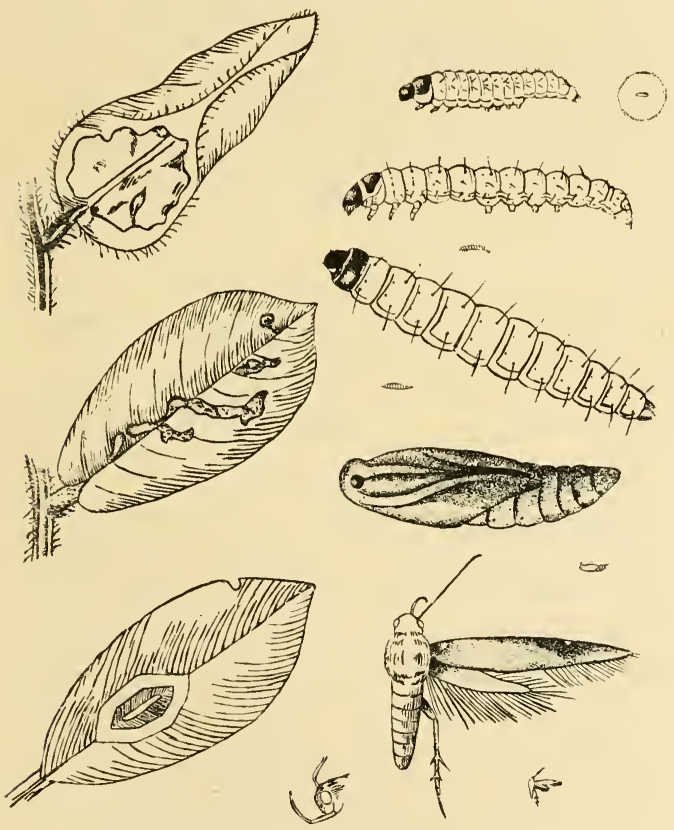

Fig. 333.-Aproarena nerteria. (Original.) 
Anacampsis nerteria.-Meyr., B.J., XVII, I39 (1906) ; Lefroy, Ent. Mem. Agri. Dept., Ind., I, 226 ; Ind. Ins. Life, p. 534.

Distribution. - Throughout the Plains of Southern India.

Lifehistory. - The egg is laid on leaves or shoots of groundnut, the caterpillar on emerging mining into the leaves, the mine showing as a yellowish or brownish blotch on the leaf. After about a week, the caterpillar emerges from the mine and webs together small leaflets, still continuing to feed on the green leaf-tissues. When full-fed it is about $6 \mathrm{~mm}$. long, moderately stout, smooth, with a few scattered short bristly hairs arising from minute blackish chitinous warts, in colour pale greenish, head and prothoracic shield blackish. Pupa yellowish or reddish-brown, in the chamber formed of spun leaflets. Life-cycle, egg three days, caterpillar I2-I4 days, pupa four days.

Foodplants.-Ground-nut. Red Gram (Cajanus indicus), Psoralea corylifolia.

Status.-A serious pest of ground-nut.

Control. - Light-traps have some considerable attraction for the moths, but no really effective method has yet been worked out.
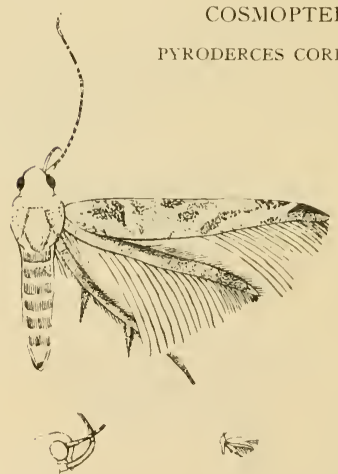

Fici. 33t.-Pyroderces coriacella. moth and profile view of head. The small outline figure shows the natural size. (Original.)

Batracladra corineslla. Snellen, Tijd. v. Ent., XLIV, 95. t. 6, f. 17 (I90I).

Stagmatophora gossy'piella.-Wlsmı, A.M.N.H. (7) XVIII, I78 I79 (I906); Mor. statt, Pflanzer, VIII, 253 (I912).

Pyroderces simple.r. Wlsm.; Durrant, Bull. Ent. Res., III, 206-207, f. 2 (I9I2) [part.].

Stagmatophora coriacella, Meyr, T.E.S. (1910), 372.

Distribution.--South Arcot. Probably throughout the Plains of Southern Inclia. 
Lifehistory. -Not known. Bred from ripe cotton-bolls, caterpillar probably feeding on the seeds.

Foodplants. - Cotton.

Stutus. - Doubtful. Will probably prove to be injurious to stored cotton-seed.

Remarks. - South Indian specimens have kindly been identified by Mr. Meyrick. It is possible that P. simplex, Wlsm. (T.E.S. (I89I), II9 I 20, t. 6, f. 58) is a prior name as stated by Durrant (l.c.) but, as this synonymy is doubtful, Snellen's name is retained for the present.

\section{CECOPHORID E.}

TONICA ZIZYPHI, Stn.

Depressaria zizyphi, Stainton, T.E.S. (N.S.), V, II 5-II6 (I859).

Dcpressaria alugusta, Wlsm., Moore's Lep. Ceylon, III, 508, t. 209, f. 5 .

Tonica sizyphi, Meyr., B.J., XX, I67 (1910).
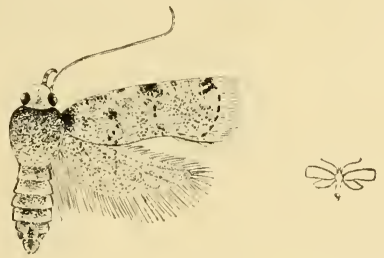

Fig. 335.-Tonica zizyphi. The small outline figure shows the natural size.

(Original.)

Distribution.-Coimbatore; Palni Hills. Probably throughout Southern India.

Lifehistory.- The caterpillar is about $8 \mathrm{~mm}$. long, slender, yellowish-green with a black head. It folds orange leaves longitudinally, feeding on young leaves and the green matter of older ones. Pupa $6 \mathrm{~mm}$. long, reddish-brown, in a cocoon of transparent white silk spun in the folded leaf; pupal period about four to five days.

Foodplants.-Citrus of various species (Orange, Lemon, etc.).

Stutus.-A very minor pest, occasionally injurious by eating off the tender shoots of young plants.

Control.- Hand-picking of caterpillars in the folded leaves. 


\section{XYLORYCTIDA.}

NEPHANTIS SERINOPA, MEyr.

Nephantis serinopa, Meyr., B.J., XVI, 603 (1905); Lefroy, Ind. Ins. Life, p. 535-536.
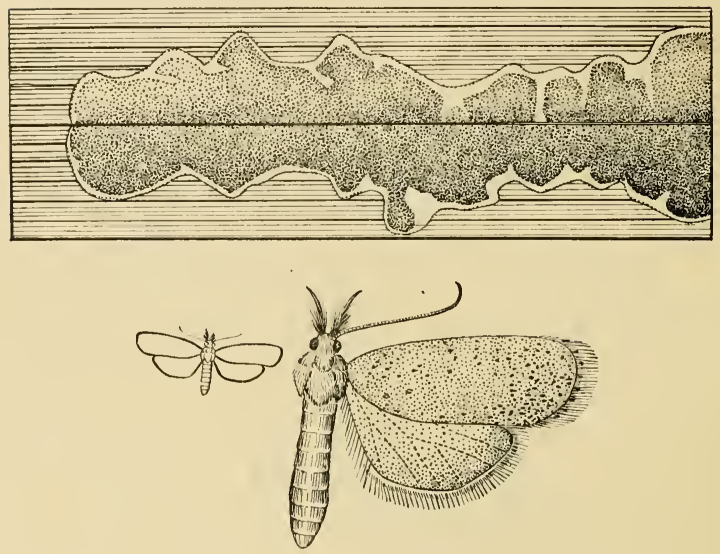

FIG. 336.-Ncphantis serinopa. Portion of Palm-leaf eaten by larva, and moth (natural size and magnified). (Original.)

Distribution.-Throughout the Plains of Southern India.

Lifehistory.--The eggs, which turn pinkish after deposition, are laid in small batches of a dozen or twenty together amongst the frass and debris of larval galleries on palm leaves. The caterpillar constructs a gallery of silk and excrementitious matter over the lower surface of palm leaves, eating away the green matter and reducing the leaf to a thin membrane so that it dries up and dies. In cases of bad infestation, practically the whole leaf may be eaten away, only the ribs remaining. The caterpillar is about $25 \mathrm{~mm}$. long, in colour greenish with faint paler lines along the body and a black head. Pupa slender, dark red-brown, in a cocoon spun in the larval gallery.

Foodplants.-Coconut and Palmyra palms. Possibly on other palms also. Not yet noted on Date or Arecanut palms. 
Status.--A serious pest of the Coconut paln, not damaging Palmyras much as a rule.

Control.-(I) Cutting and burning of first attatcked branches.

(2) Catching of moths in light-traps.

(3) Spraying with lead arsenate or other stomach-poison in the case of small areas and ornamental palms.

\section{TIN EGERIADA.}

ERETMOCERA IMPACTELLA, WIk.

Gelechial? impactella, W1k., Cat. XXIX, 637.

Eretmocera impactella, Wlsm., T.E.S. (1889), 34-35, 39, t. 6, f. I8 ; Hmpsn., Faun. Ind. Moths, 1, 208, f. I35 ; Lefroy, Ind. Ins. Life, p. 537.

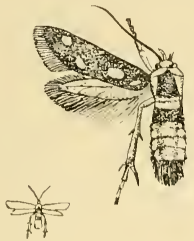

Fig. 337.-Eretmocera impactella. The small figure shows the natural size. (Original.)

Distribution.- Throughout the Plains of Southern India.

Lifehistory.--Not known.

Foodplants.-Amaranthus.

Status.-Not known as a pest.

Remarks.-A common and conspicuous little moth which flies by day and also commonly comes in to light at night.

\section{HYPONOMEUTIDÆ.}

ATTEVA FABRICIELLA, Swerl.

Phalana Tinea fabriciella, Swederus, Kngl. Svensk. Vet. Ak. Handl, VIII, 277 (1787).

Corinca niwiguttella, Wlk., Cat. XXVIII, 542-543 (I863).

Atteva fabriciella, Wlsm. in Swinh. Cat. Het. Oxf. Mus., If, 559 (I900).

Distribution.-Nilgiris, Coimbatore. 


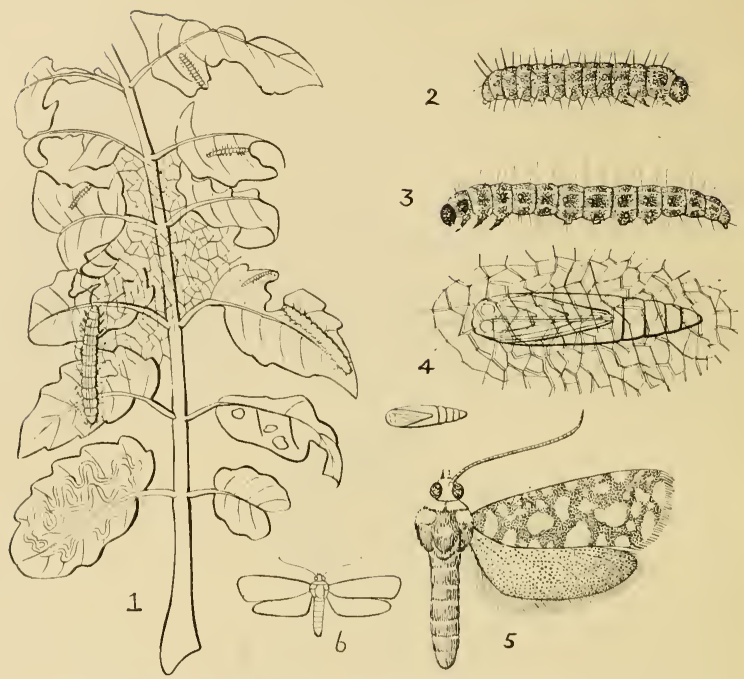

FIG. 338.-Attcva fabriciclla. 1, Leaf of Ailanthus cxcclsa webbed and eaten by larvæ (the mine of a small leaf-miner is also shown); 2, Young Larva ; 3 , Full-grown Larva ; 4, Pupa enclosed in cocoon; 5, 6, Moth, enlarged and natural size. (Original.)

Lifchistory.-The eggs are creamy-white, rounded, flattened, and beautifully sculptured; they are laid, usually on the lower surface of leaves, either singly or in small groups. The caterpillars live gregariously in a common web of fine silk spun over the leaves and shoots of the foodplant, which, in conjunction with larvæ of Eligma narcissus, they may sometimes completely defoliate. The fullgrown caterpillar is about $20 \mathrm{~mm}$. long, moderately stout, smooth, with scattered short hairs arising from small whitish warts, head blackish, body greenish-grey with paler longitudinal stripes, one faint one down the back edged on either side by a more distinct stripe, and a well-defined stripe along each side. Pupa orangebrown, in a transparent boat-shaped cocoon spun in the common web ; pupal period about ten days.

Foodplants. - Ailanthus cxcelsa.

Status.-An occasional serious pest of Ailanthus. 
Control. - The common webs are conspicuous and easily torn down and the caterpillars destroyed. Ornamental specimens of Ailanthus may be sprayed with Lead Arsenate or other stomach poison.

Remarks.-The closely-allied A. niveigutta, Wlk. known from Bengal, Silhet and China, feeds on Ailauthus excelsa, larvæ in a common very fine web. At times a perfect pest, denuding the tree of its leaves. See WIsm. (l.c.).

\section{GLYPHIPTERYGID E.}

PHYCODES R.DIATA, Ochs.

Chimara radiata, Ochs, Schmett. Europ., II, 5-6 (1808).

Phycodes hirudinicornis, Guen., Noct., II, 389, I249, t. I3, f. 5 (I852).

Tegna hyblcella, Wik., Cat. XXXV, I8Io (1866); Forsayeth, T.E.S. (1884), 379, t. I4, f. Io.

Phycodes radiata, Wlsm. in Swinh. Cat. Lep. Oxon. Mus., II, 568 (1900); Lefroy, Ind. Ins. Life, p. 538, t. 52, ff. 7 I0.
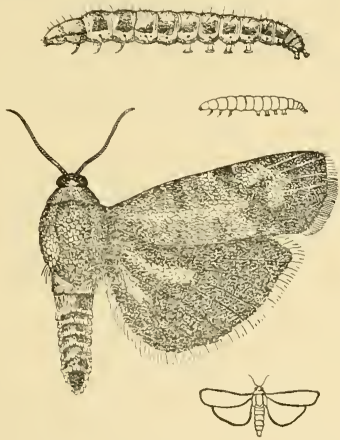

Fig. 339.-Pliycodes radiata, larva and moth. The ontline figures show the natural sizes. (Original.)

Distribution. - Bellary, Madras. Probably throughout the Plains.

Lifchistory.-Caterpillar about $20 \mathrm{~mm}$. long, moderately stout, rather flattened, smooth, with scattered short hairs, in colour dull yellowish-white with a broad interrupted dark stripe along the side, head and prothoracic shield red-brown, a broad dark band transversely across the back of meso-and meta-thoracic segments. 
The caterpillar rolls leaves of Ficus. Pupa red-brown, in a tough paper-like cocoon, occasionally spun on a leaf but more usually in a crack of the bark or similar situation; pupal period about I5 days.

Foodplants.-Ficus of various species.

Statns.-Occasionally in such numbers as to do damage to Fig-trees.

Control.-?

\section{PLUTELLIDÆ.}

PLUTELlA MACULIPENNIS, Curt.

Cer ostoma maculipennis, Curt., Brit. Ent., IX, t. 420 (I832).

Plutella cruciferarum, Zeller, Stett. Ent. Zeit, IV, 28I-283 (I 843 ); Quanjer, Tidjs. Ent. (I 906), II, I7, t. I-2.

Plutelta maculipennis, Meyr., Rec. Ind. Mus., V, 229; Lefroy, Ind. Ins. Pests, p. I52, ff. I70-I7I ; Ent. Mem. Dep. Agri., Ind., I, 225. f. 69 ; Ind. Ins. Life, p. 538 , f. 345 .

Distrilution.-Throughout Southern India.

Lifchistory. - The eggs are laid singly on leaves. The full-grown caterpillar is about $8 \mathrm{~mm}$. long, moderately stout, attenuated at each extremity, smooth, with short scattered bristly hairs, in colour pale-green with a pale-brown head and prothoracic shield. Pupa in a slight silken cocoon of open texture; pupal period about ten days.

Foodplants.-Cabbage, cauliflower, radish, mustard, and other cruciferous plants.

Status.- The caterpillar eats holes in the leaves of cabbage, etc., and may sometimes almost skeletonize the leaf. A minor pest as a rule.

Control.--Spraying with Naphthaline Emulsion in the case of edible plants.

HILAROGRAPHA CAMINODES, Meyr.

Hilarographa caminodes, Meyr., B.J., XVI, 6Io (1905); Green, Perad. Circ., II, I7, p. 250 (not named).

Lifchistory and Foodplants. - The larva bores in the root of cultivated Cardamoms and in wild Zingiberaceous plants. The eggs are laid on the exposed upper part of the bulb; the stem proper is able to resist attack (Green).

Control.-Green (l.c.) suggests earthing over the exposed bulbs.

Remarks.-Recorded as a pest of Carlamoms in Ceylon. Not yet noted from India, so far as I am aware, but included here as it is likely to occur. I have been unable to obtain a specimen for illustration. 


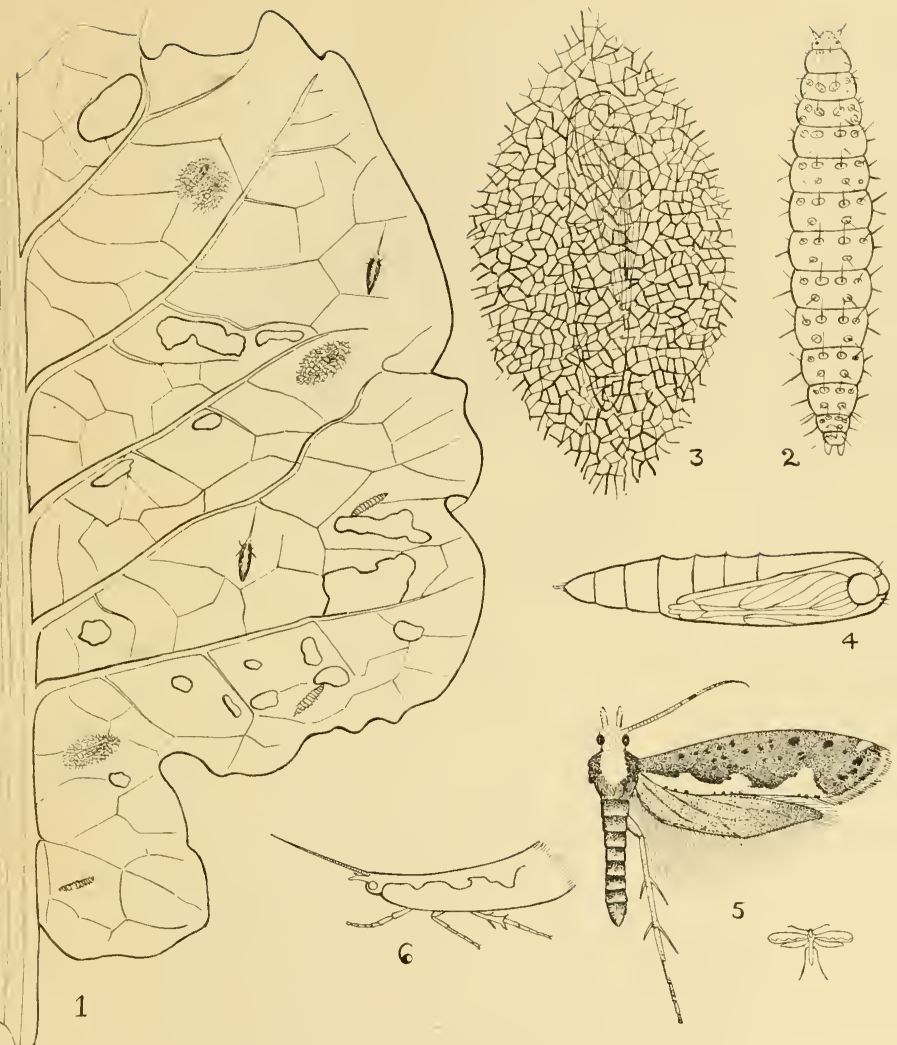

Fig.3+0.-Plutclla maculipennis. 1, Portion of Cabbage Leaf showing larsa. cocoon and moths in natural sizes and attitudes; 2, Larva; 3. Pupa enclosed in cocoon; 4 , Pupa; 5 , Moth, enlarged and natural size; 6 . sidesicw of moth in resting attitude. (Original.) 

PHYLLOCNISTID.E.

PHYLLOCNISTIS CITRELLA, Stn.

Phyllocnistis citrella, Stainton, T.E.S. (n.s.), III, 302-303 (1856); Meyr., Ann. S. Afr. (.Mus. 1909), p. 360.

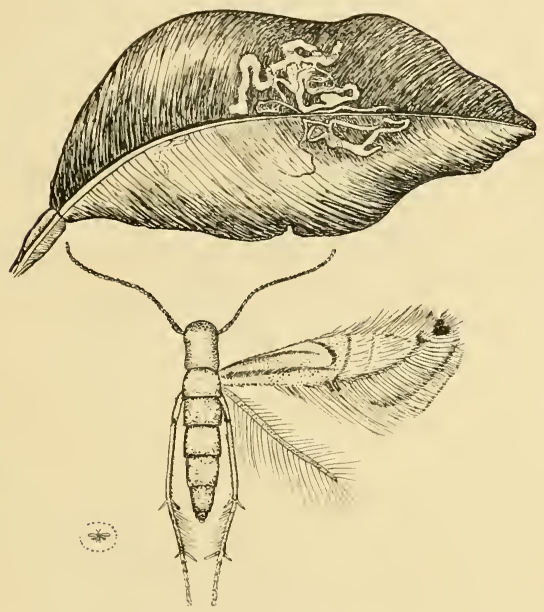

F1G. 3+1.-Phyllocnistis citrella. Larval mine in Orange leaf and moth. The small figure within the dotted circle shows the natural size of the moth. (Original.)

Distribution.-Probably throughout Southern India.

Lifehistory.-The minute, almost legless, transparent pale-green caterpillar mines tunnels between the epidermal layers of Citrus leaves. Pupa minute, yellowish, in the larval mine.

Foodplants.-Orange.

Status.-A minor pest as a rule, occasionally occurring in such large numbers that every leaf is badly mined.

Control.- The insect is so minute that it is little noticed, although the larval galleries are fairly evident. As the caterpillar mines inside the leaf it cannot be attacked by a contact or stomach-porson spray. The only practical method seems to be (i) fumigation of 
attacked trees, or (ii) crushing the caterpillars in their mines by hand.

Remarks.-Phyllocnistis minutella, Snell. (Tijds v. Ent. (I903), 87 ; van Deventer (l.c.), pp. $87-89$, t. io, ff. $4 a-c)$, described from Java as mining Citrus leaves, is perhaps the same as citrella. The early stages are excellently figured by van Deventer.

\section{TINEID Æ.}

TINEA PACHYSPILA, Meyr.

Tinea pachyspila, Meyr., B.J., XVI, 6I9 (I905); Rec. Ind. Mus., V, 23I ; Tr. Linn. Soc. (2), XIV, 305 (I9II); Lefroy, Ind. Ins. Life, p. 540 .
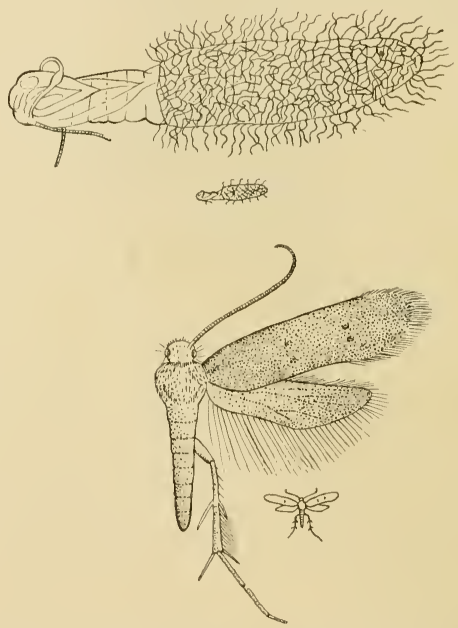

FIg. 3+2.--Tinea pachyspila. Pupa-catse projecting from larval tube, and moth. The smaller figures show the natural sizes. (Original.)

Distribution.-Trivandrum. Doubtless throughout Southern India. 
Lifehistory and Food. Larva in a case, feeding on flannel fur, etc.

Status.--A common household "Clothes Moth."

Control.-Protection of clothing by means of Naphthaline.

TRICHOPHAGA TAPETZELLA, Linn.

Tinea tapetzolla, Linn., Syst. Nat. (ed. X), p. 536 (I758); Lefroy, Ind. Ins. Life, p. 540.

Tinca tapetsella, Meyr., Handbk., pp. 785-786.

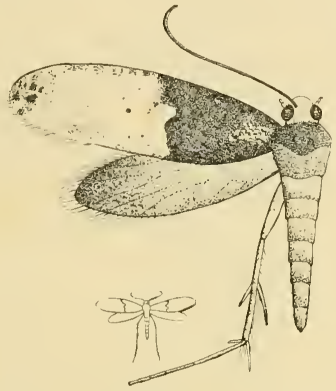

F1G. 3+3.-Trichophaga tapctzclla. The small outline figure shows the natural size. (Original.)

Distribution.-- Doubtless throughout Southern India.

Lifehistory and Food.-Cateruillar in a case on woollen fabrics, clothing, fur, cast pellets of owls, and excrementitious refuse generally.

Status.-The typical "Clothes-Moth," now carried all over the world; attacking furs especially.

Control.--Protection of clothing by Naphthaline and of mounted trophies of Game, etc., by painting the skins with an alcoholic solution of Corrosive Sublimate.

\section{HEPIALIDÆ.}

PHASSUS MALABARICUS, MO.

Phassus malabaricus, Moore, P.Z.S. (1879), 412; Hmpsn., Faun, Ind. Moths, I, 32I ; Lefroy, Ind. Ins. Life, p. 54I, f. 346. 


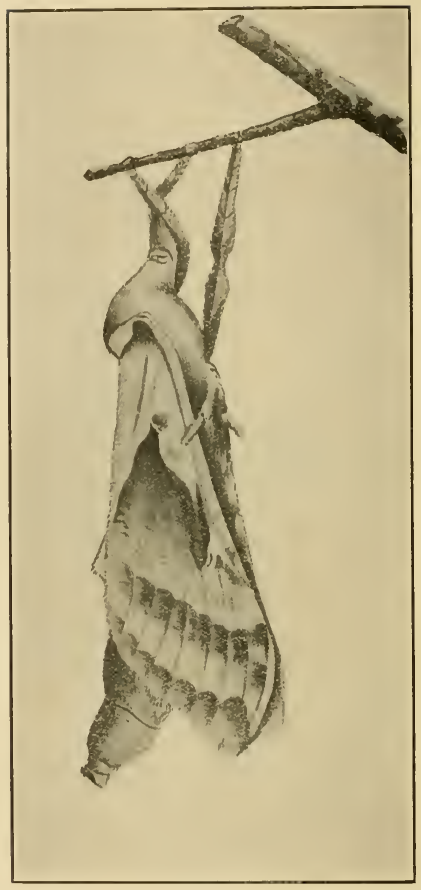

F1G. 3+t.-Phassus malabaricus in resting attitude hanging from a twig. (After Lefroy.)

Distribution.-Nilgiris; Bangalore.

Lifchistory.-The caterpillar bores in roots and pupates in the larval burrow.

Foodplant.-Has been reared from a tea-bush; probably on various roots.

Status. - Not noted as a pest but may do damage.

Control.-? 

PLATE XXXXV.
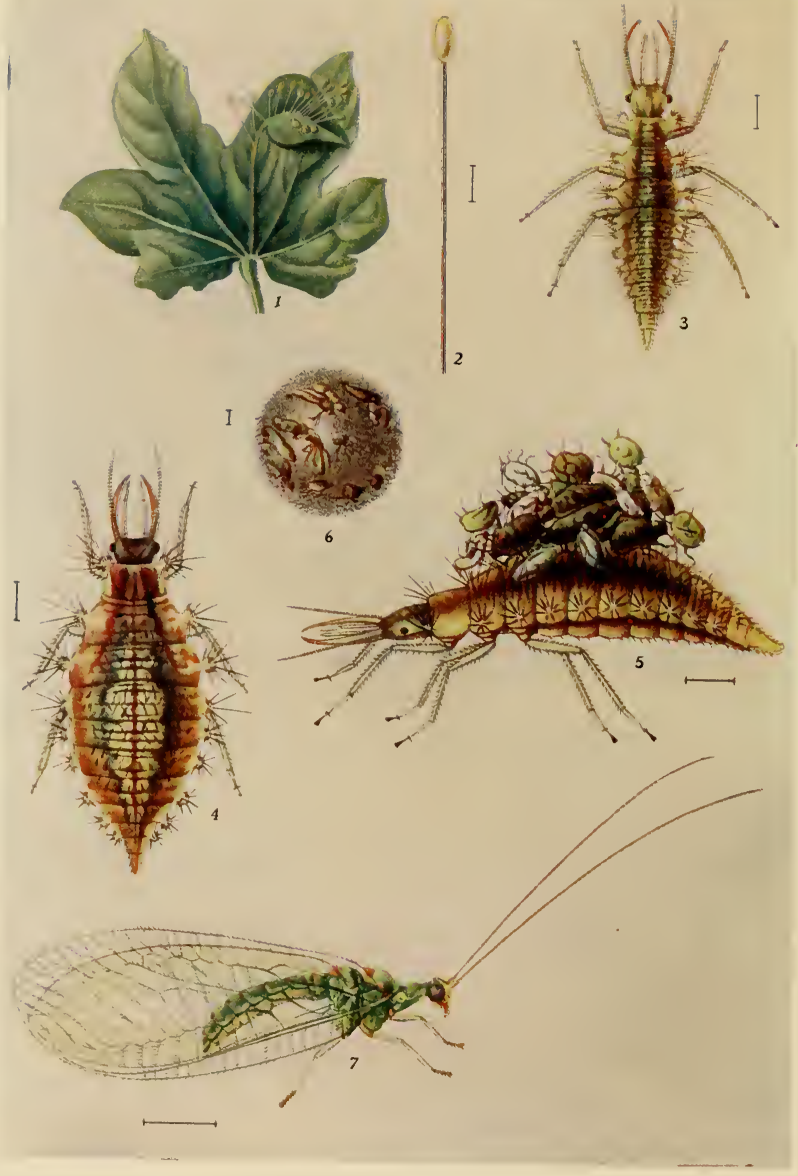

CHRYSOPA SP. 


\section{EXPLANATION OF PLATE XLV.}

\section{CHRYSOPA SP.}

FIG. 1. Group of eggs laid on leaf.

" 2. A single egg on its stalk, magnified.

"3. Young larva, magnified.

" 4. Full grown larva, magnified.

" 5. Full grown larva, literal view, showing empty skins of Aphids which it has devoured.

, 6. Cocoon, magnified.

, 7. Adult fly, magnified.

(The lines alongside the figures show the natural sizes.) 



\section{NELROPTERA \\ CHRYSOPIDE. \\ CHRYSOPA Spp. \\ (SEE PLATE XLV.)}

Chrysopa, Lefroy, Ind. Ins. Pests, p. 275, ff. 332, 33+, 336, 337 ; Ind. Ins. Life, pp. I54-I56, ff. $76-80$.

Distribution.-Throughout the Plains of Southern India.

Lifchistory.-The eggs, which are erected on the apex of long slender stalks, are laid in small clusters on leaves, twigs, etc. The larva is predaceous on Aphids which it sucks dry and (in some species) then places the empty skins on its back where they are retained by long curved spines (see Plate). The larvæ are active and voracious and destroy large numbers of Aphids. After feeding for about a week they form a rounded coconn inside which the pupal period is passed.

Food.-Aphids, especially on cotton and cholam.

Status.-Extremely beneficial.

\section{RHYNCHOTA. \\ PENTATOMIDE. \\ COPTOSOMA CRIBRARIA, Fb.}

Cimex cribrarius, Fab., Ent. Syst. Suppl., p. 53I (1798).

Coptosoma cribrarium, Distant. Faun. Ind. Rhyn., I, 22-23, f. II ; Lefrov, Ind. Ins. Life, p. 672.
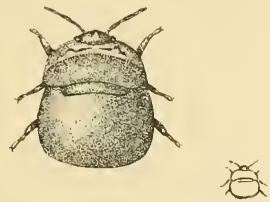

F1G. 3+5.-Coptosoma cribraria. The small outline figure shows the natural size. (Original.)

Distribution.--Throughout Southern India.

Lifchistory. - The creamy-white elongated eggs are laid in batches of about 35 eggs arranged in two rows, their bases being opposed. The young bug emerges by pushing open the lid with which the egg is provided; it is about $75 \mathrm{~mm}$. long, shining orange in colour with red eyes. In their younger stages they are gregarious but later on separate, living on the foodplant all their lives. 
The life-cycle is: - Egg, six days, nymph $8+6+9+9+10$ days, the nymphal periods representing those spent in each instar between the moults; total, about seven weeks. [T.V.R.]

Foodplants.-Lab-lab (Dolichos lat)-(ab), Green Gram (Phascolus mungo), Cluster Bean (Cyamopsis), Agathi (Seshania grandifora). Also on various wild Leguminose and Compositæ.

Status. - A minor pest of Lab-lab and Agathi.

Control.-Catching in small hand-nets.

\section{CAPPAA TAPROBANENSIS, Dall.}

Pentutoma taprohanc'ssis, Dall., List. Hem, I, 244 (I851).

Cappcea taprobanensis, Dist., Faun. Ind. Rhyn., I, I 49, f. 88.

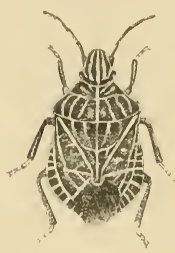

FIG. 3+6.-Cappaa taprobancusis. The small ontline figure show's the natural size. (Original.)

Distribution. - S h e v aroys, Coonoor, Bababudins; Malabar.

Lifchistory. $-\mathrm{Not}$ known. All stages probably passed on the tree.

Foodplants.-Orange.

Status.-Apparently a minor pest in the Hill Districts, the bugs sucking the juice of the twigs and shoots.

Control.- Collection by shaking over cloths, etc., spread under the tree.

DOLYCORIS INDICUS, Sta].

Dolycoris indicus, Stal., Enum. Hen, V, 76 (1876); Distant, Faun. Ind. Rhyn., I, 160, f. 96; Lefroy, Ind. Ins. Life, p. 675, t. 73, f. 10.

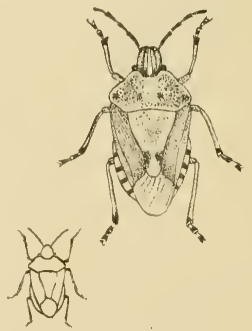

FIG. 347.-Dolycoris indicus. The outline figure shows the natural size. (Original.) 
Distribution.-Throughout Southern India.

Lifchistory.-Not known.

Foodplants. - Cholam, Cumbu (Pennisetum typhoidemm), Tenai (Setaria italica), Wheat, Safflower, Sunflower.

Status.-A minor pest.

Control.-Catching the bugs in hand-nets.

EUSARCOCORIS GUTTIGER, Thnb.

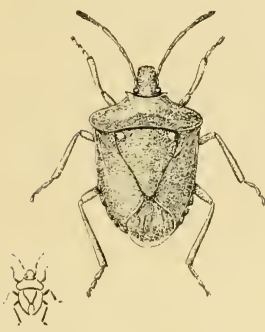

Cimex guttiger, Thunberg. Nov. Ins. Sp., II, 32, t. 2, f. 47 (I783).

Eusarcocoris guttiger, Dist., Faun. Ind. Rhyn., I, I65 ; Lefroy, Ind. Ins. Life, t. 73 , f. 5 .

Distribution.- Throughout the Plains of Southern India.

Lifcliistory.-Not known.

Foodplants.-- $\mathrm{C} \mathrm{u} \mathrm{m} \mathrm{b} \mathrm{u} \mathrm{(Pennisetum}$ typhoideum).

Status.--A minor pest of Cumbu.

Control.-Collection by hand-nets.

Fig. 3+8. - Eusarcocoris guttiger.

The outline figure shows the natural size. (Original.)

EUSARCOCORIS VENTRALIS, Westwd.

Pentatoma ventralis, Westwd., Hope Cat., I, 36 (1837).

Eusarcocoris ventralis, Distant, Faun. Ind. Rhyn., I, I67.

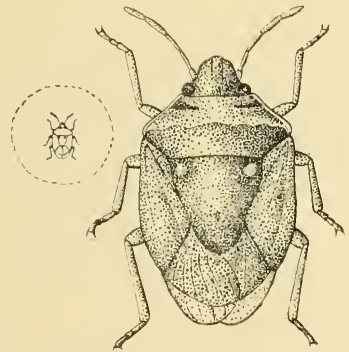

FIG. 349.-Eusarcocoris ventralis. The outline figure shows the natural size. (Original.) 
Distribution.-Ganjam, Bangalore (Distant).

Lifchistory.--Not known.

Foodplants. - Gingelly.

Status.-Found as a serious pest on one occasion.

Control.-Collection by hand-nets and by shaking plants over pans of water and oil.

ANTESTIA CRUCIATA, Fb.

Cimex cruciata, Fab., Syst. Ent., p. 714 (1775).

Autestic cruciata, Distant, Faun. Ind. Rhyn., I, I85; Lefrov, Ind. Ins. Pests, p. 235 ; Ent. Mem. Agri. Dept., Ind., I, 233.

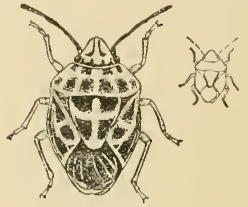

Fig. 350.-Antestia cruciata. The outline figure show the natural size. (Original.

AGONOSCELIS NUBHLA, Fb.

Cimex mbile, Fab., Syst. Ent., p. 7I 2 (1775).

Agonoscelis mubila, Distant, Faun. Incl. Rhyn., I, I89.

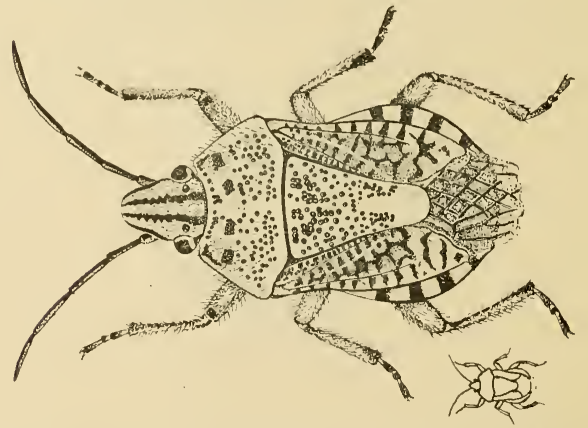

Fici. 351.--. Inomoscalis nubula. The outline figure shows the natural sict. (Original.) 
Distribution.-Throughout Southern India.

Lifchistory.-Not known.

Foodplants,-Cholam. Cumbu (Pennisetum typhoidenm), Wheat and various Pulses, Aniseed (Pimpinclla anisum).

Status. A minor pest, not yet noted as doing any serious damage.

Control.-Collection in hand-nets.

Remarks.--Very similar to Dolycoris indicus in general appearance and habits, but distinctly smaller and the abdomen is not visible when the wings are closed and is unspotted.

BAGRADA PICTA, Fb.

Cimex picta, Fab., Syst. Ent., p. 715 (1775).

Bagrada picta, Dist., Faun. Ind. Rhyn., I, I93-194, f. I I6; Lefroy, Incl. Ins. Pests, p. 233, f. 278 ; Ent. Mem. Agri. Dept., Ind., I, 232, f. 75 ; Ind. Ins. Life, p. 676 , f. 439.

(SEe Plate II, Fig. Io.)

Distribution. - Throughout Southern India.

Lifchistory.-- Not known in detail.

Foodplants.-Cruciferous plants (Cabbage, Cauliflower, Mustarcl, Turnip, etc.).

Stutus.-A minor pest of Cabbage and Cauliflower.

Control.--Hand-picking.

NEZARA VIRIDULA, Linn.

Cimcr viridula, Linn., Syst. Nat. (ecl. X), p. 444 (1758).

Nezara viridula, Distant, Faun. Ind. Rhyn., I, 220, f. I39; Lefroy, Ind. Ins. Pests, p. I68, f. I90 ; Ent. Mem. Agri. Dept., Ind., I, 230, f. 73 ; Incl. Ins. Life, p. 676 , f. 440 .

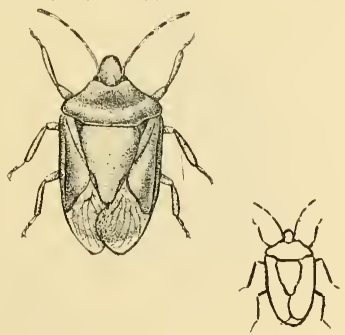

Fig. 352.-.Veatat viridula. The uutline figure shows the natural siec. (Original.) 
Distribution.-Throughout Southern India.

Lifchistory.-Not known in detail.

Foodplants. Cumbu (Pennisetum typhoideum), Wheat (Triticum sativum). Also found on Cholam, Ragi and various other plants.

Stutus.-Usually a minor pest of Cumbu and Wheat, sucking the juices of the developing grain, occasionally doing serious damage to Cumbu.

Control. - Collecting the bugs by hand or in hand-nets.

PIEZODORUS RUBROFASCIATUS, Fb.
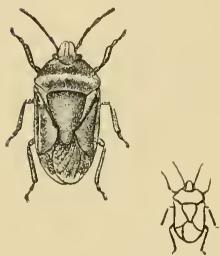

Fig. 353.-Piezodorus rubrofasciatus. The outline figure shows the natural size. (Original.)

Cimex rubrofusciatus, Fab., Mant., II, 293 ( I 787 ).

Piezodorus rubrofasciatus, Distant, Faun. Ind. Rhyn., I, 224 225, f. I42 ; Lefroy, Ind. Ins. Life, p. 676, t. 74 , f. Io.

Distribution.--Throughout the Plains of Southern India.

Lifehistory.-- Not known.

Foodplants.-Cholam and Pulses (Phaseolus) and on most low-growing plants.

Status.-A minor pest of Cholam and Pulses.

Control.-Collection by hand and in hand-nets.

MENIDA HISTRIO, Fb.

Cimex histrio, Fab., Mant., II, 296 (I787).

Menida histrio, Distant, Faun. Ind. Rhyn., I, 228.

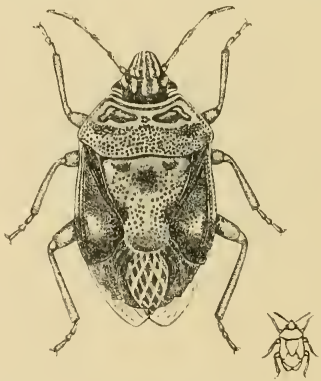

FIG. 354.-Icnida histrio. The outline figure shows the natural size. (Original 
Distribution.- Throughout Southern Inclia to about 4,000 feet.

Lifihistory.- Not known.

Foodplamts.-Paddy, Wheat. Cholam, and Pulses.

Status. A minor pest of Paddy.

Control. Collection by hand-nets.

CANTHECONA FURCELLATA, Wolff,

Cimex furcellatus, Wolft, Icones Cimic., V, I82, t. I8, f. I76 (I801).

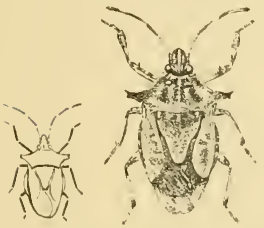

Fig. 355.-Canthicona $f u r$. cellata. The outline figure shows the natural size. (Original.)

Canthecona furcellatu, Distant. Faun. Ind. Rhyn., I, 248, f.I58; Lefroy. Ind. Ins. Life, p. 677 , t. 74, f. 2.

Distribution.--Throughout the Plains of Southern India.

Lifithistory.--The nymphs are brightly coloured with pink and blue; they were found feeding on larvæ of Athalia proxima.

Food. Predaceous on Athalia proxima: doubtless also on various small caterpillars and other insects.

Status.-Beneficial.

ANDRALLUS SPINIDENS, Fb.

Cimex spinidens, Fab., Mant., II, 285 (I787).

Audinetia spinidens, Distant, Faun. Ind. Rhyn., I, 253, f. 160; Lefroy, Ind. Ins. Life, t. 74, f. 5 .

Andrallus, Dist. (l.c.), IV, 453 [Audinctia-nom. præocc.].

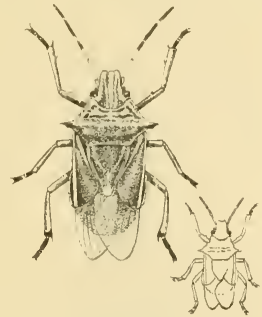

FIG. 356.-Andrallus spinidins. The outline figure shows the natural size. (Original.)

Distribution.-Throughout Southern India up to about 4,000 feet.

Lifehistory.-Not known.

Food-Has been found feeding on caterpillars of Chloridea gósoleta.

Status.-Beneficral 
CYCLOPELTA SICCIFOLIA, Westw.

Aspongopus siccifolia, Westw., Hope Cat., I, 26 (I837).

Cyclopilta siccifolia, Distant, Faun. Ind. Rhyn., I, 280 28I, f. I78; Lefroy, Ind. Ins. Life, p. 678, t. 74, f. I I.
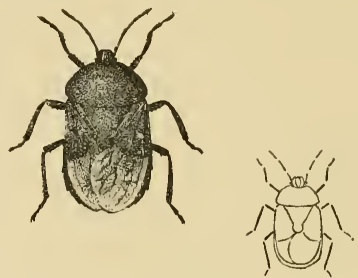

Fig. 357.-Cyclopelta siccifolia. The outline figure shows the natural size. (Original.)

Distribution.--Throughout Southern India.

Lifehistory.-Not known in detail. Nymphs similar to adult but smaller and also feed on plants.

Foodplants.-Red Gram (Cajamus indicus), Erythrina indica, Betel Vine (Piper betle).

Status.-Sometimes does considerable damage to Erythrina where this is used as a support for pepper-vines.

Control.- These bugs are sluggish and inclined to be gregarious and are therefore easily collected by hand.

ASPONGOPUS JANUS, Fb.

Cimex janus, Fab., Syst. Ent., p. 7 I4 (I775).

Aspongopus jamus, Distant, Faun. Ind. Rhyn., I, 28I-282, f. I79; Lefroy, Ind. Ins. Life, t. 74, f. 3; Minn, B.J., XX, II66-II67, figs.

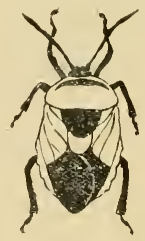

F1G. 358.-Aspongopus junus, (Original.)

Distribution. - Throughout the Plains of Southern India.

Lifchistory.-Early stages are passed on low-growing plants such as pulses. The nymph is orange-red with black legs and antennac 
and black spots down the back and a large black blotch on each side.

Foodplants.-MIost low-growing plants.

Status.-A minor pest in vegetable plots of Brinjal, Lab-lab, Pumpkins, etc.

Control.- Hand-picking.

TETRODA HISTEROIDES, Fb.

Acunthia histeroides, Fab., Ent. Syst. Suppl., p. 526 (I798).

Tetroda histeroides, Distant, Faun. Ind. Rhyn., I, 299, f. I9I.

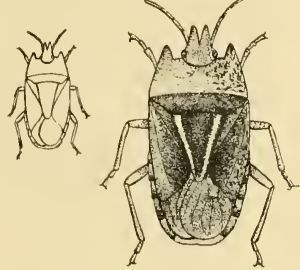

FiG. 359.-Tetroda histeroides. The outline figure shows the natural size. (Original.)

Distribution.-Salem, Coimbatore.

Lifchistory:-Not known.

Foodplants.-Paddy.

Status. - An occasional minor pest of paddy.

Control.-Collection by hand and in hancl-nets.

COREIDE.

ANOPLOCNEMIS PHASIANA, Fb.

Lygocus phasianus, Fab., Spec. Ins., II, p. 36I (I78I).

Anoplocnemis phasiana, Distant, Faun. Ind. Rhyn., I, 346347.

f. 210 ; Lefroy, Ind. Ins. Life, p. 682, f. 444 [very poor figure].

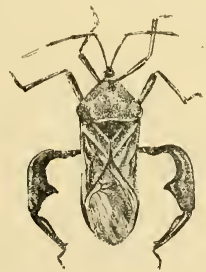

FiG. 360.-Anoptocnemis phasiana, male, (Original.) 
Distribution. Golavari, Bellary, Coimbatore. Common in the Hills.

Lifchistory.-Not known in detail.

Foodplants. -Brinjal, Red Gram (Cajanus indicus), Green Gram (Phaseolus mungo), Cholam (Erythrina).

Status.-Not a pest in the plains but sometimes a serious pest of young Erythrina trees in the Hills.

Control.--Collection by hand.

Rcmarks. - The adult bugs seem to pair off for life, a male and fentale being found commonly in close proximity.

\section{CLAVIGRALLA GIBBOSA, Spin.}

Clairgralla gibbosa, Spinola, Ess., p. 202 (I837) ; Distant, Faun. Ind. Rhyn., I, 40I 402, f. 235.

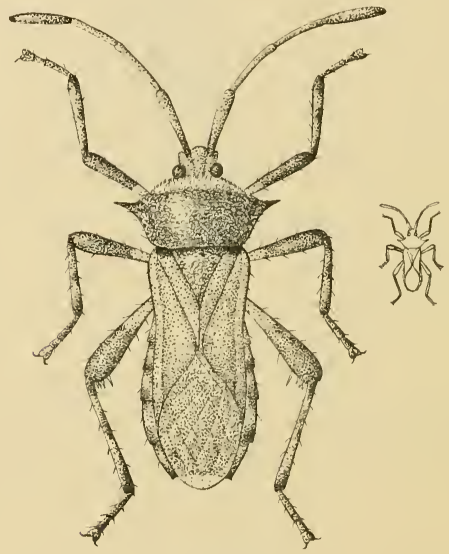

Fis. 361.-Clavigratta gibbose. The ontline figme show sthe 11 atmat size. (r)riginal.)

Distribution.- Throughout the Plains of Southern India.

Lifehistory.-Not known in cletail. Probably similar to that of C. horrens.

Foodplants.-Red Gram (Cajanus indicus), Lab-lab (Dolichos $(a b-l a b)$.

Status.-A minor pest of red gram and Lab-lab, sucking the juice of unripe seeds in the green pods, 
Control.-(I) The eggs are fairly conspicuous, usually deposited on pods, and may be collected by hand.

(2) The nymphs and adult bugs may be collected by shaking the plants over a vessel of oil and water or over a cloth saturated with oil.

\section{CLAVIGRALLA HORRENS, Dohrn.}

Clavigralla horrens, Dohrn, Stett. Ent. Zeit. (1860), 403 ; Distant, Faun. Ind. Rhyn., I, 402 ; Lefroy, Ent. Mem. Dept. Agri., Ind., I, 234; Ind. Ins. Life, t. 75 [as gibbosa].

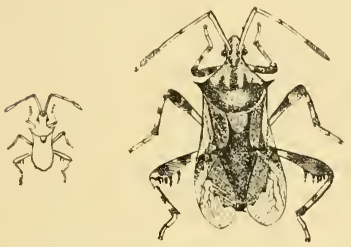

Distribution.--Throughout the Plains of Southern India.

Lifehistory:-See coloured Plate in "Indian Insect Life." Foodplants:-Red Gram (Cajamus indicus).

Status.-A minor pest of red gram.

Control.-Collection of the Fig. 362.-Clavigralla horrens.

The outline figure shows the natural size. (Original.) eggs (on pods), nymphs and bugs, and shaking the active stages off the plants into vessels of oil and water or onto cloths soaked in oil.

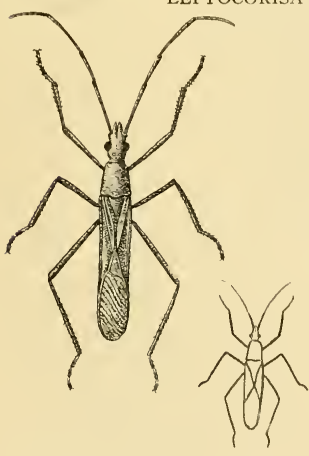

FIG. 363.-Leptocorisa varicornis. The outline figure shows the natural size, (Original.)
Gerris varicornis, Fab., Syst. Rhyng., p. 260 ( 1803 ).

Leptocorisa waricormis, Distant, Faun. Ind. Rhyn., I, 409 4I0, f. 24I; Lefroy, Ind. Ins. Pests, p. II6; Ent. Mem. Agri. Dept., Ind., I, 235, f. 76 ; II, I-I3, t. I ; Ind. Ins. Life, p. 684 , f. 446 .

Distribution.-Throughout Southern India up to 4,000 feet.

Life history.-The roundflattened, dark-brown eggs are laid in rows on leaves of paddy and grasses. The young nymphs are pale green with very long antennæ; they suck the juices of their fooclplant but are little noticeable 
as they do not affect the exposed parts of the plant and readily drop to the ground when disturbed. The bugs especially attack the ripening grain, sucking the milky juice, so that the ears turn wholly or partly white, no grain being matured.

Foodplants.-Paddy and wild grasses as a rule. Occasionally on cholam, maize, ragi (Elcusine coracana).

Status.-A serious pest of paddy, especially on the West Coast.

Control.-Collection in hand-nets has been found the most efficient method.

RIPTORTUS PEDESTRIS, Fb.

Gerris pedestris, Fab). Syst. Ent., p. 727 (1775).

Riptortus pedestris, Distant, Faun. Ind. Rhyn., I, 4I4, f. 244.
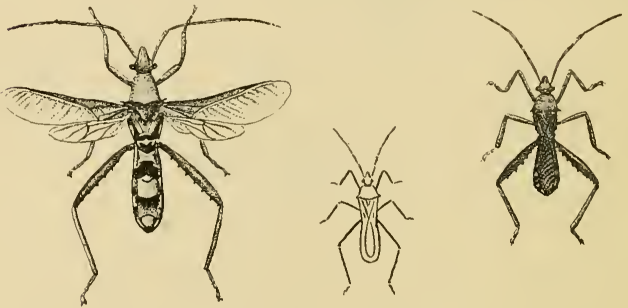

FIG. 36t.-Riptortus pedestris, with wings expanded and closed. The outline figure show's the natural size. (Original.!

Distribution. - Throughout the Plains of Southern India.

Lifchistory. - The oval, dark-brown, seed-like eggs are laid singly, and apparently only a small number ( 3 to 8 ) are deposited by one bug. The newly-hatched nymph is about $275 \mathrm{~mm}$. long and looks like a small red ant. In the second instar it is about $4 \mathrm{~mm}$. long, redi-brown in colour and in general appearance like a red tree-ant (Oecophylla smaragdina). In the third instar it is about $6.5 \mathrm{~mm}$. long and of a uniform dark colour, as it is in the fourth and fifth instars when it measures respectively 7.5 and II mm. in length. The nymph in the later stages is very active and hides itself away, so that it is little noticed. Life-cycle: egg, 6 days; nymph, 3, 4, 3, 5 . [T.V.R.] 
Foodplants. - Lab-lab (Dolichos lab-lab), Cowpea (Vigna catjang), Luffa acutangula (Tam., Pirkan), Black Gram (Phaseolus mungo radiatus) Green Gram (Ph. mungo), Wheat.

Status.-A minor pest, sucking the pods.

Control.-Collection by hand-nets.

Remarks.-Several other closely allied species occur on lowgrowing crops. The commonest are Riptortus linearis, Fb. (See Lefroy, Ind., Ins. Life, p. 684, t. 76, ff. I-5) and R. fuscus, Fb. All these are extremely similar in habits and appearance and will only be distinguished by an entomologist. On the wing they look not unlike wasps.

\section{LYGÆIDÆ.}

LYGÆUS PANDURUS, ScOp.

Cimex pandurus, Scop., Ent. Carn., p. I26 (1763).

Cimex militaris, Fab., Syst. Ent., p. 7 I 7 (1775).

Lygceus militaris, Distant, Faun. Ind. Rhyn., II, 6; Lefroy, Ind. Ins. Life, p. 686, f. 449.

Lygcus pandurus, Distant (l.c.), V, 4 .

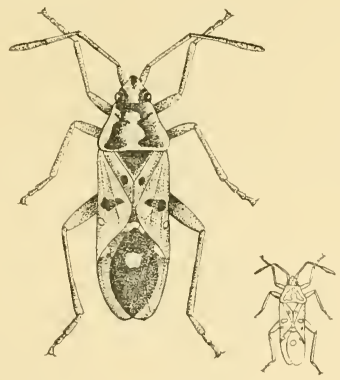

Fig. 365.-Lygreus pandurus. The smaller figure shows the natural size. (Original.)

Distribution.-Throughout the Plains of Southern India.

Lifchistory. - Not known.

Foodplants.-Calotropis, cholam, cotton, red-gram, chillies.

Status. - Not definitely known to be a pest, though often found abundantly.

Remarks. - This is one of the insects commonly confused with the cotton bug (Dysdercus cingulatus). 


\section{GRAPTOSTETHUS SERVUS, Fb.}

Cimex scrvus, Fab., Mant., II, 300 (I787).

Graptostcthus scrous, Distant, Faun. Ind. Rhyn., II, 8-9, f. 4.

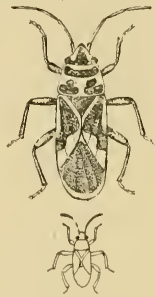

F1G. 366.-Graptostethus sirvus. The outline figure shows the natural size. (Original.)

Distribution.- Throughout Southern India.

Lifchistory.--Not known.

Foodplants.-Red-gram, sweet potato, jute capsules.

Status.-Scarcely a pest, but may do damage at times.

Control.-Collection in pans of oil and water or by shaking over oiled cloth. It is attracted to lights at night.

OXYCARENUS L.ETUS, KbY.

Oxycarcmus latus, Kirby, J. Linn. Soc., XXIV, I02 (r891); Distant, Faun. Ind. Rhyn., II, 43, f. 3I ; Lefroy, Ind. Ins. Pests, pp. 107-108, f. 126 , Ind. Ins. Life, p. 688 , f. 454.

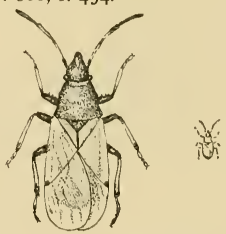

Fig. 867,--Oxycarenus latus. The outline figure shows the natural size. (Original.)

Distribution.- Throughout the Plains of Southern India.

Lifchistory.-Eggs are laid in small groups in the lint of ripe cotton-bolls or between the calyx and the boll and are cigar-shaped, grooved longitudinally, at first white, later pale yellow and afterwards orange. The young bugs feed in the bolls until full-grown.

Foodplant,-Cotton, Hibiscus csculcntus and Gogu (H. cannabinus). 
Status.-Usually a minor pest of cotton.

Control. - The bugs are generally found in old open bolls left unplucked, or in bolls attacked by bollworm whose hole of exit they use as a means of entry. All such attacked and ripe bolls should be removed regularly, and this will prevent the bugs from breeding. When they are present in numbers they are readily collected by shaking the bolls over pans of oil and water or over oiled cloths.

Remarks.-Distant's description (taken from Kirby's discoloured type) incorrectly states that the antennæare unicolorous; his figures are also incorrect as regards length of the rostrum, which extends well beyond the third pair of legs, and in omission of spinal armature on anterior femora. I am indebted to Mr. Distant for the identification of this species.

\section{APHANUS SORDIDUS, Fb.}

Cimex sordidus, Fab., Mant, II, 302 (1787).

Aphamus sordidus, Distant, Faun. Ind. Rhyn., II, 79-80, f. 62; Lefroy, Ind. Ins. Life, p. 689.

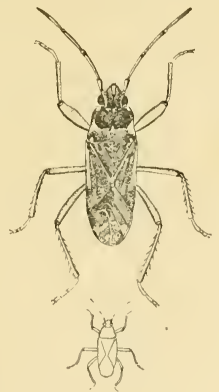

Fig. 368.-Aphanus sordidus. The outline figure shows the natural size. (Original.)

Distribution.- Throughout Southern India.

Lifehistory.-Not known.

Food.-Harvested seeds of gingelly, groundnut, cumbu, and on the plants in the fields also.

Status. - A minor pest of stored gingelly, groundnut, etc.

Control. - The bugs are readily destroyed by hand on the threshing-floor and ordinary methods used for pests of stored products will check any damage in the store-room. 


\section{PYRRHOCORIDÆ.}

DYSDERCUS CINGULATUS, Fb.

Cimc $x$ cingulatus, Fab., Syst. Ent., p. 719 (1775).

Dysdercus cingulatus, Distant, Faun. Ind. Rhyn., II, II8 II9, f. 87; Lefroy, Ind. Ins. Pests, p. I04, f. 123, 125, Ent. Mem. Agri. Dept., Ind., I, 237, f. 78, II, $47-58$, t. 5, Ind. Ins. Life, p. 692, t. 77.

(See Plate XlVi.)

Distribution.--Throughout Southern India.

Lifehistory.-The creamy-yellow eggs are laid in small masses, usually in cracks of the soil. The young bugs hatch out after. about a week and are bright red in all their stages. They feed, often gregariously, fully exposed and are consequently conspicuous. At certain times of the year adult bugs and young in all stages of growth may sometimes be found massed together in the open on tree-trunks, walls, etc., forming a scarlet splash of colour visible from a long distance. The length of the life-cycle is about 6-8 weeks.

Foodplants.-Cotton, bhindi (Hibiscus csculentus), Portia tree (Thespesia populnea), as a rule. Also occasionally on various other plants.

Status.-A serious pest of cotton.

Control.- - The bugs are conspicuous, usually found on or near the boll and are easily collected by hand or in a bag fitted with a tin funnel.

TINGIDID $Æ$.

STEPHANITIS TYPICUS, Dist.

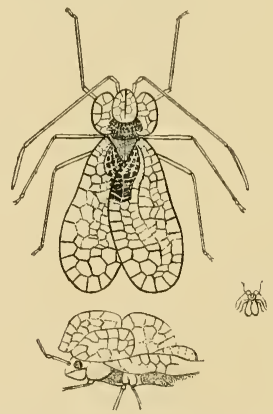

FIG. 369.-Stephanitis typicus. The lower figure shows a profile view of the head and thorax. The small outline figure shows the natural size. (After Distant.) 


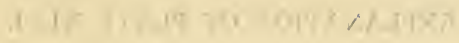

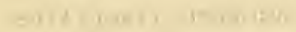

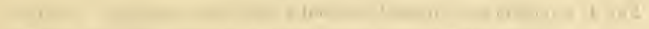

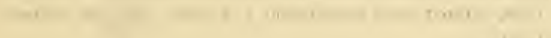

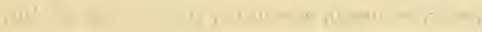
and in 1

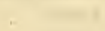

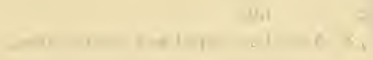




\section{EXPLANATION OF PLATE XLVI. DYSDERCUS CINGULATUS.}

Fig. 1. Group of eggs, natural size, and a single egg, magnified. On the right, without black background, is a single egg just before hatching.

" 2. Nymphs, first instar, immediately after hatching and later.

"3. Nymph, second instar.

" 4. . third "

"5. " fourth "

"6. " fifth "

"7,8. Adult bug, dorsal and ventral views.

(The lines alongside the figures show the natural sizes.) 

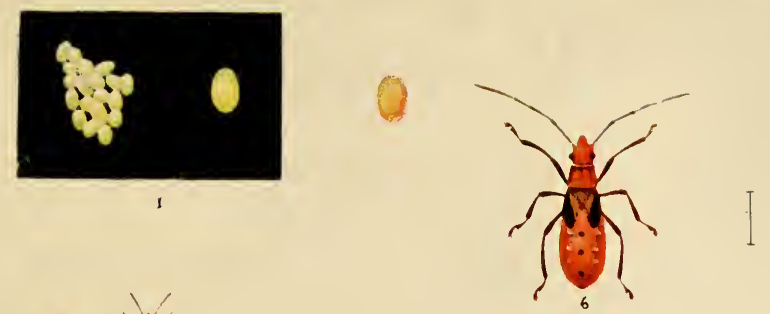

I) 2 है।
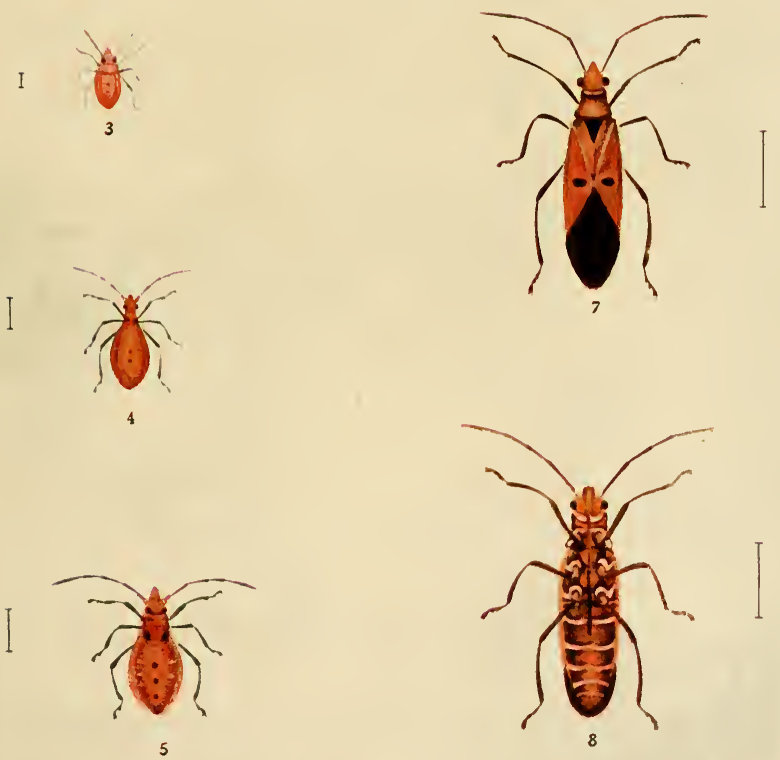

DYSDERCUS CINGULATUS. 

Cadamustus typicus, Distant, Ann. S.E. Belg., XLVII, 47 (1903), Faun. Ind. Rhyn., II, 132, f. 95.

Stephanitis typicus, Dist., Rhyn., V, I08.

Distribution. - Coimbatore, Bellary, Godavari. Probably throughout the Plains of Southern India.

Lifchistory.-Not known. Nymphs are found on the undersurface of leaves together with the adults.

Foodplants.-Turmeric, plantain. Found on cardamom in Ceylon (Green).

Status.-A very minor pest of plantain and turmeric. The leaves, where punctured, are at first spotted with yellow and later the whole leaf assumes a pale unhealthy tinge.

URENTIUS ECHINUS, Dist.

Urentius echinus, Distant, Faun. Ind. Rhyn., II, I34, f. 97 (1903).

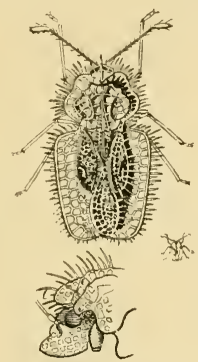

F1G. 370.-Urentius echinus. The lower figure shows a profile view of the

head. The small outline figure shows the natural size. (After Distant.)

Distribution.-Throughout the Plains of Southern India.

Lifehistory.--Not known. Eggs and nymphs occur on the leaves of foodplant with adults.

Foodplants.-Brinjal.

Status.-Sometimes a serious pest of brinjal, the leaves being sucked to such an extent that they turn yellow, dry up, and fall off the plant.

Control.-Spraying with a contact insecticide, such as Crude Oil Emulsion, in small areas where brinjal is grown as a garden crop.

MONANTHIA GLOBULIFERA, Wlk.

Tingis globulifera, WIk., Cat. Het., VI, I82 (1873).

Monanthia globulifera, Distant, Faun. Ind. Rhyn., II, I44, f. 107 , V, I23-124; Lefroy, Ind. Ins. Life; p. 693, f. 460. 


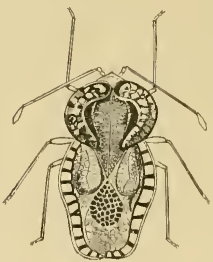

$x^{2}$

FiG. 371.-Monanthia globulifera. The small figure shows the natural size. (After Distant.)

Distribution.-Throughout the Plains of Southern India.

Lifchistory. - Not known.

Foodplants.-Tulsi (Ocimum sanctum), Safflower (Carthamus tinctoria). English Sage (Annandalc).

Status.--Sometimes a serious pest of Tulsi, the attacked leaves turning yellow.

\section{REDUVIIDA.}

\section{CONORHINUS RUBROFASCIATUS, de Geer.}

Cimex rubrofasciatus, de Geer, Mem., III, 349, t. 35, f. I2 (I773).

Conorhinus rubrofasciatus, Distant, Faun. Ind. Rhyn., II, 286, f. I89; Lefroy, Ind. Ins. Life, "p."700"; Green,'Spol.'Z Zeylan., VII, 50.

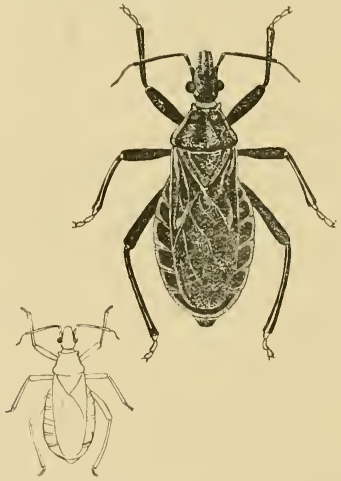

F1G. 372.-Conorhinus rubrofasciatus. The outline figure shows the natural size. (Original.) 
Distribution.-Throughout Southern India.

Lifehistory.- Nymphs are sometimes found in houses, generally in dusty corners, and cover themselves with dust and debris; they are probably predaceous on small household insects. This insect has also been found in squirrels' nests and is perhaps a natural parasite of these animals.

Food.-Probably predaceous on other insects as a rule, occasionallv attacks man, both in nymphal and adult stages, sucking blood.

Status.-Not very common as a rule, but this bug may prove important as a carrier of disease owing to its bloodsucking habits. It has been suspected of acting as a carrier of Kala-azar and an allied bug in Brazil is known to transmit a human Trypanosome.

Control.- The aclult bug is sometimes attracted to light at night.

\section{CLINOCORIDÆ.}

CLINOCORIS HEMIPTERUS, Fb.

Cimex hemipterus, Fab., Syst. Rhyng., p. II3 (1803); Horvath, Ann. Mus. Hung., X, 259.

Cimex rotundatus, Signoret, Ann. S.E. Fr. (1852), 540, t. 16 , f. 2 ; Howlett, Ind. Ins. Life, pp. 703-704, f. 474a ; Patton, Sc. Mem. Med. Dept. No. 53, Rec. Ind. Mus., II, I53, t. I3, ff. I, 2, 5.

Acanthia macrocephalus, Fieber, Eur. Hem.. p. I35 (186I); Distant, Faun. Ind. Rhyn., II, 4II, f. 262 (Cimex).

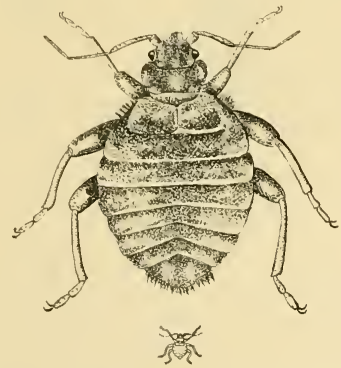

F1G. 373.-Clinocoris hemipterus. The small figure shows the natural size. (Original.)

Distribution.- Throughout Southern India.

Lifehistory.-Eggs are laid usually in cracks in wood work. The young nymphs (which are very similar to the adult but usually 
of a pale yellow colour) suck blood. The length of life-cycle depends largely on the amount of food available and may occupy two months or upwards.

Food.- The blood of man, birds and bats.

Status.-A human parasite which is not only annoying by its bite ana disgusting by its smell but also of great importance as a disseminator of disease. It is considered that the transmission of Indian Kala-azar from man to man is effected solely by bed-bugs (Clinocoris hemipterus).

Control.-Cleanliness in the house. In cases of badly infected houses fumigation may be necessary. Ordinary articles of furniture may be rubbed over with Kerosine Oil or Turpentine and Carbolic Acid. The bugs and their eggs are usually found in cracks in the woodwork.

\section{CAPSIDÆ.}

HELOPELTIS ANTONII, Sign.

Helopcltis antonii, Sign., Ann. S.E. Fr. (3), VI, 502 (I858); Distant, Faun. Ind. Rhyn., II, 440, f. 285 ; Mann, Ent. Mem. Agri. Dept. Ind., I, 32I-325; Green, Perad. Circ. I, No. 2I, II. No. 2, II. No. I7, p. 24I ; Planters' Chronicle, VIII, 206.

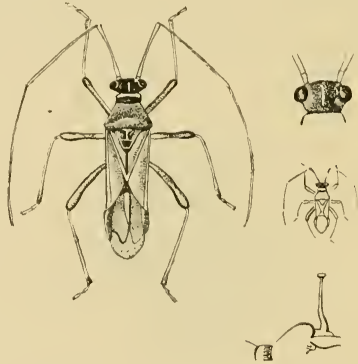

F1G. 374.-Helopeltis antonii. To the right is seen a more enlarged view of the head and a profile view of part of the thorax showing the curious erect drumstick appendage. The small ontline figure shows the natural size. (After Distant.)

Distribution.-Coimbatore, and probably throughout the Hills of Southern India.

Lifehistory.-Eggs laid singly or in small groups thrust into pods (Cacao) or in young shoots of the foodplant. After about Io days the egg hatches out into a small reddish insect, with long legs and 
antennæ, and looking not unlike a slender ant. This sucks the juice of the foodplant and grows, without altering greatly in form, until the final stage when its wings are full-sized and it attains the adult colour of red, black and white. [Green.]

Foodplants.-Mahogany, Persian Nim (Melia azedarach), Tea, Cacao, Cinchona, Annatto (Bixa orellana).

Status.-Sometimes a serious pest in the Hills.

Control.-Catching adults in hand-nets and spraying the young individuals.

$$
\text { DISPHINCTUS POLITUS, wlk. }
$$

Monalonion politus, Wlk., Cat. Het., VI, I63 (I873).

Disphinctus formosus, Kirk., B.J., XIV, 295, t. A., f. Io, t. C., f. 2 (1902); Green, Entom. (1901), II4-II5, figs.

Disphinctus politus, Distant, Faun. Ind. Rhyn., II, 444 445.

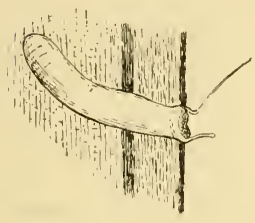

Egg, showing part exposed and section of a shoot into which it has been thrust. (After Green, Entom. (1901), 115.) $\times 20$.

FIG. 375.-Disphinctus politus.

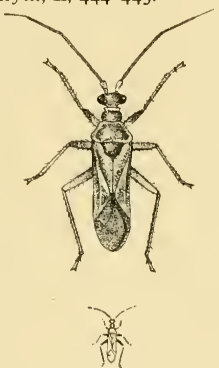

Adult insect. The outline figure shows the natural size.

(Original.)

Distribution.-Kurnul. Probably throughout the Plains of Southern India.

Lifehistory.-Egg pale creamy-white, elongate, curved, thrust into a shoot of the foodplant, its position being then marked only by a pair of divergent, glassy, horn-like processes projecting from the plant. The nymphs are small, reddish, ant-like creatures, found mostly on tender leaves which they puncture together with the adults. These latter are active and look like small Hymenoptera ; they are readily disturbed and take to wing.

Foodplants.-Betel (Piper betle).

Status.-A minor pest as a rule, occasionally locally and sporadically doing serious damage to Betel Vines. 
Control. - Catching adults in hand-nets and spraying for nymphs.

Remarks.-Very similar in appearance and habits to Helopeltis but lacks the peculiar drumstick appendage on the thorax. The allied Displuinctus humcralis is perhaps sometimes the "Mosquitoblight" of Cinchona in Southern India.

\section{CALOCORIS ANGUSTATUS, Leth.}

Calocoris angustatus, Leth., I.M.N., III, No. 2, p. 90, fig. (1893); Distant, Faun. Ind. Rhyn., II, 452 ; Lefroy, Ind. Ins. Pests, p. 236, f. 282, Ent. Mem. Agri. Dept., Ind., I, 238 , f. 79.

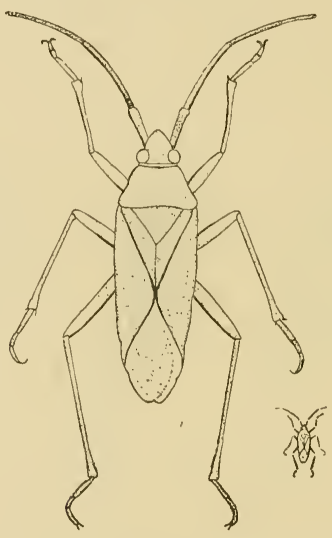

F1G. 376.-Calocoris angustatus. The outline figure shows the natural size. (Original.)

Distribution.--Throughout the Plains of Southern India.

Lifchistory.-Young nymphs are found with adults on the earheads. They are pale-green in colour and resemble the adults but are of course wingless.

Foodplants.-Cholam, maize, and probably various grasses.

Status. - A minor pest as a rule.

Control. - -?

GALLOBELICUS CRASSICORNIS, Dist.

Gallobelicus crassicornis, Dist., Faun. Incl. Rhyn., II, 478, f. 3I0; Lefroy, Ind. Ins. Life, p. 708, f. 480. 


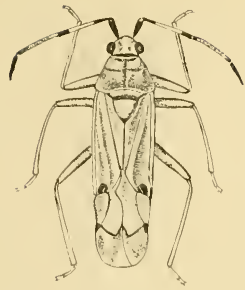

the

Fig. 377. -Gallobelicus crassicornis. The small figure shows the natural size. (Original.)

Distribution. Throughout the Plains of Southern India.

Liffhistory.- Nymphs are found with adults on the tender shoots and flower-heads of tobacco.

Foodplants.-Tobacco.

Status. - A minor pest.

Control--Catching in hand-nets and shaking plants over pans of water and oil or over oily cloths.

\section{RAGMUS IMPORTUNITAS, Dist.}

Ragmus importunitas, Dist., A.M.N.H. (8), V, I8 (I910), Faun. Ind. Rhyn., IV, 289, f. I 59.
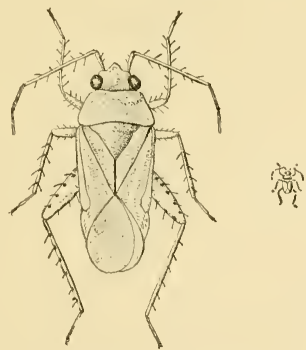

FIG. 378.-Ragmus importunitas. The small figure shows the natural size. (Original.)

Distribution.-Coimbatore. Probably throughout the Plains of Southern India. 
Lifchistory.--The creamy-white egg is cylindrical, curved, rounded at one end, the other fitted with a black flattened cap; it is thrust into the stem just beneath the bark (but not into the stem tissues proper) the black cap lying level with the outer surface of the bark. The egg has no projecting horns. The young nymph emerges after about 6 days and is green in colour with long legs and antennæ. (Y.R.R.)

\section{Foodplants. Sann Hemp (Crotalaria juncea).}

Status. - A minor pest as a rule, occasionally serious so that all the leaves curl up and assume an unhealthy pale-yellowish colour.

Control.- Use of bagnets and hand-nets while the crop is low.

Remarks. -The closely-allied $R$. pellucidus, Distant, is recorded from Cochin, but $R$. importunitas seems the only species of economic importance.

\section{FULGORIDÆ.}

\section{EURYBRACHYS TOMENTOSA, Fb.}

Cicada tomentosa, Fab., Syst. Ent., II, 324 (1775).

Eurybracilys tomentosa, Distant, Faun. Ind. Rhyn., III, 223; Lefroy, Ind. Ins. Life, p. 725.

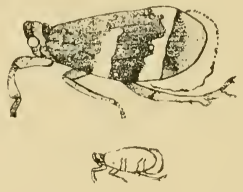

FIG. 379.-Eurybrachys tomentosa. The small figure shows the natural size. (Original.)

Distribution.- Throughout the Plains of Southern India.

Lifchistory.-Eggs are laid in masses on leaves and are covered with the white flocculent waxy efflorescence from the body of the female. Nymphs are found on the leaves; they are brownish, with long anal filaments. [Y.R.R.]

Foodplants.-Calotropis, Cotton and various Malvaceous plants. Polyphagous; found on most shrubs and plants.

Status.- Not a pest.

PHENICE MCESTA, Westwd.

Plenice mosta, Westwd., A.M.N.H. (2), VII, 209 (185I); Distant, Faun. Ind. Rhyn., III, 296-297, f. I42 ; Lefroy, Ind. Ins. Life, p. 726 , f. 499 .

Assamia dentata, Buckton, I.M.N., IV, I, t. I (I896). 


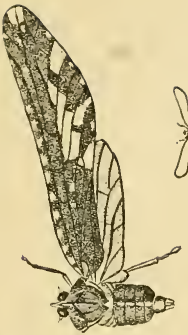

FIG. 380.-Phenice mocsta. The outline figure shows the natural size. (Original.)

Distribution.-Throughout the Plains of Southern India.

Lifehistory.-Not known. Muir (Hawaii S.P. Bull. No. 12) says that the immature stages a re passed in rotting wood; certainly only adults are found on plants.

Foodplants.-Sugar-cane and various Grasses, occasionally on Cholam, Palms and various other plants.

Status.-A very minor pest.

Control.-Catching in hand-nets.

Remarks. - Numbers of these bugs may often be seen sitting in rows on the lower side of leaves of Sugar-cane, etc., and readily jumping off and taking to wing when disturbed.

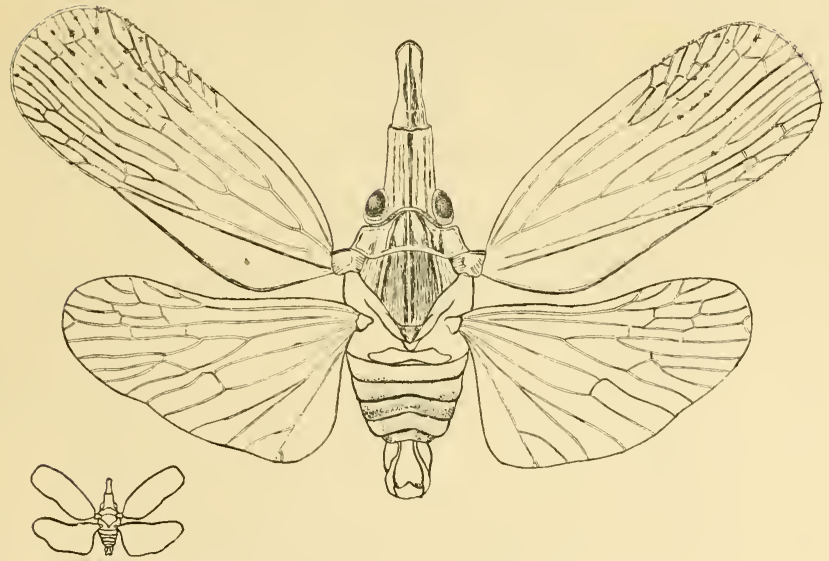

F1G. 381.-Pyrilla perpusilla. The small outline figure show's the natural size. (Original.।

PYRILLA PERPUSILLA, WIk.

Pyrops perpusilla, Walker, List Hom., II, 269 (185I).

Zamila perpusilla, Distant, Faun. Ind. Rhyn., III, 327. 
Pyrilla aberrans, Lefroy, Ind. Ins. Life, p. 727 , f. 500 (part).

Dictyophara pallida (nec Don.), Dist., F.I. Rhyn., III, 244 (part) ; Lefroy, Ind. Ins. Pests, p. I34, f. I53, Ent. Mem. Dept. Agri., Ind., I, 240 , f. 80 .

Distribution.- Throughout the Plains of Southern India.

Lifchistory. - The pale-green or yellow eggs are laid on the lower surface of a leaf of Sugar-cane, in a mass covered with filamentous white material derived from the body of the female. The young bugs are pale-brown with a pair of long straight ana] processes covered with white mealy wax; they leap actively and suck the juice of the cane. Length of life-cycle not worked out.

Foodplants. - Sugar-cane as a rule; sometimes on Maize and Cholam.

Status.-Rarely a serious pest of Cane in Southern India, but always present as a minor pest in Cane-fields.

Control.--Egg-masses and groups of young nymphs are conspicuous and leaves on which such are found should be collected and burnt.

Remarks.-I am indebted to Mr. Distant for the correct identification of this insect.

C PUNDALUOYA SIMPLICIA, Dist.

$\checkmark$ Pundaluoya simplicia, Distant, Faun. Ind. Rhyn., III, 468-469, f. 255 .
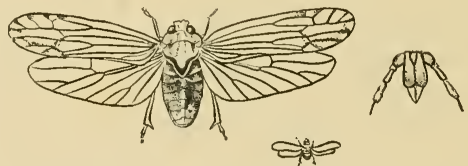

FIG. 382.-Pundaluoya simplicia, adult insect and front view of head. The outline figure shows the natural size. (After Distant.)

Distribution. - Throughout the Plains of Southern India.

Lifchistory.-The transparent-whitish, slender, curved eggs are thrust into the tissues from the upper side of the leaf, the position being indicated externally by minute slits. The young nymphs are pale yellowish and usually occur in numbers within the shelter of the leaf-sheath, being attended by black ants (Camponotus comprossus). Attacked plants assume a yellow unhealthy appearance.

Foodplants.-Cholam, Maize.

Status.-Sometimes a serious pest of cholam, usually localised in patches. In case of bad infestation practically no grain is formed. 
Control.-This is very difficult as the insects live protected within the leaf-sheaths. No satisfactory method can be suggested at present except cutting affected plants for use as green fodder.

Remarks.-The identification of this insect has kindly been confirmed by Mr. Distant. It has hitherto been confused with Liburnia psylloides, Leth (I.M.N., III, 105, fig.) but, by the figure given of the latter, differs in several points. The large spurs on the hind-legs are characteristic.

\section{CERCOPIDE.}

COSMOSCARTA RELATA, Dist.

$\checkmark$ Cosmoscarta relata, Dist., T.E.S. (I900), 669, Faun. Ind. Rhyn., IV, I43; Lallemand, Gen. Ins. fasc.. I43 (Cercopidæ), p. I36.
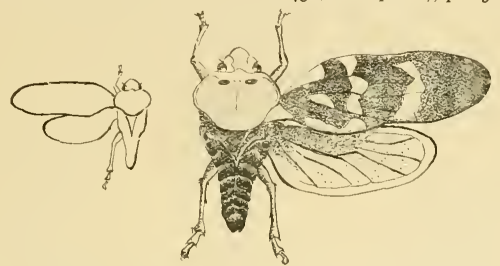

F1G. 383.-Cosmoscarta relata. The outline figure shows the natural size. (Original.)

Distribution.-Sidapur, Pollibetta (Coorg); Saklaspur (Mysore).

Lifchistory.-The immature wingless young are blackish-purple with greyish-yellow head, pronotum and legs, and with paler bands around the abdomen. They live in small colonies inside a common mass of froth from which drops of clear liquid fall down so as to wet the ground beneath the tree. The masses of froth are generally found on the stalks of young shoots and of ripening fruits and these latter often drop off the tree as a result of the infestation. The winged adult, which is blue-black with reddish pronotum and markings on the tegmina, is very active and difficult to catch.

Foodplants.-Jak (Artocurpus integrifolia).

Status.-A serious local pest of Jak in Mysore and Coorg.

Control.-Removal and destruction of the young insects enclosed in the masses of froth.

JASSIDE.

IDIOCERUS NIVEOSPARSUS, Leth.

Idiocerus niveosparsus, Lethierry, J.A.S.B., LVIII, 252 (1889); Distant, Faun. Ind. Rhyn., IV, I85, f. I2I ; Lefroy, Ind. Ins. Life, p. 736 , f. 5 II. 


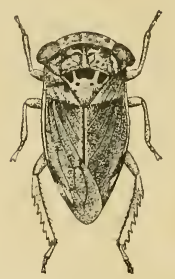

ली

FIs. 38t.-Idiocerus niveosparsus. The small outline figure shows the natural size. (Original.)

Distribution. - Throughout the Plains of Southern India.

Lifchistory. - The small eggs are laid in shoots of the foodplant. The young are similar to the adult but wingless and the legs comparatively longer. The bugs, both nymphs and adults, feed on the sap of shoots and flower-stalks, excreting a sticky substance (honeydew) which, when the bugs are numerous, is produced in very large quantity, and a characteristic black fungus soon grows on the honey-dew.

Foodplants.-Mango.

Status.- Sometimes a serious pest of mango, the honey-dew excreted by the bugs falling on the flowers so that they fail to set fruit.

Control.-Spraying of mango-trees before the flowers open if the bugs are present in any numbers. After the flowers have opened the bugs may sometimes be driven from the trees by kindling smoky fires below them.

\section{TETTIGONIELLA SPECTRA, Dist.}

$\checkmark$ Tettigoniella spectra, Distant, Faun. Ind. Rhyn., IV, 2I I, f. I37 ; Lefroy, Ind. Ins. Life, pp. 736-737, f. 5 II $^{\mathrm{a}}$.

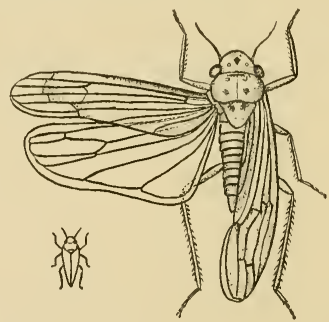

FIG. 385,-Tettigoniella spectra. The small outline figure shows the natural size. (Original.) 
Distribution. - Throughout Southern India.

Lifchistory: The yellow eggs are laid in a row in rice leaves which often become submerged. They are attacked by a Proctotrypid which walks under water in search of them (Lefroy). This parasite is figured on page 203 .

Fondplunts. Paddy.

Stitus. - Not actually noted as a pest but liable to become so as it is usually abundant in paddy-fields.

Control. The adults are strongly attracted to light and this fact may be utilized as one means of control.

\section{NephotetTix Bipunctatus, Fb.}

${ }^{P}$ Cicada bipunctate, Fab., Syst. Rhyng., p. 78 (I803).

Teplotettix hipunctatus. - Distant, Faun. Ind. Rhyn, IV, 359-36o, f. 228 .

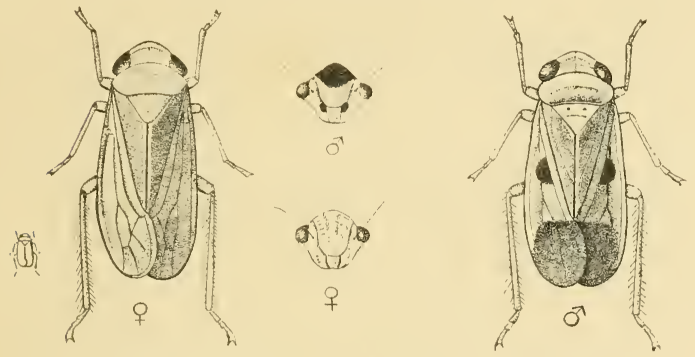

OFig. 3\$6.- Niphotettix bipunctatus, male and female and front views of heads of both sexes. The small outline figures show the natural sizes. (After Distant.)

Distribution. - Throughout the Plains of Southern India.

Lifilhistory:- Not known.

Foodplants. - Paddy. Probably on various grasses.

Stutus.- Not actually noted to do damage but sometimes appears in such enormous numbers that it ma be assumed to be at least a minor pest.

Control. - The adults fly freely to light and this fact may be utilized.

Remarks. - The female of this bug wholly lacks the black spots and black tips of the tegmina.

EMPOASCA FLAVESCEIS, Fb.

O Cicada flacescins, Fab., Ent. Syst., IV, p. 46 (I794). 
Chlorita flavescens, I.M.N., III, pt. 4, pp. 34-36, figs. Empoasca fluvescens, Distant, Faun. Jnd. Rhyn., IV, 405-406.
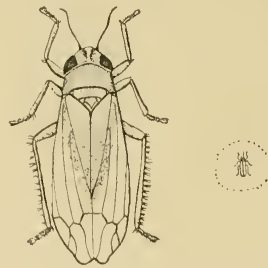

Fig. 387.-Empoasca flavescens. The small outline figure show the natural size. (Original.)

Distribution.-Probably throughout Southern India.

Lifchistory.-Not known.

Foodplants.-Tea, castor. Probably on various other plants also. Status.-Well known as "Green Fly Blight" in the tea Districts of North-East India but so far as known does not attack tea in India or Ceylon.

Control.-Spraying with contact insecticides and catching the adult bugs in hand-nets when numerous.

Remarks.- This, or a closely allied species, is sometimes very abundant on potato when grown as a field crop and may be seen in thousands hopping off the leaves as one goes through the field.

\section{PSYLLID $Æ$.}

PSYLLA ISITIS, Buckt. (Plate XLVII.)

Psylla isitis. Buckton, I.M.N., Il, p. I8, fig. ; Lefroy, A.J.I., VIII, I-26, t. I-2 (Jan. I9I3).

Distribution.-South Arcot; Tinnevelly. Probably throughout the Plains of Southern India.

Lifclistory. - The pale-yellowish-white, cylindrical eggs are laid singly on Indigo, usually near the tip of a shoot. The eggs hatch after about 5 days, the nymphs feeding on the plant for about a fortnight, during which they undergo five moults, after which they assume the adult (winged) stage.

Foodplants. - Indigo (all cultivated varieties; also found on a "wild Indigo" at Koilpatti).

Status.-Usually rather a minor pest of Indigo in Southern India. The tops of attacked plants assume a characteristic curly appearance.

Control.- (I) Spraying with soap solution.

(2) Cultivation methods. (See A.J.I. cited above.) 



\section{EXPLANATION OF PLATE $\operatorname{PLVII.~}^{2}$ PSYLLA ISITIS.}

F1G. 1. Eggs laid in groove of a leaf stalk. $x \mathbf{x} 6$.

" 2. Egg a few hours old. x 64 .

" 3. Egg about a day old. x 64 .

"4. Nymph, first stage. $\times 64$.

" 5. $"$ second stage. $\times 50$.

"6. " third " $\times 45$.

"7. " fourth " 330 .

"8. " fifth " $\times 20$.

, 9. Imago, female. $\mathrm{x} 20$.

" ro. The hind end of the abdomen of male. $x 20$.

" I I. The adult female sitting on a shoot. $\times 2$.

" I 2. The head of a Java-Natal indigo plant showing crumpling of the leaves produced by the feeding of the nymphs, with a nymph sitting just below the head. 


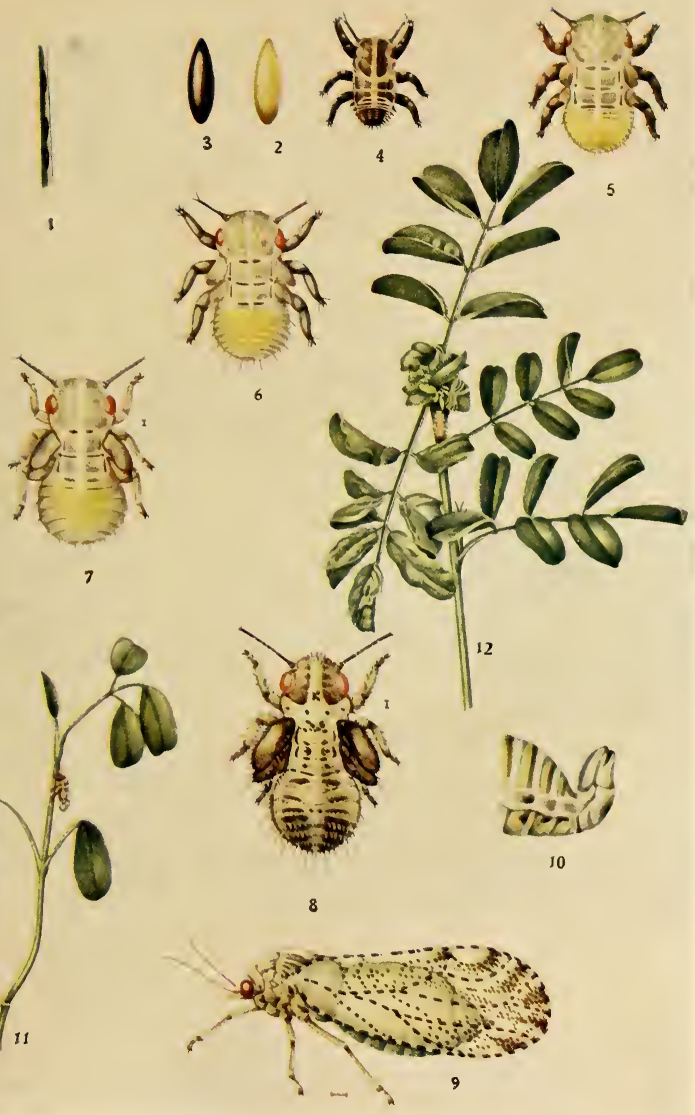

PSYLLA ISITIS. 

APHIDID E.

APHIS GOSSYPII, Glov.

Aphis gossypii, Glover, Pat. Off. Rept., p. 62 (1854); Essig, Calif Monthly Bull., I, I20-I22, f. 4I (Mar. I9I2).
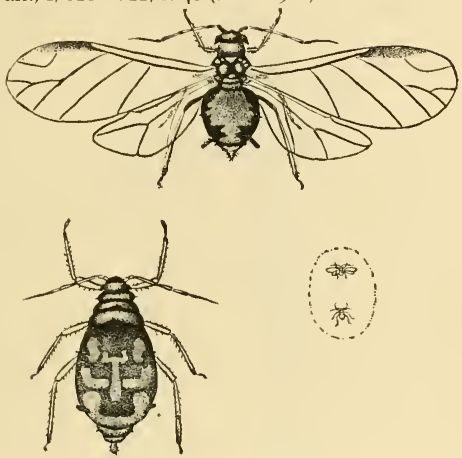

F1G. 388.-Aphis gossypii, winged and wingless females. The small figures inside the dotted oval show the natural sizes. (After Essig.)

Distribution.-Throughout Southern India.

Lifchistory.-Eggs very dark-red or brown. Nymphs green or brownish. The females as a rule produce living young, and not eggs, and these young are usually females which are themselves able to reproduce living young after about three days, no males being produced at all for a considerable number of generations. In small colonies the members are usually wingless, but, as the colony grows, winged forms are produced which fly off to found new colonies on other plants. The increase may thus be very rapicl. The insects excrete a sweet liquid (honey dew) from the anus and this is very attractive to ants which tend and defend the Aphicls; the honey dew also falls on the leaves and gives them a characteristic sticky appearance, usually rendered more conspicuous in damp weather by the growth of fungus on the honey dew.

Foodplants.-Cotton. Polyphagous; has been found on over fifty different plants in America.

Control.-Spraying with contact insecticides.

Remarks.-(I) Usually kept in check by various predaceous insects (Chrysopa, Coccinncllids, Syrphids, ctc.).

(2) Numerous other species of Aphids are found on various plants but the different species have not been identified as yet. 
SCHIZONEURA LANIGERA, Hausm.

Aphis lanigcra, Hausmann, Illig. Mag. Insekt, I, 440 (1802); buckton, A phides, III, 89, t. I05, I06; Atkinson, I.M.N., II, 52-58, fig.

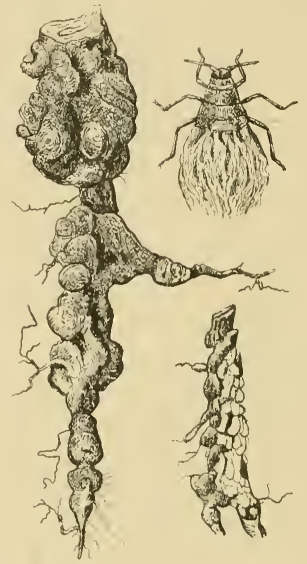

FIG. 389 -Schizoneura lanigera.

To the left is a portion of a root showing the characteristic nodules caused by the insect. To the right is seen a portion of a root with a Colony of the insects (natural size) and a single insect magnificl. (After Marlatt in Grandi.)

Distribution.-Coonoor, Bangalore.

Lifchistory.--The "American Blight," "Woolly Blight," or "Blood Louse" appears in two forms, one of which attacks the trunk and branches of apple-trees, the other the roots. The trunkliving form is usually found in crevices of the bark or at the base of twigs, etc., springing from the trunk and is covered with a white downy covering. The root-living form has also white cottony filaments. In both cases, the seat of attack is indicated by numerous gall-like excrescences. The females may be winged or wingless and can reproduce agamogenetically. Males do not seem to have been observed in India.

Foodplants.-Apple.

Status.--May be a serious pest of apple-orchards.

Control.-For trunk-living form, spraying and scrubbing of stems and affected branches with Crude Oil Emulsion or other contact 

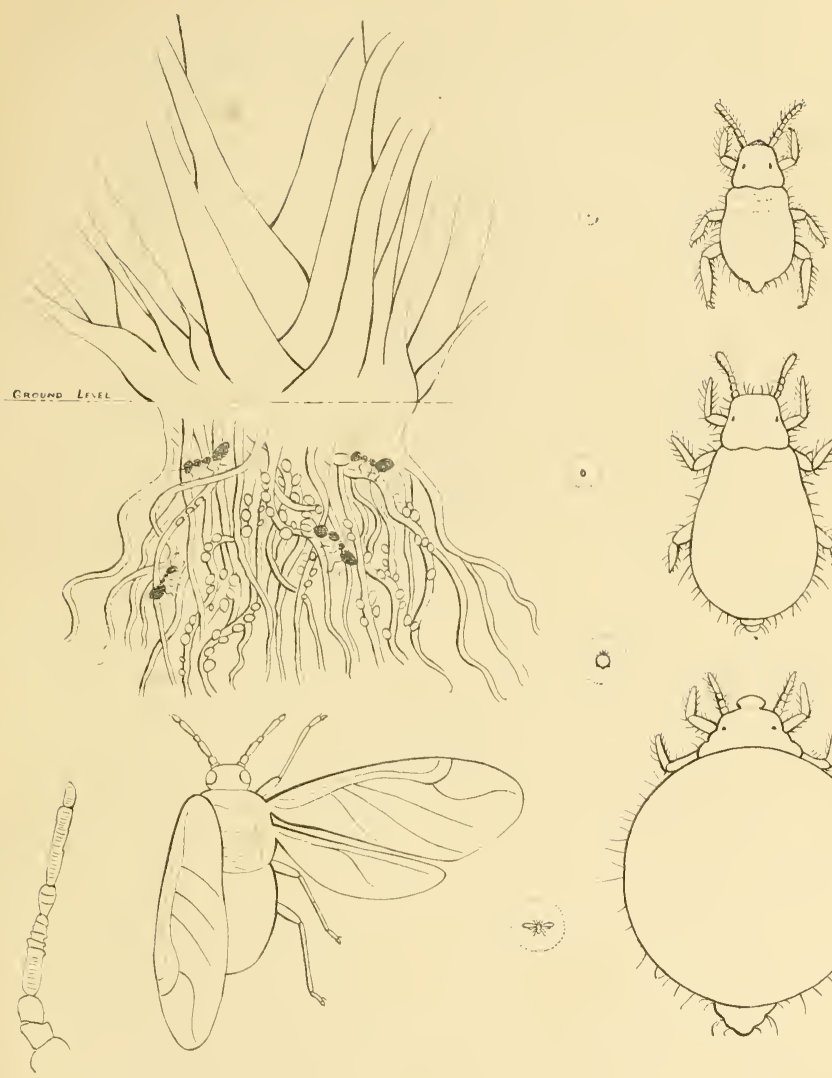

0

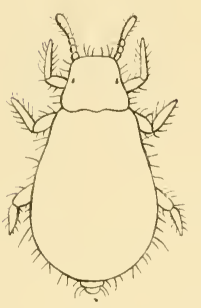

Fic. 390.-Ragi Root Aphis.

A Ragi root showing the incects (natural size) attended by ants, and young, half-grown and adult wingless and winged females. To the left is an antenna of an adult winged female, more highly magnified. The small figures within the dotted circles show the natural sizes. (Original.) 
insecticide. For root-living form, application of Crude Oil Emulsion or Kerosine Enulsion or digging in Tobacco Refuse around the roots.

The following has lately been rexommended in Europe but has not yet been tested in India. A paint is prepared of Linseed Oi) 7 lb., White Lead I lb., Zinc Oxide I lb., and this is boiled for I0 minutes and, when cold, I lb. of Turpentine is added. The paint is applied by means of a brush to all the affected parts. [Rome Bull. (I913), 49I.]

RAGI ROOT APHIS. (See figure on page 50I.)

Distribution.--Only noted at Coimbatore in August and September, but will probably be found to be widely distributed in the Plains.

Lifchistory.-The whole lifehistory is passed underground on the roots of ragi plants. The young, which are probably always produced alive, are very minute, slender, pale-yellowish-white, of the shape shown in the figure. They suck the juices from the roots of the foodplant and, as they grow, the abdomen increases in size until it assumes a globular form of about the size of a pin's head. A few winged viviparous females are also found on the roots but no males have been observed, so that reproduction is apparently normally agamogenetic. These Aphids are attended by several ants, of which the commonest and most conspicuous is Camponotus compressus, and the plants attacked may generally be picked out by the heap of small grains of earth around the stem, marking the situations where the ants have excavated chambers into the soil to visit the Aphids for the purpose of obtaining "honey-dew." The antsalso probably carry the Aphicls into new localities but the latter are also distributed by the winged adults.

Foodplants.-Ragi.

Status. - This insect may be a serious pest, sucking the juices of the plants so persistently that the whole crop may wither unless constantly irrigated and even then the yield is considerably reduced.

Control.-This is a very difficult insect to attack, as its unclerground habits make control measures difficult. The addition of Crude Oil Emulsion to the irrigation water has been tried with some success but this is not economically possible on a large scale. The searching out and destruction of the ants' nests around the ragi fields may perhaps yicld better results.

Remarks.-In general appearance and habits this specics recalls 
Tetrancura lucifuga, Zehntner (Mededeelingen van het Proefstation vor Suikerriet in West-Java "Kagok" te Pekalongan, No. 53, pp. I6-2I, t. II, ff. 29-34) but differs structurally.

\section{LACHNUS PYRI, Bucht.}

Laclinus pyri, Buckton, I.M.N., IV, 274, t. I6.
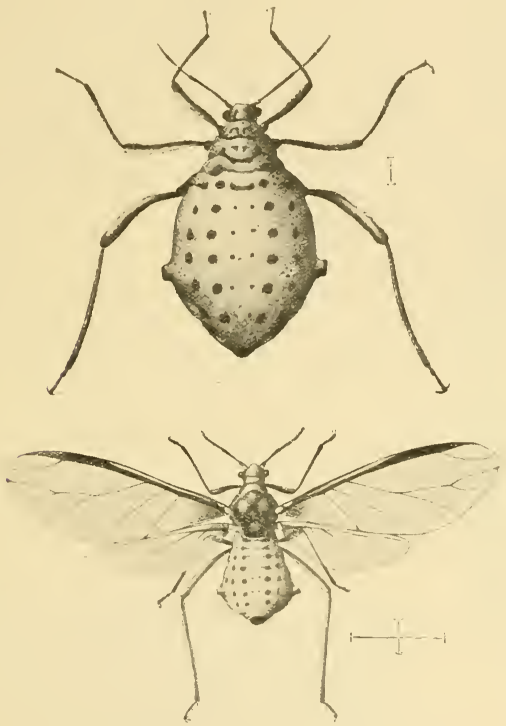

FIG. 391.-Lachnus pyri. wingless and winged adult.

The hair-lines show the natural sizes. (From Indian Museum Notes.)

Distribution.--Ootacanund; Shevaroys.

Lifehistory.--Not known in detail. Probably very similar to that of Aphis gessypii.

Foodplants.--Pear (Pyrus).

Status.-A rather serious pest, occurring in large masses on the twigs.

Control.-Spraying or brushing with any contact insecticide. 


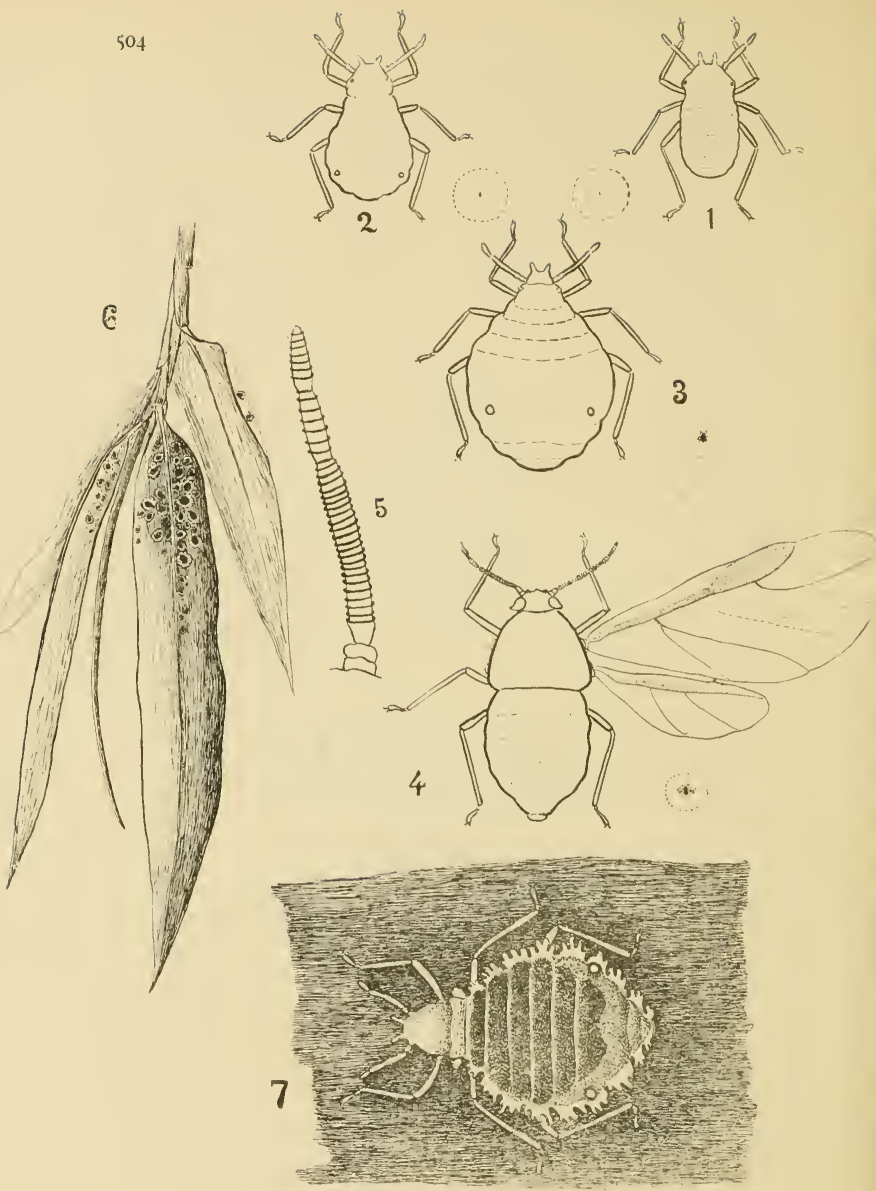

F1G. j92.-Oregma bambusa. 1, Newly-born young; 2, Hall-grown insoct ; 3, Mature wingless form; 4 , Mature winged form; 5 , Antenna of mature winged form; 6, Colony on Giant Bamboo, natural size; 7, Wingless adult, more enlarged, showing waxy filaments. The small figures within the dotted circles show the natural sizes. (Original.) 
OREGMA BAMBUS E, Buckt.

Oregma bambusa, Buckton, I.M.N., II, 87-88, $108-109$ (figs.) (I892); Schouteden, Spol. Zeyl., II, 185-I87, tab., f. 5 [redescr].

Distribution.-Coimbatore. Probably throughout Southern India.

Lifchistory. - The insects, in various stages from young to winged adults, occur on the undersurface of leaves of the Giant Bamboo (Dendrocalamus), sometimes in very large numbers so that the plant is smothered with a black fungus which grows on the honey-dew secreted by the insects, this sweet excretion being also visited by hordes of flies, ants and other insects. The young insect is pale greenish-yellow with a pair of very long projecting cephalic processes which become reduced in size in the adult insect; as it grows, the body becomes spherical, flattened, but the head and thorax remain distinct; in colour it is pale yellowish-green, the tip of the antenna darker, the eye blackish, the anterior portion of the abdomen dark-green as far as a line drawn between the siphons which scarcely project above the surface of the body; the whole of the abdomen is surrounded along its edge by a marginal border of short pure-white waxy filaments, traces of which sometimes occur also on the sicles of the thorax. In the winged adult the general colour is clull-green with a dark area on the abdomen corresponding to that in the immature form; prothorax yellowish with a pair of ill-defined brownish spots; eyes reddish; antennæ black; legs pale-greenish infuscated at apices of segments. When disturbed, the immature insects elevate their bodies at right angles to the resting surface in a very characteristic manner.

Foodplants.-Bamboo (Dcndrocalamus giganteus).

Status.-Apparently a minor pest, doing little harm even when in large numbers, although the drain of plant-juice must then be very large.

Control.-Spraying with contact insecticides and checking access of ants are practicable measures when this insect disfigures the appearance of garden-grown bamboos.

Remarks.-The insect under consideration is apparently Buckton's Oregma bambusa although, as Schouteden remarks, Buckton's "description is unusually incomplete and the drawings reproduced in his paper are not at all exact." Van der Goot (Tijds, voor Ent., LV, 330 and LVI, 13I) states that Oregma is probably identical with Cerataphis, Licht.; I leave this point for Aphidologists to settle, but it seems possible that insularis, v. d. Goot, may be identical with bambusá, Buckton. 


\section{COCONUT APHIS.}
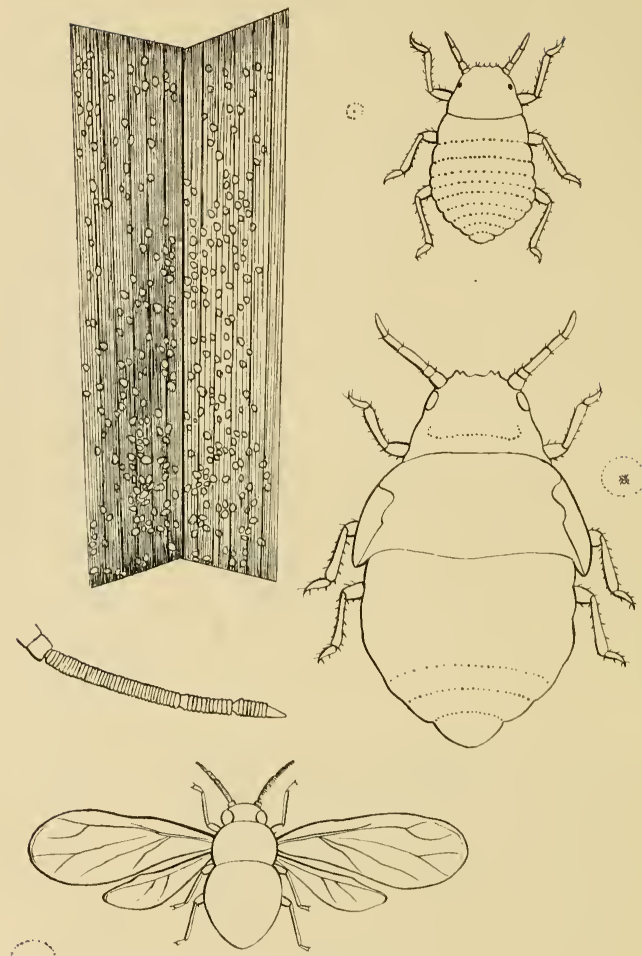

Fig. 393.-Coconut Aphis.

A part of a coconut ieaf showing a colony of the insects (natural size), young insect, wingless and winged adult and antenna of latter. (Original.)

Distribution.-Coimbatore.

Lifchistory.-Not known in detail. Winged and wingless specimens are found together in colonies on the leaves. 
Foodplants. Coconut Palm.

Statns.-A serious pest of young palms.

Control. Spraying with Crude Oil Emulsion has proved effective.

Remarks.-This Aphid was found on young coconuts which had been brought to Coimbatore from Colombo by a private owner, and it is probable that the Aphid was introduced with them. It is hoped that this colony has been exterminated but the insect is figured here in order to enable it to be recognized if found elsewhere.

\section{ALEURODID E.}

ALELRODES BERGI, Sign.

Aleurodes bergi, Signoret, Ann. S.E. Fr. (4), VIII, 800 (1868); Zehntner, Arch. Java Suiker-Ind., XIV, 969, tab. (1896).
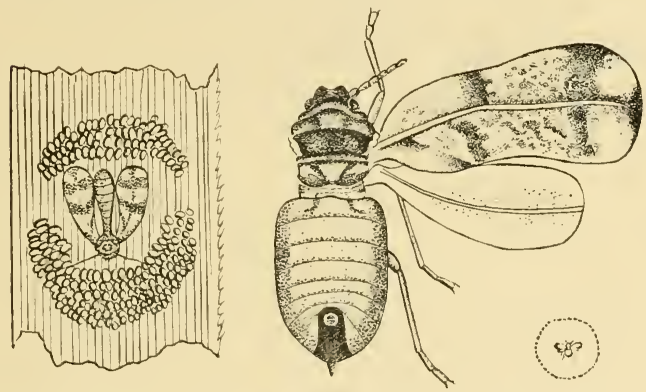

F1G. 39t.-Alcurodes bergi.

Adult female laying eggs on cane-leaf and the same more highly magnified. The small figure within the dotted circle shows the natural size. (After Zehntner.I

Distribution.-Throughout the Plains of Southern India.

Lifchistory.-Eggs are laid on cane-leaves in more or less complete concentric circles. The young nymphs live rather gregariously on the leaves and are dark-green or blackish, surrounded by a whitish waxy efflorescence.

Fooulplants.-Sugarcane.

Status.-A minor pest as a rule.

Control.-Cutting and burning of the first-attacked leaves as soon as colonies are noticed.

Remarks.-This species is merely given here as a representative of its family, of which numerous species (mostly unidentified) occur 
on various trees and plants. The commoner species noticed hitherto are:

Alcurodes citri on Orange, Jasmine, etc., A. ricini on castor, and several unnamed species on sugarcane, castor, etc.

\section{COCCIDE.}

CEROCOCCUS HIBISCI, Gr.

Ccrococcus hibisci, Green, Ent. Mem. Dept. Agri., Ind., Ii, I9 21, t. 2 , ff. $2-4$ (I908); Lefroy (l.c.), p. I22.

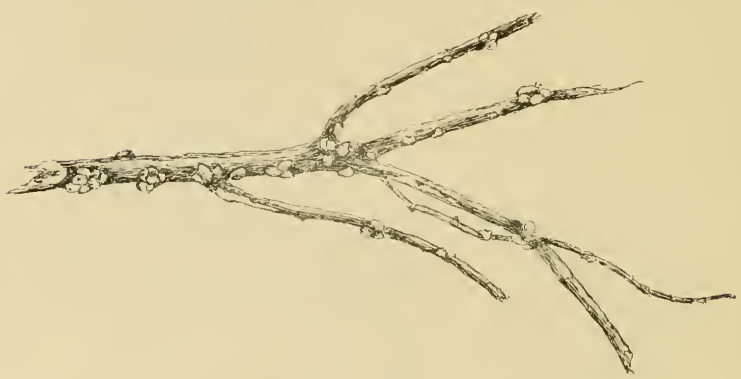

F1G. 345. Cerocuceus hibise on Cutton-stem. (Original.)

Distribution.-Godavari ; Coimbatore. Probably throughout the Plains of Southern India.

Lifehistory and Foodplants.-The conspicuous golden-yellow scales are found on twigs and stems of cotton and Hihiscus.

Status.-A minor pest of cotton.

Control.- The scales are conspicuous and easily removed by hand.

Remarks. - This species appears to be kept in check by parasites and so rarely increases to numbers sufficient to cause damage.

\section{DACTYLOPIUS CITRI, Risso.}

Dorthesia citri, Risso, Hist. Nat. des Oranges (I8I3).

Pseudococcus citri, Fernald, Cat. Cocc., pp. 99 I00; Grandi, Disp. Entom. Agraria, pp. I $40-143$, ff. 126 - 28.

Dactylopius adonidum, Athinson, I.M..N., I, 67 (nci. Linn).

Dactylopius citri, Lefroy, Ent. Mem. Dept. Agri., Indi, I, 248 (l.c.). II, I22-I24, Ind. Ins. Pests, p. 244. f. 297. 

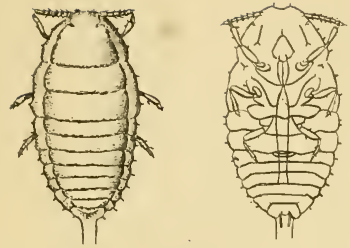

8.

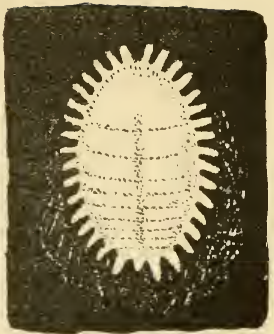

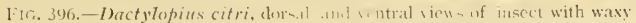
covering removed. and insect with waxy covering. The -nall figure within the dotted circle shows the natural size. I.After Grandi.)

Distribution. Throughout Southern India.

Lifihistory.-Females below ground on roots, on plants, in antshelters. (Lefroy.)

Foodplants.-Coffee, Tea, Croton, various species of Ficus, Agcratum, Erythrima, and numerous other plants.

Stutus.-An occasional serious pest of coffee, especially of young plants in the nursery.

Control.-Contact Insecticides. (See also Ent. Mem., Vol. II. No. 7, p. I23.)

\section{DACTYLOPIUS NIPE, Mask.}

Dactylopius nipce, Maskell, N.Z. Tr., XXV, 232 (1892); Green, Ent. Mem. Dept. Agri., Ind., II, 23 ; Lefroy (l.c.) p. I36. t. I2, ff. 8, 9. A.J.I., V, I62-I64.

Pscudococos mipa, Fernald, Cat. Cocc., p. I07.

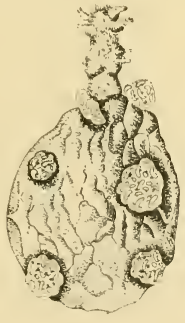

1

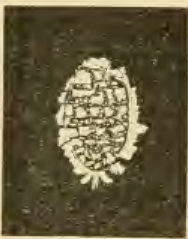

2.

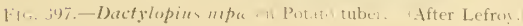


Distribution.--Probably throughout Southern Inclia.

Lifehistory and Food.-Found living on seed-potatoes, collecting in masses around the eyes, and destroying the tubers. Also found living freely on shoots of Mulberry, Cotton, Hibiscus, causing the leaves to curl up and the growing shoot also to curl up into a hard knot.

Control.- In the case of seed-potatoes, washing the potatoes with an insecticide before storing, or fumigating when in store. In the case of attack on Mulberry, etc., the twisted shoots should be plucked and burnt.

\section{DACTYLOPIUS VIRGATUS, Ckll.}

Dactylopius virgatus, Cockerell, Entom., XXVI, I78 (1893); Lefroy, Ent. Mem. Dept. Agri., Ind., II, pp. I27-I28.

Pscudococcus virgatus, Fern., Cat. Cocc., II, p. II I.

Dactylopius ceriferus, Newst., I.M.N., III, No. 5, pp. $24-25$, t. 3, f. 3 .
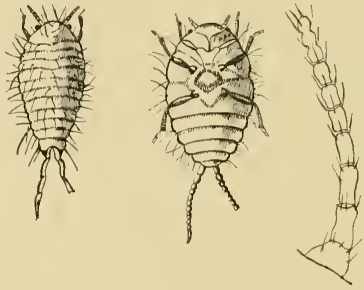

F1G. 398.-Dactytopius virgatus, dorsal and ventral views of insect (enlarged) and antenna (more highly magnified). (After Newstead.)

Distribution.-Probably throughout the Plains of Southern India.

Lifchistory.-Occurs on the leaves and young shoots of the foodplants.

Foodplants.-Cotton, Violet, Acalypha, Hibiscus, etc.

Status.--Sometimes in very large numbers on Garclen plants. A minor pest as a rule.

Control.-Spraying with contact insecticide and (in bad cases) cutting and burning of badly infested branches on plants.

PULVINARIA PSIDII, Mask.

Pulvinaria psidii, Maskell, N.Z. Trans., XXV, 223 (1892); Green, Cocc. Ceylon, IV, 264 265, t. I00; Lefroy, Ent. Mem. Dept. Agri, Ind., II, I3I-I34, Ind. Ins. Life, t. 82, f. I. 

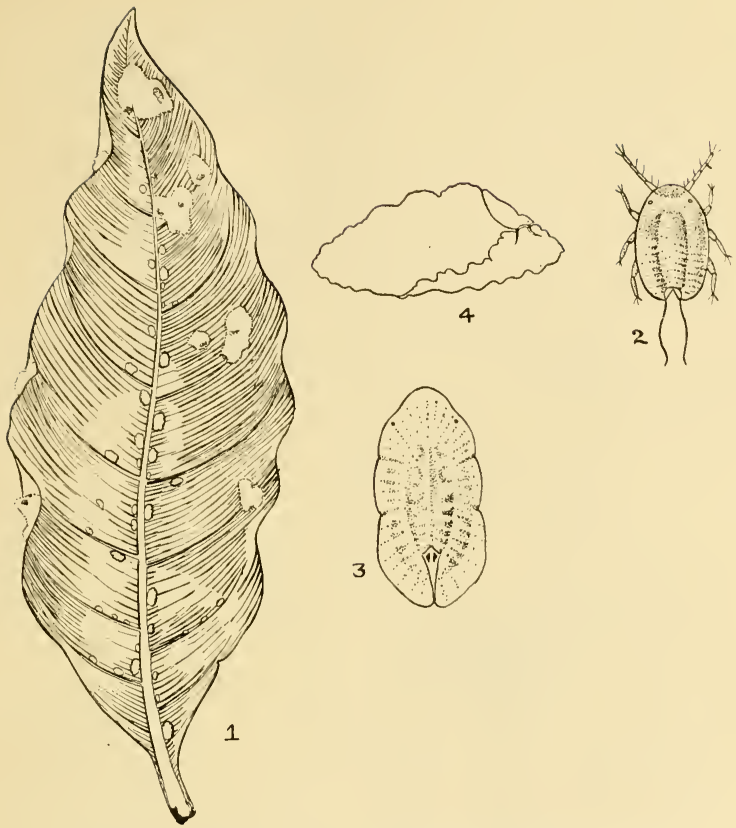

FIG. 399.-Pulvinaria psidii. 1, Insects on leaf. natural size; 2, Young

Nimph, magnified; 3 , Adult scale, magnified: 4 , Side-view of adult female showing waxy excretion. (Figs. $2-+$ after Green.)

Distribution.- Throughout Southern India.

Lifchistory.-Eggs laid in the white flocculent mass which lies under and behind the female scale and which is characteristic of this "Green Mealy Scale."

Foodplants.-Ficus glomerata, Lagerstramia lanccolata, Nango, Guava, Loquat, etc. Occasionally on Coffee.

Status.-Chiefly important in the Hill districts (Mysore, Coorg, Nilgiris and Shevaroys) as a pest of Shade Trees on Coffee Estates. When it occurs in large numbers such trees may be greatly weakened or even killed. 
Control. When the attack is localized the attacked trees should be spraved with a contact insecticide and neighbouring unattacked trees isolated by painting a ring of some sticky substance ( $\iota . g .$, tar and grease) around the trunk to prevent the young bugs crawling up.

In districts where this bug is prevalent, trees of varieties more or less immune to this scale should be utilized for shade.

The immature bugs, when found on Coffee, may easily be mistaken for Lecanium viride, but are larger and lack the dark intestinal loop characteristic of Green scale.

CEROPLASTODES CAJANI, Mask.

Eriochiton cajuni, Maskell, I.M.N., II, 6I 62, t. I, ff. 3a-n (I89I). Ceroplastol escajami, Green, Ent. Mem. Dept. Agri., Ind., I1, No. 2, pp. 32,43 .

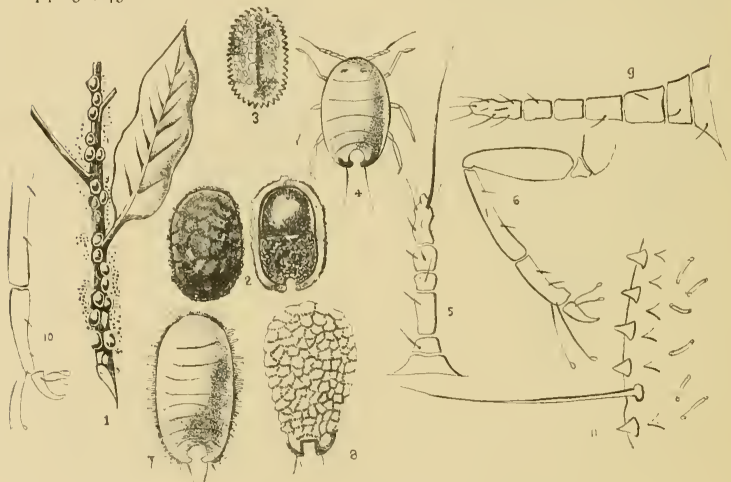

Fut. $+(n)$.-Ccroptastodes cajani. IFrm Indian Museum Xutes.)

Distribution.-Madras (N.B.--It is not clear whether the original record refers to the Presidency or the city; possibly Saidapet is intended.), Coimbatore.

Lifchistory.-The scales are scattered on the twigs of the foodplant as shown in the figure.

Fondplants.-Red Gram (Cajanus indicus), Ber (Zizyphus jujuba). Also on Tulsi (Ocimmm sanctum) and on Colens (Green).

Status.-Originally described from specimens sent in as damaging Red Gram in January 1890. Not since noted as a pest of 
cultivated crops but found in masses on twigs of Zizyphus at Coimbatore.

LECANIUM VIRIDE, Gr.

Lecanium viride, Green, Obsns. on Green Scale (I886), Cocc. Ceylon, III, 199-203, t. 69 ; Lefroy, Ent. Mem. Dept. Agri., Ind., I., 246, II, I 30-13I.
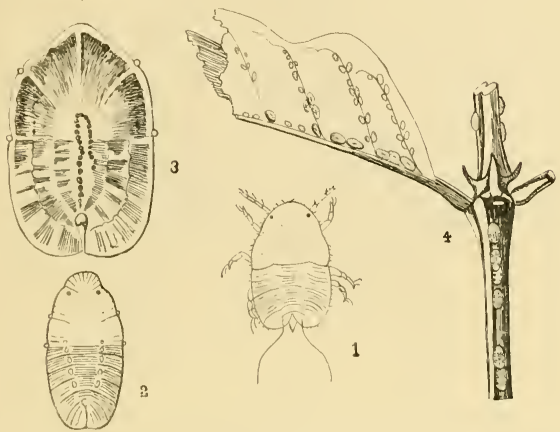

FIG. +01.-Lecanium viride. 1, Young Nymph from above, greatly magnified;

2, Female of second stage, magnified; 3, Adult female, from above, x 15 ;

4. Scales in situ on branch of Coffee, natural size. (After Green.)

Distribution.- Practically throughout Southern India.

Lifchistory.--The flattened "Green Bugs" are found on the tender twigs and leaves, usually along the veins on the underside of the latter. The presence of these scales in large numbers gives riseto a black Fungus which develops on the Honeydew falling on the upper surfaces of the leaves, and this usually attracts attention to the scales, which are not very conspicuous.

Foodplants.-Coffee, principally. Also on Guava, Loquat, Cinchona, etc.

Status.-A very serious pest of Coffee but the amount of damage done seems to depend on local conditions or on causes not yet understood. In some districts the Coffee has been absolutely wiped out by the attack of this scale, whilst in other districts, where it occurs commonly, comparatively little damage seems to result.

Control.-Spraying and Brushing of leaves where practicable. But this scale requires detailed study before any method can be recommended definitely and methods applicable will probably require modification to suit local conditions. 


\section{LECANIUM HEMISPHARICUM, TaIg.}

Lecanium hemisphericum, Targioni-Tozzetti, Studi sulle Cocc., p. 27 (I867) ; Green, Cocc. Ceylon, III, 232, t. 85 ; Lefroy, Ind. Ins. Pests, p. 244, Ent. Mem. Dept. Agri., Ind., I, 247, II, pp. I29-I30.

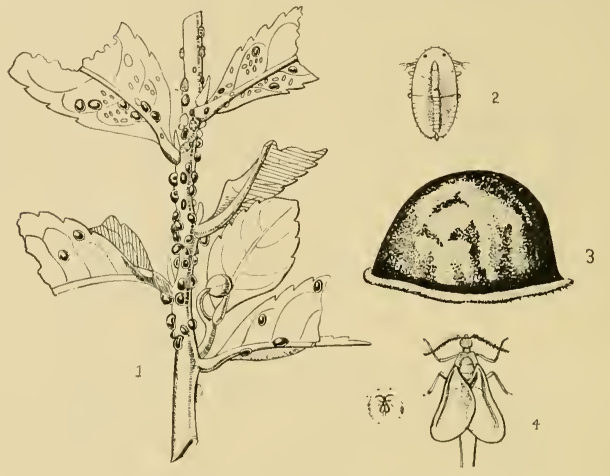

FIG. +02.-Lecanium hemispharicum. 1, Scales on twig and leaves, natural size; 2, Young Nymph, magnified; 3, Adult female ; 4. Male, magnified and natural size. (After Green.)

Distribution.-Throughout Southern India.

Lifehistory. - The rounded, shiny brown scales occur on leaves and shoots.

Foodplants.-Coffee, Tea, Loquat, Cephalandra.

Status.-The "Brown Bug " of Coffee, sometimes a serious pest of both Coffee and Tea.

LECANIUM NIGRUM, Nietn.

Lecanium nigrum, Nietner, Enem. Coffee Tree, p. 9 (I86I); Green, Cocc. Ceylon, III, 229--23I, t. 84 ; Lefroy, Ent. Mem. Dept. Agri., Ind., II, I30.

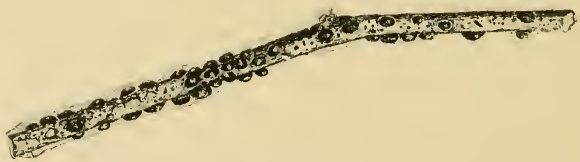

F1G. 403.-Lecanium nigrum, on Cotton stem. (Original.) 
Distribution.--Throughout Southern India.

Lifchistory--Usually on stems of the foodplant. Adults vary considerably in size, shape and colour, the latter being usually deep purple-black, sometimes dark chestnut.

Foodplants.-Cotton. Also on numerous other plants, including Hibiscus, Tea, Coffee, Hevea and Ceara Rubber, etc.

Status. Does not seem to be a pest as a rule but sometimes occurs in injurious numbers on Cotton. A minor pest of Rubber.

Control.--In the case of an outbreak on Cotton the attack is usually localized and the attacked plants should be uprooted and burnt.

\section{LECANIUM OLEÆ, Bernard.}

Chermes olea, Bernard, Mem. d'Hist. Nat. Acad. (I782).

Lecunium olea, Green, Cocc. Ceylon, p. 227-228, t. 83.

Saissetic olea, Grandi, Entom. Agri., pp. I65-I66, f. I 57.

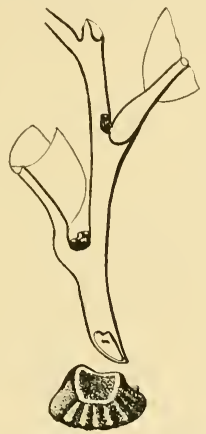

F1G. 40t.-Lecanium olea. Scales on twig, life-size; a single scale, magnified, is shown below. (After Green.)

Distribution.-Probably throughout Southern India.

Lifehistory. -This scale is dull purplish-brown in colour, in shape ovoid not flattened, with a longitudinal ridge down the back and two other transverse ridges. It lives usually on twigs or shoots.

Foodplants. -Coffee, Erythrina, Castilloa Rubber. Outside of Southern India it has been found on Olive, Citrus, Antidesma, Duranta, Thespesia, etc.

Status. -A minor pest of Coffee. 
LECANIUM MARSUPIALE, Green.

Lecanium marsupiale, Green, Cocc. Ceylon, pp. 212-213, t. 75.

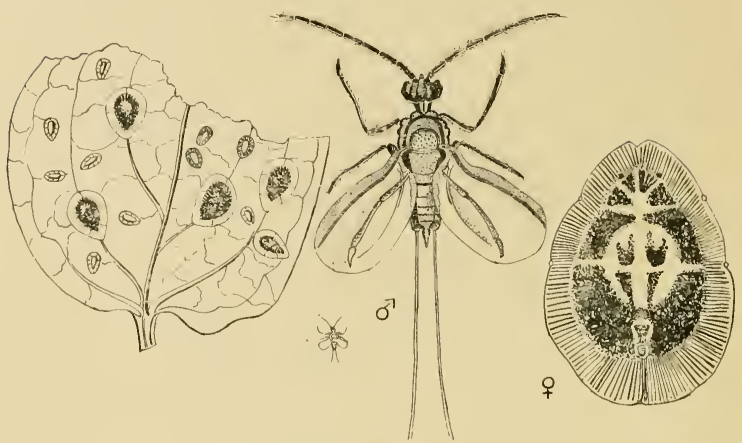

Fig. 405.-Lecanium marsupialc. On the left is a portion of leaf of Black Pepper with male and female scales, natural size; in the centre is winged male, and on the right an adult female, magnified. (After Green.)

Distribution.--Wynaad.

Lifchistory.-The large ovoid, flattened, chestnut-brown scales are surrounded by a conspicuous yellow border and are found on the upper surface of leaves of pepper. The adult scales are very large, $7 \mathrm{~mm}$. long. The young scales whitish.

Foodplants.-Pepper (Piper nigrum).

Statns.-A minor pest.

Control.-Destruction of affected leaves and spraying.

\section{HEMILECANIUM IMBRICANS, Green.}

Lecanium imbricans, Green, I.M.N., V, 94, t. I8, ff. 2, 2a-d; Lefroy, Ent. Mem. Dept. Agri., Ind., II, No. 7, p. I30; Green, Jl. Ec. Biol., V, 67 (March I9I0).

Hemilecanium imbricans, Planters' Chronicle, V, I85.

Hemilecanium theobrome, Newst., J1. Ec. Biol., III, 39 (1908).

Distribution.-Nilgiris, South Mysore (Balur District), Coorg.

Lifchistory.-The large, flattened scales form a dense silverywhite scaly covering on twigs and branches of the trees attacked. The scale is accompanied by a sooty fungus which grows in great quantities on the plants below and rapidly kills out coffee.

Foodplants. - Toon (Cedrela toona), Red Cedar (Acrocarpus fraxinifolins), Ficus mysorensis, F. glomerato and F. infectoria. 


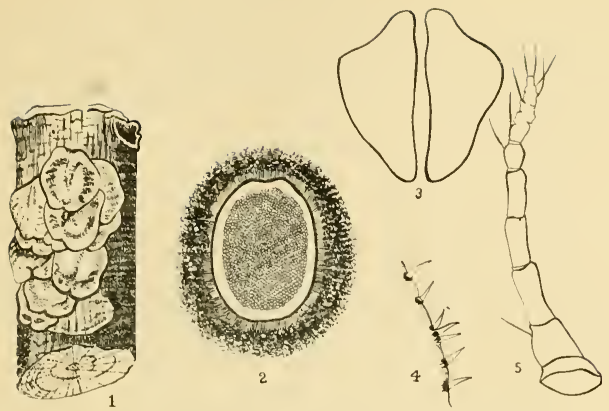

F1G. +06, - Hemilecanium imbricans. (From Indian Museum Notes.)

Status.-An indirect minor pest of Coffee, attacking shadetrees.

Control.-(I) Infected branches should be cut off and burnt and the apparently clean tree whitewashed.

(2) Replacing affected shade-trees by other trees not attacked by this insect.

\section{ASPIDIOTUS CAMELLIE, Sign.}

Aspidiotus camcllic, Signoret, Essai, p. II7 (I869); Green, Cocc. Ceylon, pp. 60 6I, t. I3, Ent. Mem. Dept. Agri., Ind., I, No. 5, p. 353.

Diaspis circulutu, Green, I.M.N., IV, p. 4.
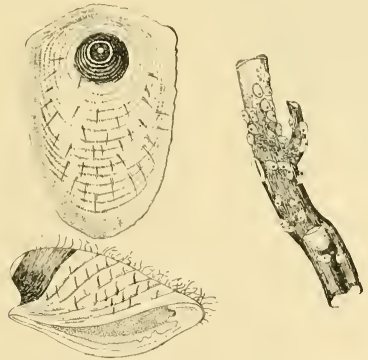

FIG. 407,-Aspidiotus camellice. Scales, natural size, on branch and two scales, magnified, seen from above and from the side. (After Green.) 
Distribution.-Probably throughout the Hills of Southern India.

Lifchistory.-These scales are usually found massed on the upper portions of young tea plants. The scale itself is chestnutbrown surrounded by a broad outer ovoid margin pale-yellow or greyish in colour.

Foodplants.-Tea, Cinchona, Acacia, Grevillea, Sapu (Michclia champaca).

Status.-Sometimes does considerable damage to young tea plants in Southern India.

Control.- In the case of very young plants complete destruction by fire, in the case of older plants drastic pruning, the prunings being burnt on the spot. There is risk of infecting other plants if attempts are made to carry affected plants elsewhere to be burnt.

\section{ASPIDIOTUS DESTRUCTOR, Sign.}

Aspidiotus destructor, Sign., Ann. S.E.Fr. (4), IX, I20 (I869); Fernald, Cat. Cocc., p. 257 ; Cotes, I.M.N., II, I68, III, 66-67 ; Lefroy, Ent. Mem. Dept. Agri., Ind., II, I37 ; Green, B.J., XIII, 70, t. B, f. 5.

Aspidiotus latanice, Green, Cocc. Ceylon, I, 49-50, t. 8 (nec Sign.).
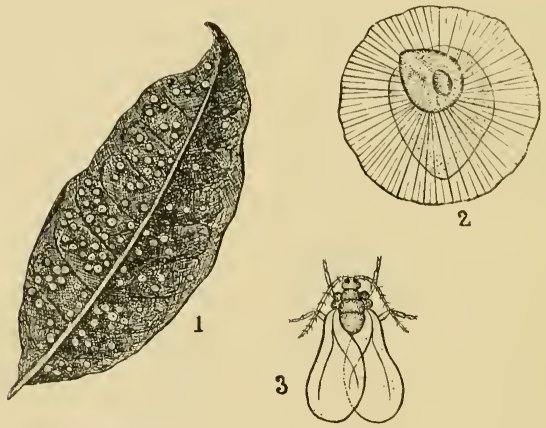

Fig. 408.-Asputiotus destructor. 1, Scales on leaf, natural size: 2, Female : and 3, Male, both magnified. (After Green.)

Distribution.--South Wynaad, Coimbatore; probably throughont the Plains of Southern India. Laccadive Islands.

Foodplants.-Coconut, Mango, Pepper.

Status.-Occasionally injurious by weakening the tree when the scale occurs in large numbers.

Control. $\rightarrow$ ? 
MYTILASPIS PIPERIS, Green.

Mytilaspis piperis, Green, Ent. Mem. Dept. Agri., Ind., II, No. 2, pp. $34^{-35}$, t. 4 , f. 18 .
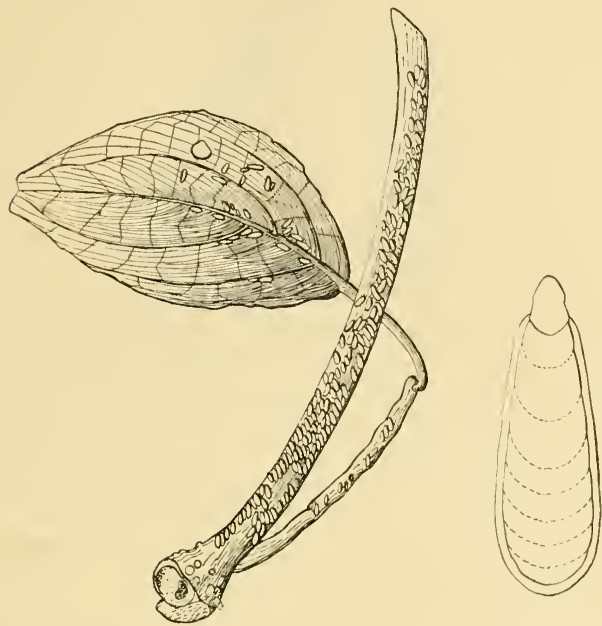

Fig. 409.-Mytilaspis pipcris. Scales, natural size, on twig and leaf of Pepper: and a single scale, magnified. (Original.)

Distribution.-Wynaad.

Lifchistory.-The long, narrow, brown scales live thickly clustered together on the young stems. The vines are attacked by this scale usually about to feet from the ground, a rusty patch bare of leaves and about a yard long being formed on the stem.

Foodplant.-Pepper (Piper nigrum).

Status.-A local, minor pest.

Control. - Spraying and destruction of attacked portions of plants.

\section{CHIONASPIS BICLAVIS, Comst.}

Chionaspis biclavis, Comstock, 2nd Rept., Dept. Ent. Corn. Univ., p. 98 (I883); Green, I.M.N., IV, 2, Ent. Mem. Dept. Agri., Ind., I, No. 5 , p. 354 , II, No. 2 , p. 36 , Cocc. Ceylon, pp. I 52 -I 54 , t. 54. 


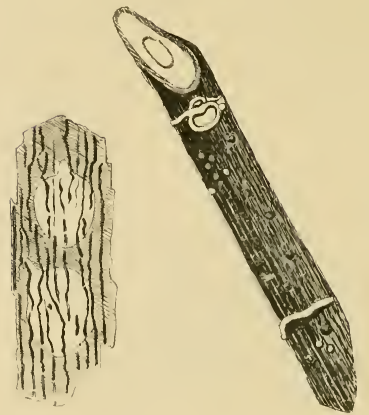

F1G. 410.-Chionaspis biclavis. On the right is seen a piece of Cinchonastem with Scales in situ, natural size; on the left is a piece of bark from a

Tea-stem showing two scales greatly enlarged. (After Green.)

Distribution.-Nilgiris.

Lifehistory.-The female scales are always found on stems or bark of the foodplant, never on leaves; they are extremely inconspicuous, being covered with the superficial fibres and loose material of the bark on which they rest. Their presence may, however, be detected by the pimply appearance of the bark.

Foodplants.-Tea, Cinchona. Occasionally on Grevillea and Coffee.

Status.- Not noted as a pest in Southern India, but Green states that it is "perhaps the most serious and widespread of all Coccidæe affecting the tea plant in Ceylon," its attacks resulting "in an unhealthy hidebound condition of the main stems and branches."

Control.--Cutting out of worst affected stems during pruning and scrubbing the remainder with a pad of coir matting moistened with Kerosine Emulsion (Green).

\section{HEMICHIONASPIS THEÆ, Mask.}

Chionaspis thea, Maskell, I.M.N., II, 60, t. I, ff. 2 a-c; Green, Cocc. Ceylon, II, p. II3, t. 33; Watt and Mann, Pests of Tea, pp. 307-309, f. 39 .

Hemichionaspis thea, Green, Ent. Mem. Dept. Agri., Ind., I, No. 5, p. 342 .

Distribution.-Throughout the Tea Districts of Southern India. 


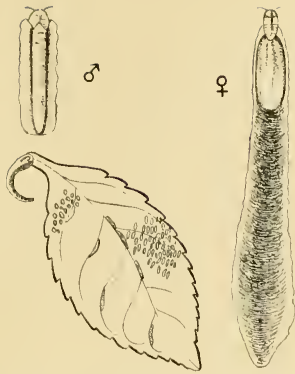

Fig. 411.-Hemichionaspis there. Male and Female Puparia on Tea-leaf. natural size and magnified. (After Green.)

Lifehistory.-The female scales are usually found on the branches of older bushes and are so like the bark that they are difficult to distinguish. The white fluted male scales are often seen in little colonies on leaves, where they are conspicuous.

Foodplants.-Tea. Also on Psychotria and other plants. [Green.] Status.-This scale scarcely seems to be a pest in Southern India.

\section{ANOPLURA. \\ PEDICULIDÆ.}

PEDICULUS CAPITIS, de Geer.

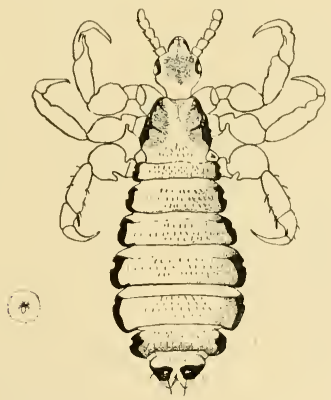

FIG. +12.-Pediculus capitis. The small figure within the dotted circle show's the natural size. (Original.) 
Pediculus humanus, Linn., Syst. Nat. (ed. X), I, p. 610 (1758) [part].

Pediculus capitis, de Geer, Mem., VII, 67, t. I, f. 6 (I778); Osborn, U.S.A. Ent. Bull. No. 5, pp. I66 167, f. 96; Lefroy, Ind. Ins. Pests, p. 264, f. 317; Howlett, Incl. Ins. Life, p. 762; Brumpt, Precis de Parasit., pp. 549-550, ff. 395-397 ; Alcock, Ent. for Med. Offrs., pp. 2I3 215; Castellani and Chalmers, Man. Trop. Med.. p. 633, ff. $267-268$ (1913).

Distribution.--Throughout Southern India.

Lifclistory.-The eggs (or nits) are fixed by the female on to a hair of the human head, the portions just behind the ears being most commonly selected. The young lice hatch out after about 5 days and are full-grown after another 10 or 12 days. The lice suck blood at least once in every 24 hours.

Food. - The blood of man.

Status.-A serious pest, as the insect may act as a carrier of disease from one host to another. It is known to carry Typhus and to produce a form of Impetigo.

Control.-Personal cleanliness. Soap and water combined with almost any of the ordinary antiseptics will be found efficient. Washing the head with ordinary kerosine-oil (care being taken not to approach any light or fire) and afterwards with soap is a simple method.

PEDICULUS HUMANUS, Linn.

Pcdiculus humanus, Linn., Syst. Nat. (ed. X), I, p. 610 (1758) [part].

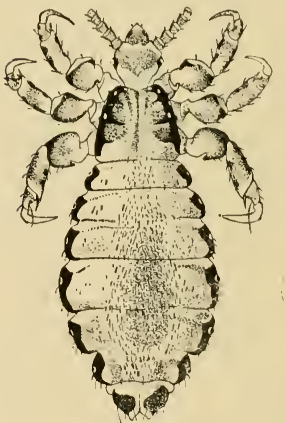

FIg. +13. Pediculus humanus. The small figure within the dotted circle shows the natural size. (Original.)
Pediculus corporis, de Geer, Mem., VII, 67, t. I, f. 7 ( I 778).

Pediculus vestimenti Nitzsch, Germar Mag. Ent., Vol. III (I8I8); Osborn, U.S.A. Ent. Bull. No. 5, pp. I67-I68, ff. 94, 97 ; Howlett, Ind. Ins. Life, p. 762 ; Brumpt, Precis de Parasit., pp. 552-554; Alcock, Entom. for Med. Offrs., pp. 2I3 -2I5; Girault, Entom. News, XXIII, 339-344; Castellani and Chalmers, Man. Trop. Med., p. 634, ff. 269-270 (I9I3).

Distribution.--Throughout Southern India. 
Lifehistory.-Eggs are laid on clothing in which the lice live except when actually sucking blood from the body. Eggs and development much as in $P$. capitis.

Food.- The blood of man. This louse has been induced to bite fowls (Neveu-Lemaire) and is said to have been taken from cattle (Osborn), but is not known to attack any host except man in a natural state.

Status. - The bite of the body louse is said to be more irritating than that of the head-louse. The former is known to carry Typhus Fever and both are equally to be avoided as possible carriers of disease.

Control.-Personal cleanliness. Baking, boiling, or fumigation of infested clothing or bedding. The newly-hatched young are only able to exist about two dlays without food so that disuse of infected clothing, etc., for a period of at least Io days should result in starving of any young emerging from eggs in the clothing. It may, however, be noted that the eggs may not hatch for five weeks in cold climates; no exact observations on this point seem to be on record for Southern India but the period may be expected to be much shorter--probably always less than a week.

\section{PHTHIRIUS PUBIS, Linn.}

Pediculus pubis, Linn., Syst. Nat. (ed. X), I, p. 61 I (I758).

Phthirius inguinalss, Leach, Zool. Miscell., III, 63, t. 5I, f. 5 (18I7); Osborn, U.S.A. Entom. Bull. No. 5, pp. 165-I66, f. 95 ; Howlett, Ind. Ins. Life, p. 762 ; Brumpt, Precis de Parasit., pp. 554-555, f. 398 ; Alcock, Entom. for Med. Offrs., p. 216, f. 96 ; Castellani and Chalmers, Man. Trop. Med., p. 634, f. 27I (I9I3).

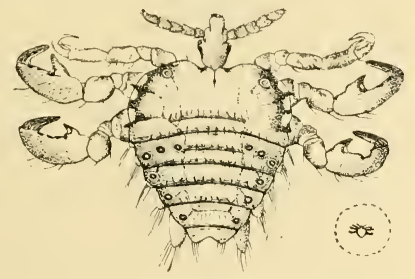

Fig. +14.-Phthirius pubis. The small figure within the dotted circle shows the natural size. (Original.)

Distribution.- Throughout Southern India.

Lifehistory.- - This minute louse, which is only about one-fifteenth of an inch long, lives on the coarse hairs of the pubic and axillary 
regions of the human body; occasionally found in the hairs of the face but in those of the head only in extremely rare cases. The eggs are fixed at the base of a hair, and the young hatch out after about a week and are full-grown after about another fortnight.

Food.- The blood of man.

Status.-An annoying and disgusting parasite whose bites produce small itching papular eruptions. Not definitely known to carry disease, but extremely likely to do so.

Control.-Personal cleanliness. These lice are highly resistant to ordinary antiseptics. Crude Oil Emulsion will probably be found effective. Mercurial ointments are usually recommended.

NOTE.-The specific name pubis, Linn., is applicable to this insect and has priority.

HÆMATOPINUS TUBERCULATUS, N. \& G.

Pediculus tubcrculatus, Nitzsch and Giebel, Zeits. f. ges. Naturw., XXIII, 32 (I 864).

Hamatopinus tuberculatus, dalla Torre, Wytsm. Gen. Ins., Anoplura, p. II (1908).

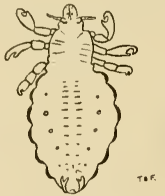

FIG, +15.-Hamatopinus tuberculatus, enlarged and

natural size. (Original.)
Distribution.--Throughout Southern India.

Lifchistory.-Not known in detail. Live on the ears of buffaloes.

Food.-Blood of buffaloes.

Status. - Not known to be a serious pest as a rule but sometimes occurs in very large numbers.

Control.-Application of Crude Oil Emulsion.

Remarks.-(I) Outside of India similar lice have been found capable of transmitting Surra (Trypanosoma evansi) from one host to another, and young lice have been found to be transported by clinging to the legs of a fly (Lyperosia) which also infests buffaloes.

(2) For other animal lice see page 185 .

\section{ORTHOPTERA.}

ACRIDID $A$.

TRYXALIS TURRITA, Linn.

Acrida turritus, Linn., Syst. Nat. (ed. X), p. 427 (1758:.

Tryxalis turrita, Lefroy, Ind. Ins. Life, p. 82, fig. 23.

Acrida turrita, Kirby, Cat. Orth. III, 92-93. 


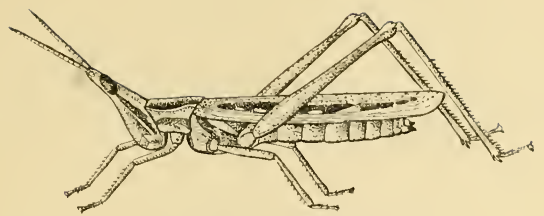

FIG. +16.-Tryxalis turrita. (Original.

Distribution.-Common throughout the Plains.

Lifehistory.-Not known.

Status.-Scarcely a pest although it often occurs in large numbers.

Control.-Easily caught by the help of small bag-nets.

EPACROMIA TAMULUS, Fb.

Gryllus tamulus, Fabr., Ent. Syst. Suppl., p. I95 (I798).

Gryllus dorsulis, Thunberg, Mem. Acad. Patersb, V, 229 (I8I5).

Epacromia dorsalis, I.M.N., III, No. 5. p. 73, figs ; Lefroy, Ind. Ins. Life, p. 83 , f. 24.

Eolopus tamulus, Kirby, Cat. Orth. III, I92.

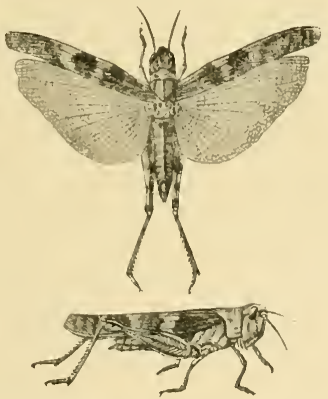

FiG. 417.-Epacromia tamulus. (From Indian Museum Notes.)

Distribution.- Throughout the Plains of Southern India; especially common in the Tinnevelly, Ramnad and Madura Districts.

Lifehistory.- Not worked out in detail. There are apparently two broods during the rains.

Foodplants. - Ragi, Cholam, Cumbu, Daincha (Sesbania aculeata). 
Status.-A local pest of some importance in the Madura and Tinnevelly Districts.

Control.-May be swept up in small bag-nets during day-time. At night, unlike most grasshoppers, this species is attracted to light, and torches or lights placed over pans of water with a film of oil on top form effective traps.

AULARCHES MILIARIS, Linn.

Gryllus miliaris, Linn., Syst. Nat. (ed. X), I, 432 (I758).

Phymateus punctatus, Fab.; Green, Perad. Circ. I, No. 9 (1898).

Aularches miliaris, Green, Perad. Circ. III, No. I6; Lefroy, Ind. Ins. Life, pp. 83-84.

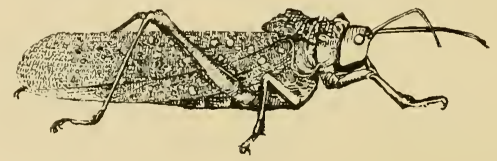

FIG. +18.--Autarches mitiaris. (Original.)

Distribution.--Shevaroys, Nilgiris, Vizagapatam and Coimbatore.

Lifclistory.-Eggs are laid in a mass in the ground in a hole, dug by the female, about 3 inches deep and half an inch in diameter. The grasshoppers usually collect in one place for coupling and egg-laying, the latter usually taking place under shade. The eggs hatch after about five months and the young hoppers take about five months to attain full growth.

Foodplants.-Coconut, Coffee, Erythrina.

Status.-This insect does little damage as a rule although often common in Coffee Districts.

Control. - The habit of the adults to congregate for the purpose of pairing and ovipositing may be utilized to destroy them in large numbers. The young hoppers on first hatching may also be collected and destroyed before they have time to do harm.

PCECILOCERUS PICTUS, Fb.

Gryllus pictus, Fab., Syst. Ent., p. 289 (1775).

Pokilocerus pictus, Serv., Orthopt, pp. 597-598.

Pocilocerus pictus, Lefroy, Ind. Ins. Pests, p. 2I 2, f. 249, Ind. Ins. Life, p. 84 ; I.M.N., III, No. 5, p. 72, fig. 

PLATE XXXXVIII.

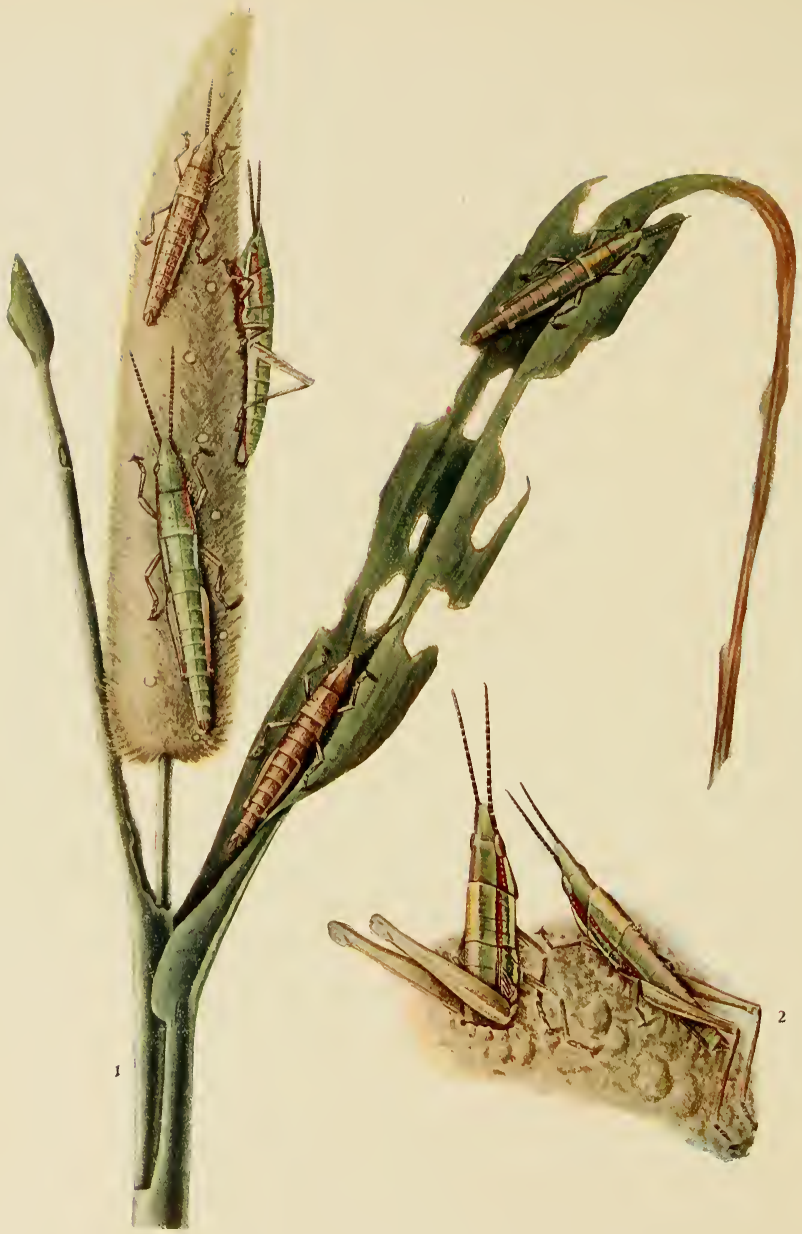

COLEMANIA SPHENARIOIDES. 


\section{EXPLANATION OF PLATE XLVIII. \\ COLEMANIA SPHENARIOIDES.}

Fig. 1. Earhead and leaf of millet eaten by the grasshoppers, natural size.

" 2. An adult grasshopper on the ground and a female laying eggs with her body thrust into the soil. 



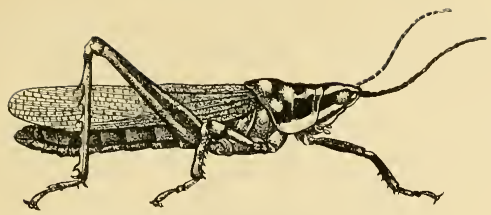

F1G. 419.-Pocilocerus pictus. (Original.)

Distribution.- Throughout the Plains of Southern India.

Lifchistory.-Not known in detail. Probably two broods in the year.

Foodplants--Calotropis. Found damaging young fig plants in Bellary District.

Status. - Not a pest as a rule.

ORTHACRIS Sp.

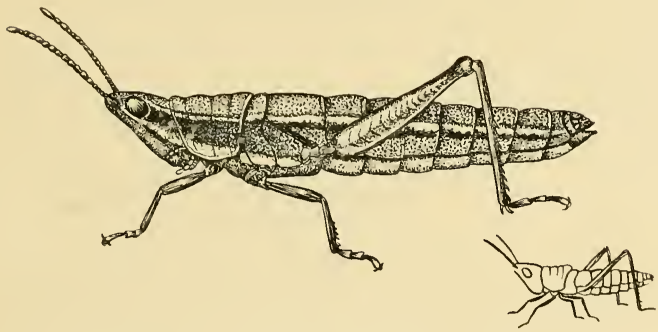

FIG. +20.-Orthacris sp. The outline figure shows the natural size.

(Original.)

Distribution.-Coimbatore, Tinnevelly, Bellary. Probably throughout the Plains of Southern India.

Lifchistory.-Not known.

Foodplants.-Ragi, Cumbu, Cholam, Groundnut, Cabbage, Brinjal, etc. On most low-growing plants.

Stutus.-A minor pest as a rule.

\section{COLEMANIA SPHENARIOIDES, Bol.}

Colemania sphenurioides, Bolivar, Bolet. R. Soc. Esp. Hist. Nat. (I910), p. 3I9; Coleman, B.J., XX, 879 (I9II); Mysore Ent. Bull. No. 2 , pp. I -43 , t. I-IO. 
Distribution.-Mysore, Bellary, Kurnul. Gradually spreading eastwards and southwards.

Lifehistory.-Eggs are laid in masses in the ground in OctoberDecember, the young nymphs emerging about June-July, after the South-West Monsoon Rains have set in. They feed on any low-growing vegetation and are full-grown about SeptemberOctober, when they pair and lay eggs. The young are similar to the adult but smaller and both stages are wingless.

Foodplants.-Cholam, Tenai, Cumbu, Green Gram, Red Gram, Cow-pea. Most low-growing crops are attacked but cotton seems fairly immune.

Control.-(i) Catching young hoppers (before they have had time to damage crops) by means of small bag-nets.

(ii) Killing adult hoppers when coupling and laying eggs.

(iii) Deep-ploughing of infested fields in December-January to destroy egg-masses.

\section{ATRACTOMORPHA CRENULATA, Fb.}

Truxalis crenulatus, Fab., Ent. Syst., II, p. 28 (I793); Serv., Orthopt, p. 584 .

Pyrgomorpha crenulata, I.M.N., III, No. 6, p. 2I, fig. ; Lefroy, Ent. Mem. Dept. Agri., Ind., I, I I9, f. 2, Ind. Ins. Life, p. 84, f. 25.

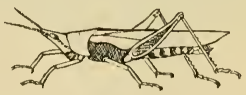

Fig. +21.-Atractomorpha crenulata. (Original.)

Distribution.-Throughout the Plains of Southern India; especially common in Coimbatore, Godavari, Kurnul and Bellary.

Foodplants.-Tobacco, Brinjal, and other vegetable crops especially Amaranthus.

Status. - Found often in company with Chrotogonus doing some appreciable injury to tobacco in nurseries.

Control.-Hand-picking.

\section{CHROTOGONUS.}

? [Ommexecha trachypterum, Blanchard, Ann. S.E. Fr., V, 6I8 619, t. 22, f. 6 (1836).

Chrotogonus trachypterus, Lefroy, Ind. Ins. Pests, p. 220, f. 265, Ent. Mem. Dept. Agri., Ind., I, II8, f. I, Ind. Ins. Life, p. 85.]

(SEe Plate XLIX.)

Distribution.-Throughout the Plains of Southern India; especially common in South Arcot, Madura, Coimbatore and Bellary. 


\section{EXPLANATION OF PLATE XLIX. CHROTOGONUS SP.}

FIG. x. Egg-mass in soil.

" 2. A single egg, magnified.

"3. Portion of egg-mass, magnified.

"4-8. Young grasshoppers in various stages, magnified.

" 9, Io, Adult grasshoppers.

(The lines alongside the figures show the natural sizes.) 
PLATE XI.IX.
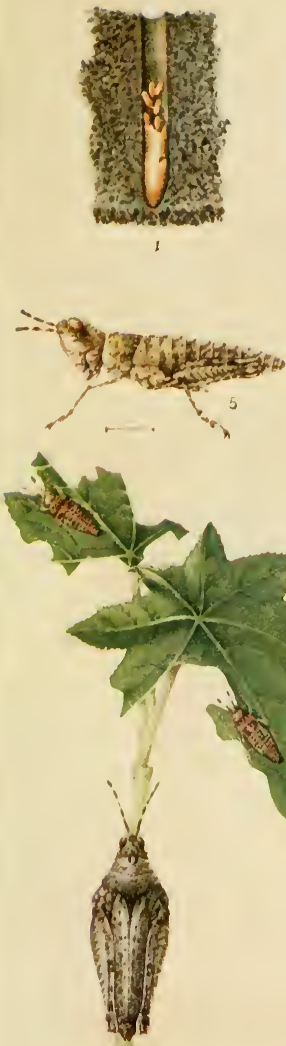

10
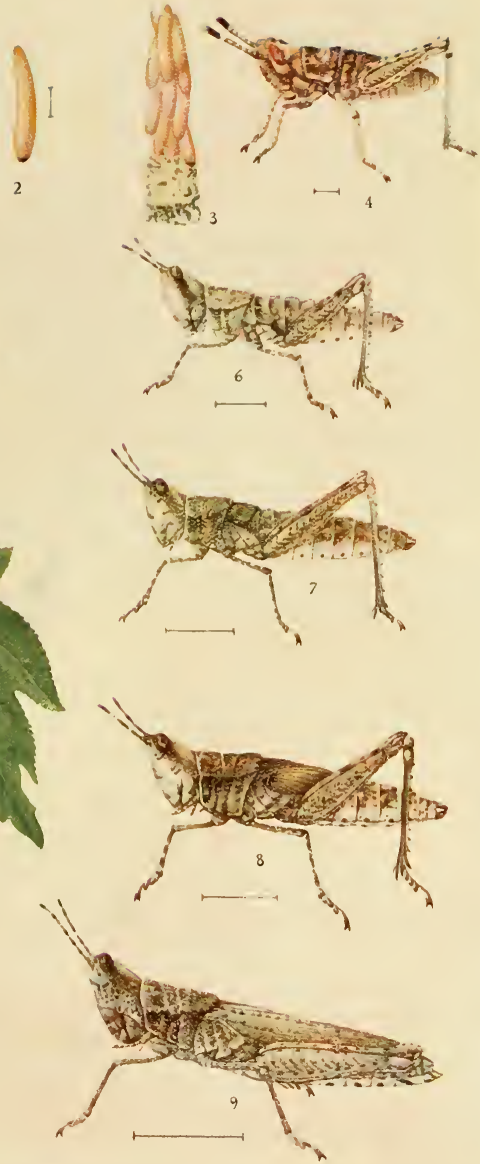

CHROTOGONUS SP. 

Lifehistory.-Eggs are laid in the ground in a mass, the young hoppers scattering on emergence and feeding on almost all green vegetation. Exact life-cycle not worked out in Madras. For stages see coloured plate.

Foodplonts.-Tobacco, groundnut, cholam, cotton, nigerseed.

Status.-Sometimes a serious pest of young tobacco, cholam, etc.

Control. - Collection in small bag-nets.

Remarks.--The exact identity of the species concerned in Southern India is not known. Probably there are several species which may be different from the Northern Indian species shown on the plate, but the general appearance and habits are very similar in all.

\section{CATANTOPS sp.}

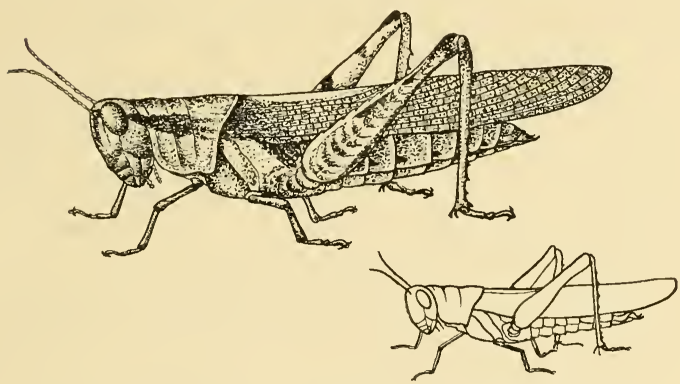

FIG. 422.-Catantops $s p$. The outline fignre shows the natural size.

(Original.)

Distribution.-Tinnevelly and Ramnad.

Lifehistory.-Not known. Perhaps two broods annually, one in July-August, the other in February-March.

Foodplants.-Cotton (bolls, flowers and leaves), grasses.

Status.-A very local and sporadic pest, occasionally doing some damage to cotton-plants by eating the young bolls.

Control.-Catching in small bag-nets or hand-nets.

Remarks.-This species is perhaps undescribed. It is somewhat similar to Catantops similis, but is larger, with longer wings and with a distinct pattern of markings on thorax, elytra and posterior femora. 


\section{CYRTACANTHACRIS SUCCINCTA, Linn.}

Gryllus succinctus, Linn., Amœen. Acad. VI, 398 (1763).

Acridium succinctum, Lefroy, Ent. Mem. Dept. Agri., Ind., I, pt. I, pp. I- 52, t. I-4, t. 8, f. I, t. 9. f. I, t. I0, ff. I, 2, Ind. Ins. Life, p. 86 , t. $2-3$.

Cyrtacanthacris succincta, Kirby, Cat. Orth. III, 448.

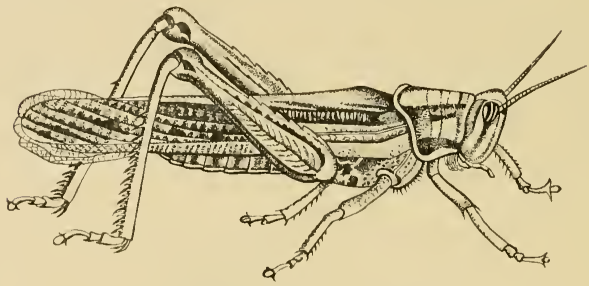

FIG. 423.-Cyrtacanthacris succincta. (After Lefroy.)

Distribution.-Bellary, Kurnul and Anantapur. A stray specimen was obtained in South Arcot in November 1907 and another from Dhavani (Nilgiris, 6,000 ft.) in December 1907. Not noted in South India since I907, but scattered individuals may occur throughout.

Lifchistory.-See Lefroy, Ent. Mem. Dept. Agr., Vol. I, No. I.

Foodplants.-All green vegetation.

Status.- The Bellary and Kurnul districts are occasionally visited by migrant swarms from Bombay, usually in May and June, when there are practically no crops on the ground, so that the damage done in Madras is slight.

Control.- Little can be done to check the locusts when a locality is visited by one of these enormous swarms. The best method of destruction is probably to burn them with torches when resting on trees at night. They are also readily destroyed when coupling by beating them with brooms, branches, etc.

CYRTACANTHACRIS RANACEA, Stoll.

Gryllus Locusta ranacous, Stoll, Spectres Saut., p. 30, t. I4. b, f. 53 (I8I3).

Acridium aeruginosum (nec Bur.), Lefroy, Ent. Mem. Agri. Dept., Ind., I, 53, t. 8 , f. 3 , t. 9 , f. 38 , t. I0, f. 5 .

Cyrtacanthacris ranacea, Lefroy, Ind. Ins. Life, p. 86, t. 6; Kirby, Cat. Orth. III, 45I. 

PLATE L.

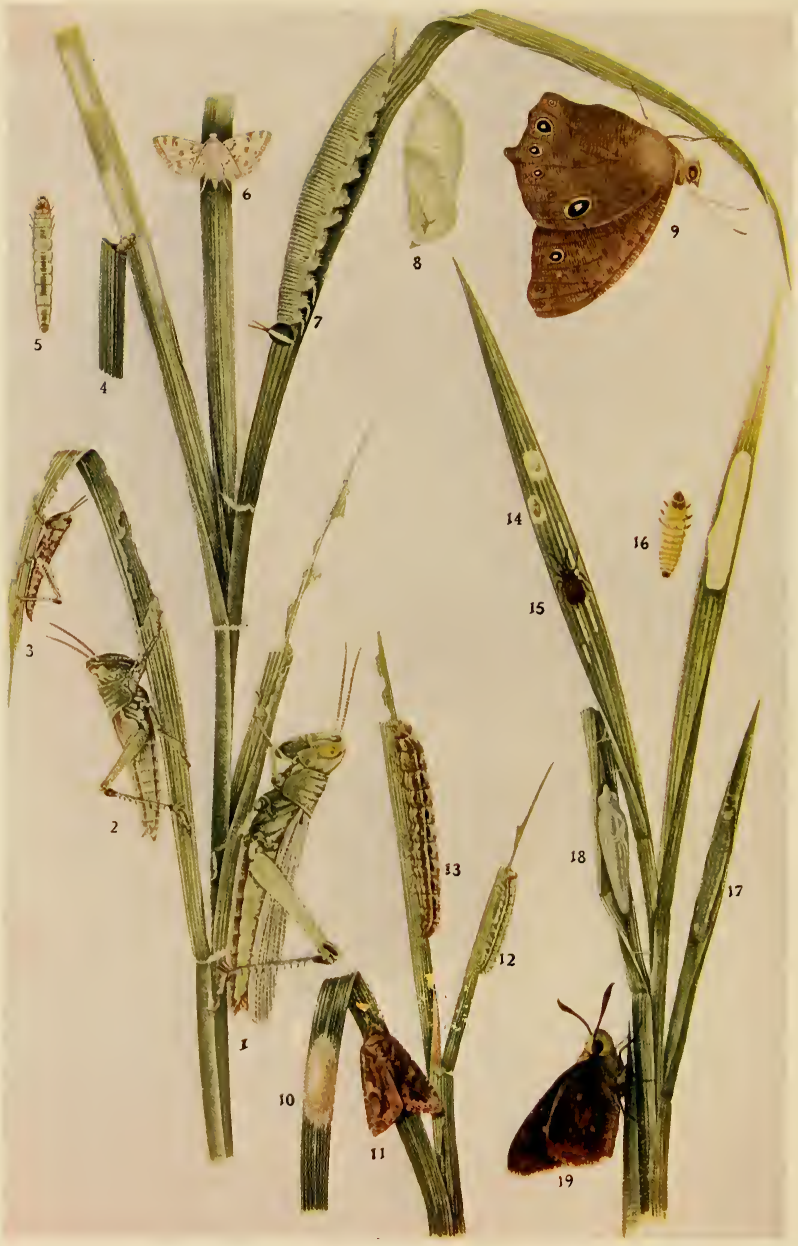

PESTS OF RICE. 


\section{EXPLANATION OF PLATE L.}

Fig. I. Hieroglyphus banian. Adult grasshopper.

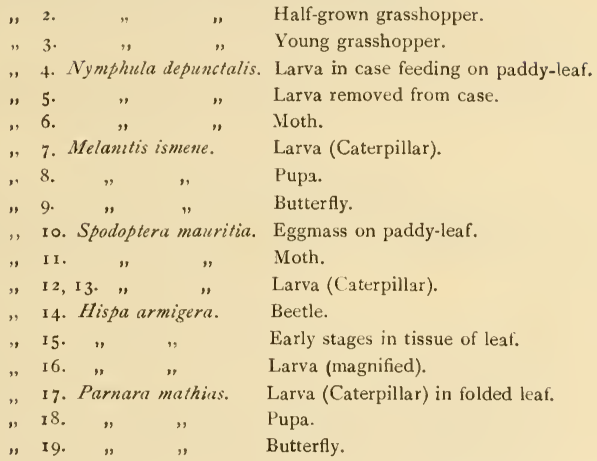





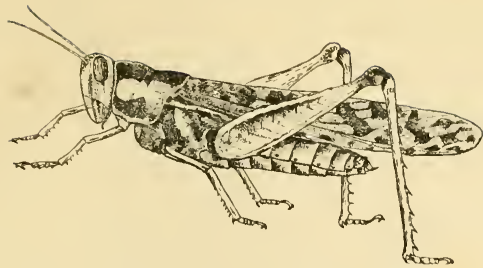

F1G. 42t.-Cyrtacanthacris ranacca. (Original.)

Distribution.-All over South India.

Lifelistory.-Not worked out in detail. The nymphs are characterized by the broad yellowish stripes on the prothorax.

Foodplants.-Cotton, castor, groundnut, ragi and various other crops.

Status.-Common, especially in cotton fields, but scarcely a pest.

Control.-Collection by hand or in nets.

HIEROGLYPHUS BANIAN, Fb.

Gryllus banian, Fab, Ent. Syst. Suppl., p. I94 (I798).

Acridium furcifer, Serv., Orthopt., p. 677, t. I4, f. I2 (1839).

Hicroglyphus banian, Lefroy, Ind. Ins. Life, p. 87, t. 7 ; Coleman, Mysore Ent. Bull., No. I, pp. I-52, t. I-5.

\section{[SEE Plate L.]}

Distribution.-Throughout the Plains of Southern India up to about 4,000 feet.

Lifehistory.-The eggs are laid in masses in the ground, usually between October and December, the young emerging about June, soon after the South-West Monsoon Rains have started. The young nymphs are brownish-yellow, with a yellowish stripe down the middle of the thorax, and do not usually assume a greenish colour until they are about to acquire wings. The developmental period for males is about 70 days, for females about 80 days.

Foodplants.-Paddy, sugarcane, maize ; chiefly on paddy.

Status.-A major pest of paddy, sometimes doing serious damage both in hopper and adult stages.

Control.-Bagging in small bag-nets.

HIEROGLYPHUS NIGRO-REPLETUS, Bol.

Hieroglyphus nigro-repletus, Bolivar, Trabajos del Museo de Cient. Nat. Madrid, No. 6, pp. 56-59 (I9I2).

Hicroglyphus banian, Lefroy, Ind. Ins. Life, f. 27, nec Fab. 


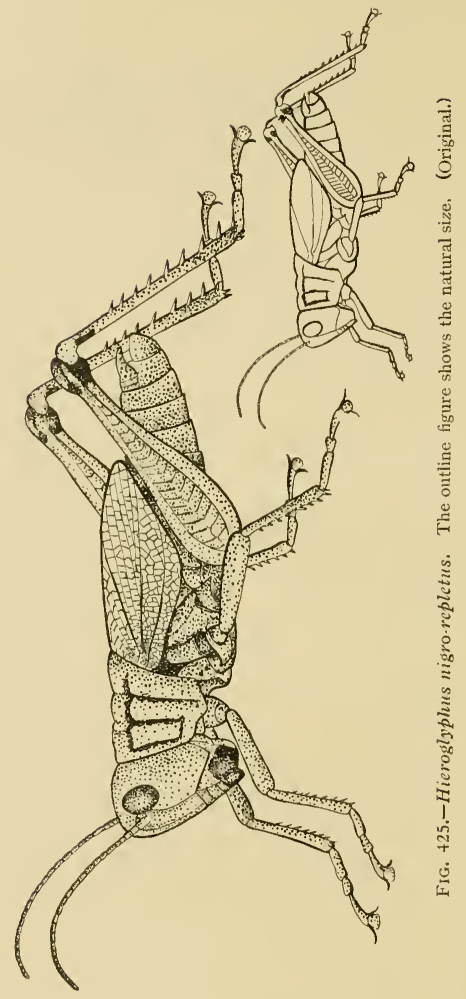

Distribution.-Bellary, Kurnul, Guntur.

Lifehistory.-Eggs are laid in November in masses at a depth of two or three inches from the soil surface. Young hoppers emerge in June-July and are adult in September-October.

Foodplants.-Cholam, tenai. 
Status.-A minor pest of cholam and tenai, not occurring in large numbers as a rule.

Control.-Catching in small bag-nets, or by hand (adults).

Remarks.-Most forms are short-winged ones, but a few forms with the wings fully developed have also been noted. These latter are, however, distinct from $H$. banian in colour markings. In 1909 specimens were received from the Bellary Farm as doing damage to cholam. This species has been named H. nigro-repletus by Senor Ignacio Bolivar and a translation of his description will appear shortly in the Journal of the Bombay Nat. Hist. Society.

\section{OXYA VELOX, Fb.}

Gryllus velox, Fab., Mant. Ins., I, 239 (I787).

Oxya velox, Lefroy, Ind. Ins. Life, p. 88; Bolivar, Ann. S.E.Fr. (I90I), 6I 3 ; Kirby, Cat. Orth., III, 393 394.

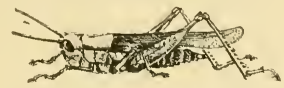

FIG. 426.-Oxya velox. (Original.)

Distrilution.--Throughout the Plains of Southern India.

Lifchistory.-Not known.

Foodplants.-Paddy chiefly. Among other crops cholam, sugarcane.

Status.-A minor pest of paddy. Sometimes this insect does some appreciable damage to paddy. Sometimes this and Hicroglyphus banian are found together in paddy fields.

Control.-Sweeping with bag-nets.

Remarks.-Adult specimens are sometimes attracted to light at night and light-traps might perhaps be of some use.

\section{PHASGONURIDÆ.}

\section{SCHIZODACTYLUS MONSTROSUS, Dr.}

Gryllus monstrosus, Drury, Illustr. II, 8I, t. 43, f I (1773); Serv., Orth., pp. 322-323; Lefroy, Ind. Ins. Pests, p. 224, f. 27I, Ent. Mem. Dept. Agri., Ind., I, I25, f. 9, Ind. Ins. Life, p. 95, f. 33. 


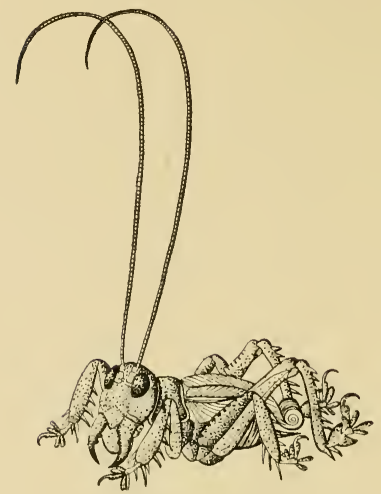

FIG. +27.-Schizodactylus monstrosus. (Original.)

Distribution.-Bellary only.

Lifclistory.-The nymphs and adults hide during the day singly in tunnels driven into the ground in sandy places, probably emerging at night to forage for their prey which consists of practically any other animal small enough to be overpowered and devoured. They will starve in captivity rather than touch vegetable food.

Food.-Predaceous on caterpillars, small frogs, etc. Not a pest. Found in sand along a river bank at Hagari.

Status.-Beneficial as destroying caterpillars, grasshoppers, etc., injurious when attacking batrachians. On the whole, probably of ineutral value to agriculture.

Remarks.-In localities where it is common this insect is often accused of damage really done by Brachtrypes.

\section{GRYLLIDÆ.}

\section{GRYLLOTALPA AFRICANA, Pal.}

Gryllotalpa africana, Palisot-Beauv., Ins. d'Afriq et d'Amér., p. 229, Orthopt, t. $2^{\text {c, f. }} 6$ (1805); Serv., Orth., p. 307 ; Lefroy, Ind. Ins. Pests, p. 224, f. 270, Ent. Mem. Dept. Agri., Ind., I, I24, f. 8, Ind. Ins. Life, p. Ior, ff. 37-38. 
Curtilla africana, Kirby, Cat. Orth. II, 6.

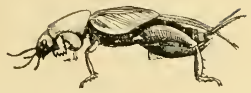

FIG. +28.-Gryllotalpa africana. (After Lefroy.)

Distribution.--South Kanara, Malabar, Madura, Coimbatore, South Arcot, Ramnad ; probably throughout the Plains of Southern India.

Lifchistory.-Not known in detail.

Food and Staths.-Not a pest, often found in damp corners of houses. Once reported as damaging sugarcane to some extent in Tellicherry (Malabar district) by gnawing the setts. Probably also predaceous on smaller animals and does damage sometimes by driving tunnels through the ground in search of food.

Control.-The insects usually prefer to live in damp localities and it is therefore possible to bring them out of their burrows by floorling the ground, when many birds readily attack them.

\section{CECANTHUS INDICUS, Sauss.}

Ecanthus indicus, Saussure, Mélanges Orth., p. 594 (I877); Lefroy, Ind. Ins. Life, p. I05, f. 42 ; Kirby, Cat. Orth. II, 74.

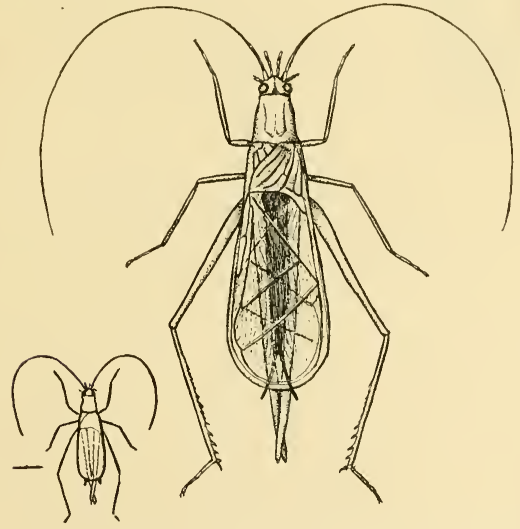

FIG. 429.-- Ecanthus indicus. The outline figure shows the natural size. (Original.) 
Distribution.-Coimbatore, Godavari, Bellary, Kistna.

Food.-Found on tobacco plants but never doing any damage to the same; they have not, however, been observed to feed on any insects though they were found in numbers on plants infested with Plant-lice, Capsids, etc. It is, however, probably predaceous on small plant-feeding insects.

Status.-Probably beneficial.

BRACHYTRYPES PORTENTOSUS, Licht.

Acheta portentosa, Licht., Cat. Mus. Zool. Hamb., III, 85 (1796).

Brachytrypes portentosus, Kirby, Cat. Orth. II, 22.

Gryllus Achcta achatina, Stoll, Spectres Saut., p. 4, t. 2', f. 8 (I8I3).

Brachytrypes achatimus, Lefroy, Ind. Ins. Pests, p. 225, f. 266, Ent. Mem. Dept. Agri., Ind., I, I22, f. 7, Ind. Ins. Life, p. I03, f. 40, Ent. Mem., Vol. IV, pp. I6I-I82, t. I0; V. S. Iyer, Ind. Forest Bull., No. II, p. 2, ff. $I^{n}, I^{b}$.
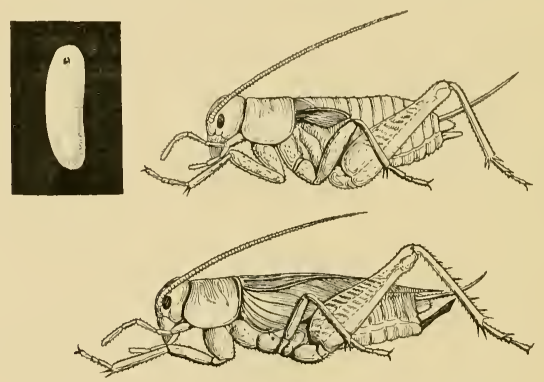

F1G. 430.-Brachytrypes portentosus. (After Lefroy.)

Distribution.-Nellore. Apparently not widely distributed in Southern India.

Lifchistory. - Eggs are laid singly at the end of burrows made into the ground. The young nymphs hatch out a fter about a month and attain the winged state after about six months. They live hidden in their burrows during the daytime, emerging at night to forage for food which they carry down into their tunnels.

Foodplants.-Casuarina (seedlings).

Status.-Noted to do damage in Casuarina nurseries. 
LIOGRYLLUS BIMACULATUS, de Geer.

Gryllus bimaculatus, de Geer, Mem. Ins., III, 52I, t. 43, f. 4 (I773).

Liogryllus bimaculatus, I.M.N., III, pt. 2, p. 97, fig; Lefroy, Ind.

Ins. Pests, p. 226, f. 269, Ind. Ins. Life, p. I04, f. 35.

Acheta bimaculata, Kirby, Cat. Orth. II, 26.

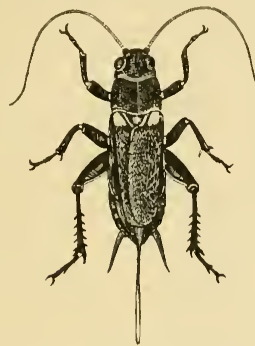

Distribution.--Throughout the Plains of Southern India.

Lifchistory. - Not known. Usually found under stones, logs, etc.

Food.-Probably feeds on decaying vegetation; possibly predaceous on other insects. Has been noted as attacking and devouring the Deccan grasshopper (Colemania) in the field.

Status.-Not a pest.

FIG. 431.-Liogryllus bimaculatus.

(Originai.)

\section{BLATTIDÆ.}

PERIPLANETA AUSTRALASI $Æ, F b$.

Blatta australasia, Fab., Syst. Ent., p. 27I (1775).

Periplaneta australasia, Marlatt, U.S.A. Ent. Bull., No. 4, p. 9I, f. 40 ; Lefroy, Ind. Ins. Life, p. 6I, f. II.

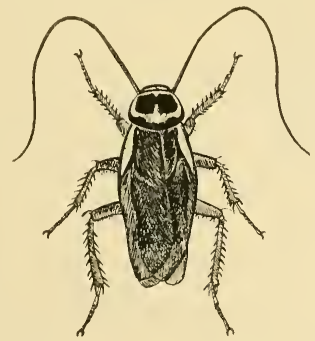

F1G. 432.-Periplaneta australasia. (Original.) 
Distribution.-Common in towns but not so common as $P$. americana (see figure 74) which seems to be dispossessing this species in many districts. Probably introduced by shipping.

Lifelistory.-The eggs are deposited all together, contained in a hard horny case. The young lead an independent existence as soon as they hatch out. The life-cycle is a long one, probably over two years from egg to adult, the adult being also long-lived.

Status.-In the field cockroaches do little, if any, damage, but in houses, especially in towns, this and other species are well-known household pests. They gnaw unsightly patches in any leather articles (harness, boots, book-binding, etc.), and not only eat any food to which they find access but contaminate it with their disgusting smell whilst there is a further possibility of their communicating pathogenic germs onto food which they touch. Cockroaches have also been shown recently to be of some importance in the occurrence of cancer in mice. Corks are frequently destroyed and form favourite places for the deposition of the egg-sacs, which are placed in holes gnawed in the cork.

Control.-Traps and paste containing borax are the best remedies. Small cockroaches may often be trapped in any empty tin with a little grease smeared around the inside and a lump of bread, etc., as bait.

BLATTELLA GERMANICA, Linn.

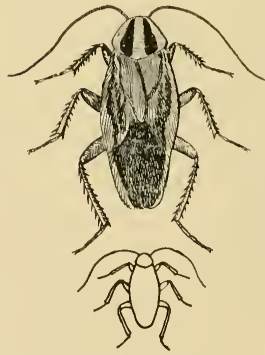

Fig. 433.-Blattella germanica.

The outline figure shows the naturál size. (Original.)
Blatta germanica, Linn., Syst. Nat. (ed. XII), p. 688 (I767).

Ectobia germanica, Marlatt, U.S.A. Ent. Bull., No. 4, p. 92, f. 42 .

Blattclla germanica, Shelford, E.M.M. (I9I I), I 54.

Phyllodromia germanica, Kirby, Cat. Orth. I, 87.

Distribution.-Common in towns. An introduced species.

Lifchistory.) See Pcriplancta Status and
Control. 
DERMAPTERA.

FORFICULIDÆ.

NALA LIVIDIPES, Duf.

Forficula lividipes, Dufour, Ann. Sc. Nat., XIII, p. 340 (I828).

Labidura lividipes, Burr, Faun. Ind. Derm., p. 97, t. 4, f. 3 I.

Nala lividipes, Burr., Gen. Ins. Derm., p. 36, t. 3, f. Io.

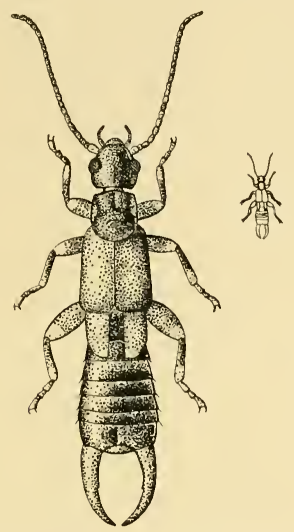

FIG. 43+.-Nala lividipes. The small figure shows the natural size. (Original.)

Distribution.-Common throughout the Plains of Southern India.

Lifelistory.-Not known.

Remarks.-This insect is included here as one of the commonest representatives of its family. Earwigs are rarely pests, but, on the contrary, are often beneficial as they are largely carnivorous and have been recorded as important predators on larvæ of Fruit-flies and of House-flies.

ISOPTERA.

MESOTERMITIDÆ.

COPTOTERMES HEIMI, Wasm.

Coptotermes heimi, Wasm., Zool. Jahrb., XVII, I04, t. 4, ff. I a-f (I902); Holmgr., B.J., XXI, 777 (I912). 


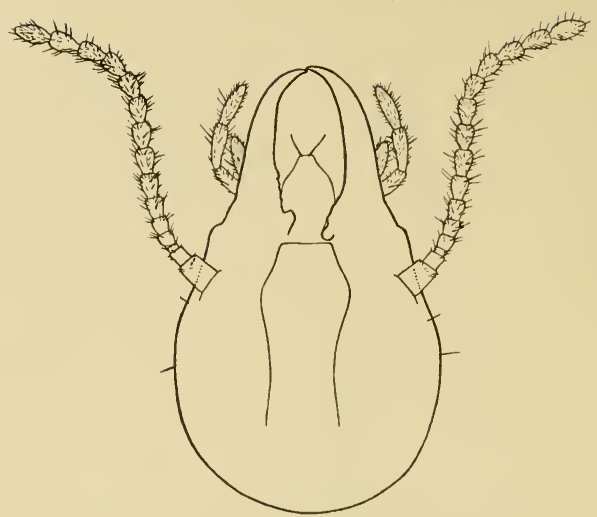

FiG, 435,-Coptotermes heimi, head of soldier (much magnified). (Original.)

Distribution.-Coimbatore, Bellary; probably throughout the Plains.

Lifehistory.-Colonies of soldiers, workers and young occur in decayed portions of living trees and in wooden beams, etc. The winged adults fly just after sunset on still evenings in January and February at Coimbatore.

Status. - In the case of living trees colonies only appear to occur in old trees and probably only occupy and perhaps enlarge already existing dead portions or hollows in the stem and branches caused by disease or injury. In the case of buildings, however, these Termites may do considerable damage by hollowing out beams, especially in the roof. Their presence is often detected by the long narrow galleries, partly excavated in the wood and covered with mud or chewed wood, which they run over tree-trunks, beams, etc. The soldiers exude a large drop of milky, sticky, latex-like liquid from the head.

Control.-Little can be done unless the headquarters of the colony can be located. It may then be destroyed by injecting poisonous fumes. Treatment with preservatives of beams intended for constructional use is indicated as a means of prevention. 
TERMITIDÆ.

\section{ODONTOTERMES Sp.}

Under this name reference is made to the Termites-whether of more than one species is uncertain, as is also the exact identitywhich commonly cover trees in the dry weather with sheets of mud under cover of which they nibble off the outer bark. The direct damage done is usually small although occasionally the Termites may eat into the inner bark but it seems probable, in some cases at least, that their attack may provide a means of entry for bacterial diseases which may affect the trees more seriously. Various mixtures are in common use for application to tree-trunks. I have found a mixture of Crude-oil Emulsion and Tar (half and half) effectual for some months at least, and it is usually only during the dry weather that trees are attacked. Pure Tar by itself willsometimes injure the tree, as will kerosine-oil. Crude-oil Emulsion (without Tar) may be applied in the case of young trees with tender bark.

The nest is below ground, the sponge-like fungus-combs being found sometimes as far as twelve feet below the surface, but usually in the first two or three below soil-level. The nests are not marked by above-ground mounds and can rarely be located exactly. (See also figure 32.)

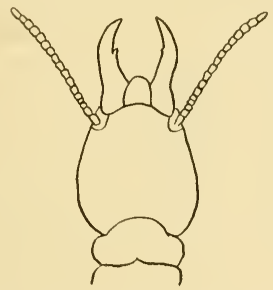

1

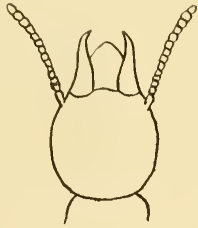

2

F1G. +36.-Outlines of heads of soldiers of (1) Odontotermes and (2) Microtermes, showing relative proportions and shape of jaws. (Original.)

\section{MICROTERMES $\mathrm{sp}$.}

Under this name reference is made to those small Termites which attack growing crops, particularly cereals and young plants. These Termites are much smaller than the species of Odontotermes and the soldiers have a relatively much smaller and weaker mandible. Their nests, which are in scattered colonies under the soil 
sometimes in or alongside the nests of other Termites, show no outward indication of their position and are almost impossible to locate.

The only method of mitigating damage, that can be suggested at present, is by the use of deterrents, whose use of ten gives young plants time to reach a point of growth at which they are little attacked. Where irrigation is practicable a bag of Crude-oil Emulsion suspended in the irrigation-channel will usually drive Termites a way temporarily. Cane setts may be dipped in a solution of Copper Sulphate before planting. Methods adopted for special crops must depend very largely on local conditions.

\section{THYSANOPTERA.}

THRIPIDÆ.

THRIPS.

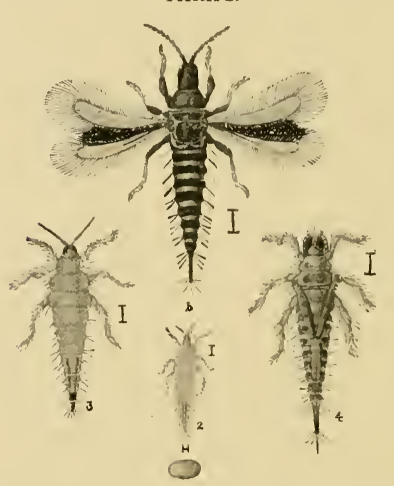

Fig. 437.-Thrips. The hair-lines show the natural sizes. (After Lefroy.)

Various species of Thrips (Scnsu latiori) occur in Southern India on various crops, such as cholam, paddy, onion, sugarcane, and groundnut, but the species concerned are very little known and cannot be discriminated without careful study. The damage done is usually small so far as particular plants are concerned, but is undoubtedly large in the aggregate, and further study of these minute insects will probably reveal that many different species 
will have to be included in the list of insects injurious to Agriculture. Their habits are various; some live in flowers and doubtless devour the pollen, a few produce galls in which they live, and many live on leaves (especially in the shelter of the leaf-sheath in crops such as cholam), piercing and eating the green matter. No practical treatment can be recommended pending further study of the species concerned.

\section{THYSANURA.}

LEPISMID Æ.

\section{CTENOLEPISMA Sp.}

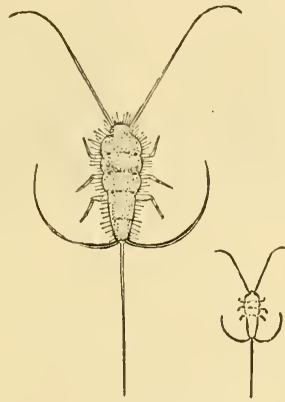

F1G. +38.-Ctenolepisma sp. The outline figure shows the natural size. (Original.)

Distribution.-Throughout Southern India. A domestic species occurring in houses amongst papers, books, pictures, etc.

Lifehistory.-Eggs are laid amongst papers, etc. The life-cycle is apparently a long one, taking about two years from egg to adult.

Status.-A regular household pest, frequently doing considerable damage to papers, office files, pictures, etc.

Control.-Books should be treated with Book Solution regularly, at least once a year, if kept in open shelves. Pictures should be painted over their backs with Naphthaline Emulsion and their frames thoroughly well made and closely lined with tin. Books in closed shelves, papers in boxes, etc., may be protected by naphthaline. (See also page I72.)

Remarks. - These Fish-insects in Southern India do not seem to be controlled by Croce as in Northern India. 


\section{ARACHNIDA.}

ACARINA (Mites).

TETRANYCHUS BIOCULATUS, W.-M.

(RED SPIDER).

Tetranychus bioculatus, Wood-Mason, Report on Tea-Mite (1884); I.M.N., III, pt. 4, pp. 48--56, figs.; Green, Perad. Circ. I, No. 17 , pp. 198-I99; Lefroy, Ind. Ins. Pests, f. 2; Watt and Mann, Pests of Tea, pp. $348-359$, f. 40 .
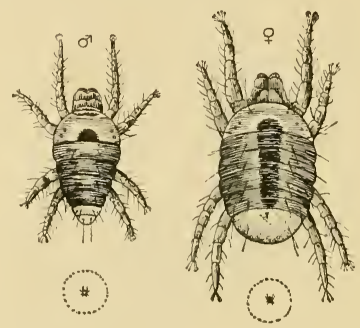

F1G. 439.-Tetranychus bioculatus, male and female. The small figures within the dotted circles show the real sizes. (Original.)

Distribution.-Probably throughout the Tea Districts of Southern India.

Lifehistory.-The mites live in colonies on the upper surface of mature leaves under a very delicate protective web. The red eggs are laid in hollows, usually close to a rib of the leaf, and the newly-hatched young have only three pairs of legs but soon attain the adult condition in which they have four pairs of legs. The female mite is only about I mm. (one twenty-fifth of an inch) between the tips of the out-stretched fore and hind legs, and the male is still smaller.

Foodplants.-Tea. Probably on other plants also; Green mentions tomato.

Status.-Sometimes a serious pest of tea. Although the mites feed only on the older leaves, the loss of sap due to their sucking the juices of the plant causes the leaves to become dry and curled and in bad cases to fall off.

Control.--(I) The mites are most injurious during spells of dry weather. Heavy rains are inimical to them. 
(2) Dusting with Flowers of Sulphur is the best remedy. By suspending two bags on the end of a pole a cooly can dust two rows of bushes at once. About I cwt. per acre is required.

(3) Spraying with Flour Paste and Sulphur is indicated as an experiment in control.

Observation.-Cotes (I.M.N., III, 48) states that Tetranychus bioculatus, W.-M., is the same species as the "Red Spider" of the Coffeetree, described as Acarus coffece by Nietner in his "Observations on the Enemies of the Coffee-tree in Ceylon," published in I86I. If this statement is correct, the Red Spider should apparently be known as Tetranychus coffea, Nietn.

\section{PHYTOPTUS CARINATUS, Green.}

\section{(PURPLE MITE.)}

Typhlodromus carinatus, Green, Ins. Pests of Tea.

Phytoptus carinatus, Green, Perad. Circ. I, No. 17, pp. 199-200; Anstead, Planters' Chron., VI, I89; Watt and Mann, Pests of Tea, pp. $365-368$, f. 42 .

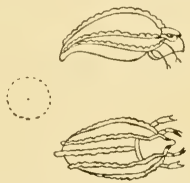

Fig, +40.-Phytoptus carinatus, seen from side and from above. The dot within the circle shows the natural size. (After Green.)

Distribution.-Nilgiris.

Lifchistory.-The Purple Mite feeds on both surfaces of the leaf, giving it a more or less uniform purplish-bronzy tint, the leaves withering and dropping in bad cases. The outer margins of the leaves are often more attacked than the central portions. The mite itself is microscopic and invisible to the naked eye, although close inspection will often show very minute white specks which are the cast-off skins of the mites. The young mites are greenish, semitransparent, pear-shaped. The adult mites are coloured dull purple and have five ridges of white waxy material along the báck; there are apparently only two pairs of legs and these are small and placed close together near the head; at the tail-end there is a sucker which acts as a prehensile organ and is used in locomotion. [Green.] 
Foodplants.-Tea.

Status.-A constant and sometimes serious pest.

Control.-Dusting with Flowers of Sulphur in the early morning, or spraying with Crude-oil Emulsion and Sulphur or with Flour Paste with or without Sulphur.

Remarks.--I have not seen this mite in Southern India and am indebted to $\mathrm{Mr}$. Anstead for information regarding its occurrence. 


\section{IN DEX.}

The Lists of Crops with their pests and of Allied Plants (pages 240-273), being already shown in order, are not indexed here also.

All names in italics are synonyms.

An asterisk (*) placed after a name means that the organism under reference is figured either on the page quoted or on a Plate inserted opposite thereto.

\section{A}

aberrans, Pyrilla, 494.*

Abdomen and appendages, 11.

abdominalis, Aulacophora, 311.*

Acacia latronum harbouring ants, 63 .

Acacia sundra, 63.

Acanthophorus serraticornis, 319.*

Acariases, 185.

Acarina, 544 .

Achæa melicerta, 386.*

achatinus, Brachytrypes, 536.*

Acherontia robbing bee-hives, 130 : larva, 131.

Acherontia styx, 402.*

Acheta bimaculata, 537."

Acontia graellsi, 385.*

Acrida turrita, 524.*

Acrididæ, 524.*

acridiorum, Coccobacillus, 124 .

Acridium ceruginosum, $530 *$; A. succinctum, 530.*

Acridotheres tristis, 224.*

Actias selene, 405.*

acuta, Chiloloba, 284.*

adonidum, Dactylopius, 508."

Adoretus bangalorensis, $285 *$ A. caliginosus bicolor, $286^{*} ;$ A, ovalis, 287.*

.Egocera venulia, 372.*

ægrotalis, Pachyzancla, $4+0$.

renescens, Hispa, 316.*

Eolopus tamulus, 525.*

reruginosum, Acridium, 530."

.Estivation, 55.

affinis, Oides, 313. *

affinis, Pempheres, 156, 339."

africana, Gryllotalpa, $53 t^{*} ;-$ leg of, $80^{\text {* }}$

Agamogenesis, 15.

Agaristidæ, 372.*

Agonoscelis nubila, $+72 . *$

agramma, Plusia, 394.*

Agricultural methods for control of pests, 82.
Agromyza, Cow-pea, 358*; Red-gram, 357."

Agromyzidæ, 356 ; - as crop-pests, 158

Agrotis segetum, 135.

Agrotis ypsilon, 57.

albistriga, Amsacta, 135*, 369.*

albuminosa, Collybia, 64.*

Alcides bubo, $337^{*} ;$ A. collaris, $337^{*}:$ A. leopardus, 338."

alcmene, Chloridolum, 323.*

Aleurodes bergi, 507 ${ }^{*} ; \mathrm{A}$. citri, $508: \mathrm{A}$. ricini, 508.

Aleurodidæ, 507; - pupal stage, 19.

Alimentary System, 14.

alternus, Stauropus, 408."

Altha nivea, 411 .*

americana, Periplaneta, 170 * ; - antenna, $5 *:-, \operatorname{leg}, 8$.

American Blight, 500.*

Amphibia, 235.

Amsacta albistriga, $135^{*}, 369 * ; \quad$ A. lactinca, 368*; A. moorei, 369.

A nacampsis nerteria, 458 ."

anastomosalis, Omphisa, 439.*

Anatomy of Insects, 2 *, $3 .^{*}$

Anatona stillata, 282.*

Ancylolomia chrysographella, +24 *

Andrallus (A udinctia) spinidens, +75 . *

Androconia, 49.

Anemotropism, 56.

angustatus, Calocoris, 490 ."

Anomala varians, 287."*

Anopheline mosquitos, 180 .

Anoplocnemis phasiana, +77 . *

Ant-attracting glands of Acacia sundra, 63.*

Ant-eater, Scaly, 215.

Antenna, 5."

Antestia cruciata, 472 .

Ant Exterminators, 121.*

Antheræa paphia, 208,

Anthrax, 190. 
Anthrenus, 174.*

Antigastra catalaunalis, $4410^{*}$

antiqua, Orgyia, eggs of, 32 .

Ant-lions, 198.

antonii, Helopeltis, 488.*

Ants, 274 *; communication amongst -.

50 ; control of - by Potassium Cyanide,

104 ; - defending plants, 63 ; food of -

$195 ;-$ in houses, $171 ;$ intelligence of - .

51.

Aphaniptera, 365.

Aphanus sordidus, 483.*

Aphididæ, 499; care of - by Ants, 66, 67. Aphis gossypii, 499.*

Aphnæus, directive markings, 39.

Apidæ, 277.

Apion sp., 331.*

Apis dorsata, 209, 277*; A. florea, 210 , $279 *$; A indica, 210, 278.*

Apoderus tranquebaricus, 335."

Apomecyna pertigera, 327.*

Aproærema (Anacampsis) nerteria, 85, $457^{*}$; parasite of -, 201.*

arachidis, Sphenoptera, 298.*

Arbela, use of name, 24.

Arbela tetraonis, 453.*

Arbelidx, 453.

archesia, Remigia, 388.*

Arctiadæ, 367.

Argasidæ, 184.

Argina cribraria, 400 ; A. syringa, 401."

Argyroploce (Cryptophlebia) illepida

(carpophaga), 449.*

Aristolochia imprisoning flies, 62.*

armigera, Chloridea (Hcliothis), 373.

armigera, Hispa, 315.*

Army Worms, 136.

Armillaria eurhiza, 64.*

Arrhinotermes flavus, 9.*

Arsenites, 99.

Arthropoda, 1, 2.

Asilidæ, 198.*

asperulus, Ceuthorrhynchus, 328.*

Aspidiotus camellix (circulata), 517\% :

A. destructor, 518.*

Aspidomorpha miliaris, $316^{\text {* }}$; A. sanctacrucis, larva, $45 . *$

Aspongopus janus, 476. *

Assamia dentata, 492.*

Assembling of males, 49 .

assulta, Chloridea (Hcliothis), 374.*

Asura conferta, 367.*

Atactogaster finitimus, 333.*

ater, Dicrurus, 223.*

Athalia proxima, 281.*

Athene brama, 226.* atomosa, Exelastis, 444.*

Atractomorpha crenulata, 528.*

atriceps, Parus, 225.

atripennis, Aulacophora, 312.*

Attacidce, 405.

Attacus ricini, 207.*

Atteva fabriciella (niviguttclla), 461.*

Attraction of sexes, 49 .

Audinetia spinidens, 475 .

Auditory organs, 47.

augias, Telicota, 419.*

augusta, Depressaria, 459.*

Aulacophora abdominalis, $311^{*}$; A. atripennis, 312*; A. cxcavata, $312^{*} ; A$.

foveicollis, $311^{*}$ : A. stevensi, 312.*

Aularches miliaris, 526*: - , means of defence, 42.

aurantiana, Laspeyresia, 450.*

aurantius, Brachypternus, 226."

aurcus, Canis, 221.

auriflua, Scirpophaga, $425 . *$

australasiz, Periplaneta, 537.*

Autospray Machines, 115.*

Azazia rubricans, 389.*

Azygophleps scalaris, 446 .

\section{B}

Babblers, 224.

babu, Phlcbotomus, 362.*

Bacterial Diseases of insect pests, 123.

Bactrocera cucurbitce, 354.*

Bag-net, 90*, 91.*

Bagrada Picta, 473.*

Bag-worms, 448.

Baits for crop-pests, 93.

Bamboo Beetles, 164, 175.

bambusæe, Oregma, 504.*

bangalorensis, Adoretus, 285.*

banian, Hieroglyphus, 531.*

Bandicoot, 216.

Banding trees, 94.

Baoris mathias, 417. .*

barbatum, Stromatium, 321.*

Barbets, 229.

Barrel Sprayers, 112.*

Batesian Mimicry, 37.

Batocera rubus, $324^{*} ;-$ simple anatomy, 2 *; B. rubra, 324.*

Batrachedra coriacella, $458^{*}$ : B. stego dyphobius, 237.

Bats, 219.

Bears, 220.

Bed-bug, $171,487 *$; - names of, 23 ; negatively phototrophic, 54 .

Bee-eaters, 230. 
Beehive, 211.*

Bees, 209, $278^{*} ;-$ in houses, 171 ; reproduction in,- 15 ; sting of $44^{*}$; warning note of,- 44 .

Beetles attacking stored products, 160 .

bergi, Aleurodes, 507.*

biclavis, Chionaspis, 519.*

bimaculatus, Liogryllus, 537.*

Binomial Nomenclature, 23.

binotalis, Crocidolomia, 437.*

bioculatus, Tetranychus, 544.*

bipartella, Phycita, 428.*

bipunctatus, Nephotettix, 497."

bipunctifer, Schonobius, 426.*

Birds, 222 ; - checking grasshoppers, 139; importance of $-.80,86$.

Bison, 214.

Biston suppressaria, 409.*

Blattella (Phyllodromia) germanica, 538."

Blattida, 537.

Blister-beetles, 185 ; - as checks on grasshoppers, 139: as crop-pests, $154^{*}$; as parasites, $204^{*}$; means of defence of - 42 .

blitealis, Noorda, $4+1 . \%$

Blood of Insects, 14.

Bloodsucker lizard, 230.

Blowfly, egg-laying habits, 55.

Blue-bottle Fly spoiling toddy, 159.

Body-louse, 523."

Boerhavia catching insects, 59: eaten by insects, 60 .

boticus, Polyommatus, 415 .

Bollworms, 23, 133.

Bombardier Beetles, 41.

Bombotelia jocosatrix, 382,*

Bombycida, 407.

Bombylidae, 203.

Bombyx mori, 205. *

Book-beetle, 295.*

Book Solution, 172 .

booduga, Mus, 216.

Bordeaux Mixture, 105.

Borborid Flies on Dung-beetles, 66 .

Boring caterpillars, 132; control of $\rightarrow$, 94.

Bos bubalus, 214; B. gaurus, 214

Boselaphus tragocamelus, 214.

Bostrychida, 293.

Brachypternus aurantius, 226."

brachyrhinus, Lius, 331.

Brachytrypes portentosus (achatinus). 536.*

Braconida, Polyembryony in, 16.

Brain of Insects, 12.

brama, Athene, 226.* brassicx, Pieris, t. 2, ff. 5-8.

Brenthidx, 344.

breviceps, Rana, 235.

Brinjal Sarrothripine, 383.*

Brodia priscotincta, 18.*

Brown Bug of Coffee, 514.*

Bruchidre, 161, 306.

Bruchus theobromæ, 307.*

bubalus, Bos, 214.

bubo, Alcides, 337.*

Bubulcus coromandus, 227.

bucephalus, Heliocopris, 281*; --, antenna, $5 *$; - ball of, 204 .

Bucket Sprayers, 108.

Buffalo, 214.

Buffalo-louse, 185.

Bufo melanostictus, 236.

Bungarus candidus, 232. *

bungarus, Naja, 233."

Buprestidx, 297; - as wood-borers, 153.

Burning Crop-pests, 94.

Butho, 237.

Butterflies, 412.

Cacopus systoma, 235.*

Cadamustus typicus, 485."

cresalis, Glyphodes, 435.*

caffer, Sphenarches, 443.*

cajani, Ceroplastodes, 512.*

Calandra oryza, $160,341 . *$

calcitrans, Stomoxys, 353.*

Calcium Carbide residue, use for, 105.

Calcium Arsenite, 100.

Calf-louse, 185.

caliginosus, Adoretus, 286.*

Calobata sp., 355. *

Calocoris angustatus, 490 .

Calotes versicolor, 230 .

camelliz, Aspidiotus, 517.*

caminodes, Hilarographa, 464.

Camponotus compressus, 277.

candidus, Bungarus, 232.*

Cane-borers, $422 \%, 425 *, 426 *$

Canine Piroplasmosis, 190.

Canis indicus, 221 ; c. aureus, 221.

Canorus, Crateropus, 224.

Cantao ocellatus, maternal solicitude in, 34.*

Cantharid beetles, Hypermetamorphosis in, 32.

Cantharide, 185, 302.

Cantharis rouxi, $302^{*}$; C. ruficollis, $305^{*}$; C. tcnuicollis, 303.* 
Canthecona furcellata, 475.* capensis, Hippobosca, 347.* capensis, Perigea (Apamca), 376.* capitis, Pediculus, 521.*

Cappæa taprobanensis, 470 .*

Capsidæ, 488.

Capua coffearia, 452. *

Caradrina exigua, 378.*

Carbolic Acid Emulsion, 102.

Carbon Bisulphide, 165.

Carboniferous Insects, 19.

Cardamom Scolytid, 344."

Carea subtilis, larva, 41.

carinata, Echis, 233.*

carinatus, Phytoptus, 545."

carinatus, Typhlodromus, 545.*

Carpenter Bees carrying Mites, 67.*

Carpet Beetles, 174."

carpophaga, Cryptophlebia, 449."

Carpophilus dimidiatus, 288 .

Caryoborus gonagra, 308.*

casei, Piophila, 186.

Cassid Beetles, $316^{\text {* }}$; 一, larval defence, 45.*

Castaneum, Tribolium, 161, 300.

Castor Aleurodid, Parasite of, 202.

catalaunalis, Antigastra, 441.*

Catantops sp., 529, *

catena, Tarache, 382.*

Caterpillars, 131.*

Catochrysops cnejus, 414 .*

Catopsilia pyranthe, 413 .*

Cats, 221.

Cattle Egret, 227.

Cattle Fly, 346.*

Causes of damage to crops, 76 .

Cecidomyiadx, $363^{*}$ : - as crop-pests, 158.

Centipedes, 237.

Centropus sinensis, 226 .

Cerambycidx, 318.

Cerataphis, 505.

Cercopidae, 495.

cerealella, Sitotroga, $163,456 . *$

Ceria sp., 37.*

ceriferus, Cerococcus, 212.

ceriferus, Dactylopius, 510.

Cerococcus ceriferus, 212; C. hibisci, 508.*

Ceroplastodes cajani, 512.*

Cerura vinula, 41.

Cetoniadx, 151, 282.

Ceuthorrhynchus asperulus, 328.*

Chalcididx, 202. *

chalcytes, Plusia, 393.

Changing time of planting, 85 .
Checks on increase, 72.

Chemotropism, 54.

cheopis, Xenopsylla, 366. *

Cheroot Beetle, 162, 295.*

Cheese Hopper, 186.

Chigoe, 186.

Chilo simplex, 423.**

Chiloloba acuta, 284.*

chinensis, Bruchus, 306.*

chinensis, Pachymerus, 306.*

Chionaspis biclavis, $519^{*} ;$ C. thea, $520^{\circ}$

Chironomida, use of forelegs, 9.

Chironomus, Pedogenesis in, 15.

Chloridea armigera, $373^{*} ; \mathrm{C}$. assulta, $374^{*}$; C. obsoleta, 373.*

Chloridolum alcmene, 323.*

Chlorita flavescens, 498.*

Chloropidx, 355.

Cholam Borer, 423.*

Cholam Fly, 356.*

Cholam, Fly pest of, 158.*

Cholam mite, 200.

Cholera, 188.

Chrotogonus, $138 *$, 528.

chrysographella, Ancylolomia, 424.*

Chrysomelidæ, 309.

Chrysopa spp., $469^{*}$; larval habits of -. 45.

Chrysopida, 198, 469.

chromataria, Earias (t. 22, f. 7).

Chunam Frog, 235.

Chyle, 14.

Cicadidx, number of moults, 31; means of defence, 43.

cichorii, Meloe, 304.

Cicindelidæ, 199: digging appendages of $-12$.

Cimex lectularius, Hypergamesis in, 16.

Cimex rotundatus, 487.*

cingulatus, Dysdercus, 484 .*

circulata, Diaspis, 517.*

Circulatory System, 13.

Cirphis unipuncta, 376.*

citrella, Phyllocnistis, 465.*

citri, Aleurodes, 508.

citri, Dactylopius (Pseudococcus), 508. *

Clania (Eumeta) crameri, 45, 448 *:

C. variegata, 448 .

Clavigralla gibbosa, $478^{*} ;$ C. horrens, 479.**

Clean cultivation, 82 .

Cleridx, 296.

Climate, effects of, 73.

Clinocoris (Cimex) hemipterus (rotundatus), 487.* 
Clinocoris lectularius, Hypergamesis in, 16.

Clothes-moths, 173, 467.*

Cnaphalocrocis medinalis, $432 . *$

cnejus, Catochrysops, 414 .

Cobra, 232."

Coccida, 508 ; pupal stage of,-- 18.

Coccinella septempunctata, 291.*

Coccinellide, 200, 291.

Coccobacillus acridiorum, 124.

Cockchafers, $150 *, 285$.

Cockroaches, 170, 538* : means of defence, 36 ; palæoznic - 35 ; Spermatozoa of,- 55 .

Coconut Aphis, 506.*

Codling Moth, 134.

Colophora sp., 291.*

coeruleus, Bungarus, 232."

Cólosterna scabrata, $325^{*}$ : C. scabrator, 325 * : C. spinator, 325.*

coffex. Tetranychus, 545.

coffer, Zeuzera, 446.*

coffearia, Homona (Capua), 452.*

Coffee Borers, 153, $323 *$ : bug pests of -. 147i - Scale, 513. *

colaca, Parnara, 418.*

Cold Storage for control of pests, 168.

Colemania sphenarioides, 527 * : Bombylid parasite of,- 203.

Coleoptera as pests of stored products, 160 . collaris, Alcides, 337.*

Collybia albuminosa, 64.*

Commensalism, definition of, 65 .

compressus, Camponotus, 277.*

conducta, Euplexia, 376 *

conferta, Asura, 367.*

conica, Eumenes, $197^{*}$ : pupa of - 32.*

Conjunctivitis, 189.

Conorbinus rubrofasciatus, 486 . *

Contact Poisons, 96, 101.

Contarinia attacking cotton-buds, 158 , 363.*

convolvuli, Herse, 6$\} *$, 401.*

convulsionarius, Termes, means of defence, 44: communication amongst, 50.

Cooly itch, 186.

Copper Aceto-Arsenite, 99.

Copper Sulphate for cane setts, 105.

Copra itch, 186.

Coptocycla, 317."

Coptosoma cribraria, 469.*

Coptotermes heimi, 539.*

Coracias indica, 223.

Coreidx, 477. *

coriacella (gossypiella), Pyroderces, 458.* coromandus, Bubulcus, 227.

Corvus macrorhynchus, 228 : C. splen dens, 228.*

Cosmophila erosa, $391^{*}$ : C. sabulifera 390.*

Cosmopolites sordidus, 342 .*

Cosmopterygidx, 458 .

Cosmoscarta relata, $495 . *$

Cossyphus depressus, 300 .

Cotton, bug pests of, $146,484,148$.

Cotton-hugs, collection of, 89 .

Cotton, destruction of old crop, 83.

Cotton Seed. Pests of, 134.

Cotton Stem Weevil, 156, 339.*

Coucal, 226.

Cow-pea Agromyza, 358.*

Coxa, 8.*

Crab-louse, 523.*

Crabs, 237.

crameri, Clania, $45,4+8$.

crassicaudata, Manis, 215.

crassicornis, Gallobelicus, 490.*

Crateropus canorus, 224 : C. griseus, 224.

Creatonotus gangis, $369^{*}:$ C. interruptus, 369.*

Cremastogaster in Acacia thorns, 63.

crenulata, Atractomorpha, 528.*

cretacea, Eublemma, 381.*

cribraria, Argina, 400.*

cribraria, Coptosoma, 469.*

Crickets, $534 ;-$ in houses, 172 ; - as crop-pests, 139.

Cricula trifenestrata, 405.*

cristatus, Sus, 214.

critica, Eucelis, 450.*

Crocidolomia binotalis, 437 .*

Crops, area and value, 75 ; rotation of-.

84; trap, 84 ; mixed, 84.

Crow-pheasant, 226.

Crows, 227.*

cruciata, Antestia, 472.*

Crude Oil Emulsion, 101.

cruciferarum, Plutella, 464."

Cryptophlebia carpopltaga, 449.*

Cryptorhynchus mangiferæ, 341 * $^{*}$

Cryptothripa occulta, 383.

Cryptozoic animals, 54.

Ctenocephalus felis, $367 . *$

Ctenolepisma, 543.*

Cucujidæ, 290.

cucurbita, Dacus, 354.*

Culex fatigans, 361.*

Culicidx, 361."

Culicine mosquitos, 180 .*

cupreoviridis, Earias (t. 22, f. 7).

Curculionidæ, 327. 
Curtilla africana, 535.*

Cutworms, 135.

cyanea, Scutellista, 24.*

cyanipennis, Hispa, 316.*

cyanophlyctis, Rana, 235.

Cyclopelta siccifolia, 476.*

Cyclops, 188.

Cylas formicarius, 156, 334.*

Cynopterus sphinx, $219 ;$ C. marginatus, 219.

Cyrtacanthacris ranacea, $530^{*}$; antenna, $5^{*} ;-\operatorname{leg}, 8$; C. succincta, $530 .^{*}$

\section{D}

Dactylopius citri, 508** D. nipæ, 509*: D. virgatus (ceriferus), 510.*

Dacus cucurbitæ, 354.*

Damage by insects, notation, 74 : annual amount, 76 .

Dasychira mendosa, $396^{*}$ : D. securis, 397.*

Deadhearts, 95.

Dead organic matter, Insects and, 204.

Dead trees, necessity for destruction, 95.

Death-feint in weevils, 37.

Deaths from insect-borne diseases, 76 .

Death's-Head Moth, larval stridulation, 48.

Deccan Grasshopper, 527.*

Deer, 214.

Definition, meaning of, 25.

Deilephila nerii, 403.*

Delhi Boil, 189.

Demodex folliculorum, 186.

demoleus, Papilio, 412.*

Dendrocitta rufa, 225.

Dengue, 187.

dentata, Assamia, 492.*

Depressaria zizybhi (augusta), 459.*

depressus, Cossyphus, 300.*

depunctalis, Nymphula, 45, 430.*

Dermatophilus penetrans, 186 .

Dermestes sp., 293 *; D. vulpinus, 292.*

Dermestes surinamensis, 290.*

Dermestidæ, 292.

derogata, Sylepta, 434.*

Descent of Insects, 19.*

destructor, Aspidiotus, 518.*

Devonian Insects, 18.

Diaspis circulata, 517.*

Diatræa sp., 422*; D. venosata (striatalis), 422 .

Diatræa, Parasite of, 200.*

Dichocrocis punctiferalis, 433.*
Dichomeris (Ypsolophus) ianthes (ochrophanes), 456.*

Dicrurus ater, 223.*

Dictyophara pallida, 494.*

dimidiatus, Carpophilus, 288.*

Diopsidæ, eyes of, 7 .

Directive markings, 39.

Dischidia, 63.

Diseases carried by insects, 187.

Disphinctus politus (formosus), 489.*

dodecastigma, Epilachna, 292.*

Dog Fly, 347.*

Dolycoris indicus, 470 **

dominica, Rhizopertha, 294.*

dorsalis, Epacromia, 525.*

dorsata, Apis, 277.*

Dorylus orientalis, 274.*

Dorysthenes rostratus, $318 *$; - antenna, 5.*

Dragonflies, $195^{*}$; eyes of,- 7 .

Draining to control pests, 87.

Drill-sown crops, advantages of, 88 .

Drongo, 223.*

Drosera, 1, 59.

Drugs, Insects used as, 212.

Dryophis mycterizans, 36.

Dung Beetles, 204, 282.

Dusky cotton-bug, 482,*

dux, Lucilia, 348.*

Dynastidæ, 285.

Dysdercus cingulatus, 484.*

Dysenteries, 188.

\section{$\mathbf{E}$}

Earias cupreoviridis (chromataria), t. 32 f. 7 ; E. fabia, $133,385^{*}$; E. insulana, $133,384 . *$

Earwigs, $539^{*}$; forceps of,- 12 ; maternal solicitude in -, 33 .

Ecdysis, 31.

Echidnophaga gallinaceus, 365. *

echinus, Urentius, 485.*

Echis carinata, 233.*

Eciton hamata, 50.

Ectobia germanica, 538.*

Ectoparasites, 68.

Eelworms, 238.*

Egg Stage, 28.

Egrets, 227.

Elephantiasis, 188.

Elephants, 214.

Eligma narcissus, 383.*

elongata, Mecopoda, leg, 8* *

elongella, Stenachroia, 421.*

Empoasca flavescens, 497 .* 
Endoparasites, 68.

Enteric Fever, 188.

Epacromia tamulus (dorsalis), 525.*

Ephemerids, respiratory system, 13.

Ephestia, 163.*

Epicauta, 306.*

Epidemic Dropsy, 188.

Epilachna dodecastigma, $155,292^{*}$; E. $28^{-}$ punctata, 155, 292.*

Epimys norvegicus, 216; E. rufescens, 216.

Episomus lacerta, $327^{*}$ : E. montanus, antenna, 5.*

equitans, Limosina, 66.

Eretmocera impactella, 461. *

Eretmocerus sp., 202.*

Eriochiton cajani, 512."

Eri Silkworm, 207.*

Eristalis, larva of, 13.

erosa, Cosmophila, 391.*

Erotylidæ, 290.*

Estigmene lactinea, 368.*

Etiella zinckenella, 429.*

Eublemma, larval habits, 45.

Eublemma olivacea, $380^{*}$; E. scitula (cretacea), $199 \%, 381$ *

Eucelis critica, 450.*

Eucosmidæ, $4+9$.

Eugnamptus marginatus, 329.*

Eumenes conica, $197^{*}$; pupa of - , 32.*

Eumenes flavopicta, 37.*

Euproctis fraterna, $398^{*}$ : E. scintillans, 399.*

Eupterote mollifera, 40t.*

Eupterotida, 40 .

Euplexia conducta, 376."

-Eurybrachys tomentosa, 492."

eurhiza, Armillaria, 64.*

Eusarcocoris guttiger, 471 * : Eentralis, 471.*

Eutelia jocosatrix, 382."

Eutermes, means of defence, 42.

Euxoa segetis, $57,375 .{ }^{*}$

Euzophera perticella, 428 .

excavata, Aulacophora, 312."

Exelastis atomosa, 444.*

exigua, Laphygma Caradrina), 378."

Extension Rods, 118.

Eye-fly, 355*; - in houses, 175.

Eyes of insects, 6.*

\section{F.}

fabia, Earias, 385.*

fabriciella, Atteva, 461.*

Facets of Eye, number of, 7.

farinosa, Paramecops, 332.*

fascialis, Hymenia (Zinckenia), 431." fasciata, Stegomyia, 175.*

tasciculana, Homona, 452.*

fastuosa, Psiloptera, 297.*

Fat Bodies, 14.

fatigans, Culex, 361.

Fatua longicornis, 290.*

felis, Ctenocephalus, $367 .^{*}$

Femur, 8.*

ferrugineum, Tribolium, 161, 30C."

ferrugineus, Rhynchophorus, 153 * 343 *

Fertilisation of flowers, 60 .

ficus, Hypsa, 400*

Field-mouse, Southern, 216."

Field-rat, Soft-furred, 216.

Filaria-carrying mosquitos, 181.

Filariasis, 188.

Filiform Antennæ, 5.*

finitimus, Atactogaster, 333.*

Fireflies, 45.

Fires to control crop-pests, 94.

Fish, 236.

Fish-Insect, 172, 543. *

Fishoil Soap, 104.

flavescens, Empoasca, 497.

flaviceps, Pycnosoma, 348.

flavopicta, Eumenes, 37.*

flavus, Arrhinotermes, nymph, 9.*

Fleas, 365.

florea, Apis, 279."

Flour Paste, 104.

Flowers and insects, 60.

Flush-worm, 453.*

Flying Foxes, 219.

Fodder, use of attacked crop as, 87.

folus, Udaspes, 420 .*

Forests, effects of destruction of, 77 .

Forficulidae, 539.

Formic Acid discharged by ants, 41.

formicarius, Cylas, 156, 334.*

Formicidæ, 274.

formosus, Disphinctus, 489.*

fornicatus, Xyleborus, 345.*

Fossil Insects, 18.

fovcicollis, Aulacophora, 311.

Fowls as insect-hunters, 86.

Framboesia tropica, 188.

francilloni, Hippobosca, 347.*

fraterna, Euproctis, 398.*

Frogs, 235.

frugalis, Remigia, 388.

Fruit-bat, Southern Short-nosed, 219.

Fruit-boring Caterpillars, 134.

Fruit Flies, 157, 354 ; - attracted by oils, $55,57$.

Fulgoridæ, 492, 
Fumigation by Carbon Bisulphide, 165 ; - by Hydrocyanic Acid Gas, 166 ; of plants, 119.

Funambulus palmarum, 215.

Fungal Diseases, control of pests by, 123.

Fungi grown by Termites, 63 . funicola, Siphonella, 355.* furcellata, Canthecona, 475.* furcifer, Hieroglyphus, 531.* Furniture Beetles, 164, 175.

\section{G}

Galeodes indicus, 237.

Galleria mellonella, +21 .*

Gall-flies, 363.

gallinaceus, Echidnophaga, 365.*

Gallobelicus crassicornis, 490.*

Gangara thyrsis, 417.*

gangeticus, Scarabæus, 66.

gangis, Creatonotus, 369.*

Garden Crops, bug pests of, 147.

Gaur, 214.

gaurus, Bos, 214.

Gelechida, 454.

Gelechia gossypiella, 454.*

geminata, Solenopsis, 274.*

Geometridæe, 131, 409.

Geotropism, 55.

Gerbille, 215.*

Gerbille-louse 185.

germanica, Blattella (Pliyllodromia), 538.*

Gerrida, rheotropic habits, 56.

gibbosa, Clavigralla, 478.*

giganteus, Pteropus, 219.

Gingelly Gall-fly, 158, 364.*

glaucinans, Homoptera, 389.*

globosa, Xystrocera, 321.*

globulifera, Monanthia, 485.*

gloriosa, Polytela, 375.*

Glow-worms, 45.

Glyphipterygidx, 463.

Glyphodes cresalis, $435^{*}$ : C. indica, 435.*

Gnathospastoides rouxi, 302, *

Gnorimoschema heliopa, 454. *ै?

Goat-louse, 185.

gonagra, Caryoborus, 308.*

Gongylus gongylodes, habits, 195; - . antenna, $5 *$, - , leg, 8.*

Gonocephalum hofmannseggi, 299.*

gossypii, Aphis, 499.*

gossypiella, Gelechia, 454.*

gossybiella, Stagmatophora, 458.* govinda, Milvus, 227.

gracillimum, Monomorium, 275.*

graellsi, Acontia, 385.*

Grain, storage of, 161, 164 .

Grammodes stolida, 387,*

Graptostethus servus, 482.*

Grasshoppers, 525 ; --, ploughing up eggmasses of, 85 .

Green-fly, 499.*

gossypii, Sphenoptera, 298* *

Green-gram Weevil, 336.*

Greenia, mites of genus, $67 . *$

Green Scale of Coffee, $513 *$, introduction of,- 78 : attacked by fungi, 123.

gremius, Suastus, 418 ."

grisator, Sthenias, 153, 326.*

griseus, Crateropus, 224.

Gryllidae, 534 .

Gryllotalpa africana, $534 *$; - leg, $8^{*}$; maternal solicitude in,$- 3+$.

Guinea-worm, 188.

Gunomys kok, 216.

guttiger, Eusarcocoris, 471. *

Gyrinida, eyes of, 7 .

H

Hæmatopinus spinulosus, stenopsis, stephensi, suis, tuberculatus, vituli, 185.

Hæmatopinus tuberculatus, 524.*

Hairy Caterpillars, 42.

Haliastur indus, 227.

Hamadryad, 233."

hamata, Eciton, 50.

Hand-net, 89 *, 90.*

Hand-picking of pests, 88 .

Haplochilus lineatus, 236.*

Hares, 219.

Harpactor sp., poison-gland of, $44^{*} *$

Hawk-moths, 401 .

Head, Appendages of, 4.*

Head-louse, 521."

hecabe, Terias, 414.

heimi, Coptotermes, 539.

Heliocopris bucephalus, $281 *$ : . antenna, 5 * ; ball of,- 204 .

heliopa, Gnorimoschema, 454.*

Heliothis armigera, $373^{*} ; \boldsymbol{H}$. assulta, $374 * ; H$. obsoleta, 373.*

Heliotropism, 54.

Hellula undalis, 437 , *

Helopeltis antonii, 488.*

Hemichionaspis thex, 520.* 
Hemilecanium imbricans (theobrome), 516.*

hemipterus, Clinocoris (Cinc $x$ ), 24. 487.*

hemisphæricum, Lecanium, 514.*

Hepialida, 467 .

Hermaphroditism, 15.

Herse convolvuli, $61 \%, 401$.*

Hesperiadz, 417.

Heterusia, means of defence, 42 .

Heterusia virescens, $4+8$. *

hexadactyla, Orneodes, pupa, 30.*

Hexapoda, 2.

Hibernation, 55 .

bibisci, Cerococcus, 508.*

hieroglyphica, Nyctipao, clicking sound of, 48.*

Hieroglyphus banian (furcifcr), 531 * H. nigro-repletus, 531 . $*$

Hippobosca capensis, $347 *$ :H. francilloni, $3+7^{*}$, H. maculata, $3+6^{*}: H$. sir'c, $3+6 . *$

Hippoboscida, $3+6$.

hirudinicornis, Phycoles, 463.*

Hispa cenescens, 316 *; H. armigera, 315 * : H. cyanipennis, 316.*

Hispella ramosa, 314 .*

Hispina, 155.

histeroides, Tetroda, 477.*

histrio, Menida, 474. *

hofmannseggi, Gonocephalum, 299.*

Holder Pressure Sprayers, 115.*

Homona (Capua) coffearia, 452.*

Homoptera glaucinans, 389.*

Honey dew, 66.

Hoopoe, 223.

Hopper-dozers, 92.

horrens, Clavigralla, 479 .

Hose for Sprayers, 118.

Housefly, 169, 183: - larval moults, 31.

House-mouse, Indian, 216.

House-sparrow, 230.

Hover-flies, 358.*

humanus, Pediculus, 522.*

Hilarographa caminodes, 464.

Hyblea puera, 392.*

hybleella, Tegna, 463.*

Hydnophytum, 63.

Hydrocyanic Acid gas, 120, 166

Hydrotropism, 56.

Hymenia (Zinckcuia) fascialis (recurvalis), 431.*

Hypergamesis, 16.

Hypermetamorphosis, 32.

Hyperparasites, 68.
Hypsa ficus, 400 .

Hypsida, 400.

Hypsolophus ianthes, 456 .*

Hyponomeutida, 461.

hyrtaca, Metanastria, +09.*

hystrix, Platypria, 316.*

\section{I}

ianthes, Dichomeris (Ypsolophus), 456 * Ichneumonidx; 202 ; - ovipositor of, 12.

Idiocerus niveosparsus, +95.*

illepida (carpophagia) Argyroploce

(Cryptophlebia), +49.*

imbricans, Hemilecanium, 516.*

impactella, Eretmocera, 461. *

impolita, Rhytinota, 301.*

Imported Pests, 78.

importunitas, Ragmus, 491."

1ncrease, rate of, in insects, 71 .

indica, Apis, 278.

indica, Coracias, 223.

indica, Glyphodes, +35. *

indica, Mylabris, 154.*

indicus, Ecanthus, 535.

indica, Tatera, 215.*

indica, Upupa, 223.

indicata, Nacoleia, 433.*

indicum, Tapinoma, in Acacia thorns, 63. indicus, Canis, 221.

indicus, Dolycoris, 470.*

indicus, Galeodes, 237.

indus, Haliastur, 227.

indus, Orychodes, $344^{*}$

inferens, Sesamia (Nonagria), 379.*

inficita, Saluria (Ponjalia), +27 *

infusella, Phycita, 428 .*

inguinalis, Phthirius, 523.*

Insecticides, Application of, 97.

Insecticidal methods for control of pests. 95.

Insectivorous animals, education of, 38.

Insectivorous plants, 59.

insignis, Philæmatomyia, 352.*

insulana, Earias, 384.*

Instar, 31 .

intacta, Scirpobhaga, +25.*

interruptus, Creatonotus, 369.*

Iodine, Smell of, discharged by beetles. +1 .

1pidæ, 34t; - Cultivating plants, 63.

iridipennis, Xylocopa, eye, $6 .^{*}$

Irrigation to control pests, 87.

Isitis, Psylla, 498.* 
ismene, Melanitis, 412.*

isocrates, Virachola, $416^{*} ;$ - directive markings 39.*

Itch, 185.

Ixodidw, 184.

1xodoidea. 184.

\section{J}

Jackal, 220.

Jalamandalam, 237.

janus, Aspongopus, 476.*

Japygidz, forceps of, 12.

jarbas, Rapala, antenna, 5.*

Jassidze, 495.

Jay, Blue, 223.

"Jerry Munglum," 237.

Jigger, 186.

jocosatrix, Bombotelia (Eutelia), 382.*

Jute Apion, 331.*

\section{K}

Kala Azar, 187.

Kerosine Emulsion, 102.

Key to important Orders, 21.

King Cobra, 233.*

King-crow, 223. *

Kites, 227.

Knapsack Sprayers, 110.*

kœnigana (aurantiana), Laspeyresia, 450 .*

kok, Gunomys, 216.

Krait, 232.*

kuehniella, Ephestia, 163.*

Kumblihula, 42, 135,* $369 *$; - control $82,85,88$.

Kumblipuchi, 42, 135 * : - control of, $82,85,88$

kundoo, Oriolus, 224.

\section{$\mathbf{L}$}

\section{Labidura lividipes, 539.*}

Lac, 212.

lacerta, Episomus, 327.*

Lace-wing Flies, 198.

lachesis, Acherontia, robbing bee-hives, 130.

Lachnus pyri, 503.*

lactinea, Estigmene, 368.*

Lady-bird Beetles, 200, 391 ; - , geotropic habits, 56 .

latus, Oxycarenus, 482.*

lanigera, Schizoneura, 500.*

Laphygma exigua, 378.*

Larval stage, 29.
Larva, Structure of, 30.

Lasiocampida, 409 ; - larval defence, 43.

Lasioderma serricorne, 162, 295* : L. testaceum, 295.*

lasiurus, Platacanthomys, 215.

Laspeyresia konigana (aurantiana), $450^{*} ;$ L. torodelta, 451 * : L. tricentra, 451.*

latanim, Aspidiotus, 518.*

Latin names, 23.

Lead Arsenate, 98.

Lead Arsenite, 99.

Lead Chromate, 98.

Leaf-mining caterpillars, 136.

Lecanium hemispharicum, $514^{*} ; \boldsymbol{L}$. imbricans, $516^{*}$; L. marsupiale, $516 *$; L. nigrum, $514 *$; L. olea, $515 *$; L. viride, 513.*

Lecanium viride, $147,513^{*}$; introduction of - 178 ; - attacked by fungi, 123.*

Legislation for control of pests, 125.

Legs, 8.*

leopardus, Alcides, 338.*

lepida, 1'arasa, 410.

Lepidoptera attacking stored products, 160.

Lepidopterous mouth-parts, 4 .

Lepismidee, 543.

Leprosy, 188.

Leptispa pygmaa, 313.*

Leptocorisa varicornis, $82,146 * 479 . *$

Leucania inferens, 379.*

Leucinodes orbonalis, $436 . *$

lewisii, Perga, maternal solicitude in, 34.

Lice, 522 ; - of domestic animals, 185.

Lichens, composition of, 65 .

lienigianus, Pterophorus, 445.*

Life, length of, 32 .

Light, attraction of, for insects, 57.

Light-traps, 57, 92.

Limacodida, 410 ; stinging larvæ of 43.

Lime as a repellent, 105

Lime-Sulphur, 101, 103.

Limosina equitans, 66.

lineatus, Haplochilus, 236.*

Linseed Oil Emulsion, 102.

Liogryllus bimaculatus, 537.*

littoralis, Prodenia, 377.*

litura, Prodenia 377.*

lividipes, Nala (Labidura), 539.*

Lixus brachyrhinus, 331.*

Lizards, 230 
lobata, Stenodictya, 9.*

Local pests defined, 128.

locusts, 137 ; - as food, 212.

London Purple, 100.

Longicorn Beetles, 315.

longicornis, Fatua, 290.*

Loopers, 132

Lucilia, 186.

Lucilia dux, $348^{*}$; L. flaviceps, 348 *

Luminosity in insects, 45 .

Lycænidæ, 414

Lycanid Caterpillars, glands of, 66, 67.

Lygicida. Lygæus pandurus (militaris). 481 .

Lymantriadæ, 395

Lyroderma lyra, 220.

Lytta tenuicollis, 303.*

\section{$\mathbf{M}$}

Macalla moncusalis, 429.*

macharalis, Pyrausta, 442.*

macrocephalus, Cimex (Acanthia), 24. 487.*

Macrones vittatus, 236.

maculata, Hippobosca, 346.*

maculatus, Rhacophorus, 235.

maculipennis, Plutella, 464.*

maderaspatensis, Motacilla, 225.

madurensis, Nisotra, 310.*

Major pests defined, 128 .

malabarica, Bandicota, 216.

malabaricus, Phassus, 467.*

Malabar Spiny Mouse, 215.

Malaria, 177, 183; - carrying mosquitos,

181 ; - parasite, life-cycles of, 182.

Malpighian Tubules, 14.

manei, Mus, 216.

mangifera, Cryptorbynchus, 341.*

Mango:-Hoppers, 94, 495* - leafboring weevil, $334 *$; - weevil, 156 . 341.*

Manis crassicaudata, 215.

Mantidæ, 195: predaceous leg of,$- 8 . *$

Marasmarcha atomosa, 444.*

Marasmia trapezalis, 432. *

marginatus, Eugnamptus, 329.*

marginatus, Cynopterus, 219.

marsupiale, Lecanium, 516.*

Maruca testulalis, 440 .

Mass infection, 184.

Maternal solicitude, 33 .

mathias, Parnara, 417.*

mauritánicus, Tenebroides, 289.*

mauritia, Spodoptera, 378.*

Mayflies, respiratory system, 13.
Measures and Weights, 126.

Mechanical methods for control of croppests, 88 .

Mecopoda elongata, leg, $8 *$; avipositor, 12.

medinalis, Cnaphalocrocis, 432.*

Melanitis ismene, 412.*

melanocephalus, Oriolus, 224.

melanostictus, Bufo, 236.

melicerta, Achæa (Ophiusa) , 386.*

mellonella, Galleria, 421.*

Meloida, 185, 302.

meltada, Millardia, 216.

Melursus ursinus, 220.

Membracidæe, maternal solicitude in, 34. mendosa, Olene (Dasychira) , 396.*

Menida histrio, 474 .*

Merops viridis, 230.

Mesotermitidæ, 539.

Metanastria hyrtaca, 409.*

Metazoa, 1

meticulosalis, Terastia, 133,438 .*

Metriona sp., 318.*

Miastor, definition of, 183.

Miastor, Pedogenesis in, 15.

Mice, 215, 218.

Micromalthidæ, Pedogenesis in, 15.

Micropezidx, 355 ;-, use of forelegs, 9.

microscopica, Orneodes, wing, 11.*

Microtermes sp., $5+1 . *$

Microvelia, stridulation of, 48 .

Migration-flights, 56 .

miliaris, Aularches, 526.*

miliaris, Aspidomorpha, 316.*

Militaris, Lygaus, 481 .*

Millardia meltada, 216.

Millipedes, 237.

Milvus govinda, 227.

Mimicry, 37.

Minor pests defined, 128.

minutus, Phlebotomus, 362.*

Mites, 544.

Mixed crops, 84 .

modesta, Phidodonta, 315.*

mosta, Phenice, 492.*

Mole-cricket, $534^{*}$ : maternal solicitude in,- 34 .

Mole-rat, Southern, 216.

mollifera, Eupterote, 404.*

Monanthia globulifera, 485.*

moncusalis, Macalla, 429.*

Mongoose, 221.

Moniliform Antennæ, 5.*

Monkey-louse, 185.

Monkeys, 222.

Monolepta signata, 310.* 
Monomorium gracillimum, 275, * monostigma, Scirpophaga, 426.* monstrosus, Schizodactylus, $533 * ;-\ldots$, leg of, $8 . *$

montanus, Episomus, antenna, 5.* moorei, Amsacta, 369.

mordax, Priotyrannus, 319.*

mori, Bombyx, 205.*

Mosquitos, $361^{*}$; - and Malaria, 177-183: in houses, $175^{*}$; irritation of - bites, 184: - use of hind-legs, 9.

Motacilla maderaspatensis, 225.

Moult, 31 .

Mouth-parts, 4.*

Mulberry Silkworm, 205."

Mullerian mimicry, 37.

multilinealis, Sylepta, 434.*

Mungos mungo, 221 .

Mus booduga, 216; M. manei, 216.

Mus decumanus, 216; M. ruttus, 216.

Musca bezzii, 351: M1. convexifrons, 351 : M. domestica, 349*; M. gibsoni, 351 ; M. nebulo, $349^{*}$; M. pattoni, 350* Muscidæ, 348.

mycterizans, Dryophis, 36.

Myiases, 185, 186.

Mylabridte, 302.

Mylabris indica, 154.*

Mylabris pustulutar, $303^{*} ;$ M. sidae, 303.*

Mynahs, 224.*

Myrmecodia, 63.

Myrmecophilous insects, 66.

Myrmeleonidx, 198.

Mytilaspis piperis, 519."

\section{N}

Nacoleia indicata (vulgalis), 433.*

Naja bungarus, 233 *: N. naja, 232 *;

N. tripudians, 232.*

Nala (Labidura) lividipes, 539.*

Names, validity of, 25 .

Naphthaline Emulsion, 100.

narcissus, Eligma, 383.*

Nauseous taste of insects, 40.

Necrobia rufipes, $296{ }^{*}$

neglecta, Sphenoptera; 298.

Nemoptera, wings of, 11.

Neocerambyx paris, 322.* -.

Nepenthes, 59,60 .

Nephantis serinopa, $460 . * \cdots \ldots . . . .$.

nephelotis, Plotheia, 25. . . $\quad \ldots . .$.

Nephotettix bipunctatus, $497 *$. .......

nerii, Deilephila, $403 .{ }^{*} \cdots . . . . . . \%$ nerteria, Aproærema (Anacampsis), 85 , $457^{*}$; parasite of,$- 201 *^{*}$

Nervous system, 12.

Nesokia bandicota, 216.

Neuration, system of, 10.*

Newly-introduced crops, 79.

Nezara viridula, 473 *

niger, Paradoxurus, 221.

Night-jars, 226.

nigro-repletus, Hieroglyphus, 531.

nigrum, Lecanium, 514.*

Nilgai, 214.

Nilgiri cockchafers, 150 .* $^{*}$

nipæ, Dactylopius (Pseudococcus), 509.*

Nisotra madurensis, 310.*

nitidula. Tarache, $381 .^{*}$

Nitidulidx, 288.

nivea, Altha, $411 . *$

niveosparsus, 1diocerus, 495.*

niviguttella, Corinca, 461.*

Noctuida, 373.

Nomenclature, Rules of, 23.

Nanagria inferens, $379^{*} ;$ N. uniformis 379.*

Noorda blitealis, $441 . *$

norvegicus, Epimys, 216.

Notodontidæ, 408.

Nozzles of Sprayers, 118.

nubila, Agonoscelis, 472.*

Number of Insects, 22.

Nyctipao hieroglyphica, clicking sound of, $48 . *$

Nymph, 29.

Nymphalidæ 412: Рupæ of -, 31.

Nymphosis in Termites, 18 .

Nymphula depunctalis, 45,430 * , larval respiratory system of,- 13 .

\section{0}

obesus, Odontotermes, 142.*

obsoleta, Chloridea (Heliothis), 373.*

occulta, Cryptothripa, 383.

ocellatus, Cantao, maternal solicitude in $34 . *$

Ocelli, 7.*

Ocinara varians, 407.*

ochrophanes, Ypsolophus, 456.*

Odonata, 195.*

Odontotermes obesus, 142 .* $^{*}$

Odontotermes sp., $541^{*}$; - fungus on comb of,- 64 .

बicanthus indicus; 535

Gecophoridx, 459; .

Cecophylla smaragidina, $41,276 . *$

Estridæ, 347 
Estrus ovis, 186, 347, *

Oides aftinis, 313.*

olea, Lecanium, 515.*

olea, Trisopsis, eye, $6 . *$

Olene (Dasychira mendosa, 396.*

olivacea, Eublemma, 380.*

Omphisa anastomosalis, 439.*

opalinoides, Tarache, 382.*

Opatrum, 299.*

operculella, Phthorimaa, 163, $455 *$ : ...

introduction and damage, 79 .

Ophideres, 130.

Ophiusit melicerte, 386.*

Orange Leaf-miner, 465.*

orbonalis, Leucinodes, $436 . *$

Orders of Insects, 20.

Orectochilus semivestitus, eye, 6.*

Oregma bambusæ, 504.*

Orgyia antiqua, eggs of, 32 .

Orgyia postica, $395^{*}$; antenna of - . 5.*

orichalcea, Plusia, 393.*

Oriental Sore, 189.

orientalis, Dorylus, 274 .*

orientalis, Zonabris, 304 .

Orioles, 224.

Ornaments, Insects used as, 213.

Orneodes hexadactyla, pupa, 30 .*

Orneodidx, wings of, 11."

Orthacris sp., 527.*

Orthopterous mouth-parts, t.*

Orychodes indus, $344 . *$

Oryctes rhinoceros, 151*, 152*, $285 *$ : control of - 95.

oryzz, Calandra, 160, 341.*

Osmaterium, 41.

ovalis, Adoretus, 287.*

Ovipositor, 12,15 .

ovis, (Estrus, 186, 347.*

Ovum, 28.

Owls, 226 *

Oxya velox, 533."

Oxybelus squamosus, 280.*

Oxycarenus latus, 482.*

Oxycetonia versicolor, 283.*

1'achymerus chinensis, 306.* pachyspila, Tinea, 466 *

Pachyzancla agrotalis, 440 .

Paddy Stem-borer, 426.

Paints, metallic, as insecticides, 100.

Palæornis torquatus, 229.*

Palamnzus, 237.

pallida, Dictyophara, 494.*

palmarum, Funambulus, 215.

Palm Beetle, $153^{*} ;$ control of,- 95.
Yalm-civet, Indian, 221.

Palm Weevil, $3+3 *$; control of,- 95.

pandurus, Lygæus, 481.*

Pangolin, 215.

Pangonia sp., 360.*

panicea, Sitodrepa, 162, 295.*

Pantala flavescens, eye, 6.*

Papers, preservation of, 172.

paphia, Antherae, 208.*

Papilionidæ, 412 : pupæ of -.31 .

Papilio demoleus, 412.*

Pappataci Fever, 187.

Paradoxurus niger, 221.

Paramecops farinosa, 332.*

Parasa lepida, 410.*

Parasites, 200 ; definition of,$- 68 ;-$ of crop-pests, 124.

Parasitism, mode of occurrence, 69.*

Paratyphoid Fever, 188.

Paris Green, 99.

paris, Neocerambyx, 322.*

Parnara colaca, 418 * : P. mathias, 417 .*

Parroquets, 229.*

Parthenogenesis, 15.

Parus atriceps, 225.

Passalid beetles, parental solicitude in, 33: stridulation in - 49.

Pectinate Antennæ, 6.*

pedator, Xanthopimpla, 201.*

pedestris, Riptortus, 480 .*

Pedogenesis, 15.

Pedicinus eurygaster, 185.

Pediculidæ, 521

Pediculoides ventricosus, 186.

Pediculus capitis, 521* ; P. humanus (vestimenti), 522 *, P. pubis, 523 * P. tuberculatus, 524.*

Pempheres affinis, 156, 339 .

penetrans, Dermatophilus, 186.

Pentatomida, 469: maternal solicitude in -., 34 .

peponis, Plusia, 394.*

Perga lewisii, maternal solicitude in, 34.

Pericallia ricini, 370.*

Perigea capensis, 376. $*$

Periplaneta americana, $170 * ;--$, antenna, $5 *,-, \operatorname{leg}, 8^{*} ; \quad P$. australasiz 537.*

Perisphæria, means of defence, 36. perpusilla, Pyrilla (Zamila), 493.* perticella, Euzophera, 428. * pertigera, Apomecyna, 327.*

Pest, definition of, 74 .

Phanerozoic animals, 54.

Phasgonuridx, 533 ; auditory organs of -.9 . 
phasiana, Anoplocnemis, 477.*

Phassus malabaricus, 467. *

Phenice moesta (dentata), 492 *

Phidodonta modesta, 315.*

Philæmatomyia insignis, 352.*

Phlebotomus minutus, $362^{*} ; P / h l$. babu, 362.*

Phoresie, 66.

Phototaxis. 53.

Phototropism, 53.

Phthirius pubis, 523.*

Phthorimæa operculella (solanclla), 163 $455^{*}$; introduction and damage 79.

Phycita infusella (bipartella), $428 . *$

Phycodes radiata, 463."

Phylaitis sp., 339."

Phyllocnistida, 465.

Phyllocnistis citrella, $465 *$; P. minutella, 466.

Phyllodromia germanica, 538.*

Phylogeny of Hexapods, 19.*

Phymateus punctatus, 526.*

Physorhynchus, 237.

Phytoptus carinatus, 545 *.

picta, Bagrada, 473.*

Pictures, preservation of, 172.

pictus, Pcecilocerus, 526. *

Pieridæ, 413 ; pupæe of,- 31.

Pieris brassicæ, t. 2, ff. 5-8.

J'iezodorus rubrofas ciatus, 474 .*

Pig, 214.

Pig-louse, 185.

Piophila casei, 186.

piperis, Mytilaspis, 519.*

Pitcher-plant, 59.

Plague, 187.

Plague-flea, 366.*

Platacanthomys lasiurus, 215

Platypria hystrix, 316.*

Platyptilia pusillidactyla, 444 .*

Plotheia nephelotis, 25.

Ploughing for control of pests, 85 .

Plume-moths, 443.

Plusia orichalcea, $393 *$; P. peponis (agramma), $394^{*}$; P. signata (? chalcytes), 392.*

Plutella maculipennis (crucifcrarum), 464.*

Plutellidx, 464 .

Pocilocerus pictus, 526*

Poison-gland of Harpactor, $44^{*}$

Polistes in houses, 171.

politus, Disphinctus, 489.*

politus, Trachelizus, antenna, 5.*

Pollinia attached to insects, 62.*

Polyembryony, 16
Polyommatus bøticus, 415 *

Polyphagous caterpillars, 136

Polytela gloriose, 375.*

pomonella, Cydia, 134

Porcupines, 218.

portentosus, Brachytrypes, 536*

postica, Orgyia, 395* : antenna of - 5.*

Potassium Cyanide for checking ants, 104.

Potato Moth, 23, 79, 163, 455."

Poujadia inficita, 427.*

Power Sprayers, 116.

Powdered insecticides, application of, 106.*

Predaceous insects, 194.

Pressure Sprayers, 113.*

Primary Parasitism, 68.

Priority, Law of, 24.

Priotyrannus mordax, 319.*

priscotincta, Brodia, 18.*

Proctotrypidx, 202,*

Prodenia litura (littoralis), 377.*

Protective resemblance, 35 .

Prothoracic wings, 9.*

Protozoa, 1.

proxima, Athalia, 281.*

Psalis (Dasychira) securis, 397.*

Pacudococcus citri, 508*, Ps. nipe, 509 *: Ps. virgatus, 510.

psidii, Pulvinaria, 510.*

Psiloptera fastuosa, 297.*

Psychidx, 448.

Psychodidæ, 362.

Psylla isitis, 498.*

Psyllidæ, 498.

Pterophorida, 443: wings of --, 11.

Pterophorus lienigianus (scrindibanus), 445.*

1 'teropus giganteus, 219.

Ptinidæ, 295.

pubis, Phthirius, 523.*

Publication, definition of, 25.

puera, Hyblæa, 392.*

pulchella, Utetheisa, 371.*

pulchelloides, Utetheisa, 372 .

Pulicida, 366: thoracic spiracles of 13.

Pulse Beetles, 161.

Pulvinaria psidii, 510.*

punctatus, Phymatcus, 526.*

punctiferalis, Dichocrocis, 433 .*

Pundaluoya simplicia, 494.*

Pupal stage, 27 ; extended periods of - . 33.

Purple Mite, 545.*

pusillidactyla, Platyptilia, 444.*

pusillum, Synodendron, 394." 
pustulata, Zonabris, 303.*

Pycnosoma, 186.

Pycnosoma flaviceps, 348 *

pygmxa, Leptispa, 313.*

pyranthe, Catopsilia, 413.*

Pyralida', 421.*

Pyrausta macharalis, 442.*

pyri, Lachnus, 503 *

Pyrilla perpusilla (aberrans), 494.*

Pyroderces (Batrachedra) coriacella, 458 .*

Pyroderces simplex, 458, 459.

Pyrgomorpha crenulata, 528.*

Pyrrhocorida, 484.

\section{0}

quadripes, Xylotrechus, 323.*

\section{R}

radiata, Phycodes, 463.*

Ragi Borer, 427.

Ragi Root Aphis, 502.*

Ragmus importunitas, 491.*

ramosa, Hispella, 314.*

Rana breviceps, 235 ; R. cyanophlyctis,

R. tigrina, 235.

ranacea, Cyrtacanthacris, $530^{*}:$ - antenna, $5^{*} ;-\operatorname{leg}, 8 . *$

Rapala jarbas, antenna, 5. *

Raptorial legs, 196.

Rat-louse, 185.

Rats, 215-218.

Reactions, Tropic, 54.*

recurvalis, Phalcena, 431."

Red Borer of Coffee, 446.*

Red-gram Agromyza, $357^{*}$

Red Palm Weevil, 153.*

Red Spider, 544 *

Red Tree Ant, 41.

Reduviidæ, 486 : defence by mouth-parts, $44^{*}$; maternal solicitude in,- 34 .

Relapsing Fever, 187.

relata, Cosmoscarta, $495 .^{5}$

Remigia undata (archcsia), $388^{*}:$ R. frugalis, 388.*

Repellents, 105.

Reproduction in Insects, 15.

Reproductive System, 14.

Resistant varieties of crops, 87 .

Respiratory System, 13.

Rhacophorus maculatus, 235.

Rbeotropism, 56 .

Rhinal Myiasis, 186. rhinoceros, Oryctes, $151 *, 152 *, 285 *$ control of,- 95.

Rhizopertha dominica, 294**

Rhizoglyphus parasiticus, 186.

Rhynchophorus ferrugineus, $153 *, 3+3 *$ :

Rhytinota impolita, 301.*

Rice-bug, 146*, 479.*

Rice Case-worm, $430 . *$

Rice Weevil, 160, 341.*

ricini, Aleurodes, 508.

ricini, Attacus, 207. *

ricini, Pericallia, 370.*

Riptortus pedestris, $480^{*}$, R. linearis, 481 ; R. fuscus, 481.

Robber-flies, 198.*

robustalis, Simplicia, 395.*

Roller, Indian, 223.

Root-boring caterpillars, 133.

Rose chafers, 151, 282.

Rosin Compound, 102.

Rosin Wash, 102.

rostratus, Dorysthenes, $318^{*}$; antenna of - 5.*

Rotation of Crops, 84 .

rotundatus, Cimex, 24, 487.*

rouxi, Gnathospastoides, 302.*

rubra, Batocera, 324.*

rubricans, Azazia (Thermesia), 389.*

rubrofasciatus, Conorhinus, 486 .*

rubrofasciatus, Piezodorus, $474 . *$

rubus, Batocera, 324*: Simple anatomy of,$- 2^{*}$

rufa, Dendrocitta, 225.

rufescens, Epimys, 216.

ruficollis, Sarcophaga, 186.

rufipes. Necrobia, 296.*

rugosa, Sathrophyllia, $35^{*}$; leg of,$- 8 .^{*}$

Rules of Nomenclature, 23.

Russell's Viper, 233.*

Rutelidx, 285.

\section{$\mathbf{S}$}

sabulifera, Cosmophila, 390.*

Saissetia (see Lecanium).

Saluria inficita, 427.*

sanctæ-crucis, Aspidomorpha, Larva, 45.*

Sand-flies, 362 ; - in houses, 175.

Sandfly Fever, 187.

Sarcophaga ruficollis, 186.

Sarcopsyllidæ, 365.

Sarrothripine, Brinjal, 383.*

Sathrophyltia rugosa, $35^{*}$; - , leg. $8 .^{*}$

Saturniadæ, 405.

Sawflies, 281.

Sawfly, maternal solicitude in, 34 . 
Scabies, 185 .

scabrata, Calostcrna, 325.*

Scabrator, Coelosterna, 325.*

scalaris, Azygophleps, 446.*

Scale-Insects, 508 ; - tended by ants,

66,67 ,

Scarabaida, 281.

Scarabæus gangeticus, 66 ,

Scelimena, leg, 8.*

Scelodonta strigicollis, 309."

scintillans, Enproctis, 399.*

Scirpophaga auriflua (intacta) $425^{*}$ : S. monostigma, 426.*

scitula, Eublemma, $199 *, 381 *$

Schizodactylus monstrosus, $533^{*}$; - ley, 8.*

Schizoneura lanigera, 500.*

Schonobius bipunctifer, 426 . *

Scolopendra, 239.

Scolytida, 344: - cultivating plants, 63. Scorpions, 237.

Screening fruit and vegetables, 94.

Scutellista cyanea, 24 .

Scymnus, 200.

Secondary Parasitism, 68.

securis, Psalis (Dasychira), 397.*

segetis, Euxoa, 57, 135, 375.*

selene, Actias, 405.*

Semi-loopers, 132.

semivestitus, Orectochilus, eye, 6.* septempunctata, Coccinella, 291.*

serindibanus, Pterophorus, 445."

serinopa, Nephantis, 460.*

Serrate Antennæ, 5.*

serraticcps, Pulcx, 367."

serraticornis, Acanthophorus, 319.*

serricorne, Lasioderma, 162, 295.*

servus, Graptostethus, 482.*

Sesamia inferens, 379.*

Setaceous Antenna, 5.*

Sheep-fly, 186.

Shoot-boring caterpillars, 133 .

Shot-hole Borer, $345^{*}$. - cultivating plants, 63.

Shrews, 220.

siccifolia, Cyclopelta, $476 . *$

side, Mylabris, 303.*

signata, Monolepta, 310.*

signata, Plusia, 392.*

Silk, 205.

Silvanus surinamensis, 161, 290.*

simplex, Chilo, 423.*

simplicia, Pundalnoya, 494.*

Simplicia robustalis, 395.*

sinensis, Centropus, 226.

Sinoxylon sudanicum, 293.*
Siphonaptera, 365 .

Siphonella funicola, 355.*

Sitodrepa panicea, 162, 295.*

Sitotroga cerealella, 163, 456**

siva, Taragama, 43.*

sivce, Hippobosca, 346.*

Sloth-Bear, 220.

Slugs, 239.

smaragdina, (Ecophylla, 41, 276.*

Snails, 239.

Snakes, 231: snake-bite, treatment of. 234.

Soap as an insecticide, 104.

solanella, Bryotropha, 455."

Solenopsis geminata, 274.*

Solicitude for young, 33 .

sordidus, Aphanus, 483.

sordidus, Cosmopolites, 342.*

Spanworms, 132.

Sparrow, 230.

spectra, Tettigoniella, $496^{*}$, parasite of - 203.*

Spence, on classification, 25.

Sphegidæ, 280.

Sphenarches caffer, 443.*

sphenarioides, Colemania, $527 *$; Bombylid parasite of,- 204 .

Sphenoptera arachidis, 298*: S. gossypii, $298 *$ : S. neglecta, 398.

Sphingida, 401.

sphinx, Cynopterus, 219.

Spiders, 237.

spinator, Colosterna, 325.*

Spines, use of, 43 .

spinidens, Indrallus (Aulinctia), 475.*

Spiracles, 13.

Spodoptera mauritia, 378.*

Sporadic pests defined, 128.

Spraving Machinery, 106: selection of -

116 ; upkeep of,- 118.

squamosus, Oxvbelus, 280 ."

Squire Ant Exterminator, 123.*

Squirrels, 215.

Stadia, 31.

Stagmatophora coriacella (sossypiclla), 458.*

Stauropus alternus, 408.*

Steam for control of granary-pests, 167.

stegodyphobius, Batrachedra, 237.

Stegodyplus, 237.

Stegomyia, eggs of, 32 .

Stegomyia fasciata, 175.*

Stem-boring caterpillars, 133.

Stenacliroia elongella, +21 .*

Stenodictya lobata, 9.*

Stephanitis (Cadamustus) typicus, 484 . 
Stevensi, Aulacophora, 312.*

Sthenias grisator, 153, 326.*

Stibara sp., 327.*

Stigmata, 13.

stillata, Anatona, 282.*

Stimulation of plant-growth, 86 .

Sting of Honey-bee, 4t, *

Stink Glands, 14, 41 .

stolida, Grammodes, 387.*

Stomach Poisons, 96, 97.

Stomoxys calcitrans, 353.*

Strainers for Sprayers, 117.

Strepsiptera, Hypermetamorphosis in, 32. striatalis, Diatrca, $\$ 22$.

striatus, Tabanus, $358^{*}:$ - eve of, $6 . *$

Stridulation in insects, +7 .

strigicollis, Scelodonta, 309.*

Stromatium barbatum, 321.*

Stubble, danger of leaving, on ground, 82.*

styx, Acherontia, $402 *$ - robbing beehives, 131.

Suastus gremius, +18.*

subtilis, Carea, larva, 41.

succincta, Cyrtacanthacris, 530.*

sudanicum, Sinoxvlon, 293."

Sugarcane Setts, treatment with Copper Sulphate, 105.

Sulphur for use against Mites, 103.

Sundew, 1, 59 .

suppressaria. Biston, 409,*

surinamensis, Silvanus, 161, 290.

Surra, 189.

Surul puchi, 85,457 .*

Sus cristatus, 214.

Swarming Caterpillars, 136.

Sweet-potato, beetle pests of, 155, 156 .

Sw eet-potato Weevil, 335.*

sykesii, Teleopsis, eye, 6 *

Sylepta derogata (multilincalis), 434.*

Symbiosis, definition of, 65 .

Synolendron dominicum, $204 *$ S. pusillum, 294.*

syringa, Irgina, to1.*

Syringe, Spraying, $107 *$ : -- Injection, 132. *

Syrphida, 198, 358.*

systoma, Cacopus, 235.*

\section{T}

Tabanidx, 358; eyes of,- 7 .

Tabanus striatus, 358 : eye of,$- 6^{*}$

Tachinidæ, 203.

tamulus (dorsalis), Epacromia (Eolopus). 525.*

tapetzella, Trichophaga (Tinea), 467.*
Tapinoma indicum in . Icacia thorns, 63.

taprobanensis, Capprea. 470 *

Tarache nitidula (catena), 381*: T opali noides, 382.*

Taragama siva. 43.*

Tarsus, 8.*

Tasar Silkworm, 208,*

Tatera indica, 215.*

Tea Tortrix, 452.

Teleopsis sykesii, eye. $6 . *$

Telicota augias, +19.*

Tenebrio mauritanicus, 289,*

Tenebrionidae, 299.

Tenebroides mauritanicus, 289.*

tenuicollis, Lytta, 303.*

Tenthredinidæ, 281.

Terastia meticulosalis, 438 *

Terias hecabe, $41+*$

Termes convulsionarius, means of defence. 44: communication amongst, 50 .

Terme's obesus, 142 . *

Termites, $139,5+1 *$; absence of eyes in-, 7 ; - as crop-pests, 143,$543 ;-$ as food, 212 : castes of,$- 140^{*}$, communication amongst - 50 ; control of - by machines, 121 * - cultivating Fungi, 63, - encouraged by stubble, 83 ; - in buildings, 144, 171; means of defence of -. 41 ; nymphosis in -, 18; prothoracic wings in $-9 *$. preservation of wood against $-, 144,172$.

Termitidx, 541*

Termitophilous insects, 66 .

Termitoxenia, reputed hermaphroditic, 15 . testaceum, Lasioderma, 295.*

testulalis, Maruca, 440.*

Tetranychus bioculatus, $544^{*}$; T coffeæ, 545 .

tetraonis, Arbela, $453 . *$

Tetroda histeroides, $477 . *$

Tettigoniella spectra $496^{*}$, parasite of -. 203.*

there, Hemichionaspis, 520.*

theobromæ, Bruchus, 307."

theobrome, Hemilecanium, 516.*

theobromatis, Bruchus, 307.*

Thereiceryx zeylonicus, 229.

Thermesia rubricans, $389 *$

Thermotropism, 55.

Thigmotropism, 55.

Thorax, Appendages of, 7 .

Three Day's Fever, 187.

Thripida, $5+2$

Thrips, 542.*

thyrsis, Gangara, 417 *

Tibia, 8." 
Ticks, 184 ; feeding habits, 184.

Tiger-beetles, 199.

tigrina, Rana, 235.

Tinægeriadæ, 461.

Tinea pachyspila, $466^{*} ; T$. tapetiella, 467.*

Tineidæ, 466.

Tingididæ, 484 .

Tits, 225.

Toads, 236.

Tobacco Decoctions, 103. .. Dust, 105.

Toddy Cat, 221.

tomentosa, Eurybrachys, 492.*

Tonica zizyphi (augusta), 459.* torodelta, Laspeyresia, 451.*

torquatus, Palæornis, 229.*

Tortoise Beetles, 155.

Tortricidæ, 452.

Trachelizus politus, antenna, 5.* trachypterus, Chrotogonus, 528. tragocamelus, Boselaphus, 214. tranquebaricus, Apoderus, 335.* Trap-crops, 84.

trapezalis, Marasmia, 432.*

Tree Pie, 225.

Trenching of cropped areas, 93.

Tribolium castaneum $161,300 * ; T$. ferru gineum, 300.*

tricentra, Laspeyresia, 451.*

Trichophaga tapetzella, 467.*

trifenestrata, Cricula, 405.*

tripudians, Naja, 232."

Trisopsis olea, eye, 6.*

tristis, Acridotheres, 224.*

Trochanter, 8.*

Trogositidæ, 289.

Trophies, preservation of, 173 .

Trypaneidxe, 354.

Trypanosomes causing diseases in animals, 189-190.

Tryxalis turrita, 524.*

tuberculatus, Hæmatopinus, 524.*

turrita, tryxalis (Acrida), 524.*

Typhlodromus carinatus, 545.*

Typhoid Fever, 188.

typicus, Stephanitis (Cadamustus), 484.*

Tyroglyphus longior castellanii, 186.

\section{U}

Udaspes folus, 420 .*

undalis, Hellula, +37.*

undata, Remigia, 388.*

uniformis, Nonagria, 379.*

unipuncta, Cirphis, 376.*

Universal Ant Exterminator, 122, *
Upupa indica, 223.

Urates in scales, 40 .

Urentius echinus, 485.*

ursinus, Melursus, 220.

Utetheisa pulchella, 371, ${ }^{*}$ : U. pulchelloides, 372 .

\section{V}

Valid Names, 25.

Vampire, Indian, 220.

varians, Anomala, 287**

varians, Ocinara, 407, *

varicornis, Leptocorisa, 146*, 479.*

variegata, Clania, 448.

Vegetables, spraying of, 97, 100.

Veins of wing, names, 10.*.

velox, Oxya, 533.*

venosata, Diatræa, 422 .

ventralis, Eusarcocoris, 471.*

venulia, Egocera, 372.*

versicolor, Calotes, 230.

versicolor, Oxycetonia, 283.*

vestimenti, Pediculus, 522.*

vigintiocto-punctata, Epilachna, 292.*

vinula, Cerura, 41.

Vipera russellii, 233.*

Virachola isocrates, $416^{*} ;-$, directive markings, 39.*

virescens, Heterusia, 448.*

virgatus, Dactylopius (Pseudococcus), 510.*

viride, Lecanium, 147, 513* ; - introduction of, 78 ; - attacked by fungi, 123.

viridis, Merops, 230.

viridula, Nezara, 473.*

vittatus, Macrones, 236.

Viviparity, 33.

vulgalis, Nacolcia, 433.*

vulpinus, Dermestes, 292.*

\section{W}

Wagtails, 225.

Warning coloration, 38 .

Wasps, 196; - in houses, 171 ; colours of $-, 38$.

Water-beetles, 199.

Wax-moth, 421.*

Weeds, Insects checking, 204.

Weevils, $327^{*}$; - and death-feint, 37 ; as crop-pests, 155: hardness of,- 42.

Weights and Measures, 126.

Wings, 9; prothoracic, $9^{*}$; structure of, $10^{*}$, shapes of $11^{*}$; parts of 11 .

Whale Oil Soap, 104.

IVhipsnake, Green, 36. 
Whirligig Beetles, eyes of, 7 .

White-ants (see Termites).

White Borer of Coffee, 323.*

White-grub, 150.*

Whitewash, 106.

Woodpeckers, 226.*

Woolly Bears, 135.*

Woolly Blight, 500.*

\section{X}

Xanthopimpla pedator, 201.* Xenopsylla cheopis, 366."

Xyleborus fornicatus, 345.*

Xylocopa, mouth-parts, 4 * . - carrying Mites, $67^{*}:-$ in houses, 171.

Xylocopa iridipennis, eye, 6.*

Xyloryctidx, 460.

Xylotrechus quadripes, 323.*

Xylotrupes, means of defence, 44.

Xystrocera globosa, 321.*
Yaw's, 188.

Yellow Fever, 187.

ypsilon, Agrotis, 57.

Ypsolophus ianthes, 456.*

\section{$\mathbf{Z}$}

Zamila perpusilla, 493.*

Zeuzera coffex, 446 .*

Zeuzerida, $4+6$.

zeylonicus, Thereiceryx, 229.

Zinc Arsenite, 99.

zinckenella, Etiella, 429.*

Zinckenia fascialis, 431.*

zizyphi, Tonica, 459.*

Zonabris pustulata, $303^{*} ; \mathrm{Z}$. orientalis, 304.

Zygænida, 448 . 




